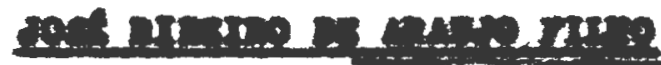

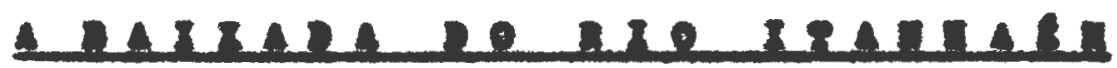

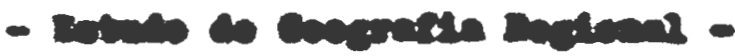

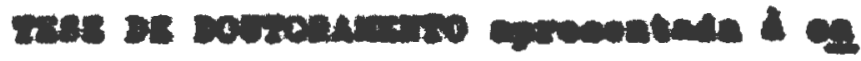

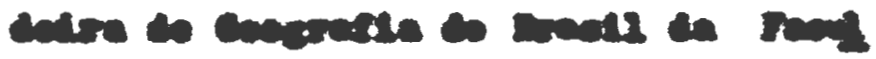

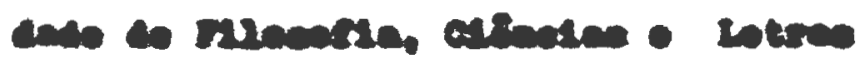

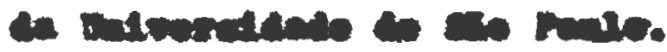




\section{$\cos \operatorname{cose}$}

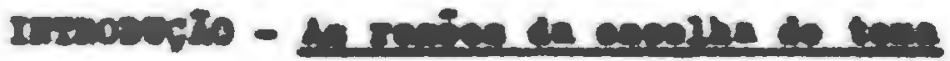

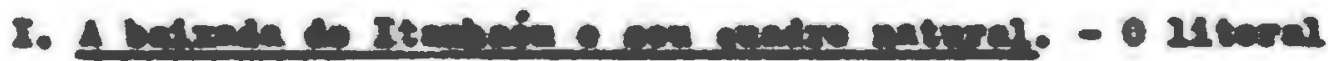

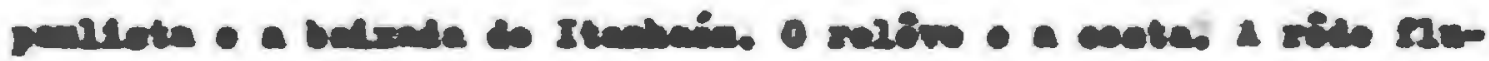

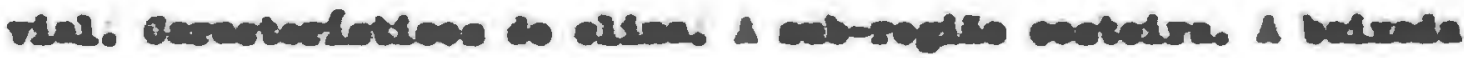

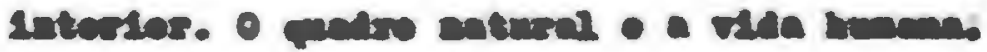

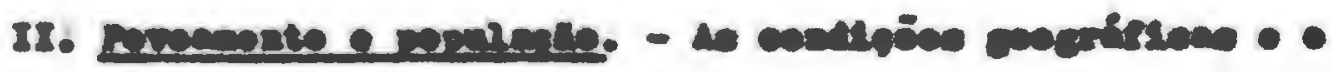

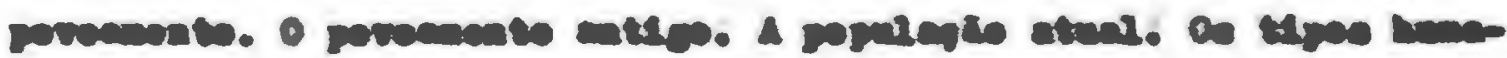

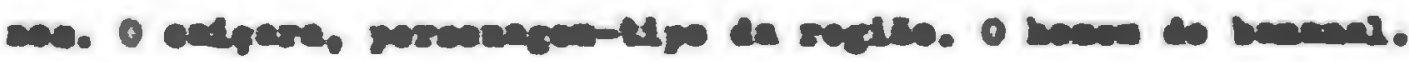

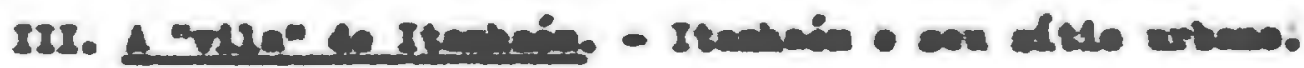

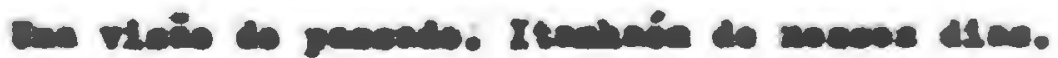

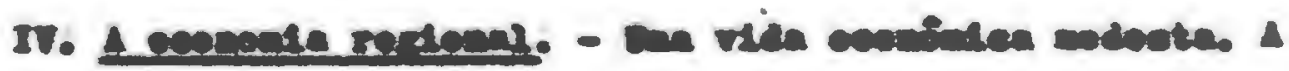

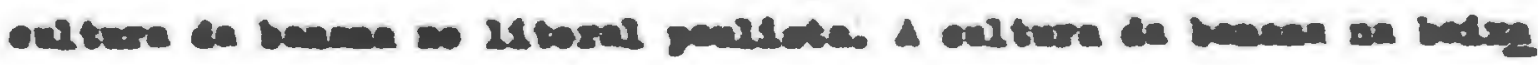

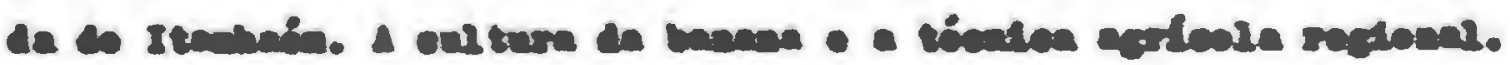
camencos: 


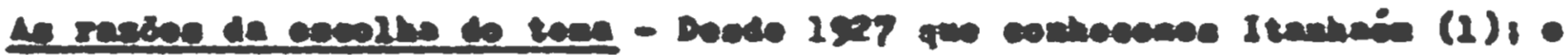

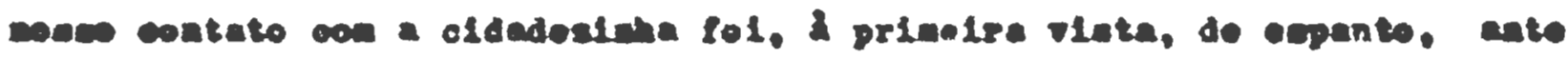

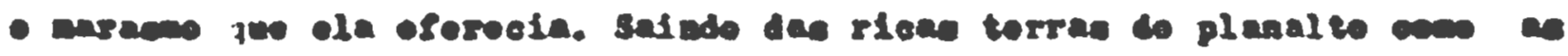

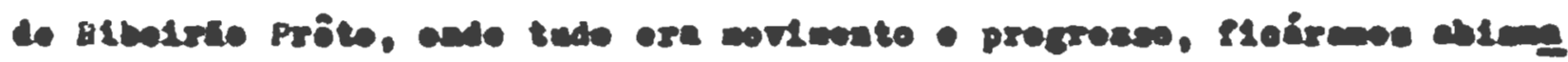

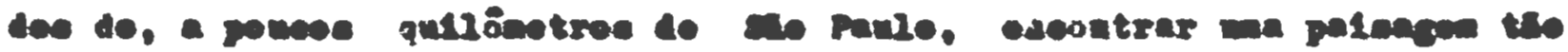

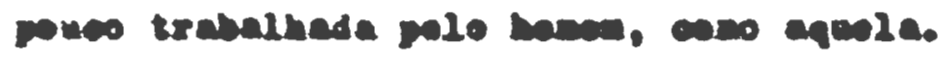

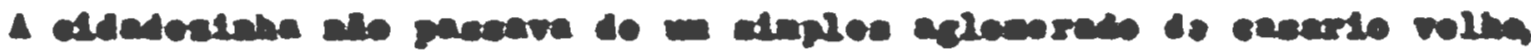

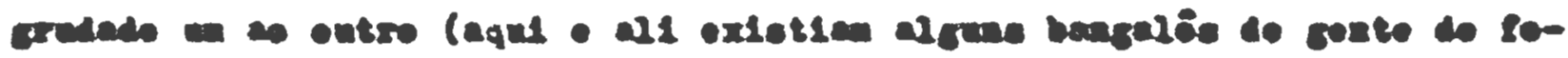

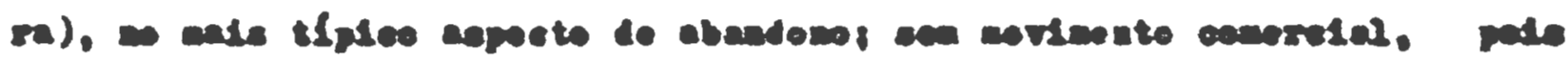

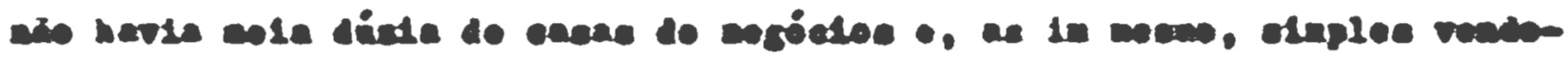

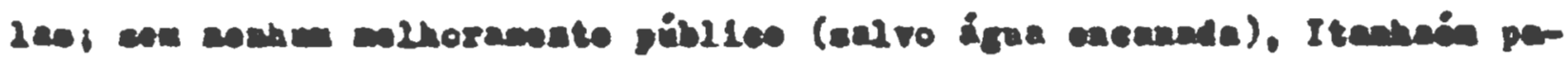
reoik-seo nulg une vila que própolacente una cldade.

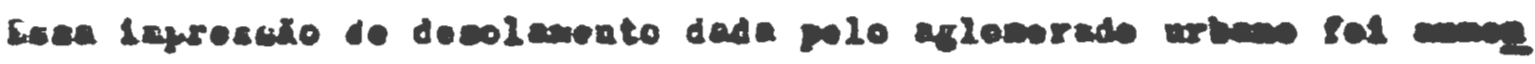

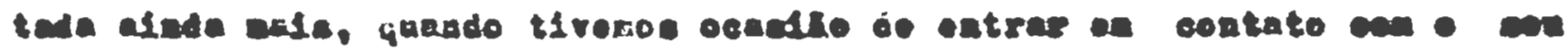

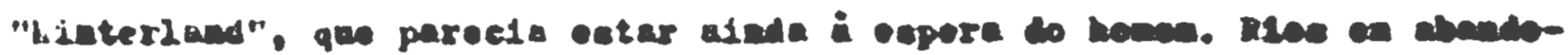

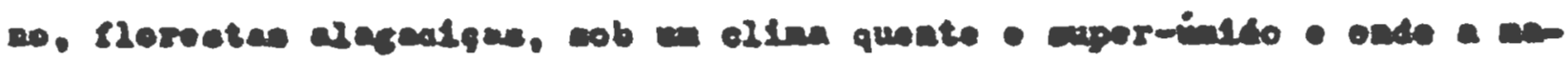

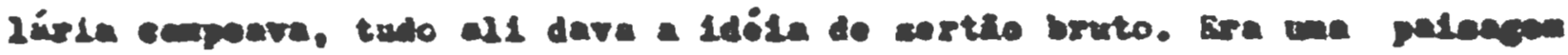

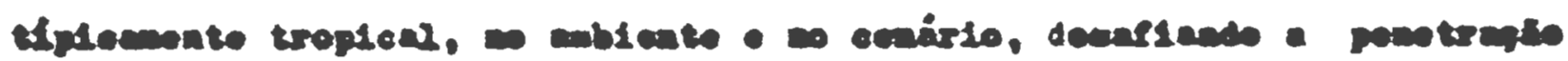

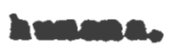

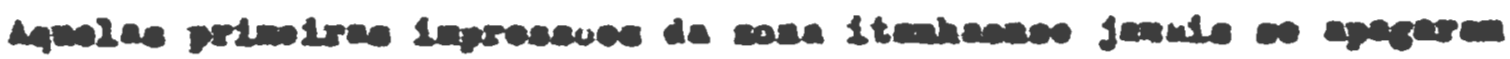
1. now mabirle.

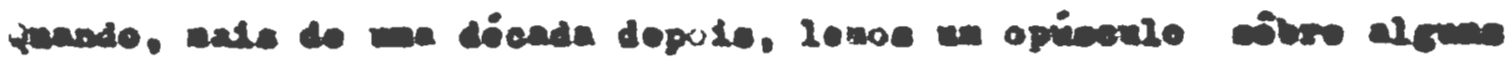

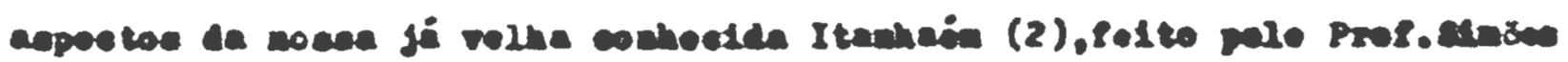

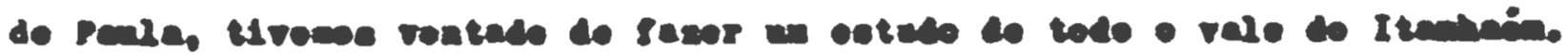

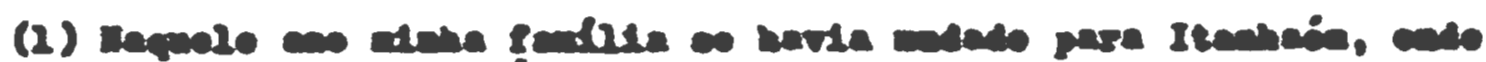

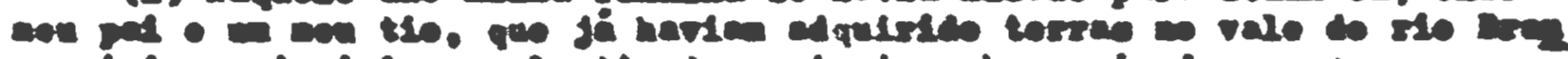

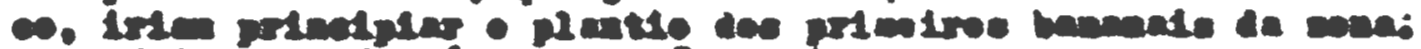

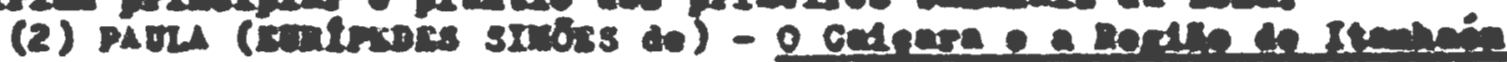

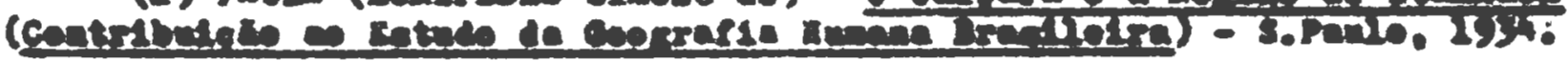




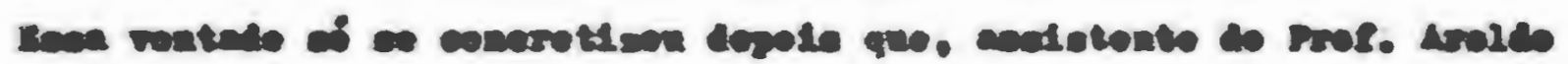

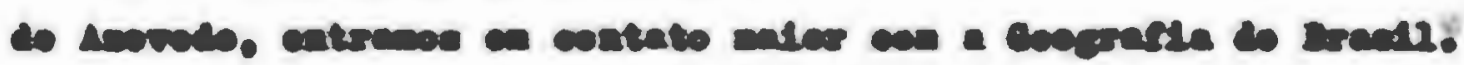

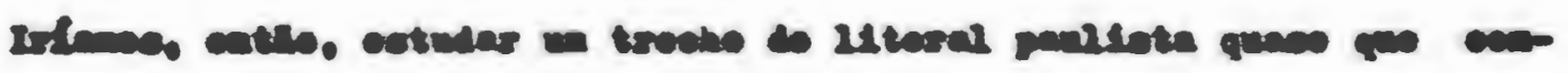

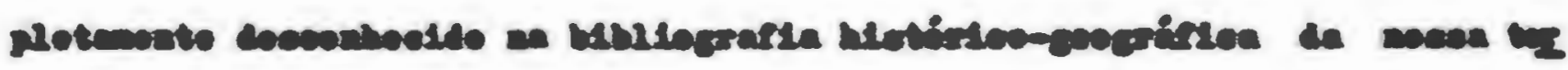
re (3).

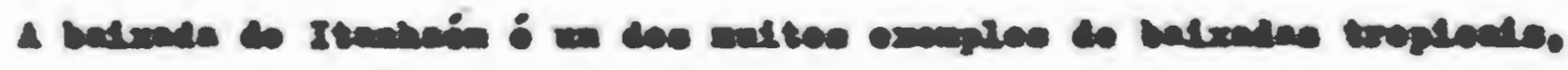

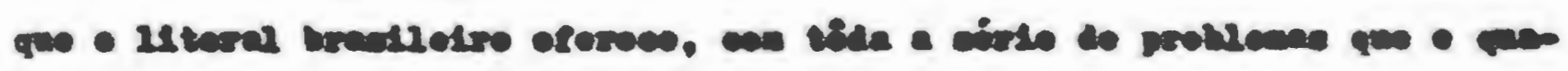

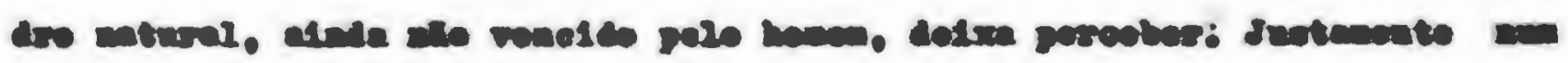

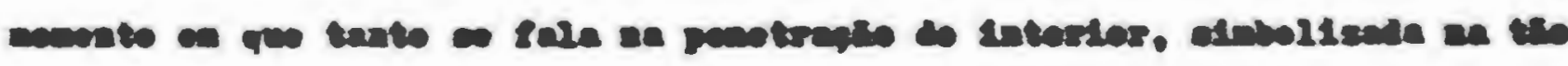

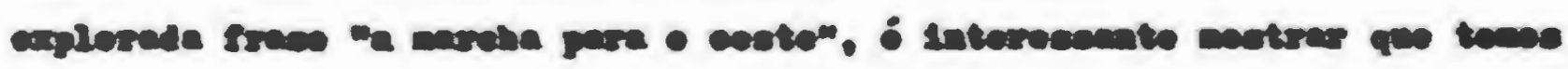

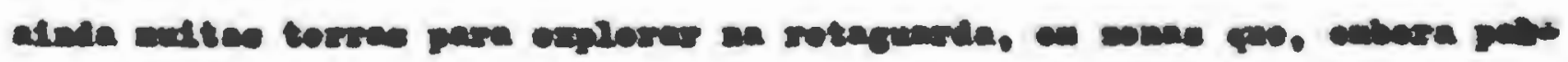

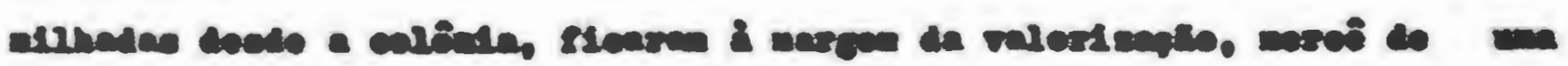

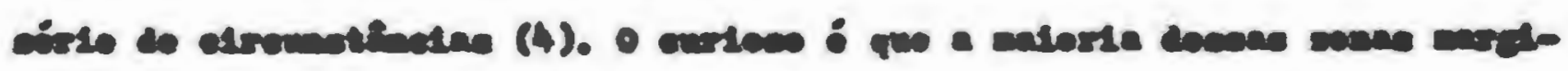

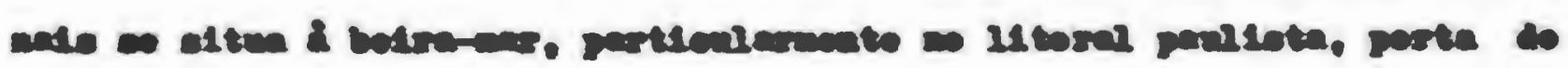

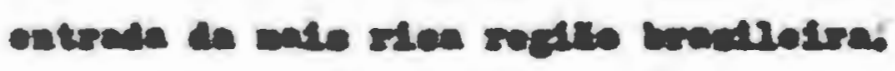

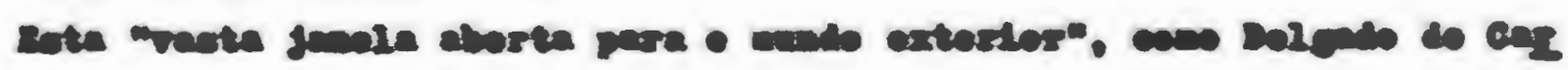

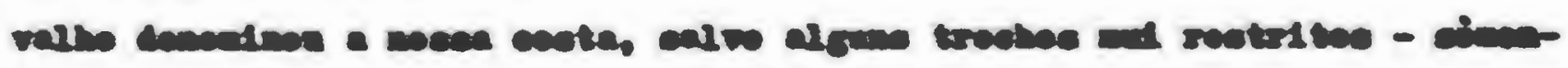

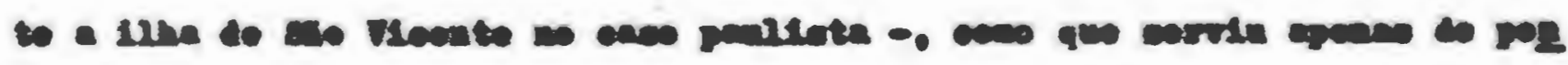

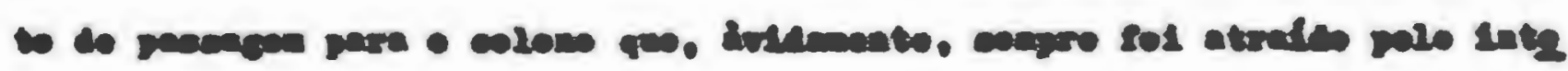

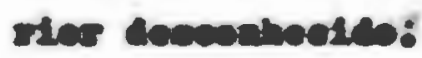

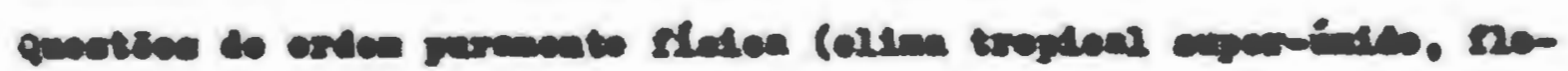

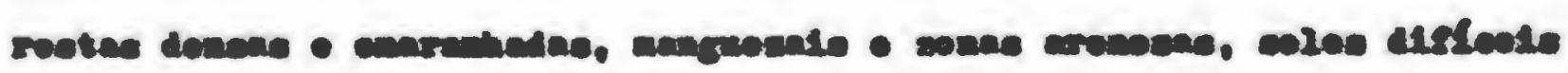

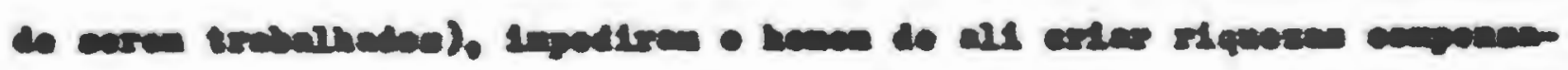

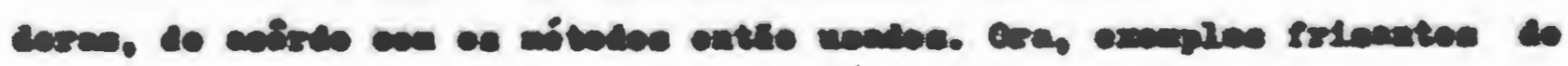

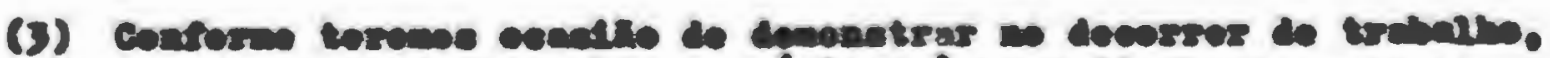

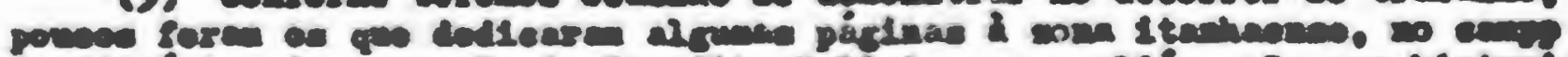

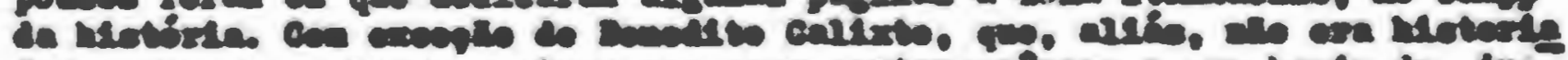

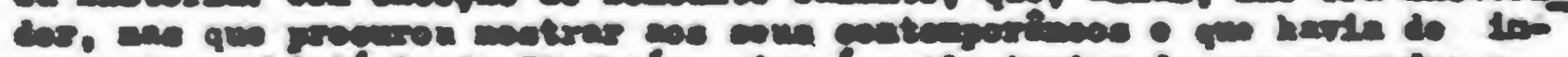

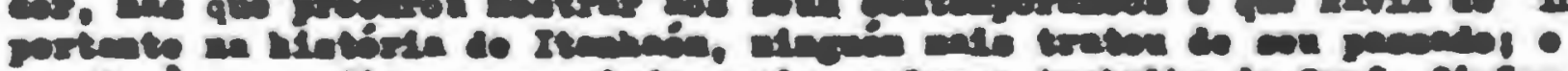

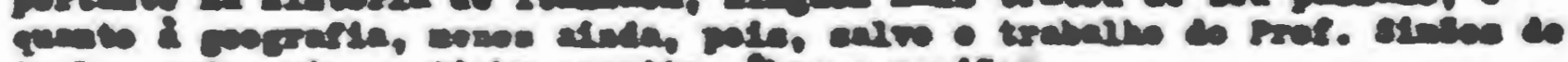

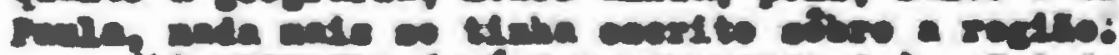

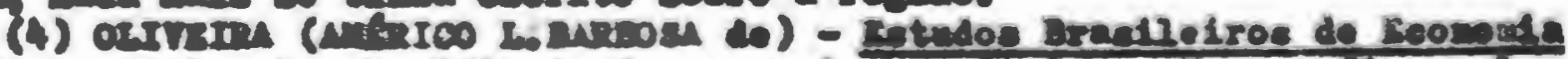

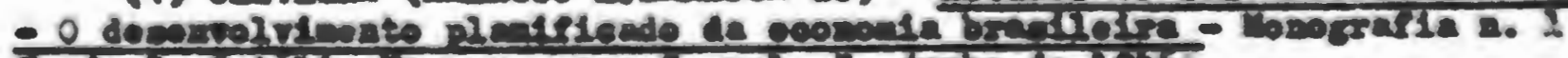

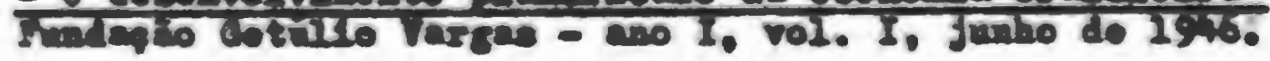




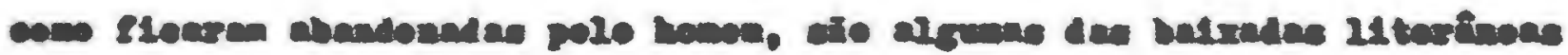

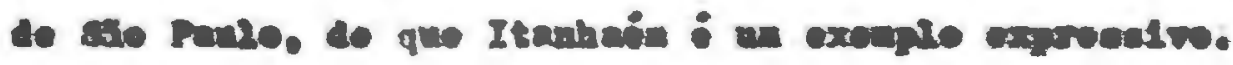

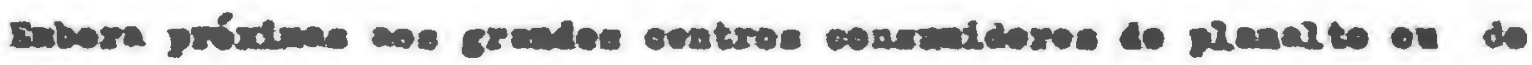

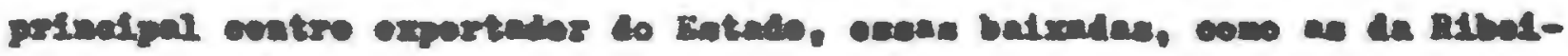

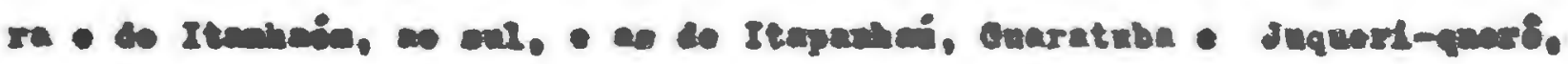

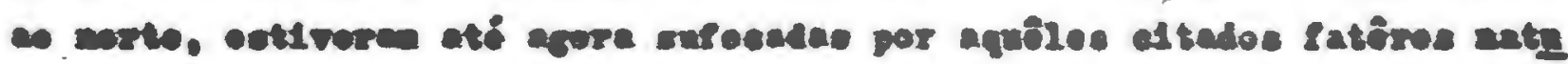

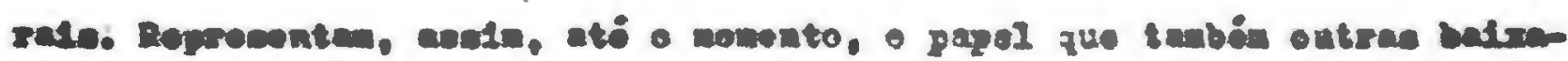

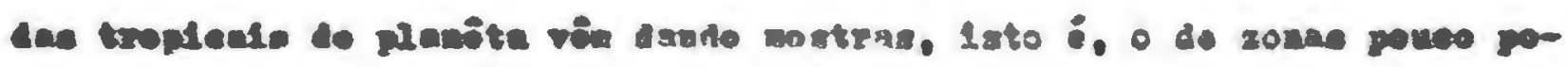

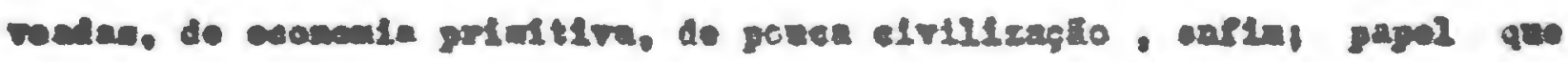

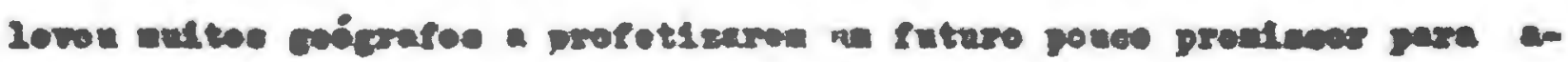

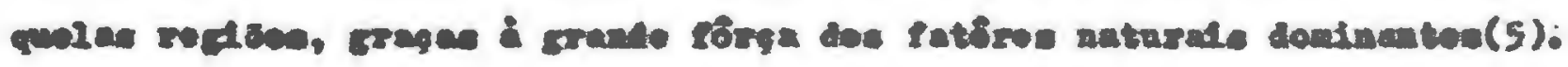

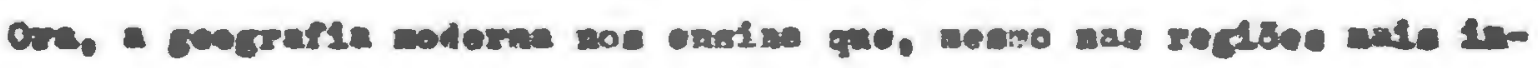

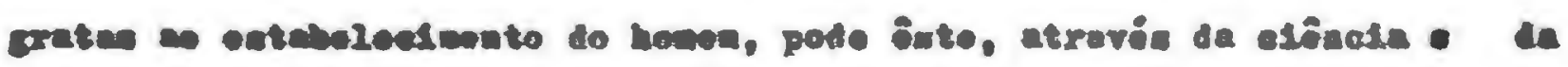

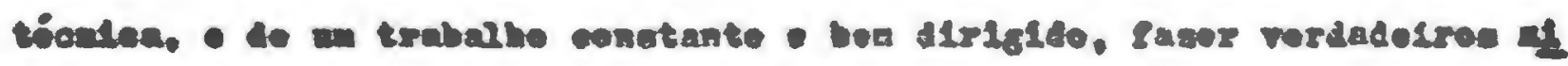

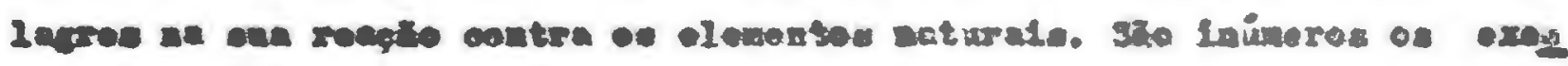

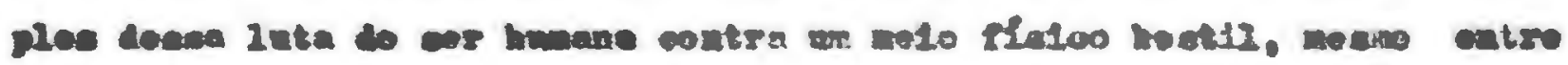

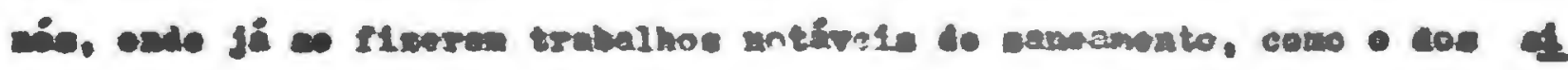

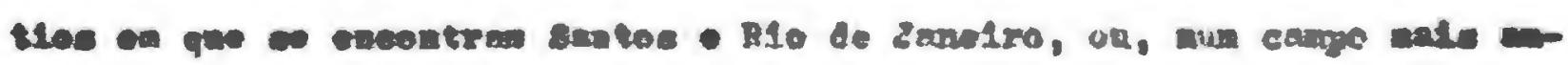

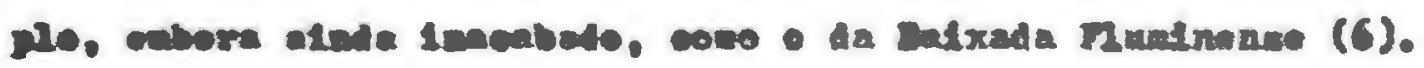

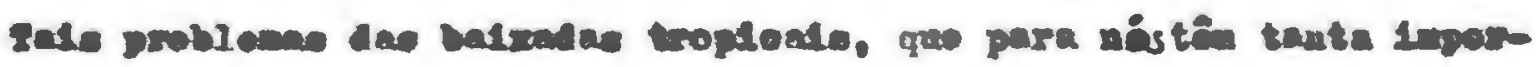

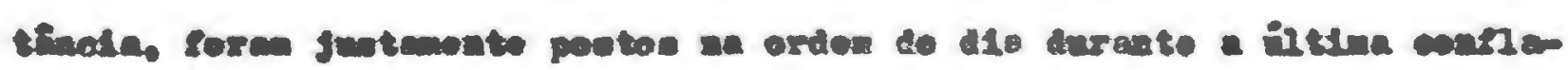

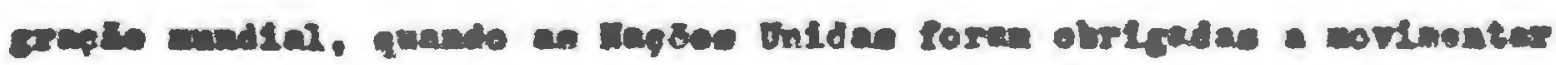

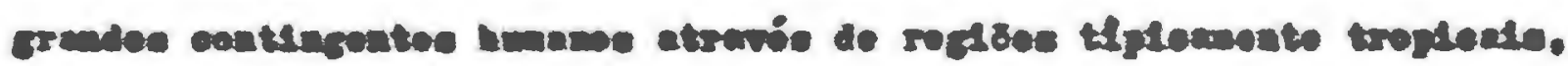

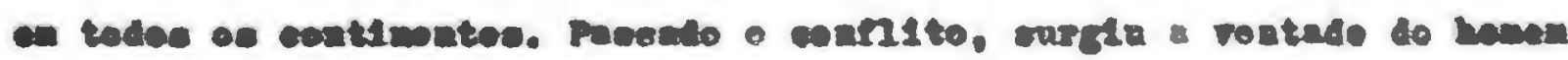

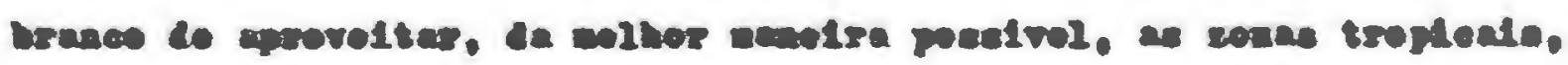

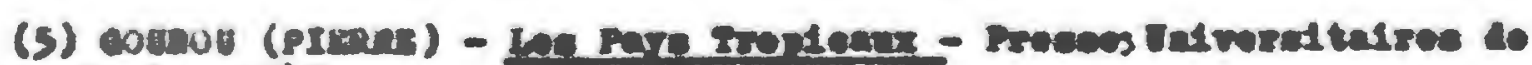
Tranes, Pavke. 284.

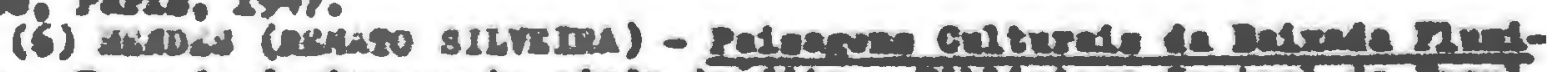

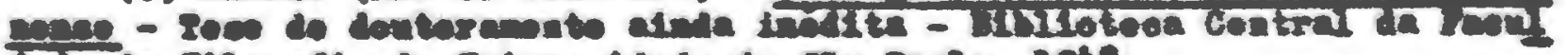

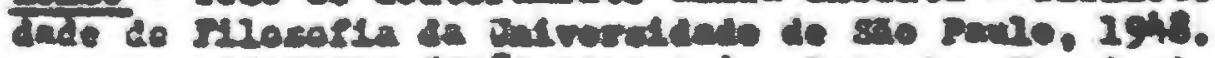

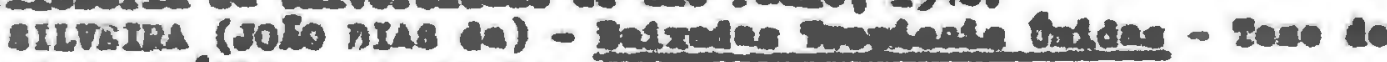

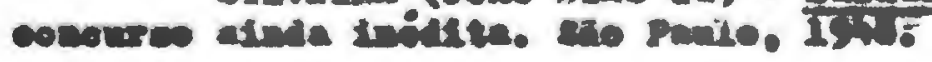


prinolpalmonto as atturatas nos proxindiades le Litoralo (7):

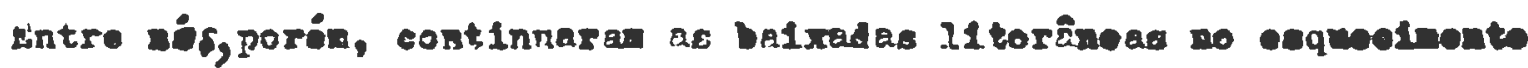
on resultado da fanose "rearohe para o oeste".

dí: tempe, pole, de lazermos qualquer coloh ov prol de sonal qwe,

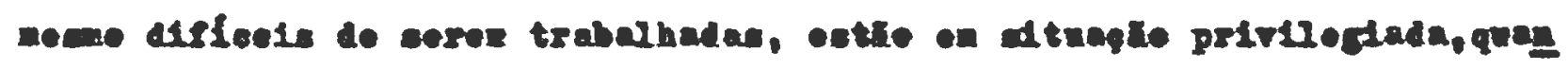

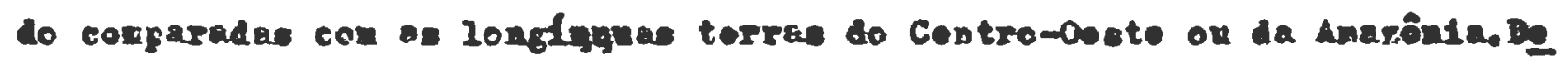
veros, entos to mats noda, exploxar, sontro doe nótodos raolonale de tra

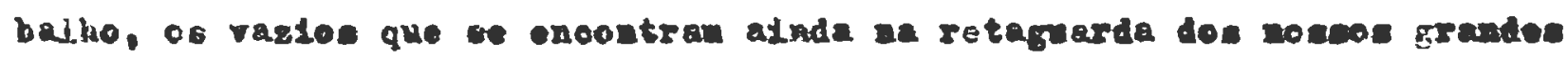
cestroe, colondzando-os o mole ureve poedrel. Povoando neasac bulzades

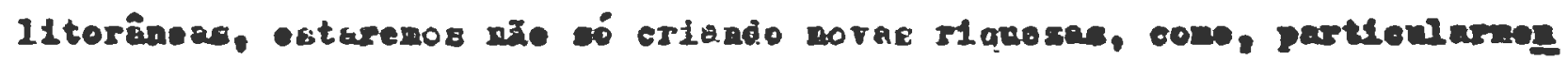

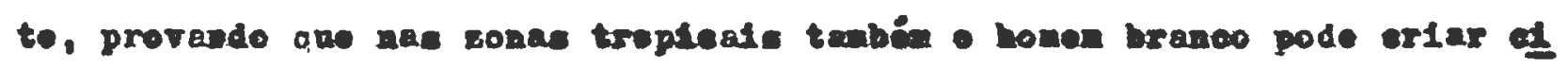

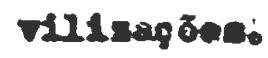

Reaponsível for esea rida merginal que atnda hoje levan allhgos io

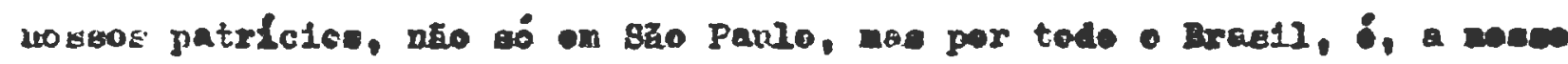

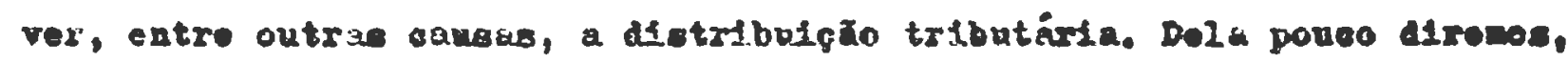

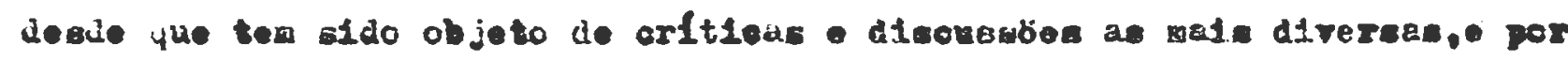

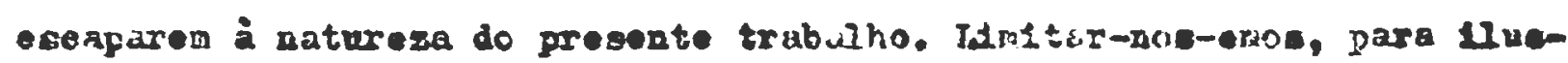

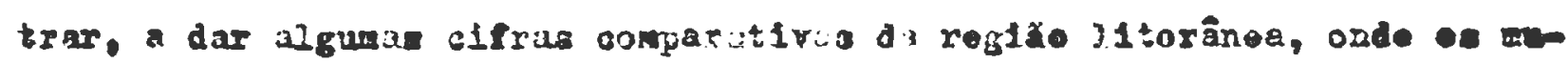

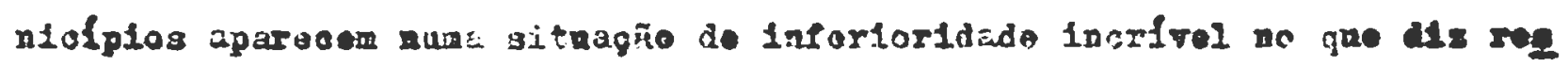

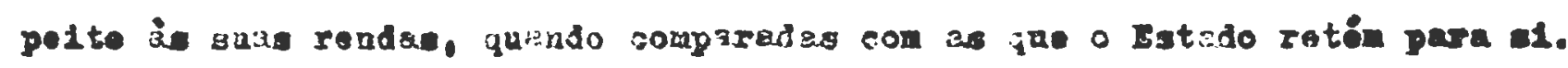

\section{ANO DB 1946 (8)}

\section{Mniéno10s}

$\operatorname{sentos} \ldots \ldots \ldots \ldots$

săo Vicente ........

Itanha: $\ldots \ldots \ldots$......

Igucipe $\ldots \ldots \ldots \ldots$

$T_{b}=$ tubis $\ldots \ldots \ldots \ldots$

\section{Renda estadual (Cr.3)}

$259: 226: 513 \ldots \ldots \ldots \ldots \ldots \ldots$

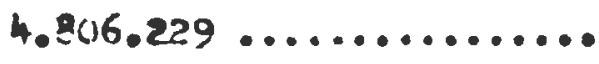

839.380

4.04 .380

$259.76 \bar{c}$
Rende munteipal

25.365 .178

2:290:534

27.544

218.746

72.968

(7) COMROJ (PIXSRT) - op.cit.. sxo Pealo:

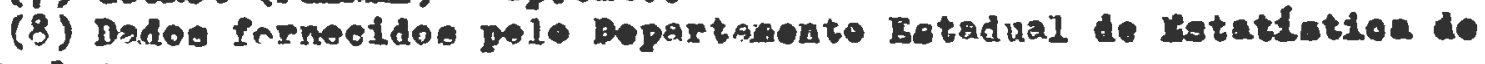




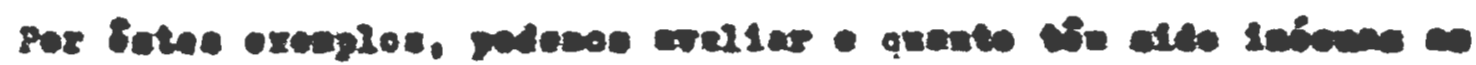

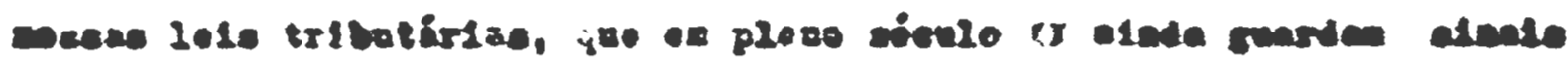

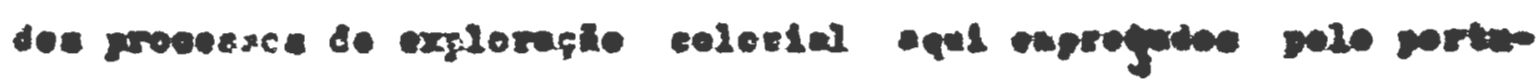
ancen (9).

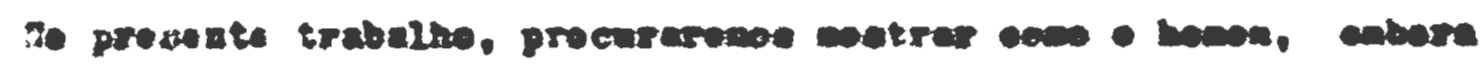

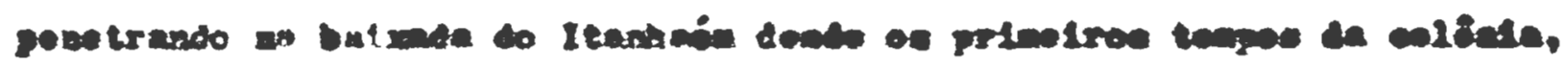

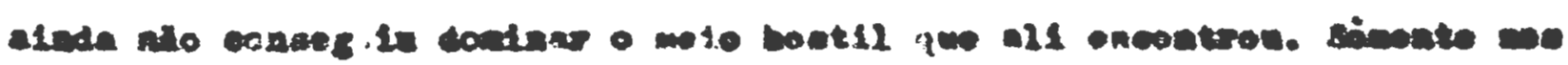

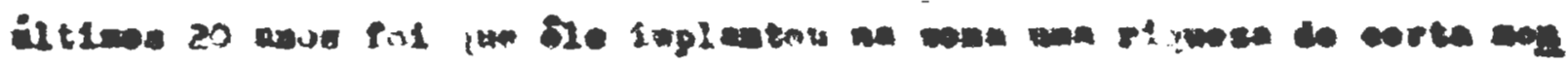

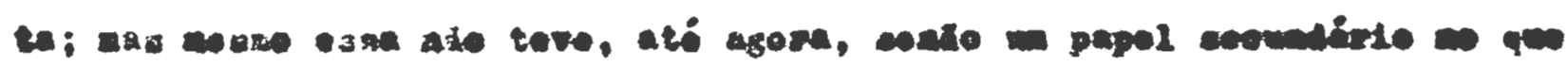

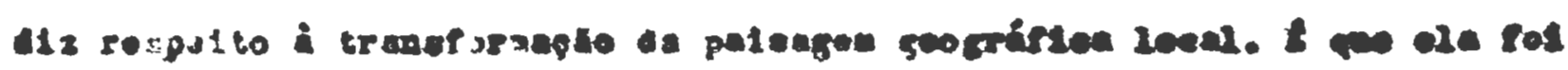

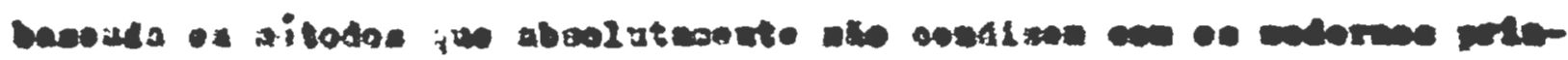

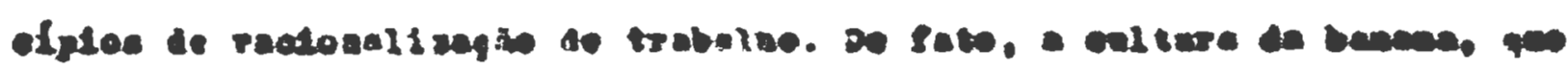

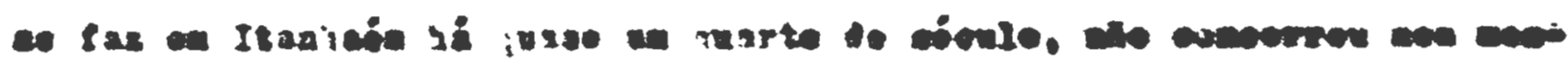

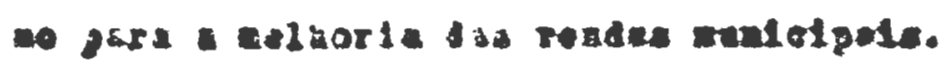

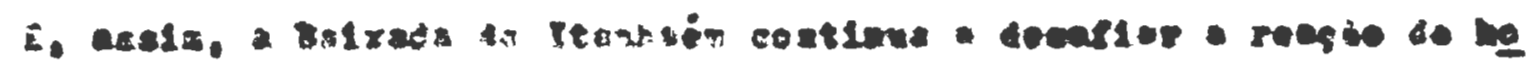

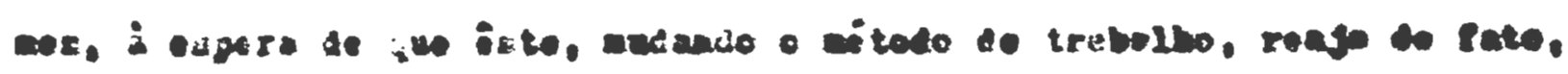

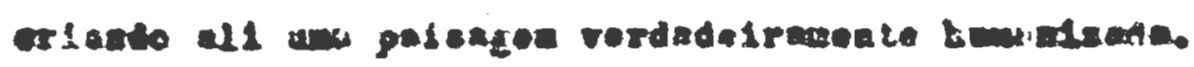

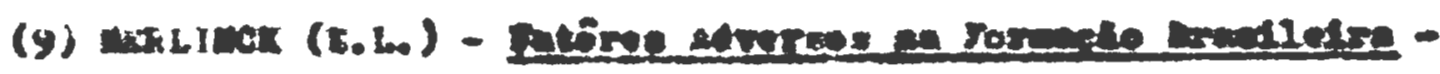
as pare. $29+6$. 


\section{captereI}

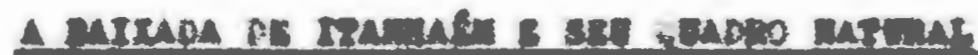

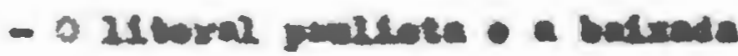

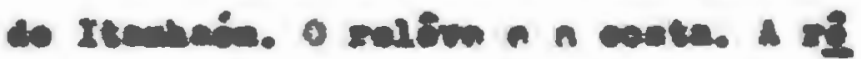

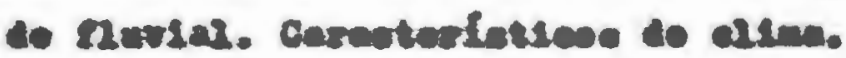

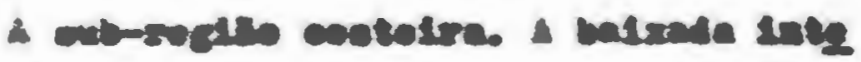

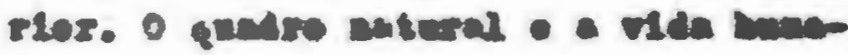
at.

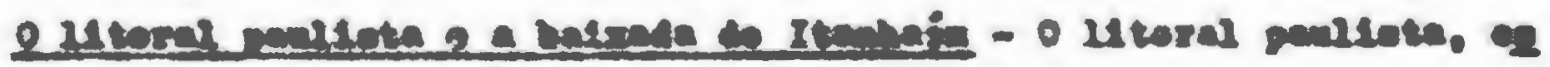

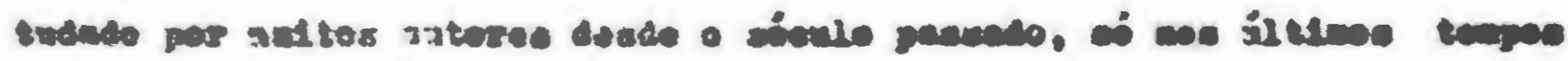

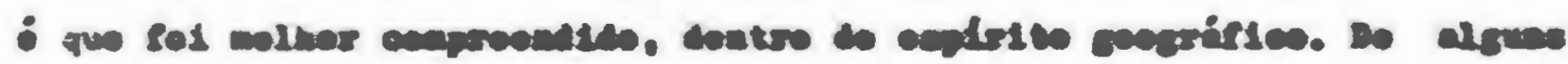

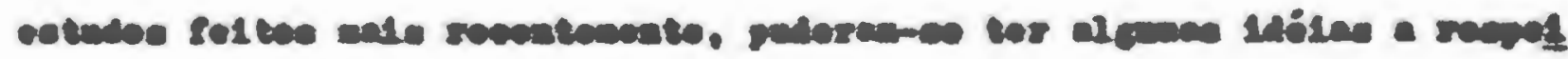

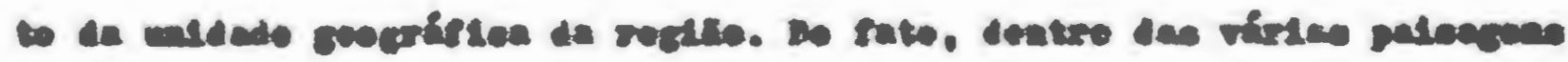

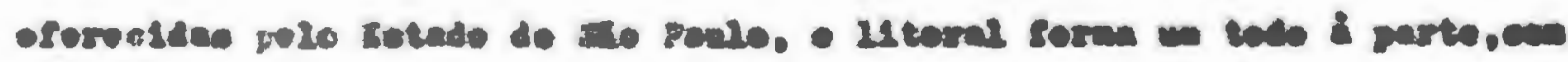

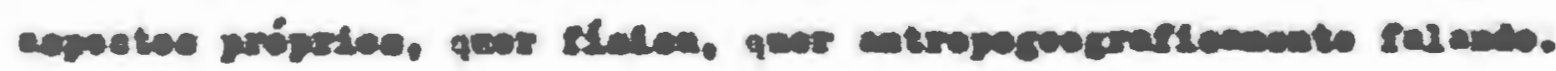

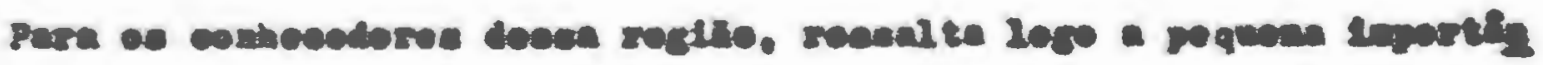

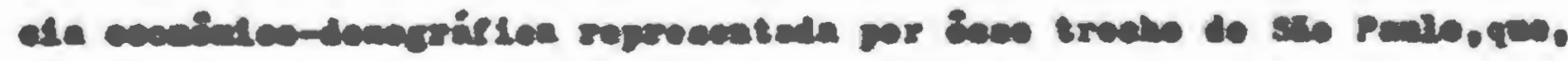

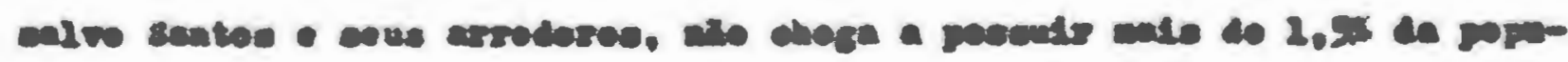

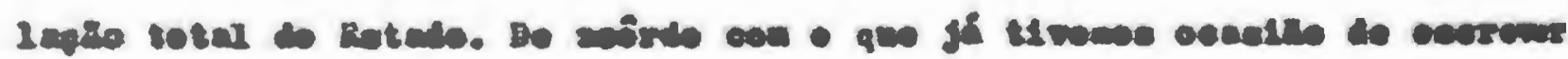

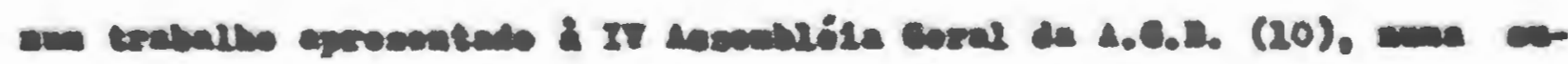

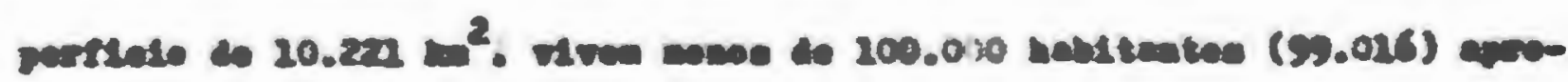

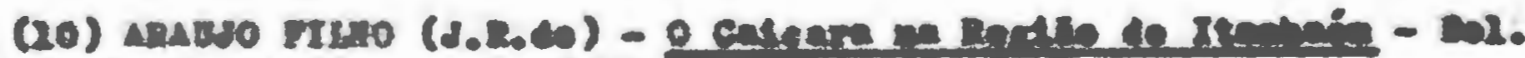

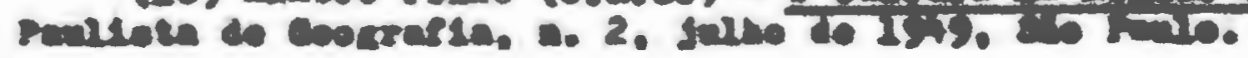




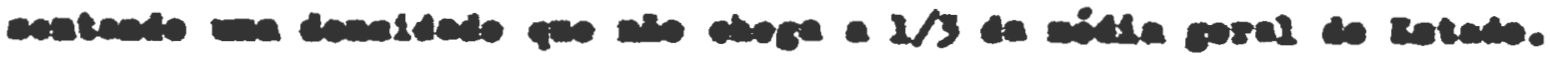

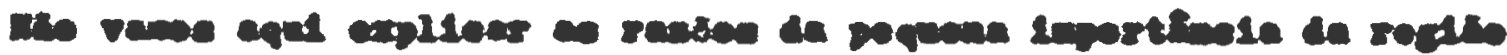

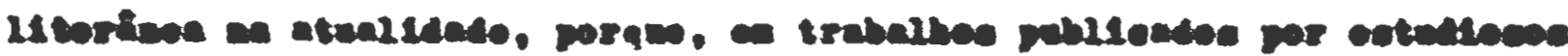

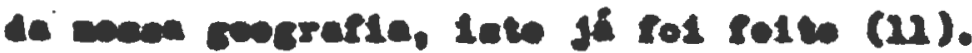

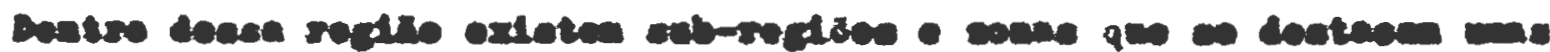

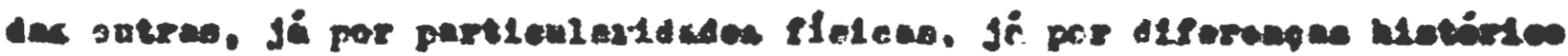

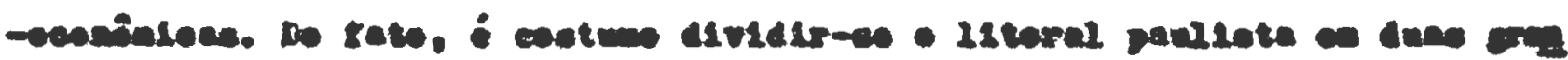

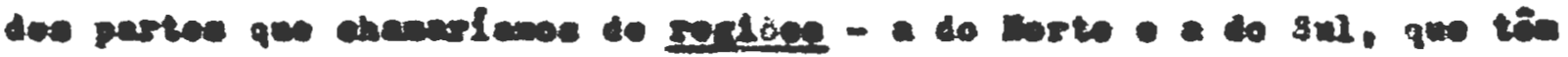

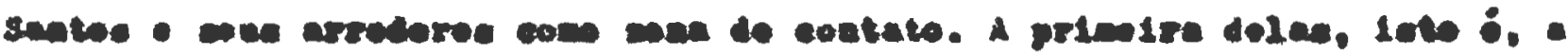

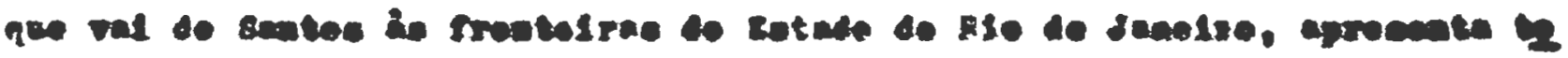

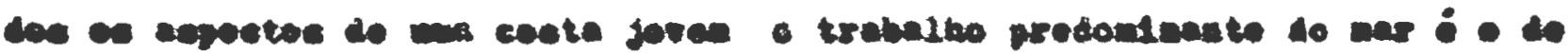

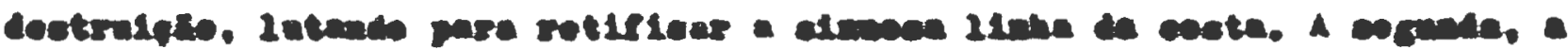

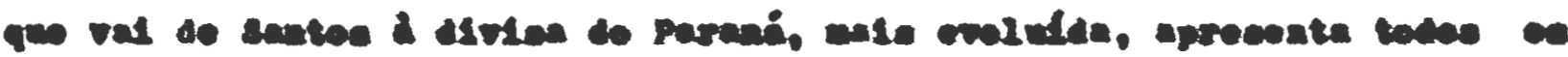

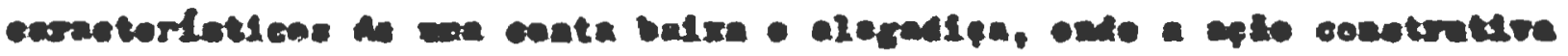

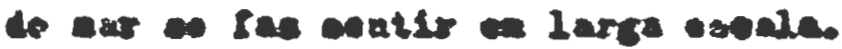

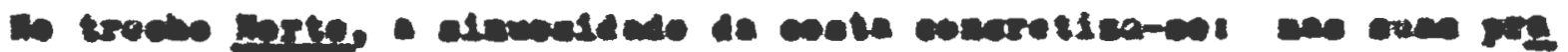

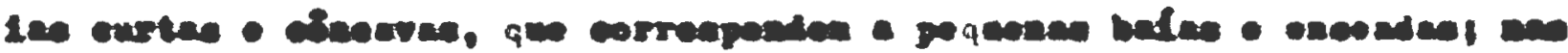

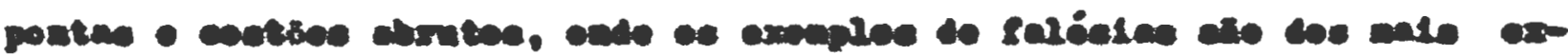

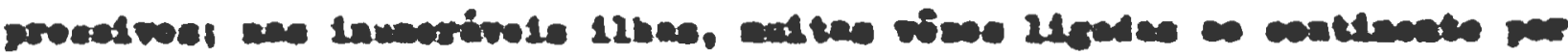

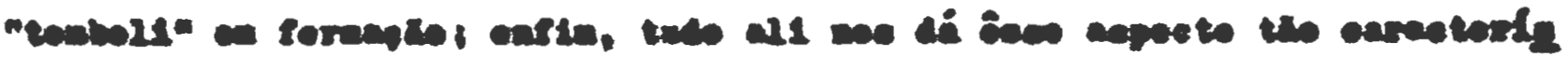

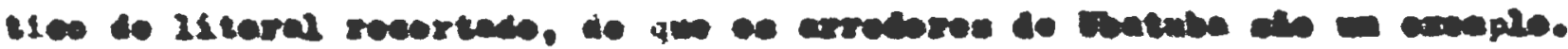

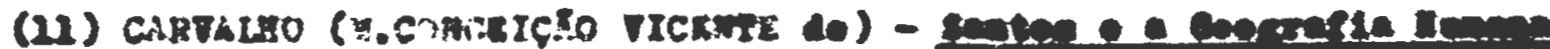

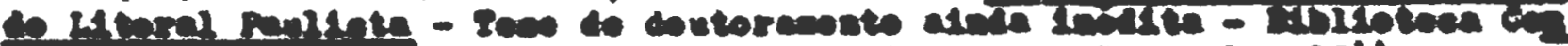

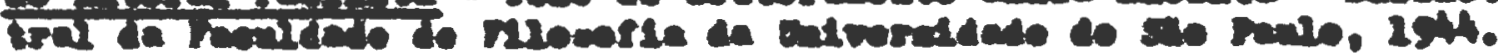

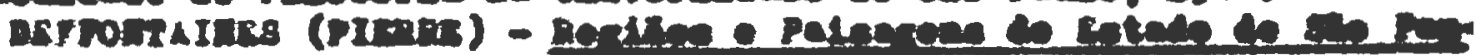

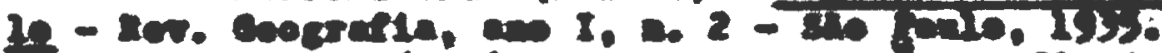

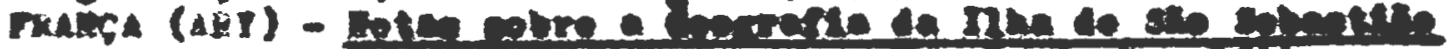

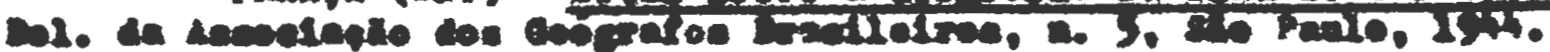




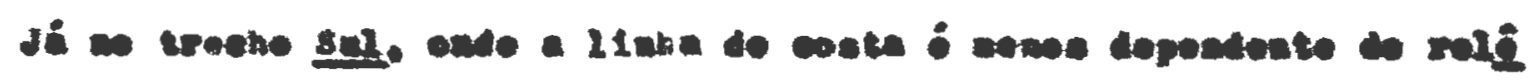

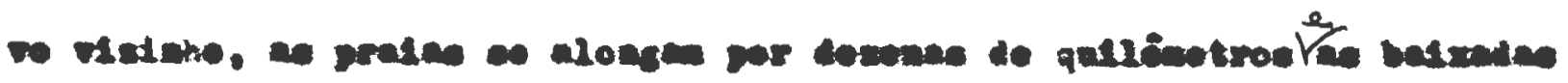

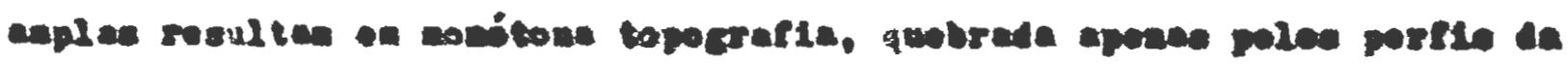
corre is Perwagl coube, wo horisonte.

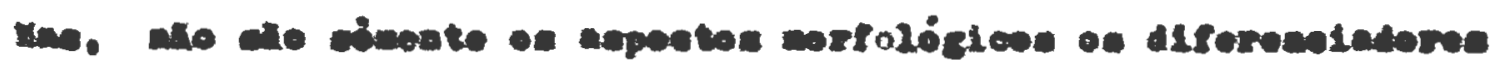

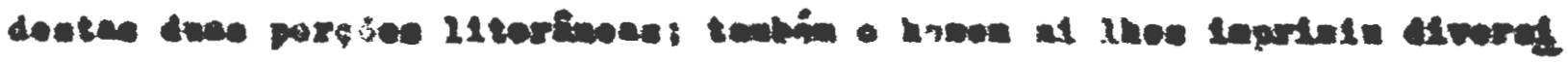

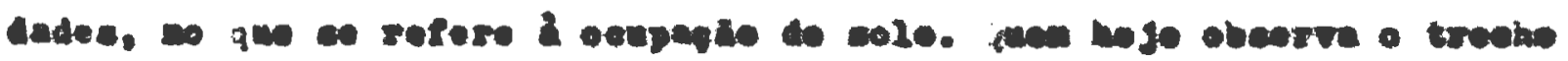

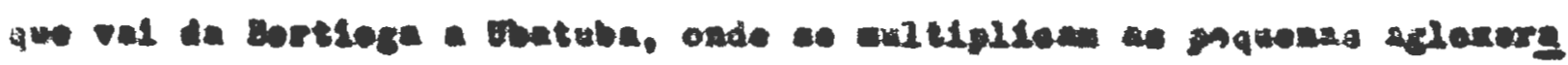

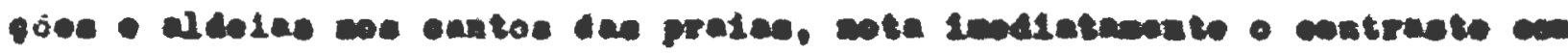

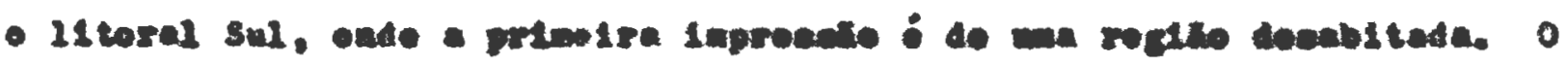

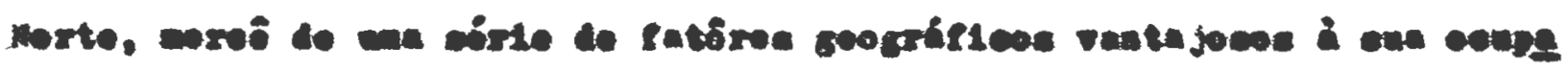

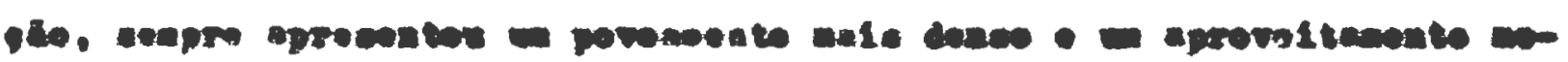
Ihor per parte to hesen, suo isol.

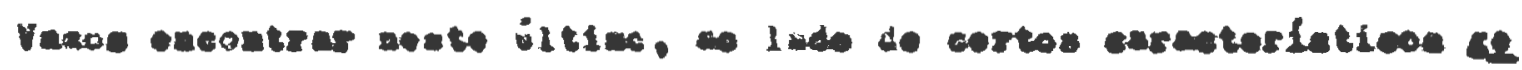

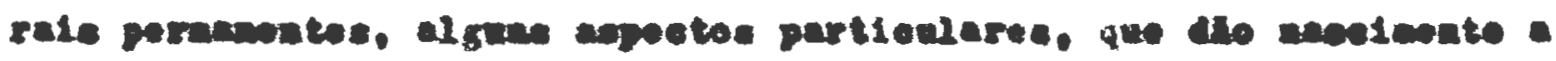

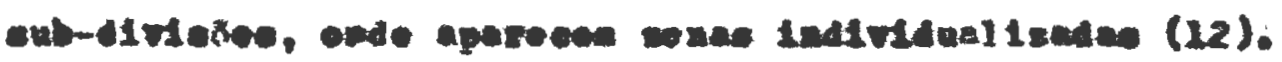

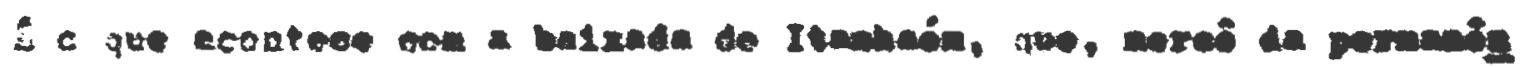

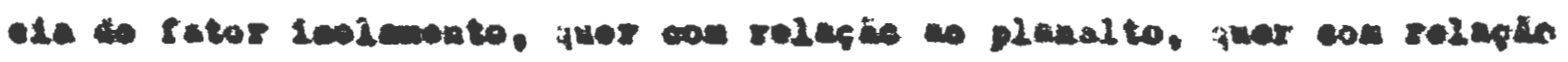

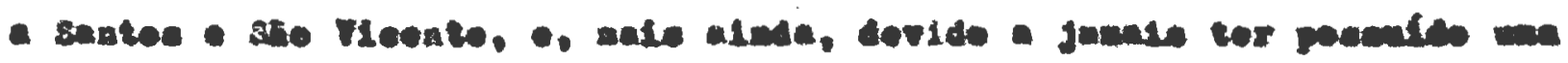

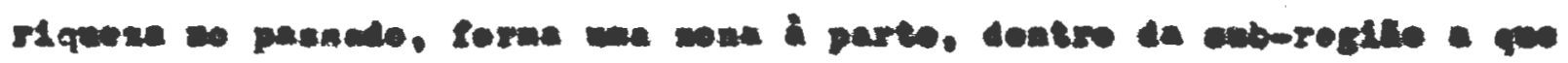

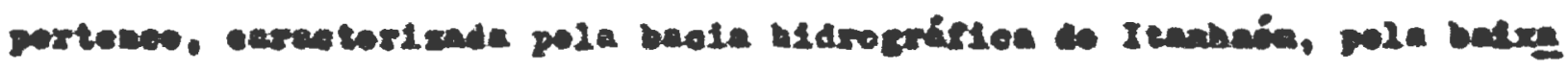

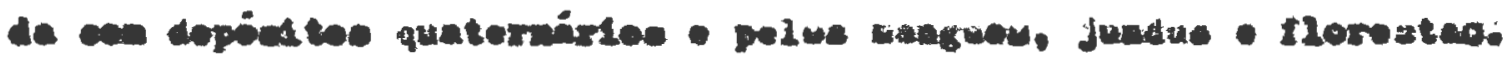

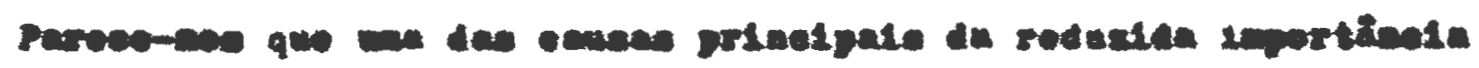

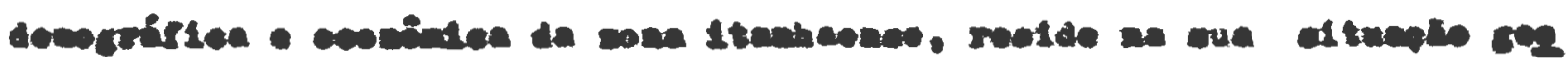

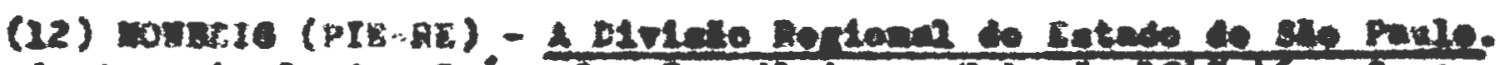

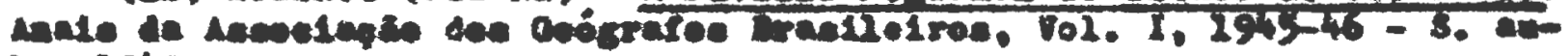
20. 2949. 


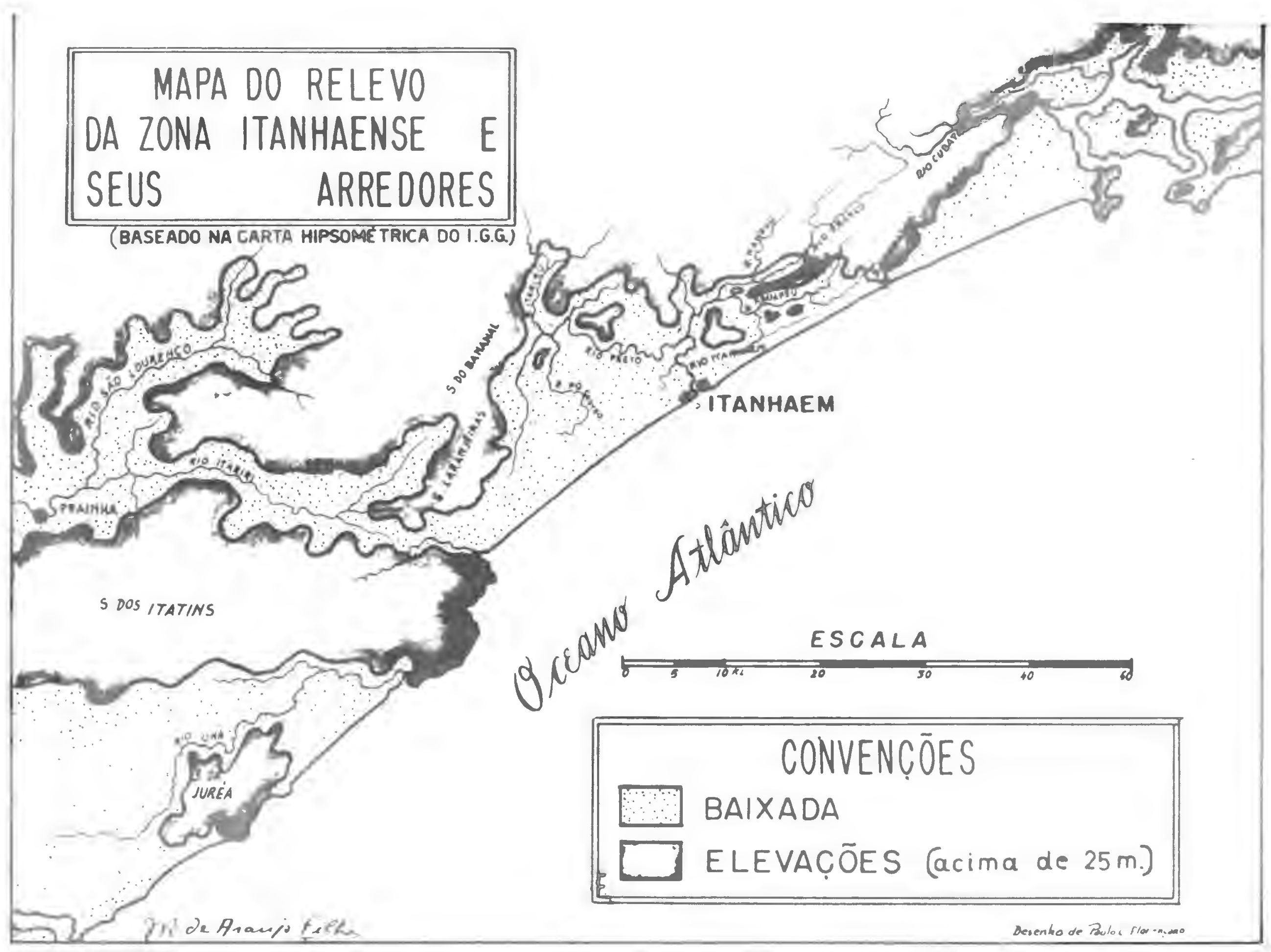




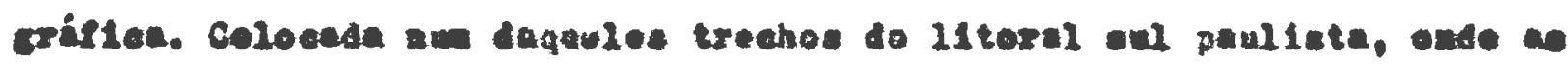

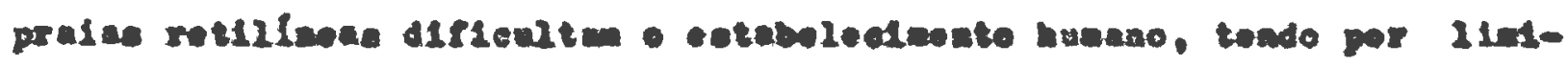

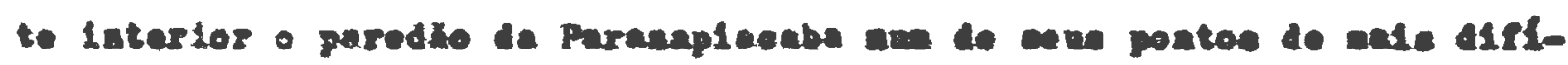

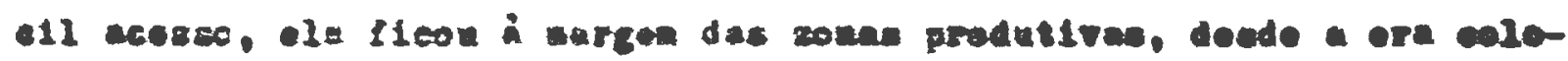
atal.

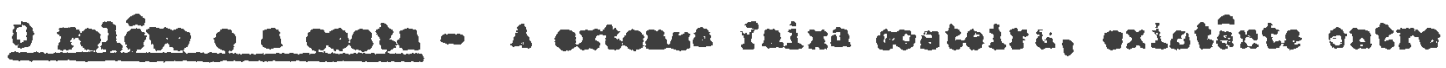

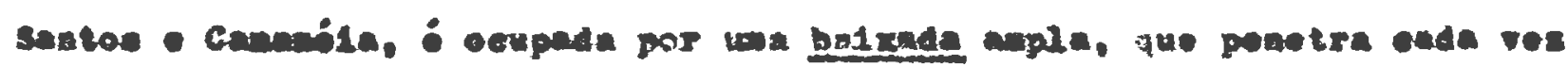

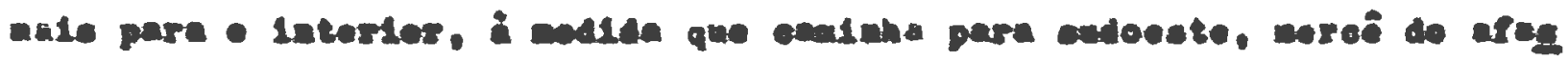

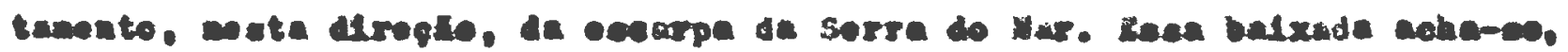

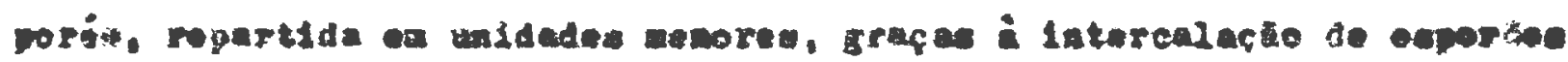

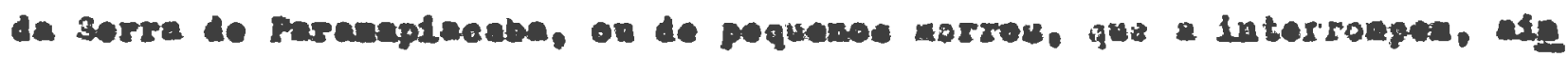

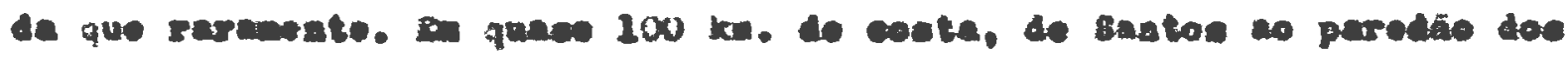

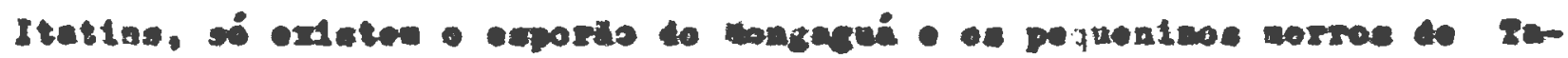

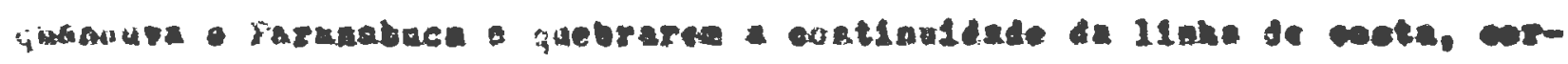

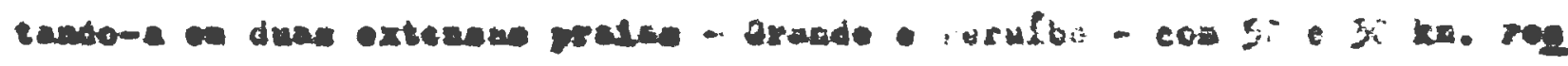
poetivaneato.

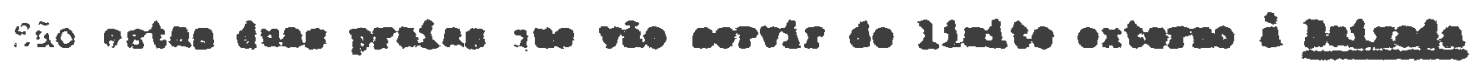

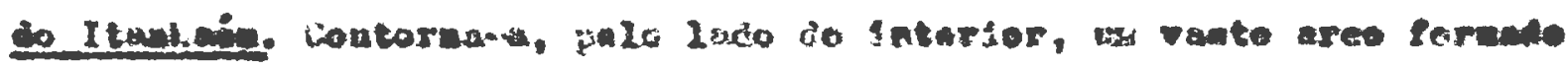

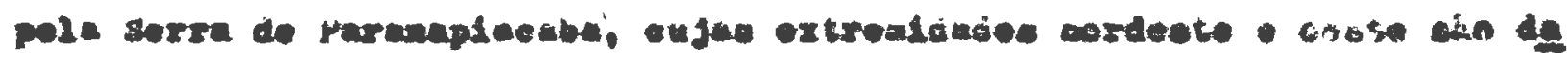

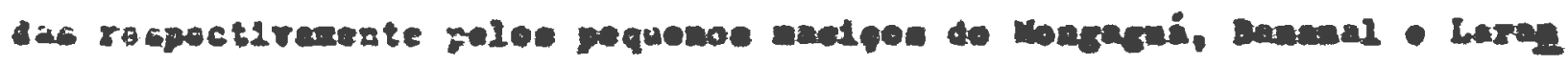

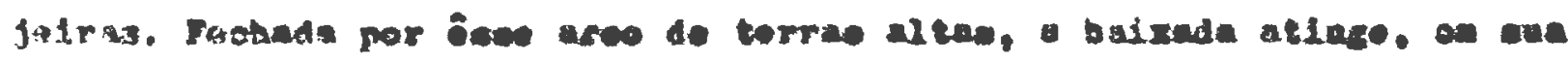

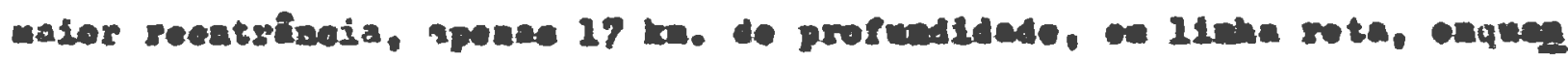
to que one anperflelo pode ser avaliade on $392 \mathrm{~lm}^{2}$. 


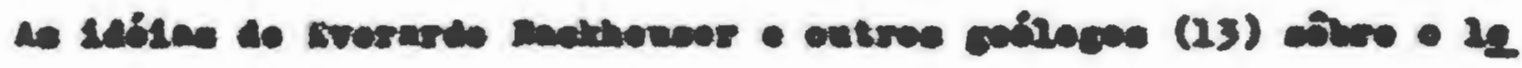

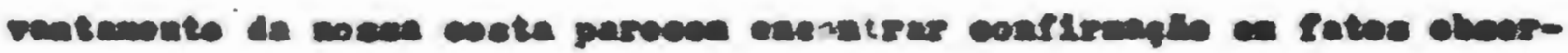

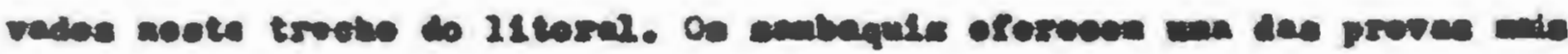

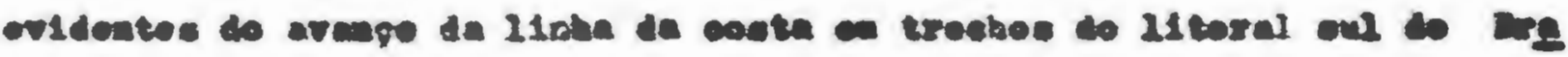

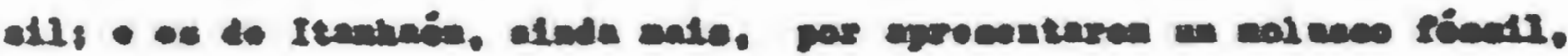

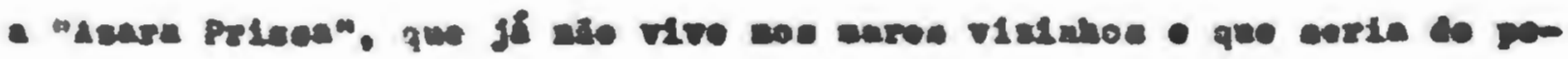

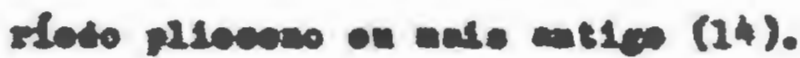

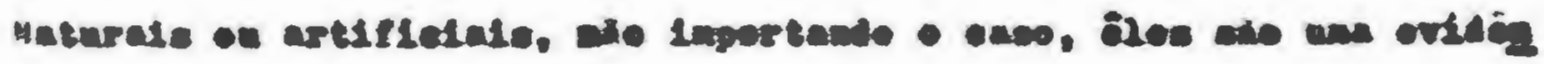

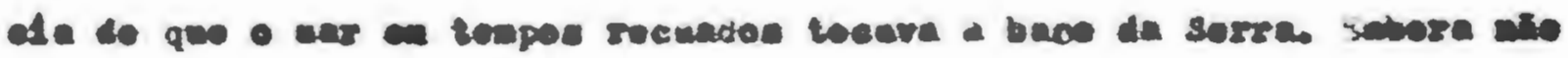

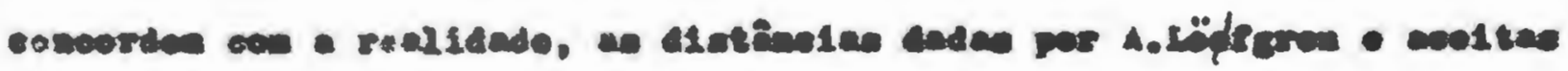

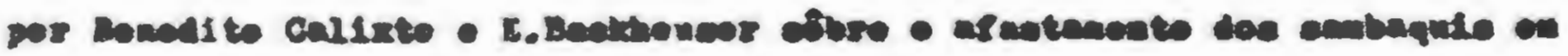

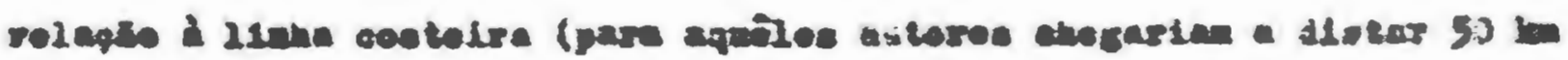

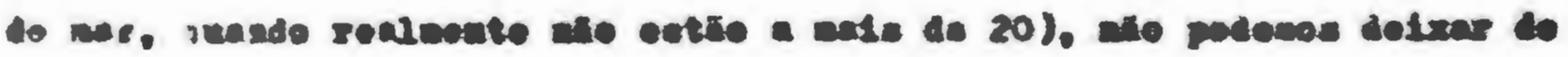

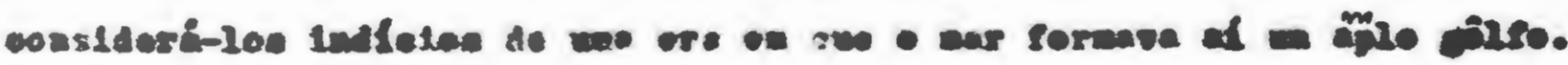

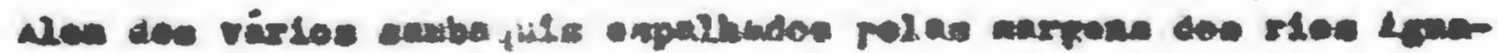

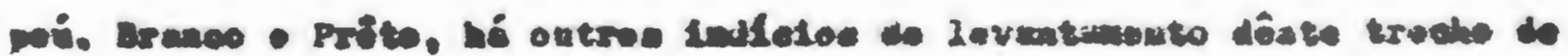

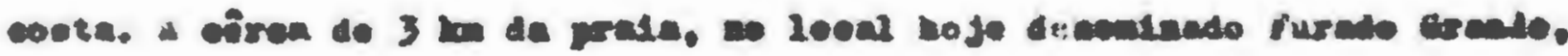

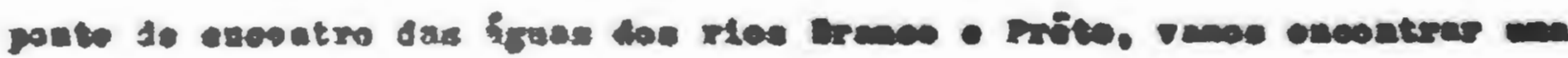

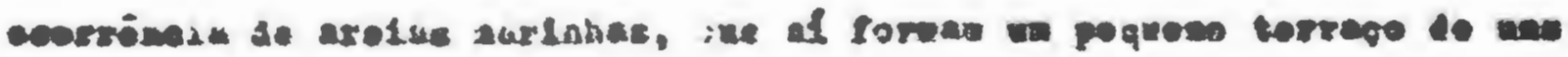

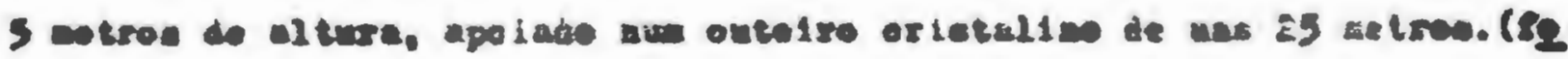

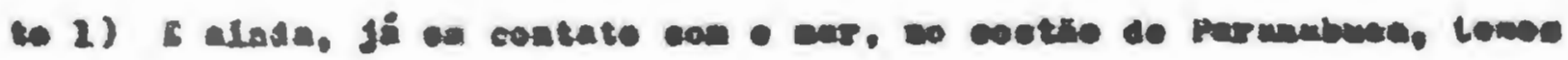

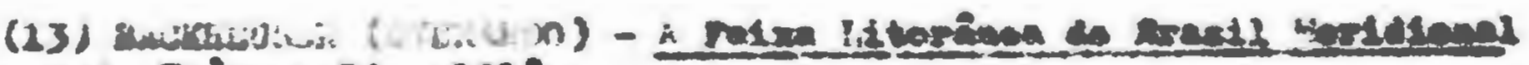

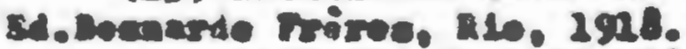

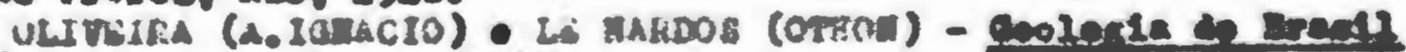

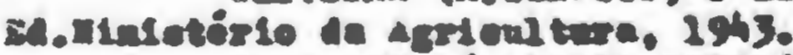
ches. 240. $28+3$.

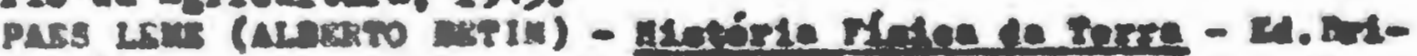

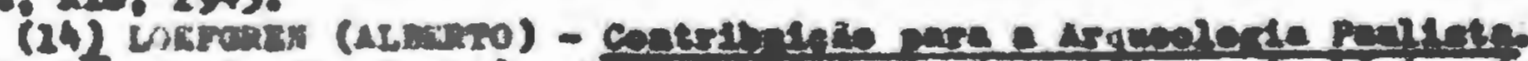

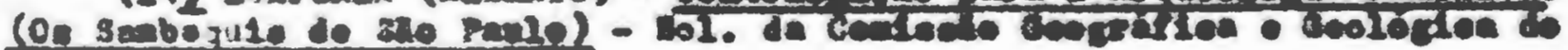

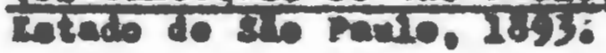


outra prova do recuo do mar, narcedo por dols alvele, wo alulno do pla

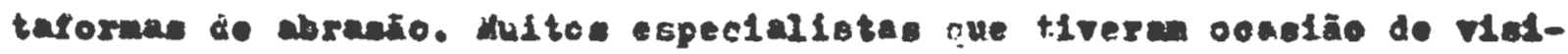
tar este costho foram unânimes on aflrax a extetônela de una sérî de torraçon an 20cal (15). (foto 2)

Parece-soe, portanto evidente que a recularieapio da linha de cog

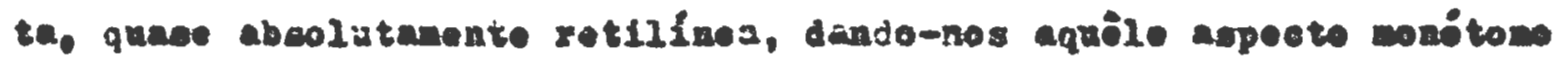
que já tivomo oeariāo de frisar a que tanta individualidade dá a co-

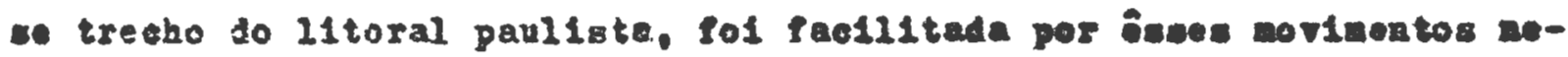
gativo do max.

A rêde nuvlel - Enbora nio poseamos diser que exteta un lagamar

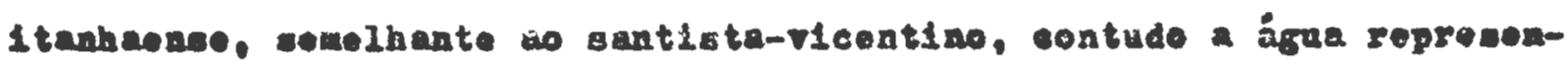
ta of lus papel 1mportantlasino, deode que lonbronos wo entaron atuda ae terras, on grande parte, consolidadee - Itvros do longol Ilquelde.

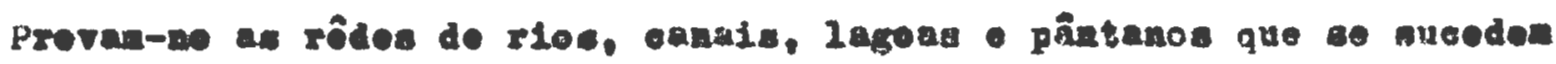
en tôda a sona, deade al proxdmidades do mar ató o wopó da serra (16). Poucoe form os ourson que fujeran renoer sozinhos baixada - atin gir o nar, organtzando una pequena rôde do afluonter tal tato ao dou

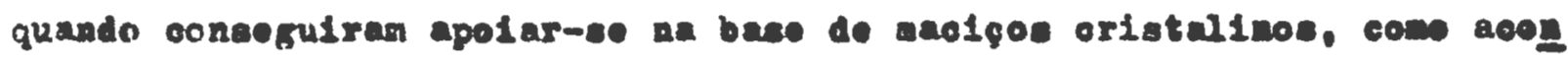
tocen con o Perufbo, Junto do Itatins, on con o Mongagia defendido pe 10 morro do meeno none. Donimam balxada o slo Itanhain ountralisador

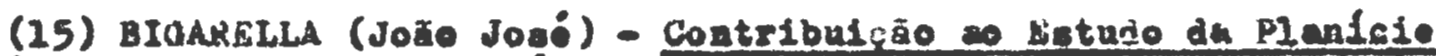

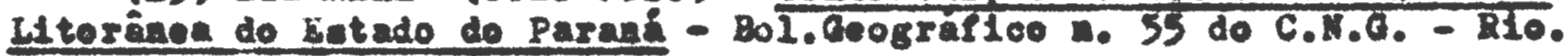

Hette trabaliho a antor elta os exemplos daqueles torrapos vieltado por 6lo por profesaores do Departanento de Genlogla da ra

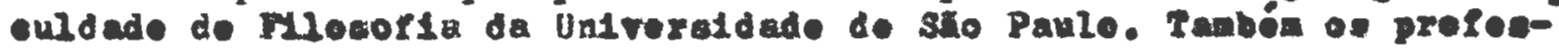
cores e absintontes do Dopartamento de Geografia, on vielta resente. tiveran oportunidade de conf1rmar, alida una res, o fato.

(16) Devesoe resaultar a importância que até hefe ponsuen os le Vantanonto feltos pala Conluexo Geojtalloa - Geológlea de Eatado do sa. Paulo on todo - Iltoral paulieta, cujos rolatór1os, - partieularmesito os napas eão os maja perfoltos que temos. 
Foto 1.

Aepboto do terrago na fos do rio Preto, onde hl ocorrencis de areiss marinhes. (foto do autor).
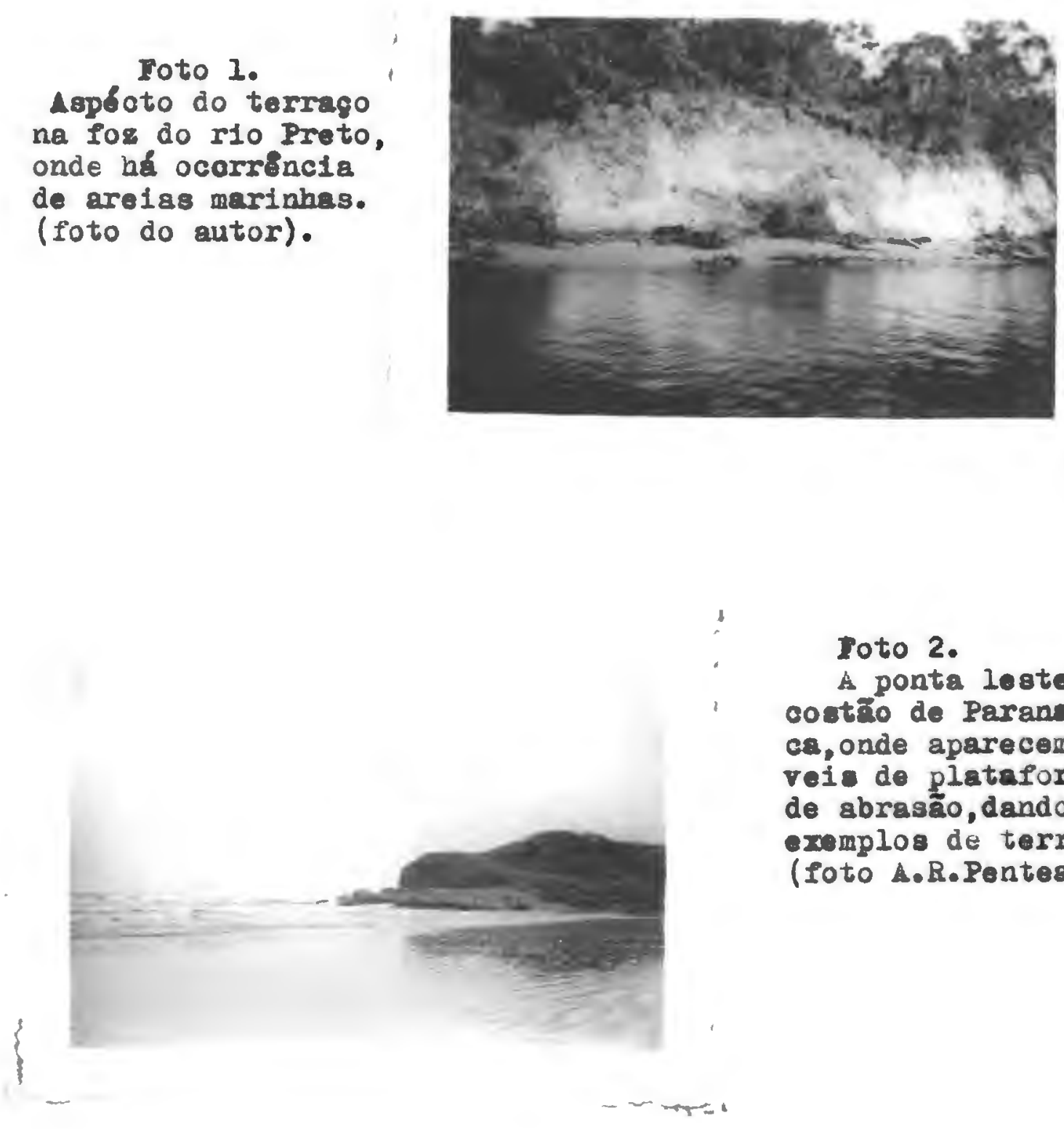

Ioto 2.

A ponta leste do coetioo de Paranabu ca, onde aparecem nfveí de plataformar de abrasăo, dando - noe exemplos de terragos (foto A.R.Penteado).

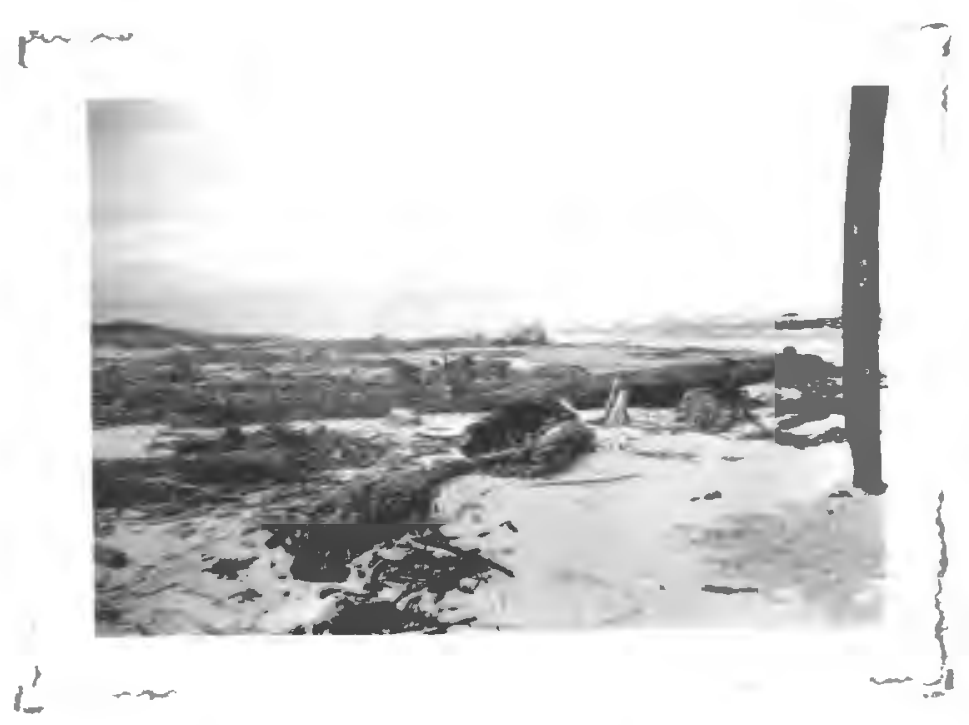

Foto 3. A extremidade sul da praia Grande alom de aer de "tombo", aparece,por ocasiäo das grandes chelas do I tanhab́n, coberta de detritos trazidos pelas dguas daquelo rio; säo troncos de árvores, troncos de bananelras, cachos e folhas, arranoados dos sitios inundados, que forram as arelas da praia. o que a foto nos mostra. (foto do autor). 


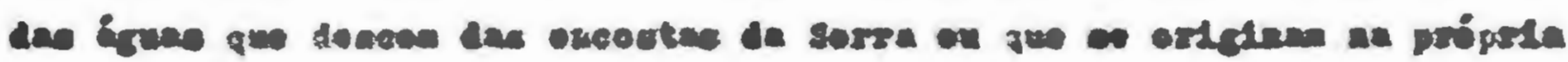

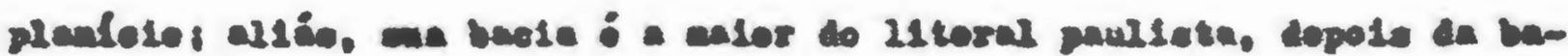

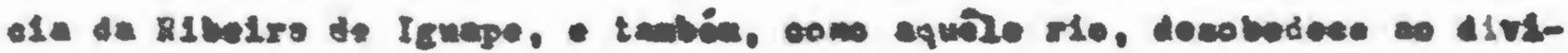

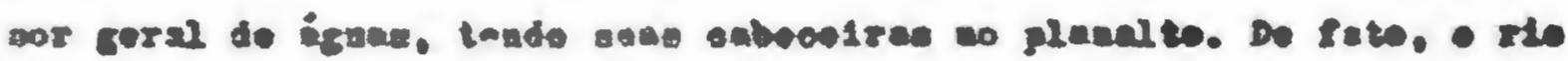

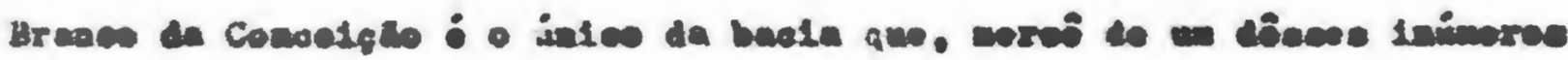

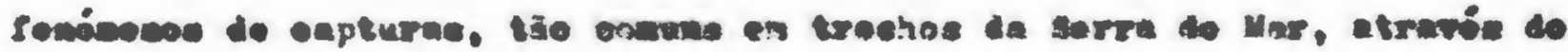

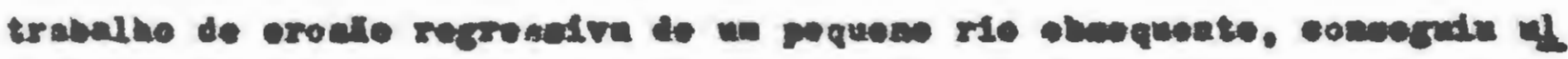

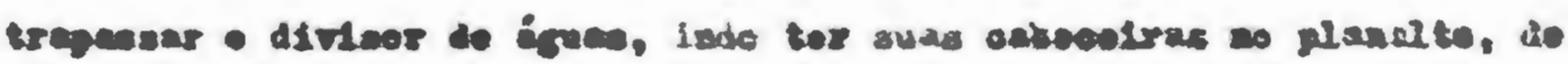

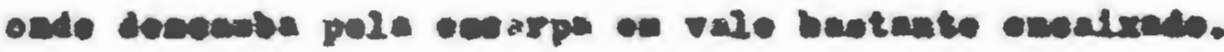

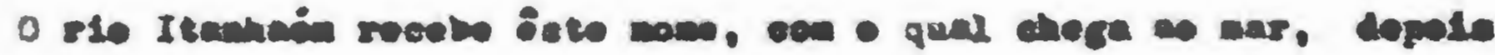

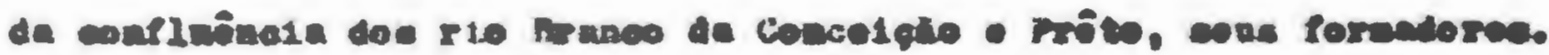

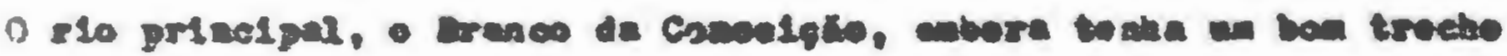

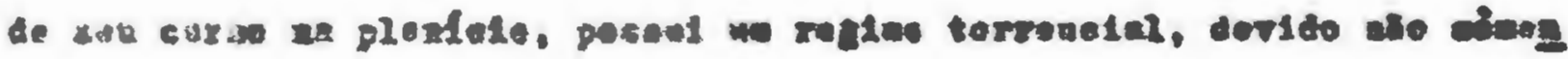

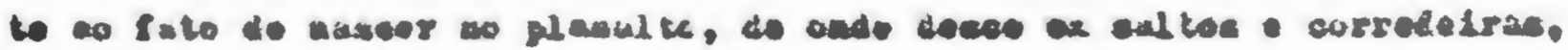

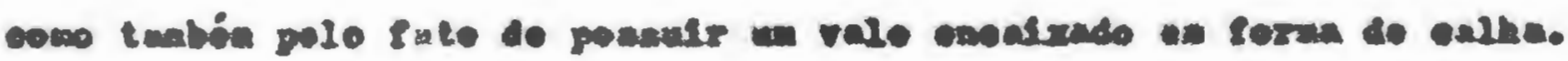

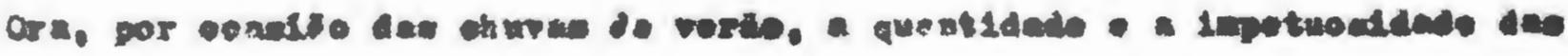

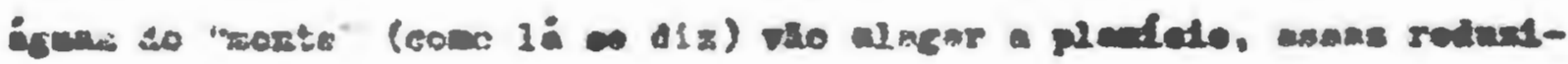

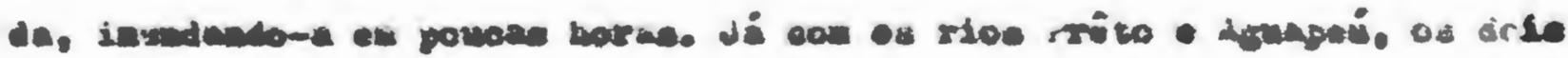

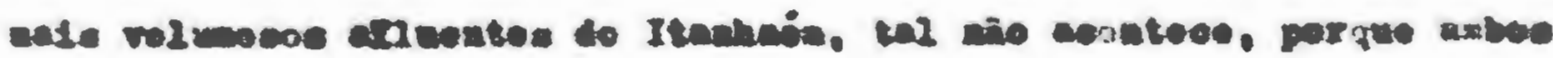

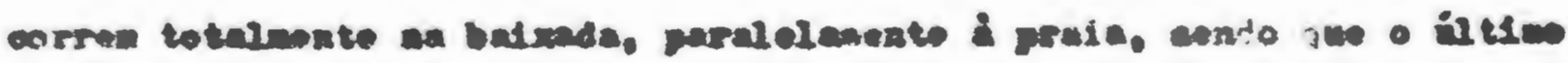

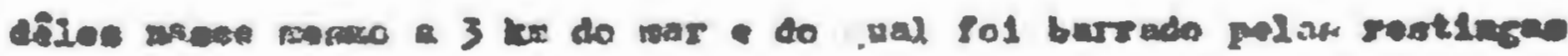

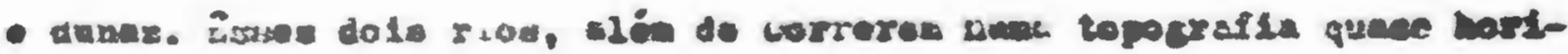

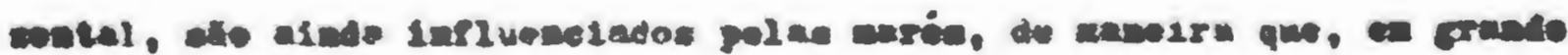

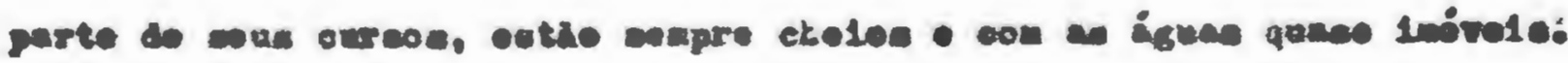

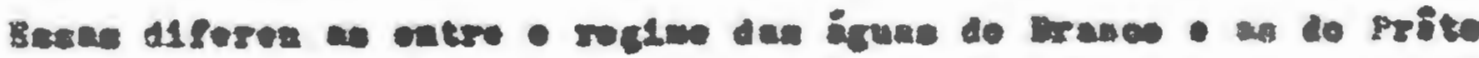




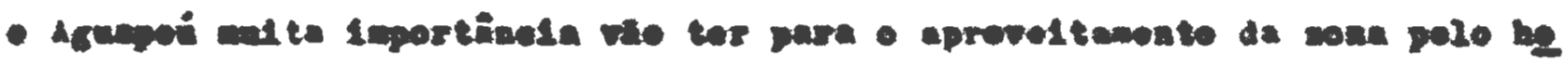

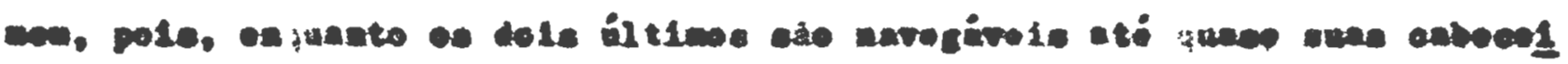

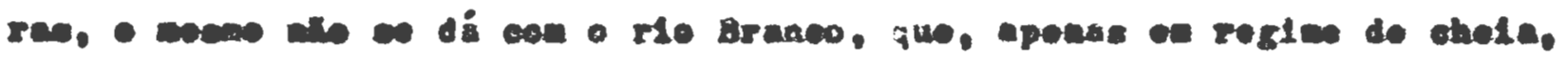

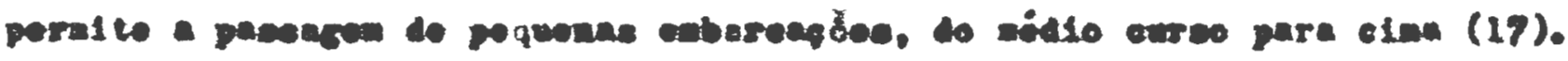

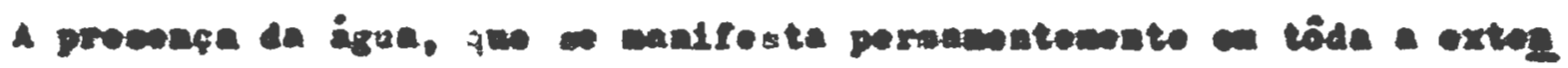

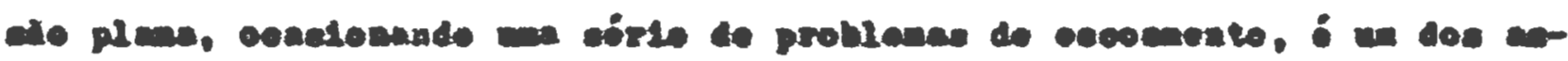

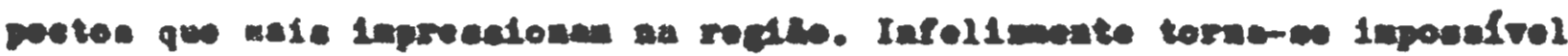

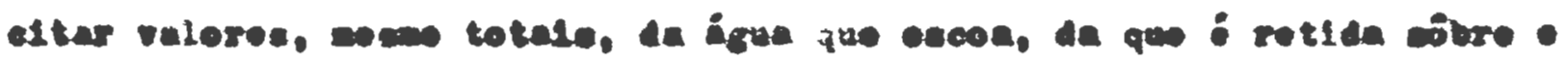

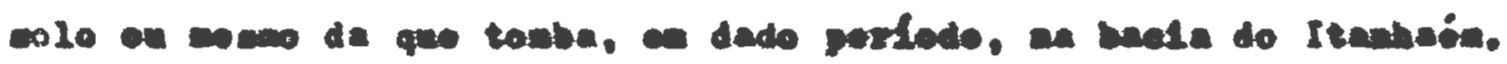

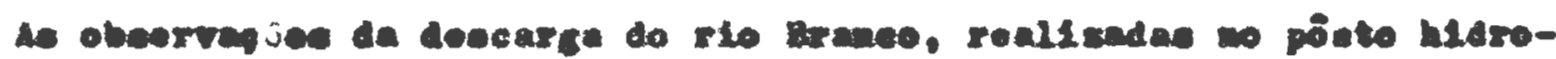

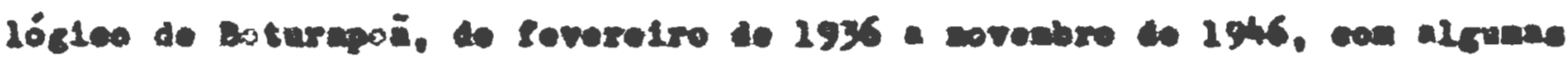

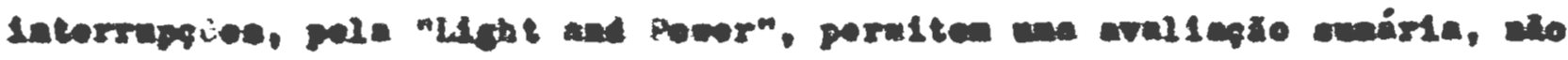

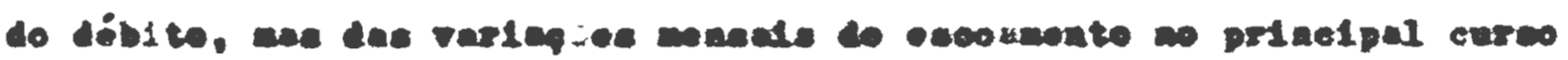

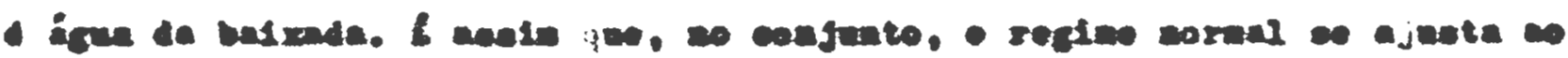

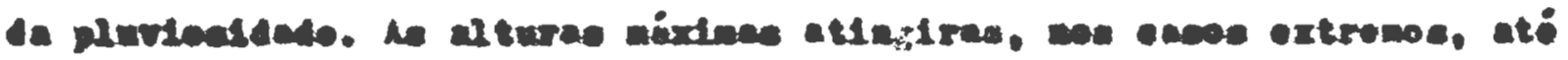

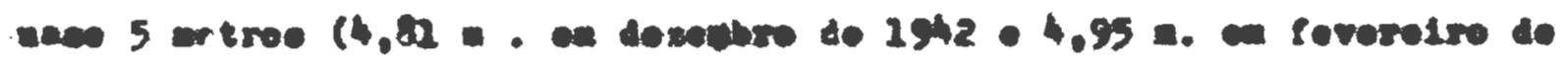

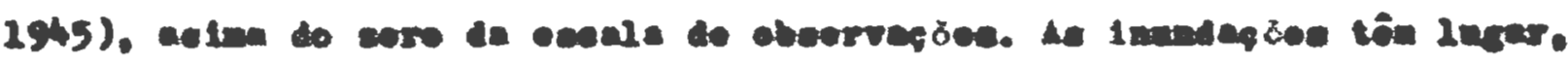

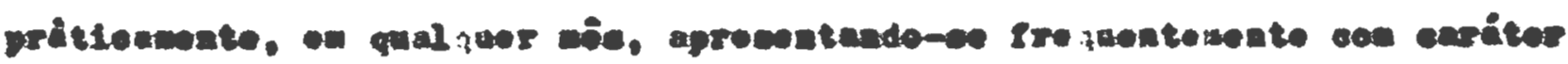

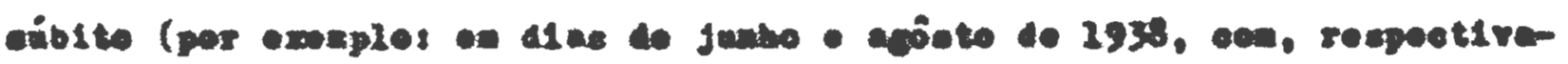

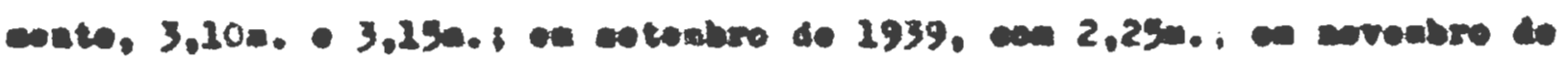

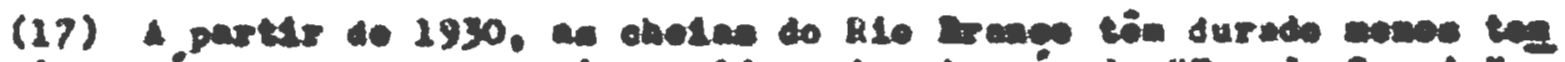

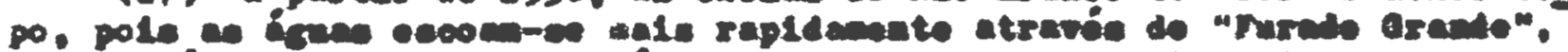

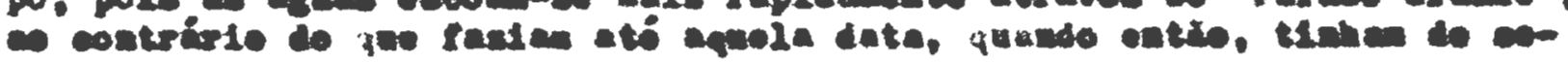

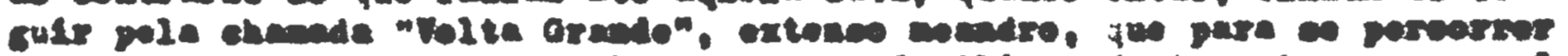

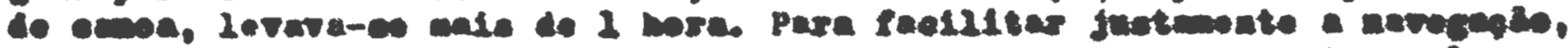

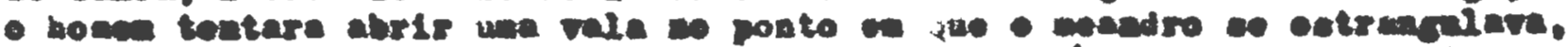

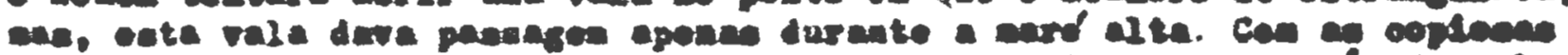

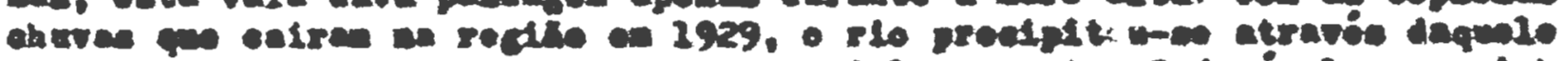

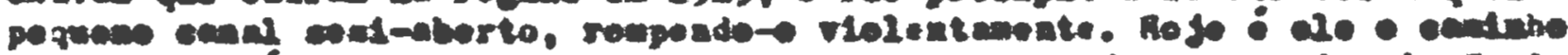

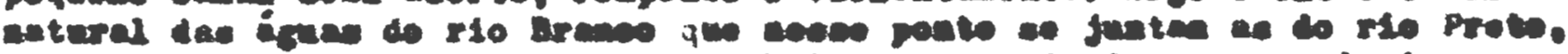

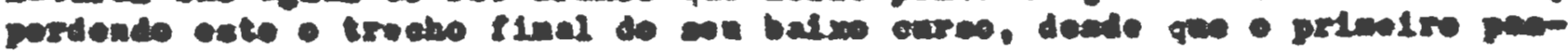
con a correr e cou lagas: 


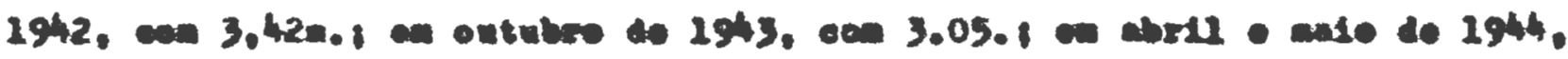

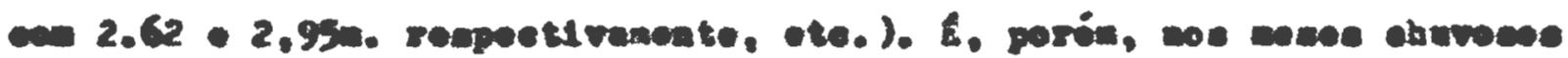

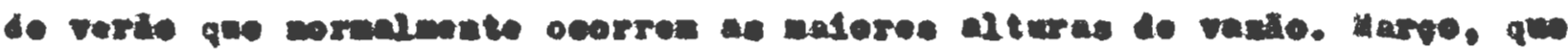

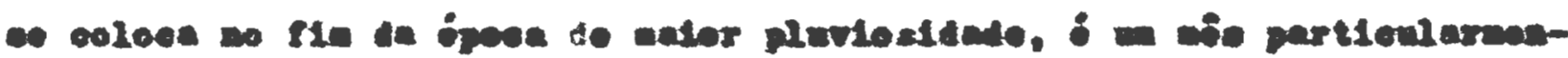

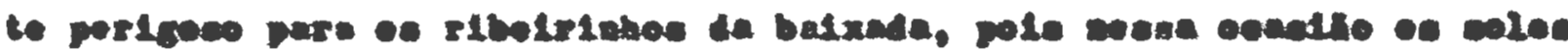

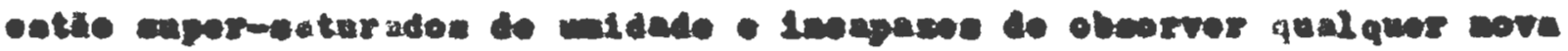
earca d' icuas

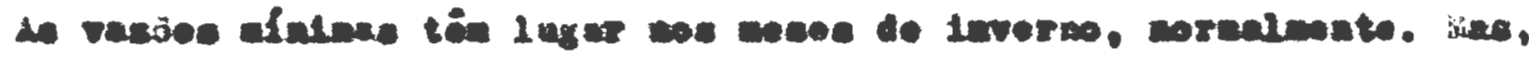

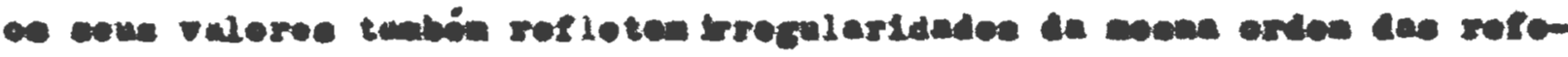

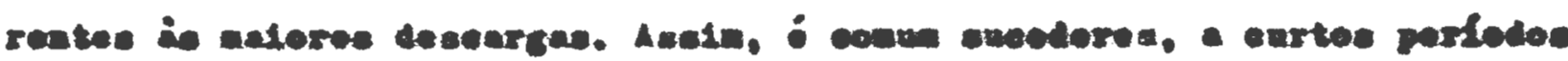

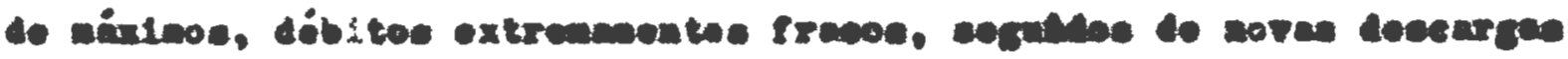
elereder:

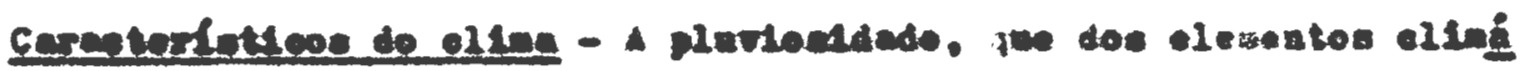

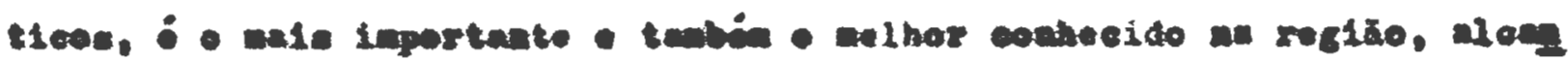

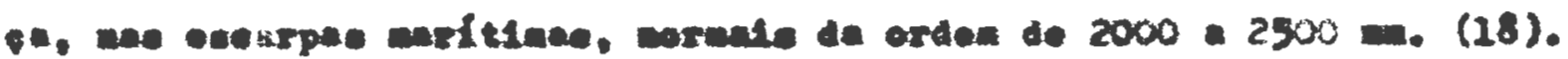

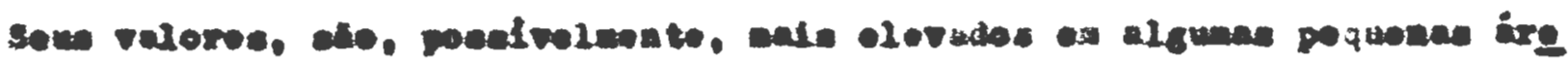

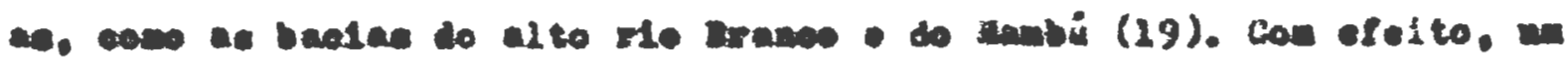

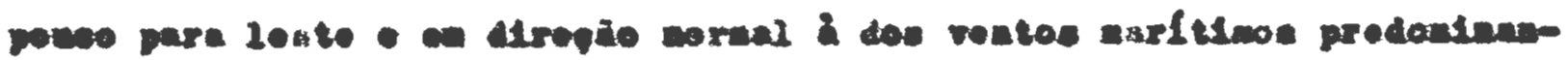

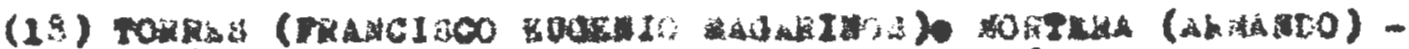

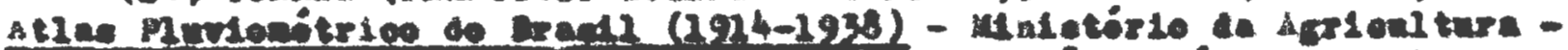

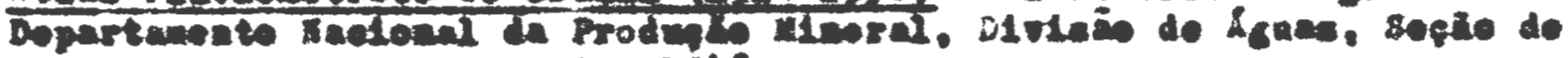
Eldrolog1e - Dol. D. 5, n10, 2948:

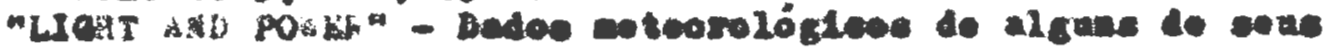
sostos.

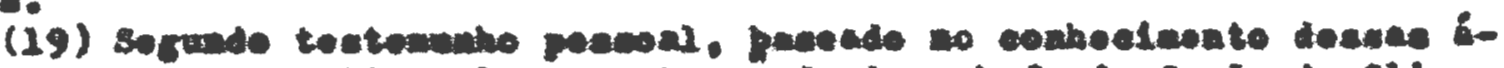

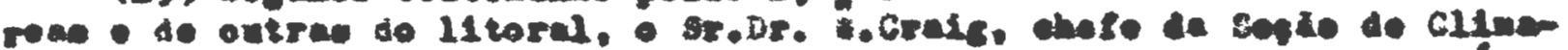

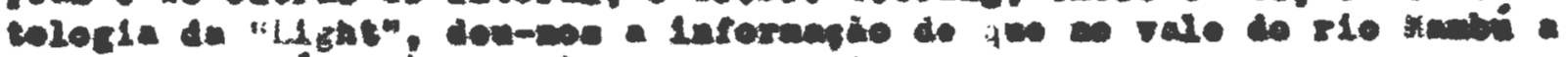
pluvioctdede : do 4000 - $4500 \mathrm{~m}$. mavale.

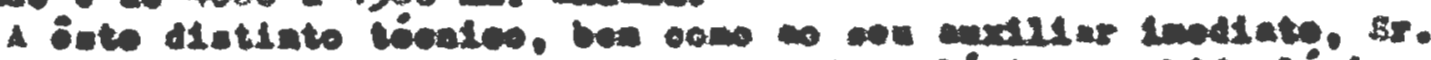

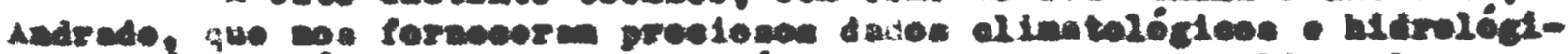

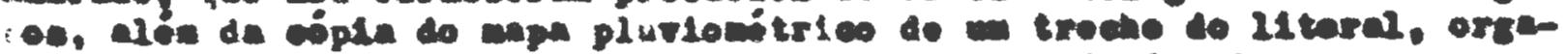

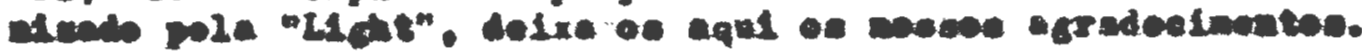




\section{1}

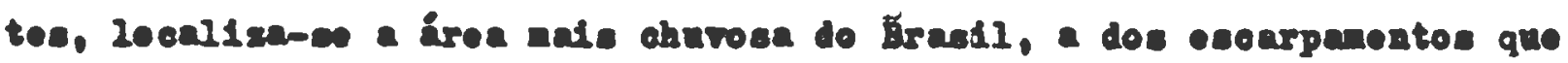

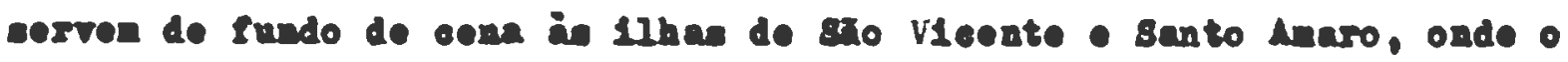
pôto pluvlonótrleo de Itapanhai analnalou a Inproselonanto sódsa do 4500 an. en 29 anos de observapoes (20).

8one levados a eres que as escarpas qu lintten a oeste a balrada

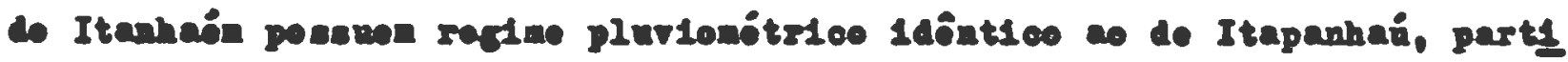

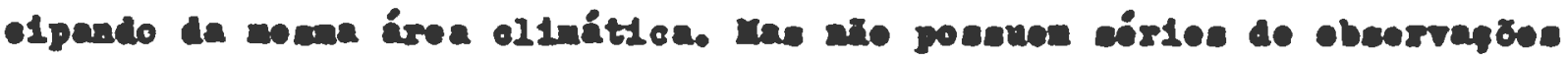

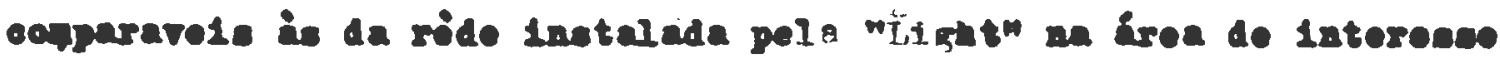
para os coue reservatórios do planalto. Por bese notivo, delxamos do at1llsar aqul os dados fraquentírios que nos 501 poselvel obtor a qu tcิ valor mutto roduzido (21).

Recolhendo as ohuvas da bacia para encandnhi-lae so nar, a badrada apresenta, porón, afvele pluvionótricos ben laferiores aos das ecearpas, oon ten aldo regletrado nos poston pluvionótricos de Itanhán, - Prasa Grande (rempet1ranente con 2581,8 • 2325,9 m. anuads).

Anplemente aberta para o ar, cono : a planfole, - oferecendo as d1reglo dos rentos narftinos prodontuantes (8 - SE) poucos obstheulos,

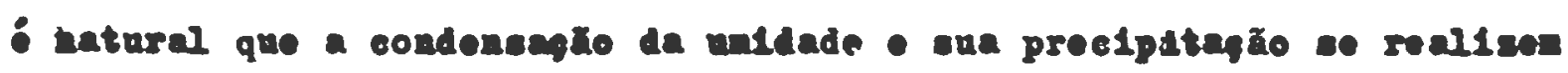
de encontro soe paredóen da serra, - tanbén que os rentos dolron à sua retaguarda nonores posatbllidades de ehura.

So wa betrada : ande on monos defintdo, no decorror do ano, wa pe slodo cheo, que ton lagar de junho a outubro, nas esearpas, pelo contrẹ r10, todos os nesee wo ohurosos, sobresatindo, come antural, os do re sĩo. F"en narę, entrotanto, que tôn lugar as nats pesades churas, que

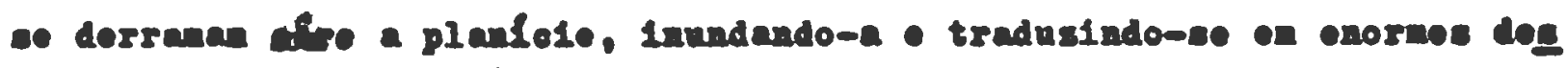
- 1938. 


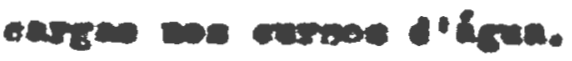

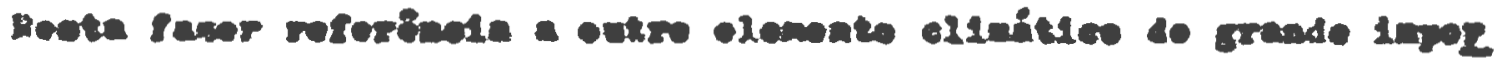

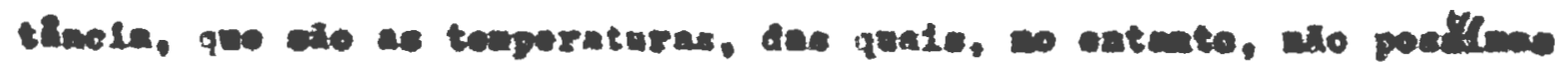

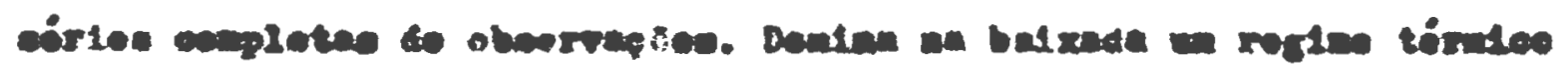

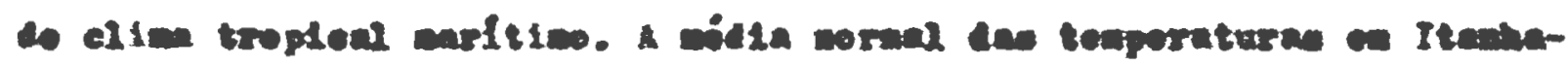

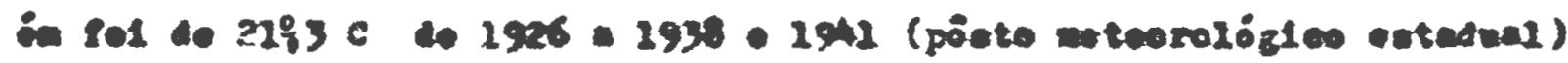

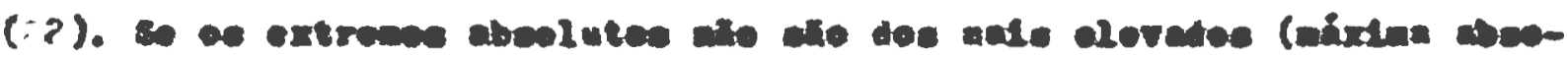

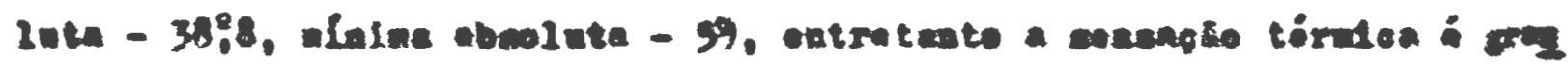

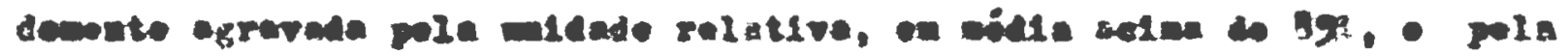

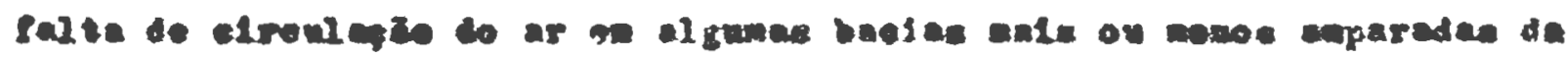

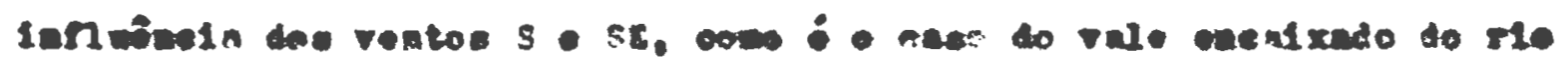
Dranco.

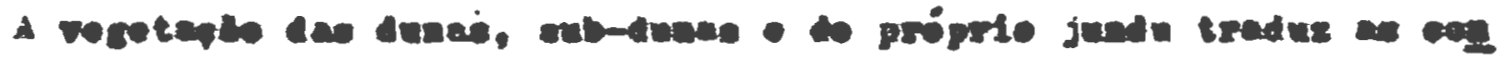

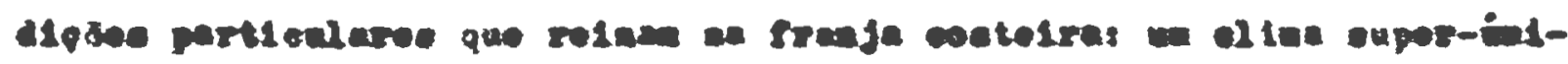

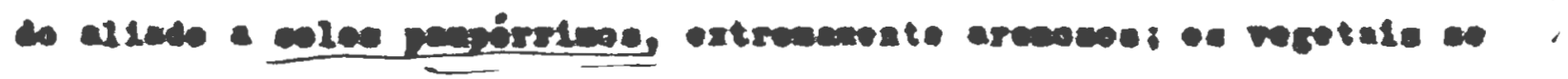

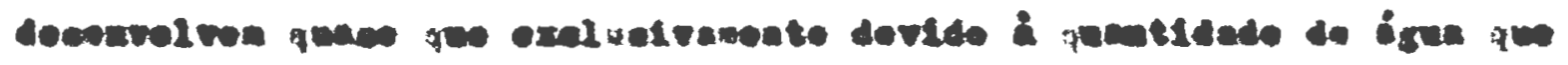

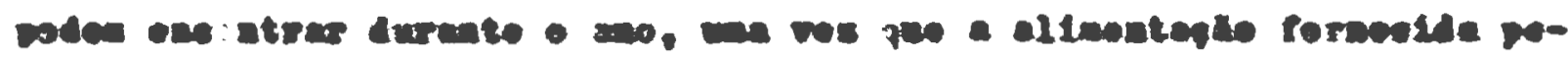

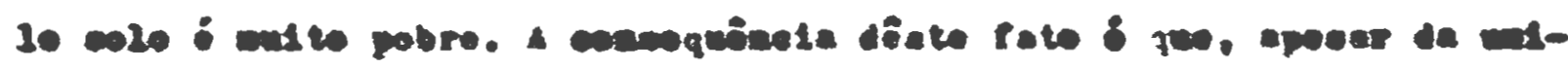

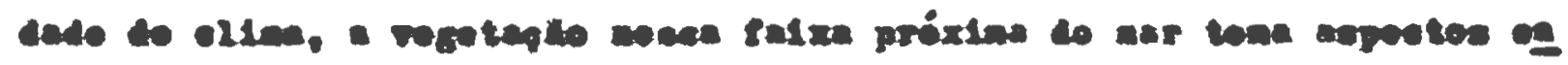

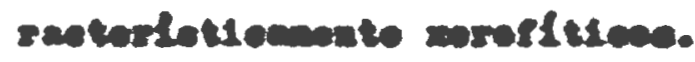

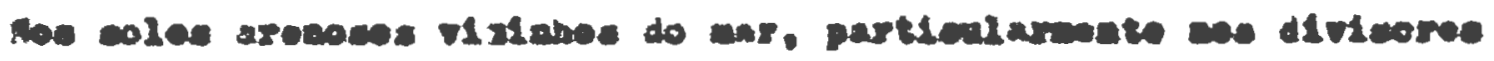

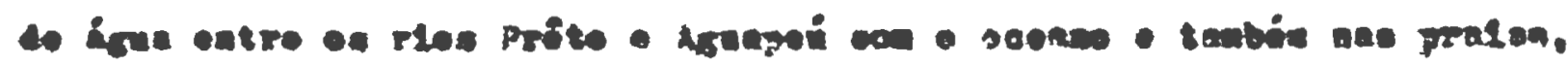

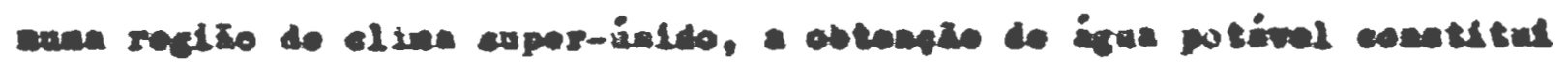

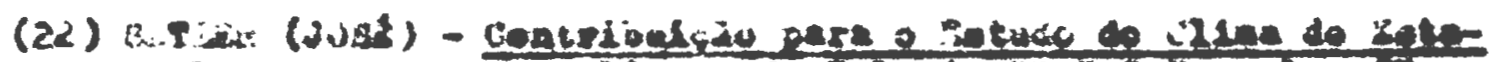

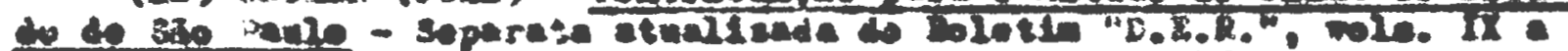

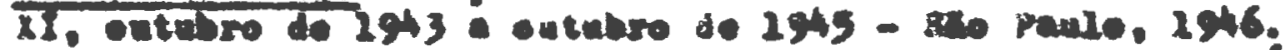

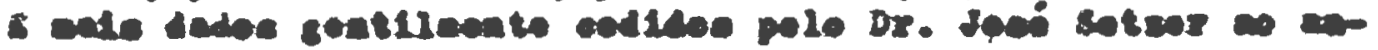
cor do procente traballe. 


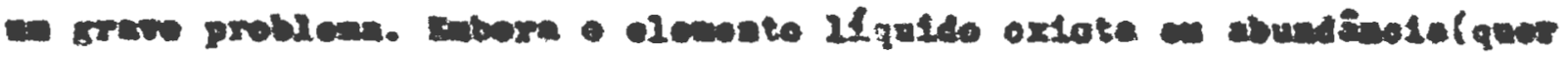

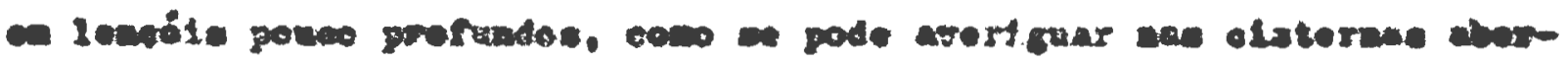

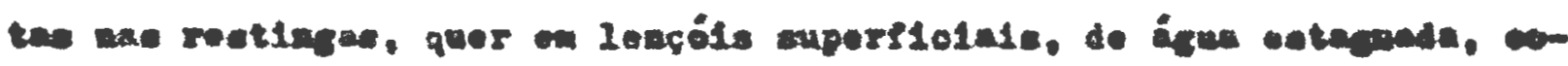

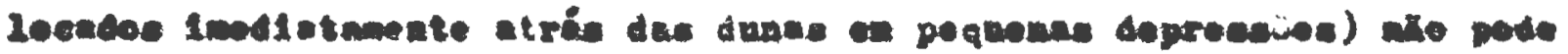

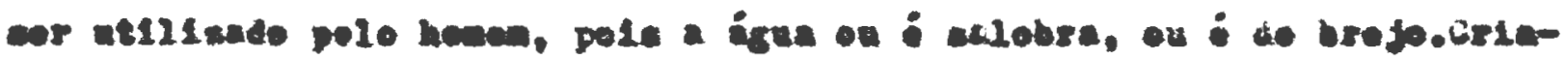

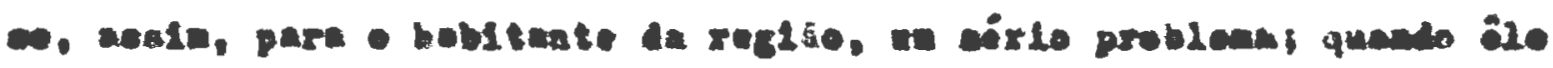

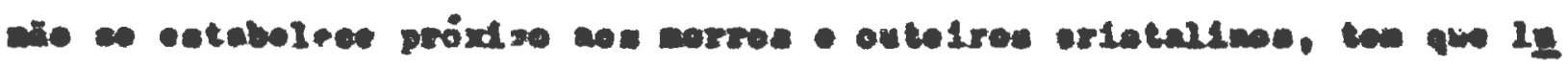

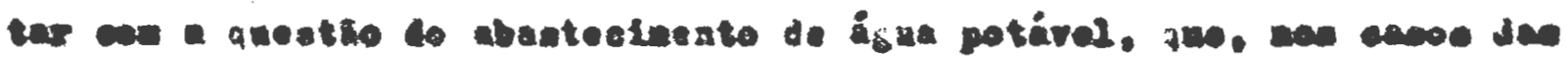

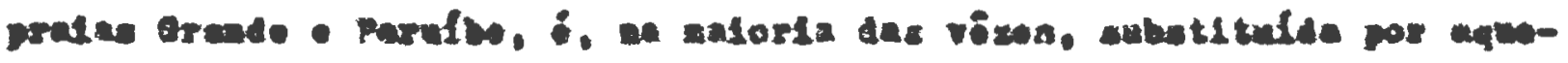

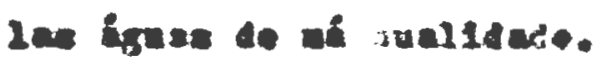

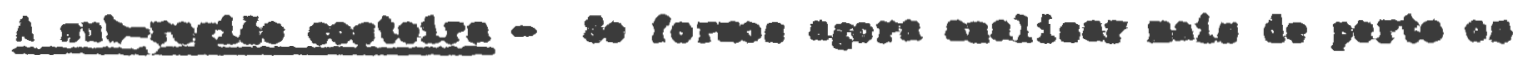

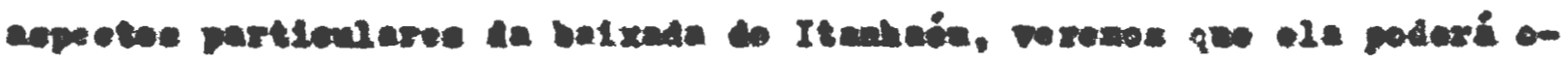

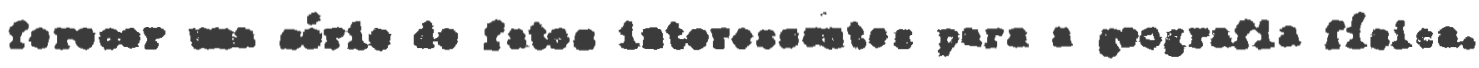

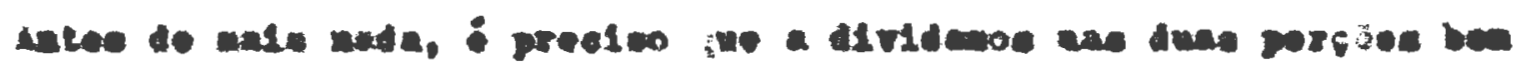

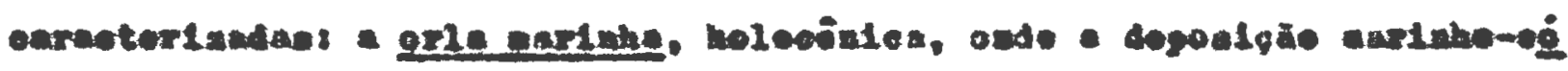

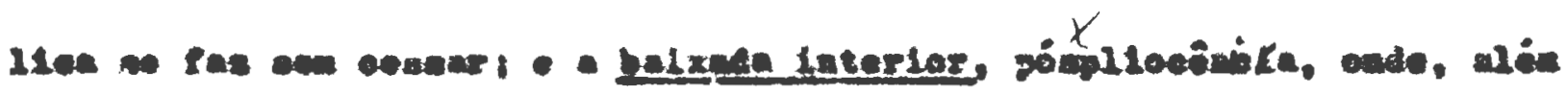

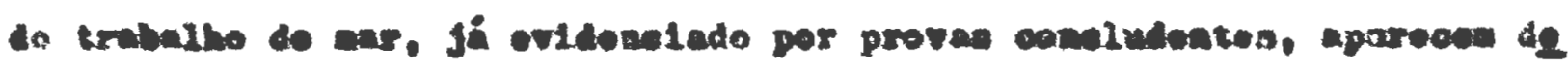

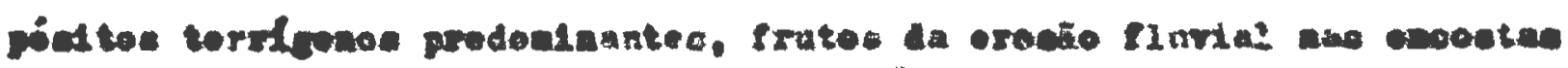
1. Pareaplacaba.

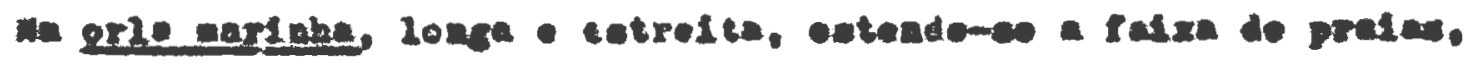

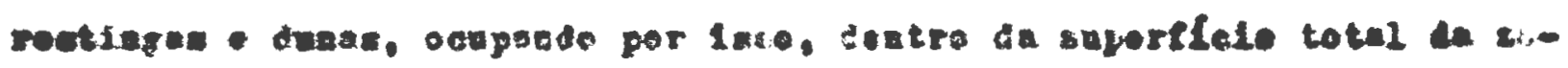

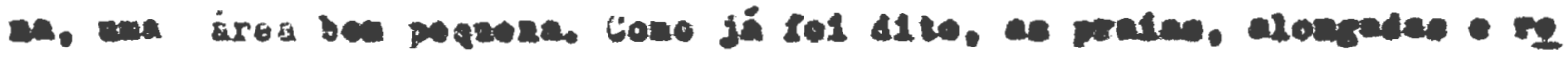

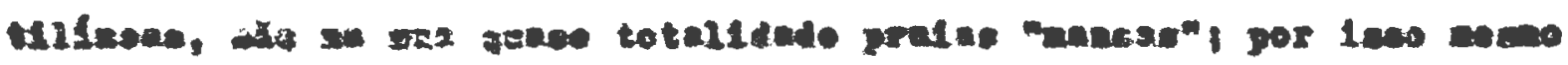

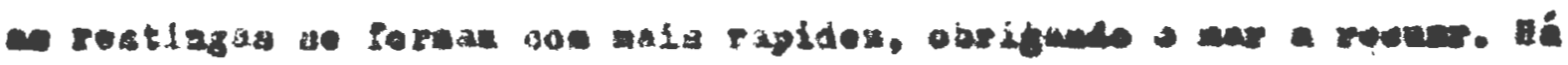




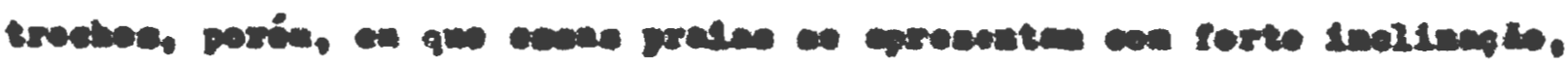

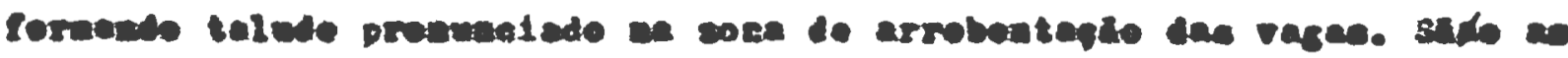

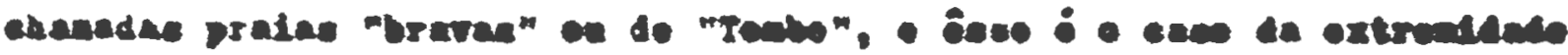

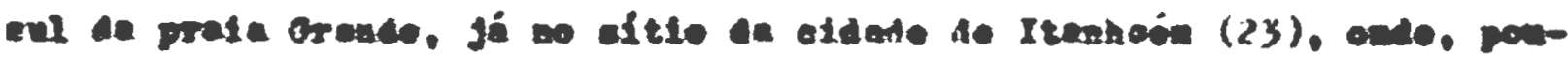

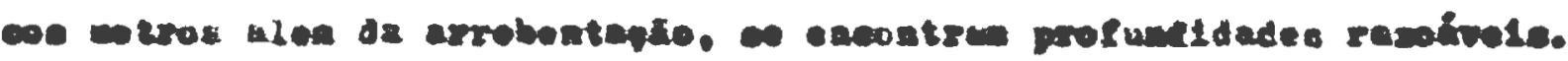

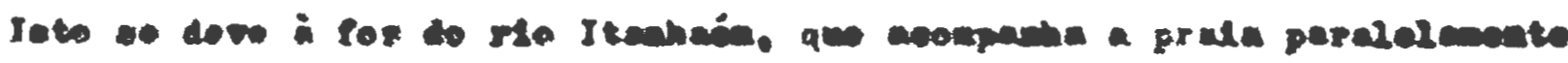

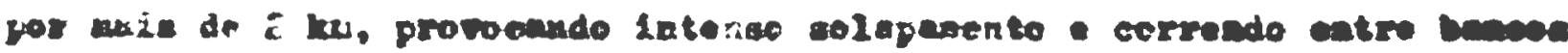
Larolar movedfac. (Iete 3)

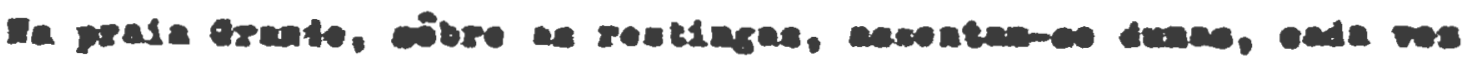

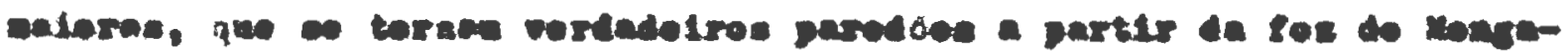

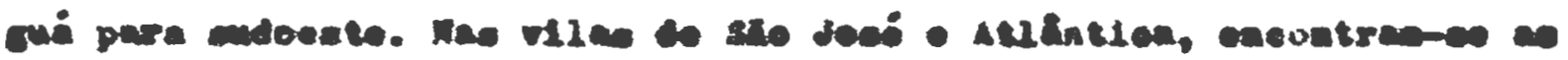

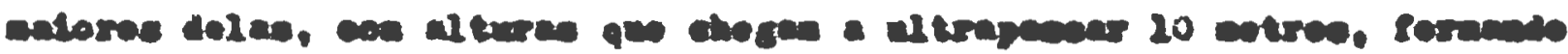

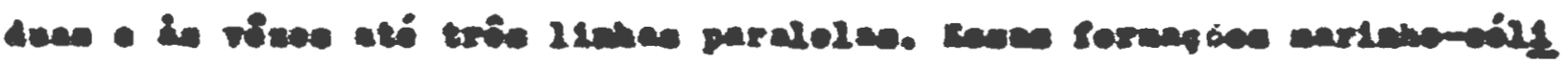

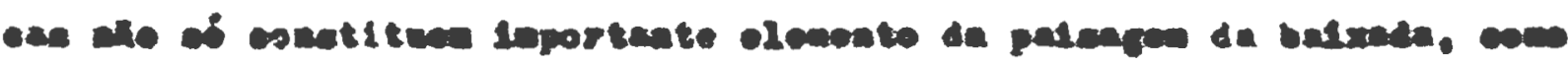

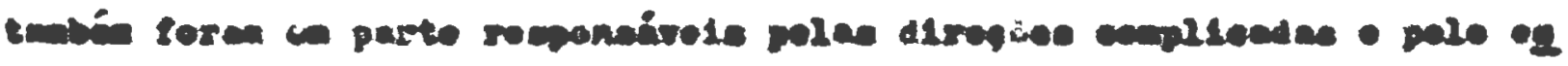

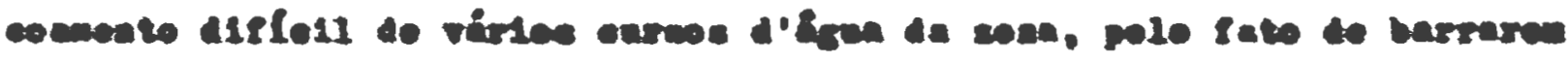

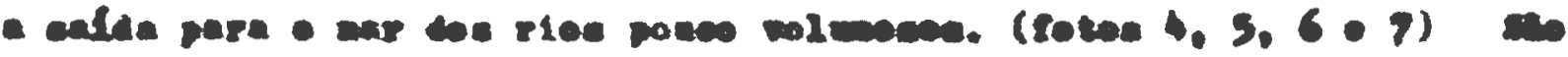

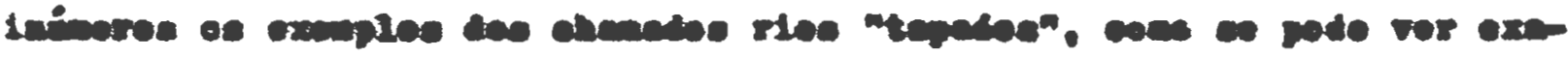

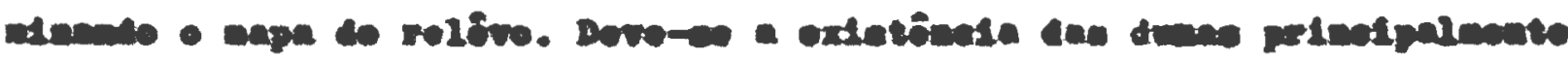

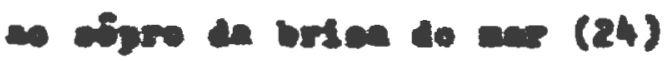

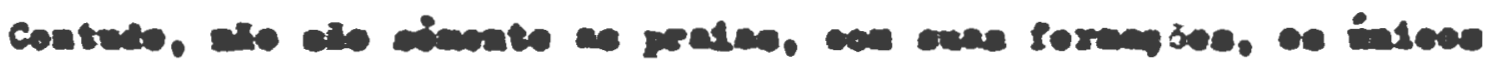

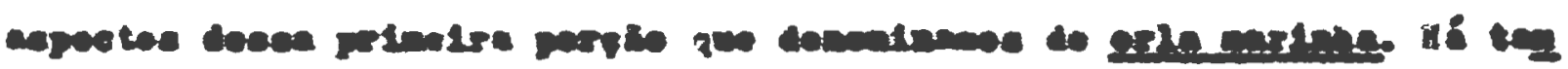

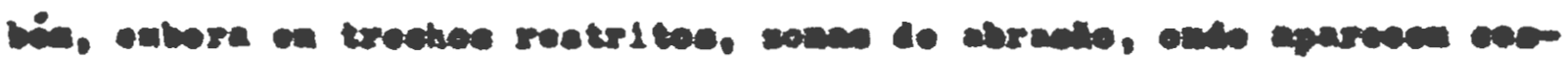

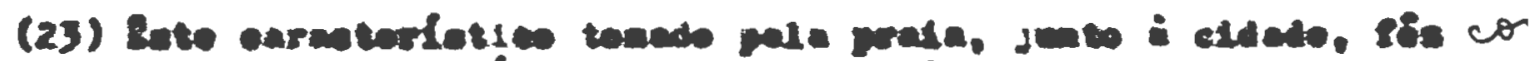

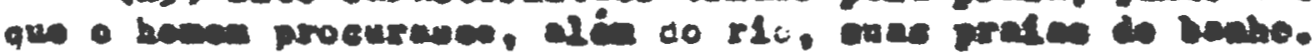

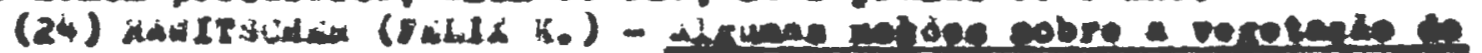

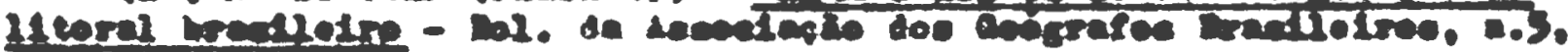
ila Falo, 197. 


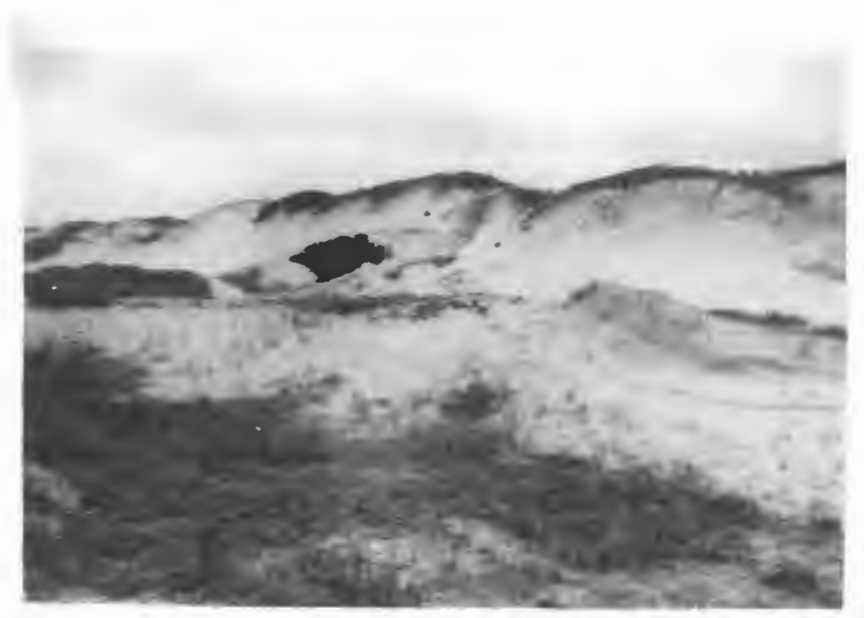

Ioto 4.

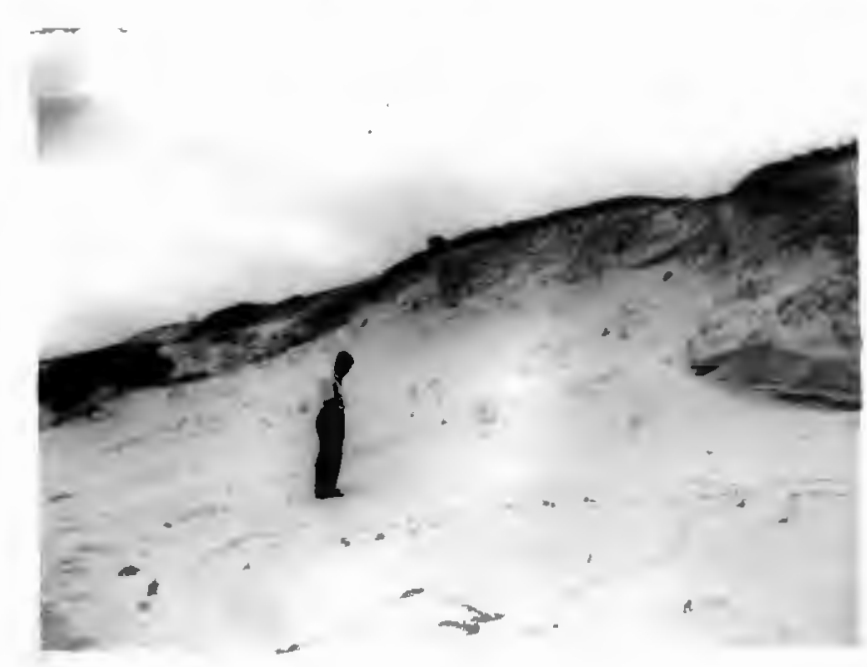

Poto 4 a.

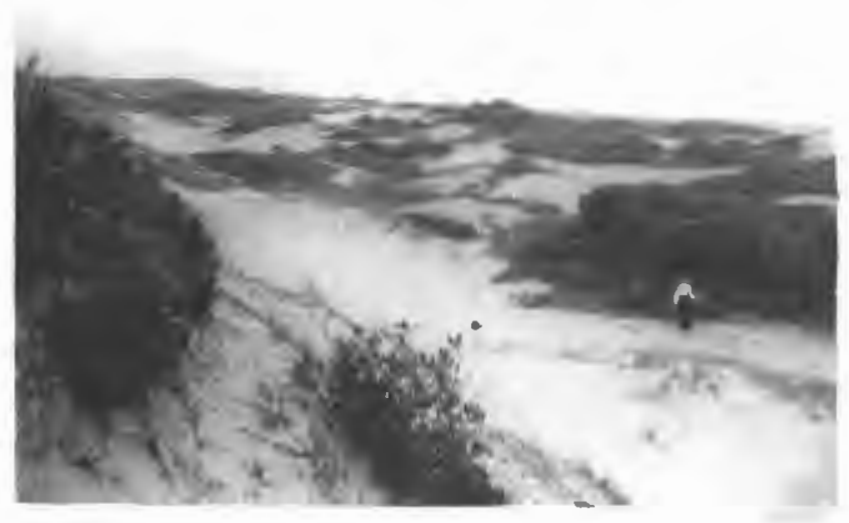

Foto 5.

IInhas de dunas na praia Grande oobertas pela vegetaça peandita na face voitada para o mar e por capöes de jun dú no reverso. (fotos do autor). 


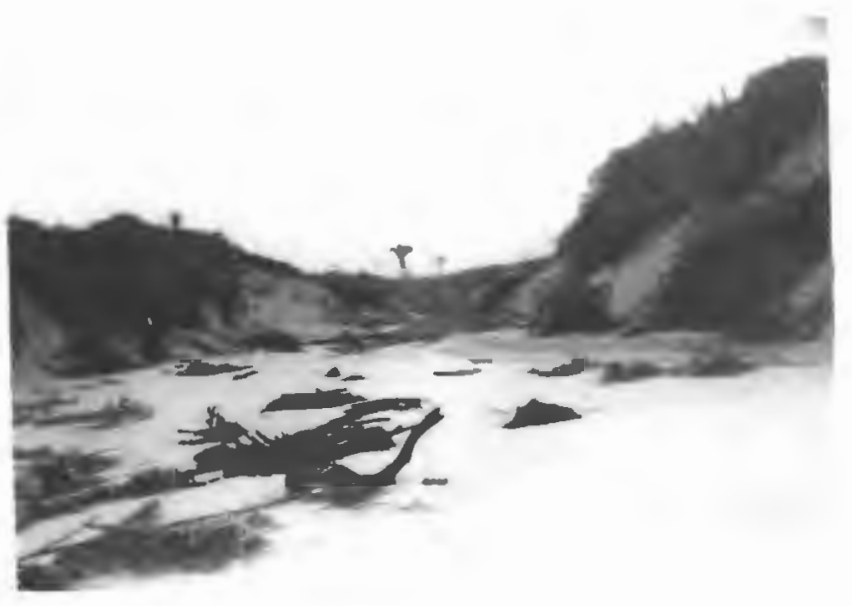

Foto 6.

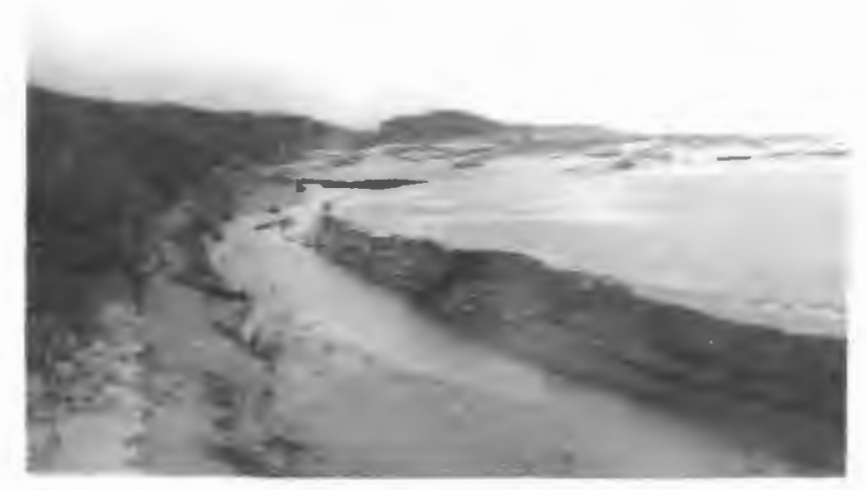

Foto 7.

Bxomplos de rlos "tapados" que na Época de Verỉo coneeguem venoer a barragen oferecida pelas duna, abrindo verdadelros "boquelrōes" pare alinglren a praie. Multan vezes estes rios ato obrigados a ineandrar por vários gaile metros entre a praia o a cuna antes de cuegareis ao zar. (fotoe do autor). 


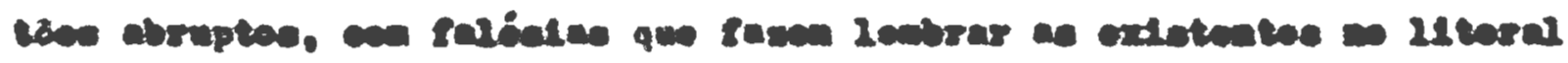

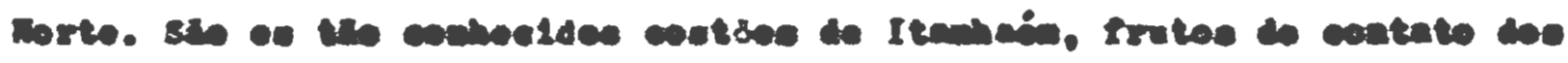

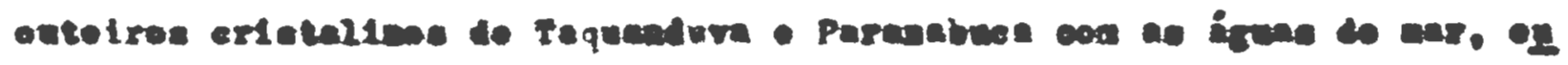

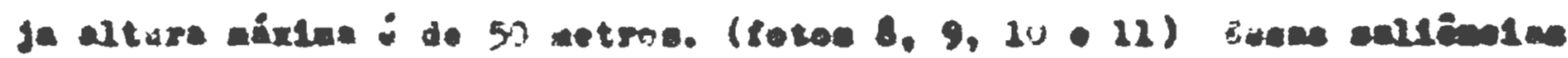

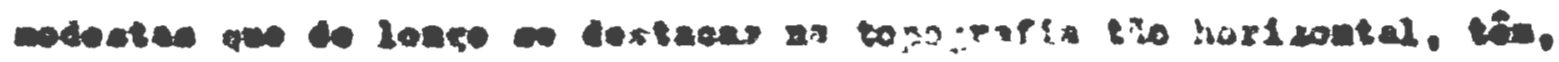

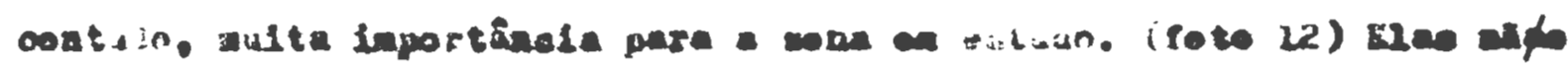

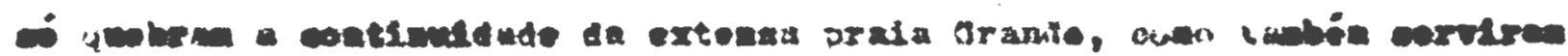

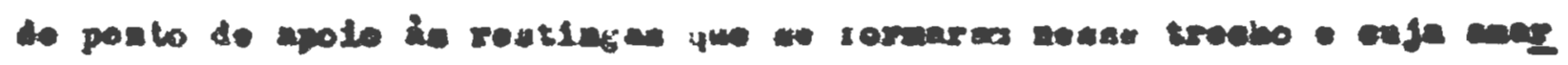

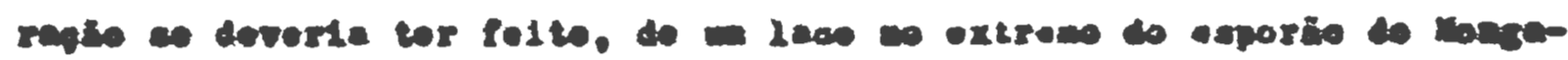

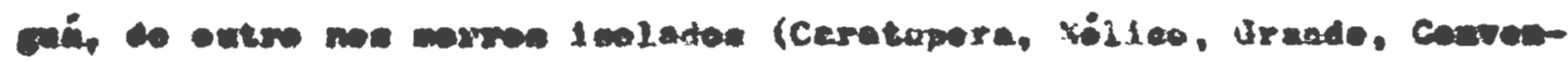

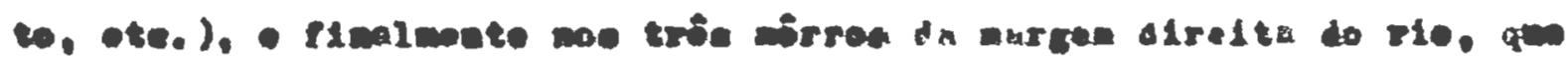

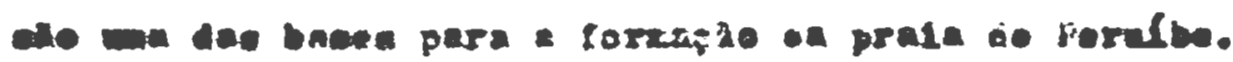

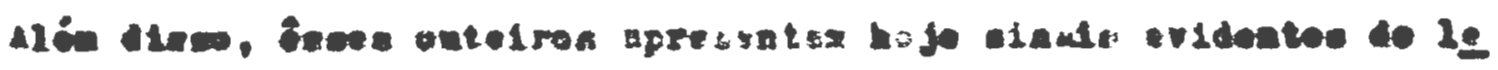

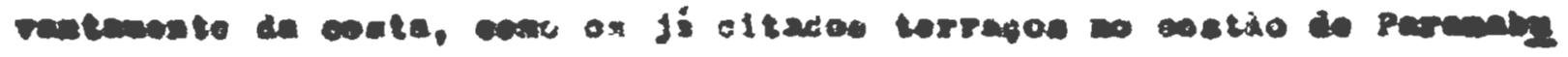

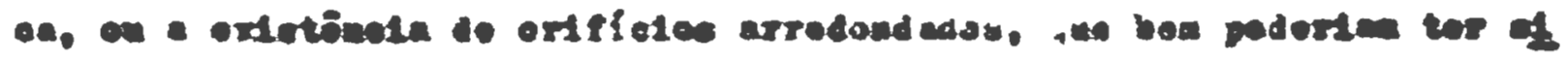

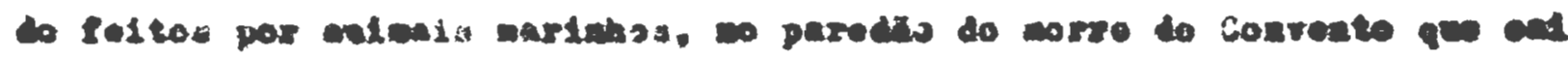

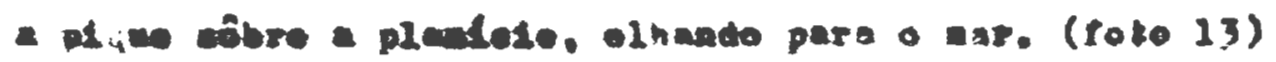

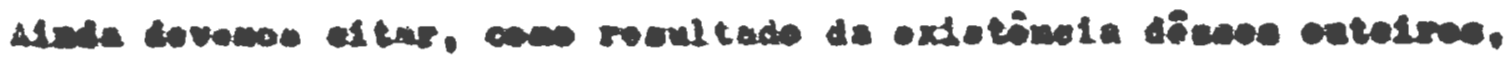

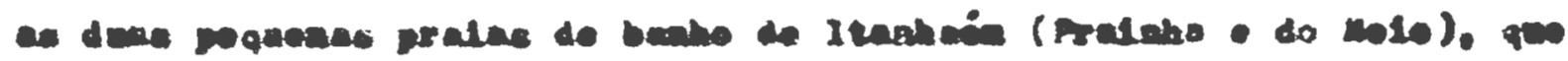

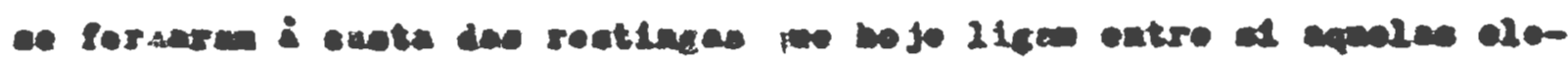
19.9.4.

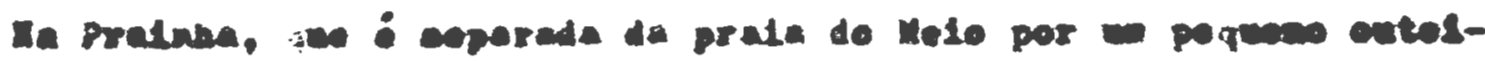

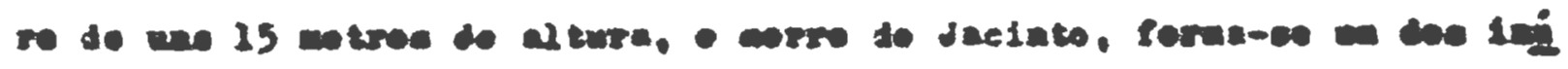

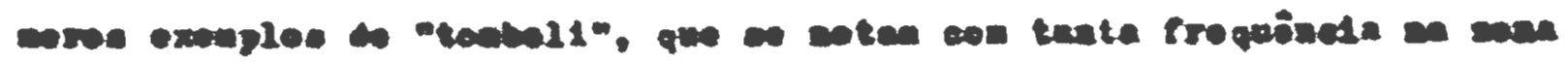

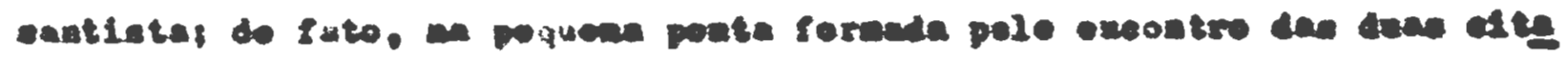

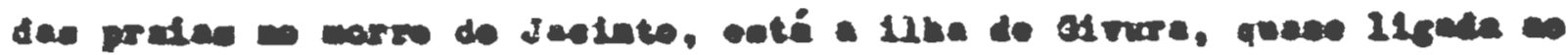




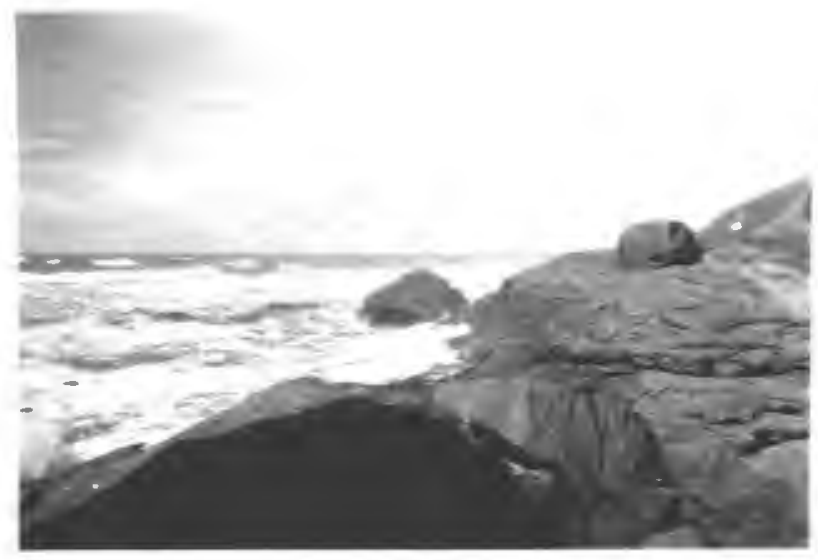

Fotos o 9.

Aspéctos do costão de Paranabuca.

(fotos do autor).

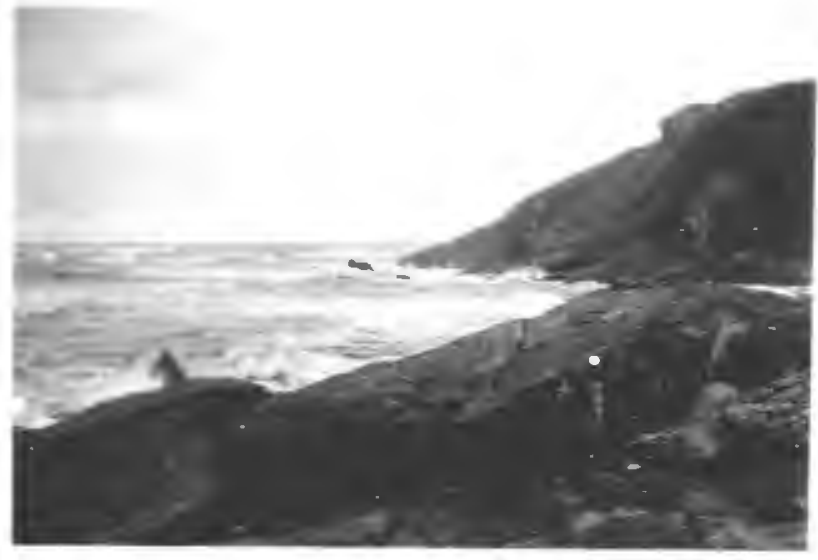

Toto 10.

Une Palbeia no costio de Taquandura. Foto t1rade na marf basxe. (Loto do autor).
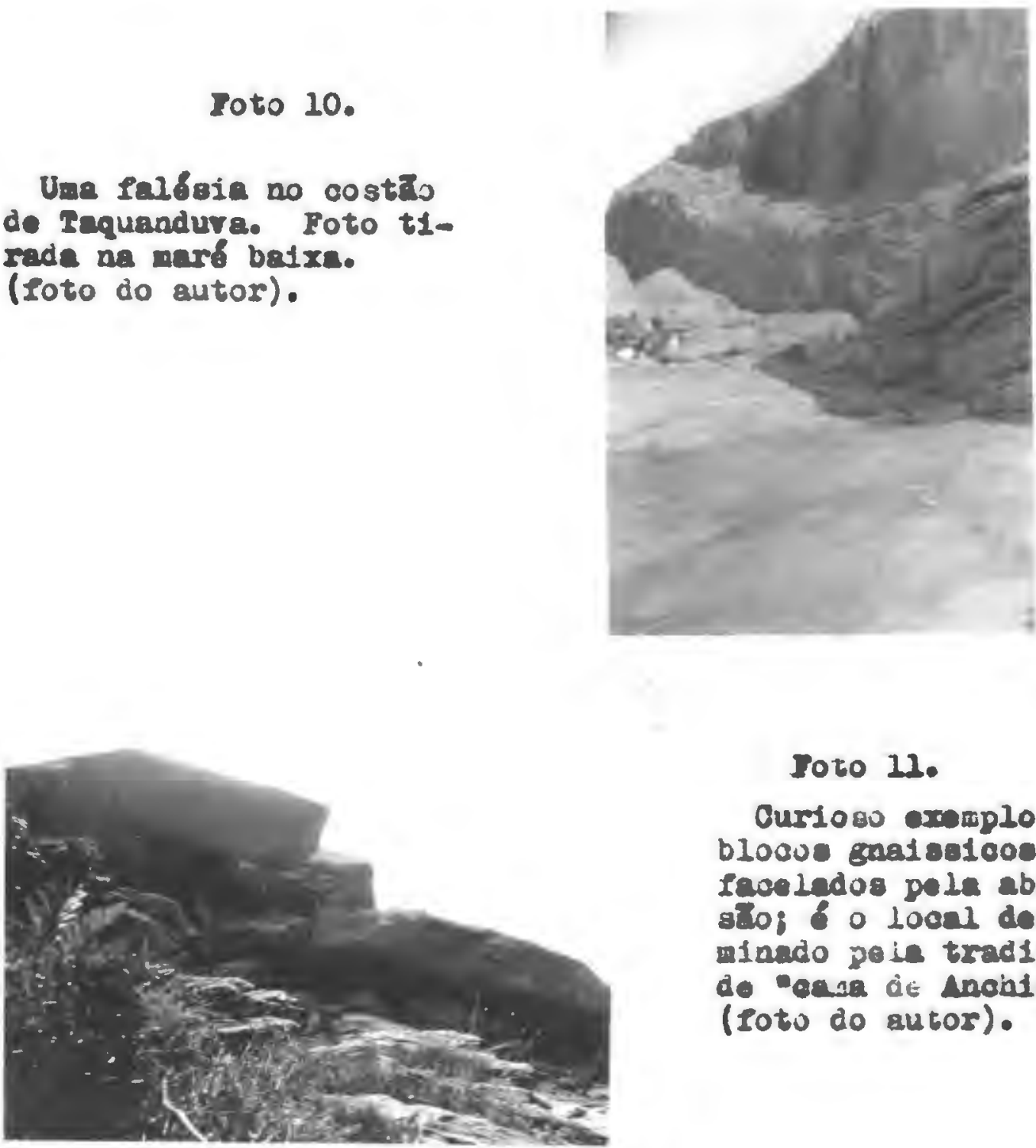

Toto 11.

Curioso expenplo de blocue gnaiseloos esfroeledos pela abra slo; o loonl dono minado poin tradigio de "onsa de Anonietr". (roto do autor). 


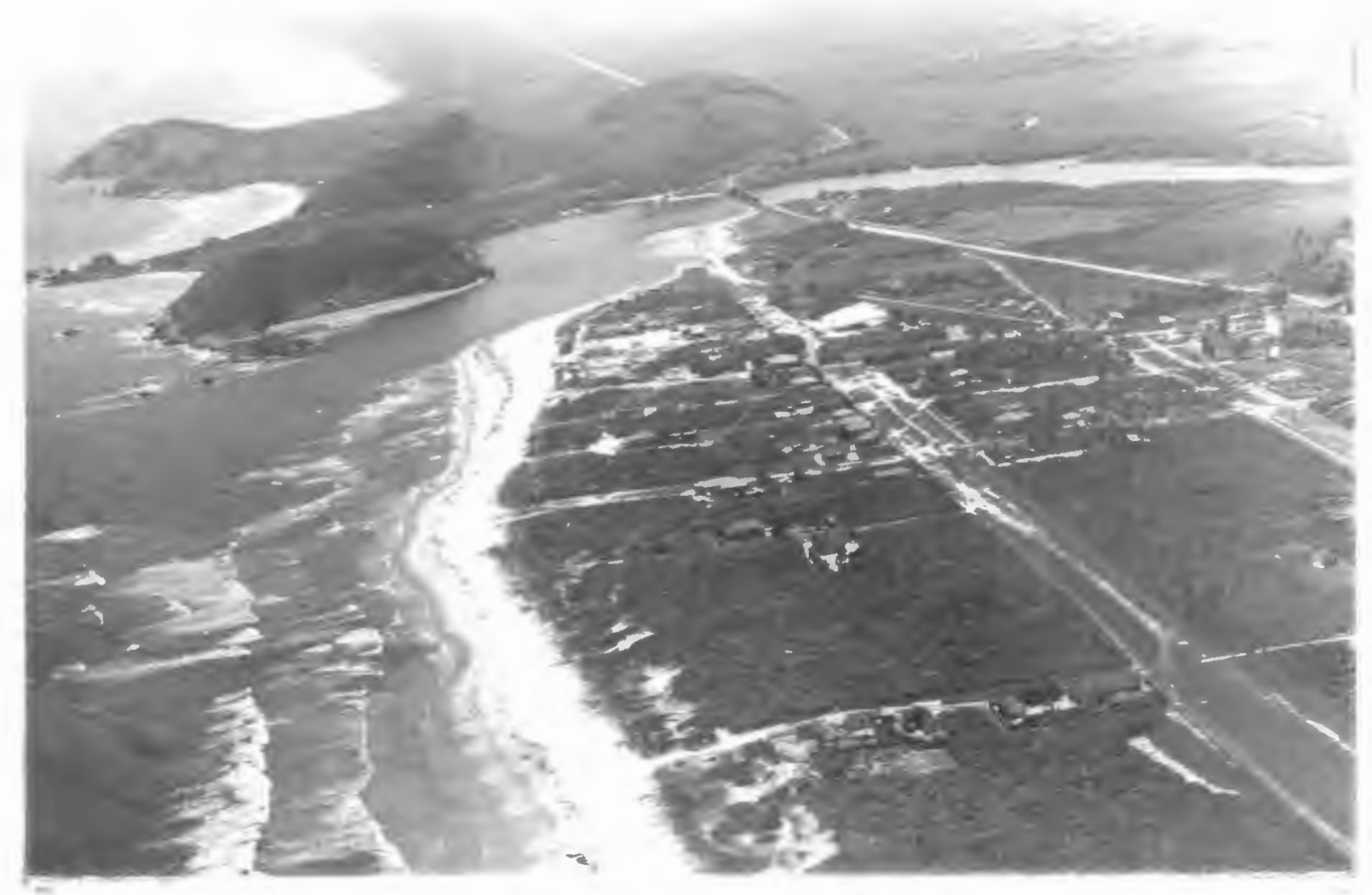

Toto 12. Visto aérea do aitio de Itanhaén, onde se dester cam alem do treoho primitivo da cidade, a parte baixa da mesma $a$ beire do rio, ouja for toca hoje as bases dos morros Taquanduva e Cunha Hore1ra, ao contrório do que fazia na époea colontal, quando sua barra era perpendicular a prata,confor we se $\nabla E$ no mape reconstituido por Benedito Calixto. wates morios serviram de ponio de apoio as restingas que forman as prainhas de banho da cidace, ben como \& extensa prata de Peruibe, cuja porģio norte ainda se ve na fotografia. $\lambda$ di reita, nota-3e a nftida diferenza entre o jundú - os manen sais. (foto do C.I.G. - Diretório Regional de jeografia no Estado de Săo Paulo). 


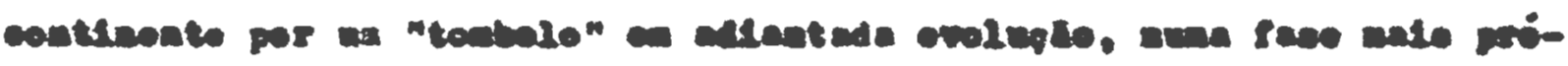

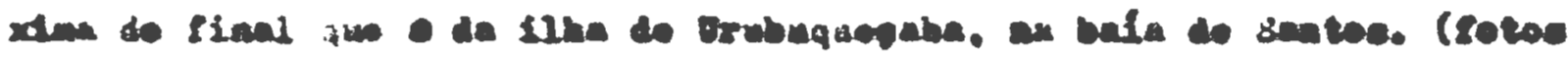
$14 \cdot 151$

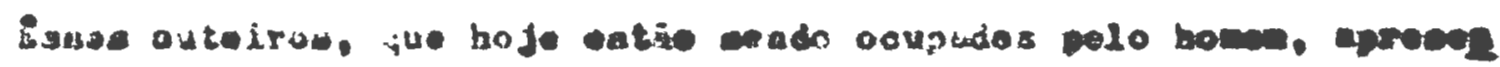

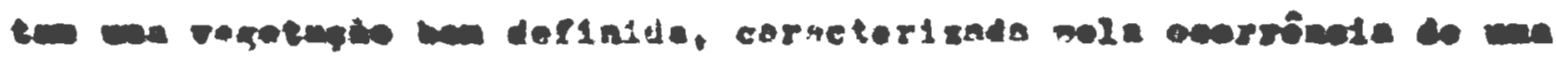

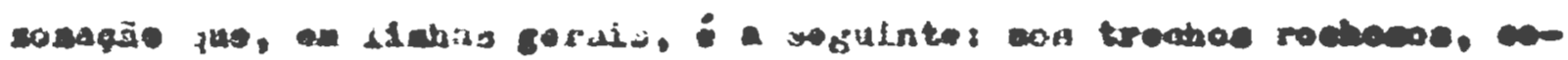

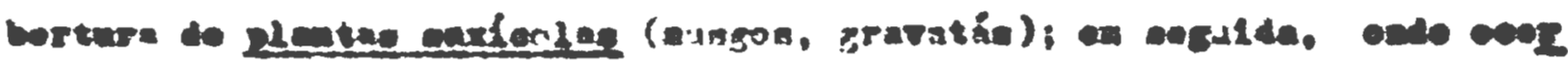

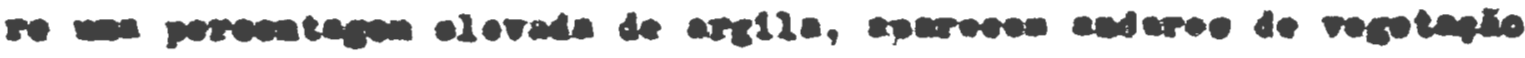

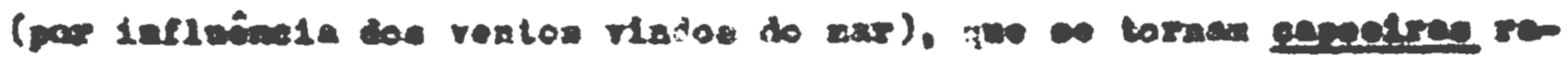

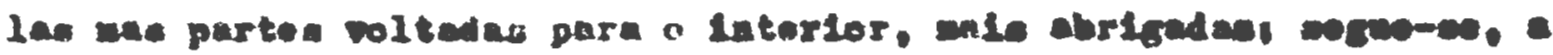

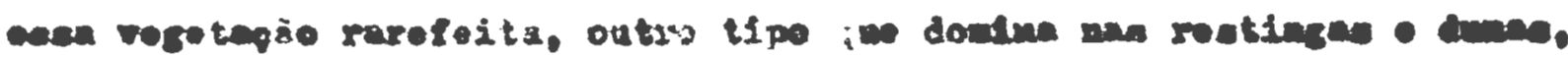

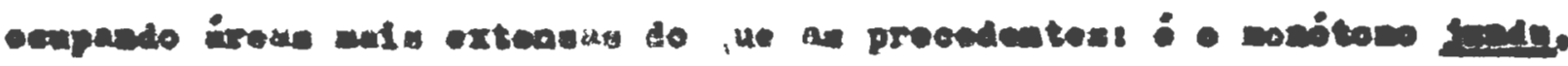

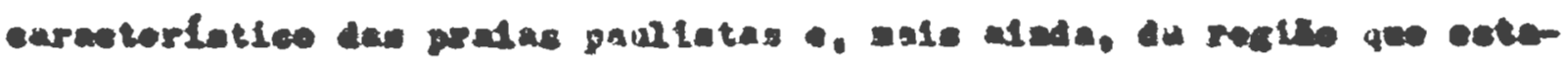

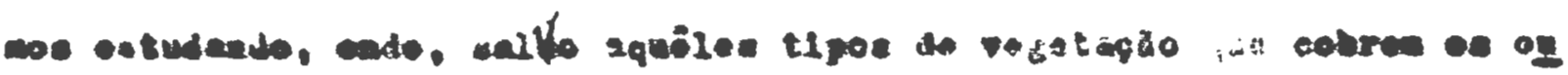

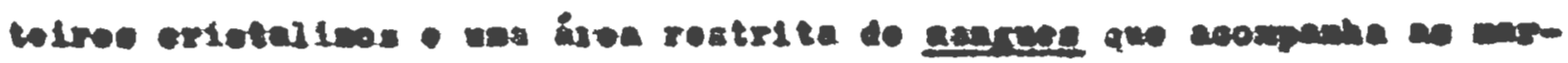

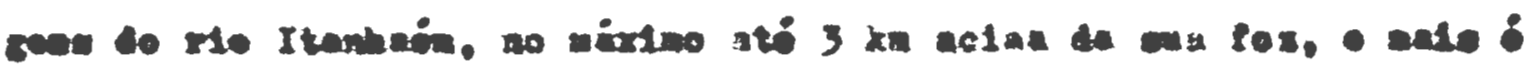

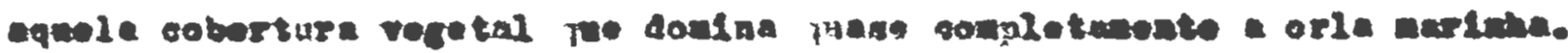

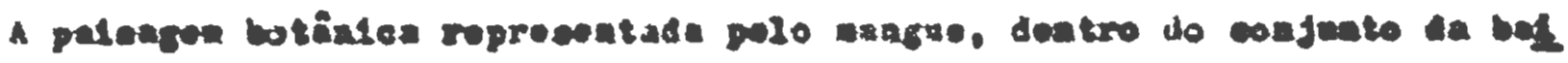

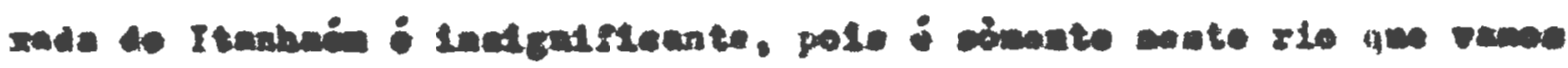

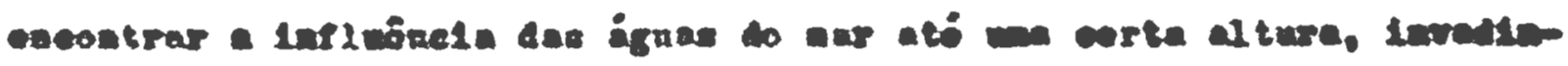

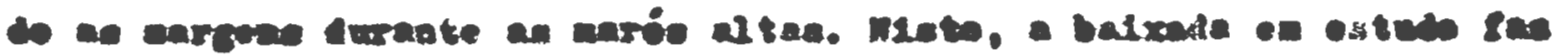

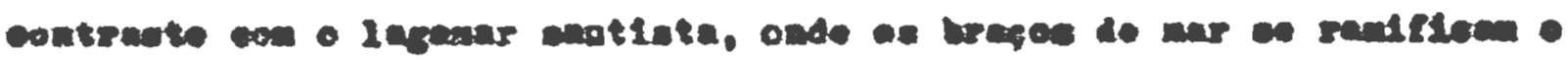

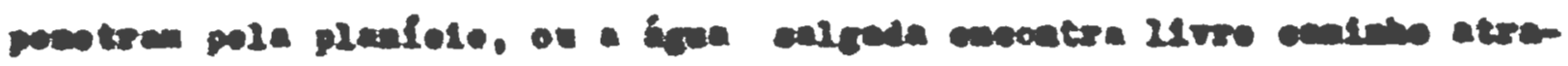

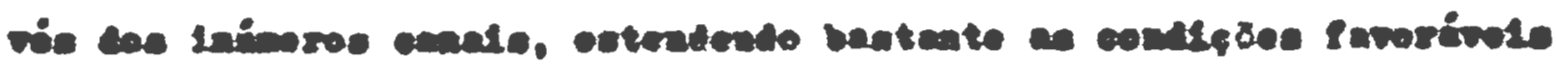

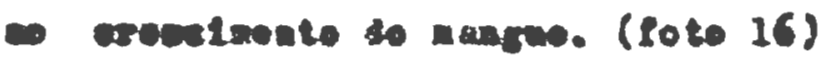




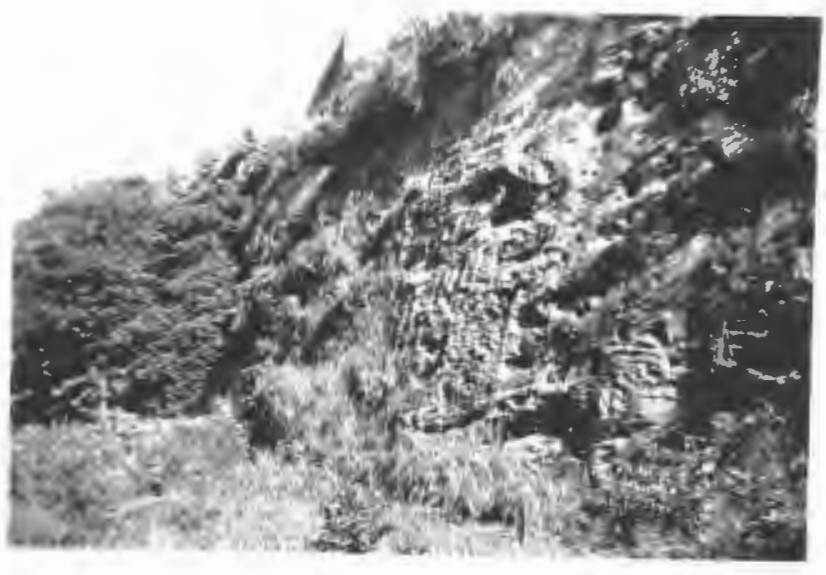

Toto 13. 0 paredzo do morro do Convento, oncie se obser ram orfffcios arredondacos provavelmeate oriundos do tra baluo de abrasto aliado e erosāo orgenica ce aningis marinhos. (foto do autor).

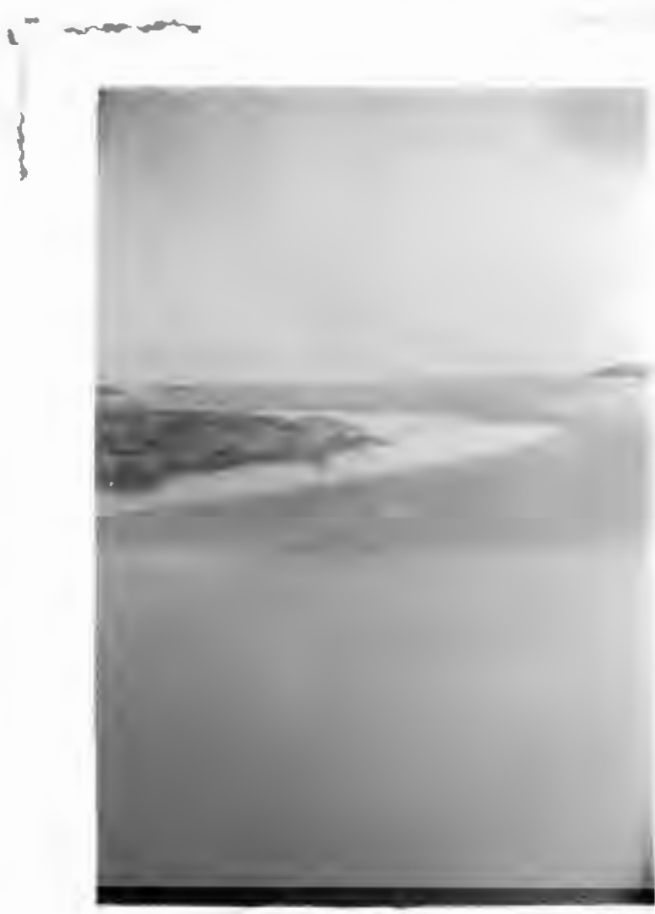

Fotos 14 - 15.

I Iha do Givira quesi IIgaca ao continente pelo "tombolo" que no detalhe aparece durante a meré baixa; nessa ocasiäo apenas un ertreito canal isola a 1lna. (Fotos do autor). 


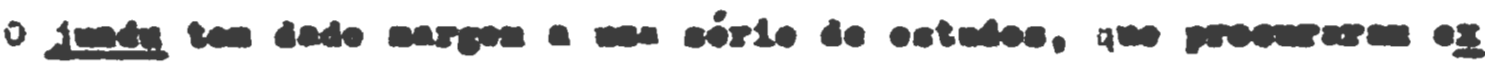

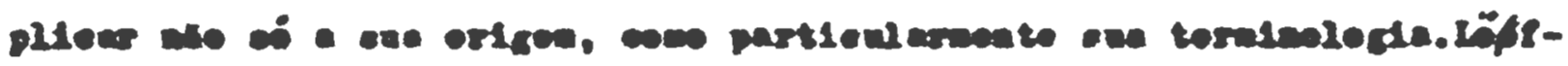

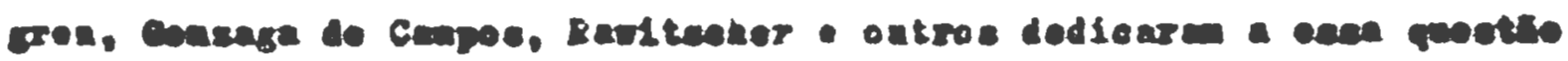

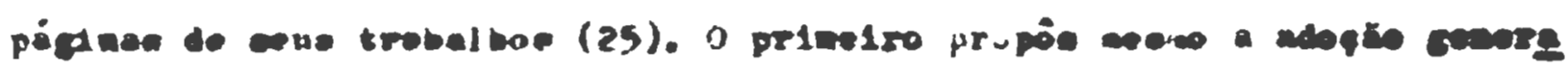

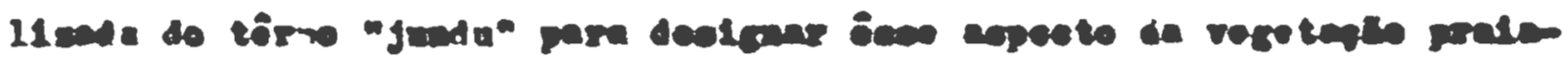

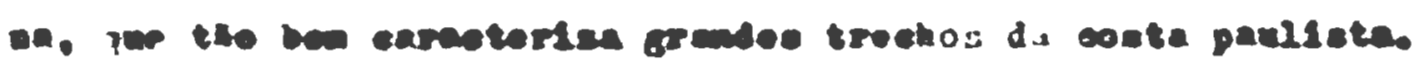

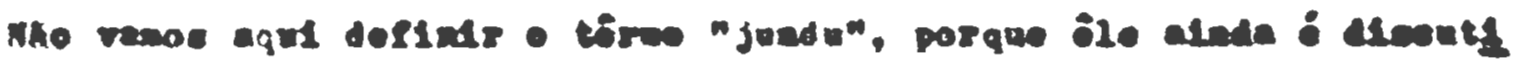

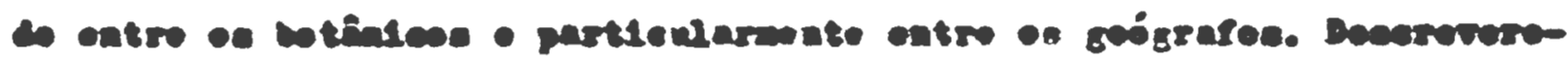

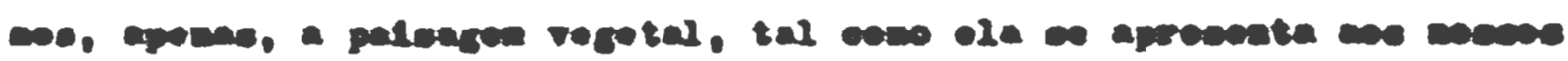
ollun moea reglio. (foto 17 )

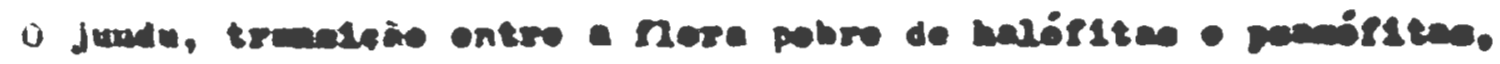

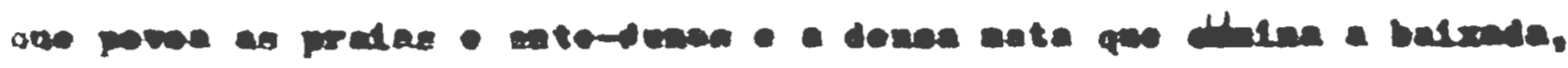

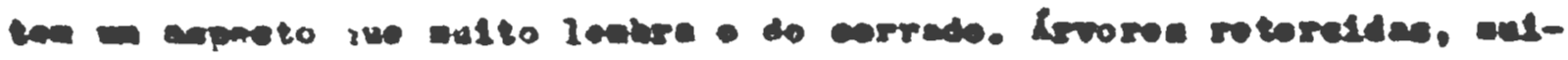

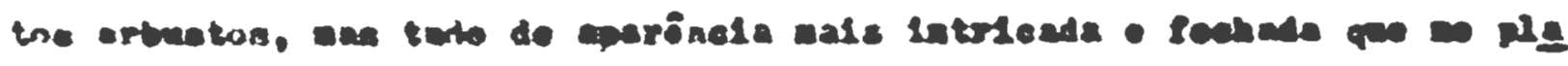

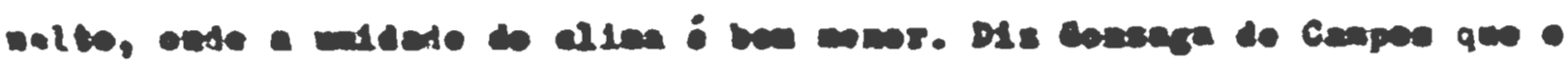

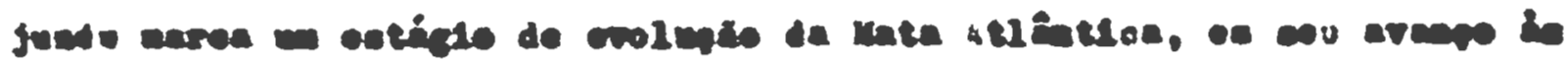

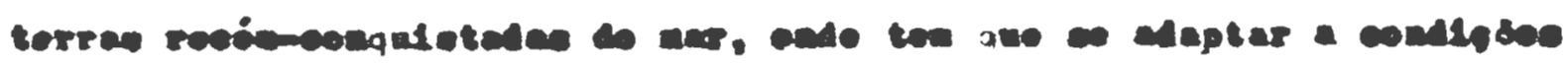

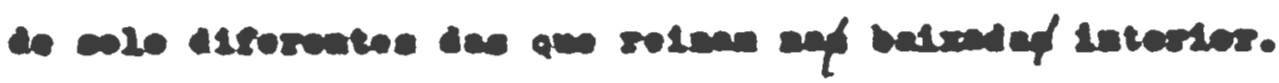

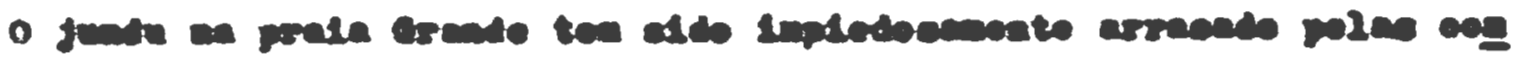

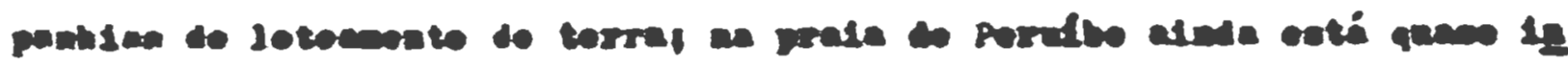

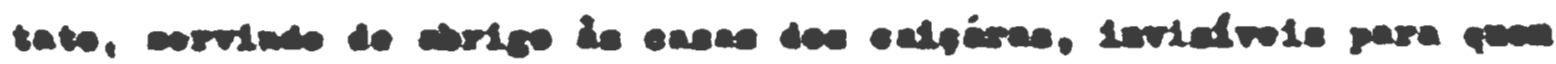

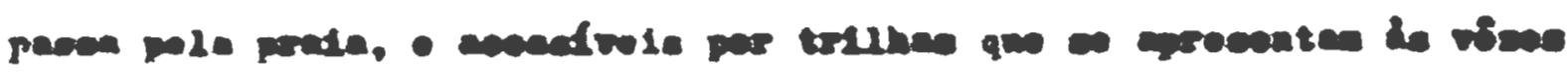

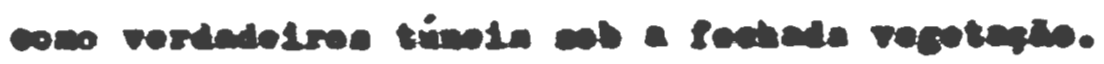

\section{(25) Löparie (Alukrtu) -}

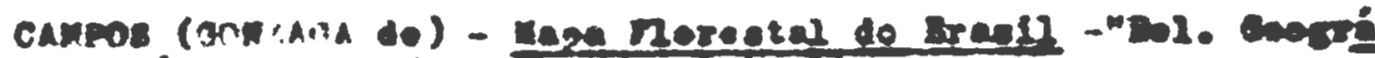

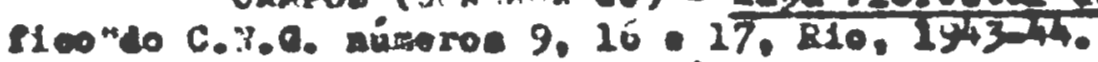

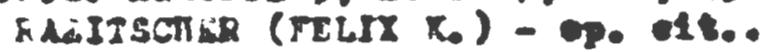




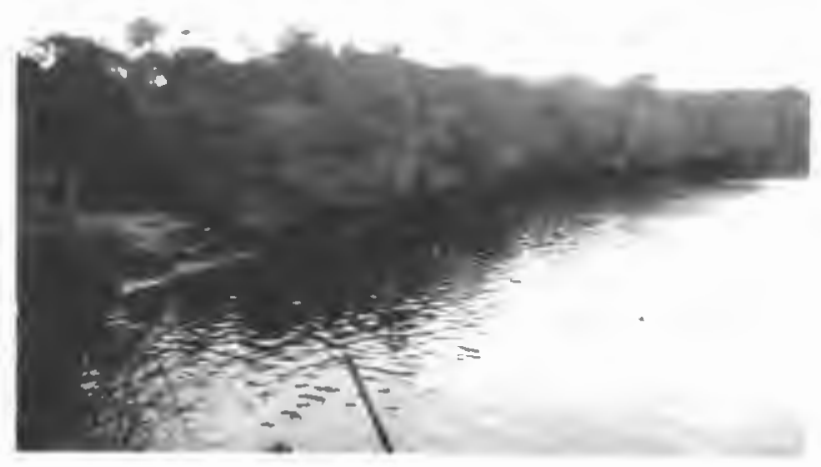

Toto 16.

$\nabla 1$ sta tomada da ponto da estraga de ferro, abranzendo os mangue jals da margex direita do I taunaém. (foto do autor).

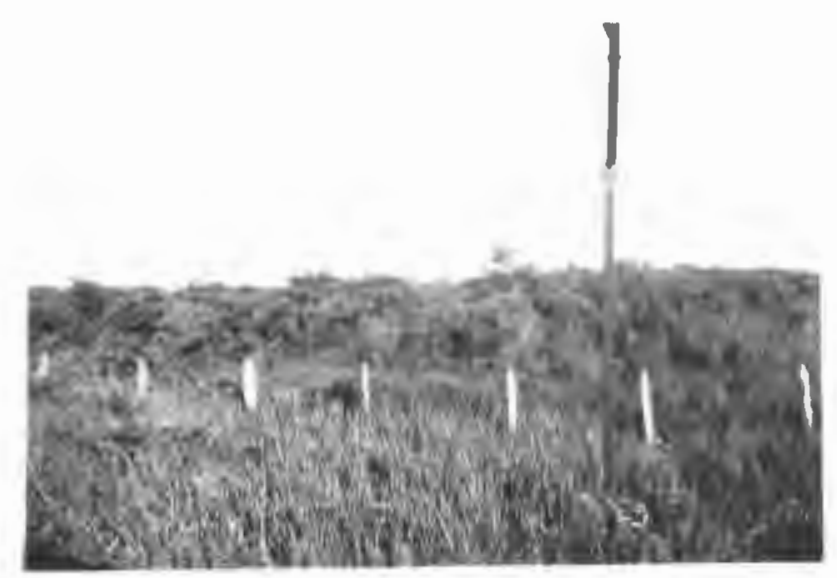

rots 17.

Vleta do jundú nos arredores de oidade de Itanhafe. (futo do autor). 


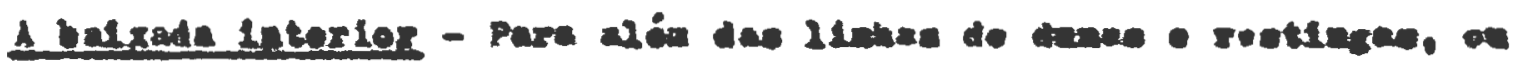

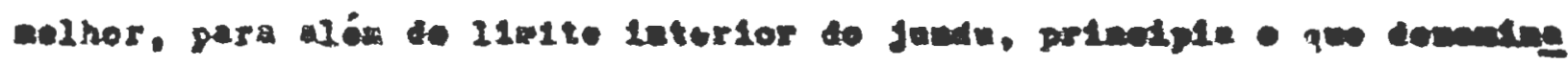

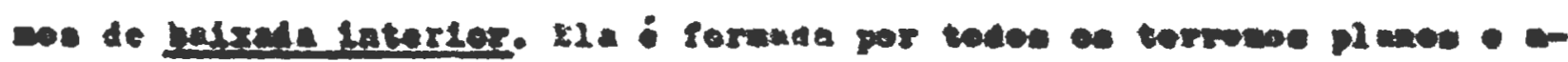

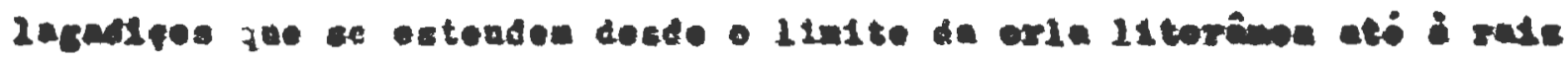
do serre do the

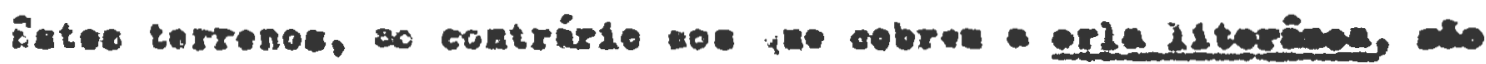

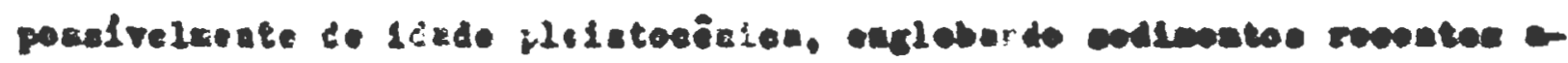

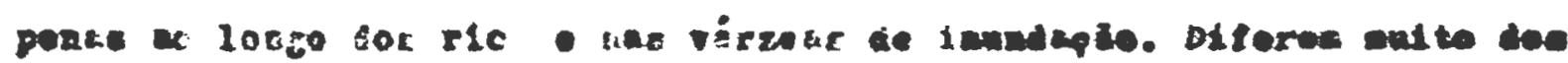

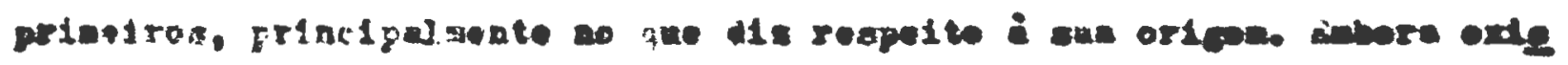

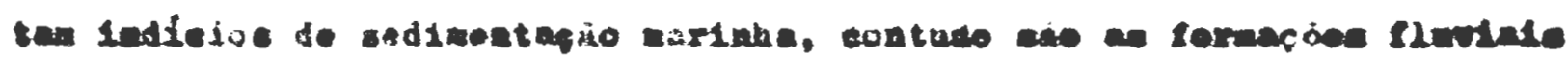

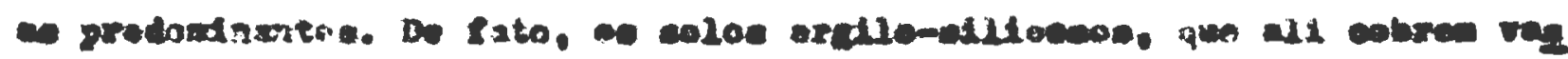

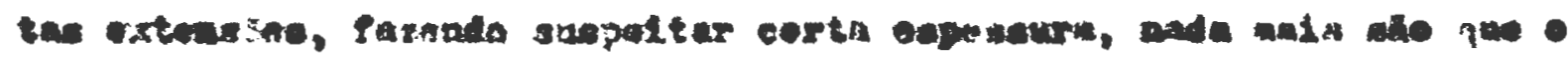

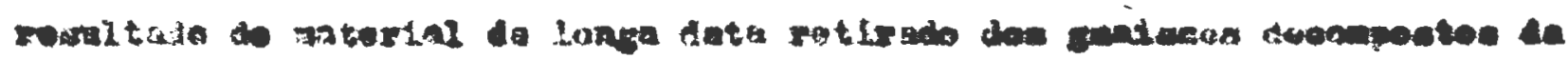

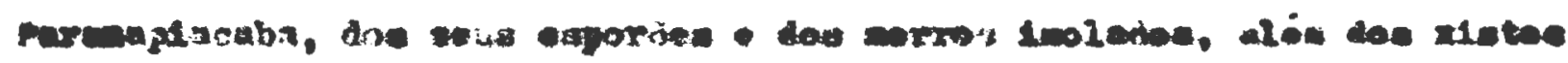

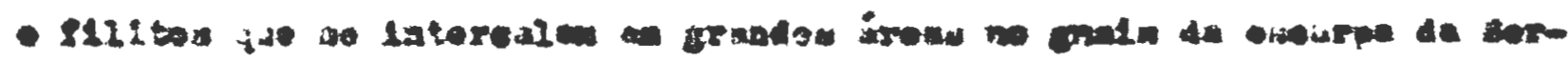
s..

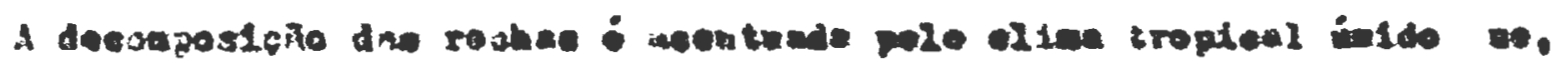

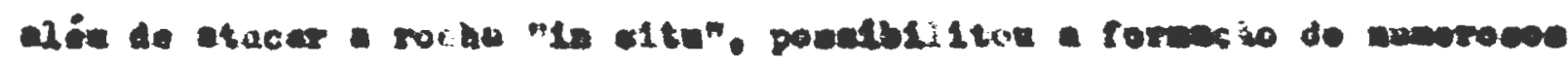

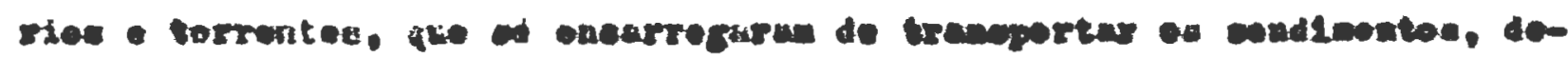

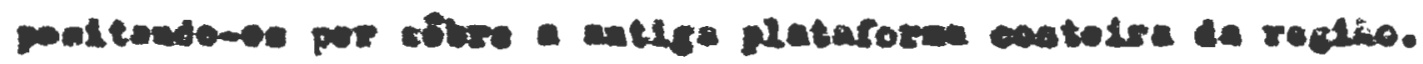

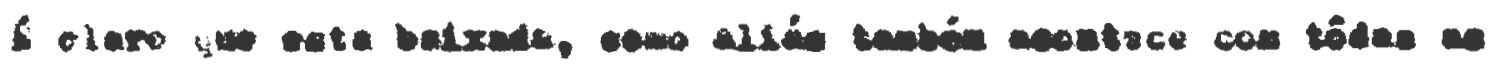

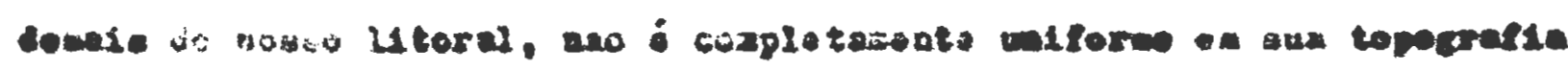

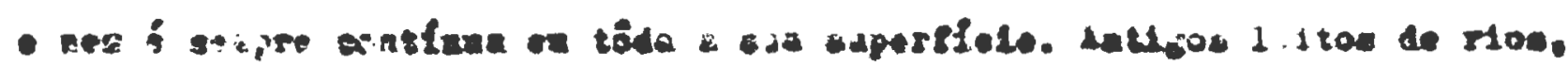

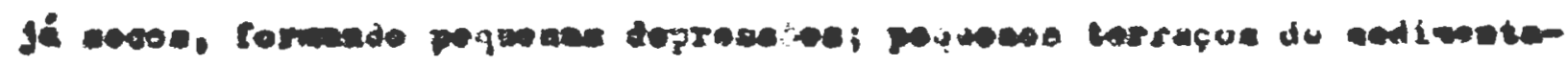

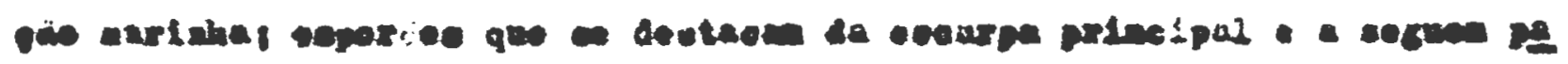




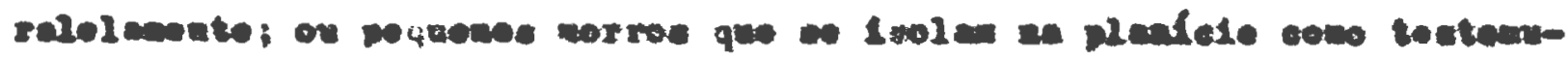

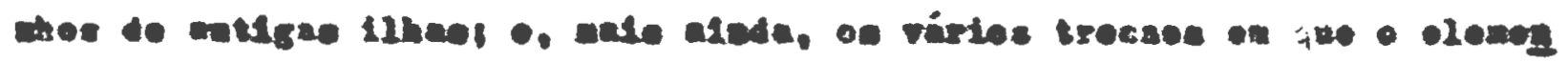

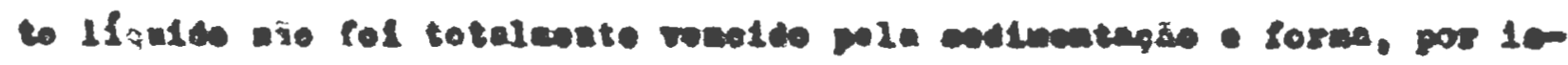

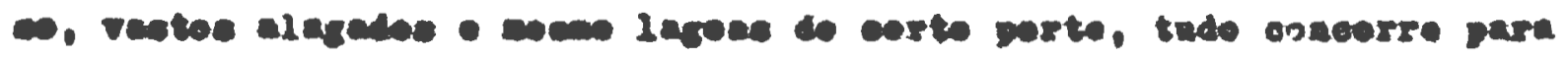

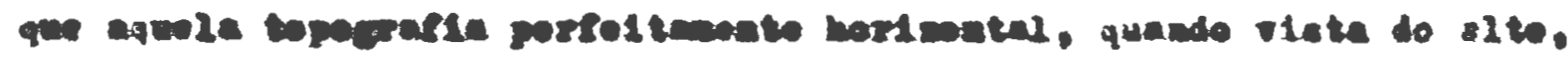

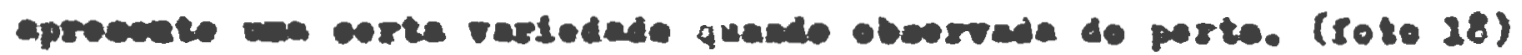

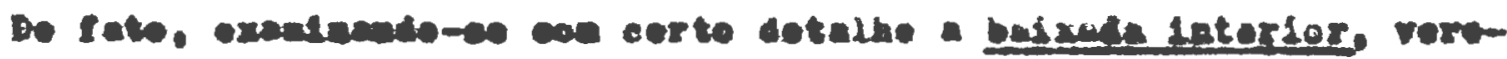

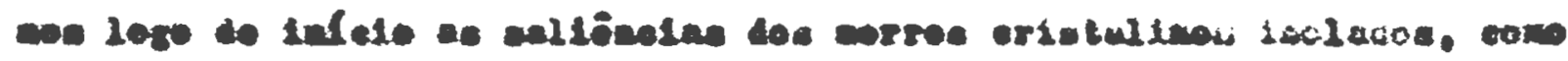

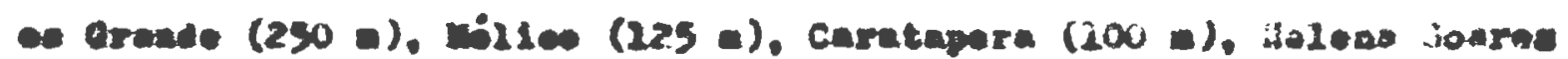

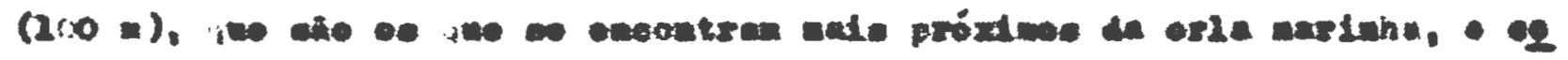

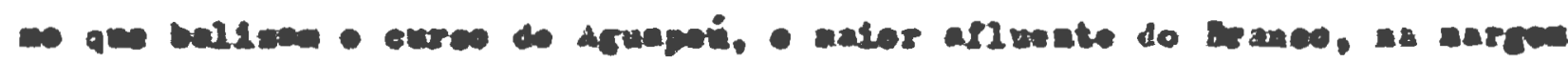

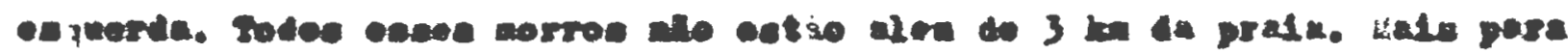

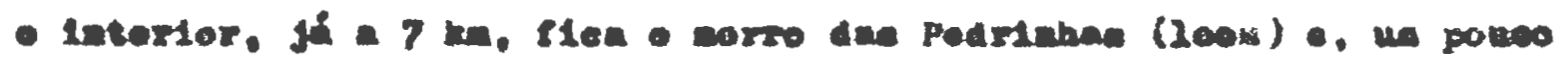

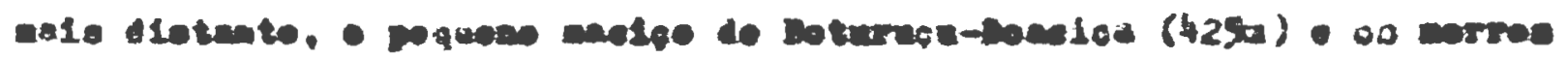

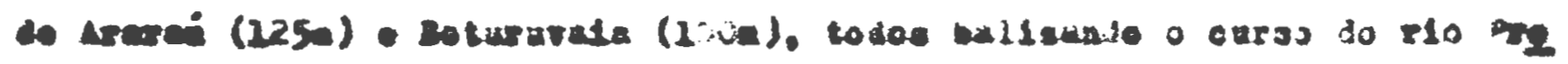

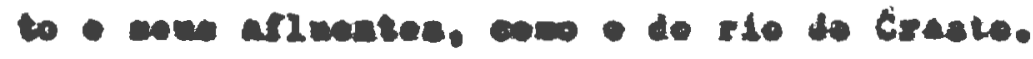

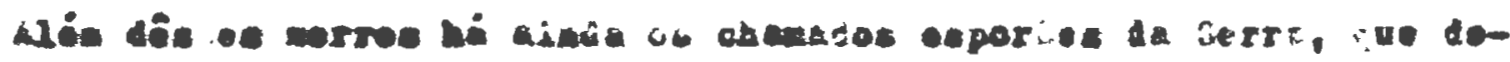

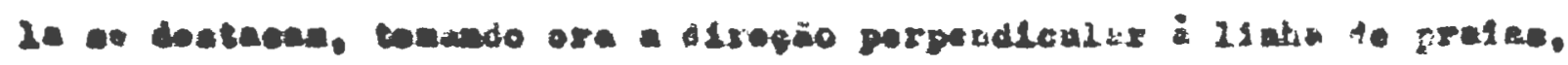

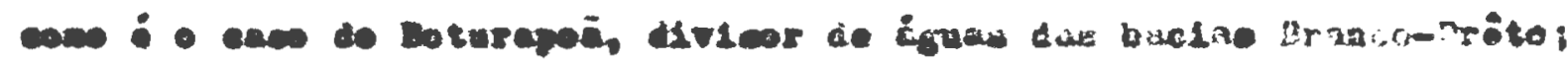

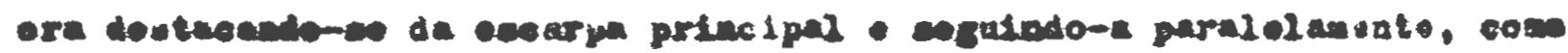

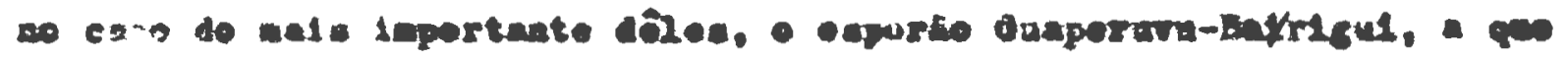

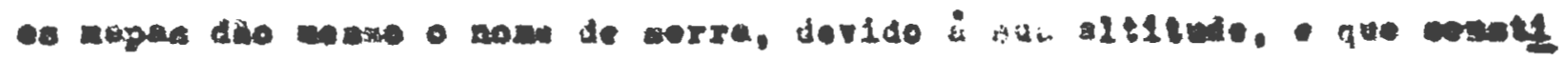

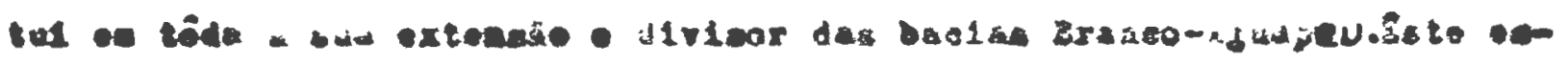

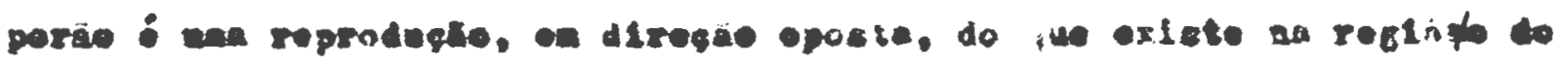

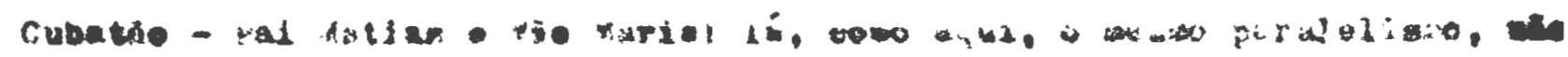




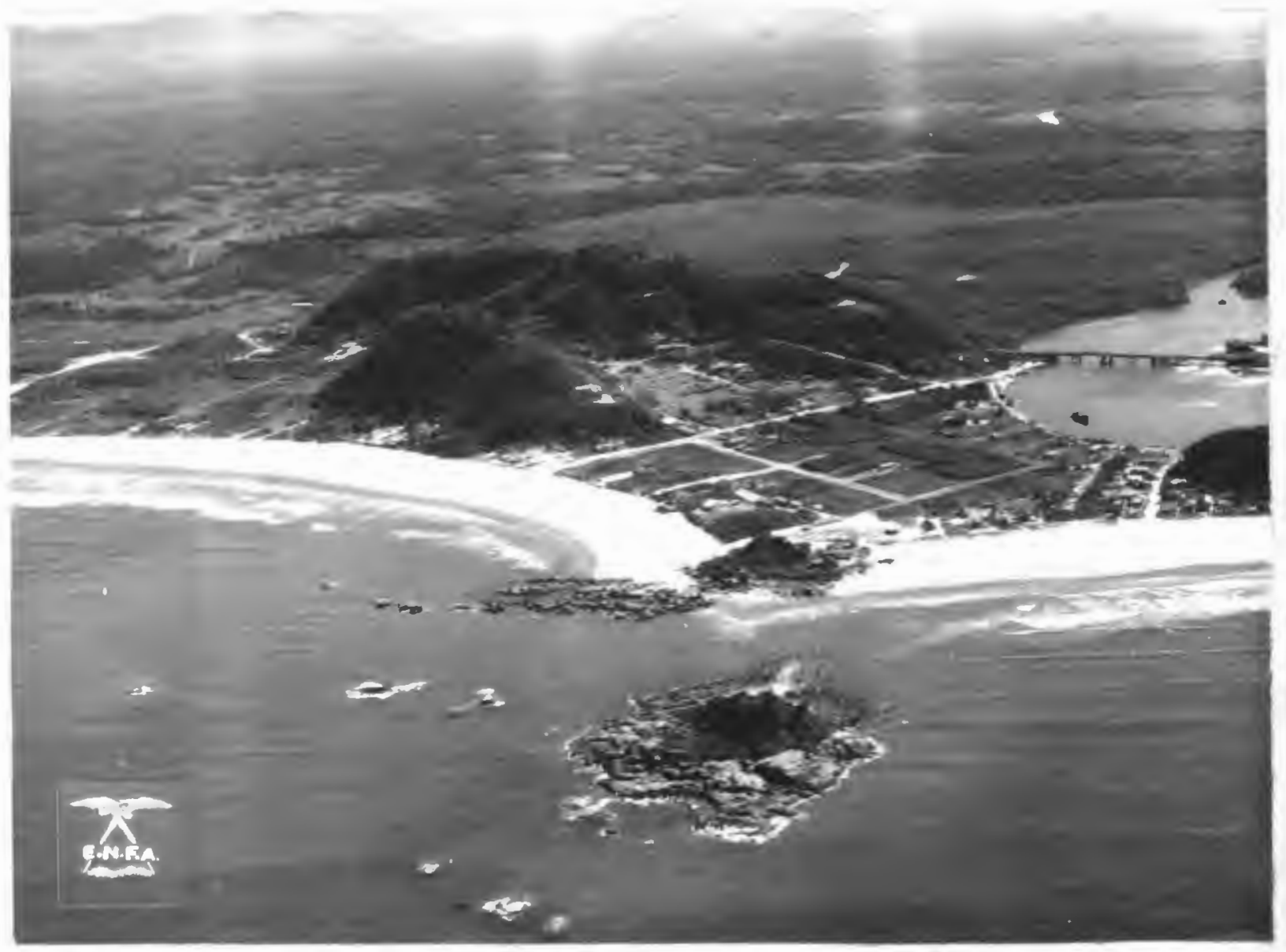

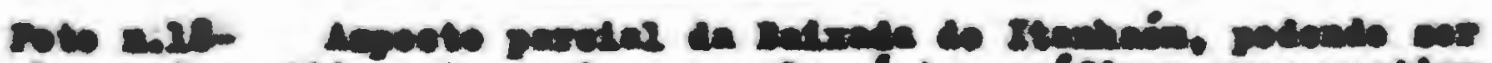

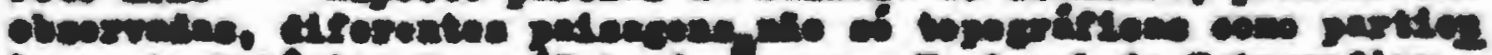

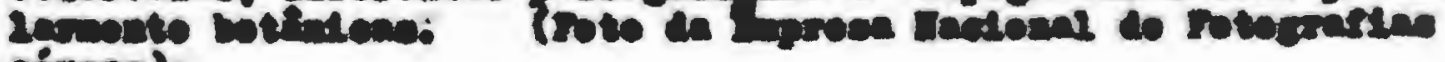
simes). 


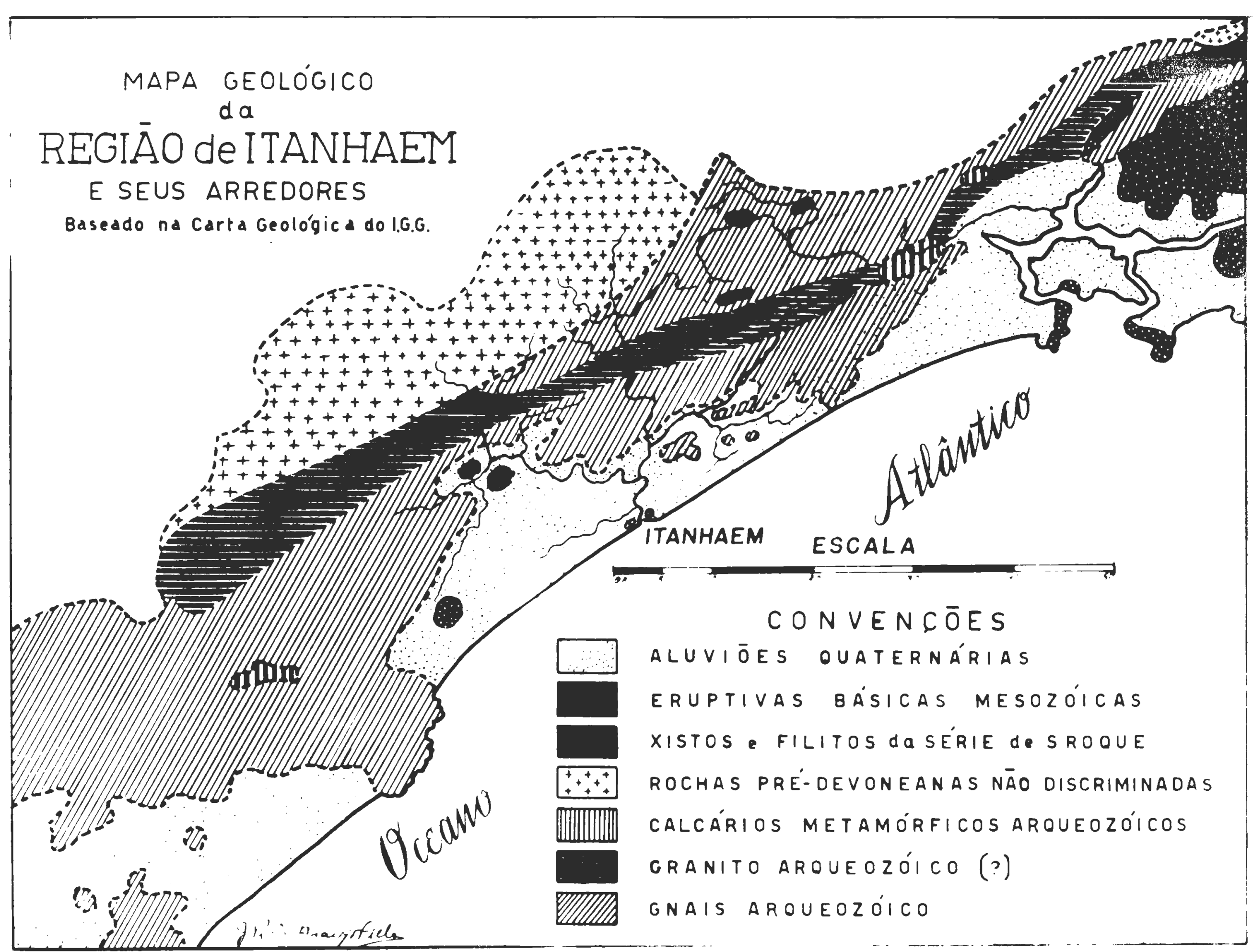




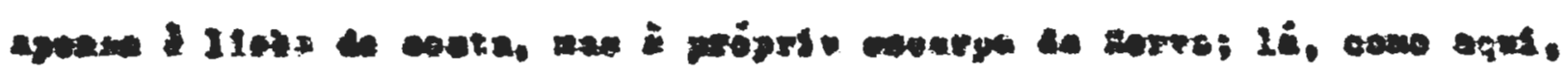

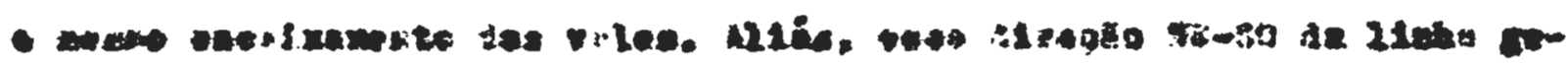

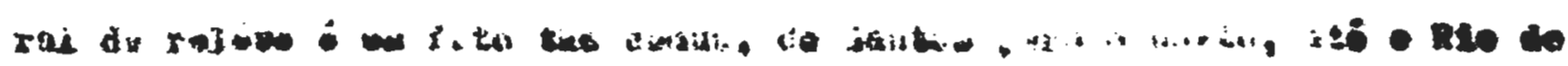

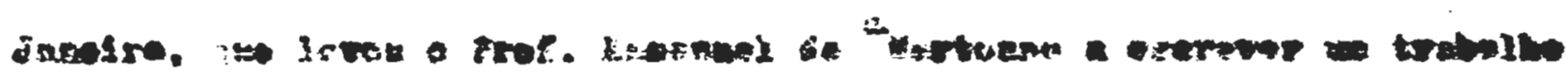

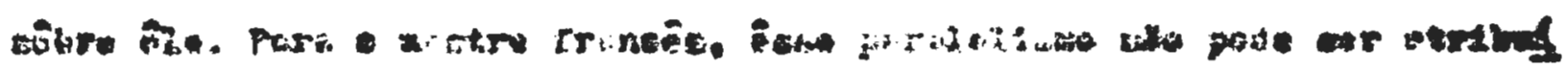

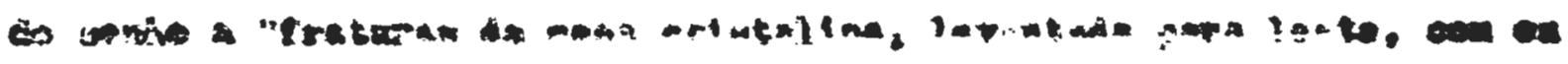

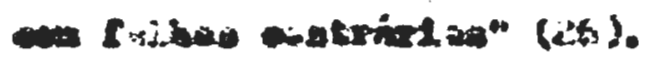

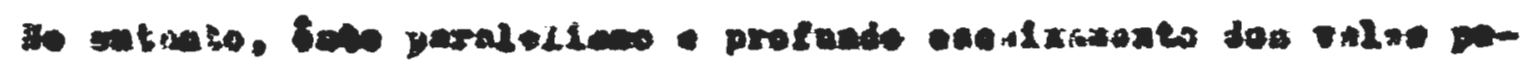

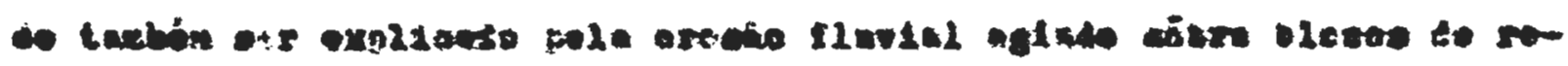

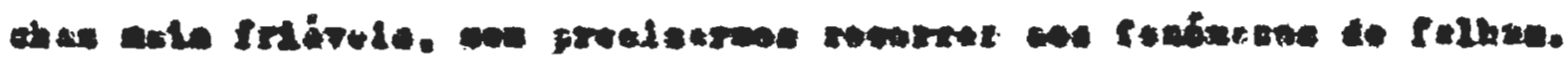

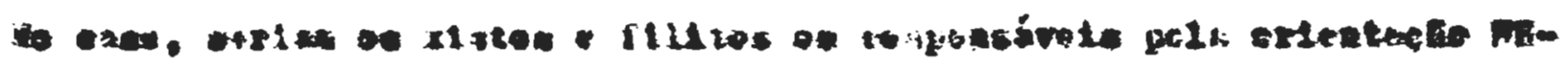

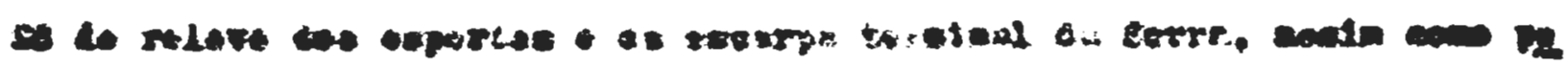

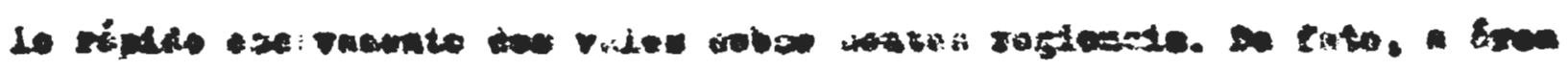

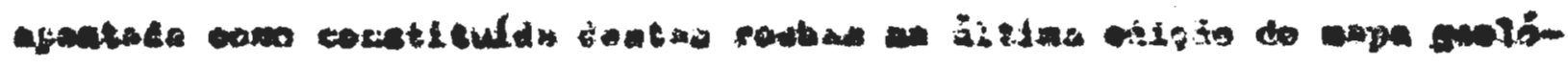

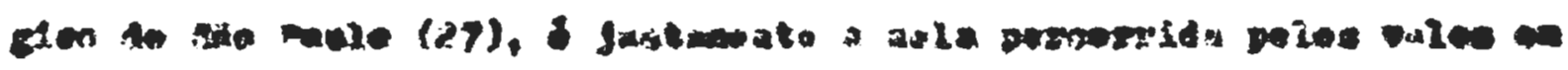

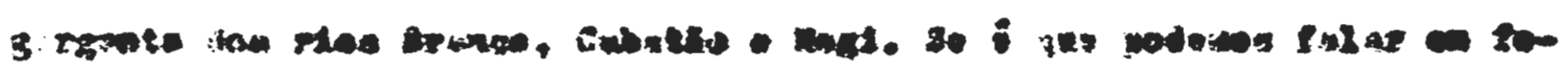

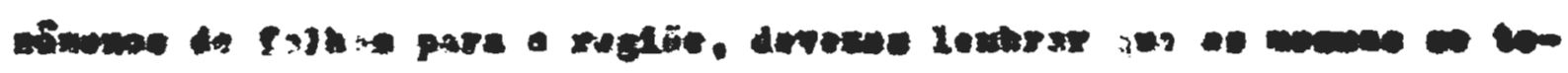

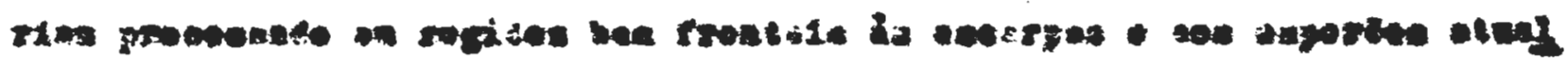

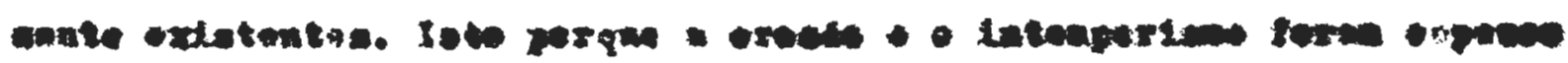

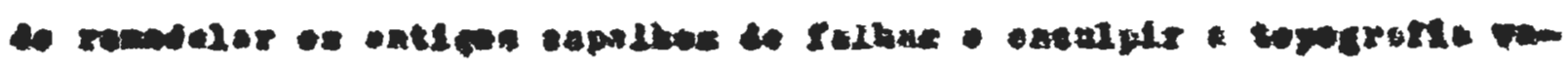

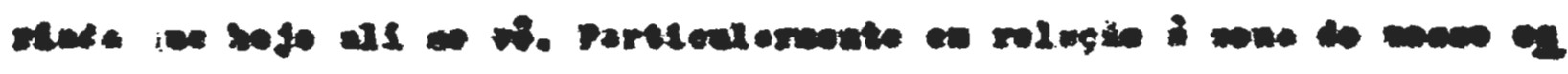

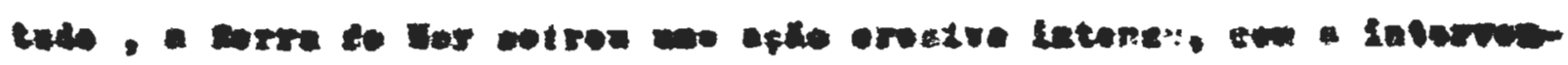

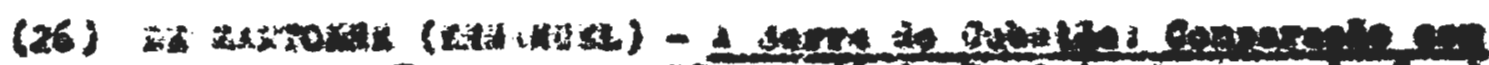

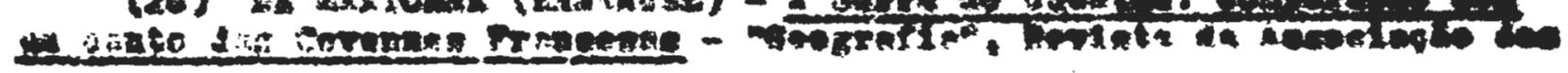

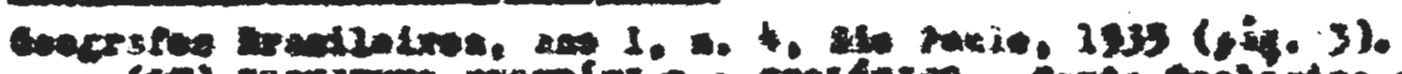

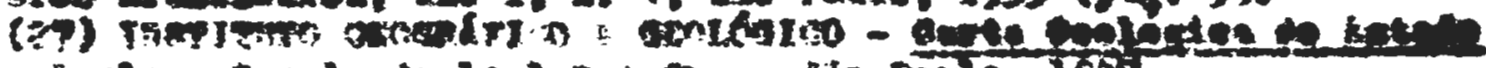

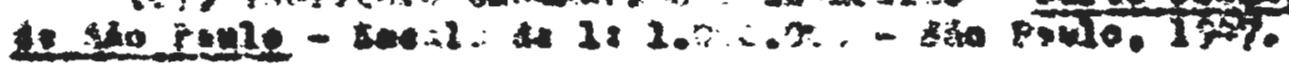




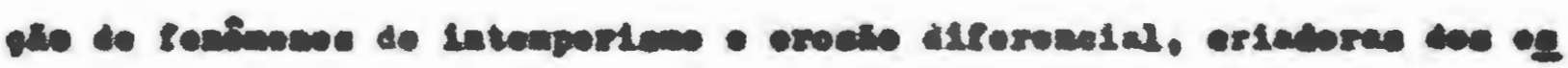

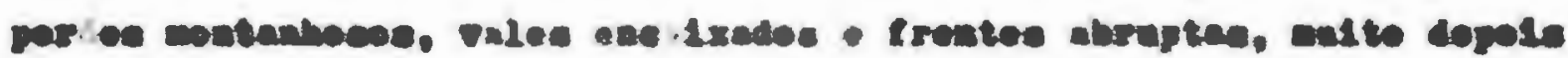

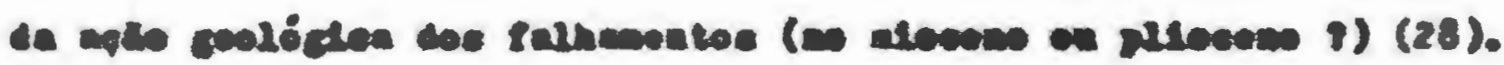

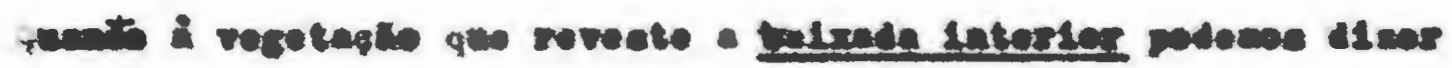

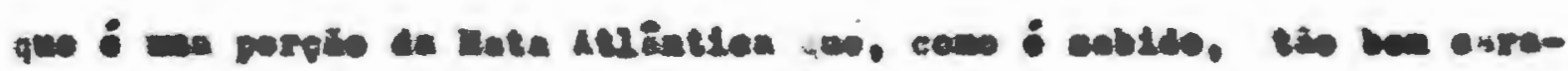

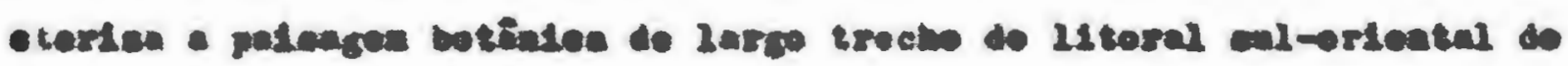

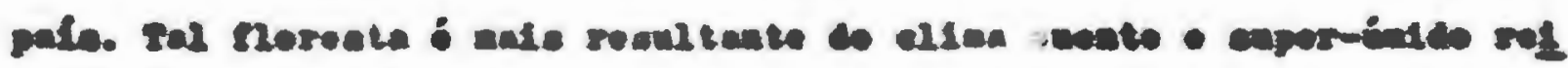

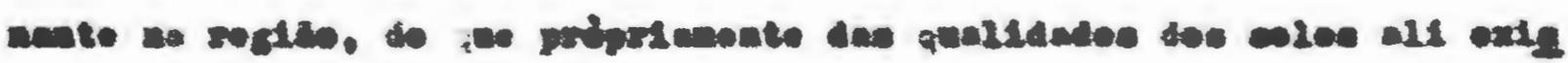

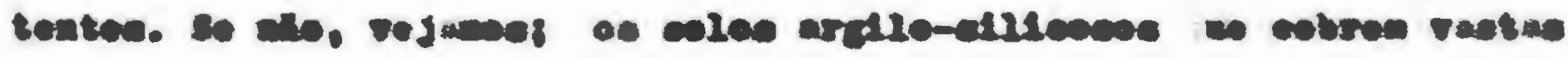

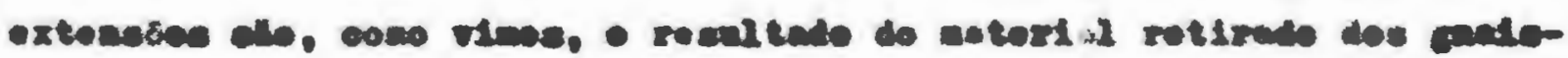

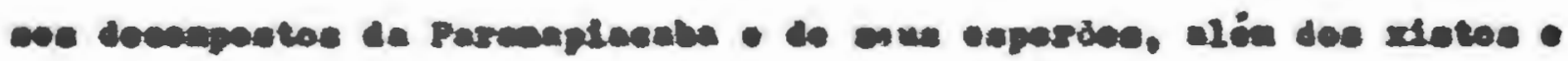

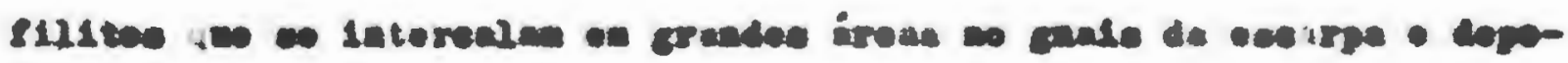

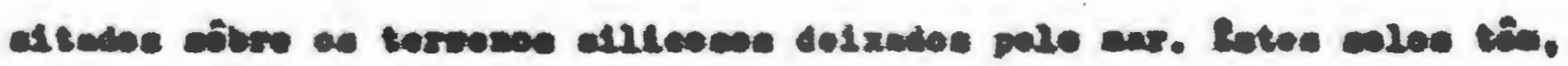

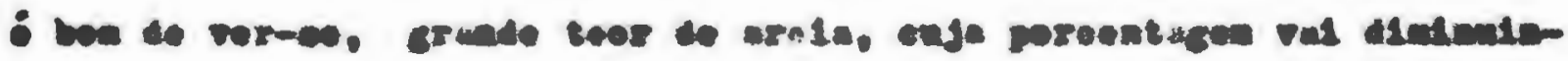

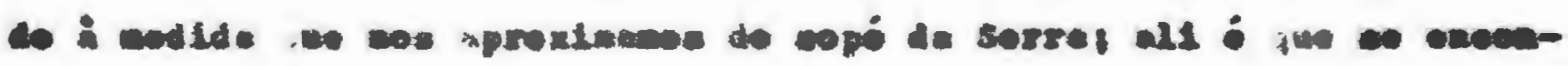

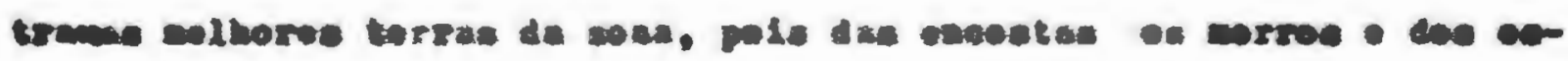

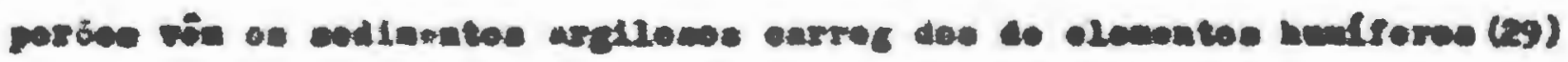

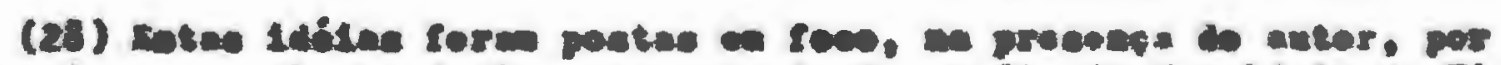

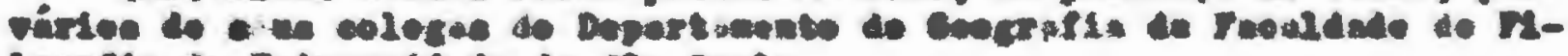

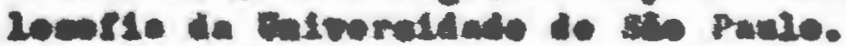

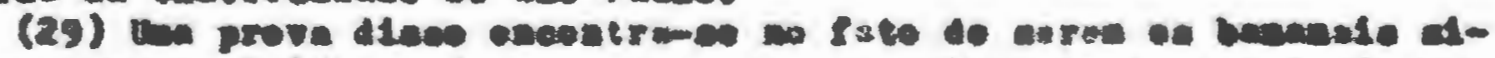

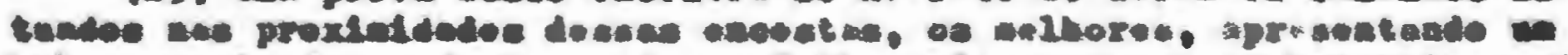

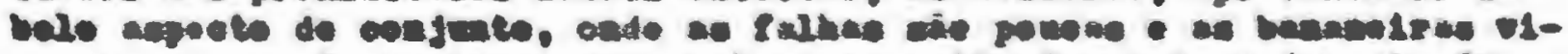

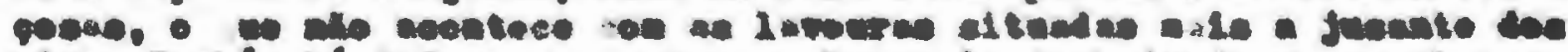

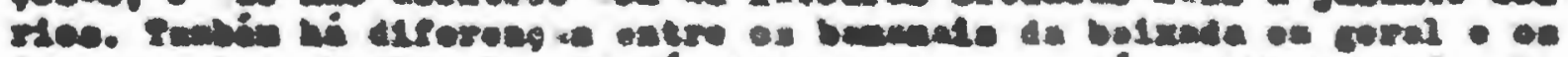

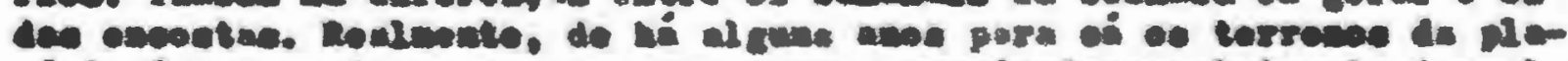

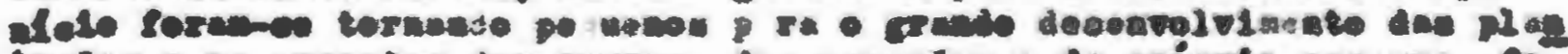

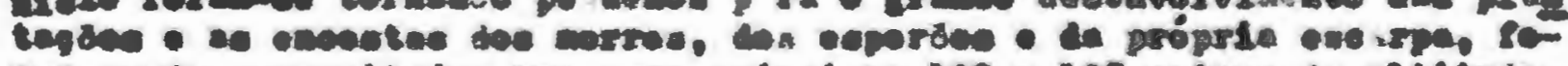

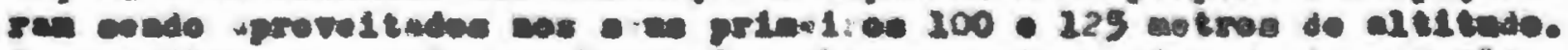

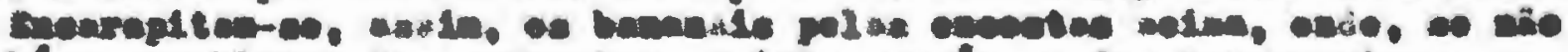

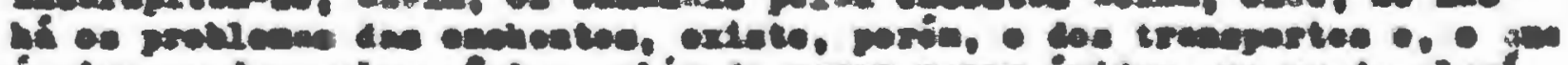

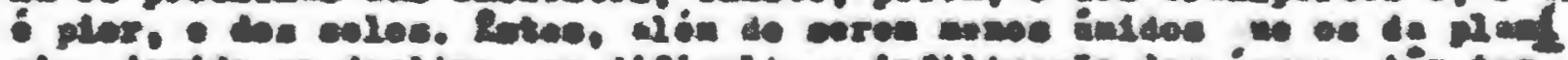

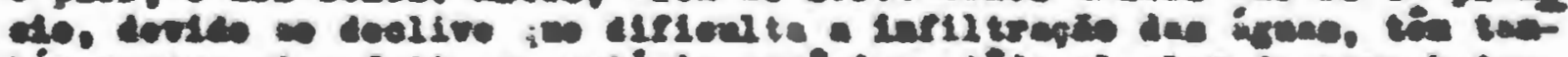

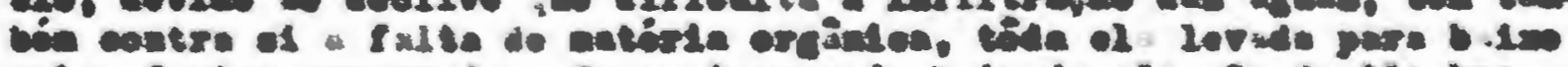

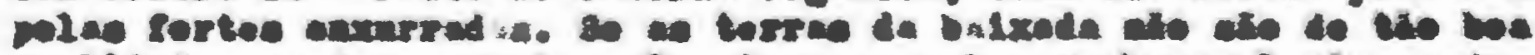

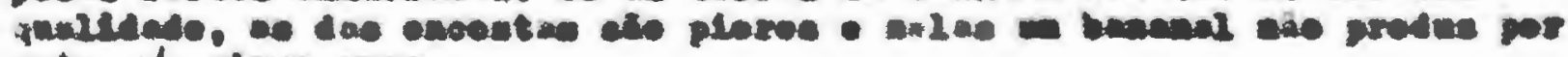
ente de elnoo anos. 


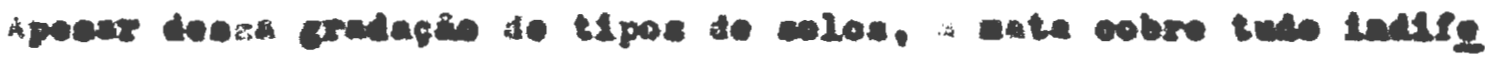

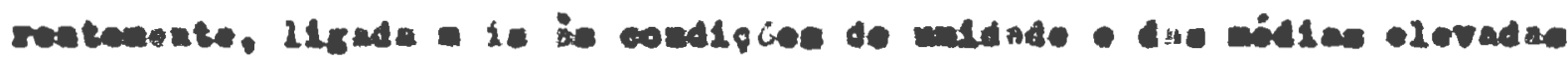
ds teaperature. (Ioto 29)

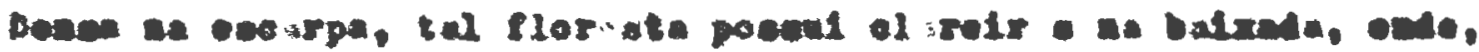

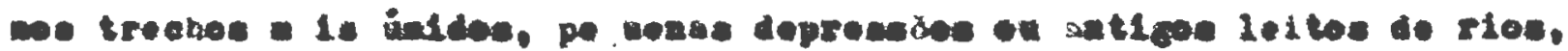

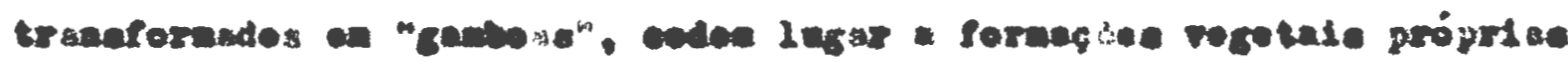
d. al in dos, roprecont idso cobrotudo paloe plrisale e enebotule.

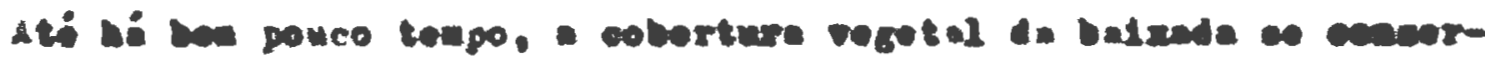

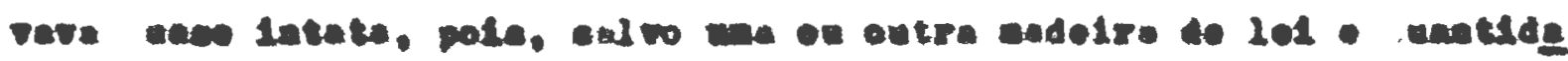

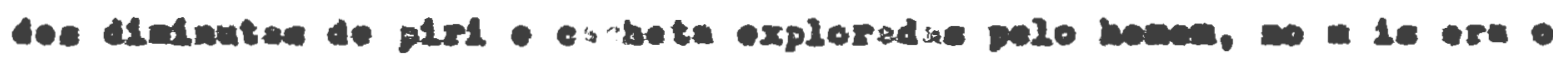

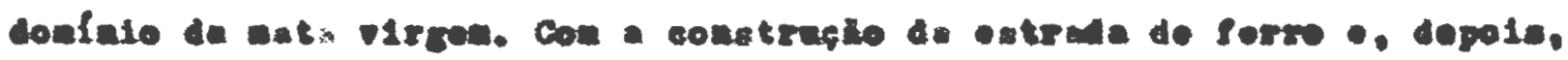

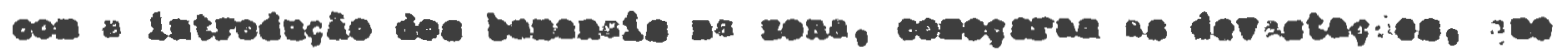

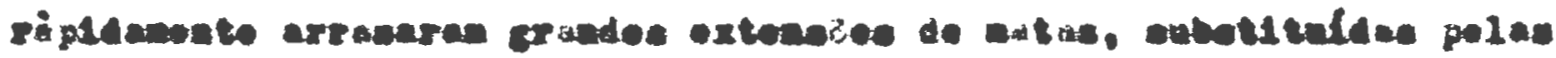

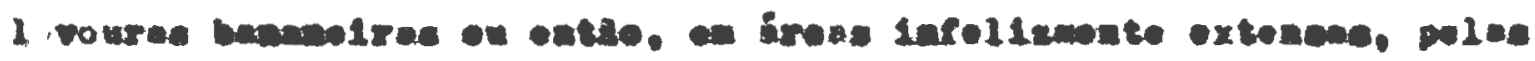

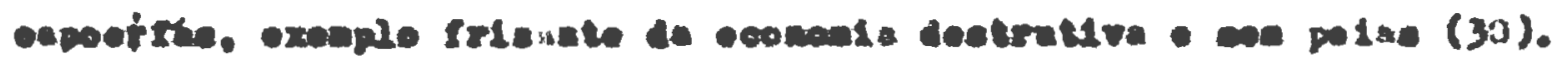

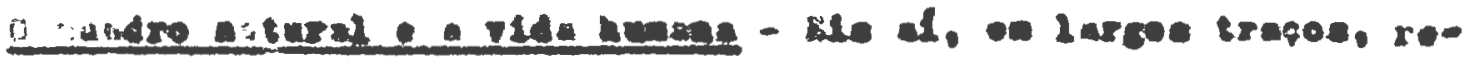

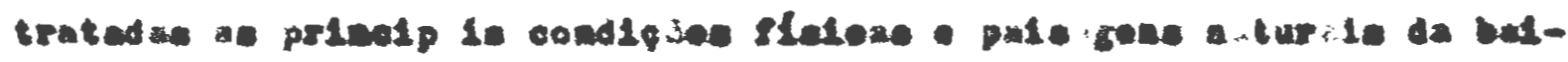

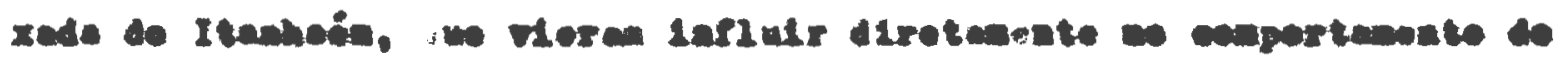

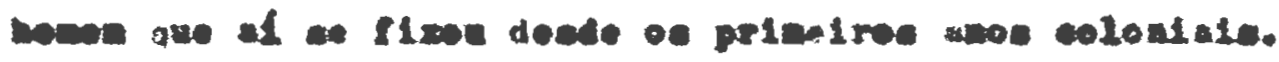

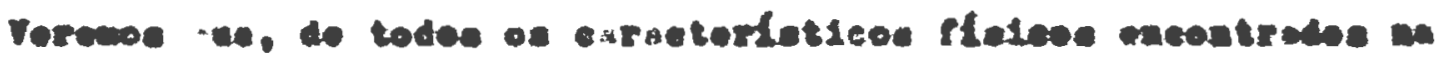

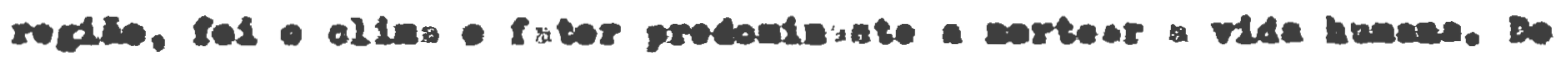

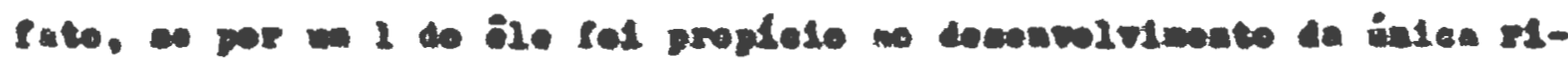

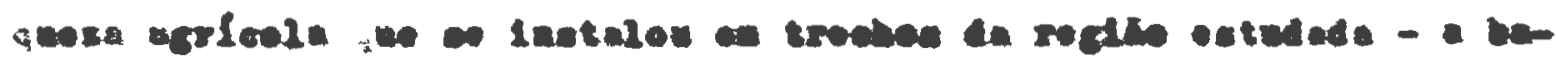

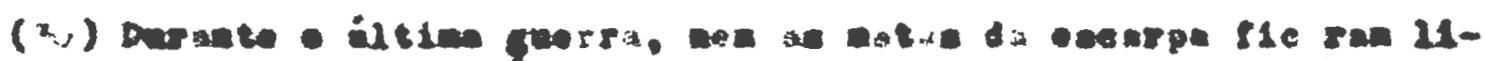

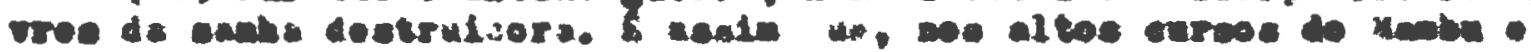

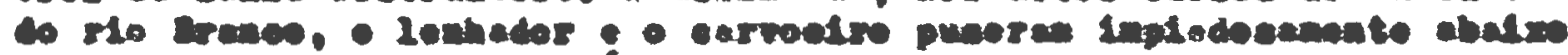

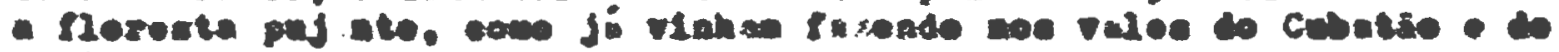
noct. 


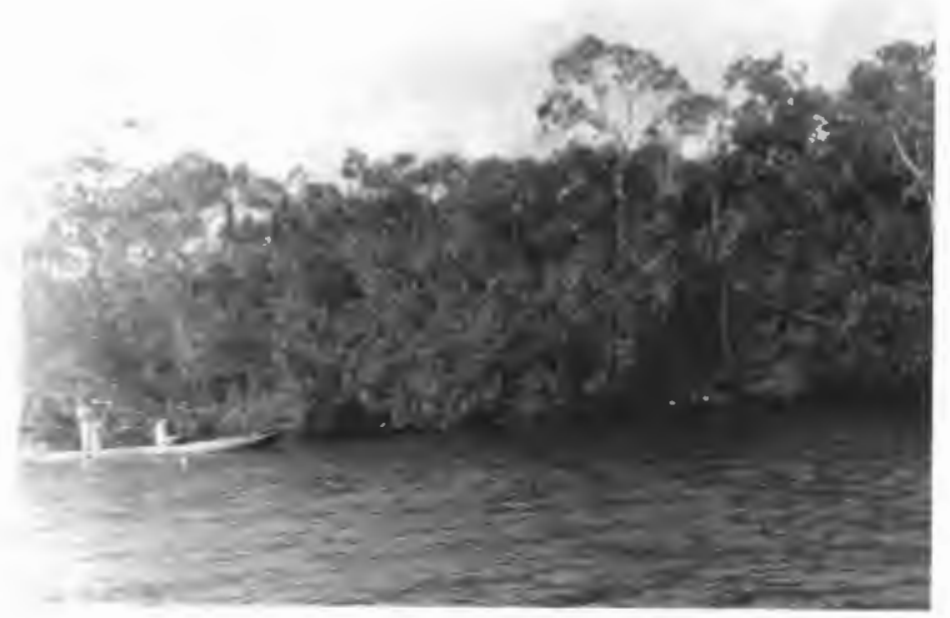

Toto 19.
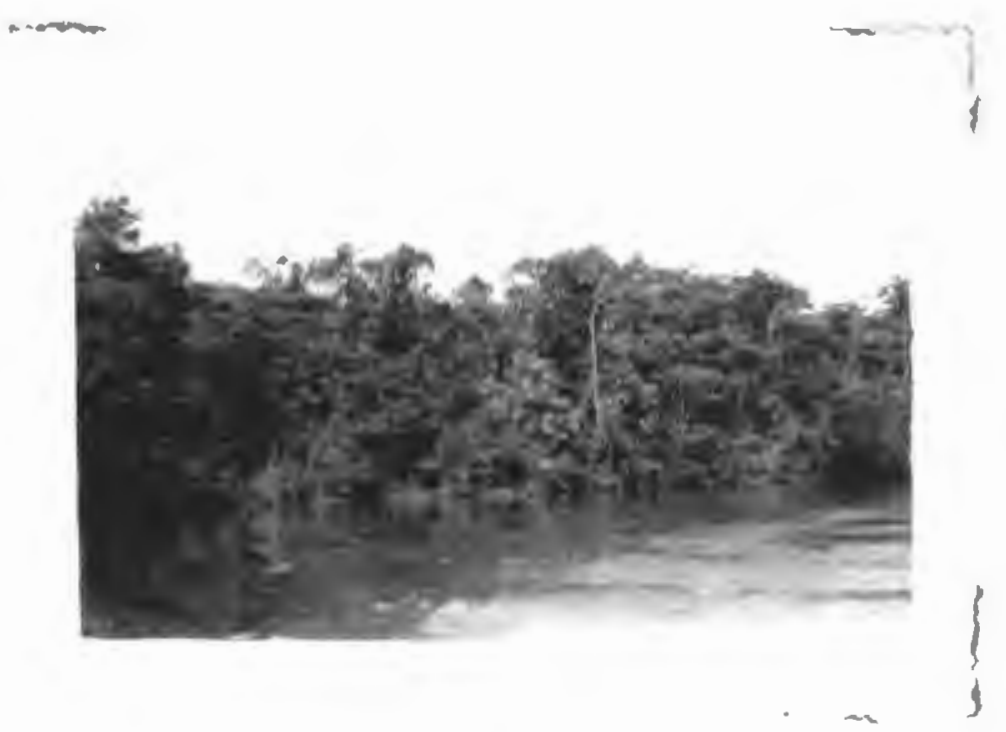

Toto 198.

Aeplotos in mata da balxada, no médio oureo do rio Preto:

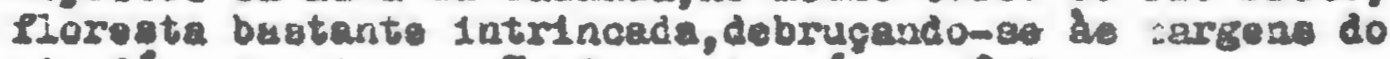
r10,dk-noe a 1murecefo ce um 1gapd amazônico. (Lotos Plerre Gourou - A.R.Pentendo). 


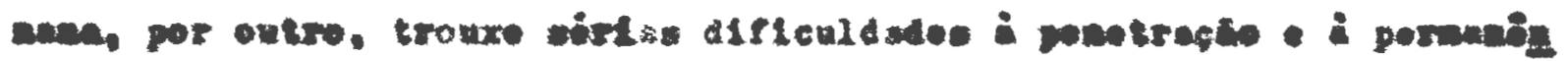

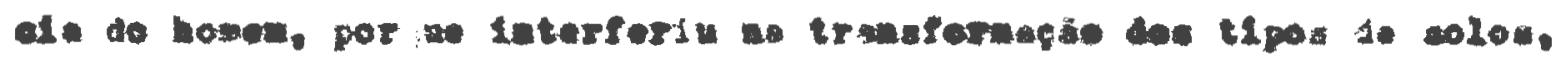

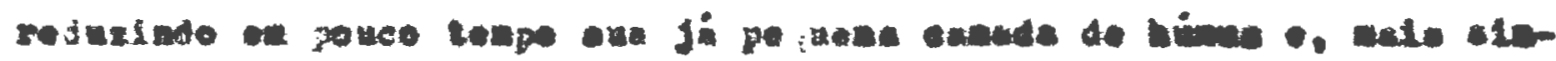

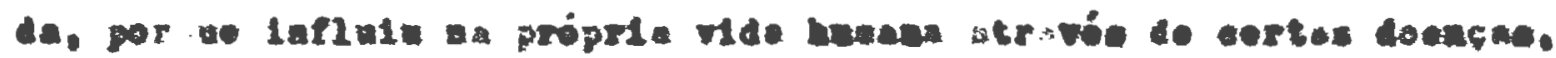

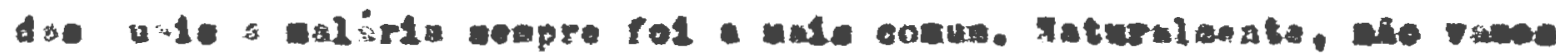

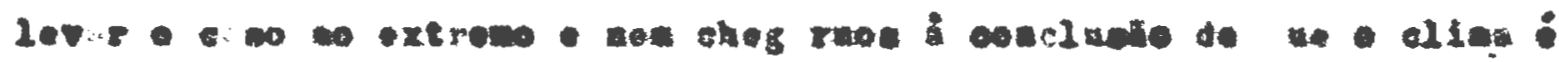

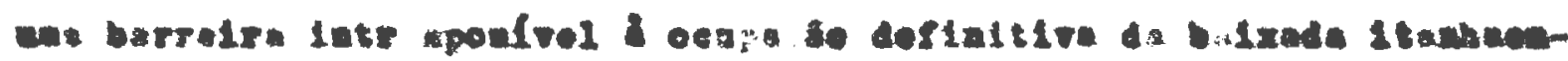

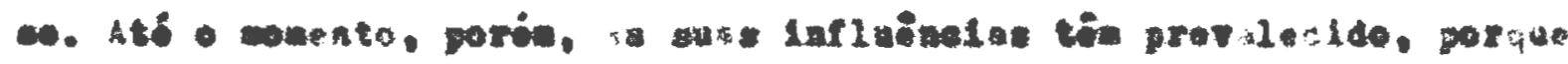

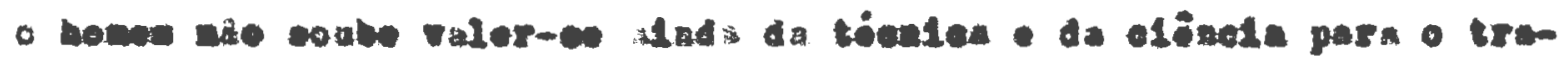
balto rupal in illoge.

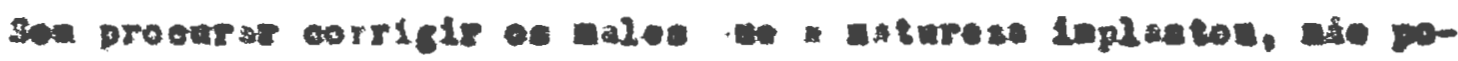

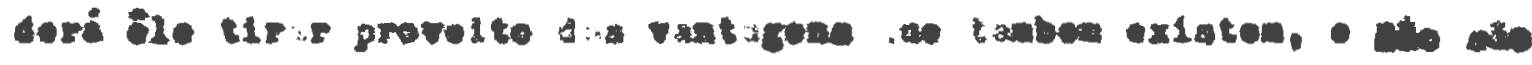

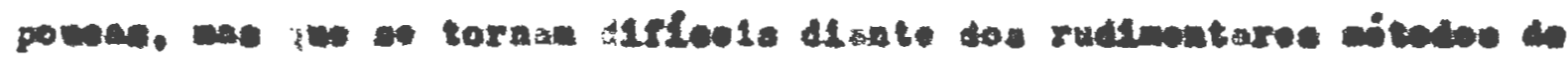
provolimato.

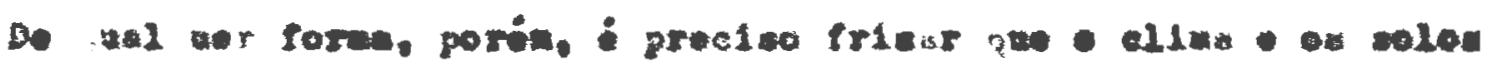

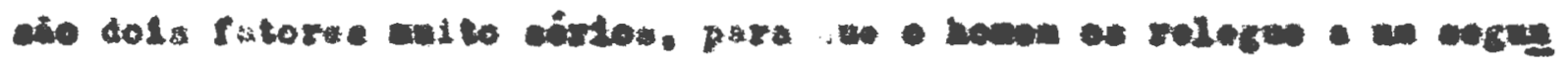

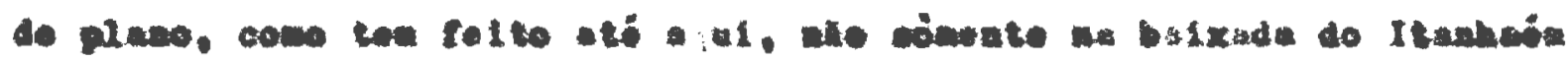

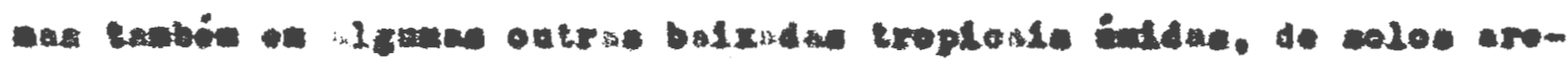

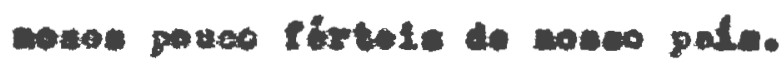




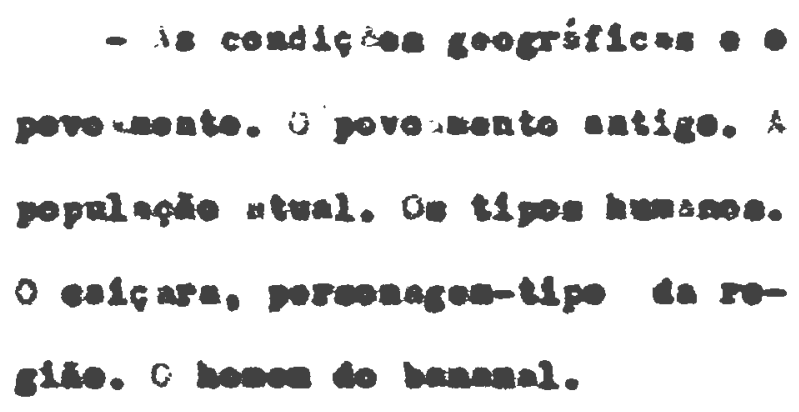

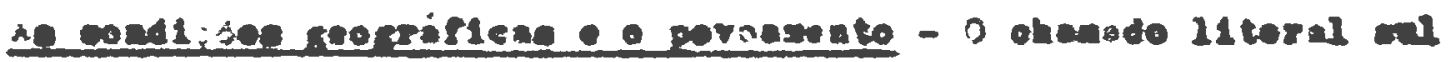

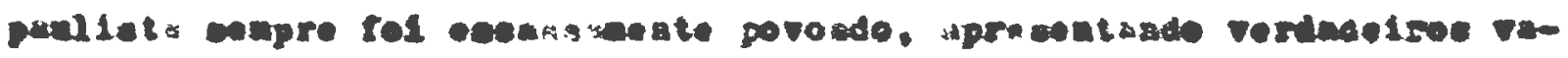

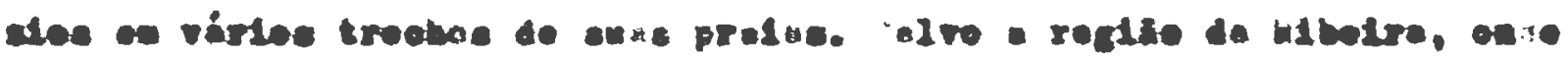

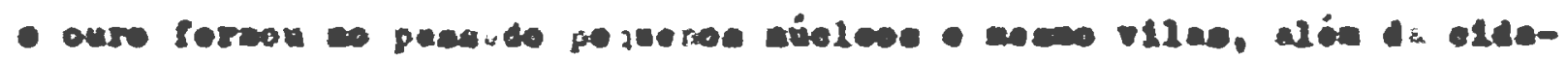

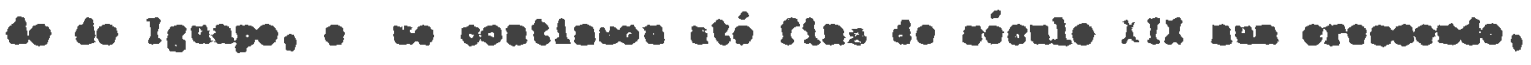

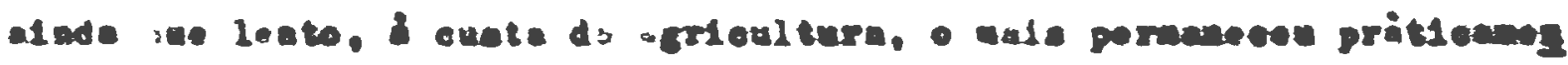

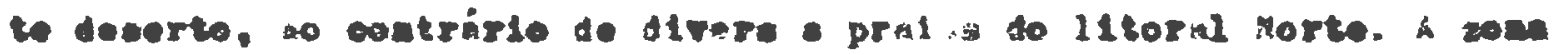

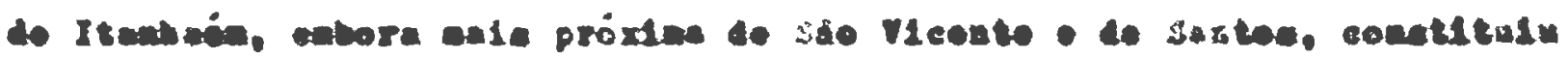

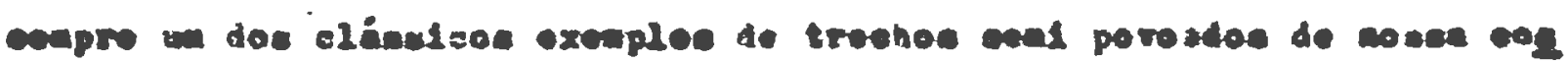
6.

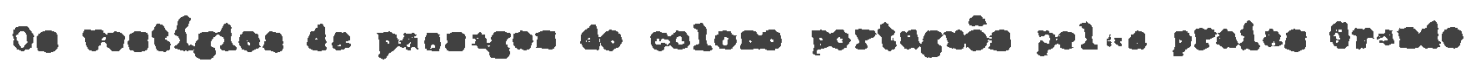

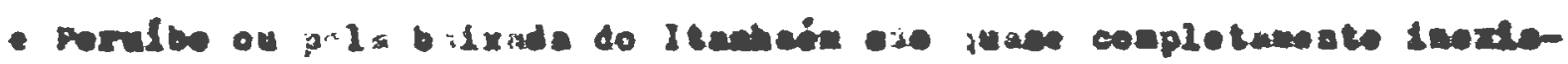

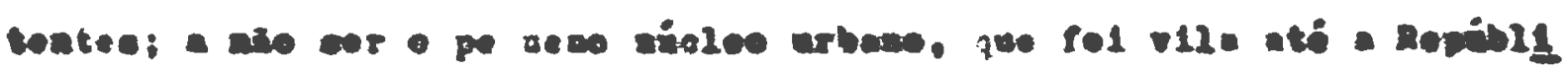




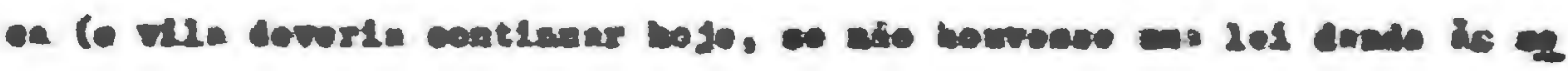

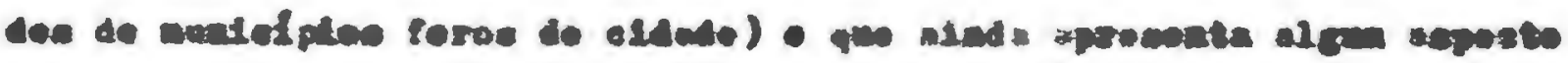

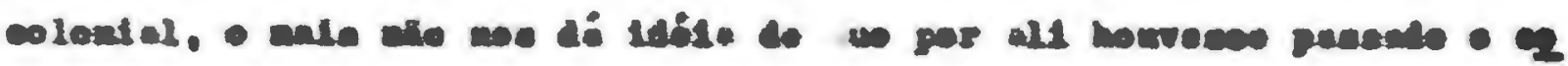

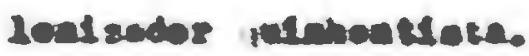

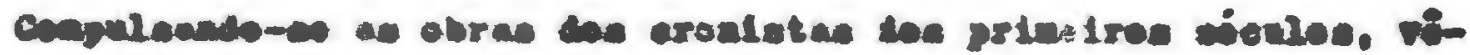

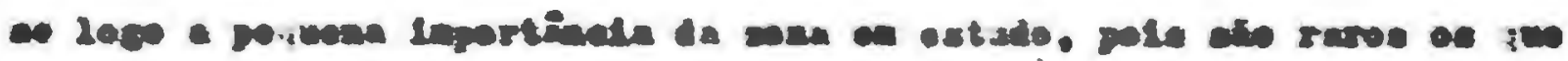

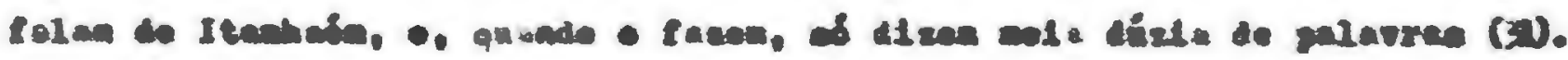

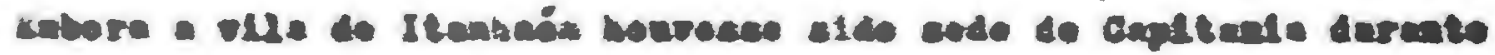

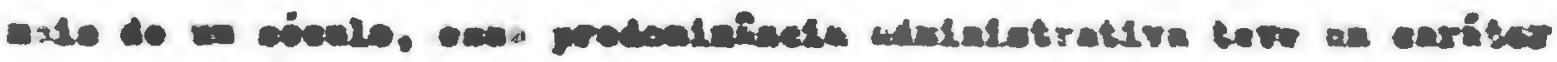

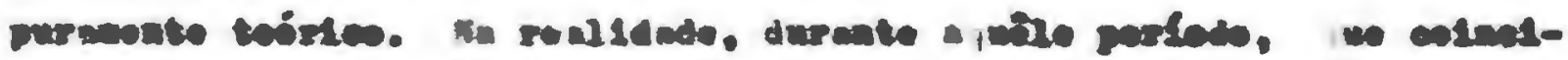

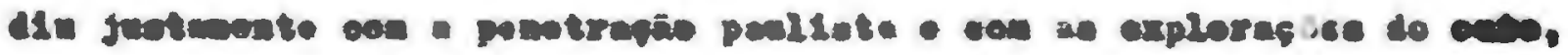

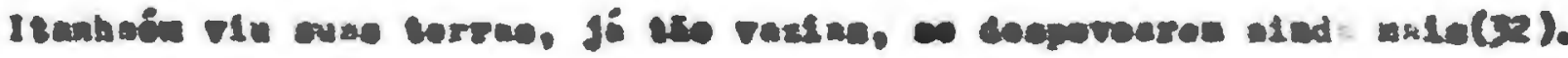

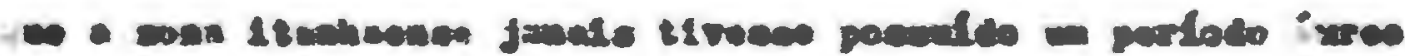

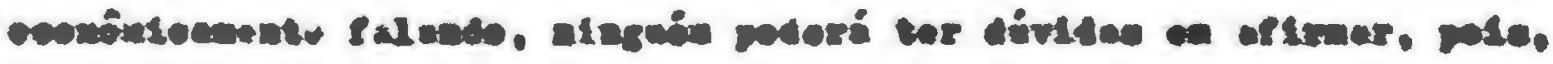

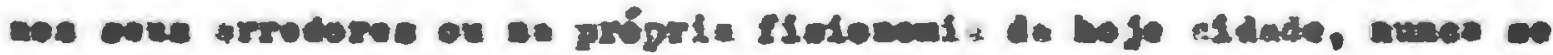

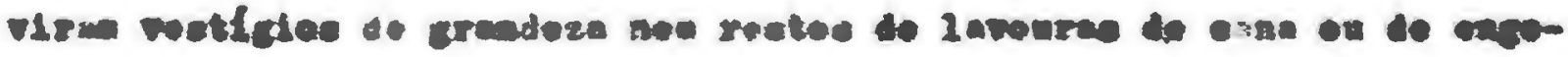

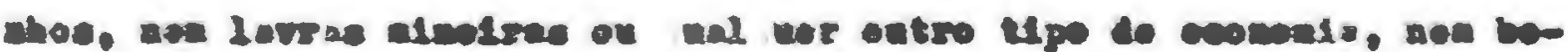

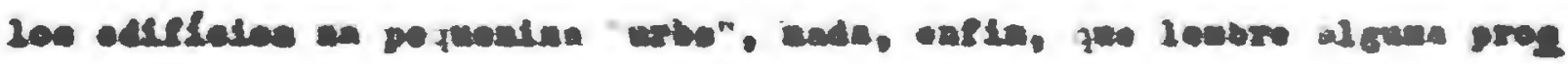

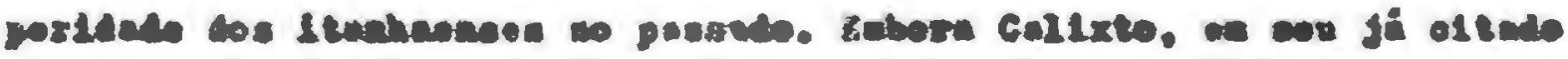

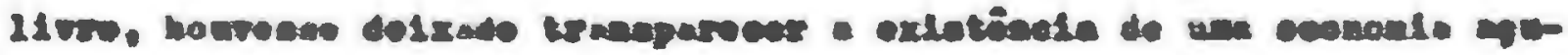

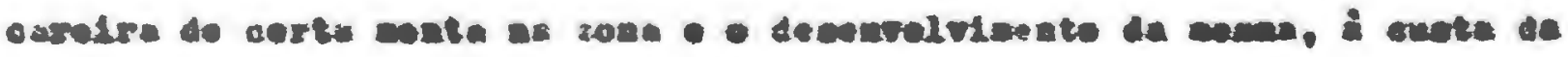

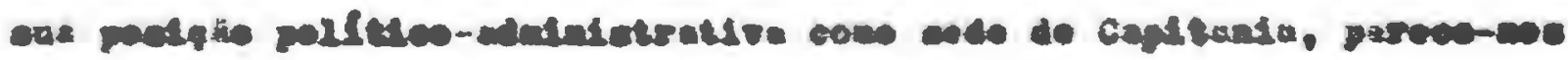

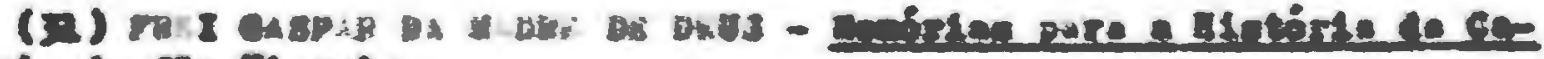
Aterde de sto recitas

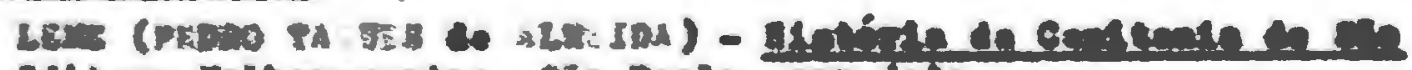

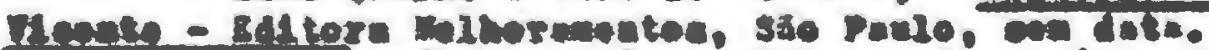

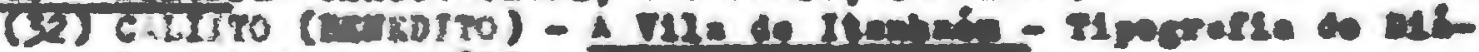
ro do santes - Bances. 2kss. 


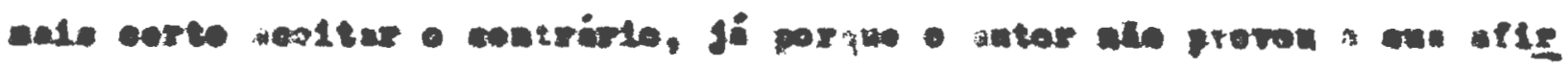

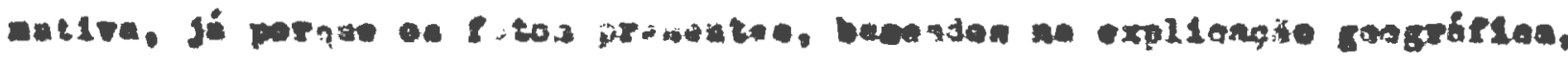
ace we laven tnl oosel wate.

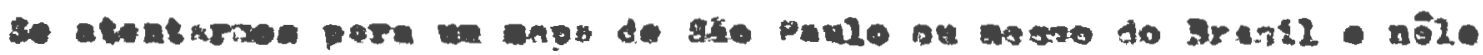

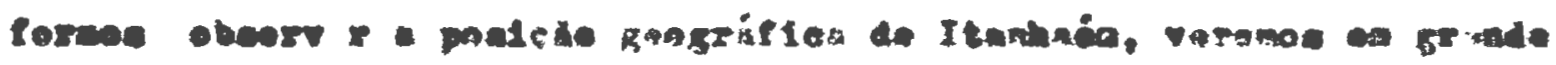

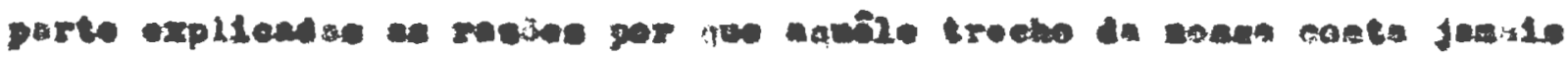

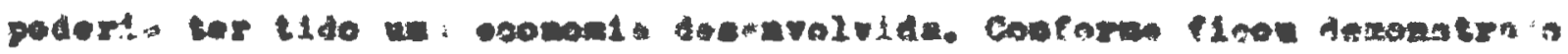

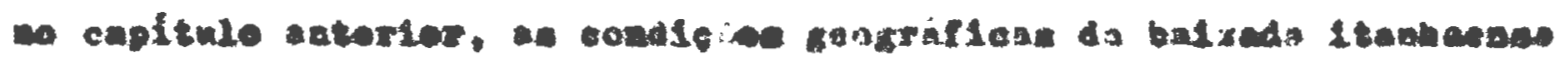

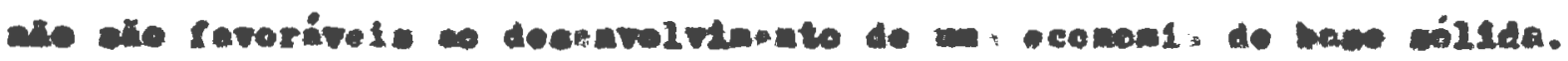

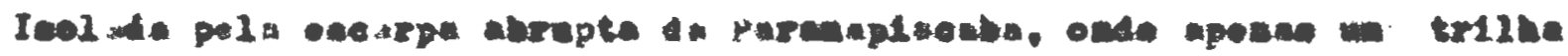

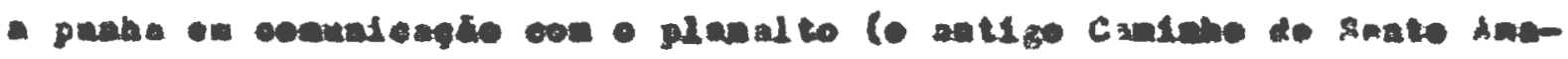

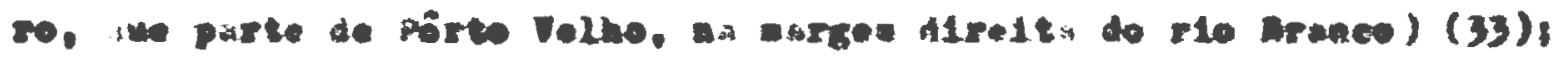

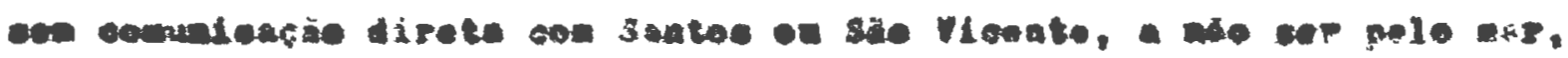

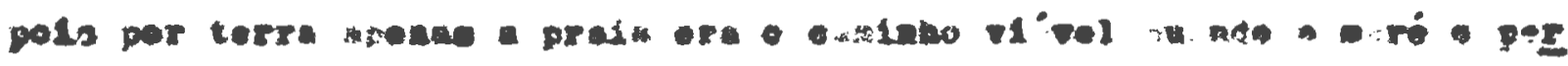

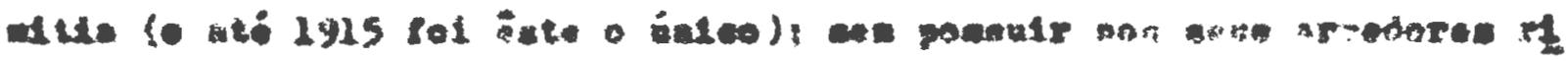

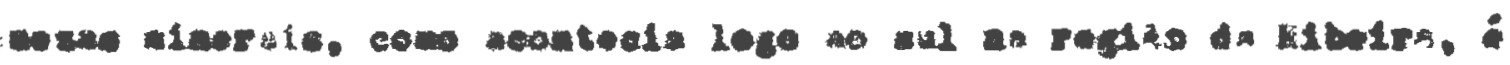

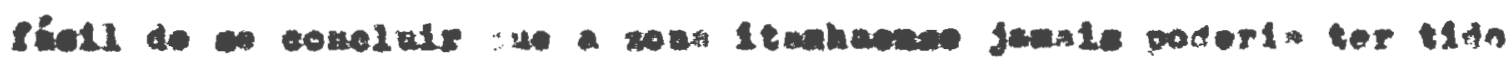

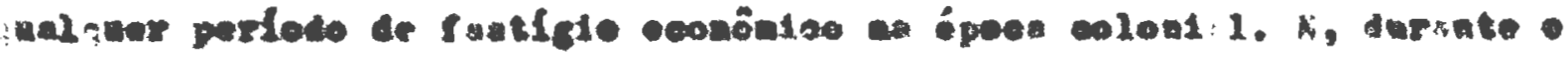

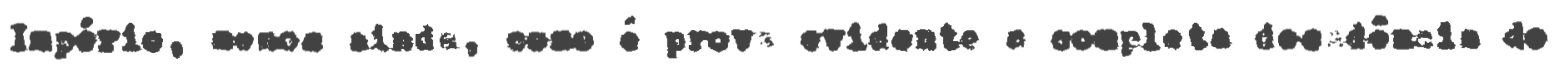

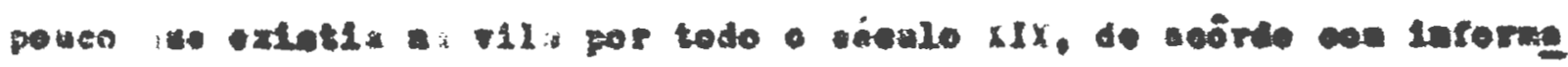

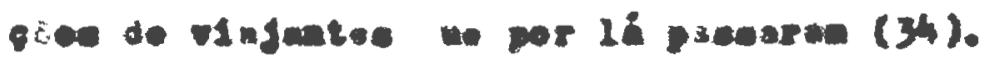

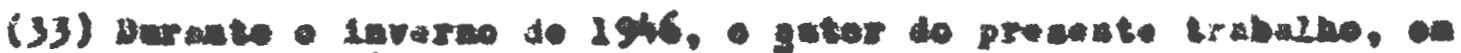

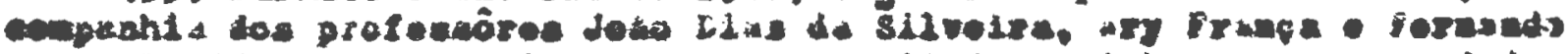

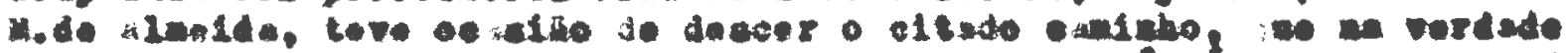

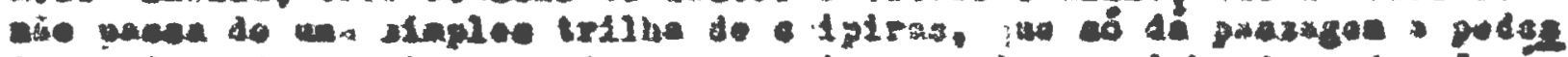

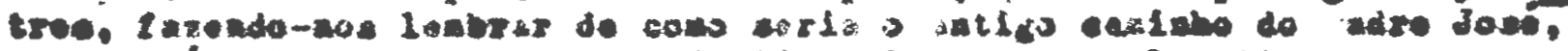

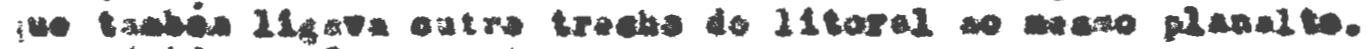

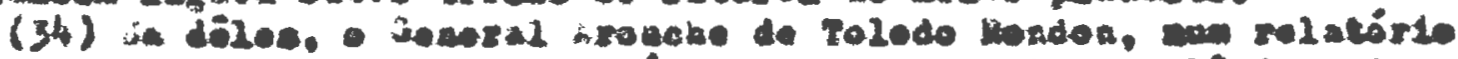

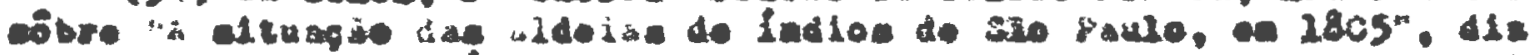

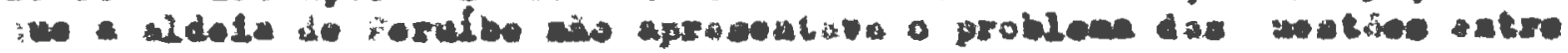




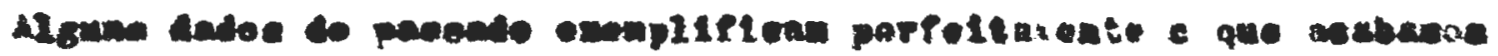

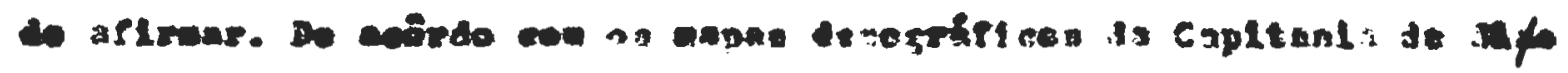

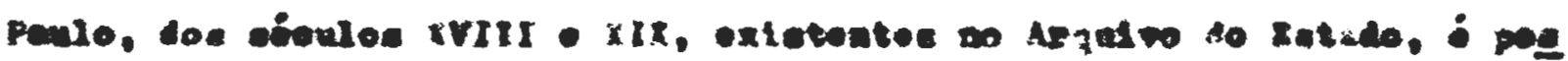

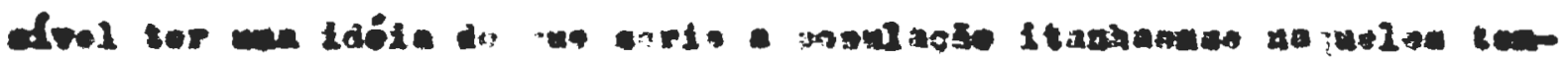
seses

$$
\begin{aligned}
& \text { 1763/84 ....... 203y hateante } \\
& \text { ¿8.9........ }: 273 \text { * } \\
& \text { lky? .......... 1565 }
\end{aligned}
$$

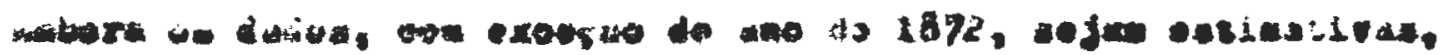

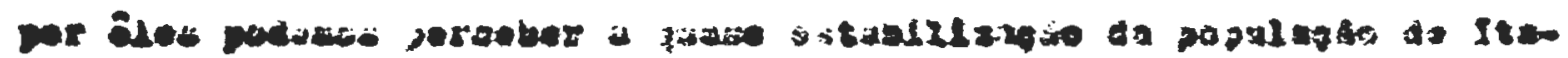

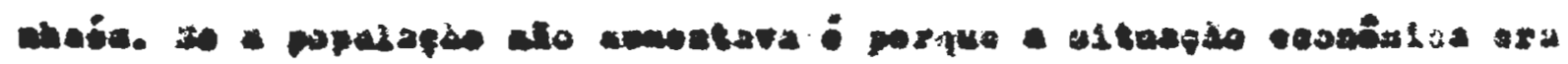

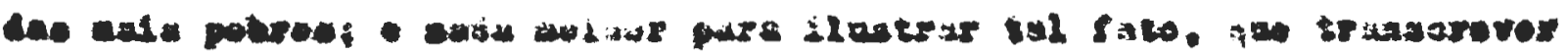

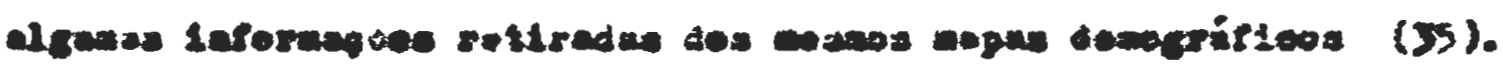

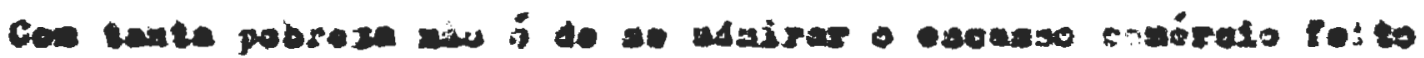

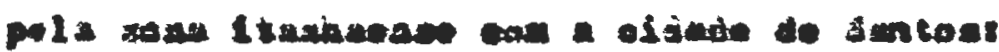

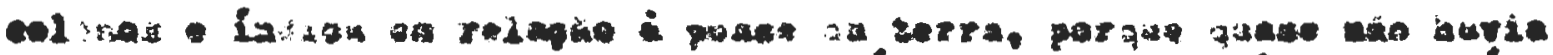

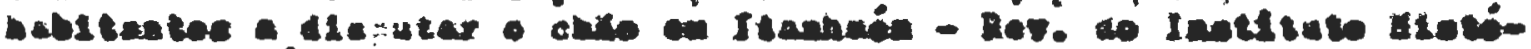

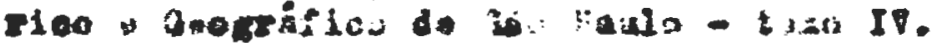

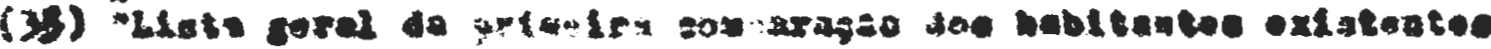
- 1505 - cospantos

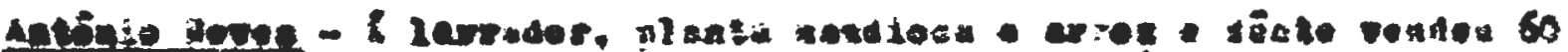

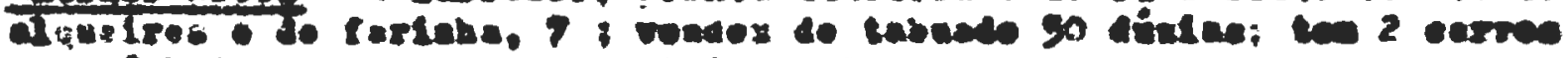

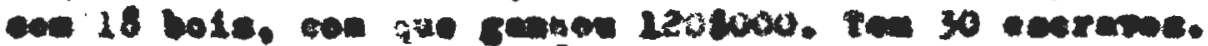

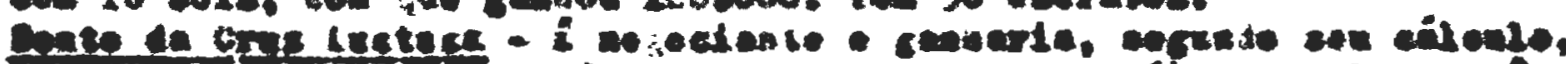

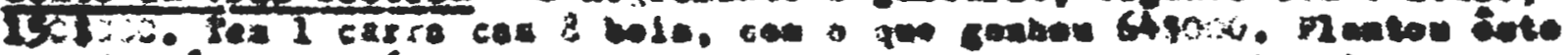

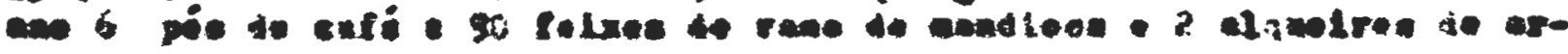
soe.

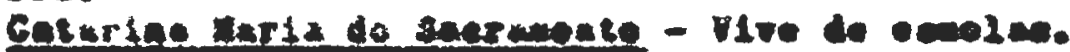

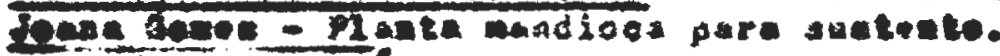

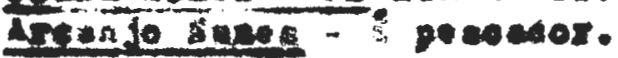

\section{-...........}

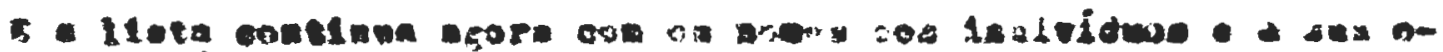

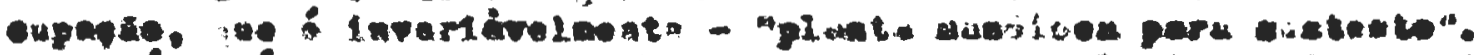

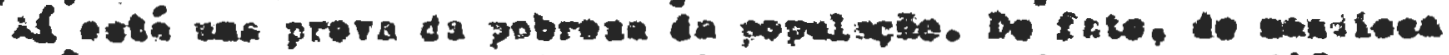

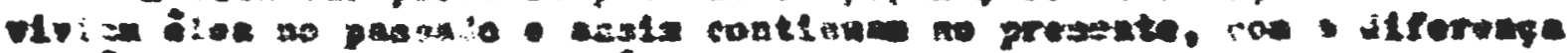

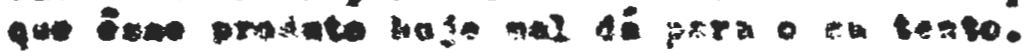


Drartarese $-1802(36)$

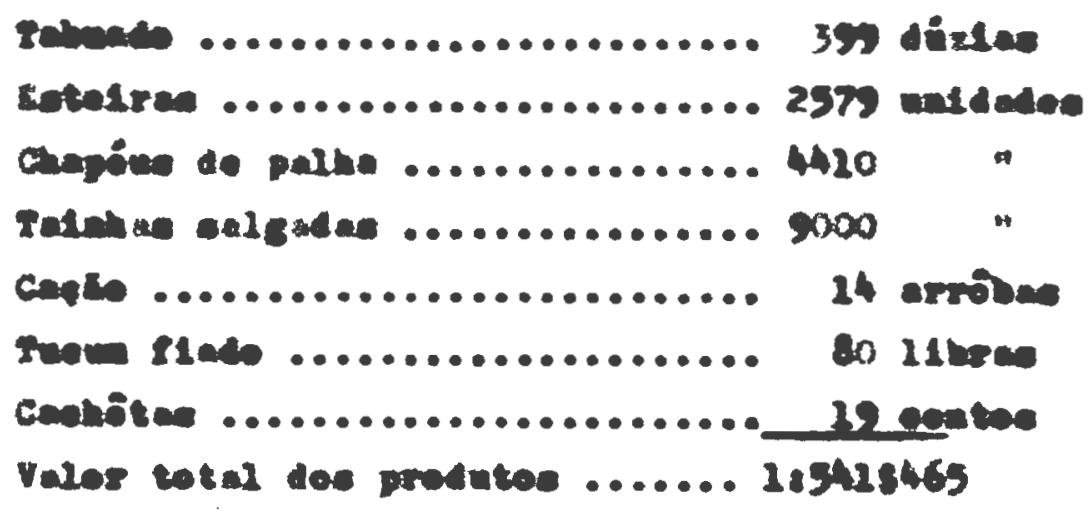

Iorater -1805

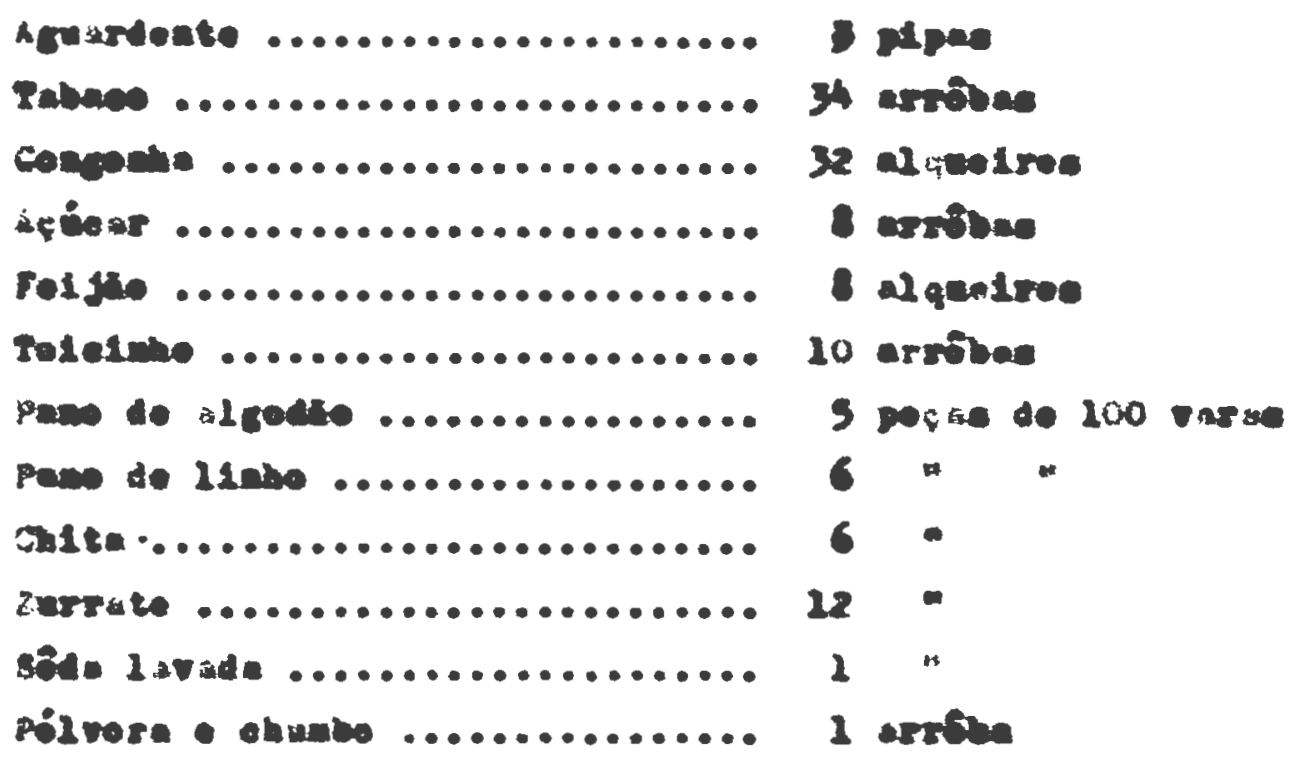

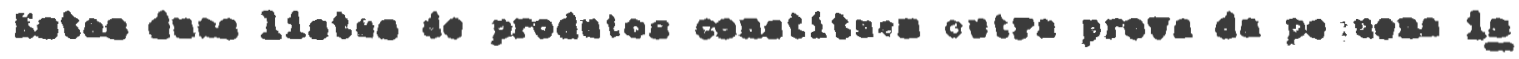

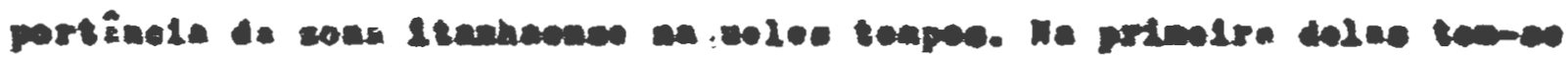

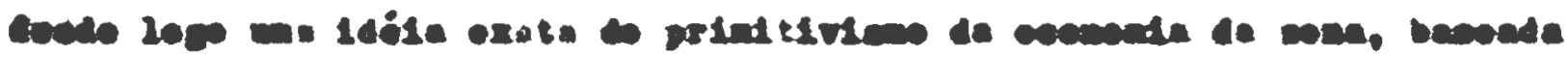

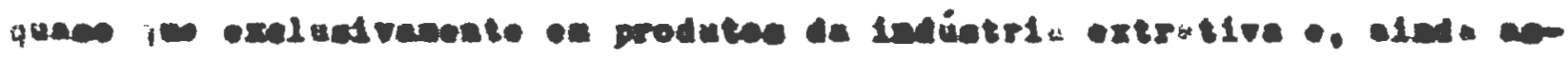

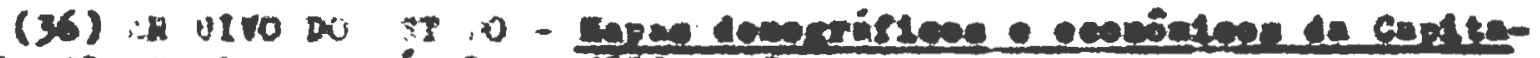
ale de sie paule we cievien IVII e IIX.

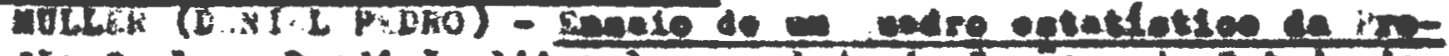

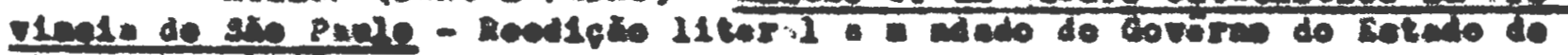
Sho Panlo. IST3

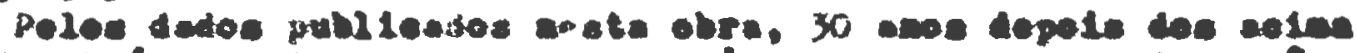

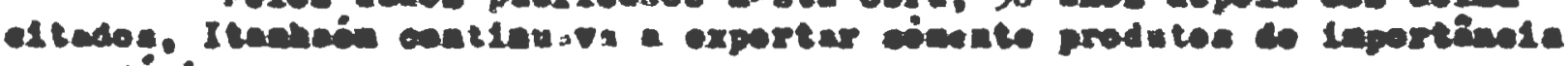
ceosuda árla. 


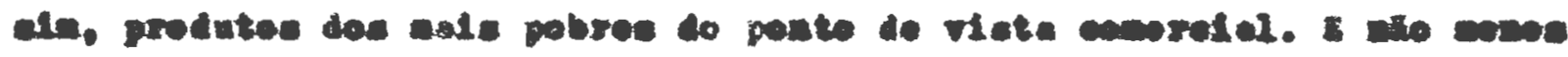

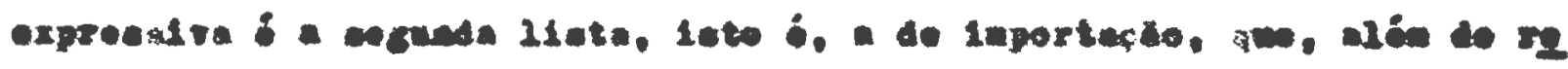

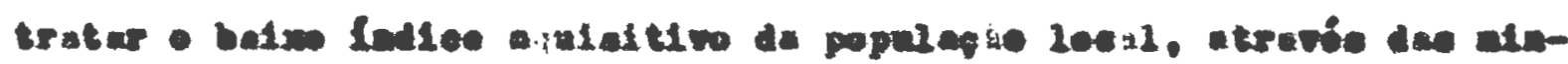

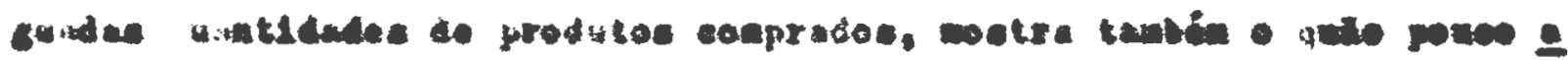

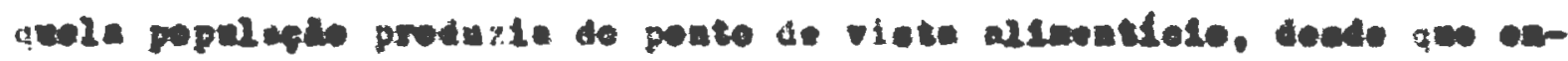

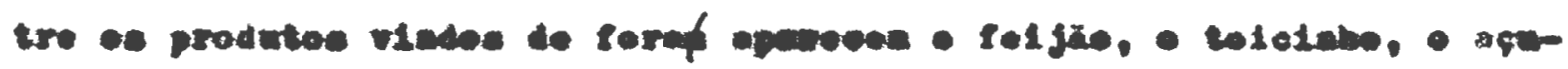
car, agrardonte. ete..

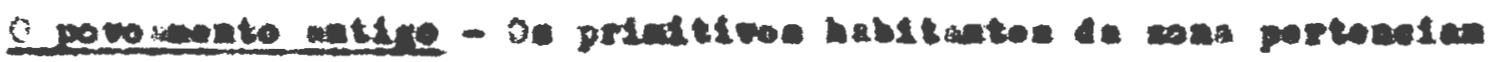

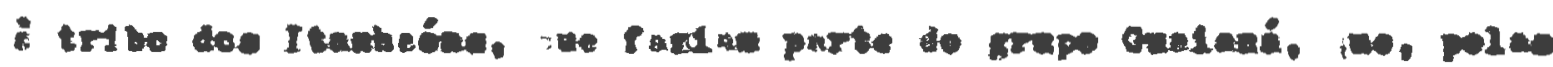

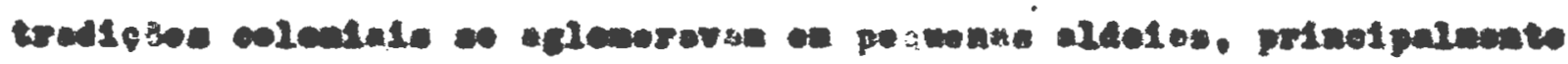

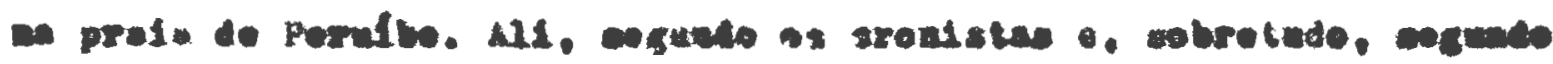

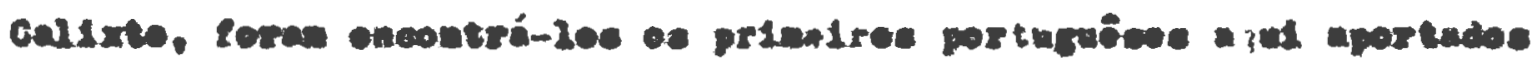
con tartie is fones.

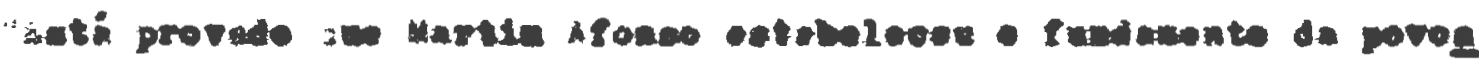

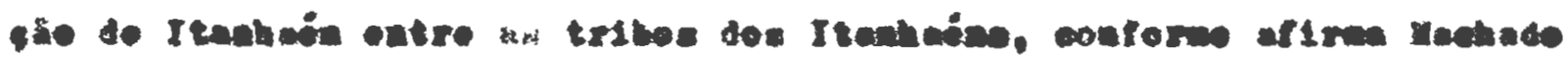

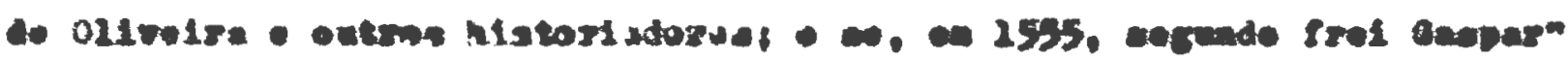

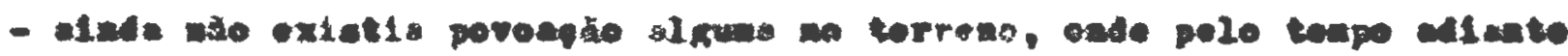

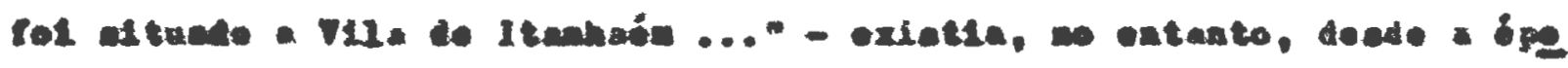

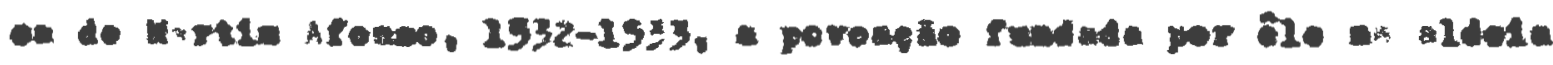

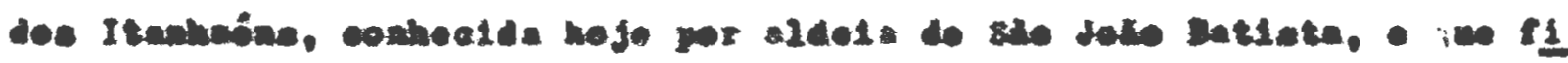

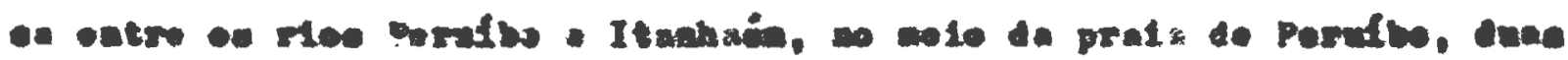

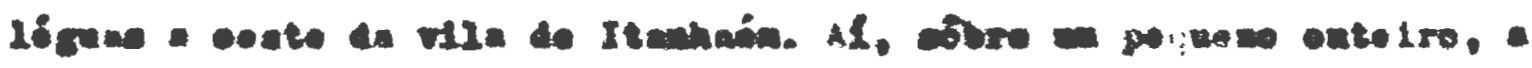

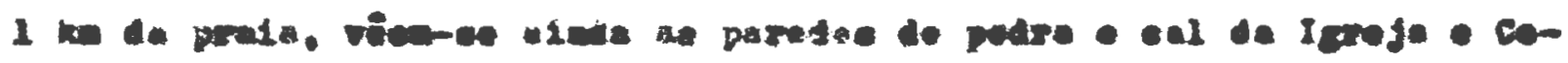

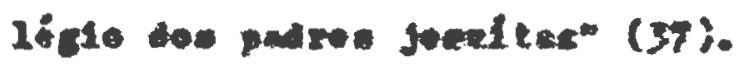

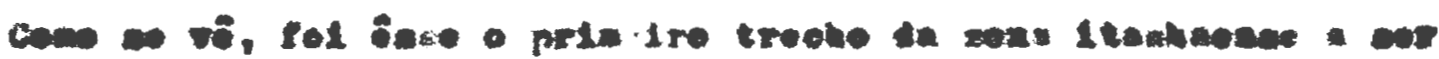




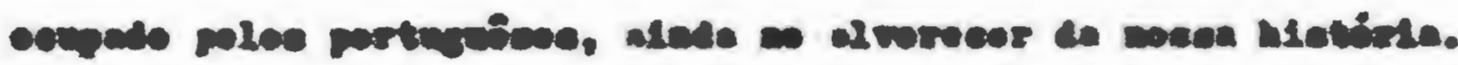

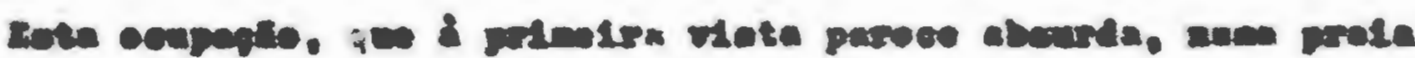

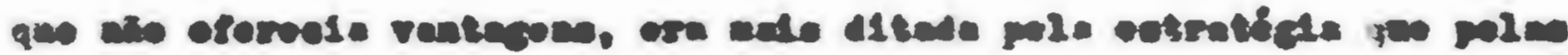

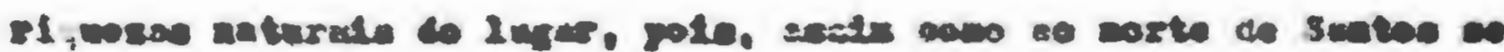

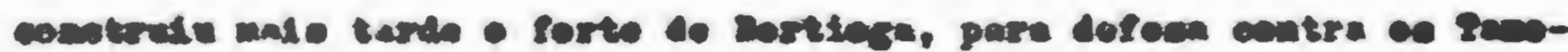

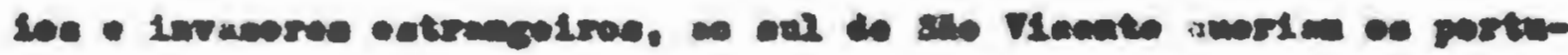

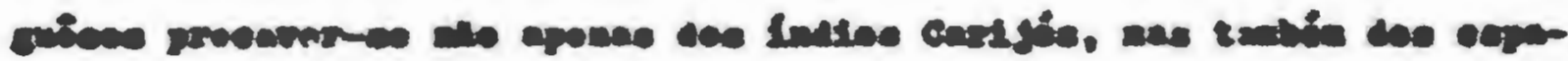

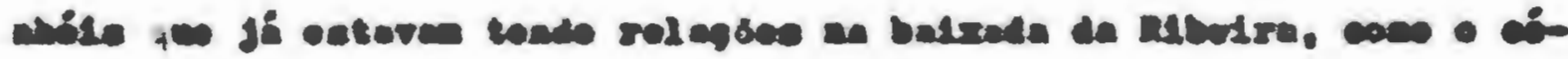
lober bacharel de cennaile (3a).

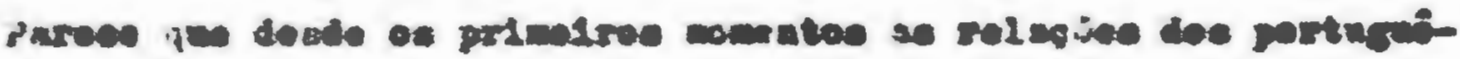

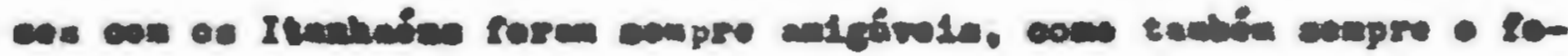

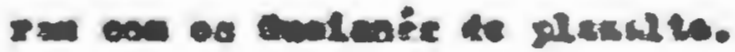

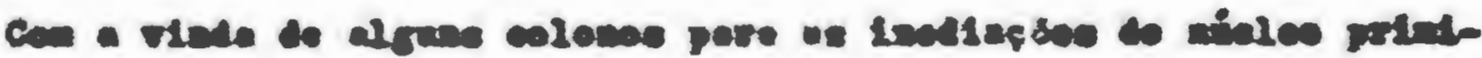

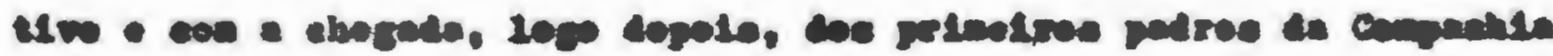

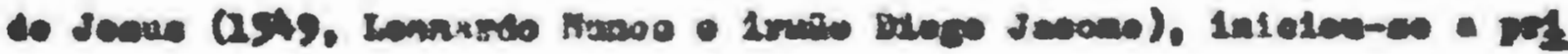

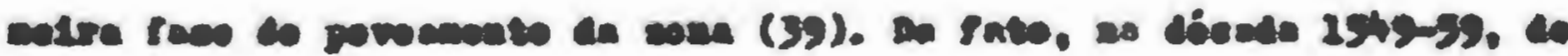

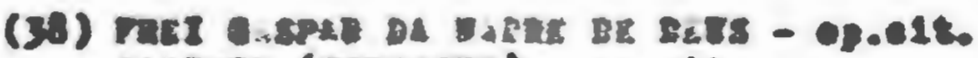

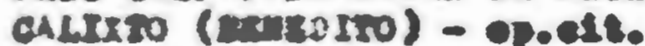

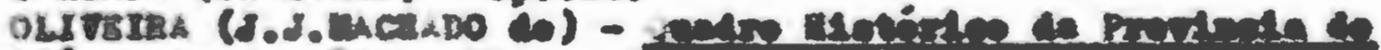

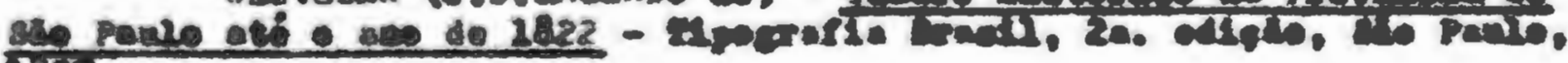
I597.

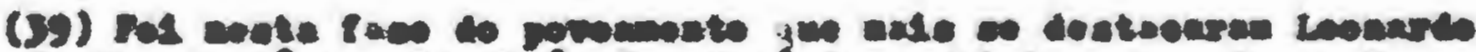

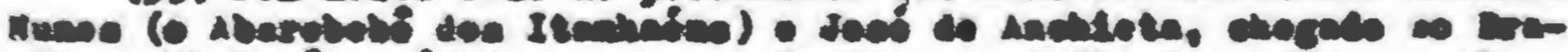

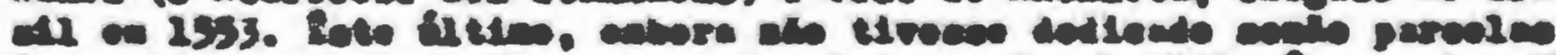

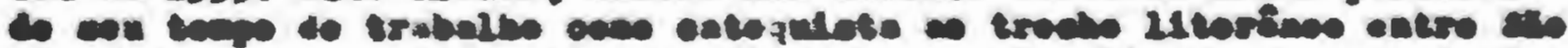

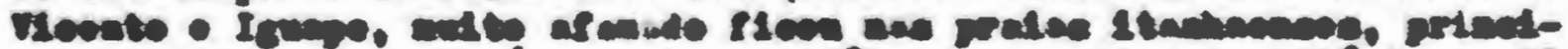

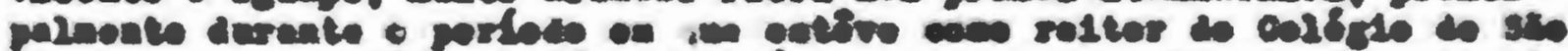

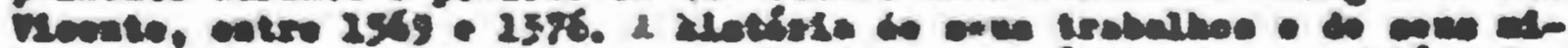

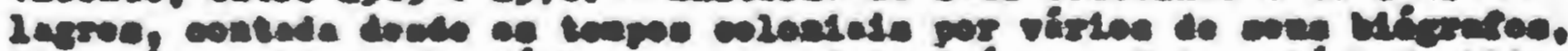

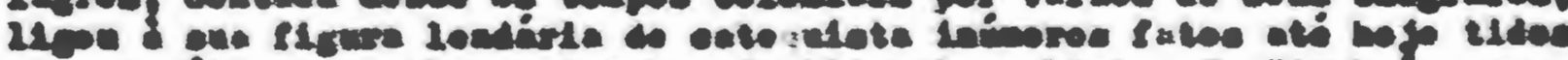

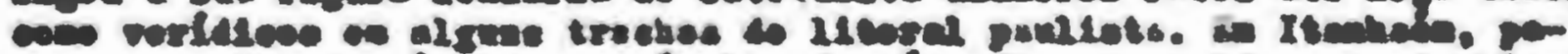

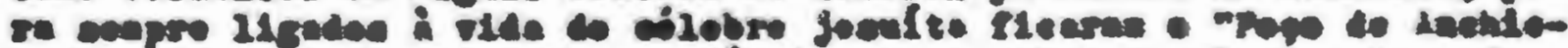

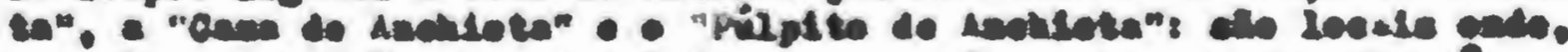

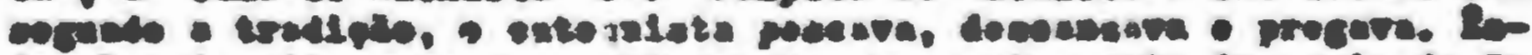

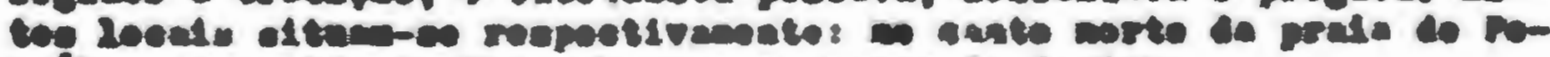

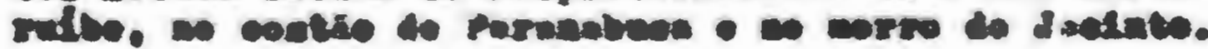




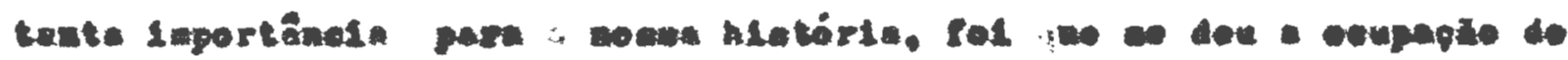

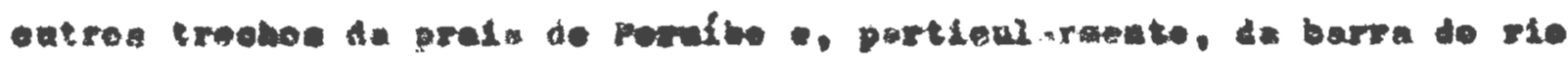

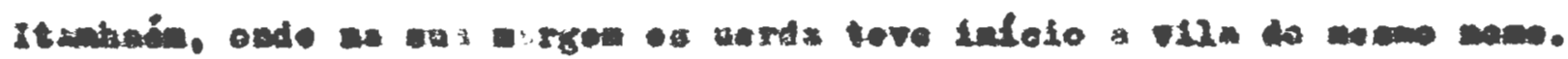

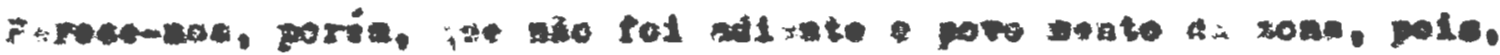

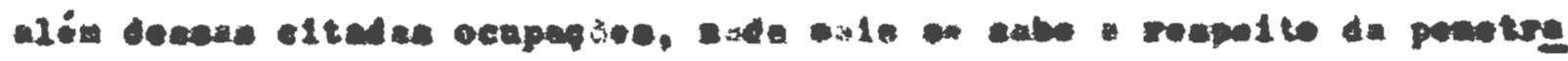

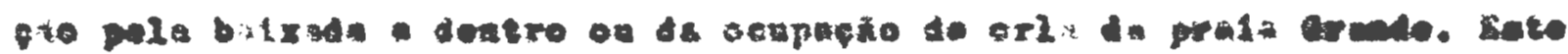

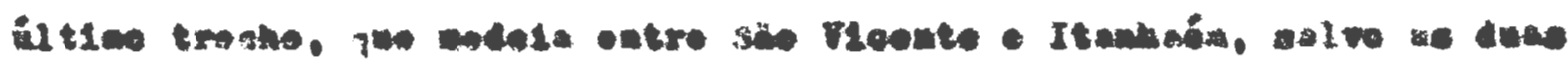

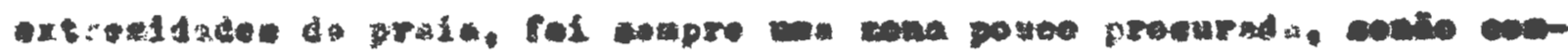

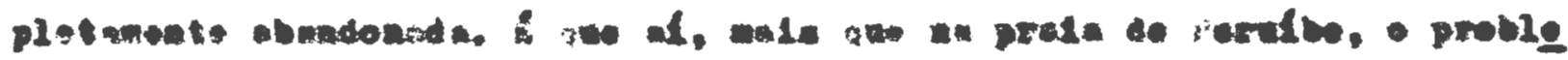

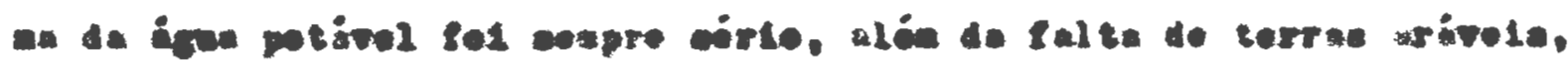
are w10 extron

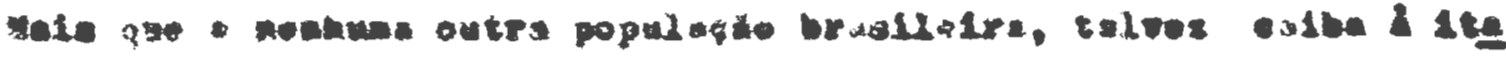

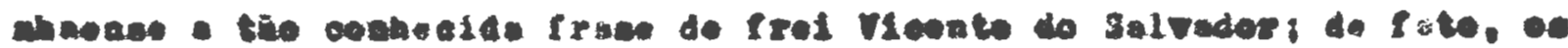

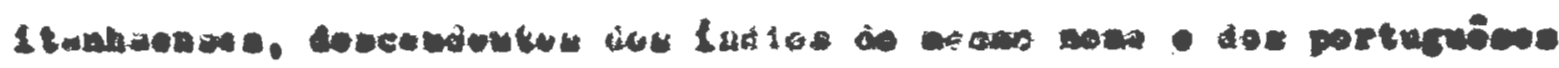

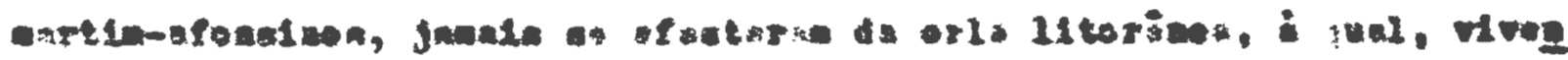

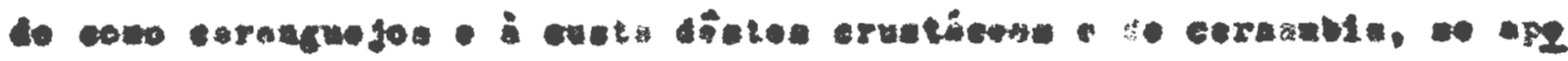

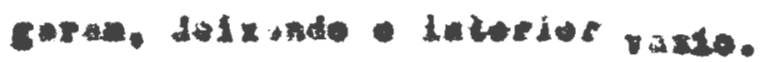

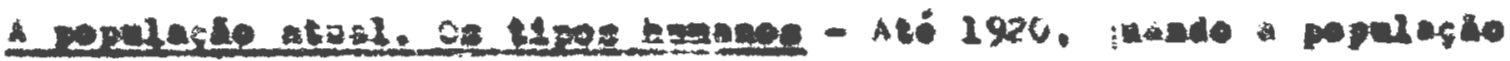

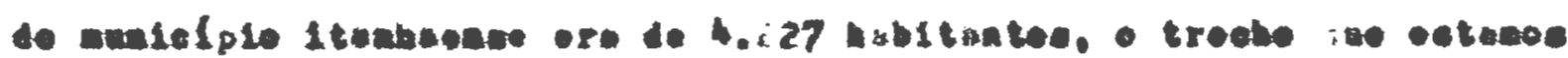

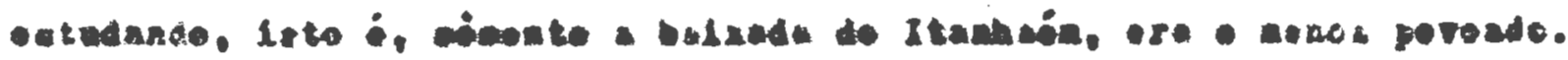

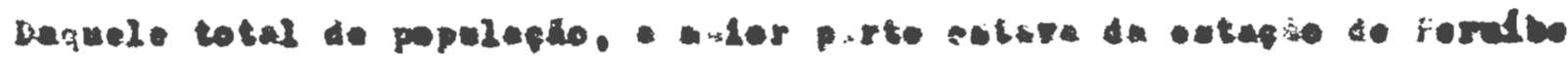

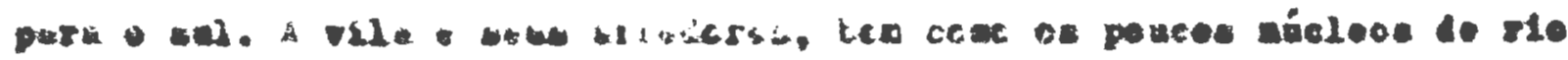

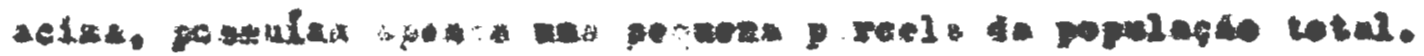

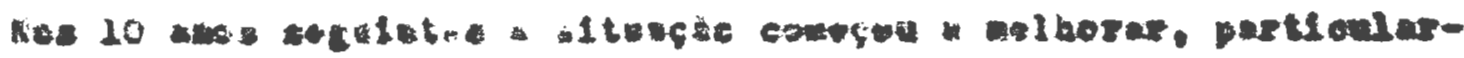

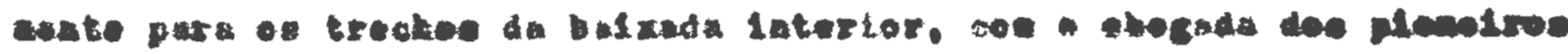




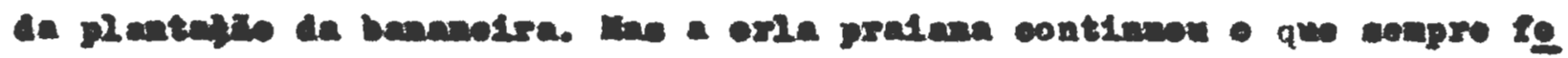
ra - parecante poroada - atragada.

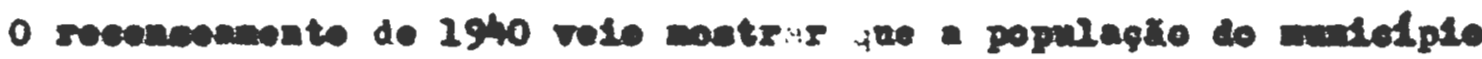
aunetara, atingindo entio a clira de 11.052 habitentee (39). Wo entan-

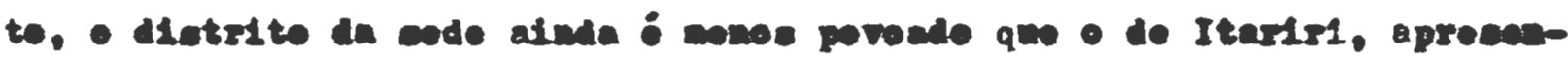

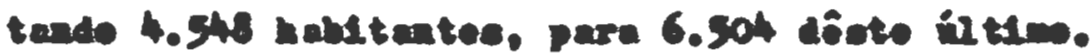

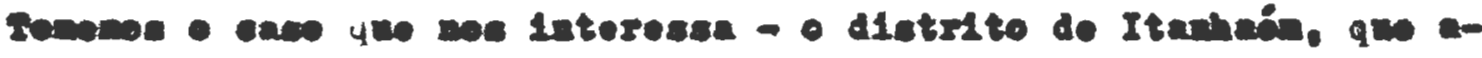

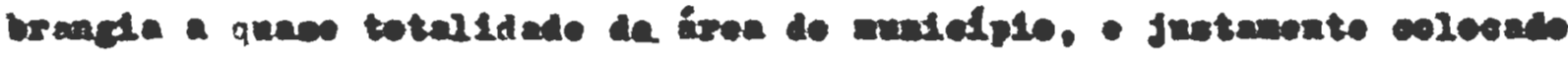

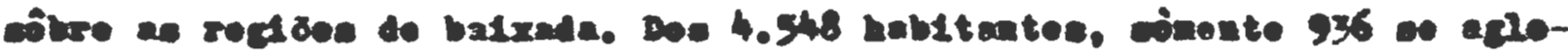

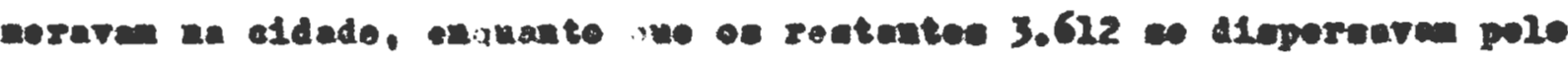
Interter da balrada on acoupanhando ar exteneas yrales.

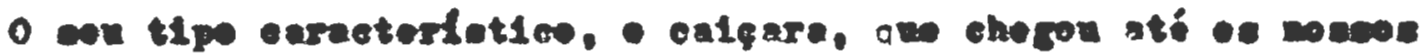

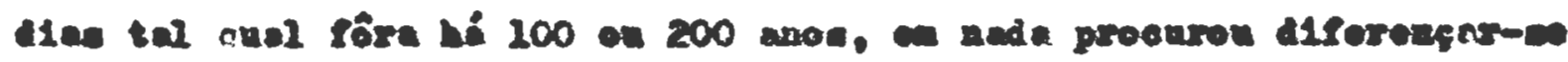

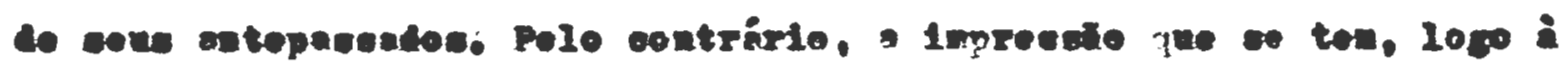

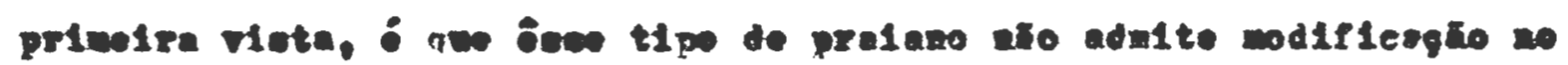

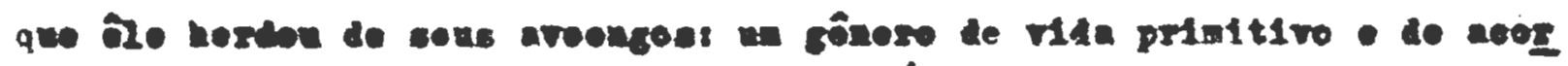

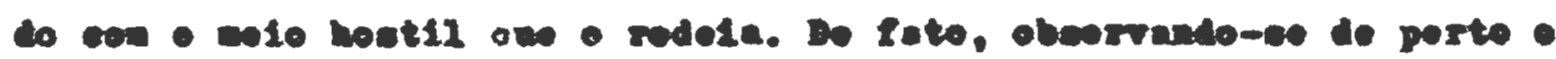

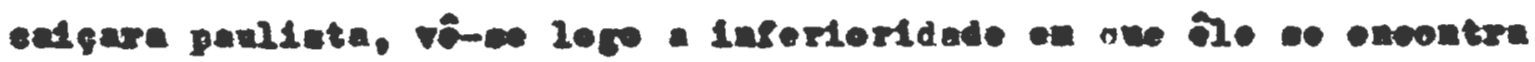

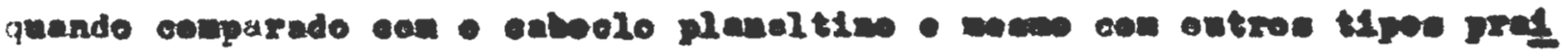

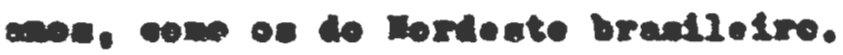

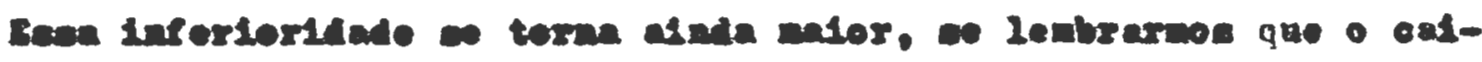

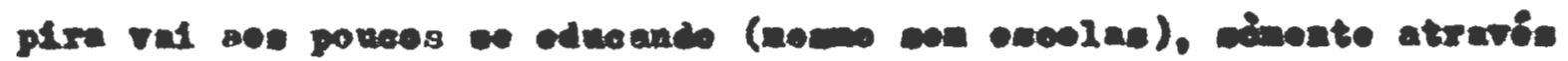

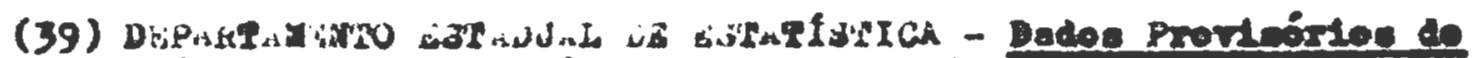

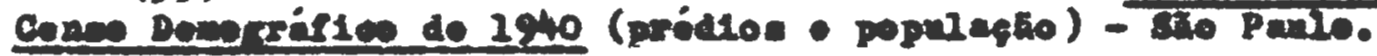

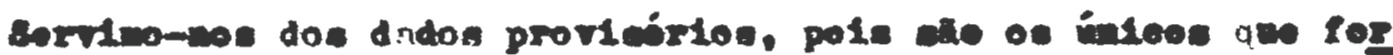

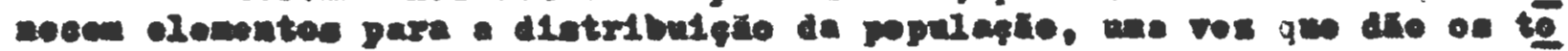
tall da populacio urbana - rural on separado.

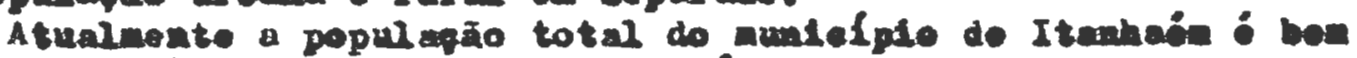

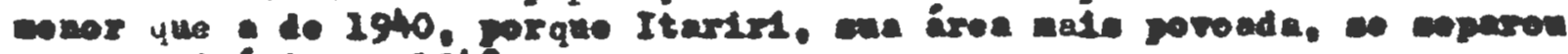
como meteiplo on 1948: 


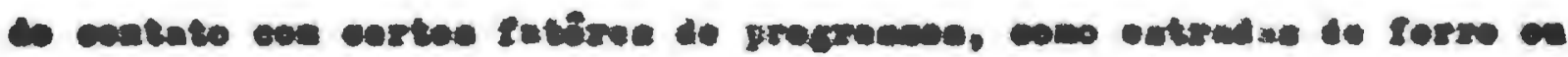

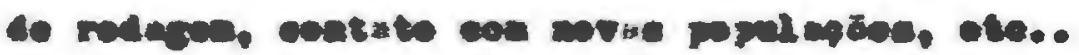

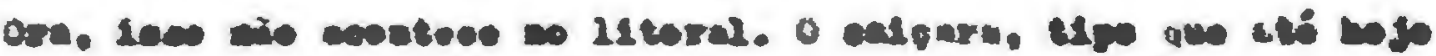

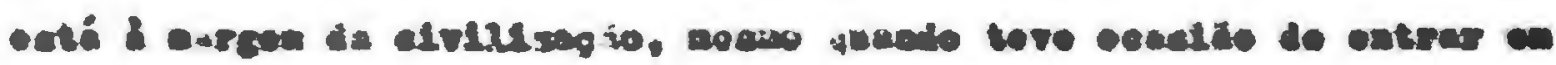

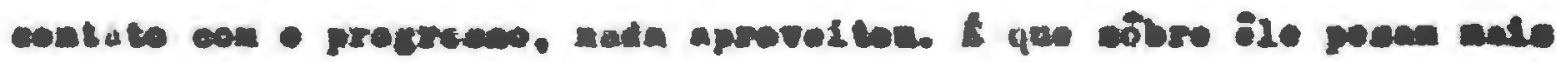

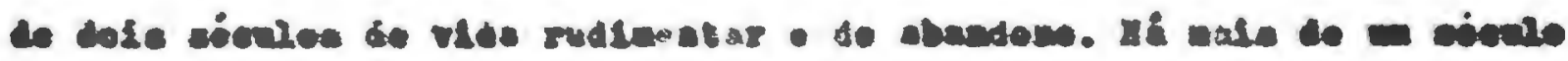

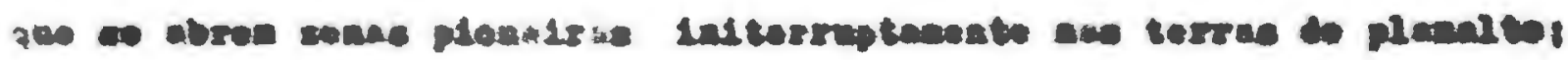

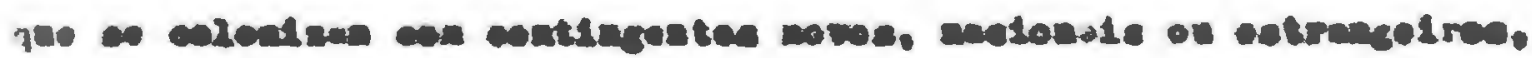

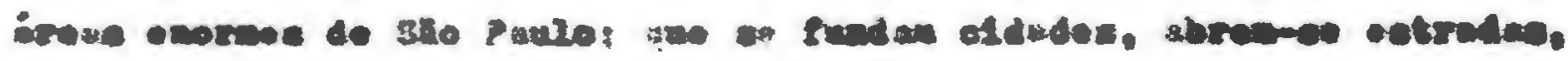

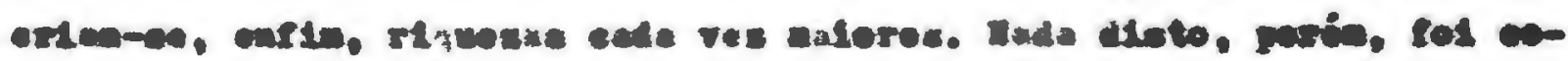

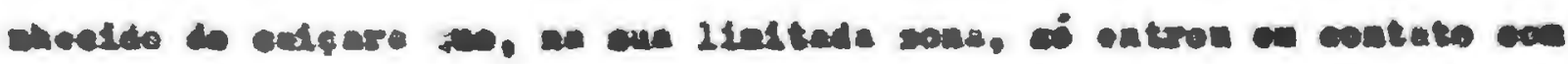
- anturese book13.

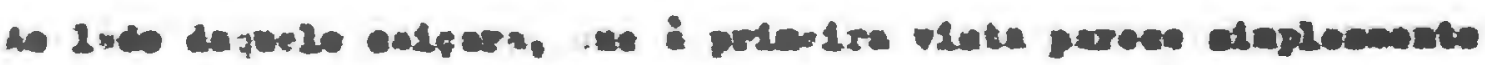

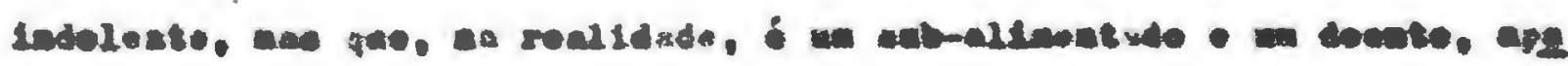

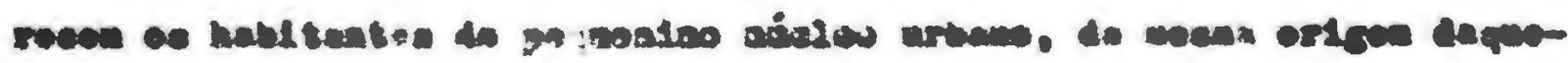

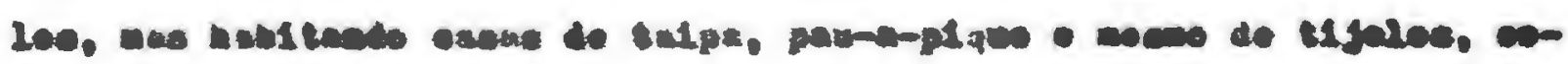

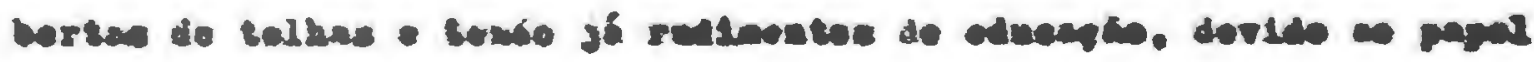

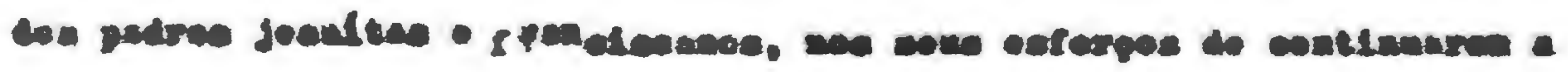

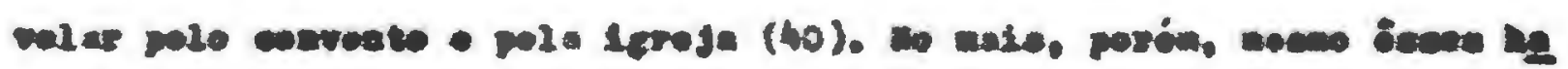

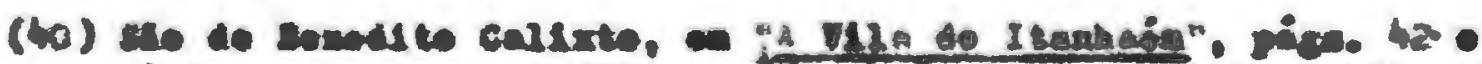

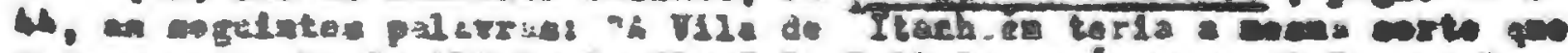

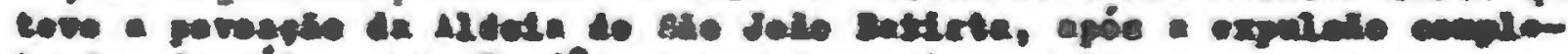

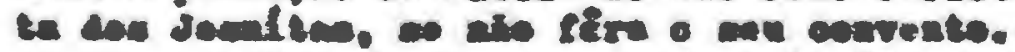

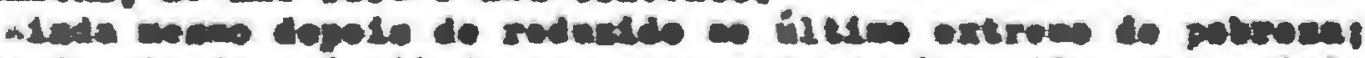

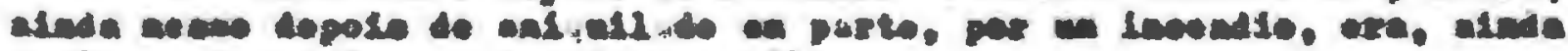

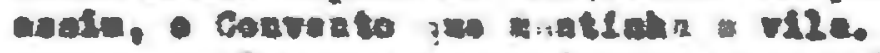
e. Tou groval.

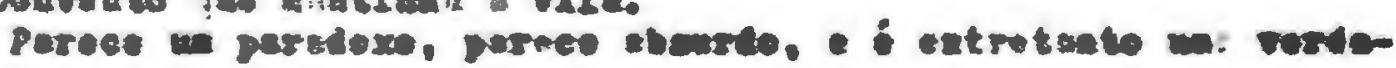

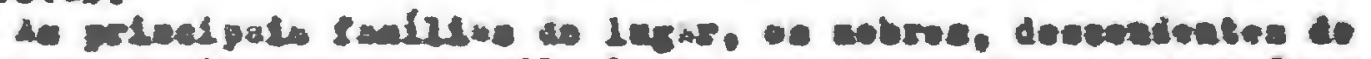

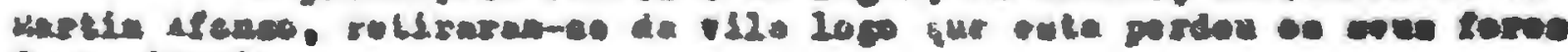
de opdente.

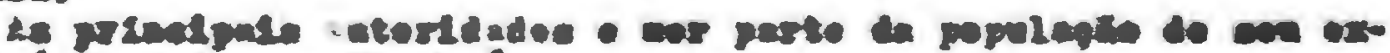

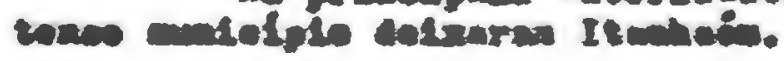




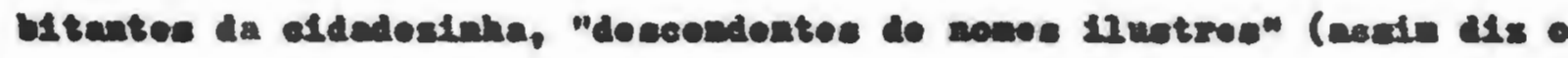

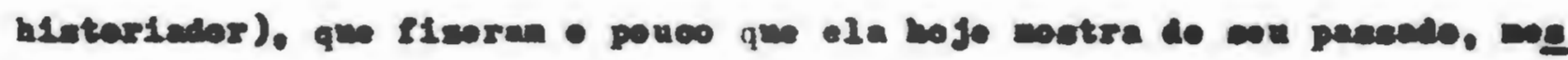

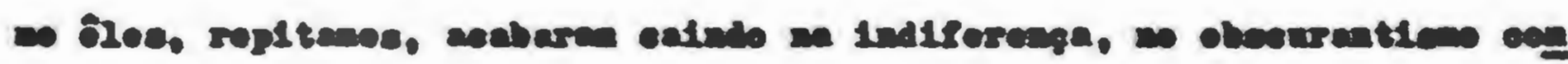

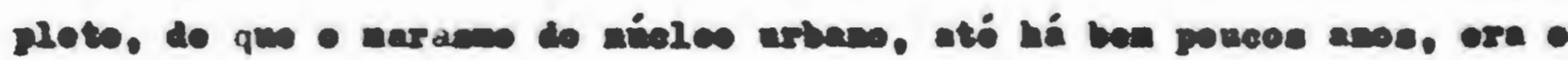

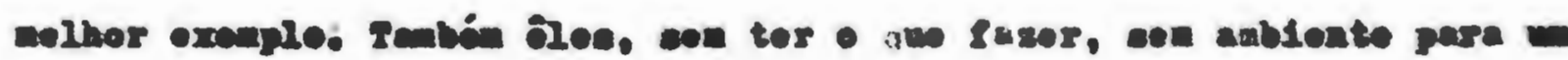

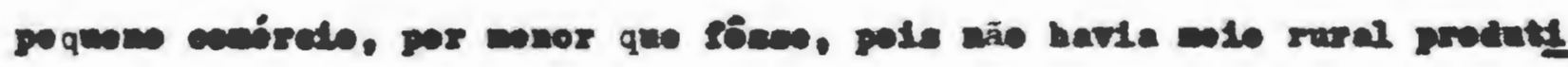

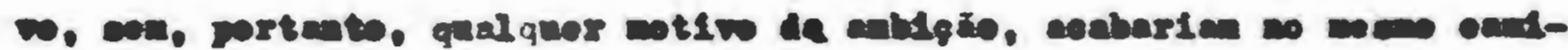

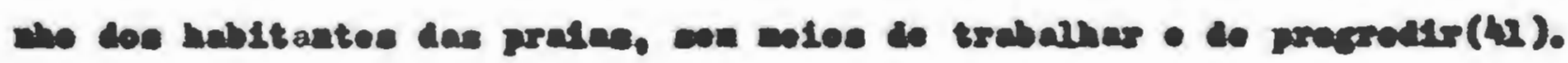

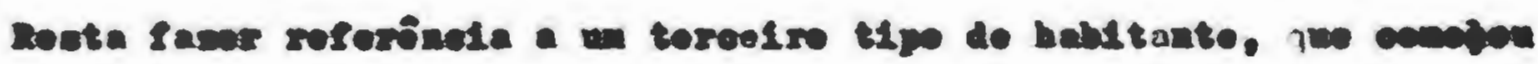

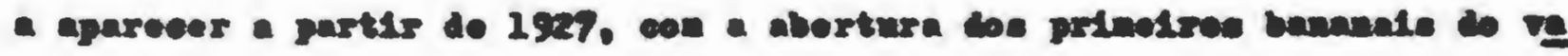

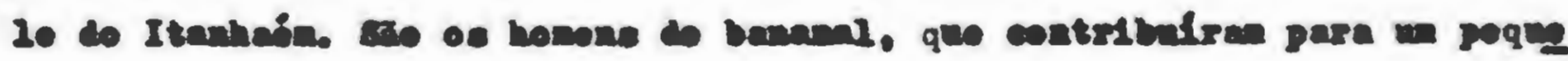

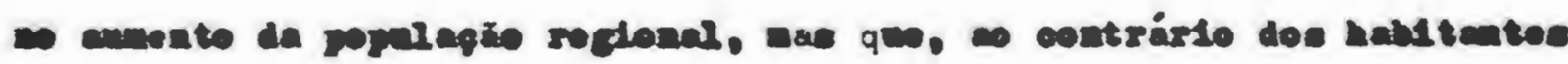

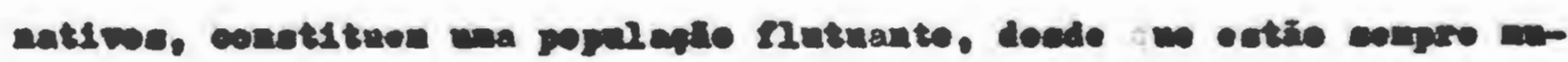

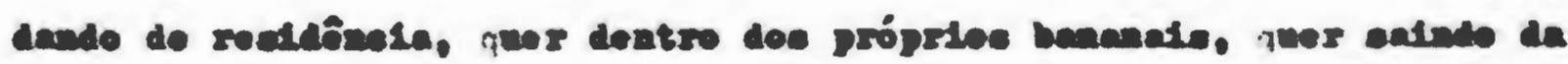

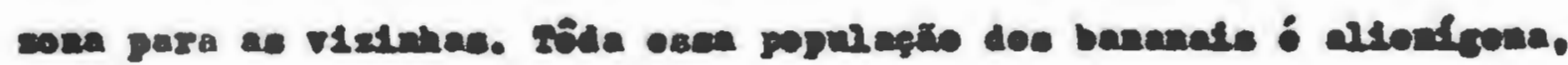

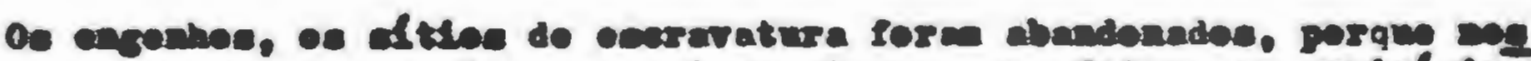

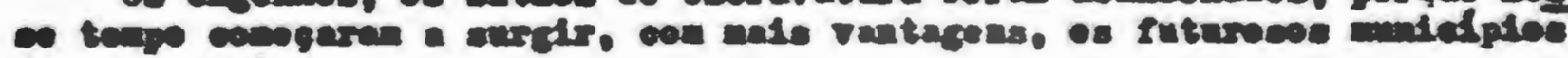
do corza cotin...

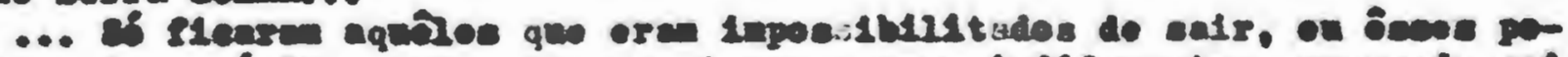

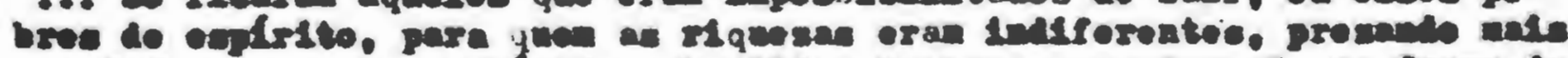

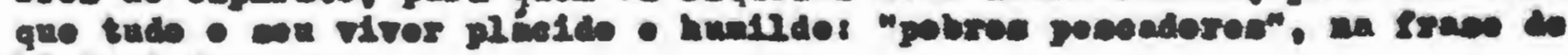
hiotorlador.

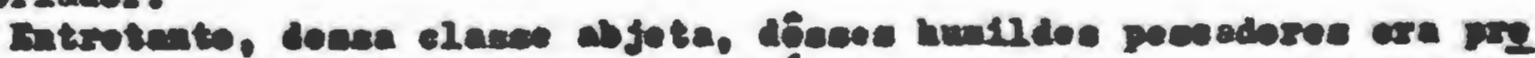

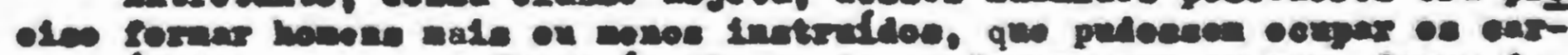

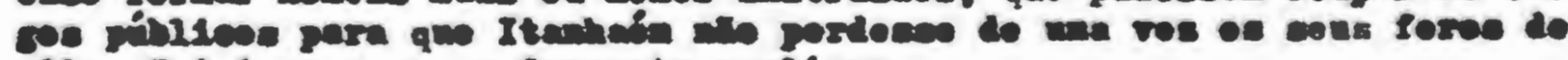

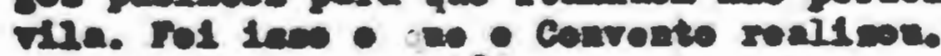

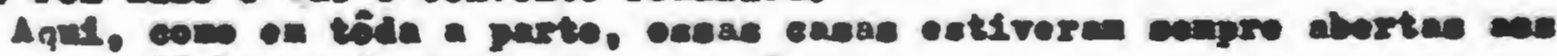

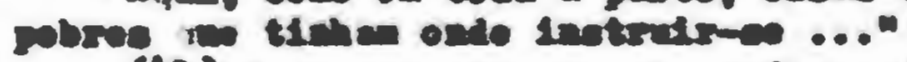

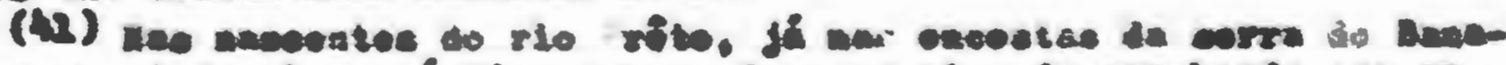

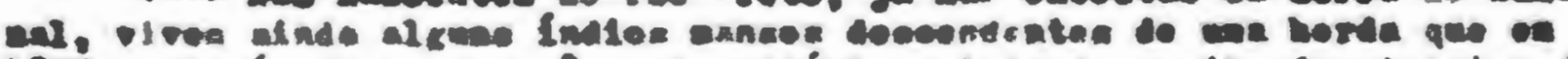

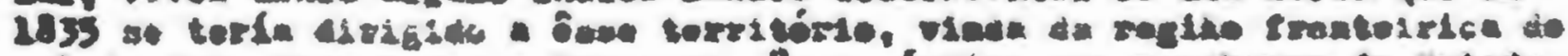

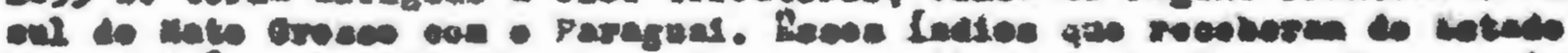

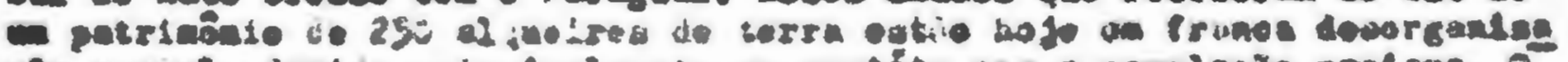

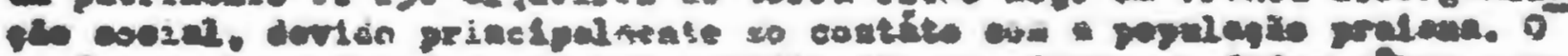

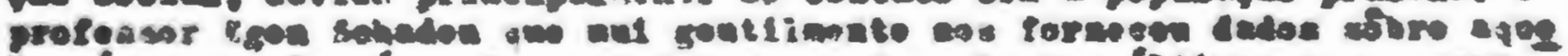

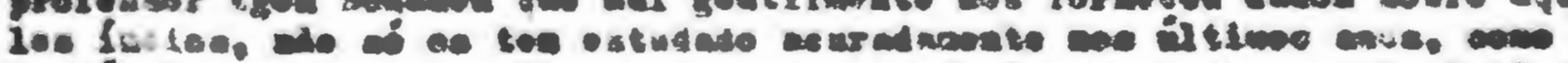

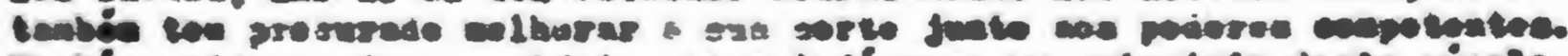

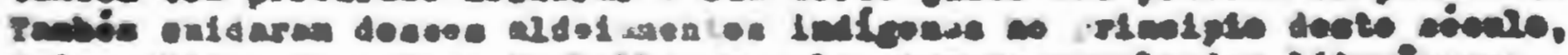

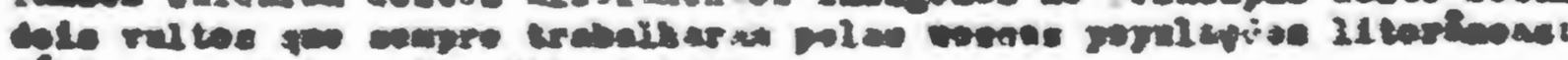

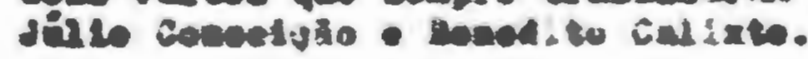




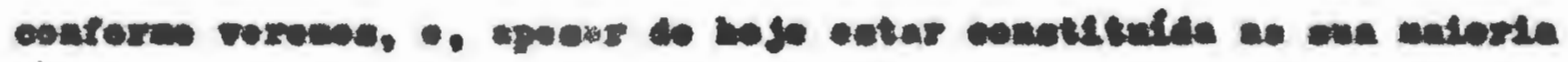

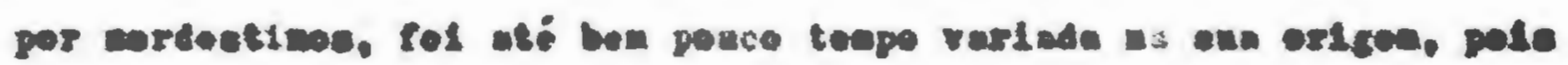

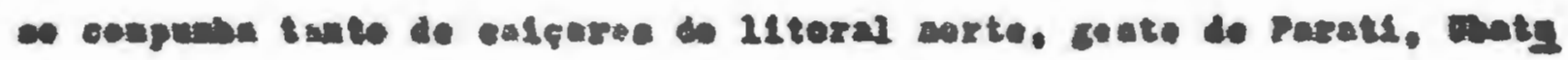

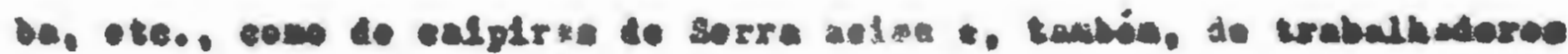

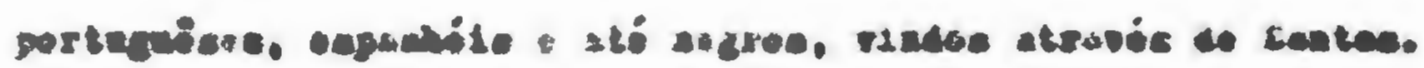

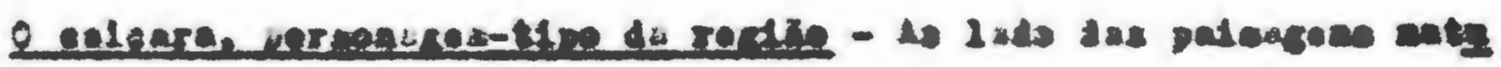

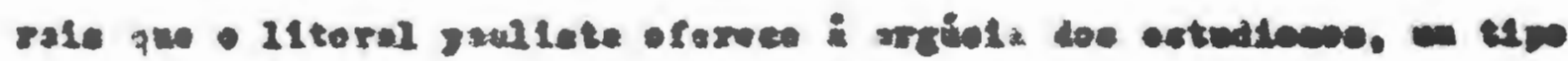

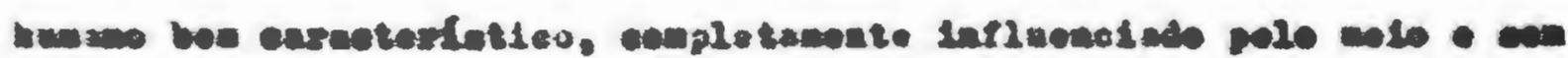

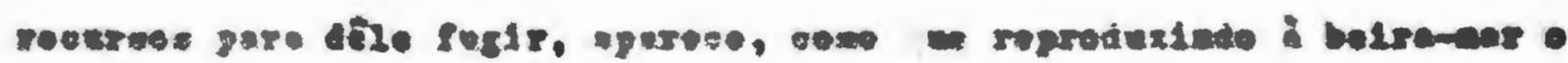

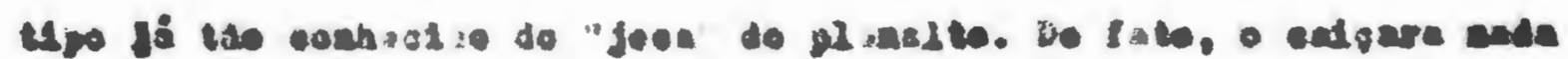

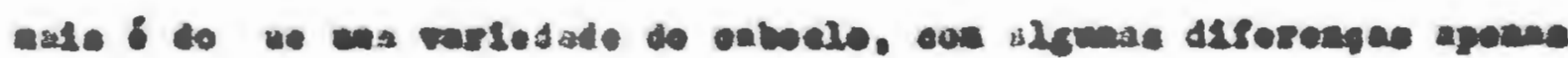

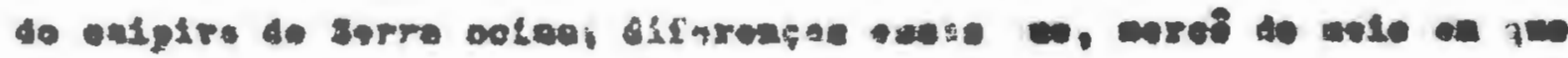

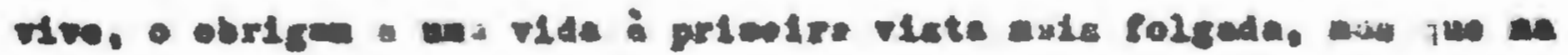

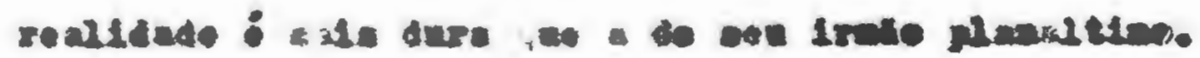

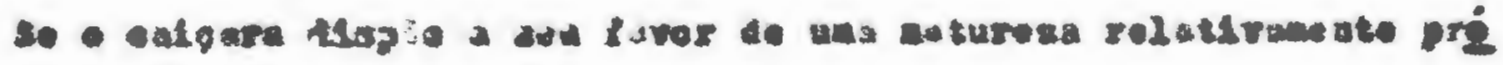

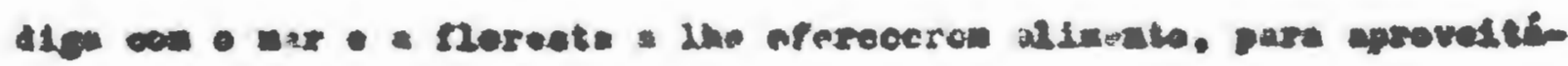

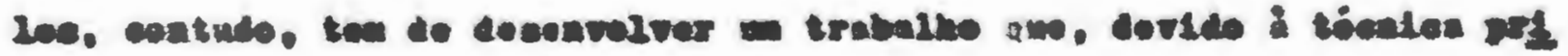

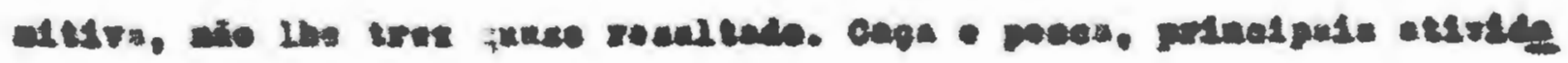

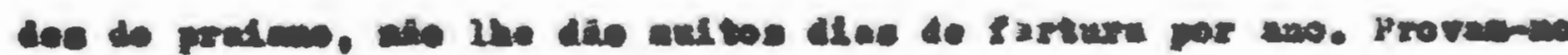

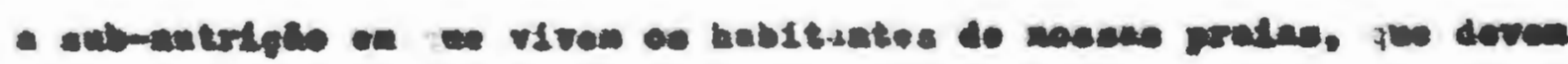

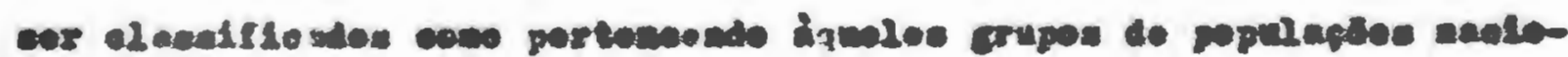

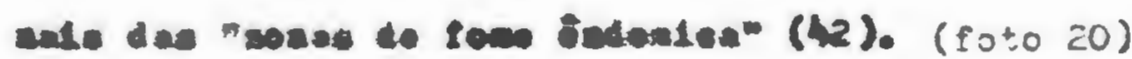

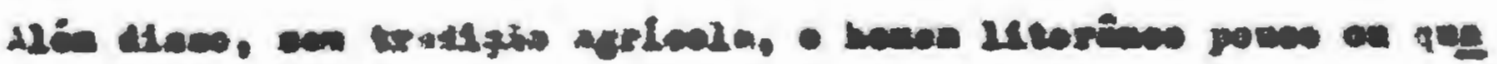

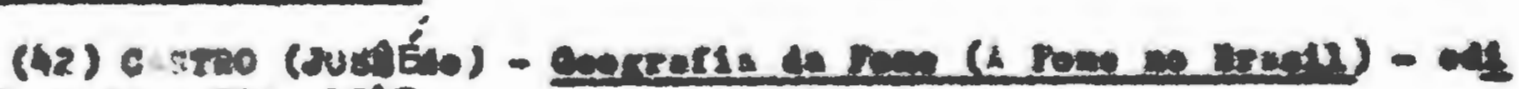
gle crusedro, Re, Xfirt. 


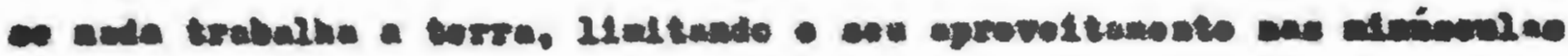

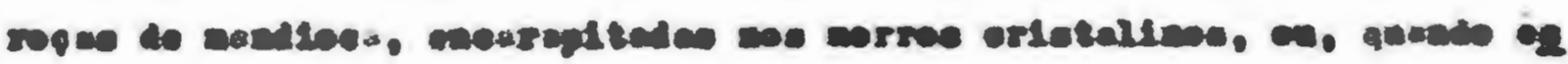

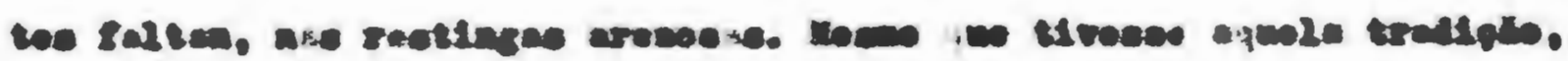

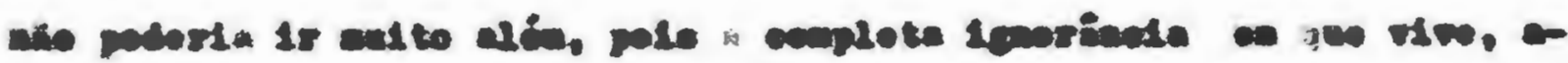

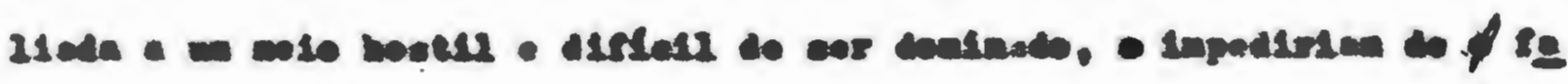
-20.

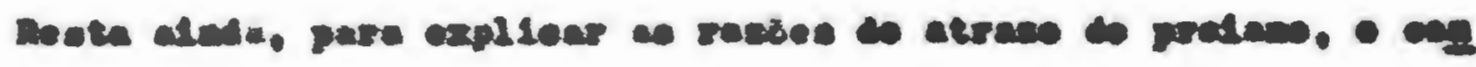

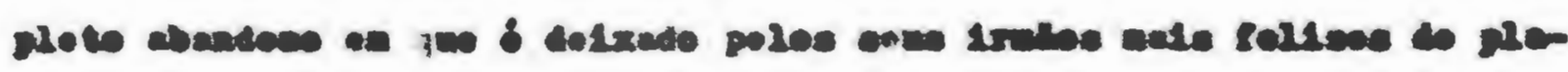

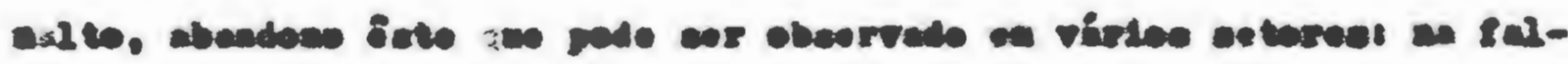

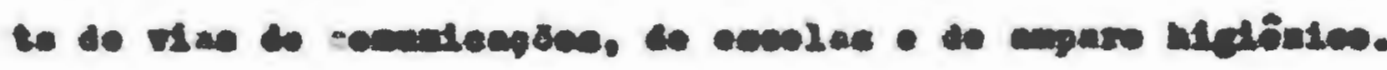

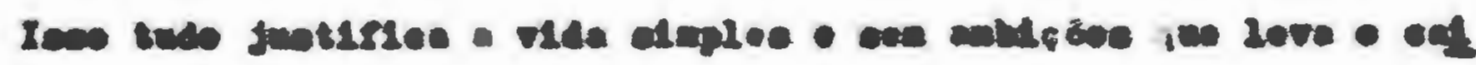

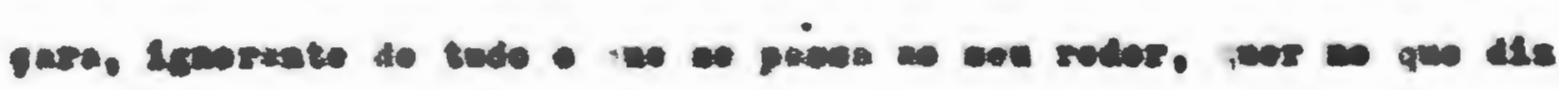

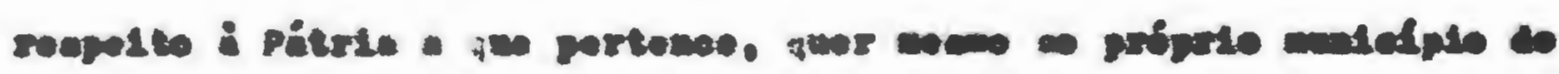
gand an pala sas japto.

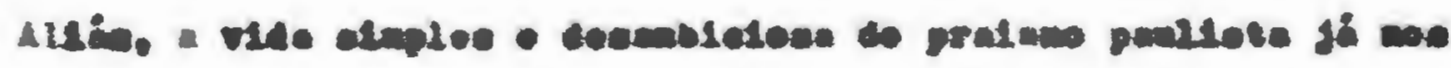

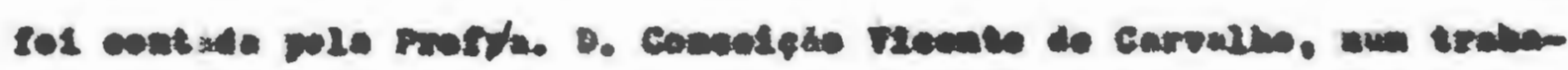

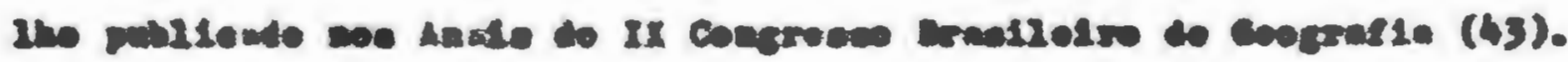

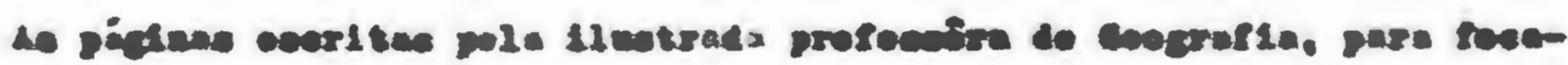

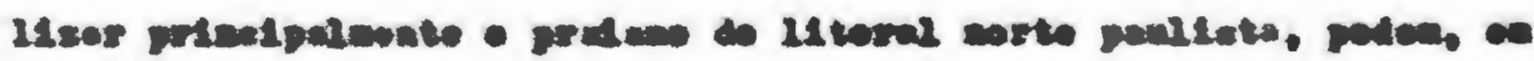

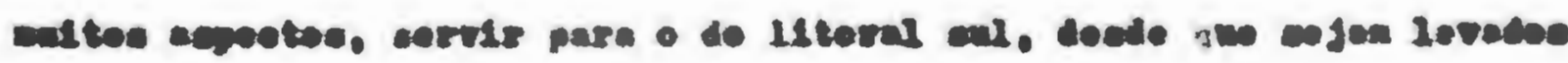

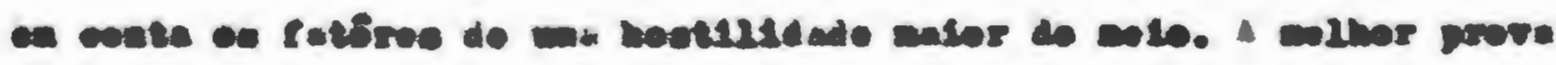

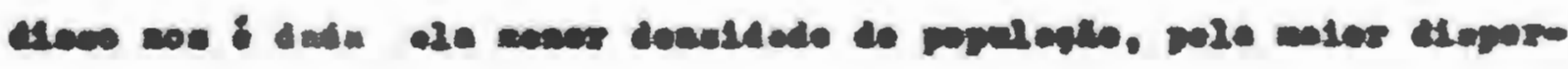

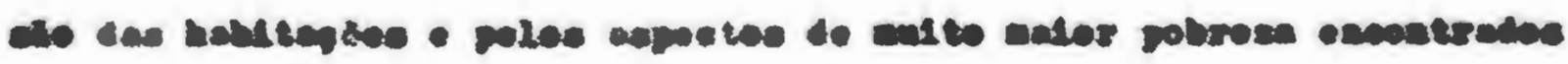

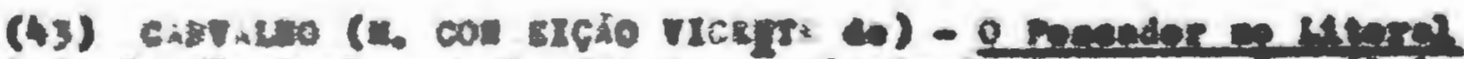

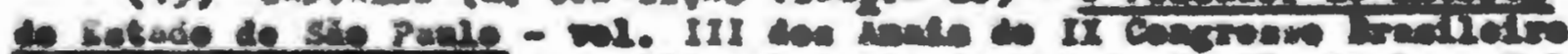

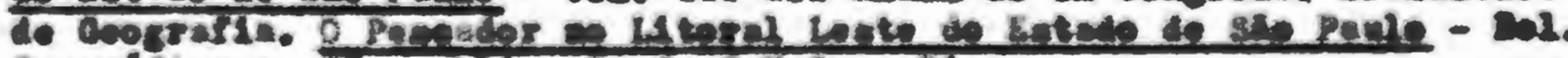

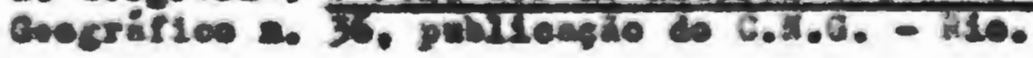


- prala coldere.

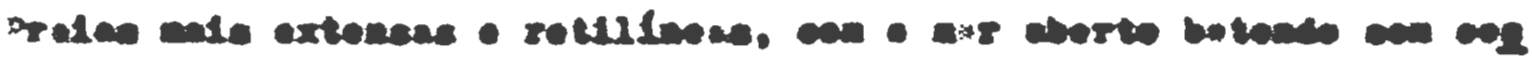

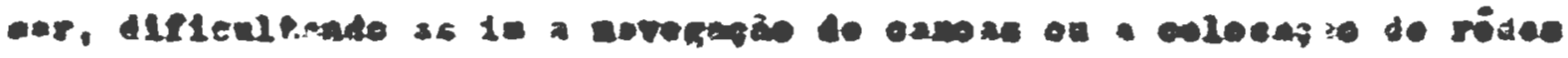

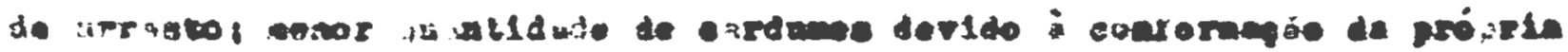

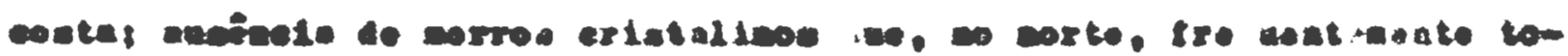

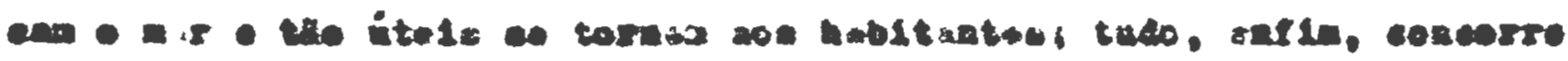

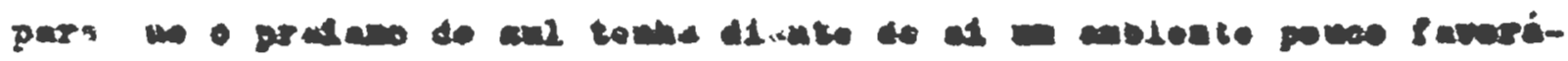
wel in in protecese.

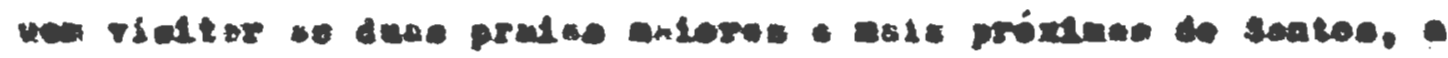

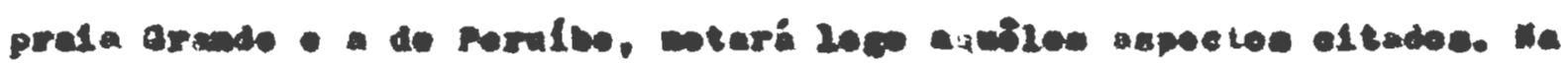

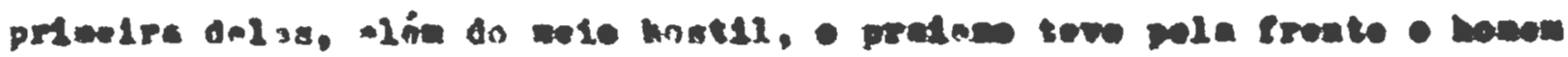

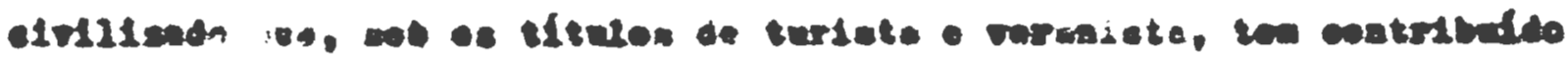

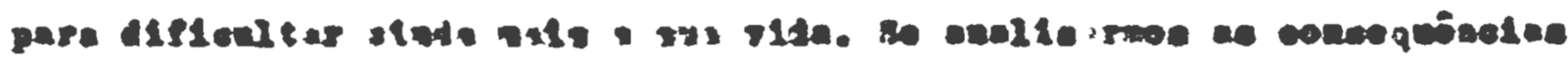

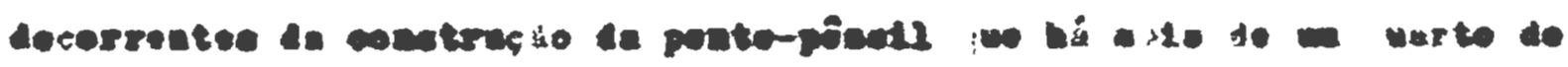

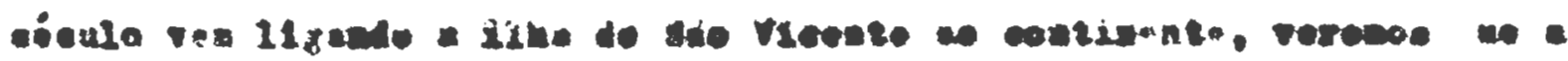

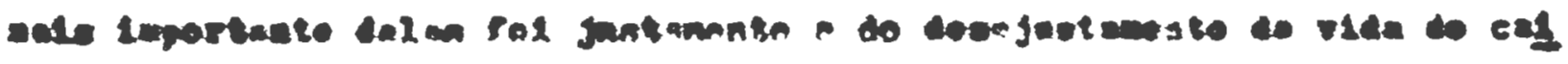

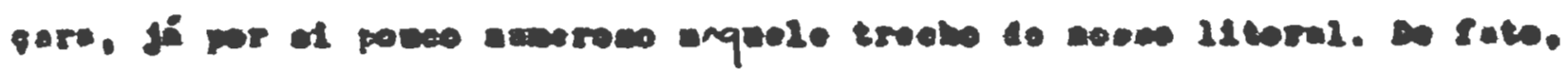

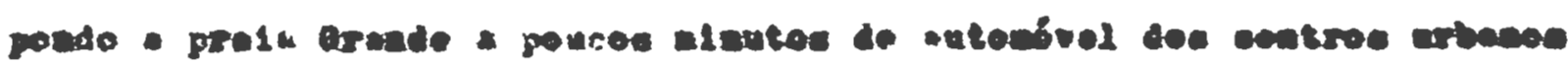

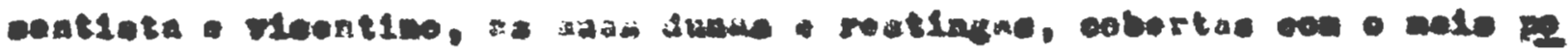

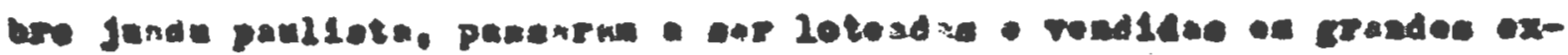

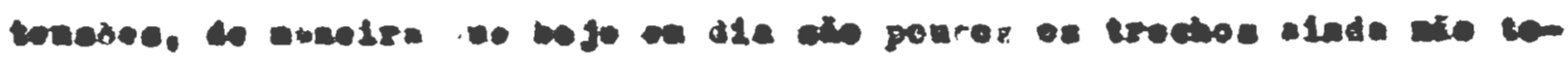

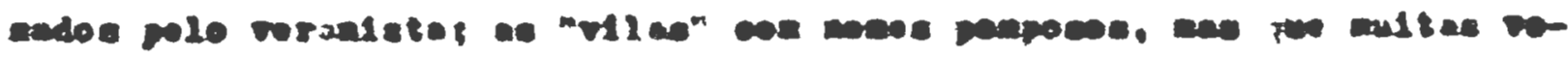

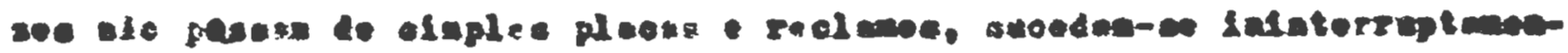

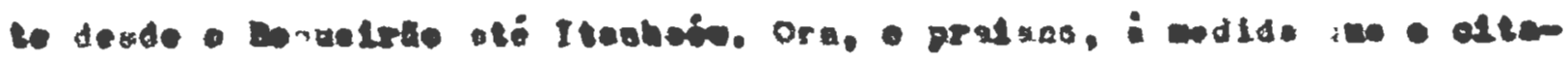

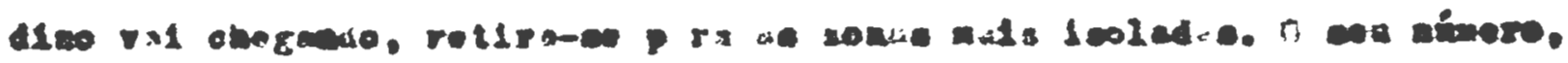




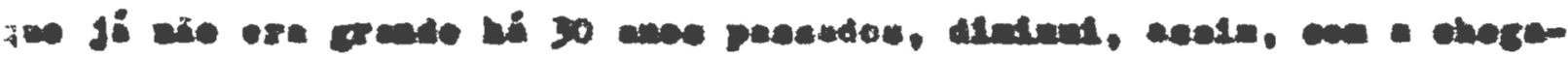

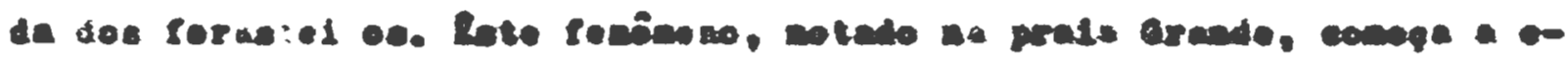

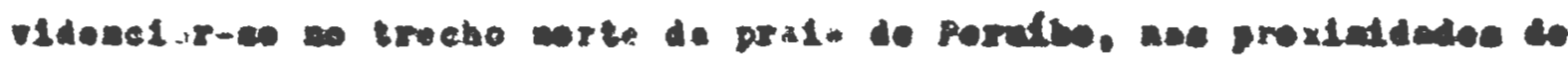
Itanaine.

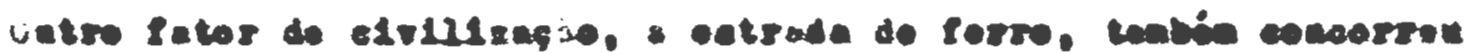

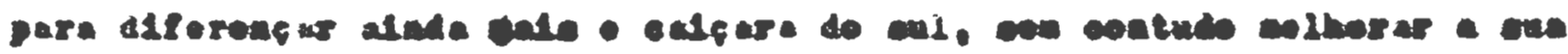

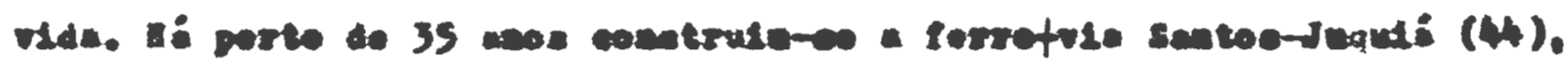

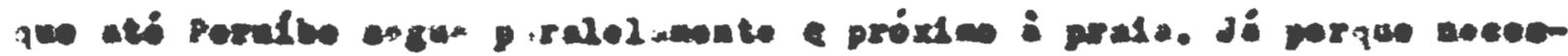

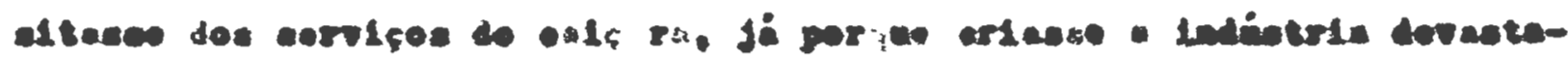

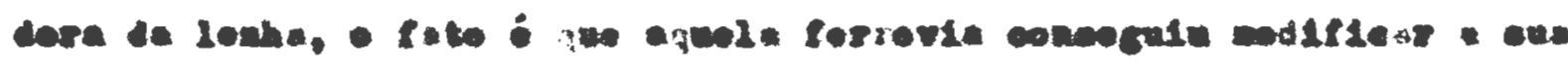

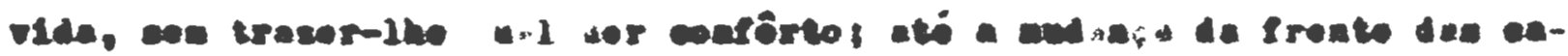

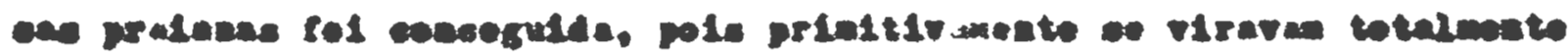

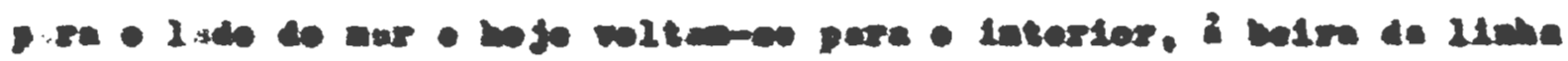

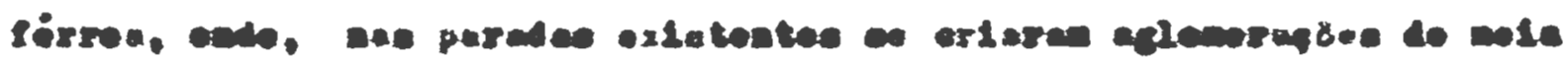

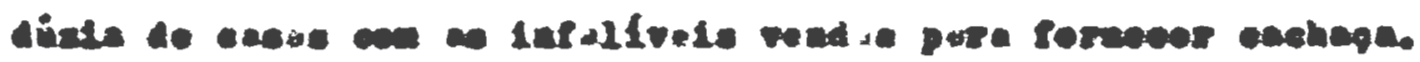

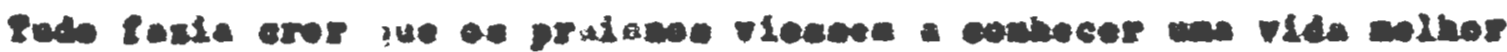

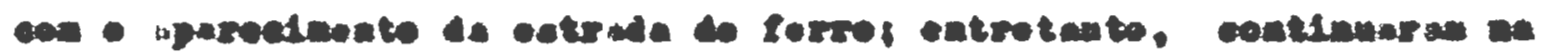

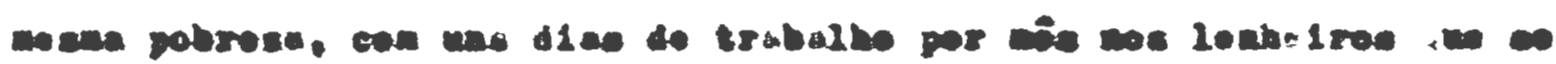

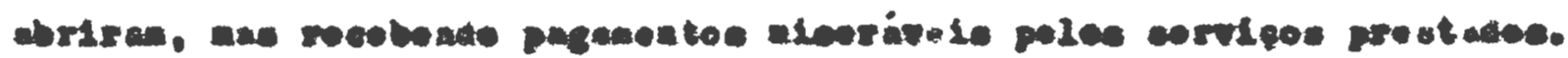

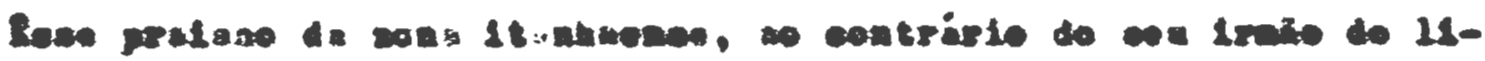

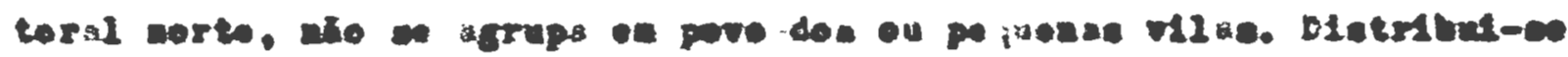

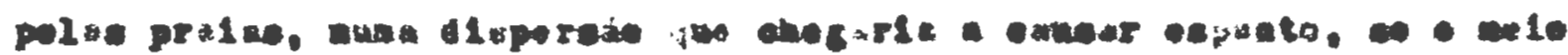

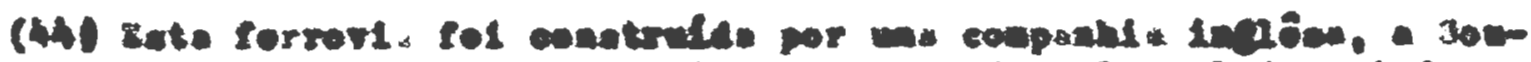

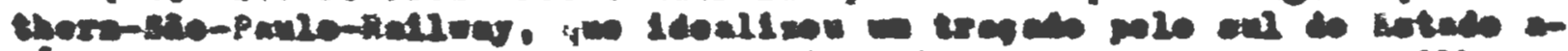

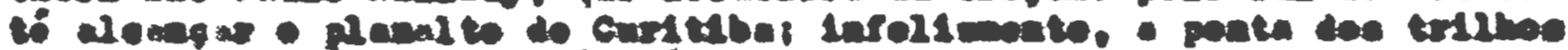

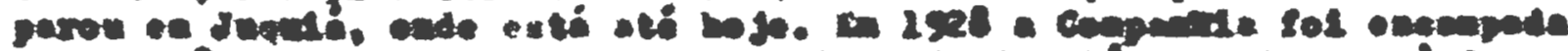

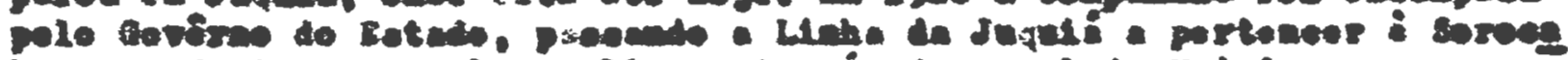

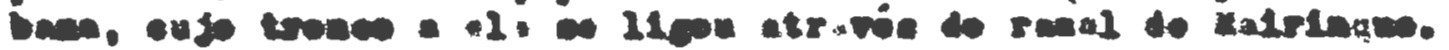




\section{7}

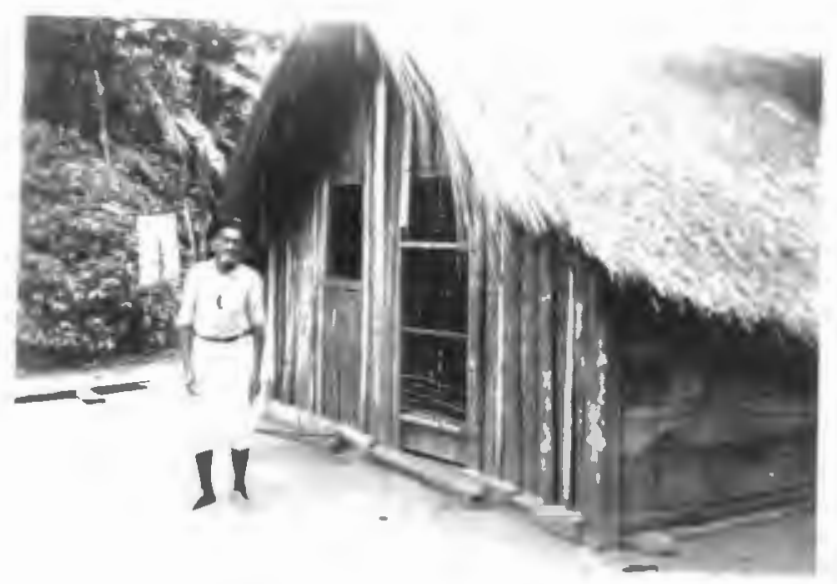

Foto 20. 21po de preiano em cujo flelco notam-so os tragoe delxados pola diflell luta pela aubatatinola. (foto do eutor).

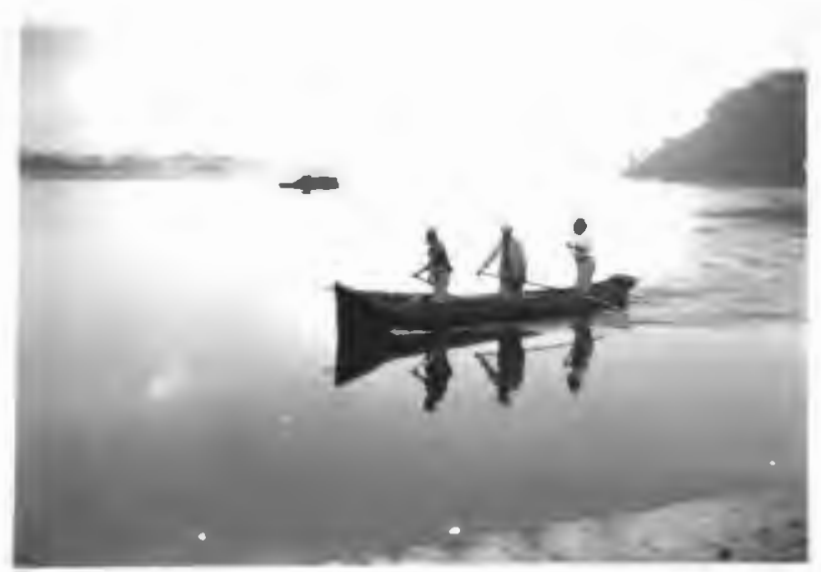

Poto 21.

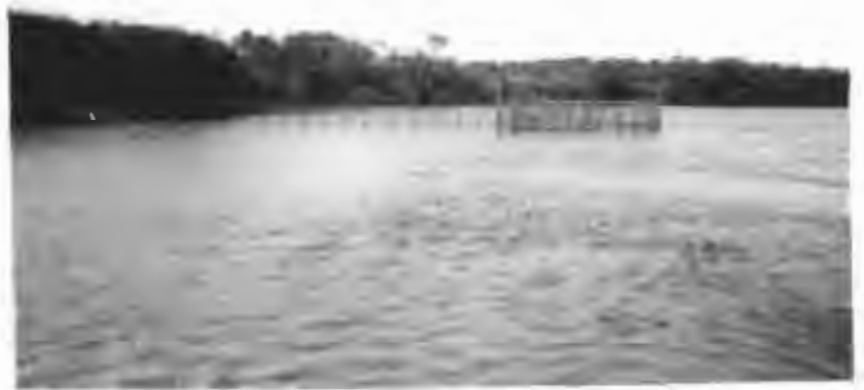

Toto. 21a.

Calgares que alnda moram no balrro da Prajna ancio de canoa para uma v181ta ao cerco; 830 rucimentar aparelibo de pesce que no iltorai Norte de tanto regultadu, no r10 Itanhabr an da para allwentar os seus conos,decde que $b$ leito somente lo margens do $\mathrm{H}_{1}$, onde sel tocam os eardunes. Itto \& dovido 2 proiblgto ofleid, por eer o Itanhale un slo naregirel. (fotos do autor). 


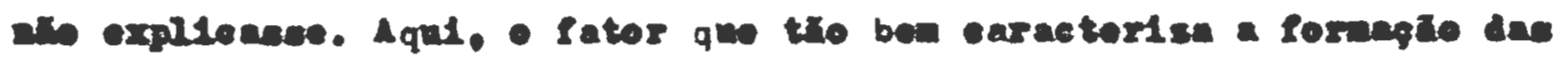

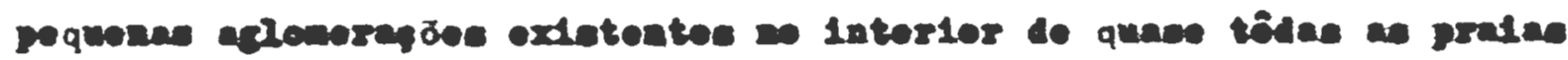

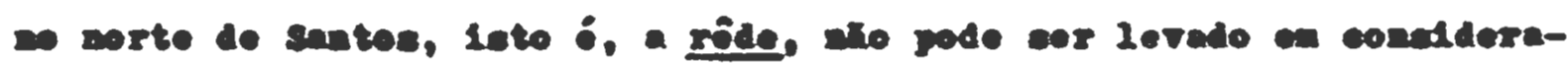

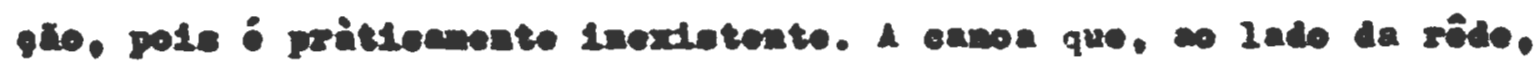

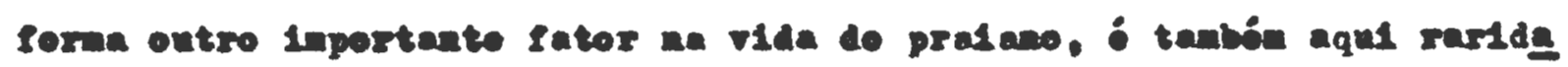

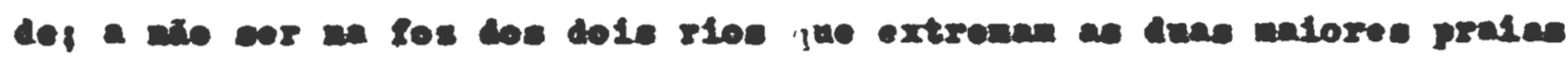

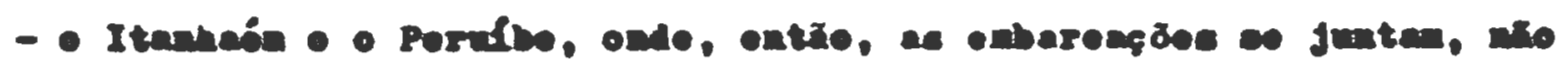
co encontra, conso expopelonaleonte, w t1jo qual awer do bereo. (foto

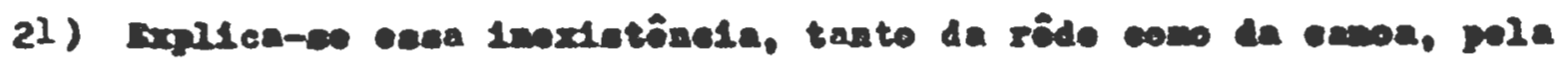

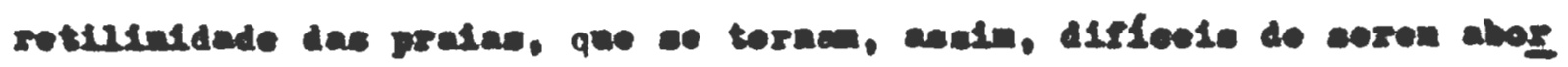

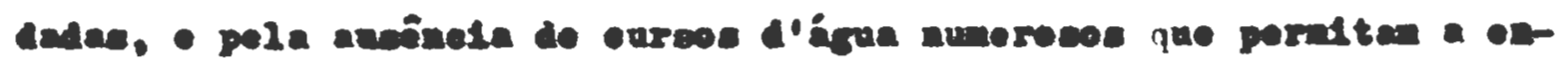
trada de eardume.

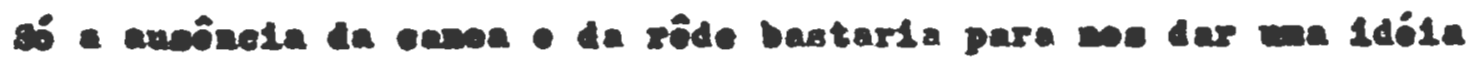
de ceno : diferente, sol virloe appictos, a vida do pratan ltanhas-

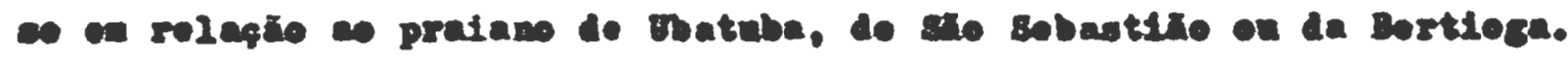

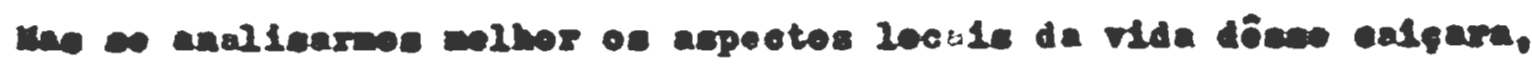

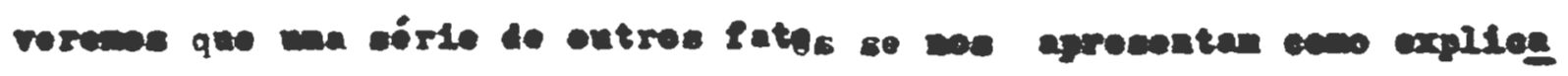

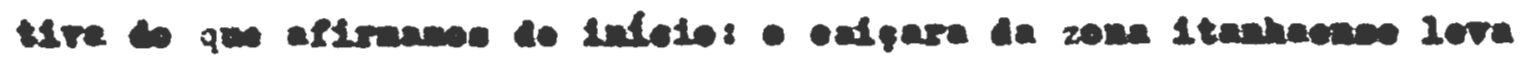
ter rla neorivel.

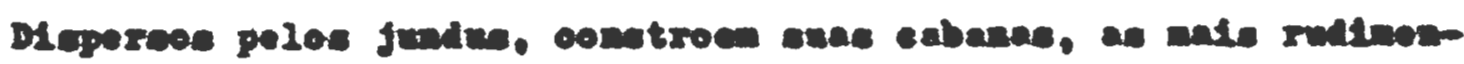

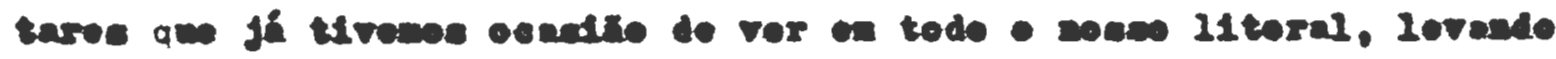

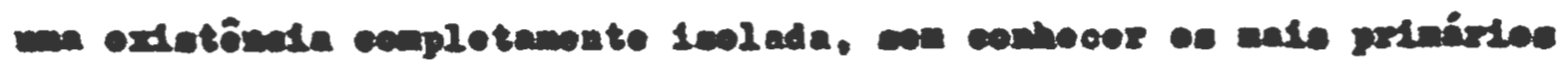

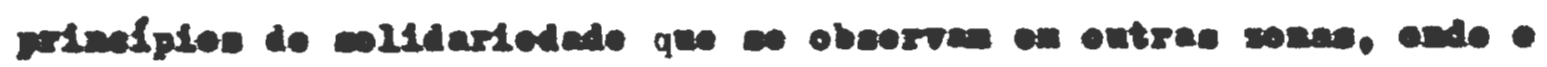

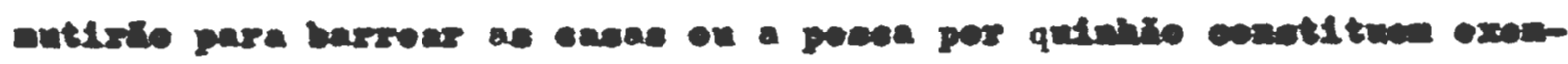
slos.

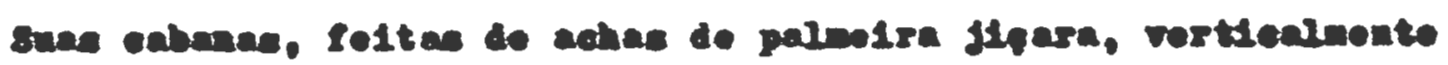




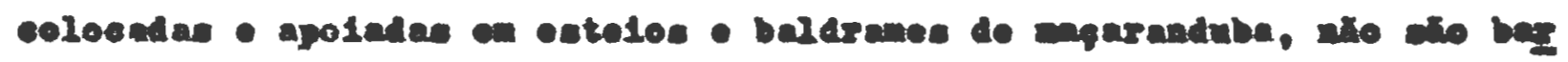
rockas, pole a arcl

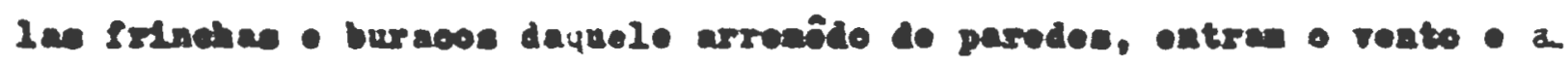
chura, que vio concorrer, con a nalirla - o enarelko, para plorar a caide doe habltantes. Whe cobortac de capo, coso a lonale do 11 toral,

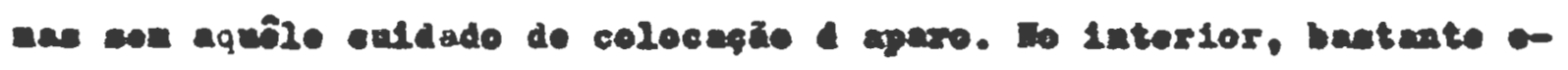

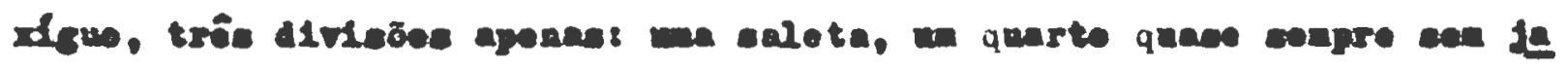

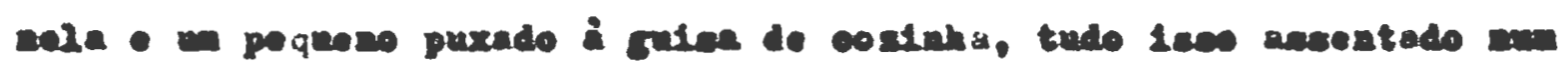
chic do torra batida, or minor, de urola. (fotos $-c ;-3$ )

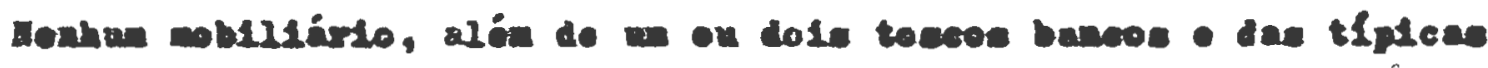

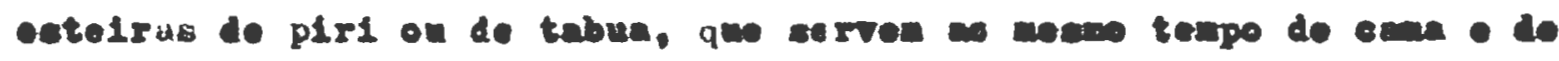

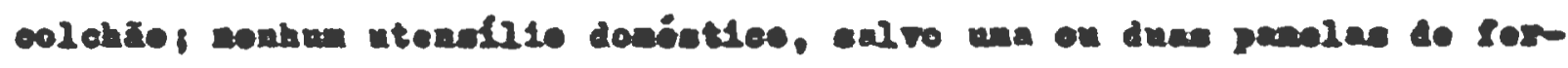

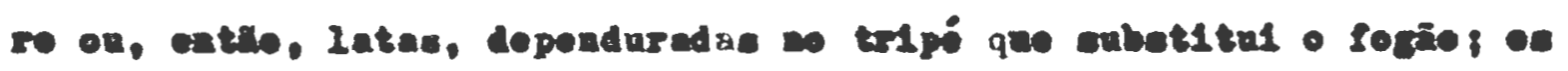

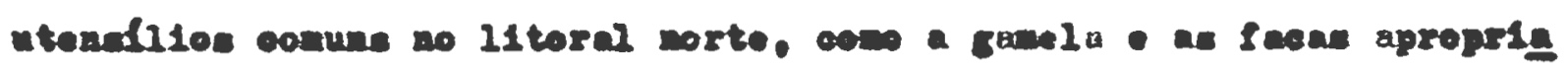

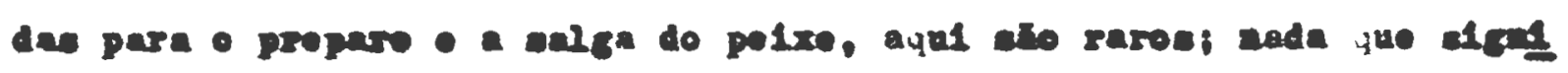
Ilque conteto con o nar, alí do sambrí para catar comambl na recea-

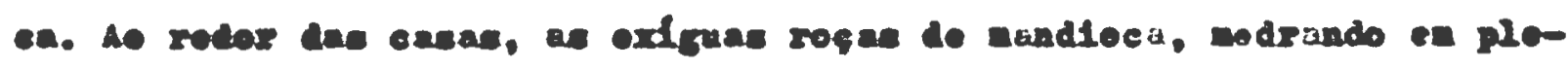
na are1a, - we pie de eana pore fazer o eafó de "cruaropa", tudo rodoade peloe infulfrole pie de bananelra branes, ì vôsos já cobertoo polo juade. (rotoe, , - .)

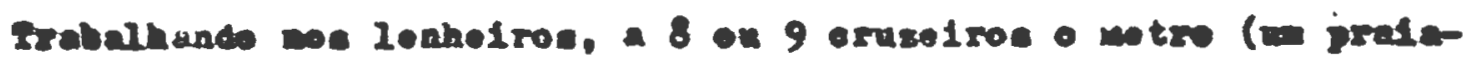

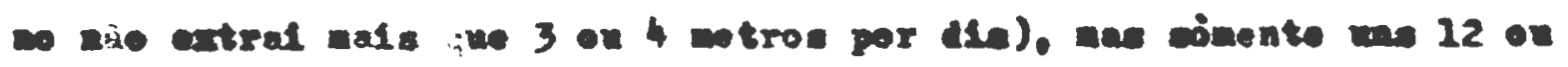

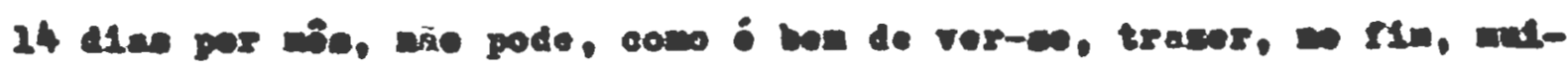

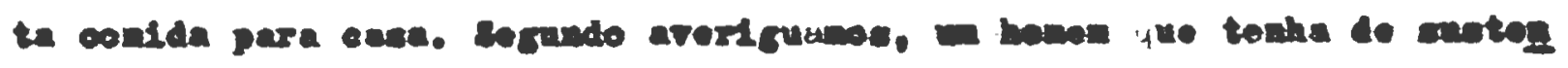

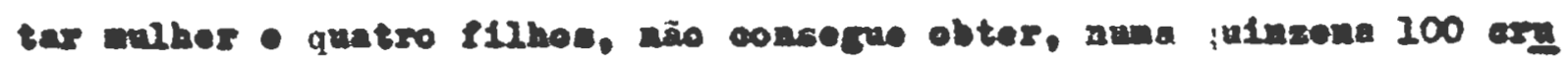

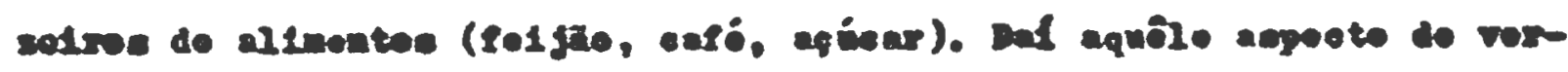

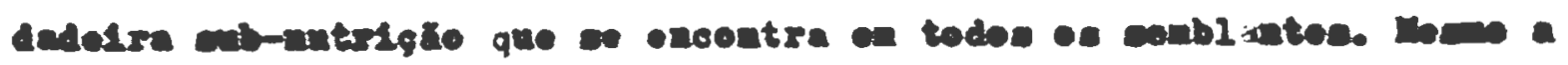


50

Fotos 22 e 23.

\section{A "casa"do caiçara}

Na primeira foto uma habitação melnor construida,ëmbora se notem al guns aspéctos mal cuidados, como o da cobertura, Ionde o sapé foi colocado irregularmente. $\mathrm{Na}$ se - I gunda, uma verdadeira cabana, sem janelas e cuja porta fica encostada à parede durante o dia. (fotos do autor).
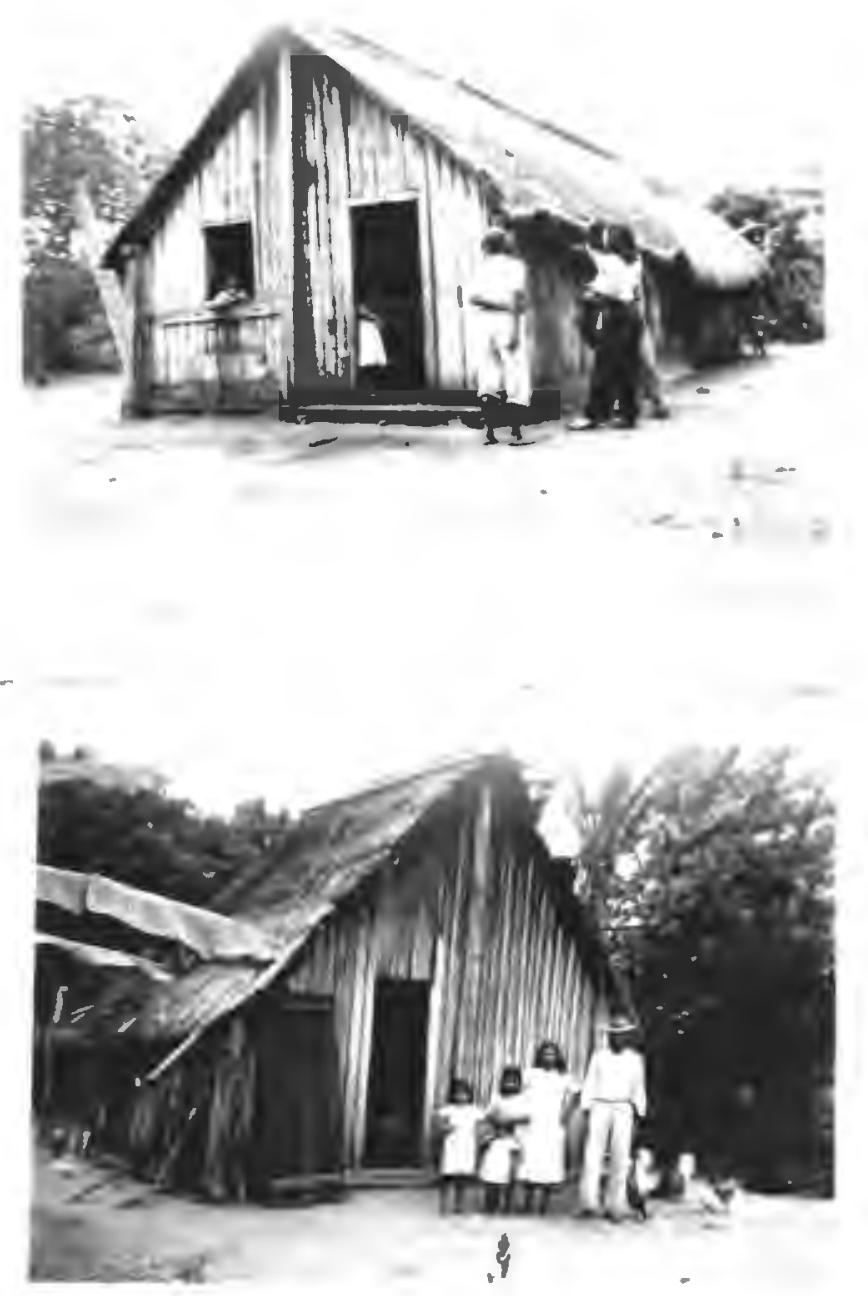

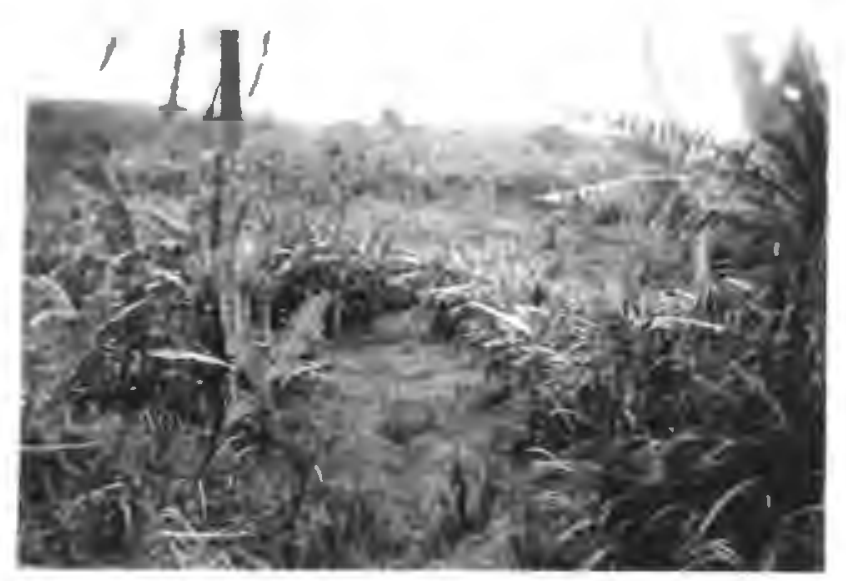

$\sim$

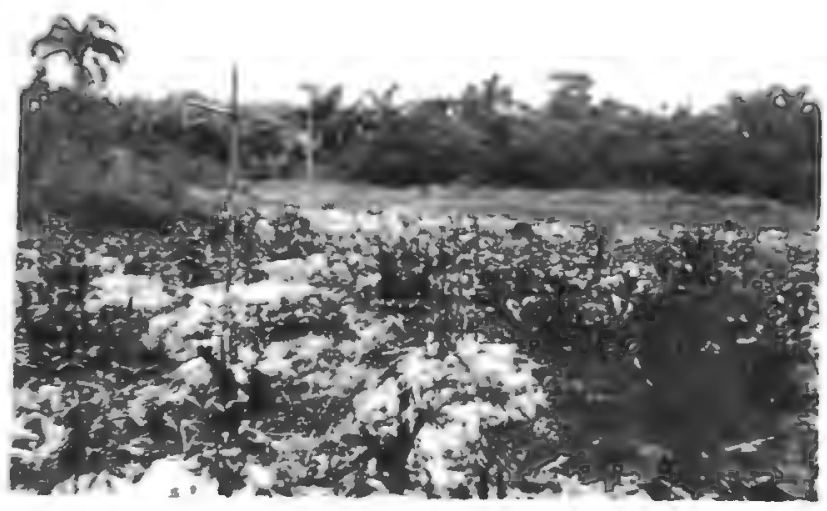

Foto 24.

Uma roça na praia de Peruibe. Notese a confusão dos produtos "cultivados" (mandioca,cana, banana, etc.) (foto do autor).

\section{Foto 25.}

Um pequeno mandiocal, onde aparece uma cruz para evi. tar mau olbado. (foto do autor). 


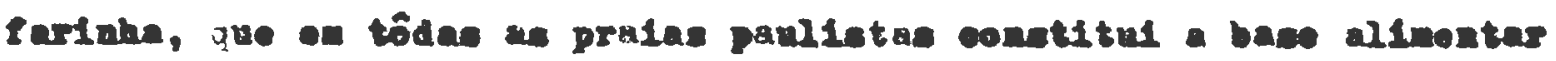

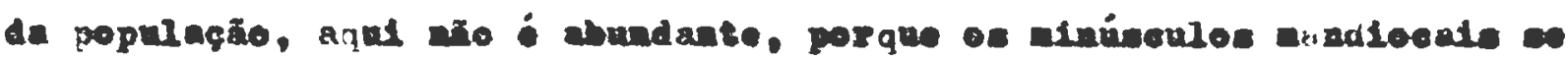

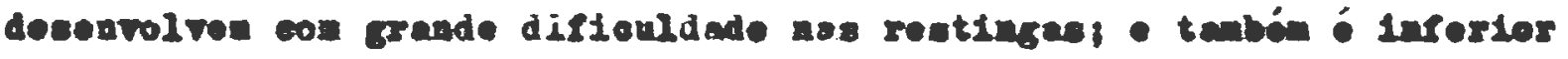

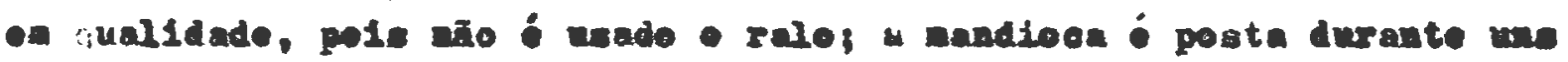

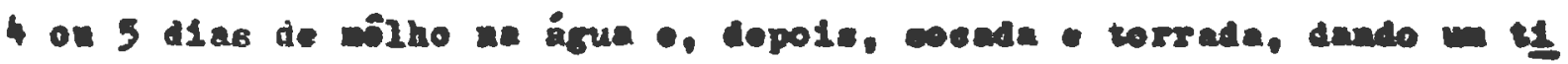
pe do farinka cremona, chela de earogea.

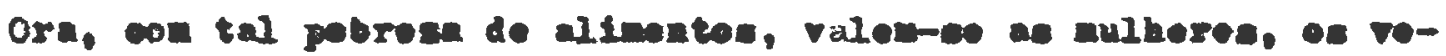

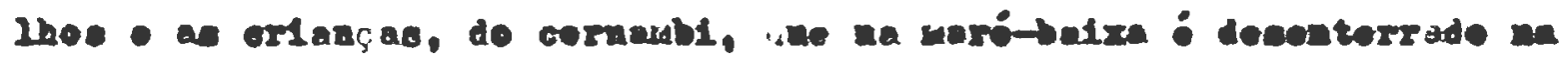

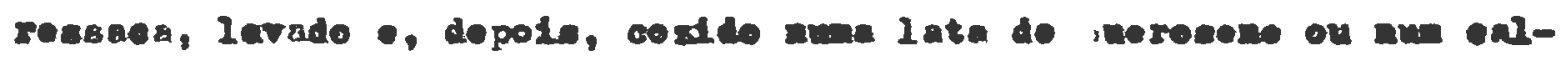
de1räo grande. (Potes $26,27 \pm 28$ )

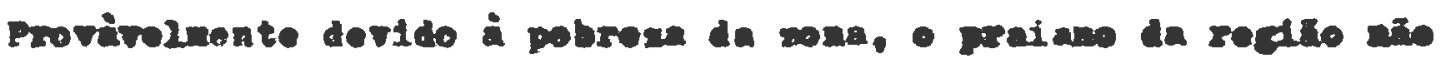

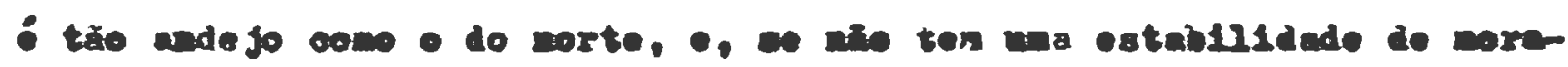

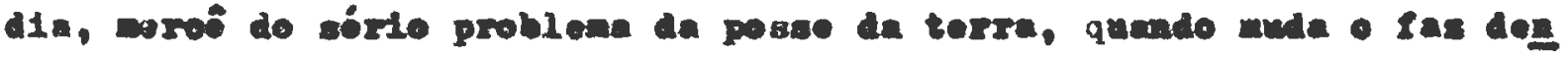

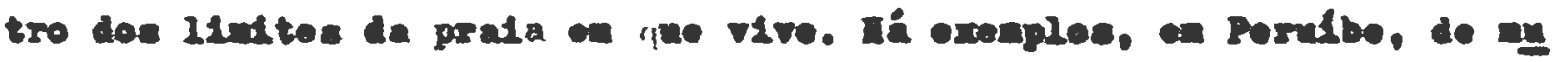

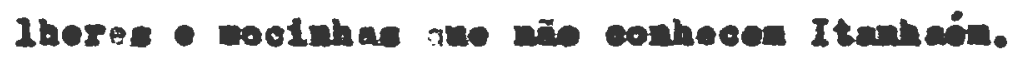

Alén dêste tlpo de praiano do litoral cul, há atada an son. Io

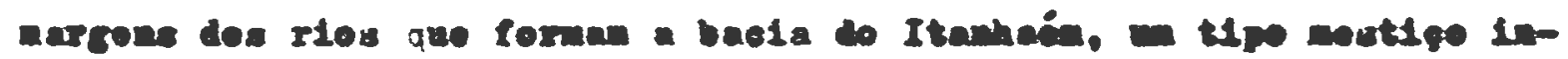

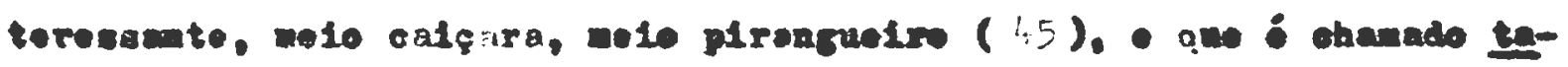

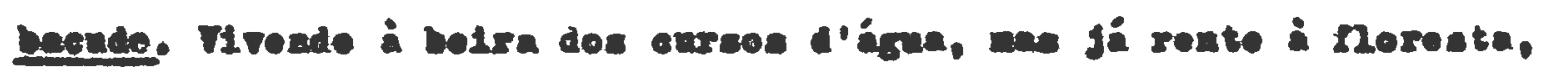

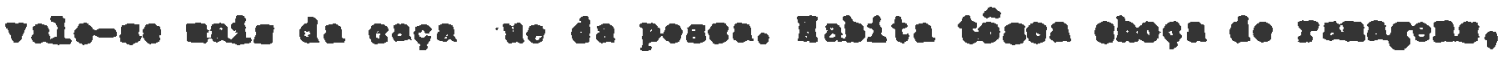

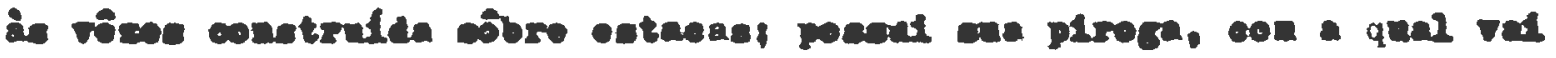

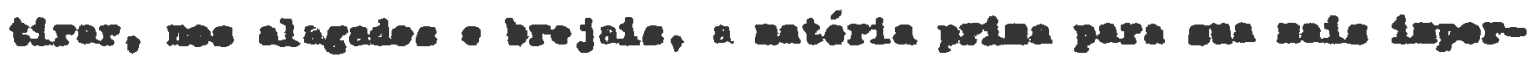
tante Indintria, a do fabreo do ectolrae do tabe ou purs extad

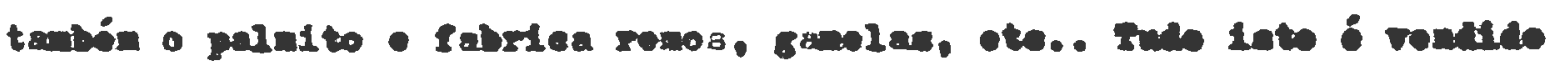

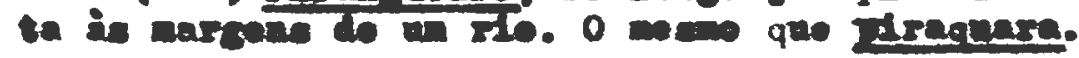


52

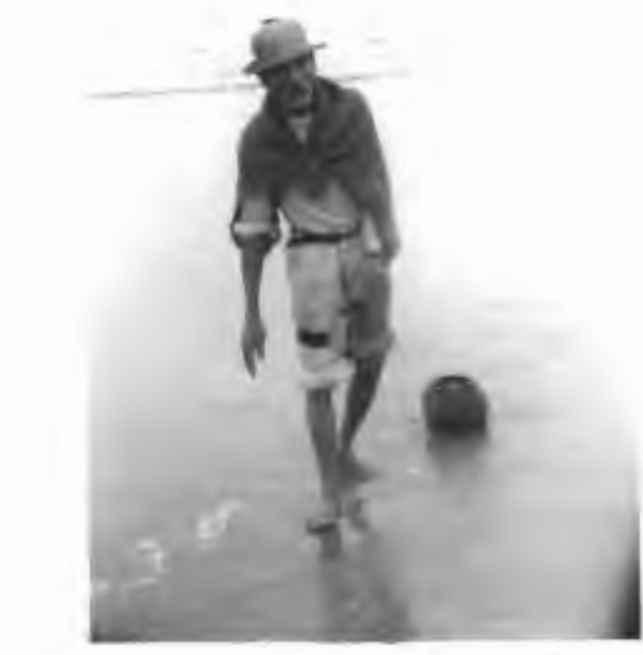

Ioto 26.

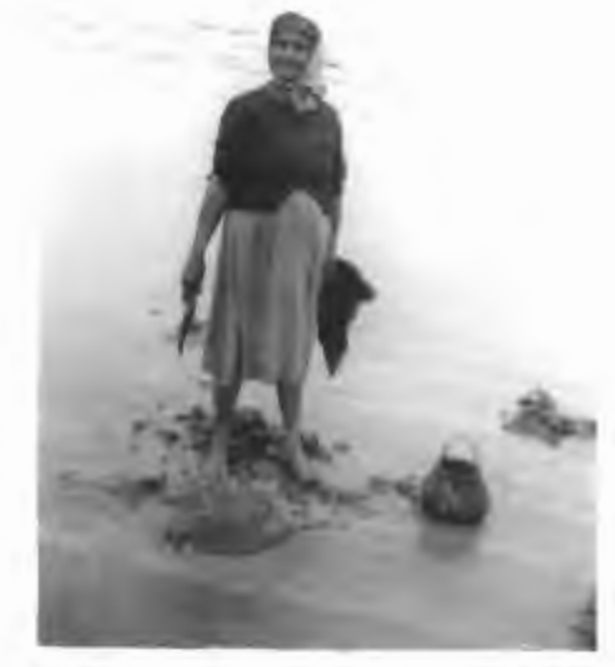

Ioto 27.

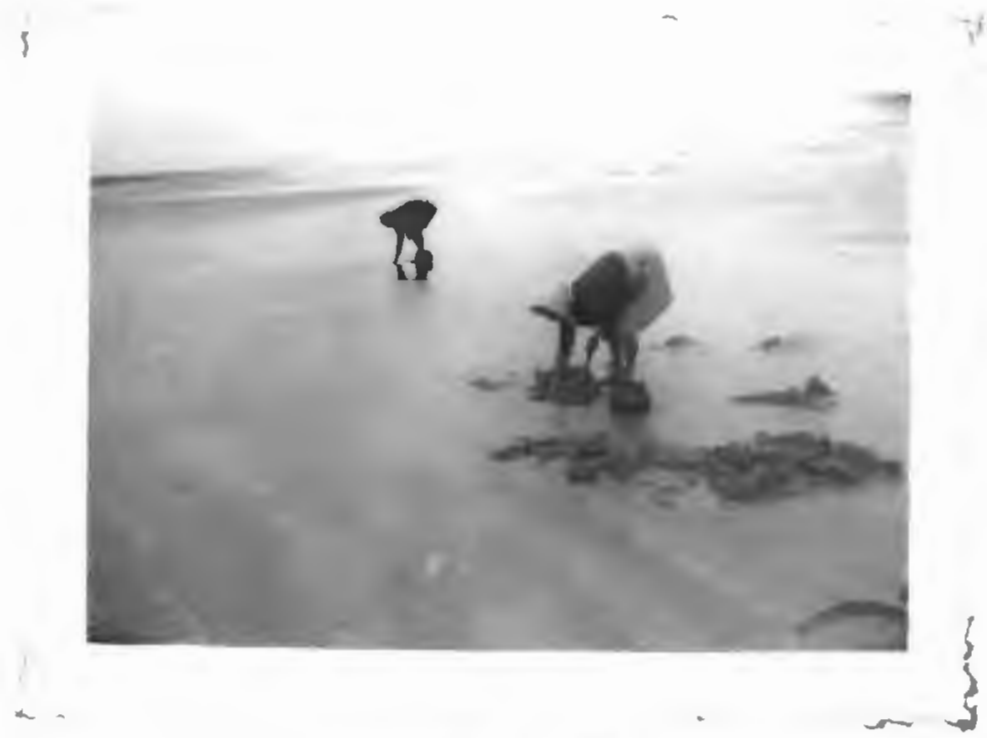

Toto 28.

Las duas primelrae fotos um casal de onigeras preparadoe pare desonterrar certhmbl; veom-se 08 epotrecios usedos: uma pequesa faca pare esoavar a areia onde se abrige o molusco - um samburd onde 36 o val depostteado. He tercoira foto, ambos em plean functio.

(foros do autor). 


\section{5}

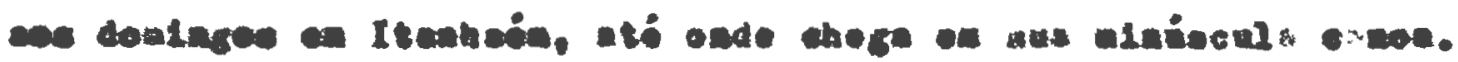

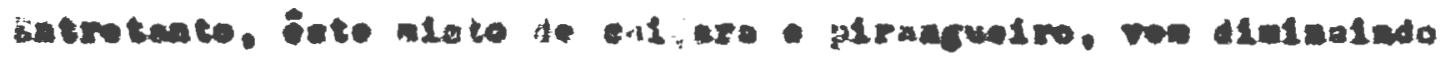

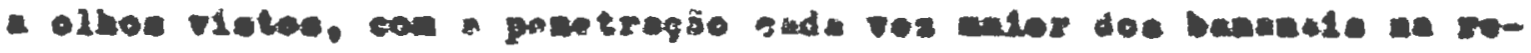

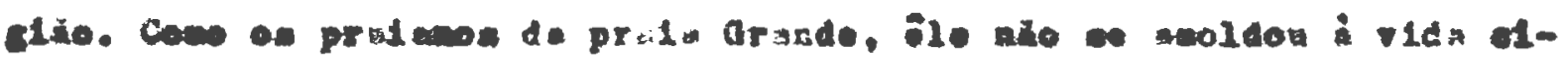

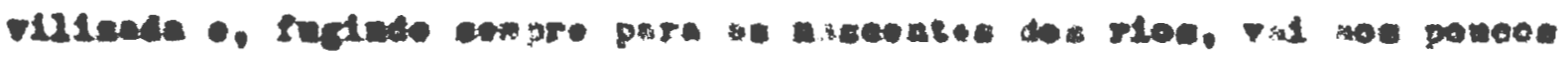
Les purecende.

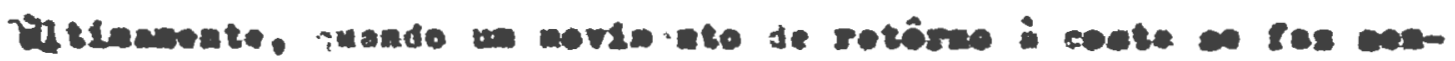

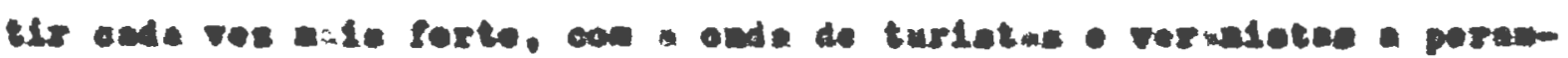

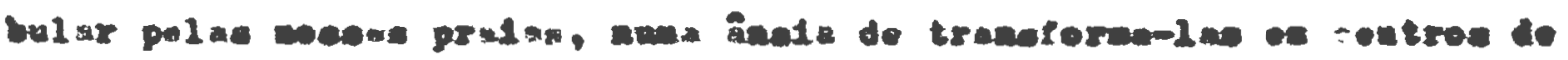

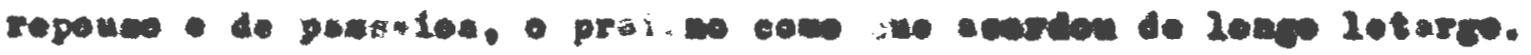

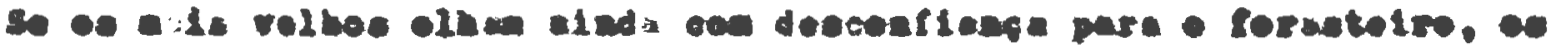

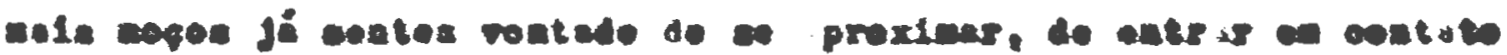

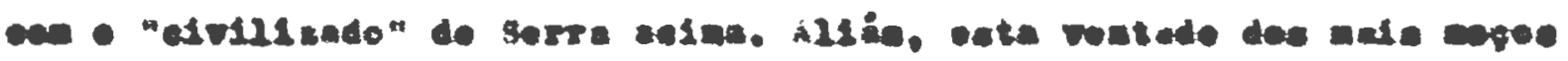

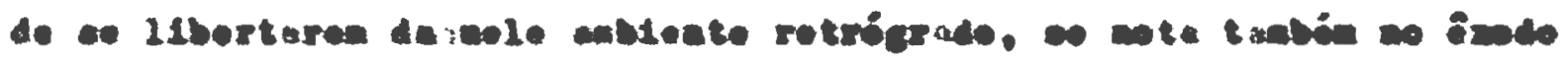

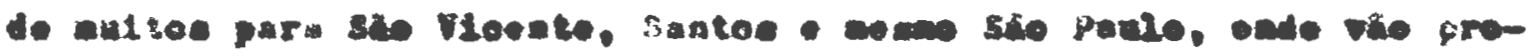
earar mova vida.

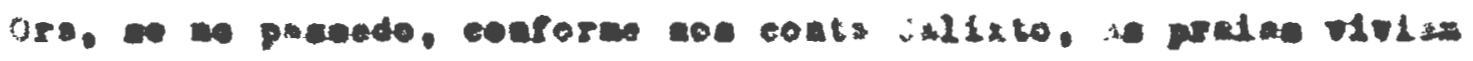

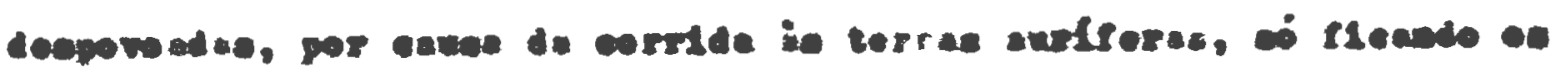

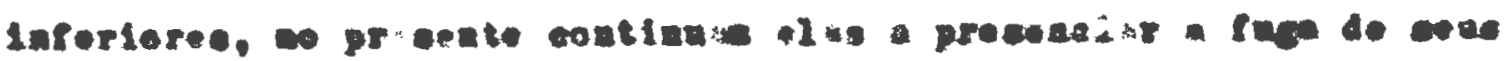

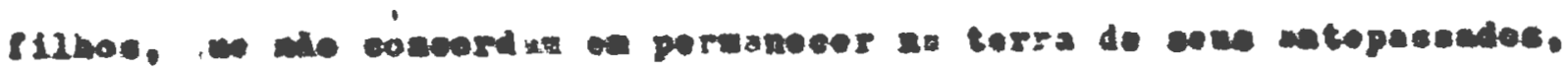

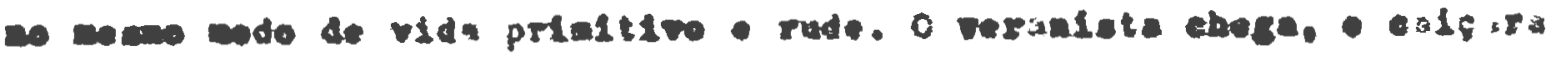

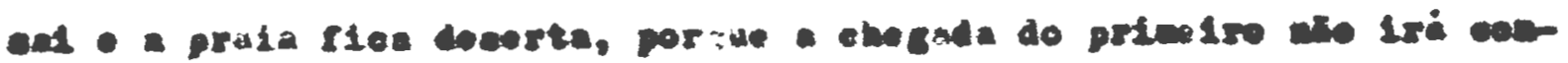

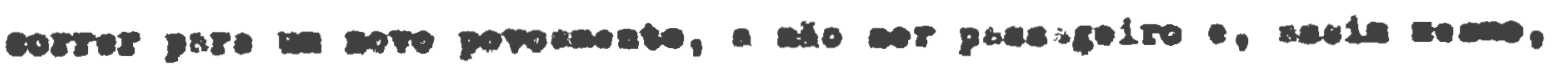

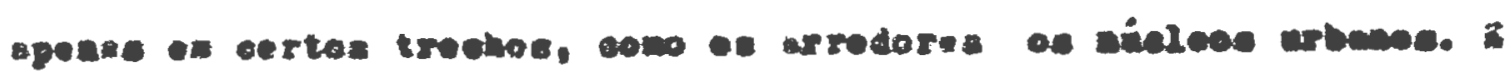

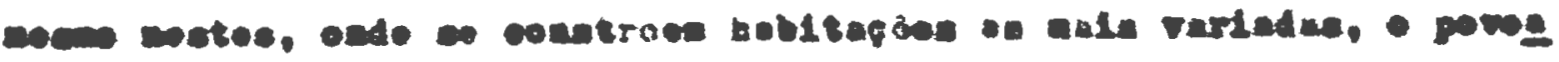




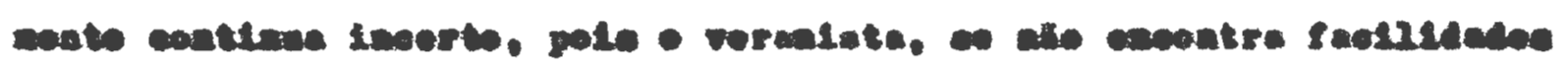

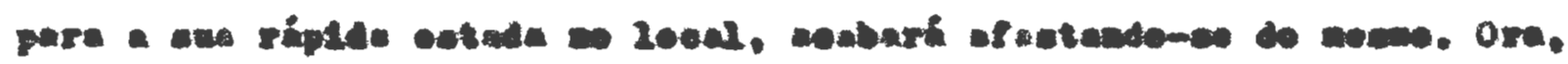

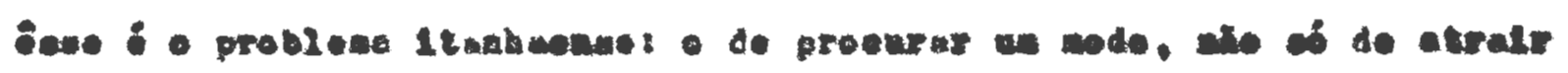

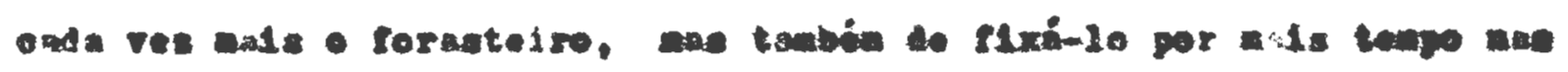

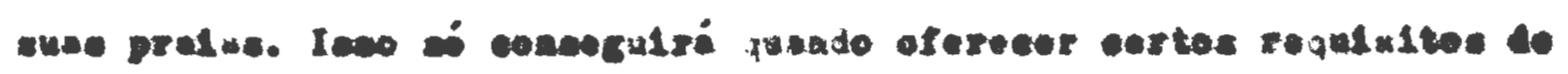

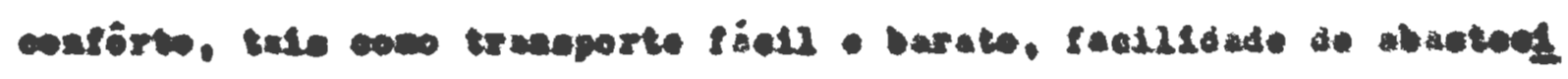

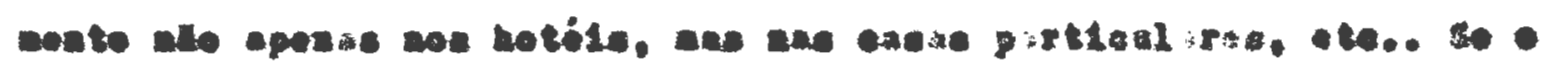

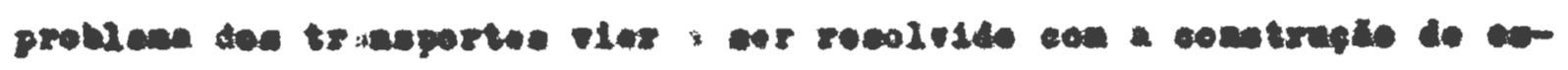

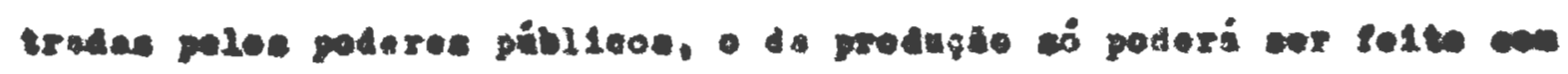
- cedengio - portanto. trancternagio do ealgara.

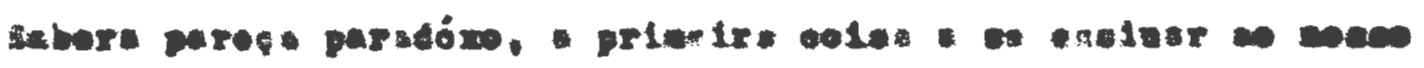

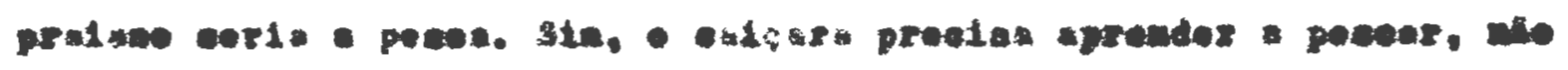

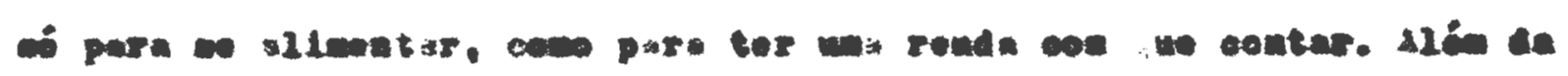

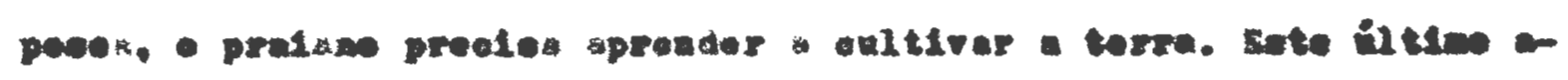

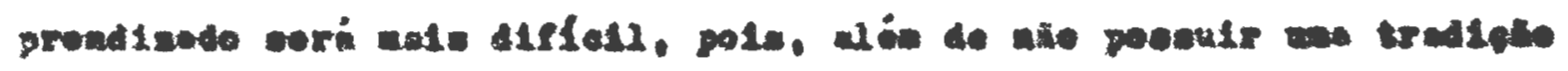

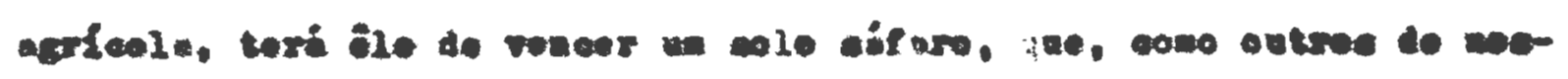

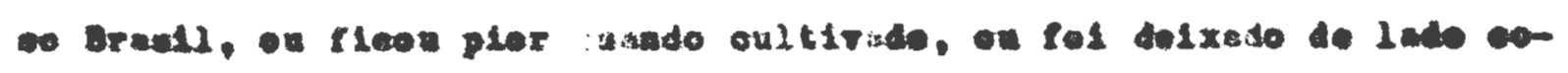

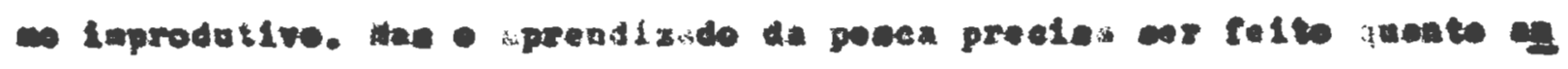

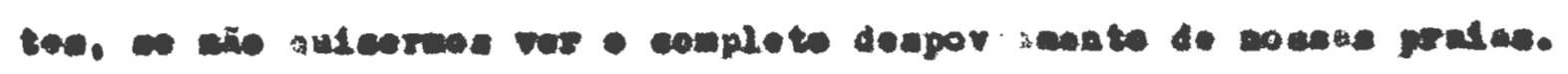

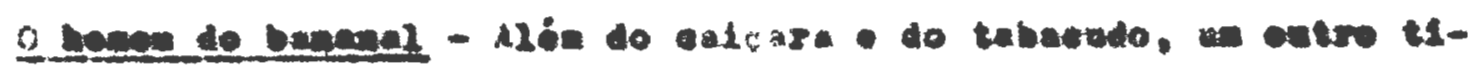

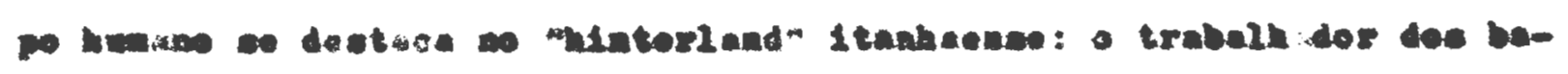

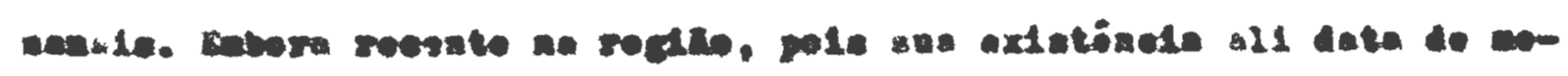

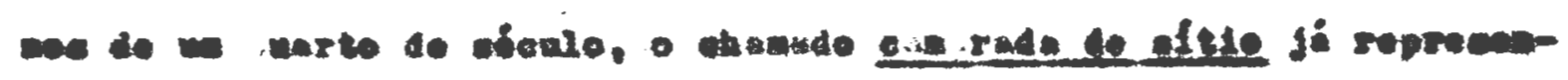

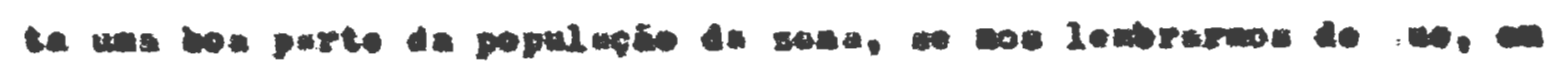

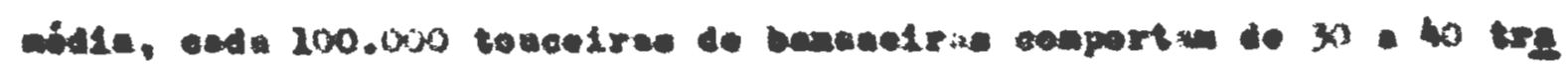




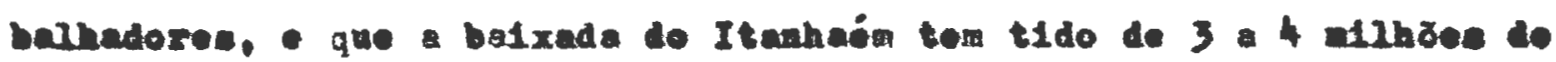

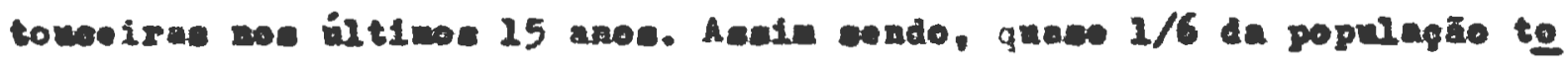
tel do muntolplo cerla roprosentsda pelo "ounarada do altio".

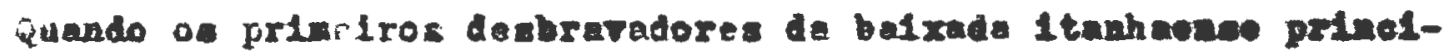

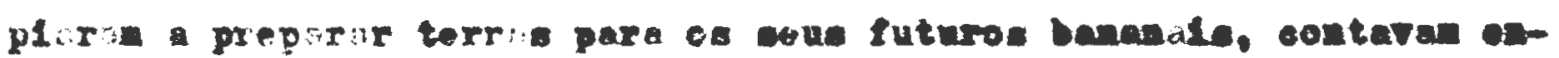
contrar trobalhadorma própria zoma, ruor an Nla e wa pralas pró

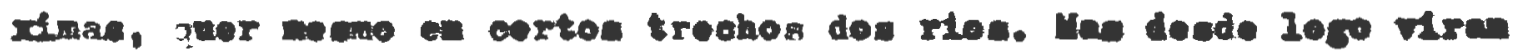

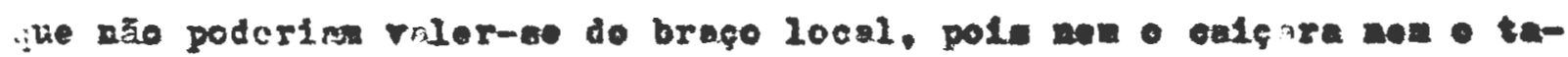
bacudo d rian conte da tirefa. Allie, gi se tinha oxomplo doe bana-

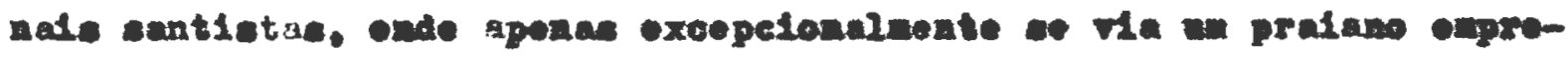

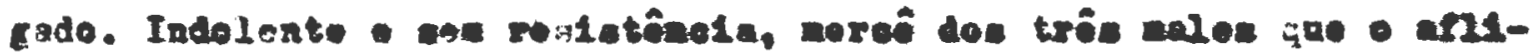

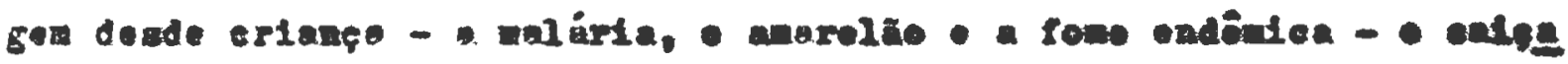

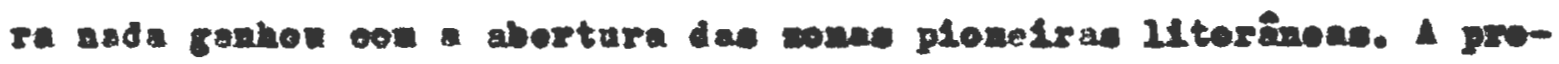

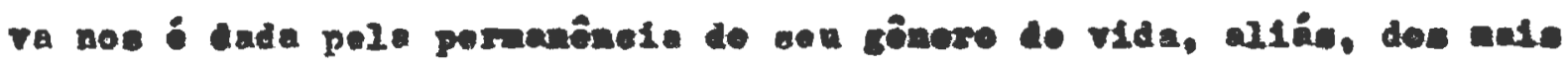

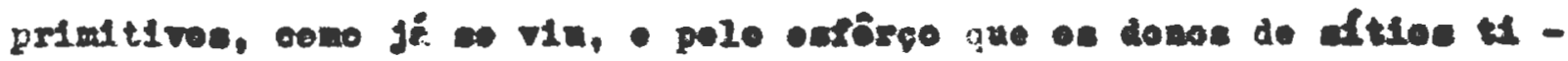
reran guo denponder para conecgul fóra os con trabalhadores ( 1.6 ):

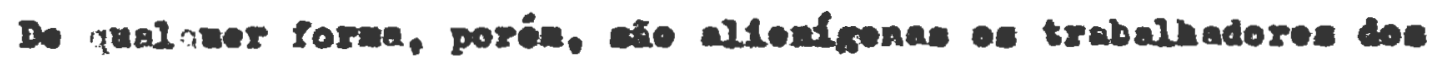

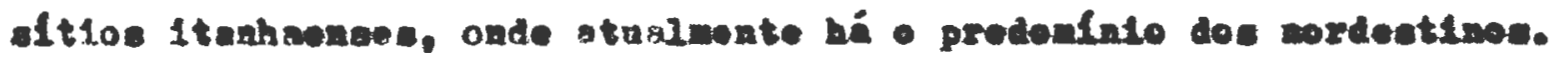

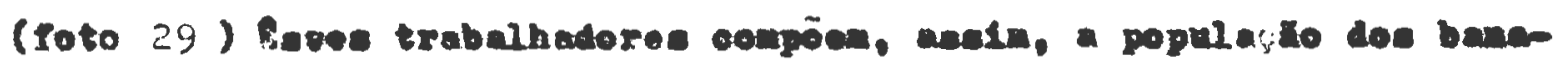
nals, que sadn ton en comun quor con a populagko protana 10eal, quer

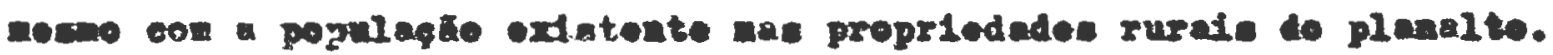

(46) Até 1932-33. - croces doe trabalhadores doe oft1ee 1ta-

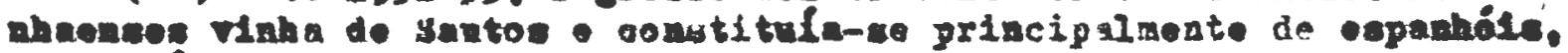

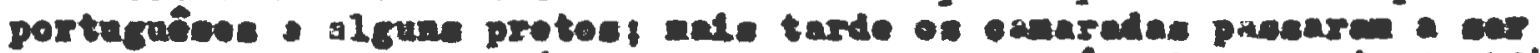

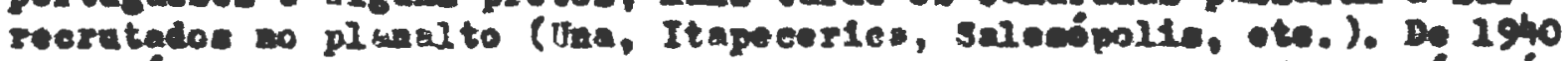

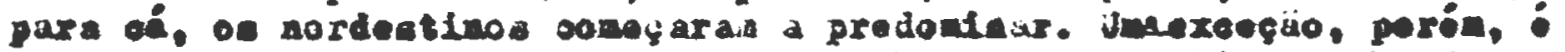

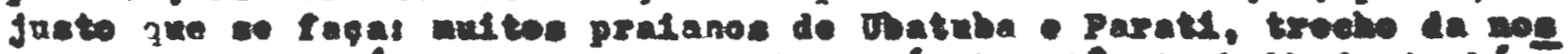

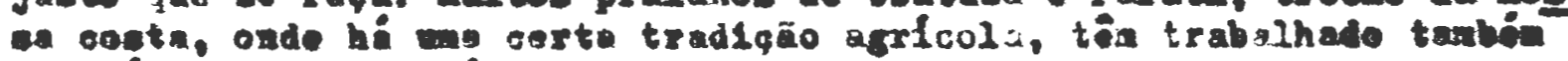
we eltloe de Itminain. 


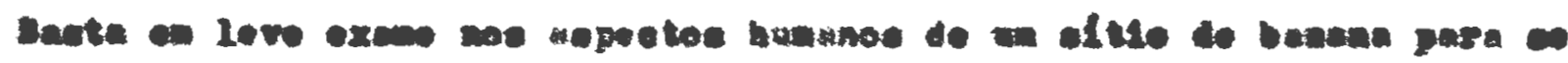

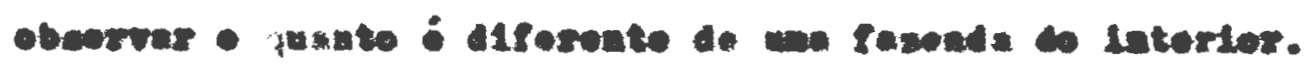

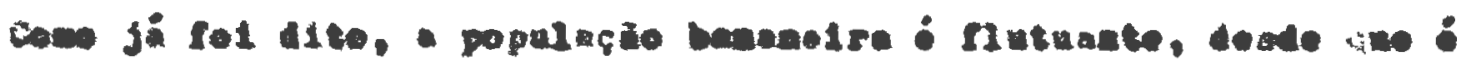

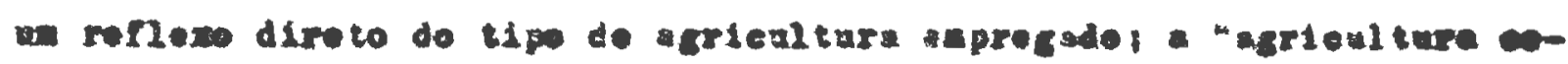

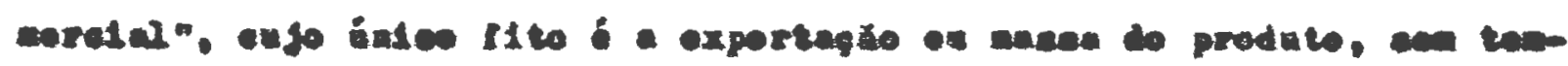

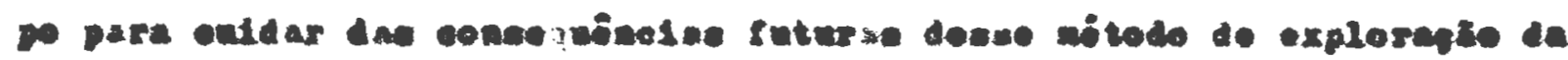

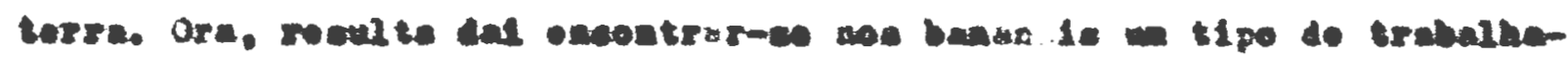

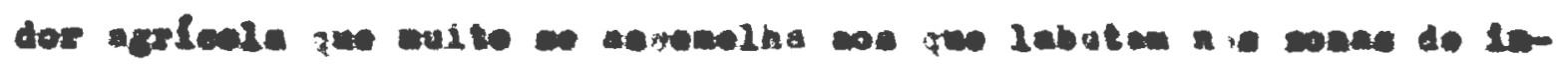

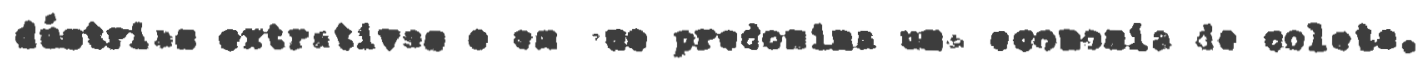

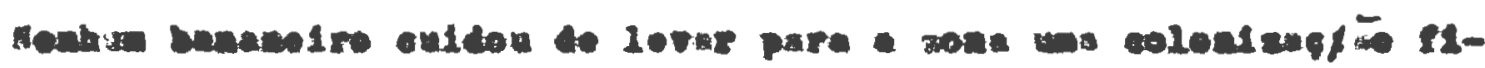

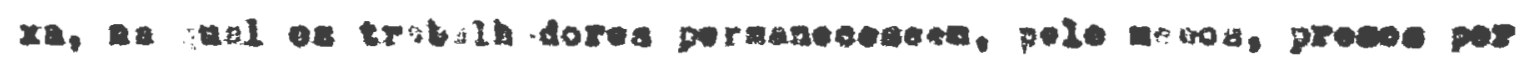

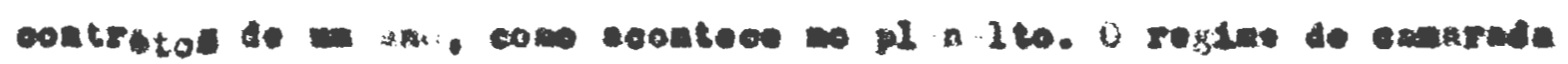

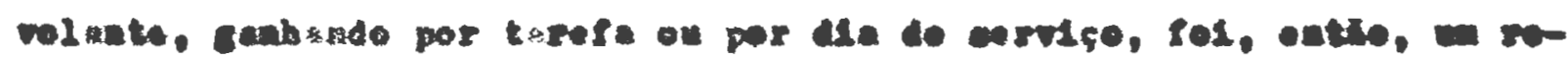

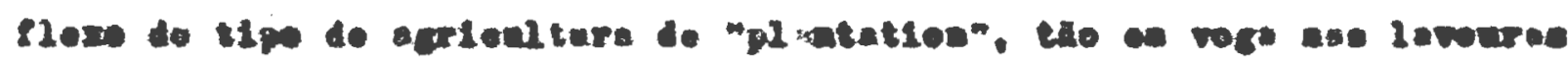

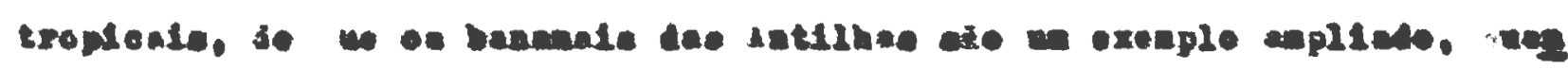

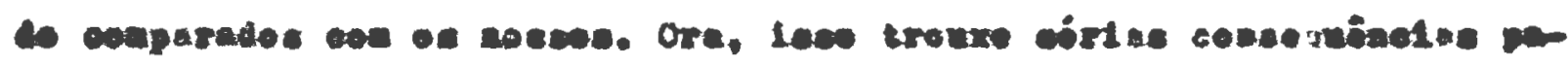

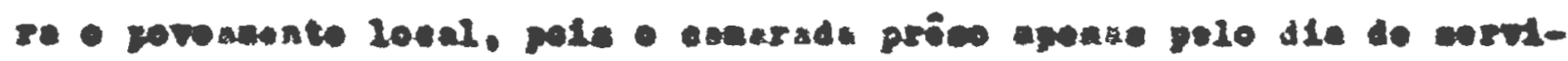

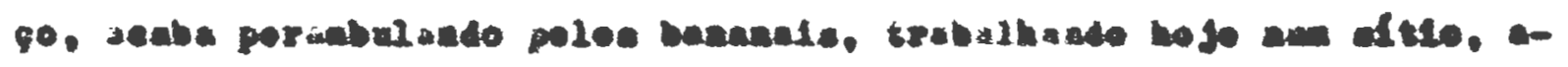

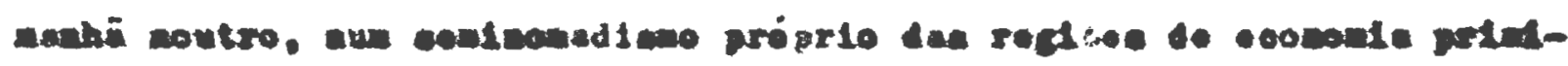

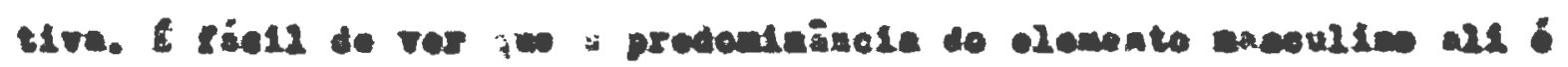

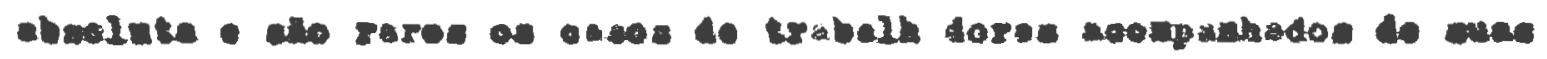

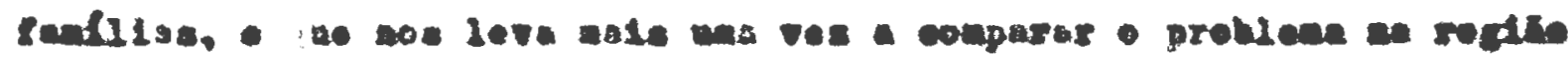

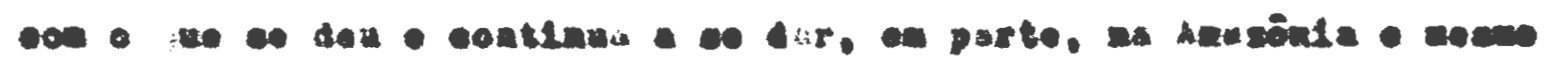

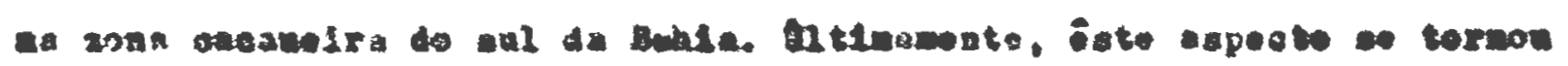

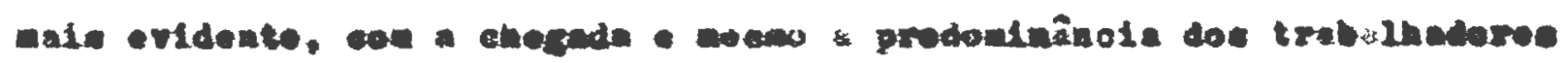

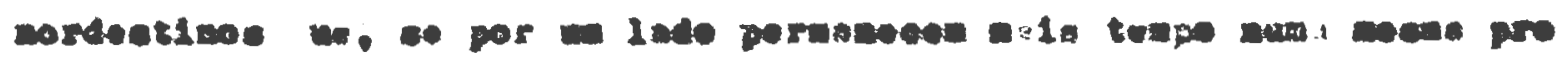




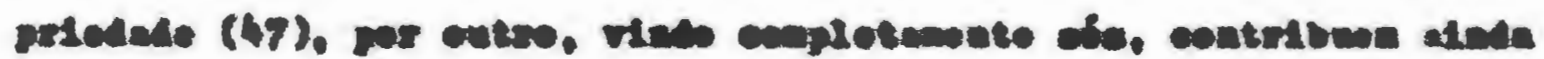

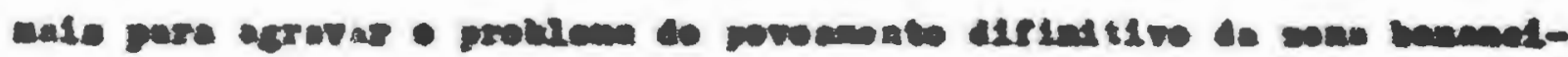
ra.

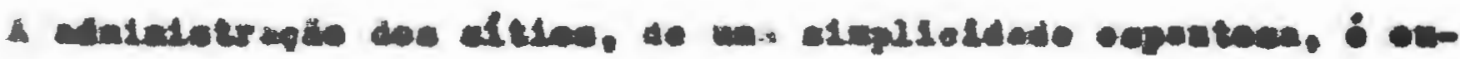

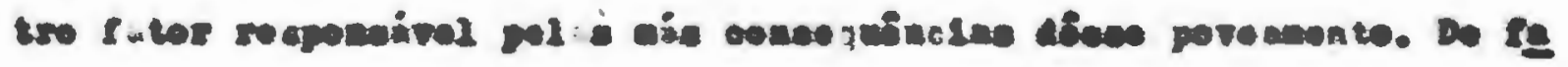

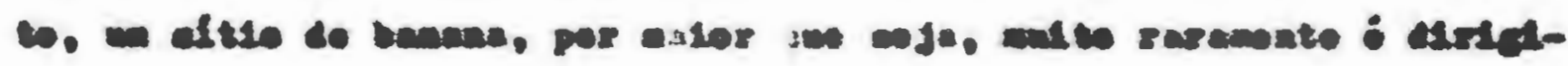

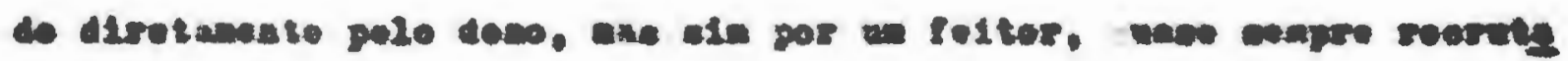

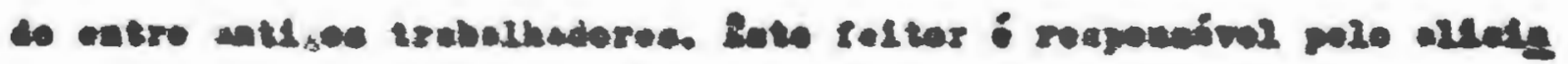

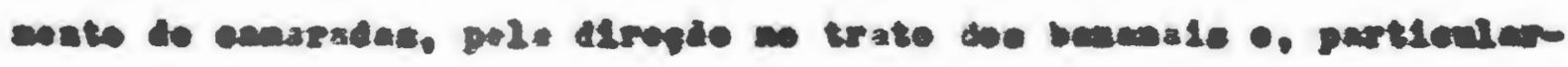

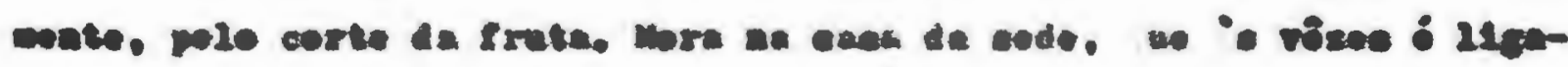

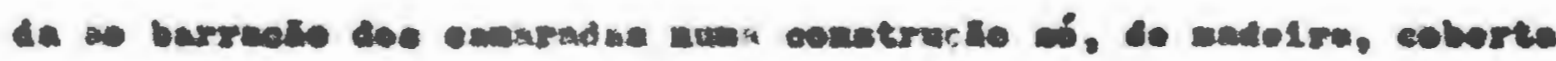

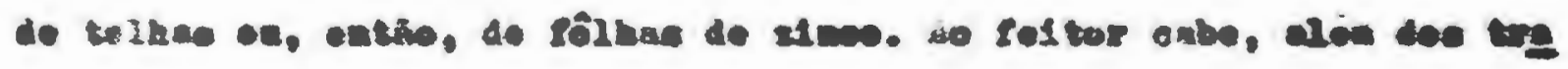

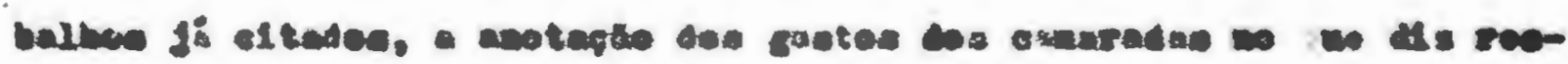

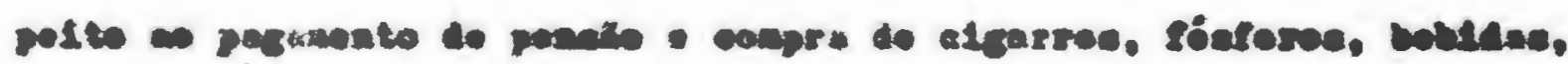
๑te..

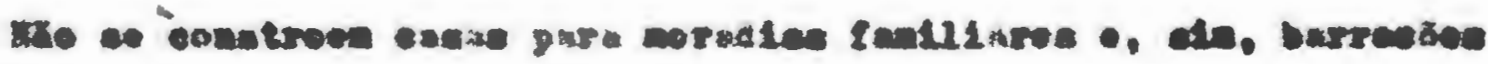

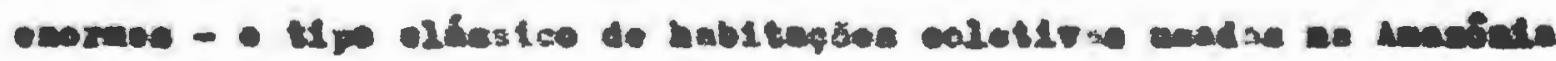

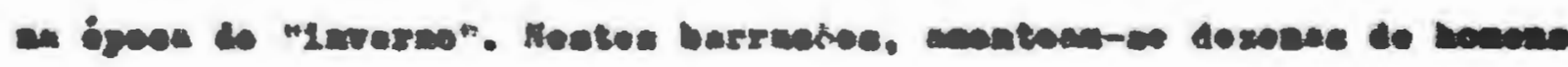

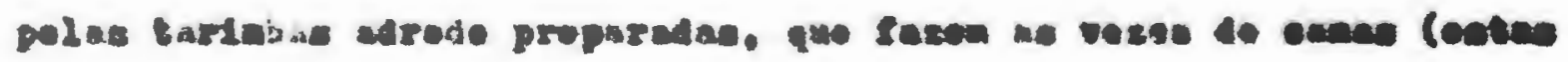

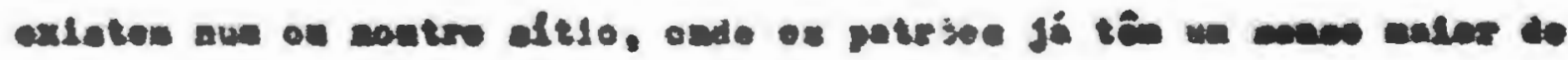

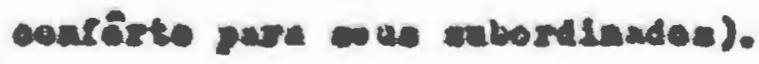

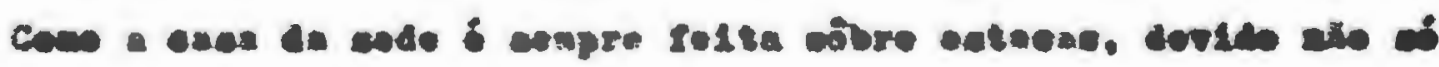

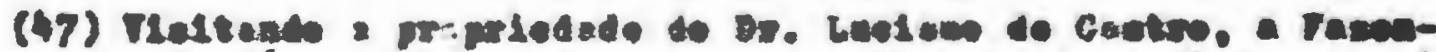

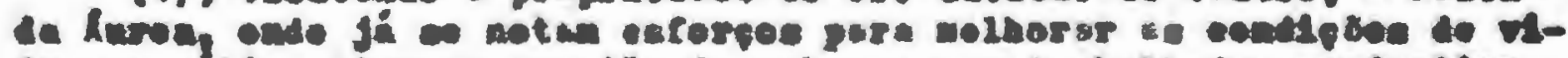

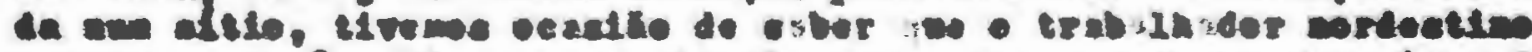

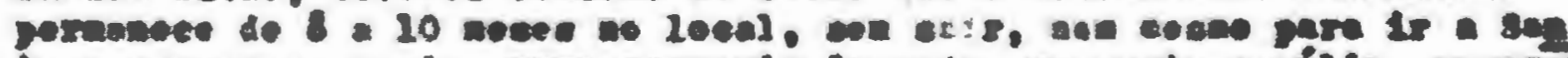

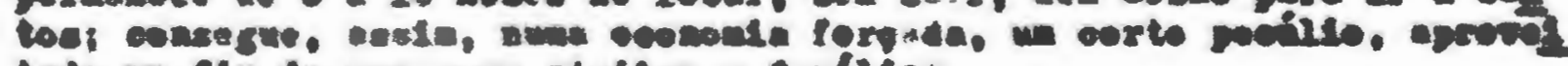

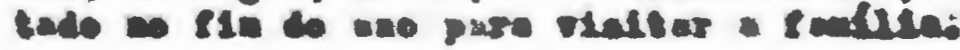




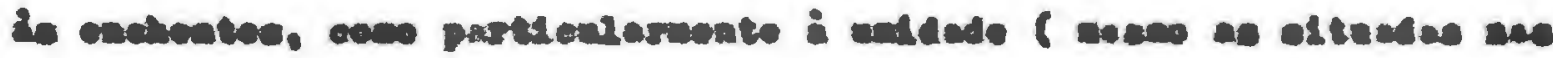

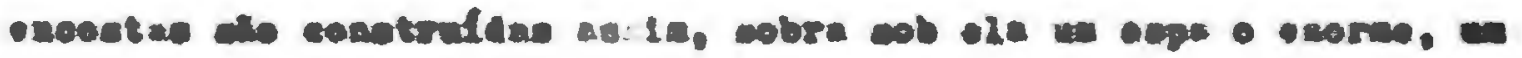

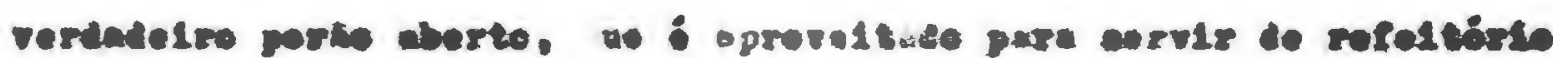

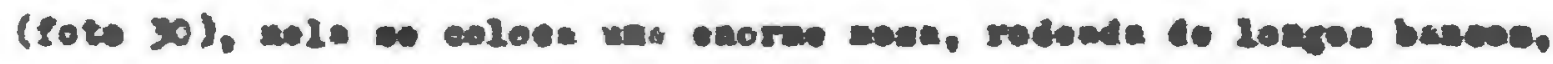

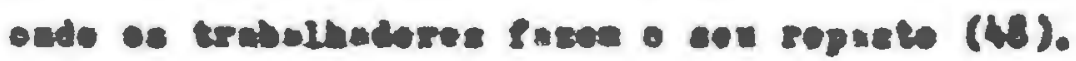

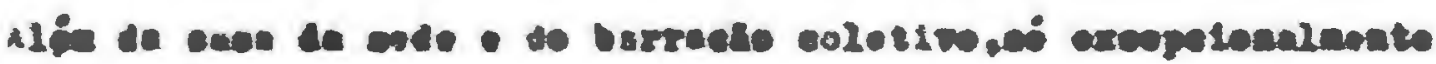

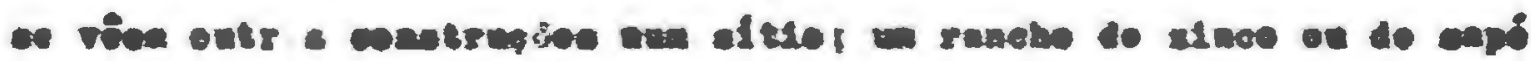

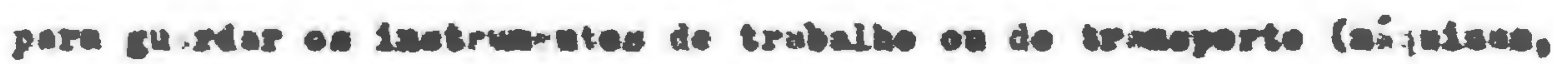

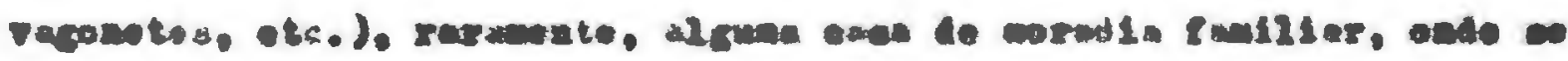

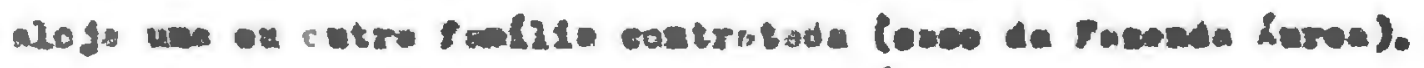

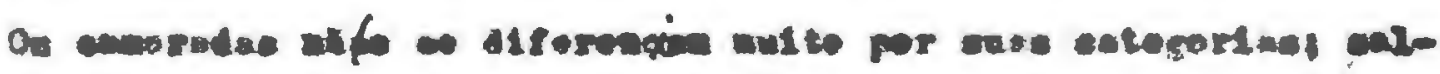

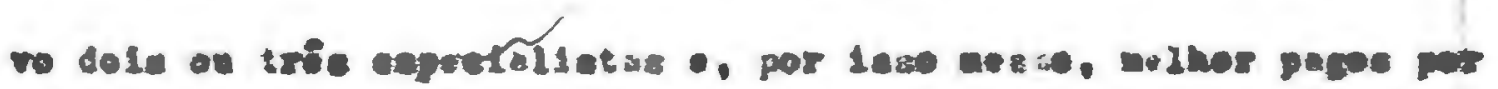

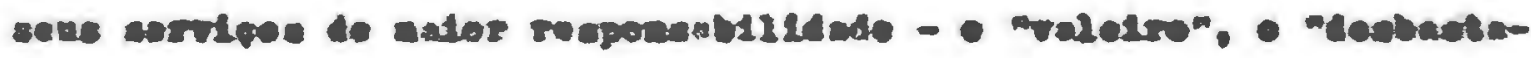

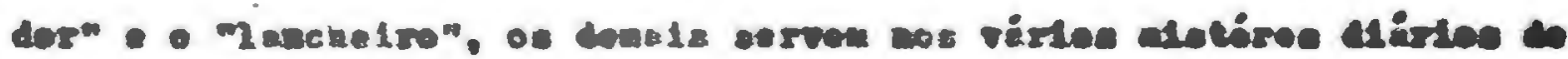

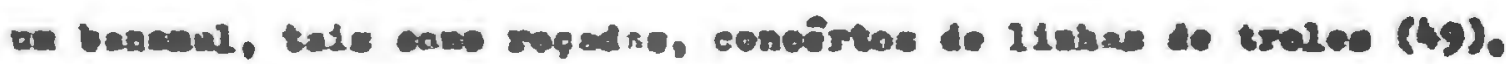

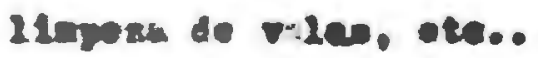

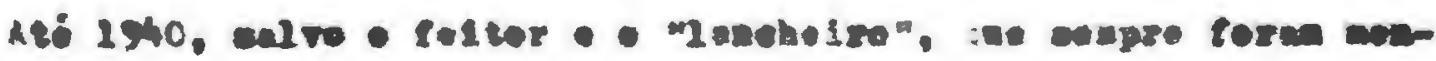

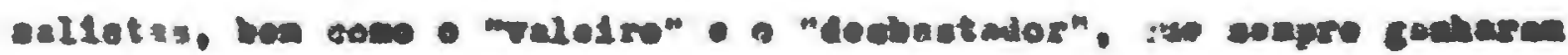

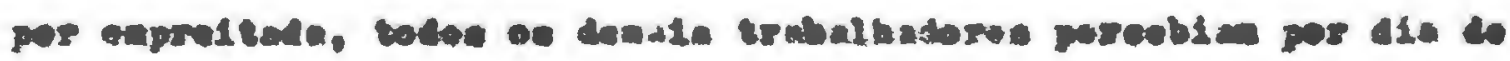

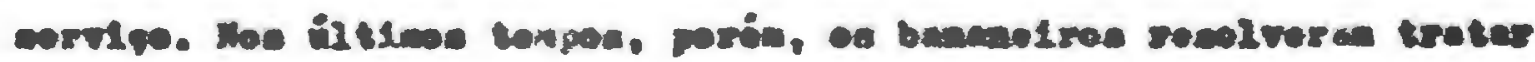

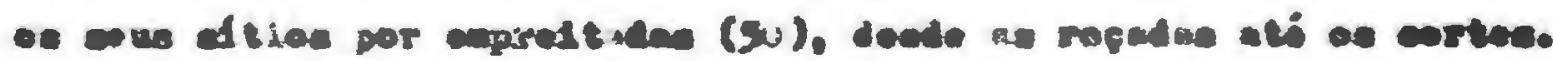

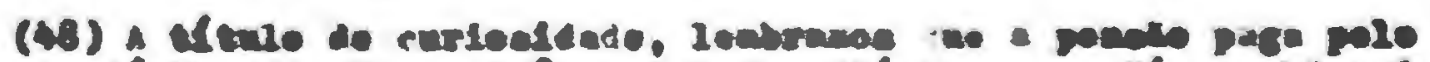

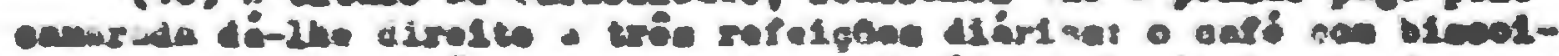

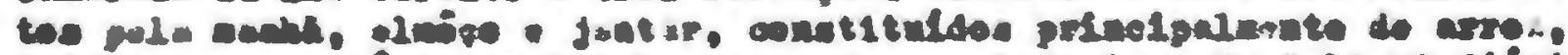

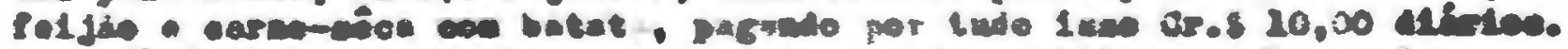
21 tertione.

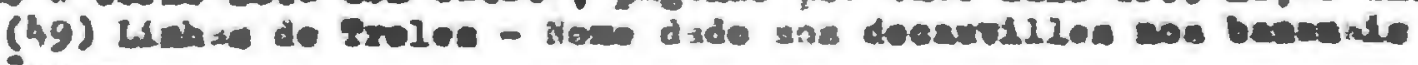

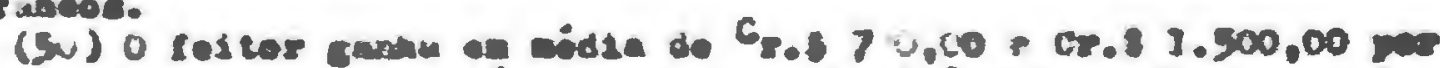

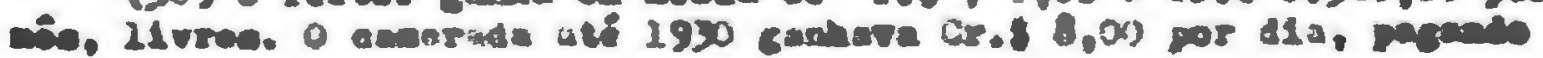




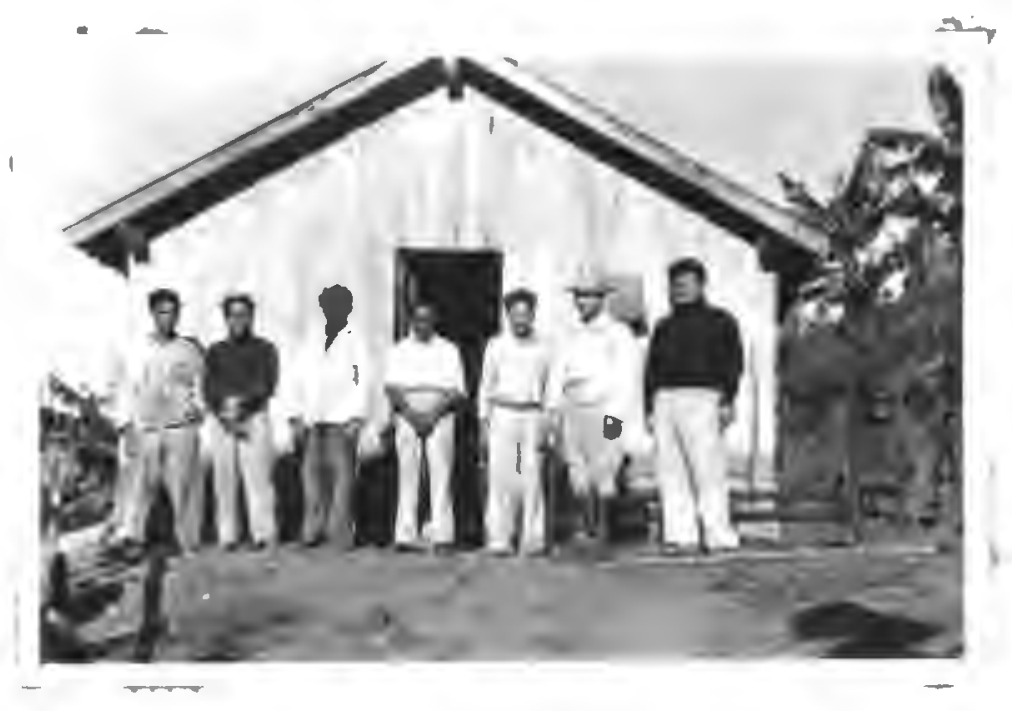

Ioto 29. Un grupo de trabalhadores nordestinos, juntamente com o administrador da "Pazencia furea". defronte ao barracāo dos camarada. (foto A.R.Penteado).

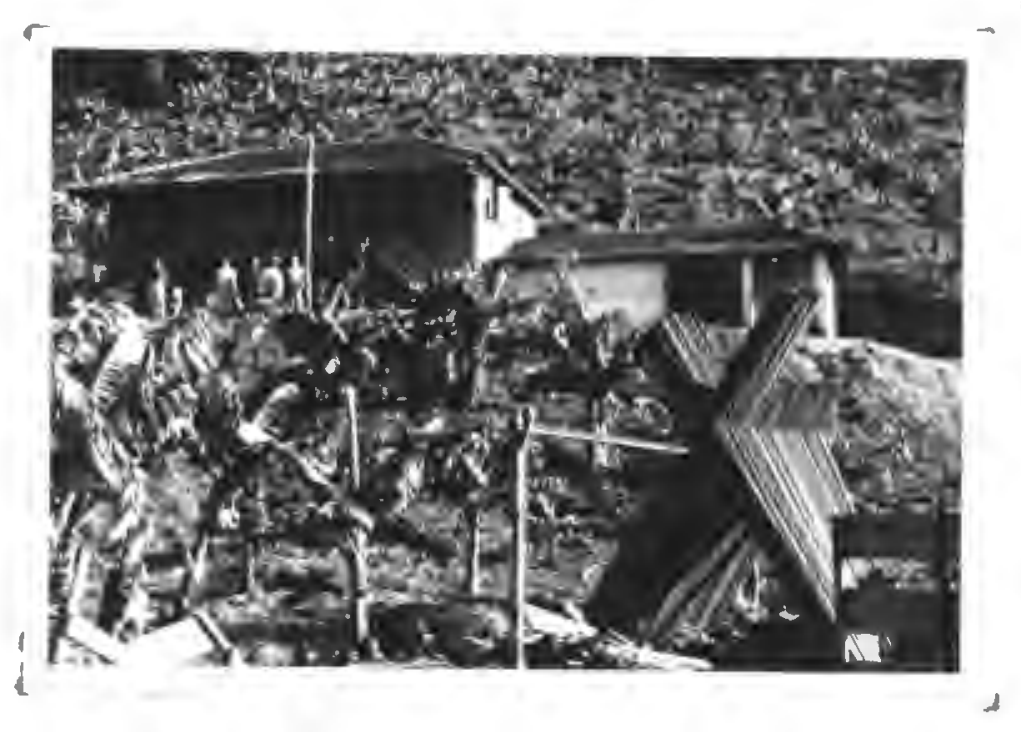

Poto 30. 4 casa la séde da "Fazenda Aurea" na encosia de um morro,e onde se nota o porlo alto que serve de sala de refolçōes 208 camaradaj. (roto A.R.Penieado). 


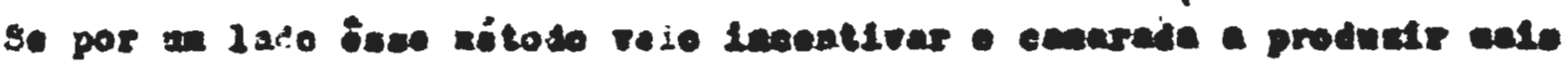

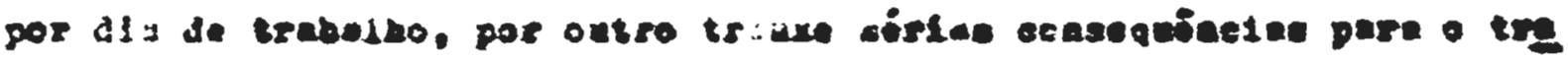

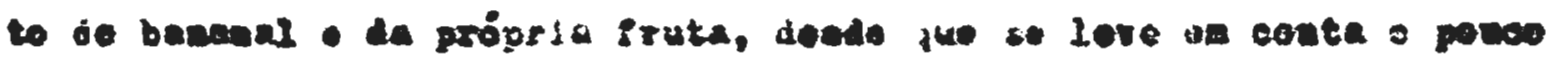

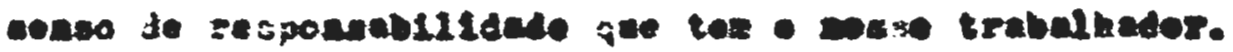

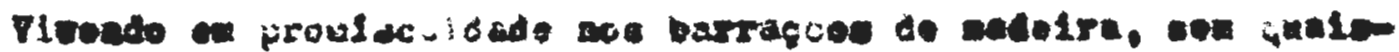

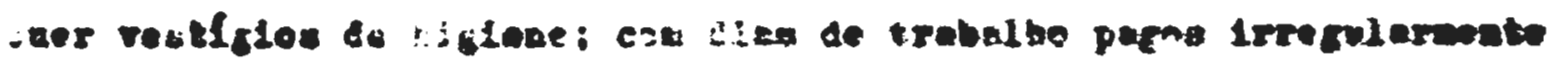

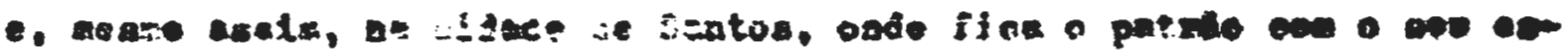

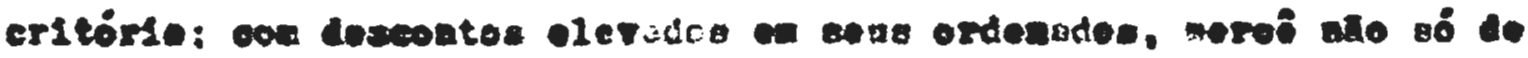

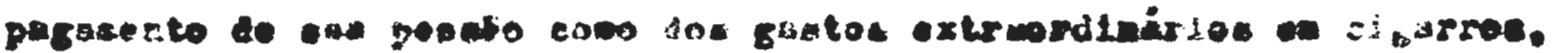

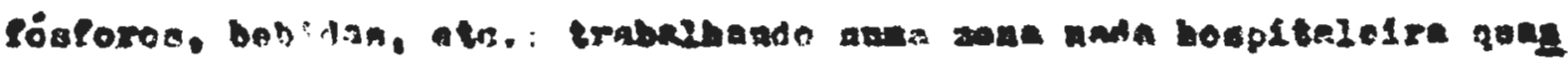

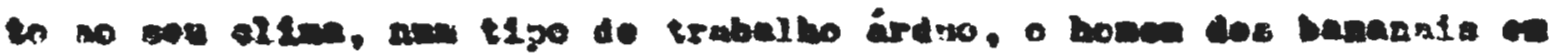

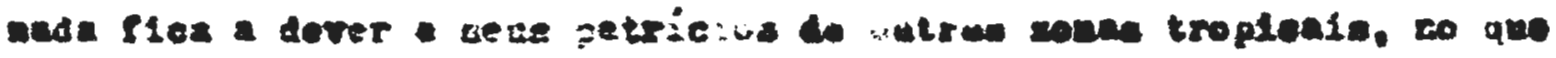

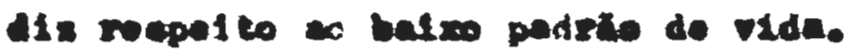

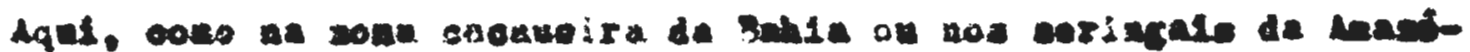

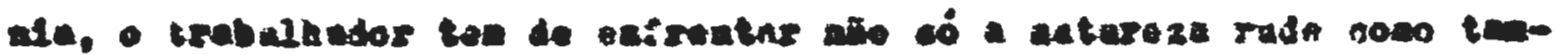

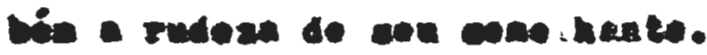

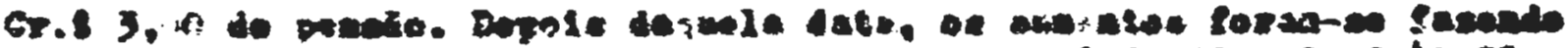

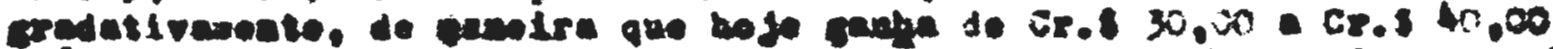

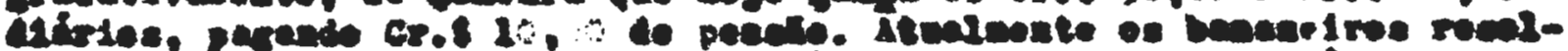

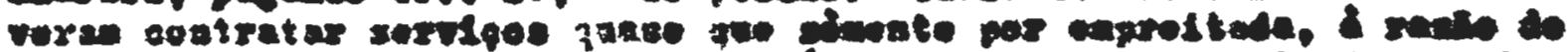

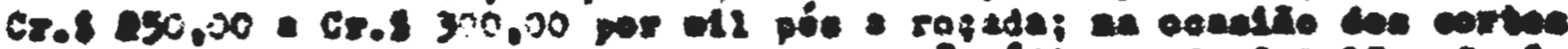

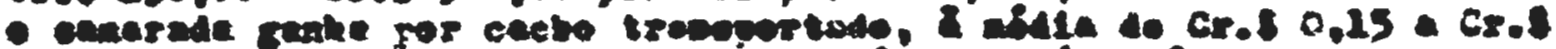

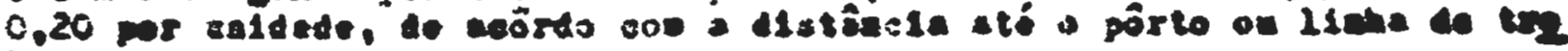
2..
} 


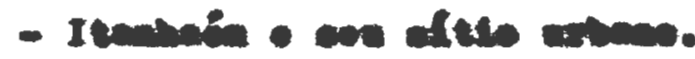

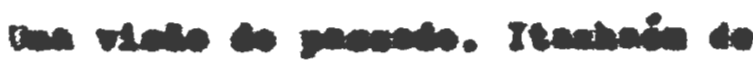
nower diect

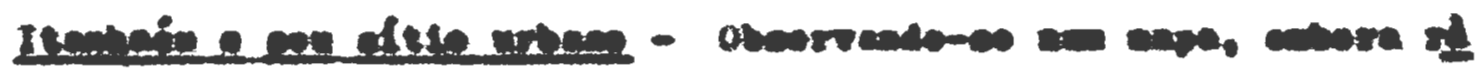

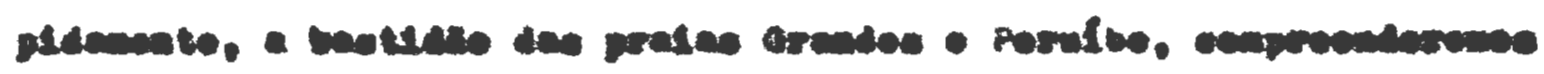

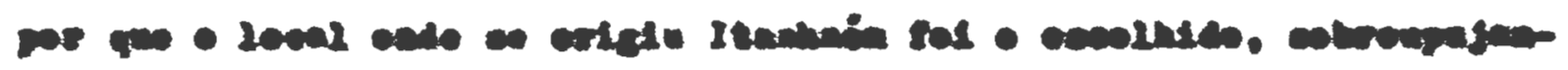

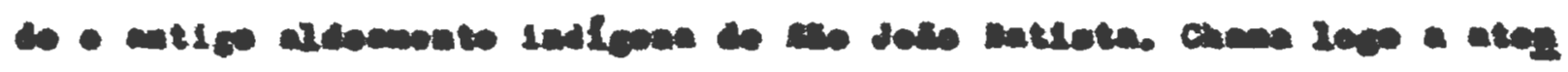

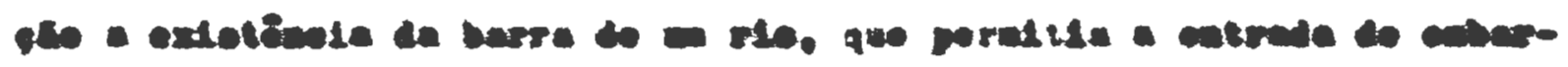

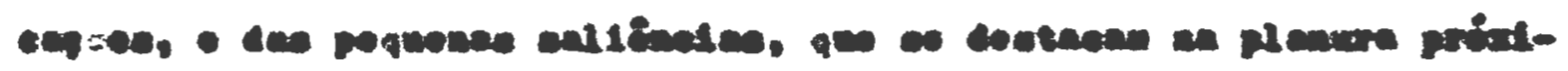

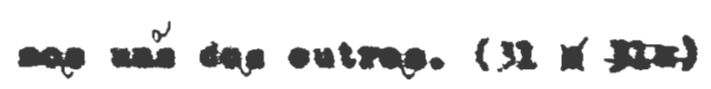

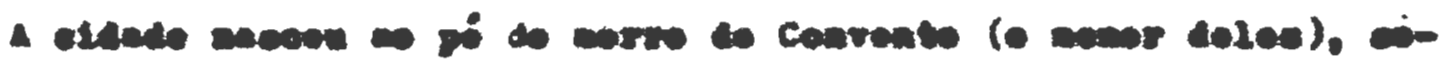

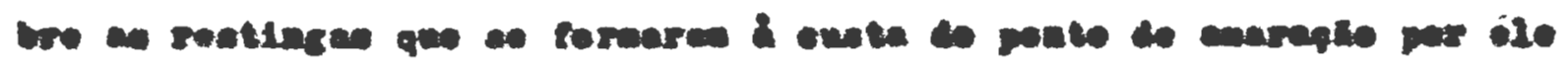

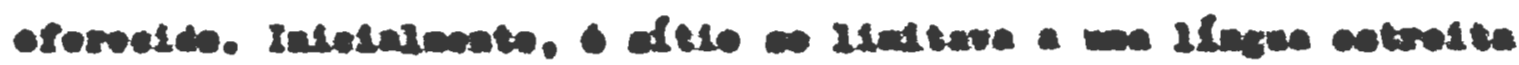

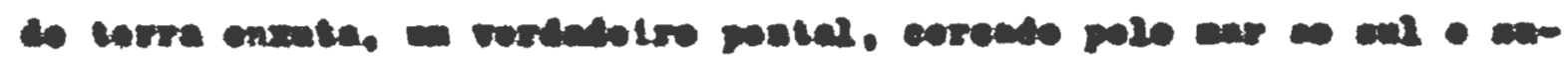

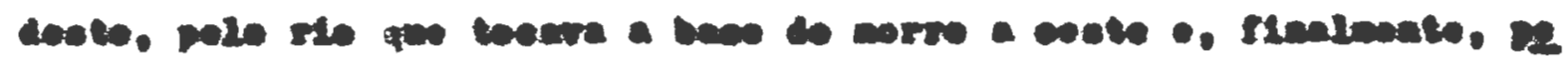

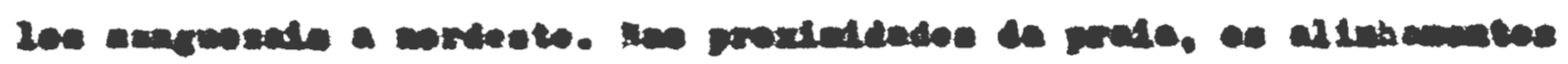

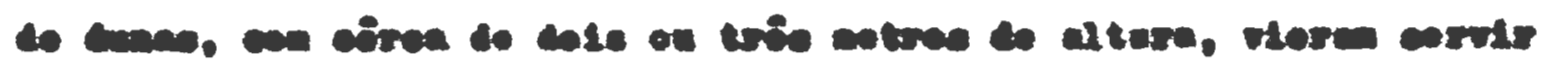

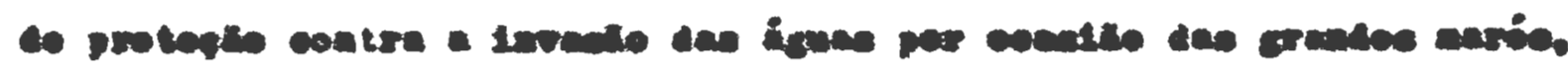

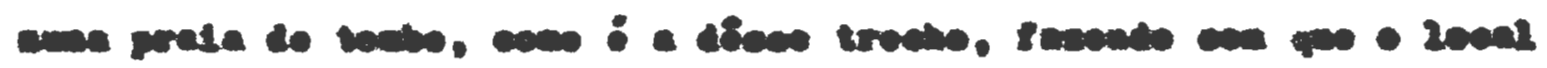

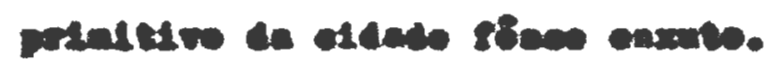




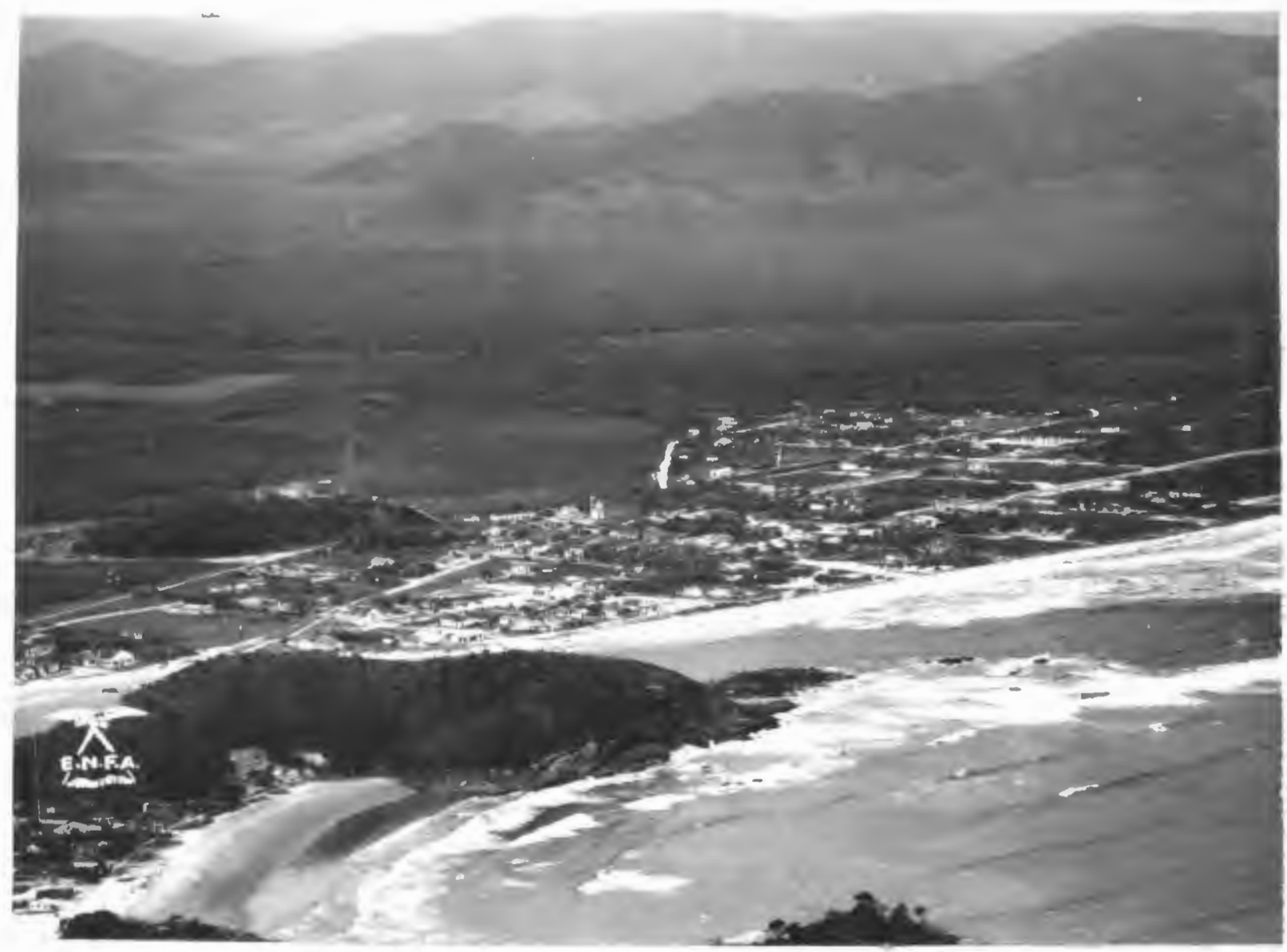

Foto n.31- Vieta do ifto de Itanhaém, aparecendo alem do Morro do Convento, ao pé do qual teria nascido a cidade, à fos lo rio, entre o IInal da Prata Grande - o Morro de Taquanduva. Suceden-se no fundo, trecho da Batrada Interior e ecarpas do Morro Grande da Paranapiaoaba. 


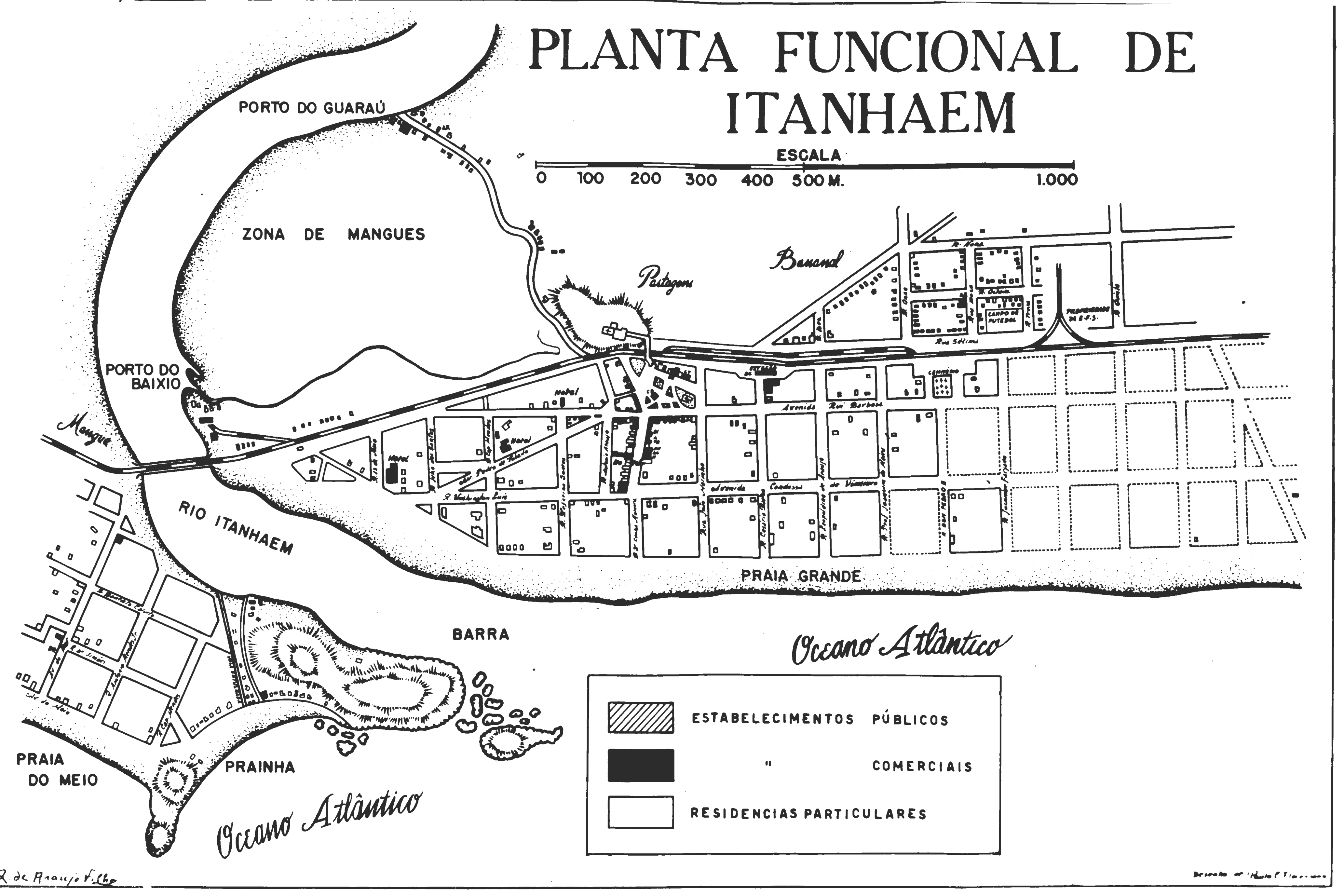




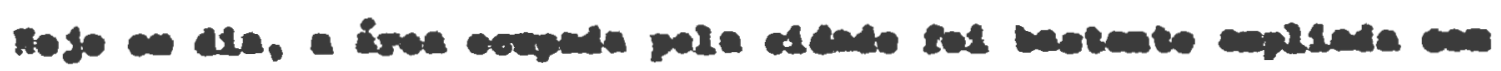

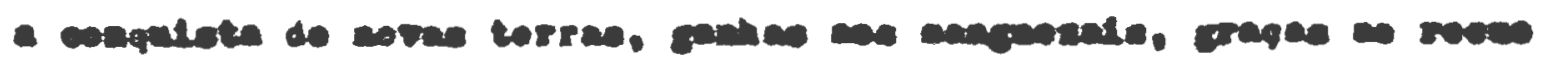

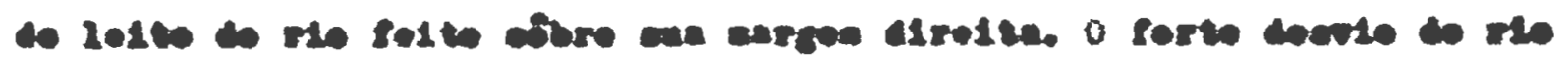

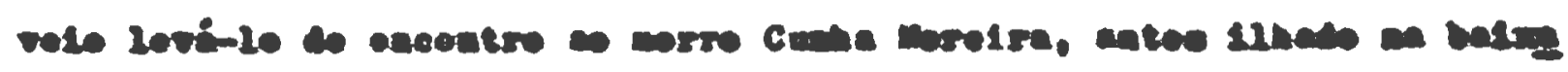

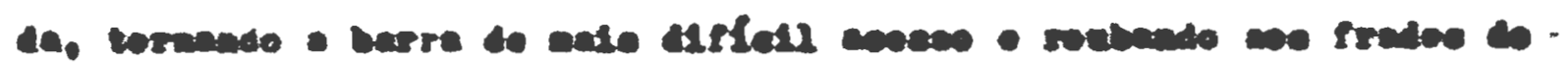

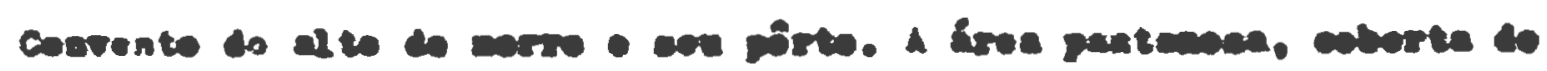

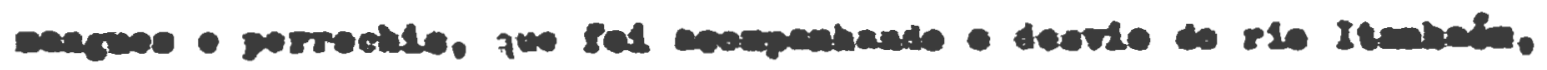

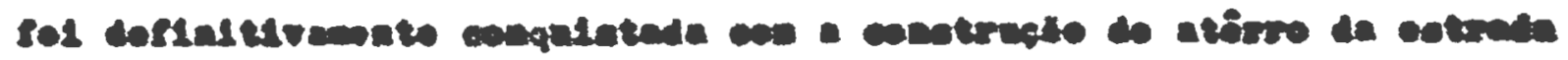

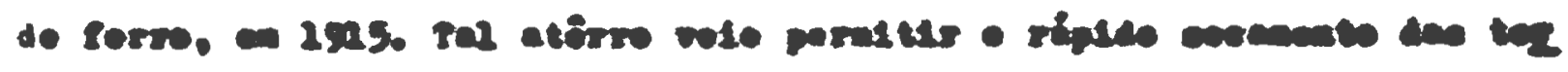

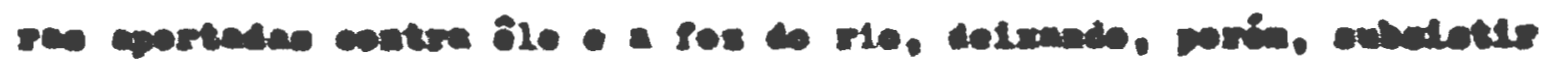

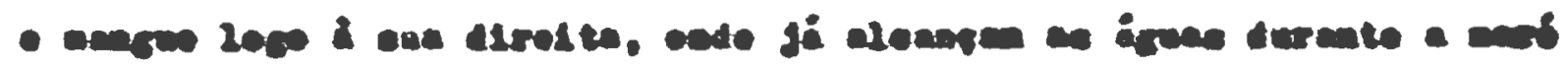
ara.

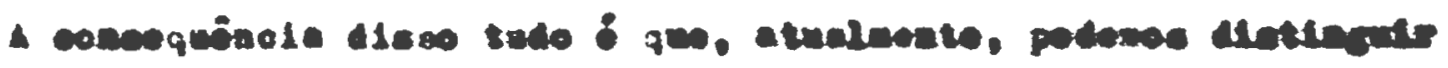

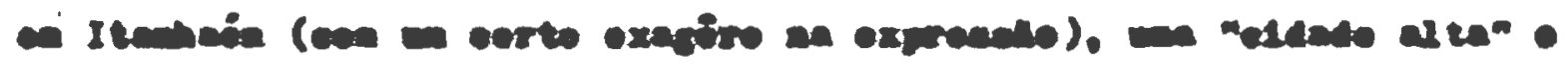
neided valinan.

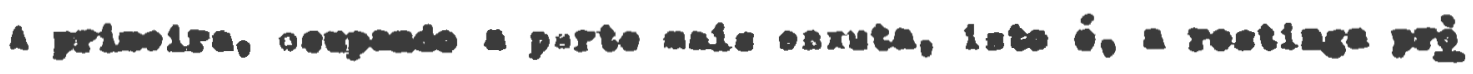

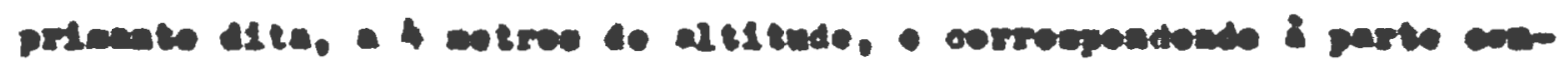

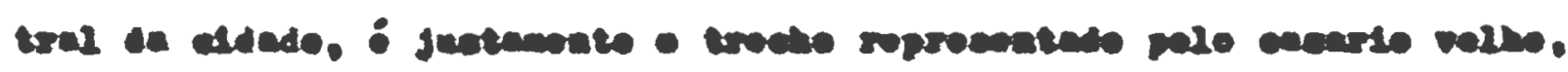

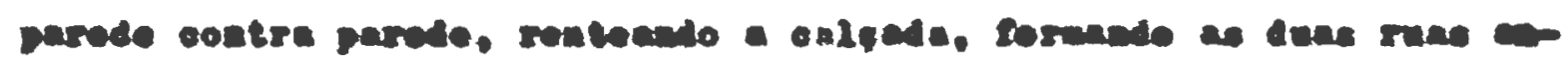

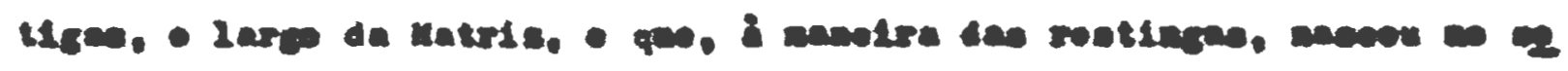

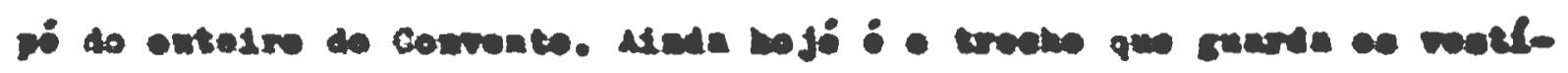

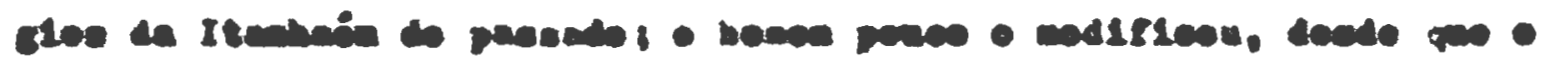
canotrutu. (soles 32, 33, 34, 35)

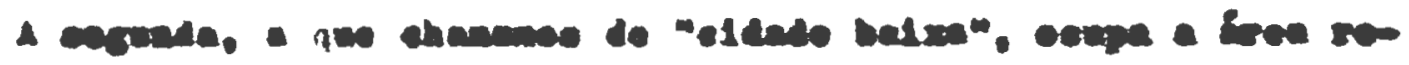

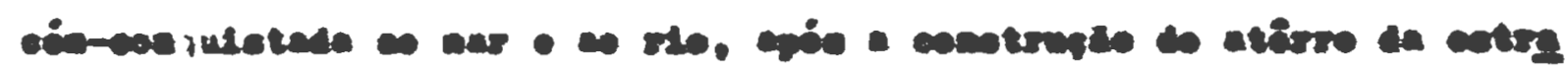


Na primeira o si tio primitivo da cidade, com 0 morro do vonvanto e e os manguesais limitando-o ao fundo (norte); na segunda, uma vista da boje parte ve Iha da cidade, com - casarío grudado um ao outro. Ifotos Paulo Florençano e Aroldo de Azevedo).
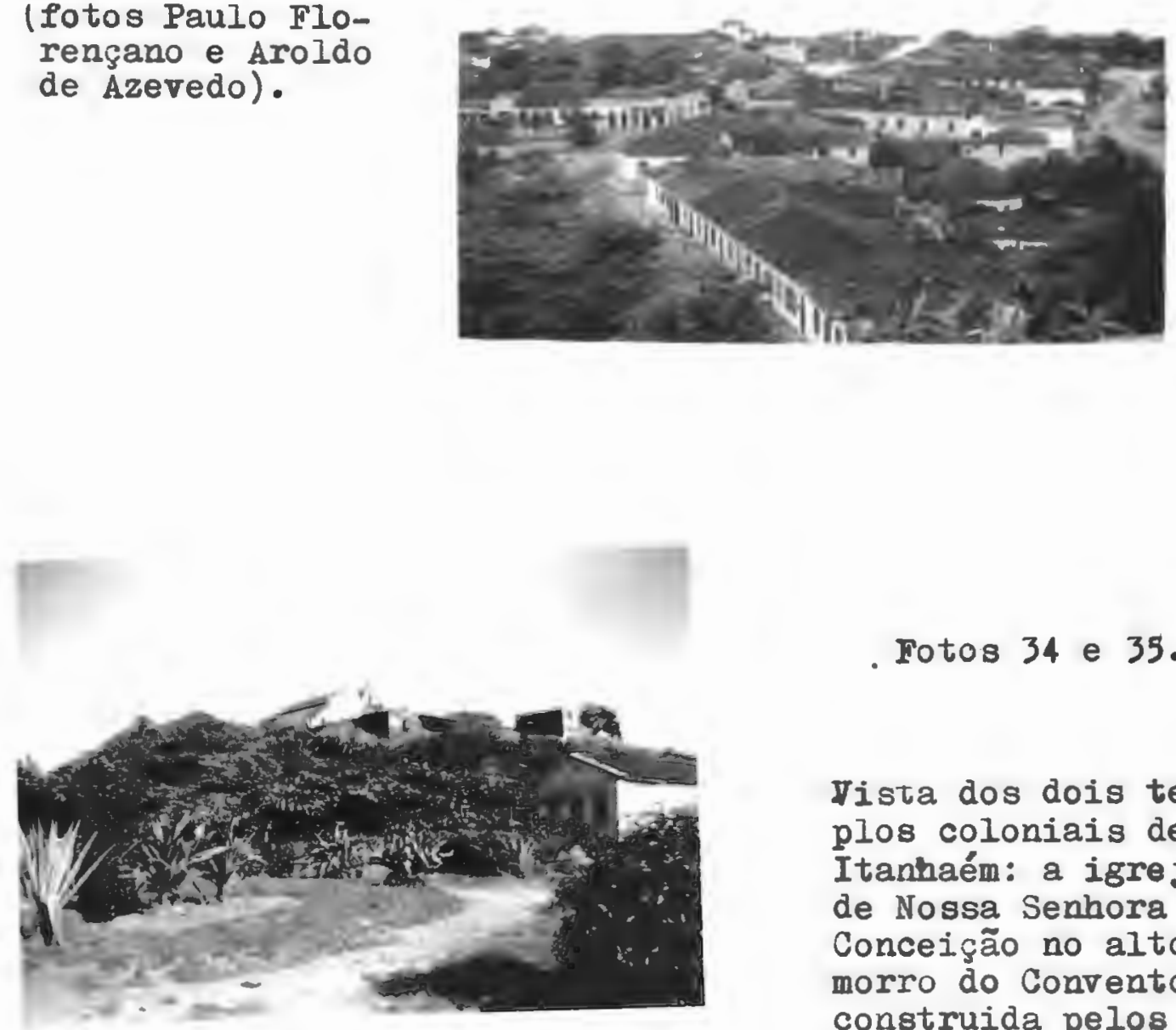

Fotos 34 e 35.

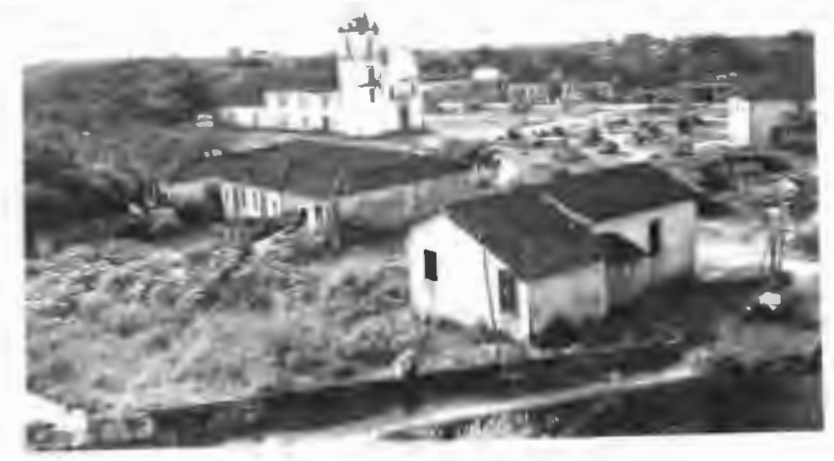

\#ista dos dois templos coloniais de Itanhaém: a igreja de Nossa Senhora da Conceição no alto do morro do Convento, construida pelps fi.? franciscanos no sécu IoXVII; e a matriz de Sant ina, que data de meiados do século XVIII.

(fotos do autor). 


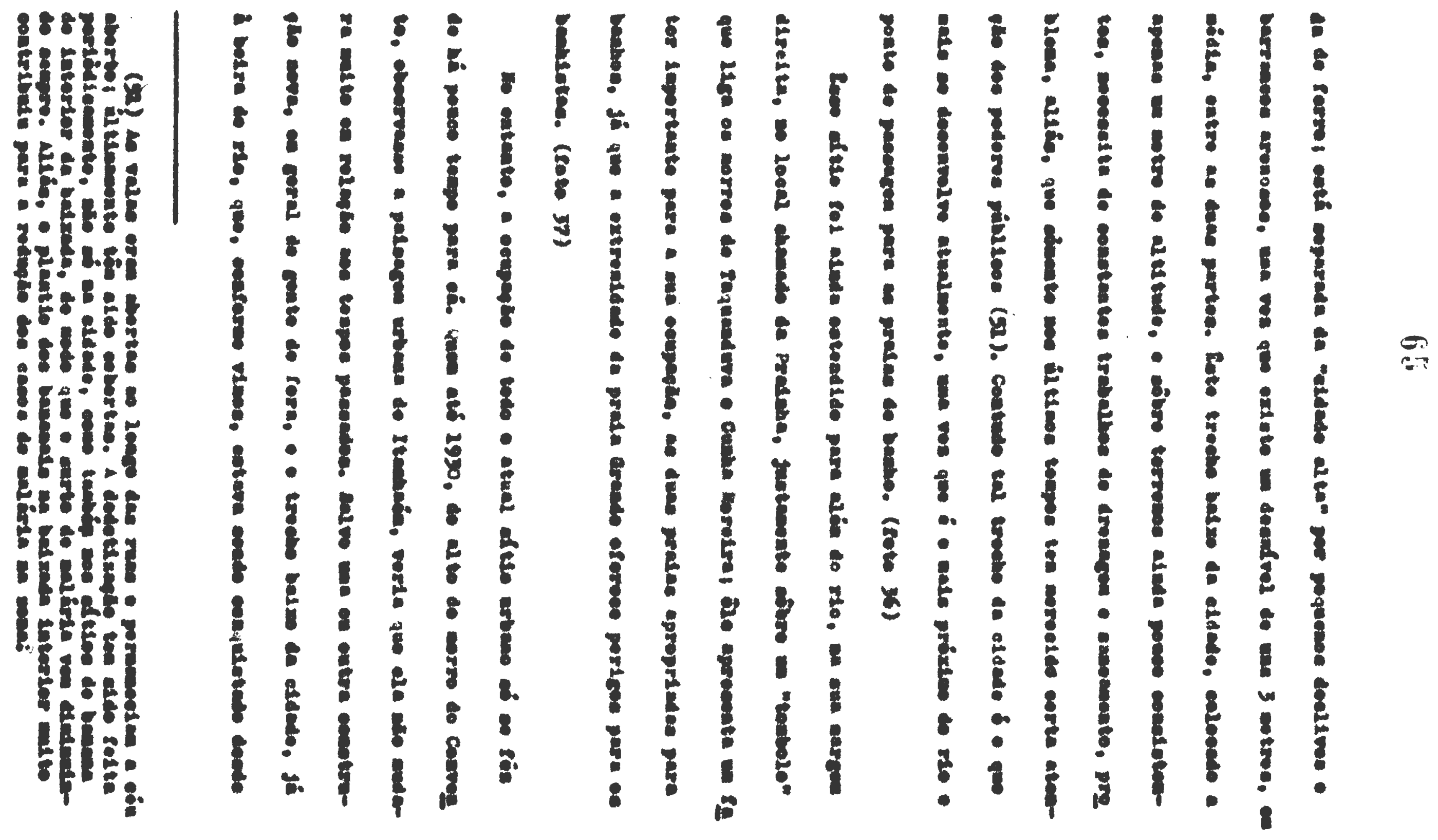




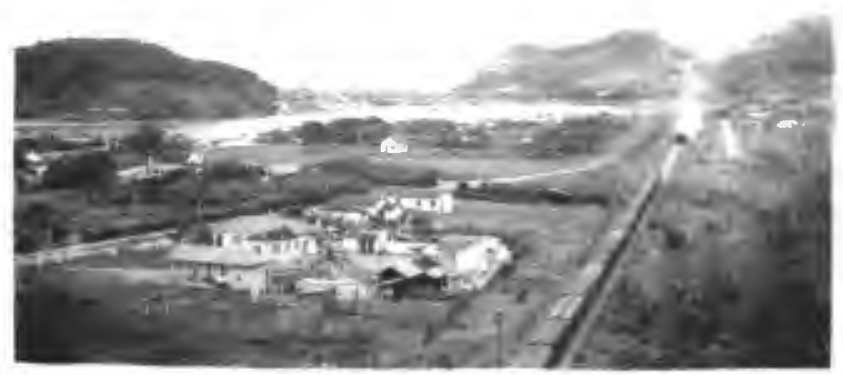

Joto 36.

0 trecho ba1xo ile aldede na parte geilua so manarue

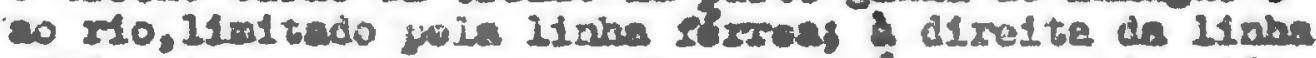

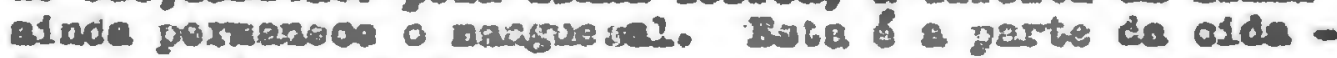

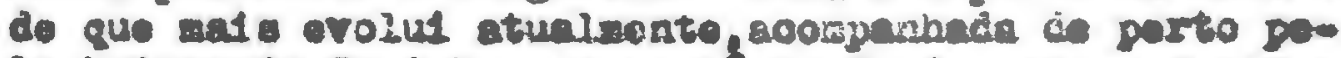

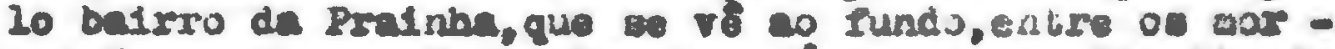

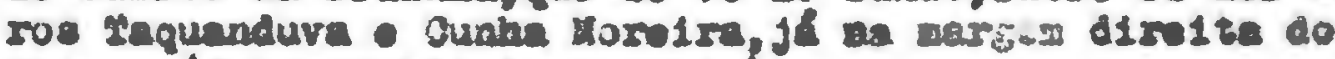
210. (foto aroldo de Asorredo)

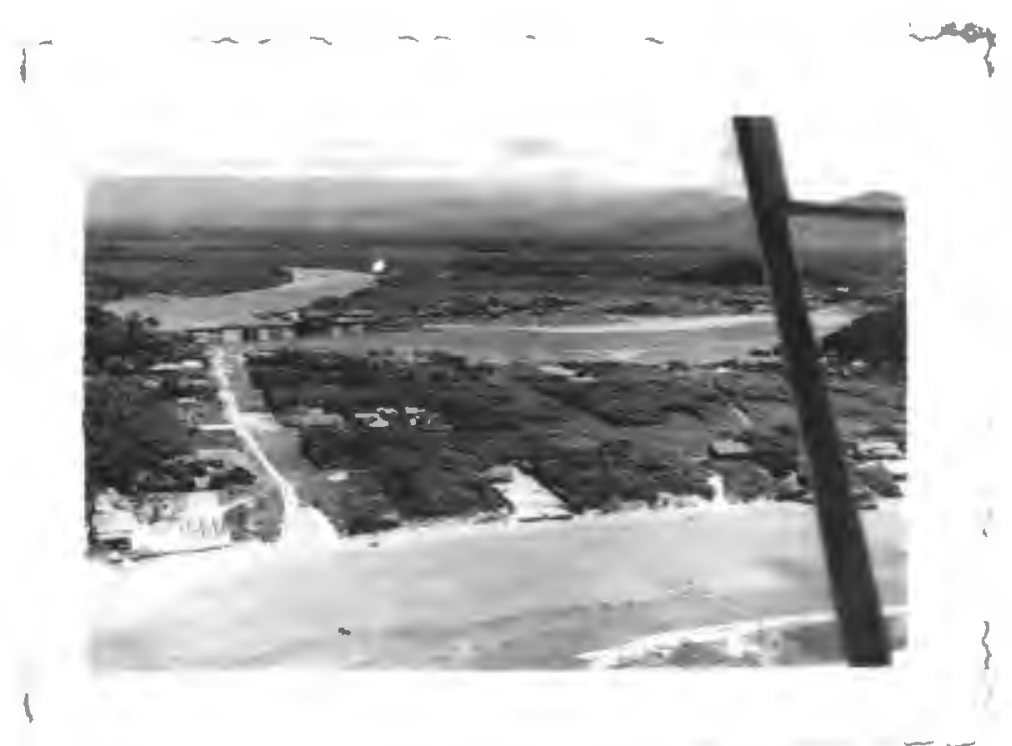

roto 31.

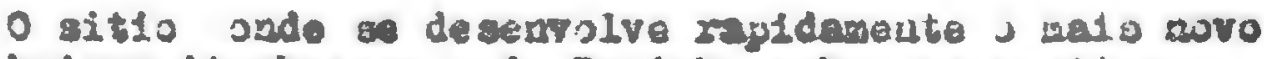

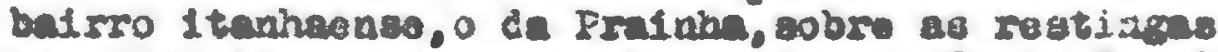
que buje $11 \mathrm{gam}$ os morros Iaquanduva o Ounha "orvire. Ainda podemoe obeorvar na fotogrerla ponte de Ju quik, o parto do Beixlo, un troobo de befxada i.iterlor

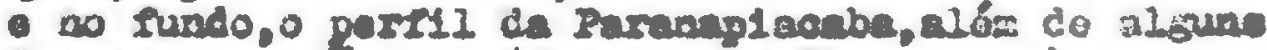
de saus ecportes. (roto Peulo Florangano). 


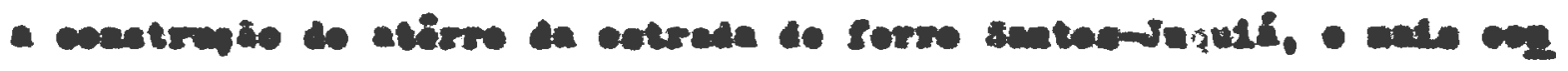

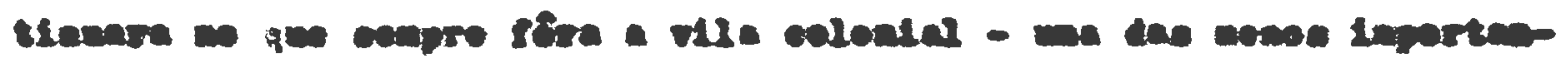

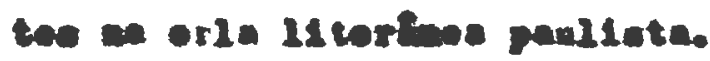

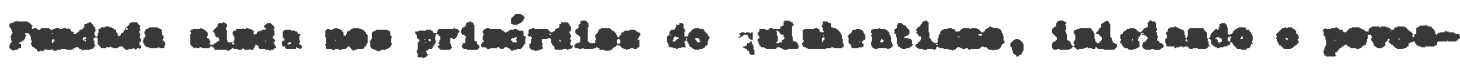

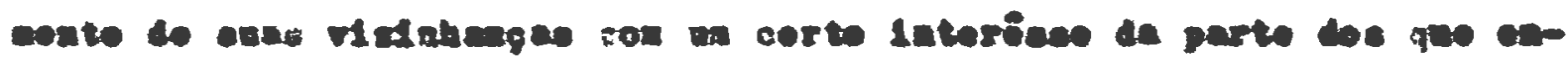

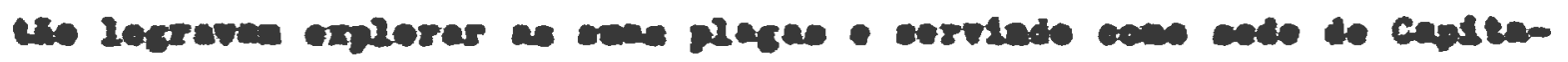

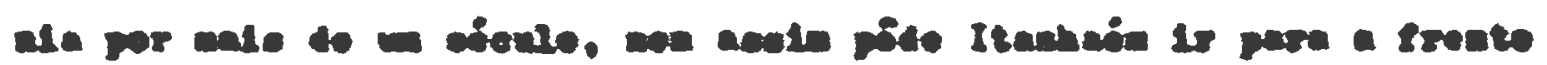

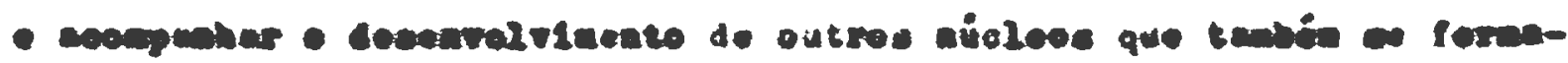

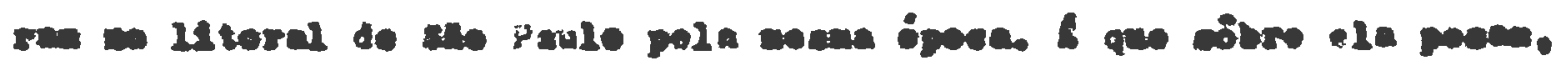

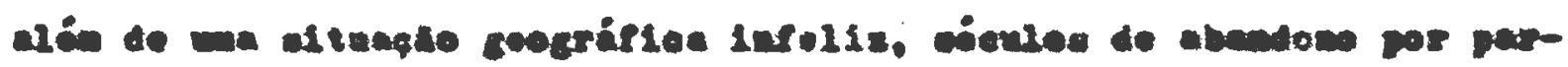

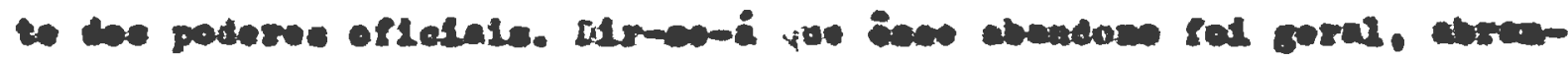

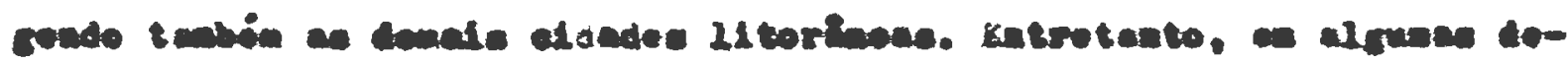

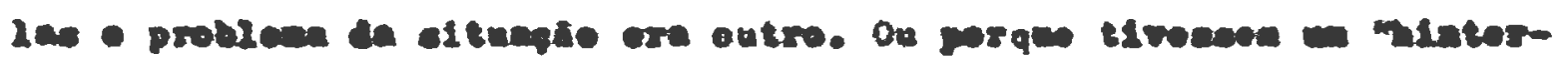

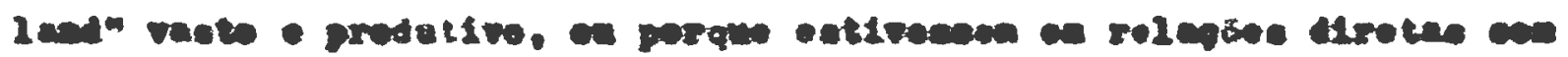

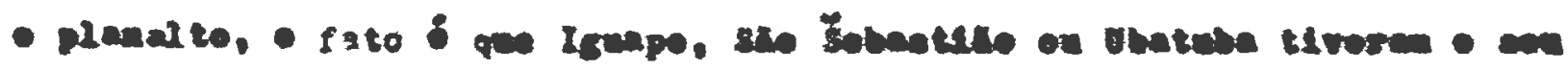

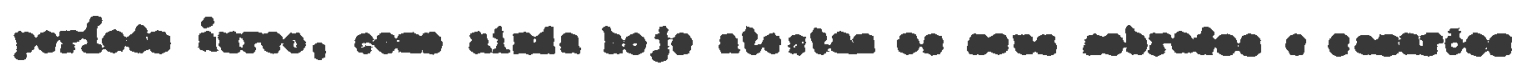

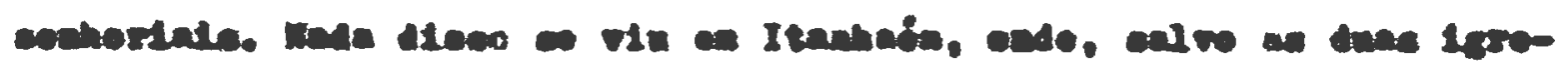

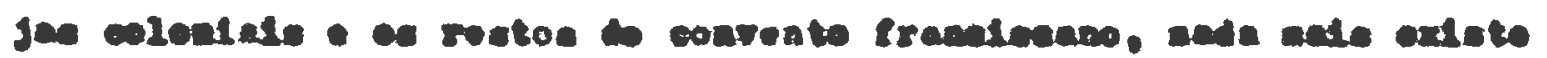

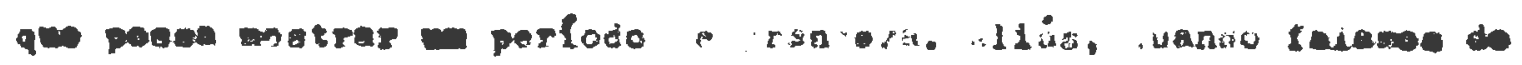

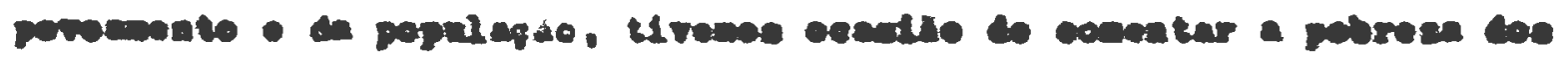

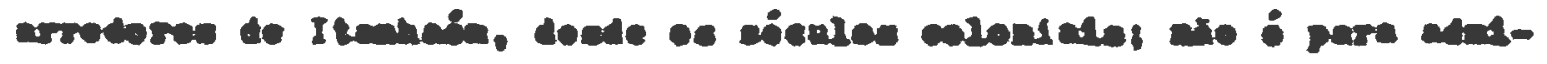

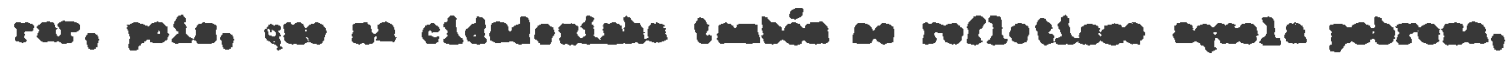

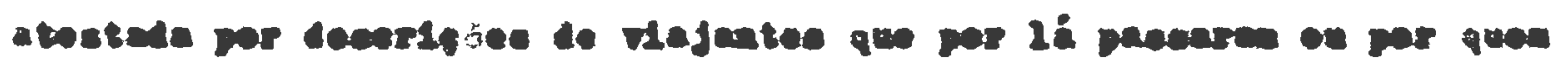

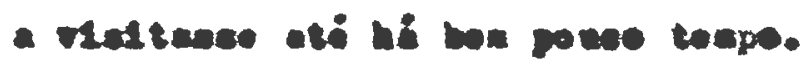

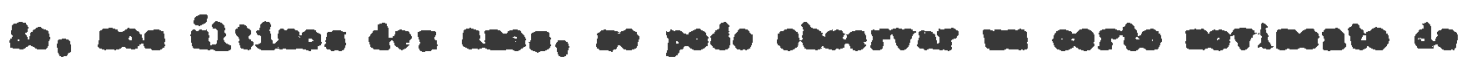

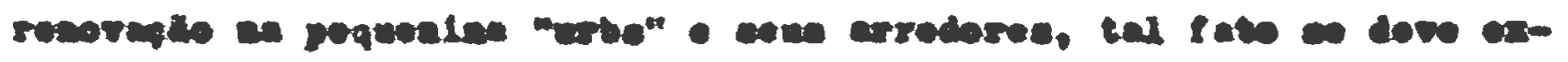




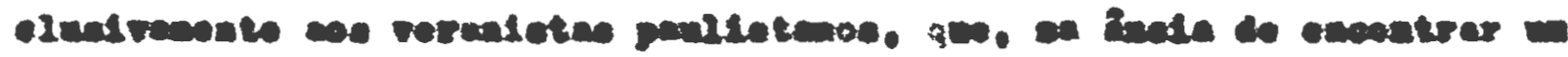

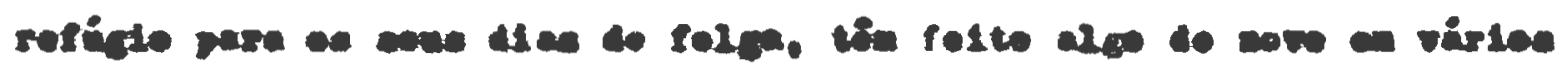

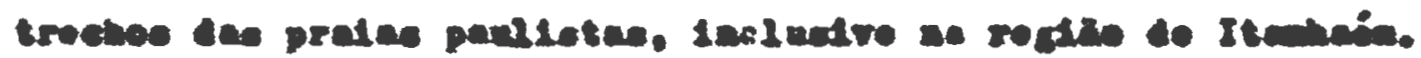

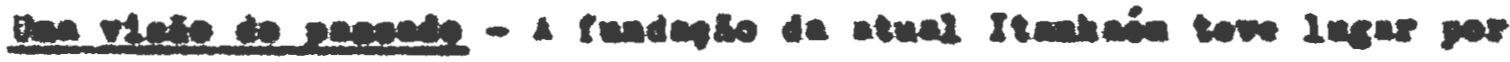

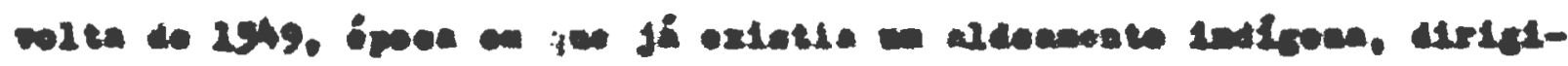

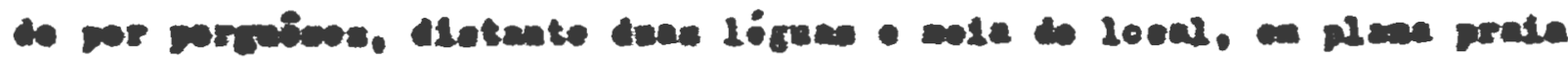

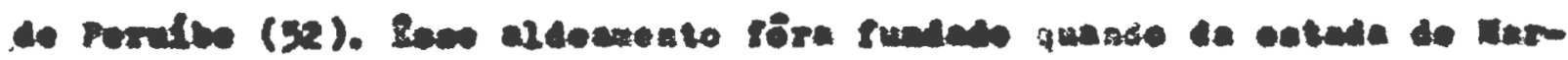

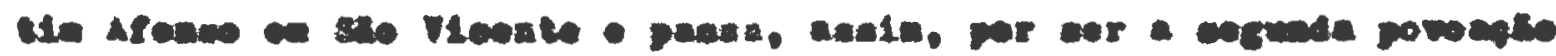

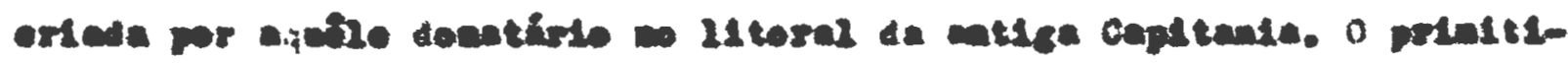

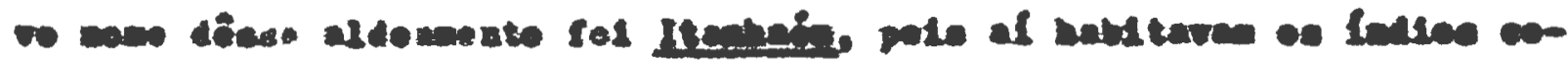

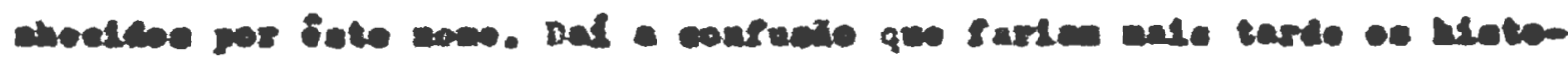

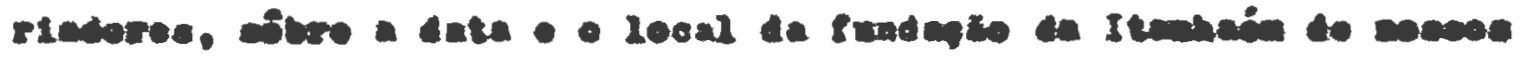
1se.

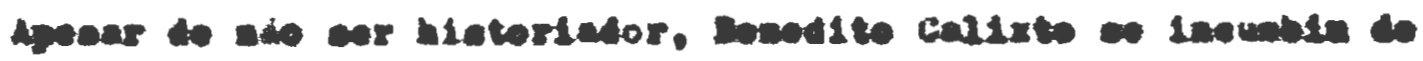

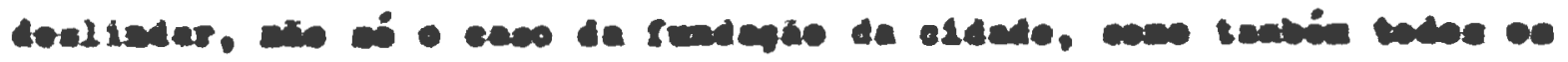

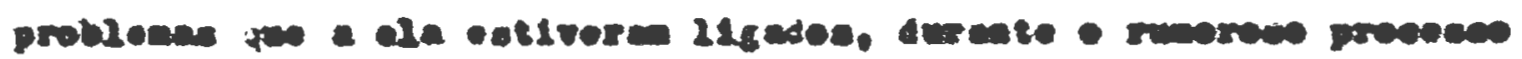

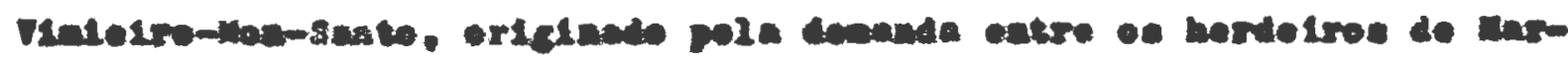

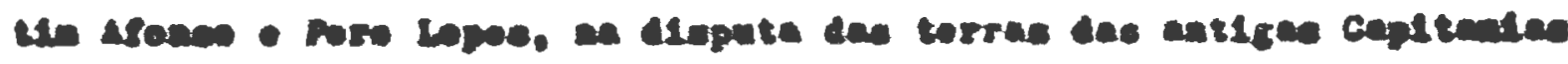

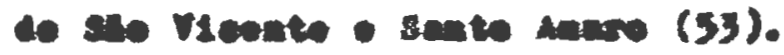

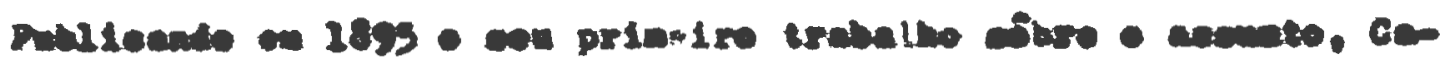

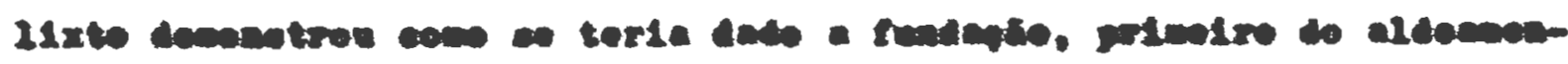

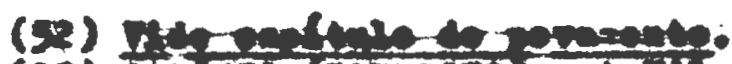

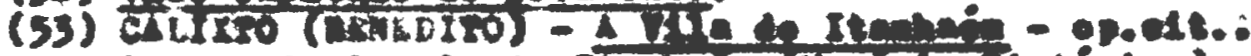

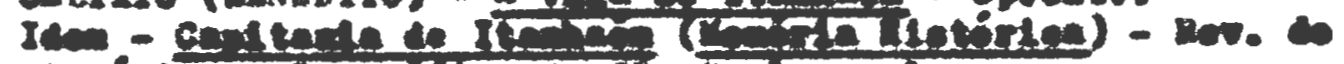

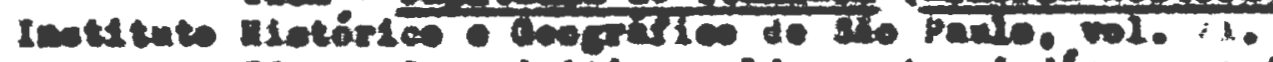

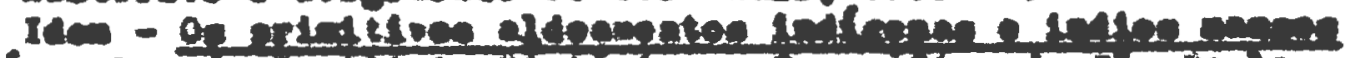

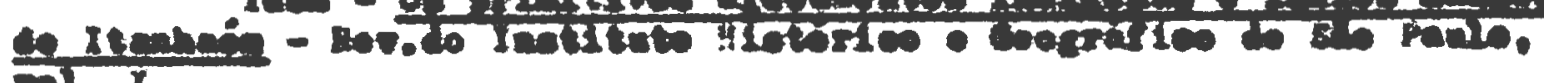
ni. $x_{0}$ 


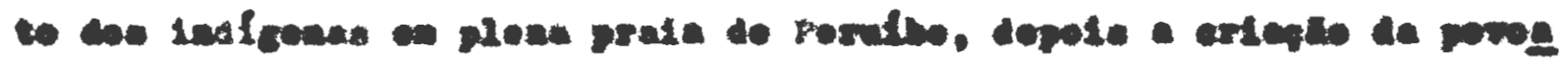

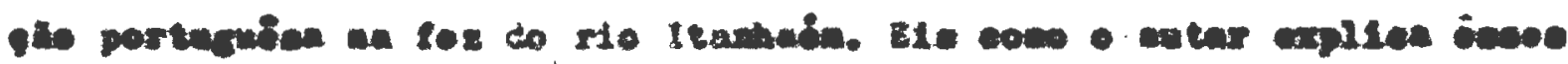

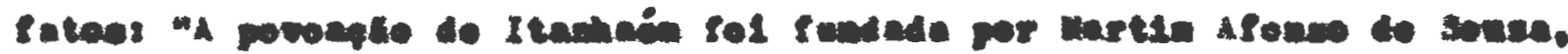

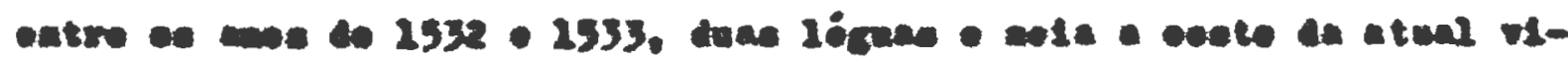

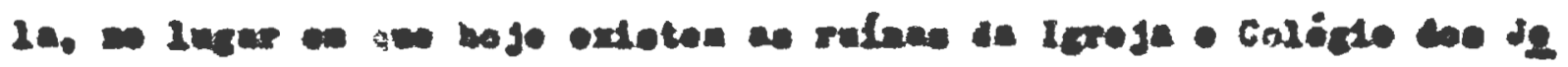

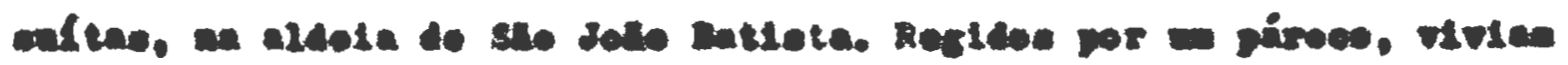

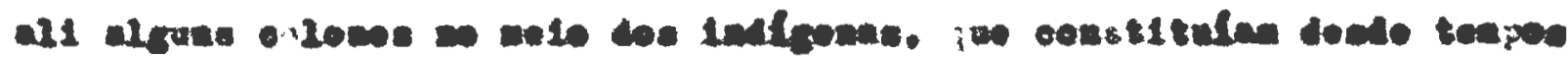

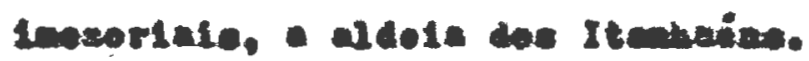

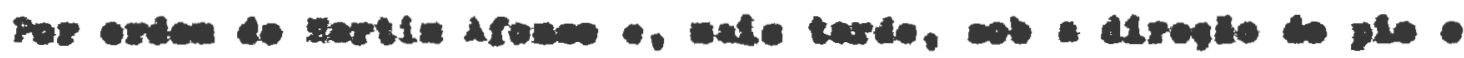

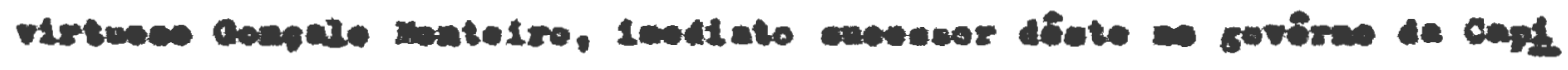

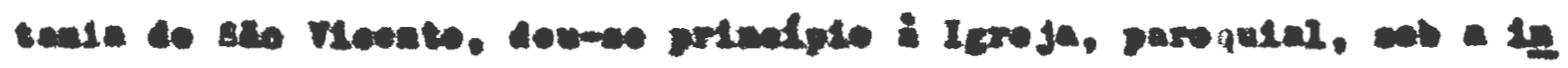

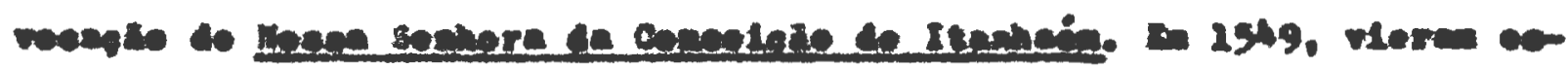

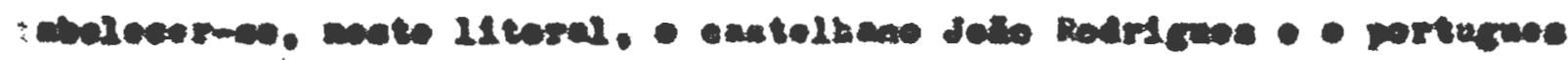

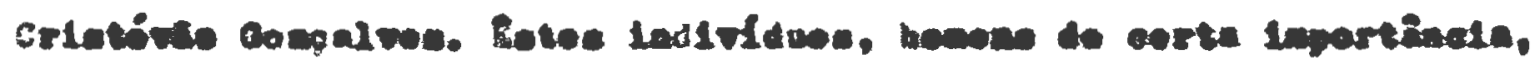

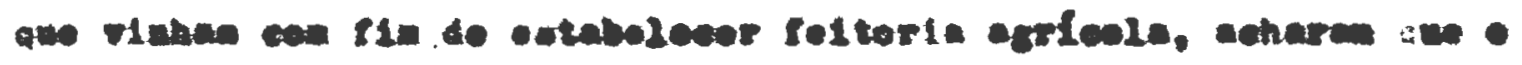

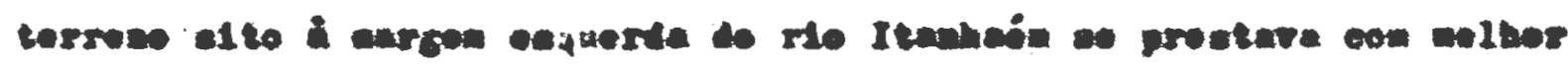

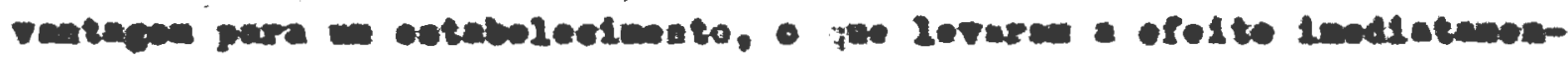
ton (st).

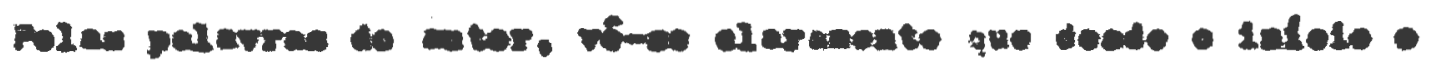

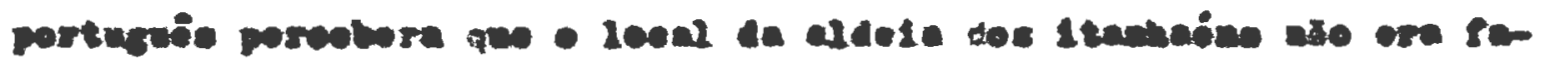

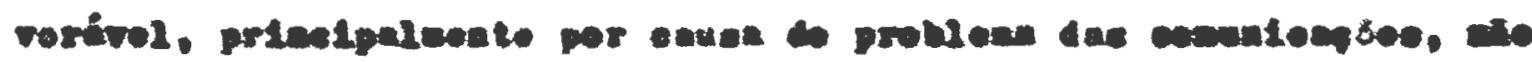

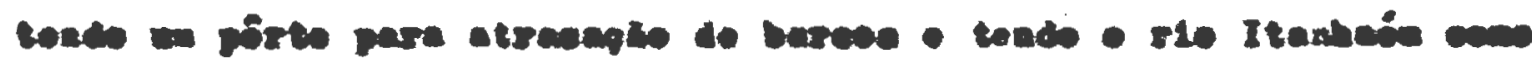

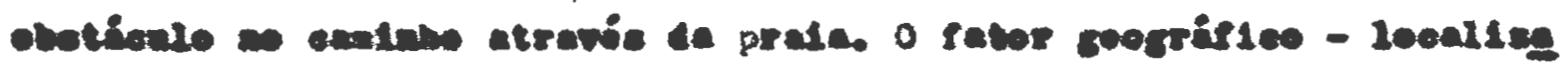

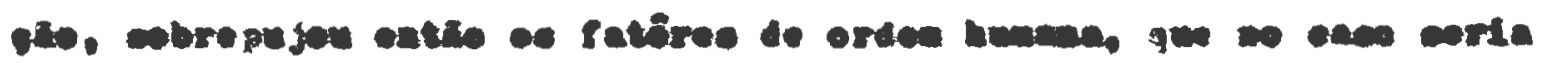

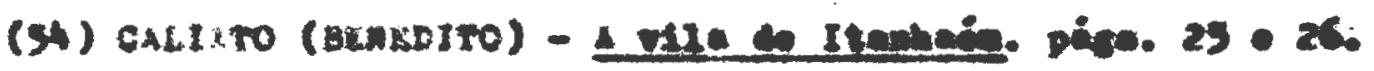




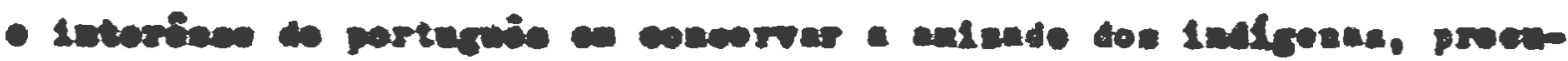

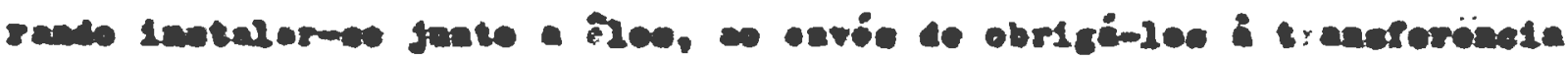

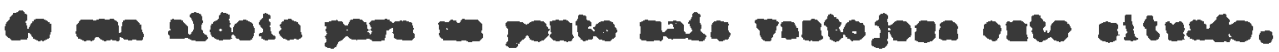

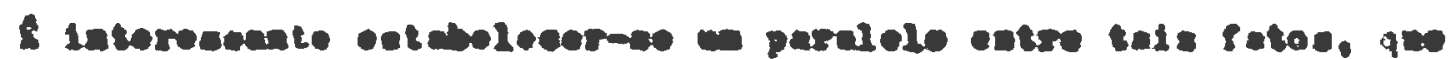

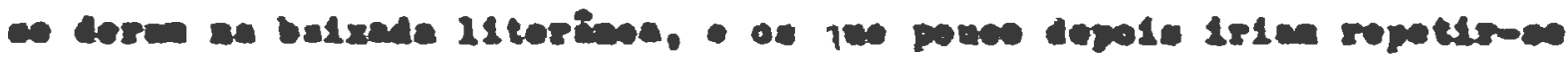

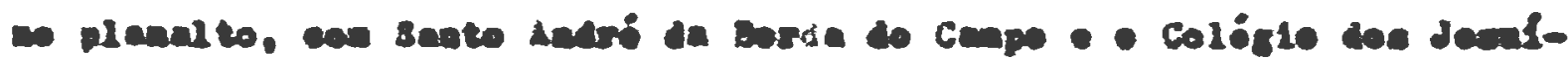

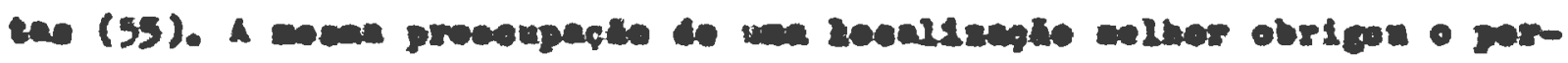

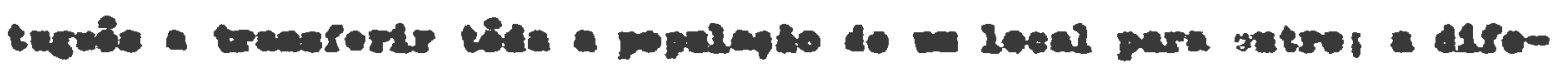

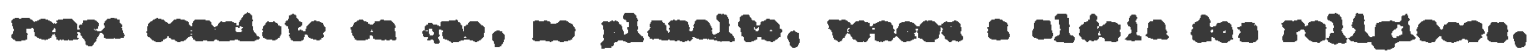

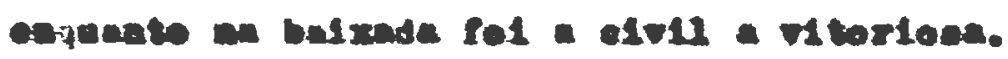

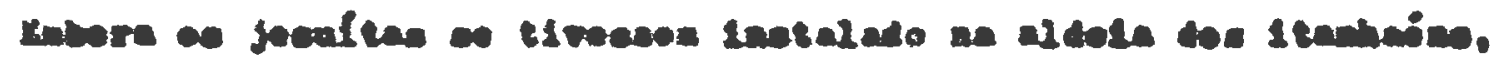

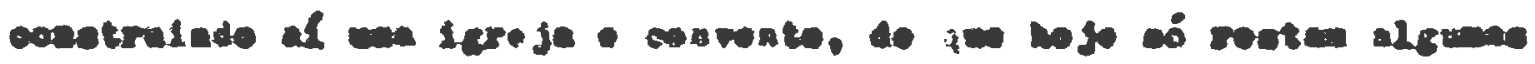

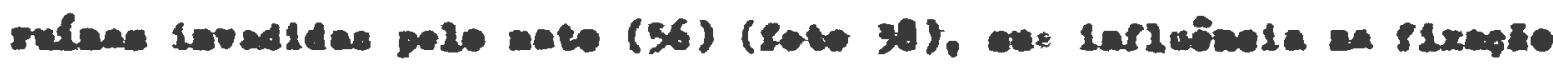

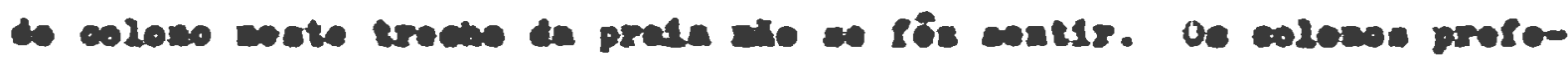

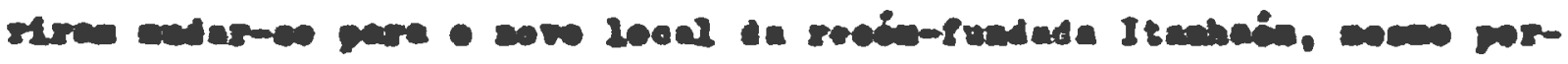

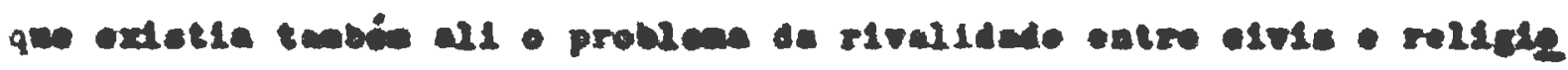

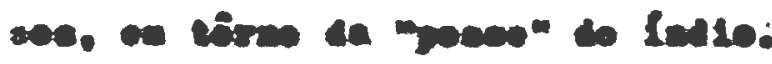

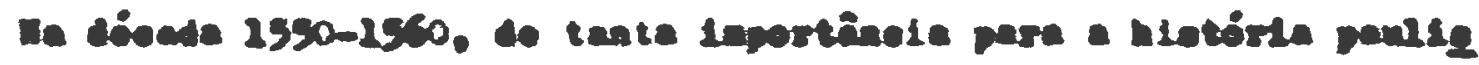

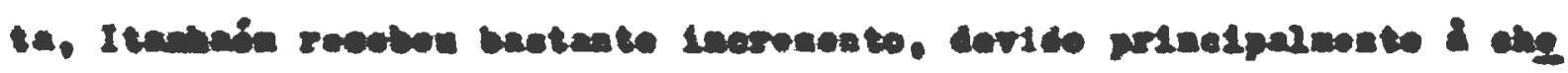

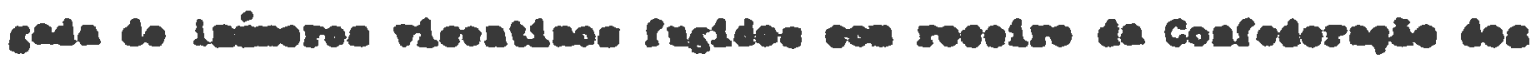

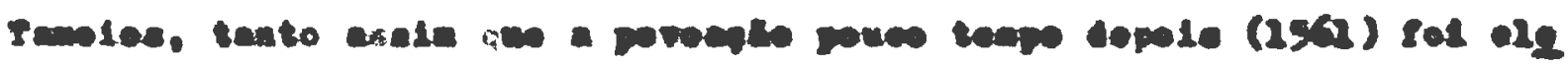

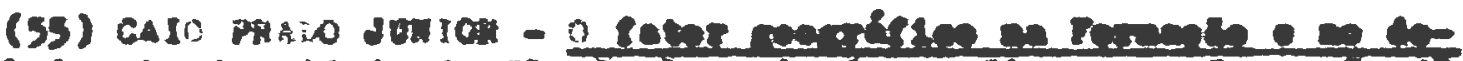

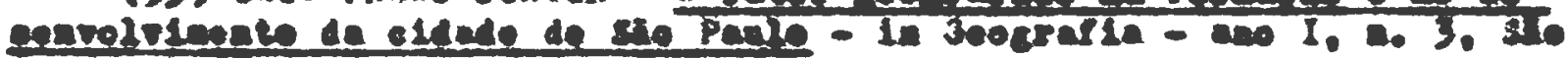
Tanio. 1933.

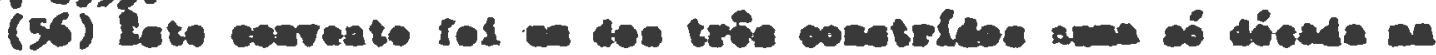

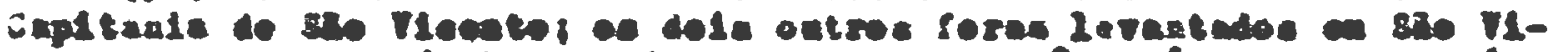

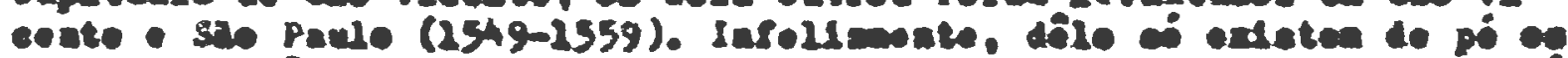

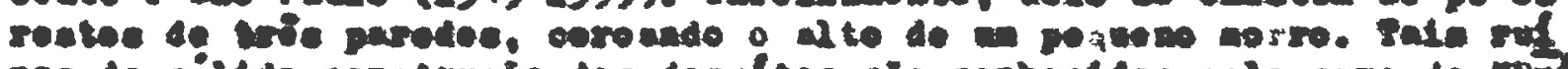

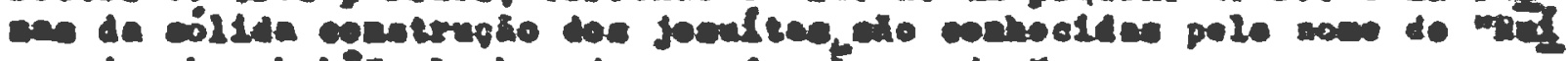

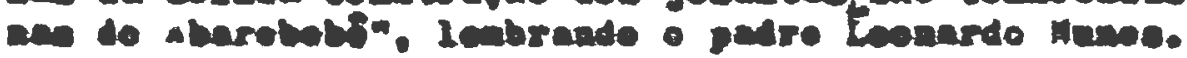




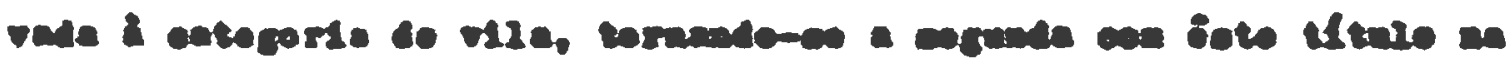
Coptanta de sto Fiante (57).

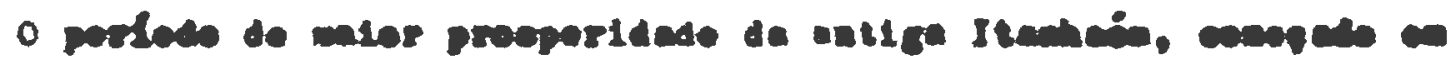

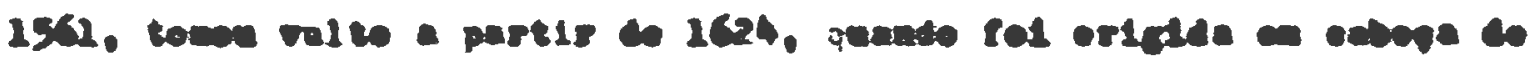

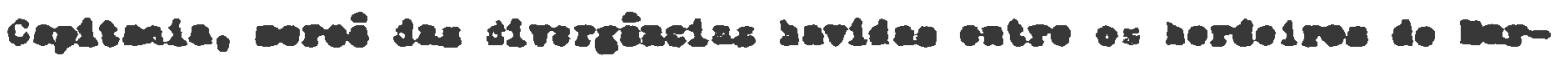

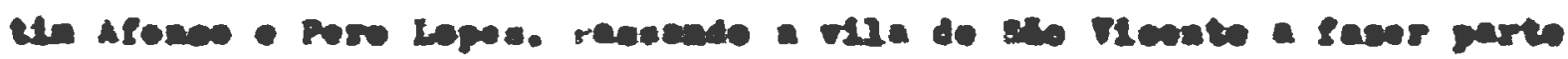

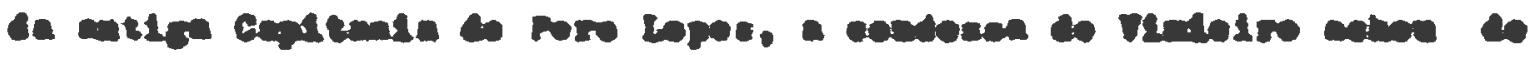

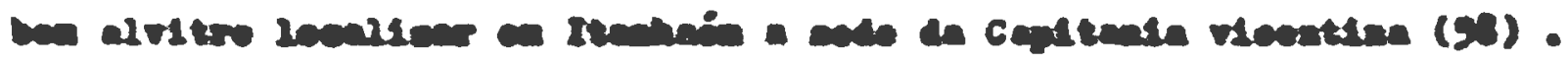

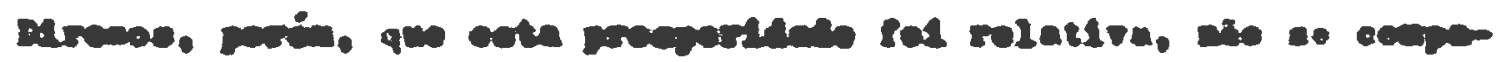

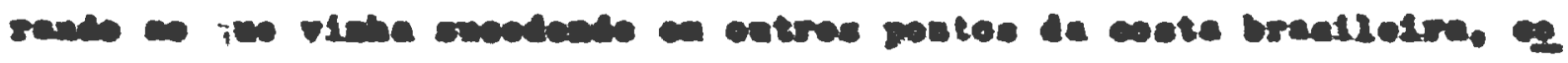

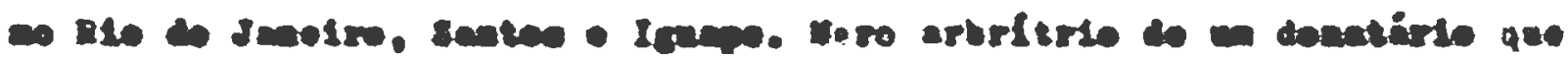

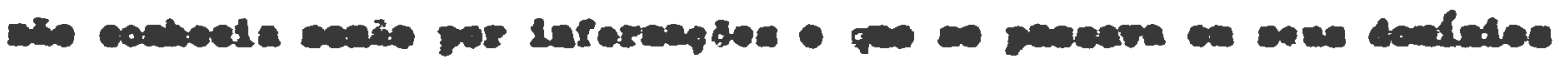

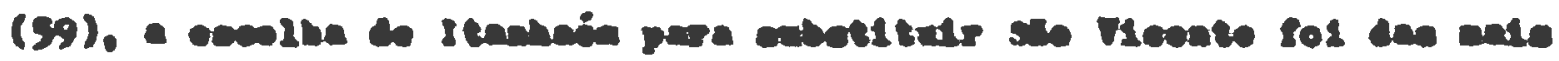

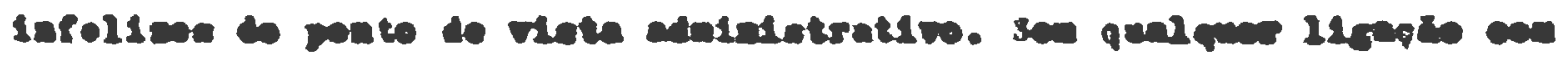

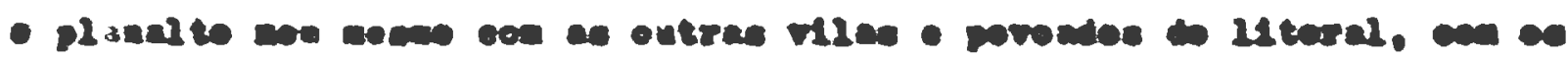

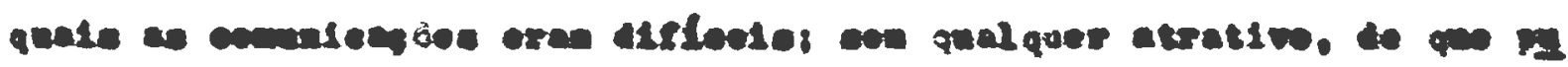

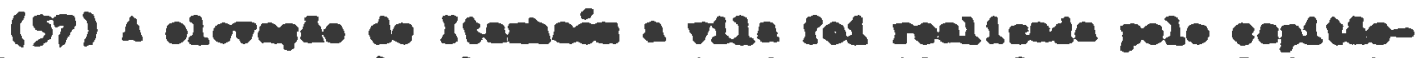

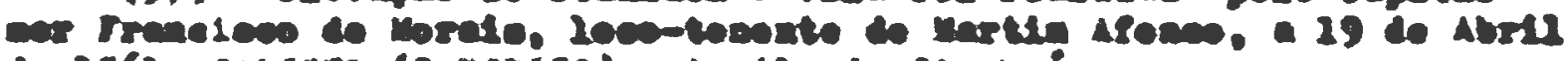

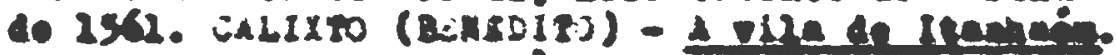

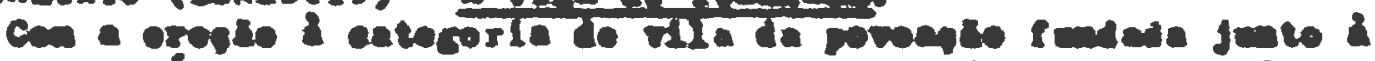

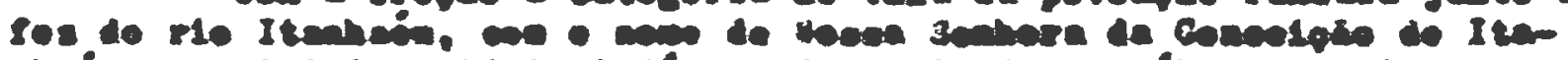

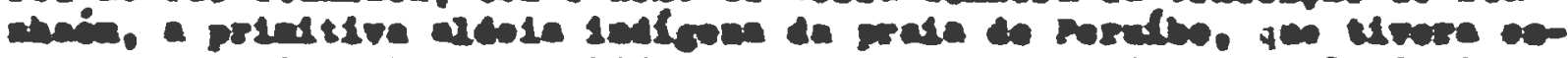

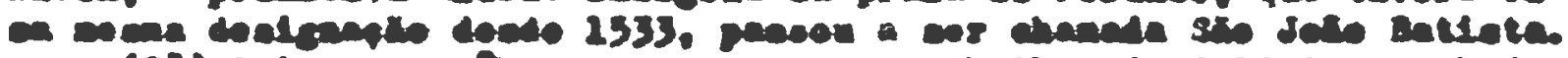

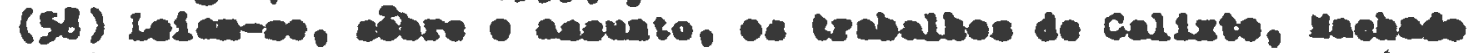

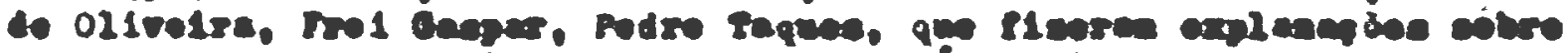

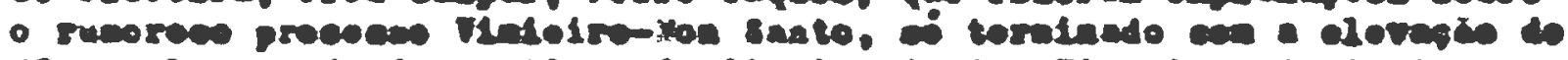

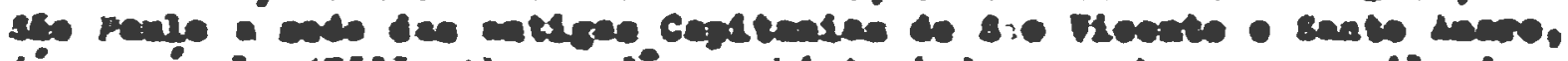

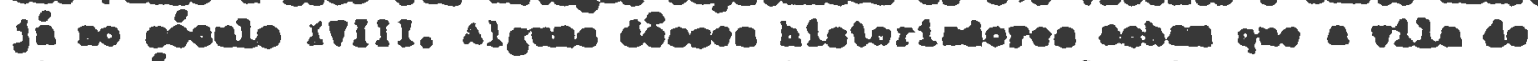

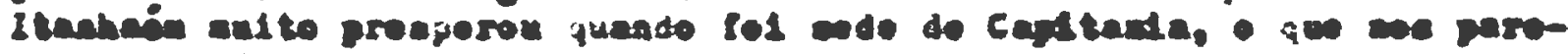
co exacerab.

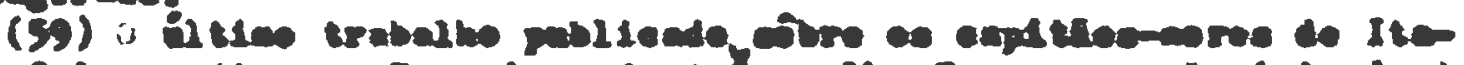

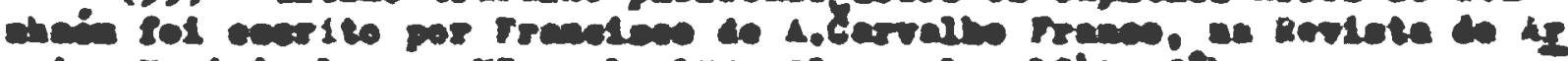

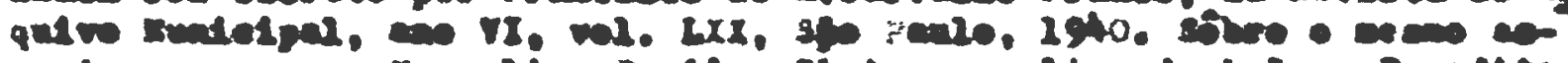

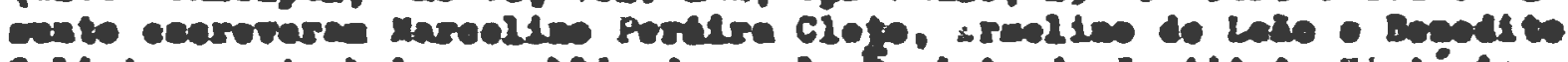

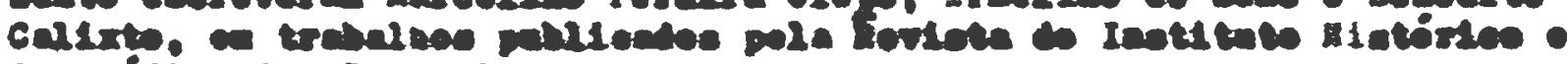
coecróitice de to paule. 


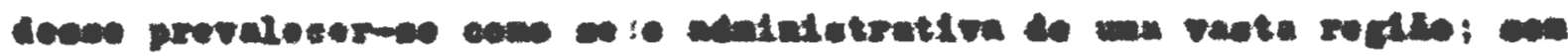

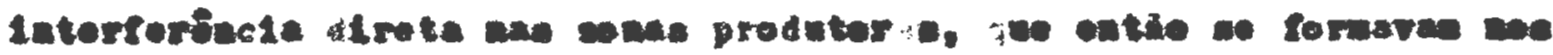

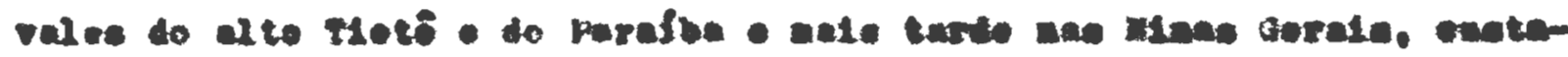

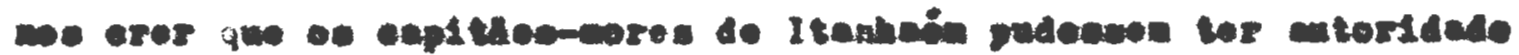

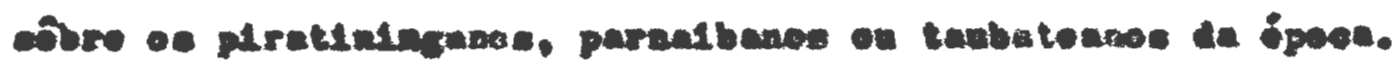

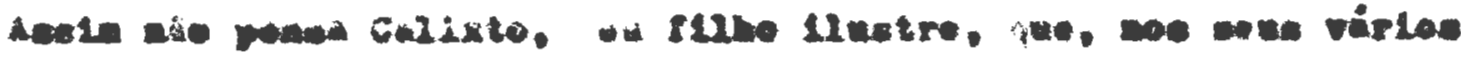

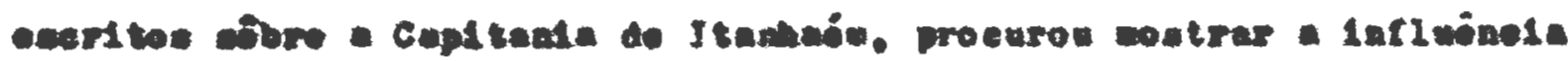

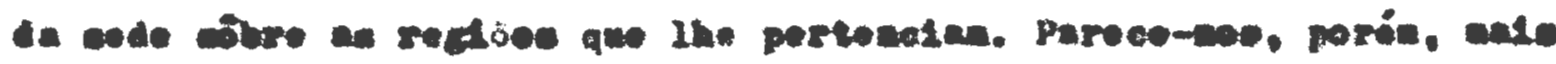

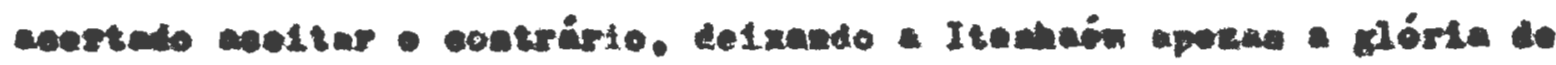

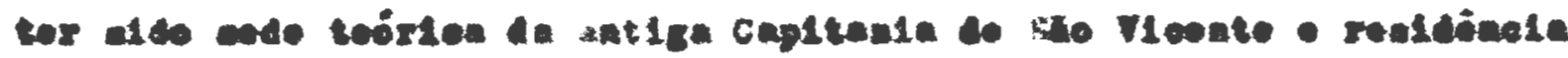

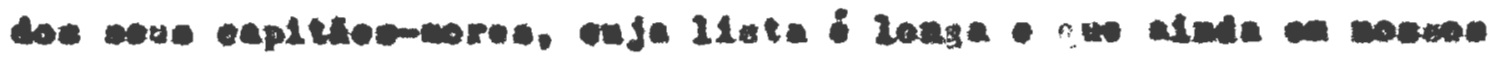

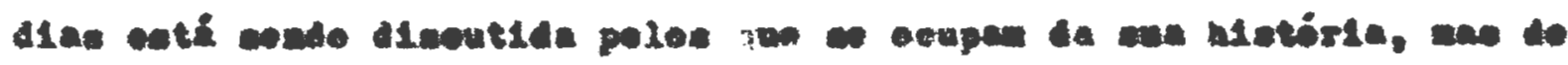

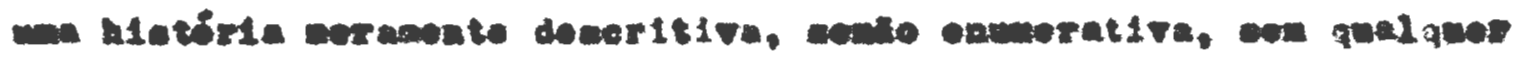
appect Interpatative.

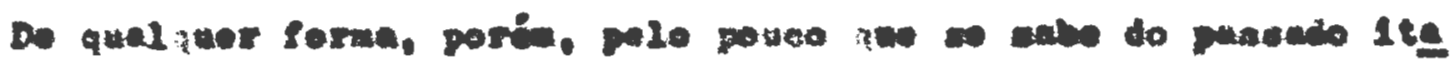

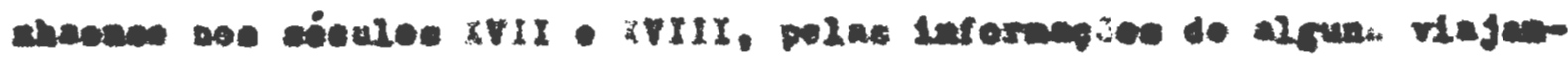

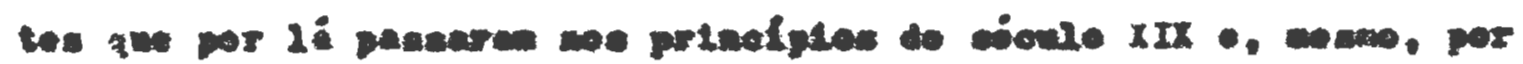

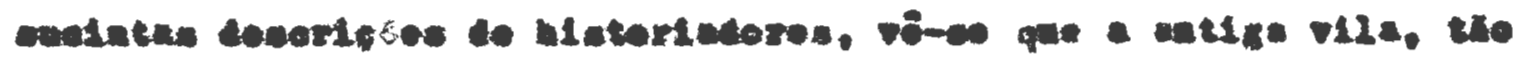

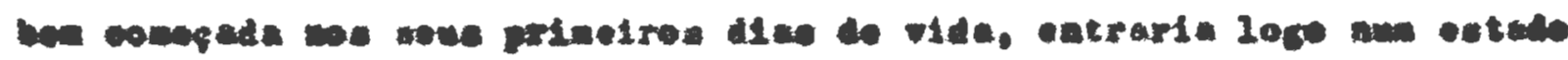

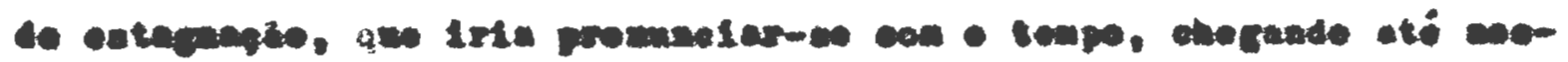
coe disa.

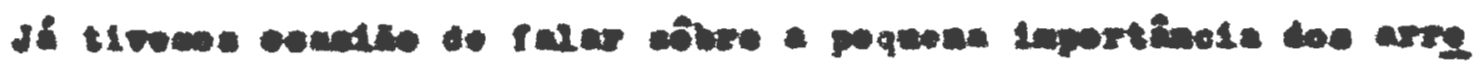

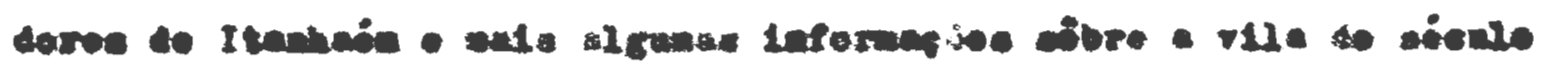

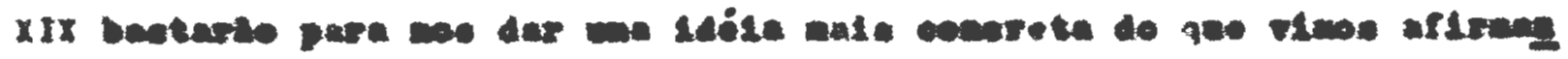

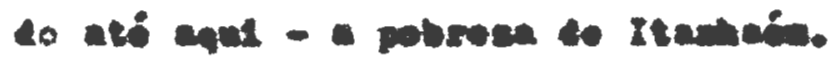

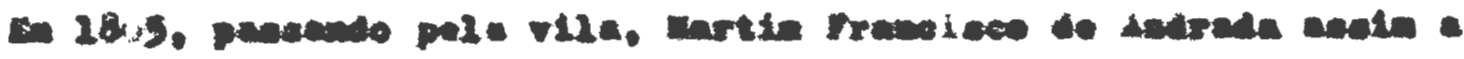




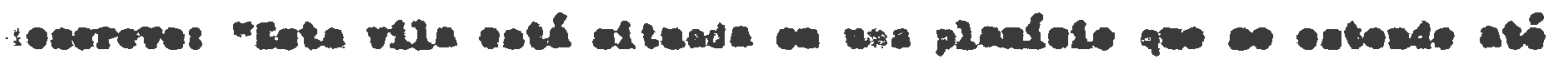

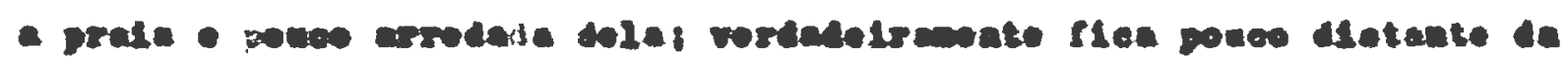

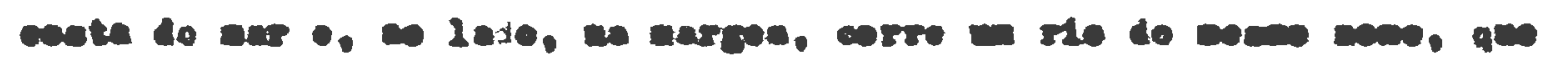

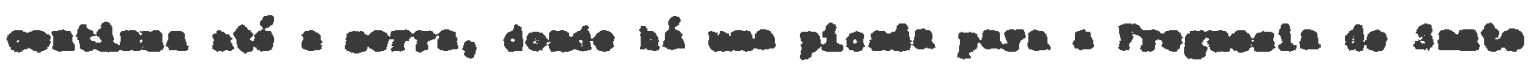

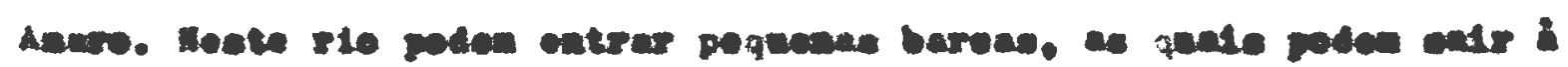

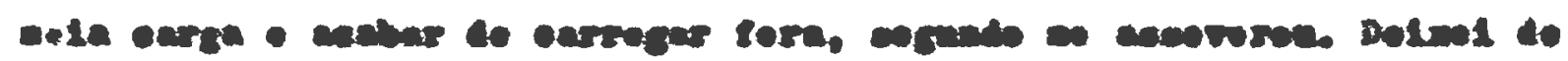

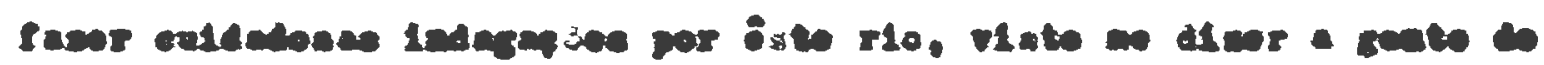

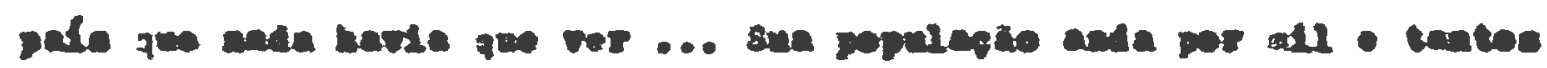

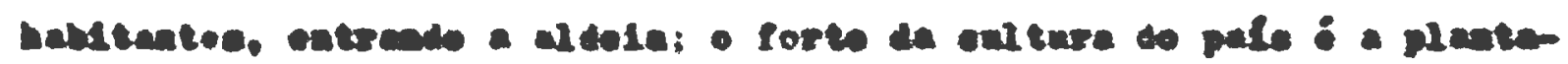

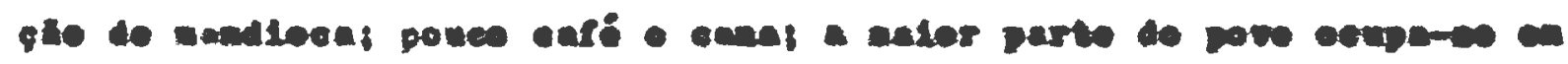

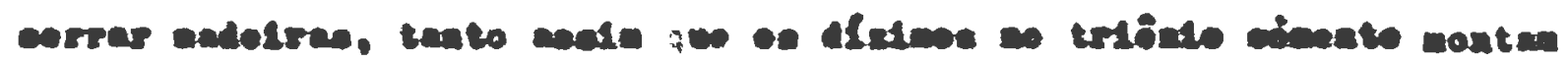

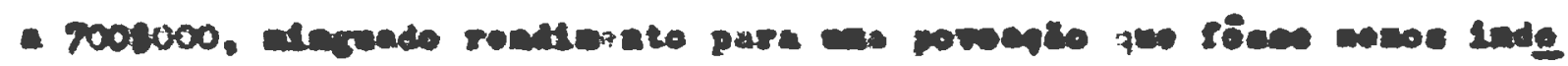
lonte - ande et1va". (60)

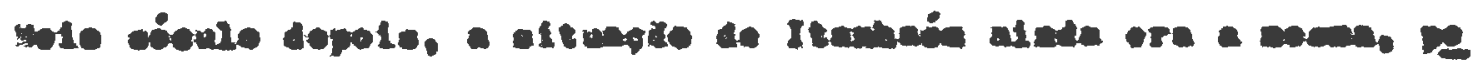

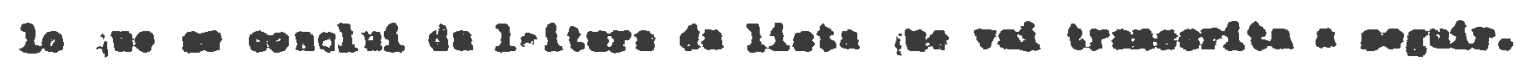

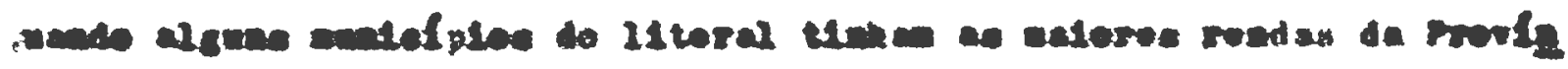

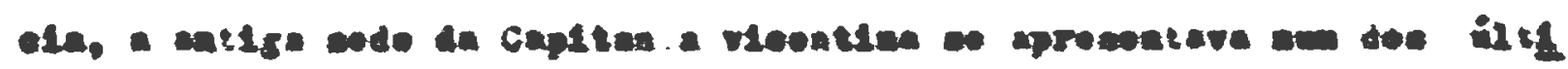
no Iugarees:

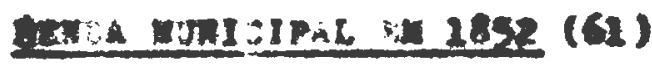

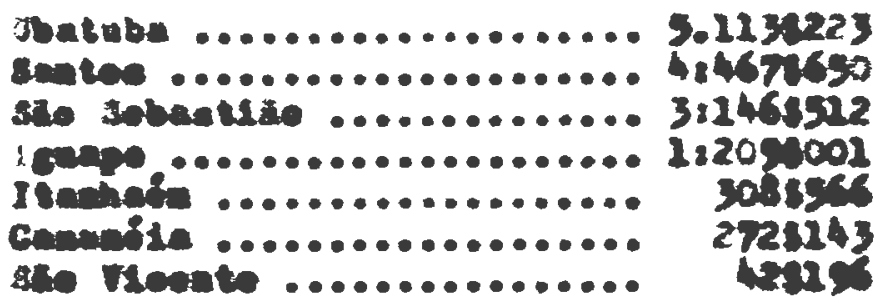

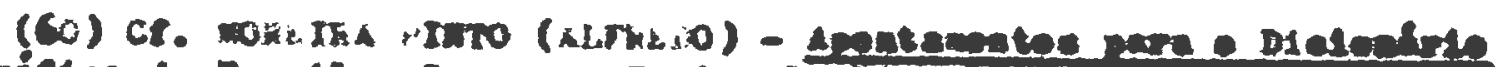

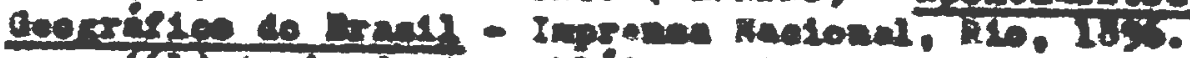

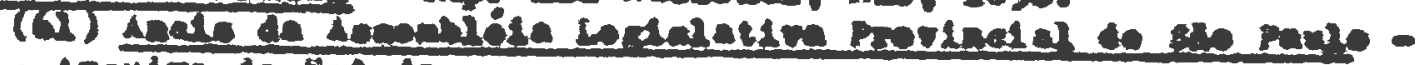
2032 - Naquion do Bat.de. 


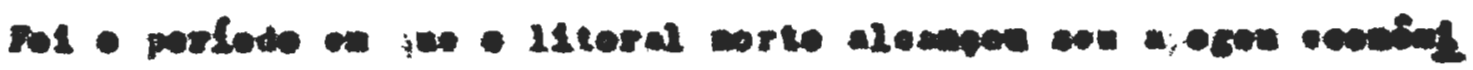

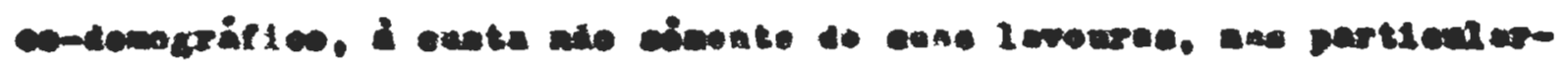

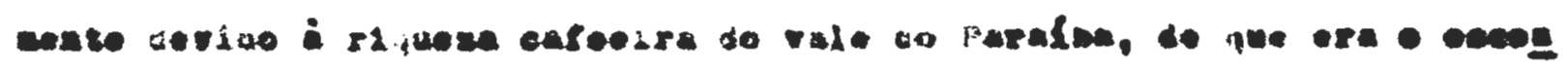

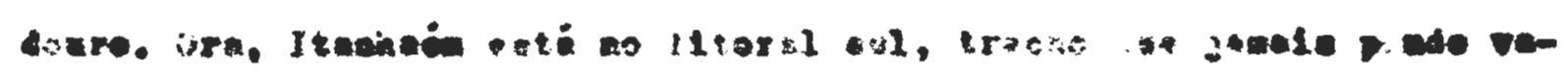

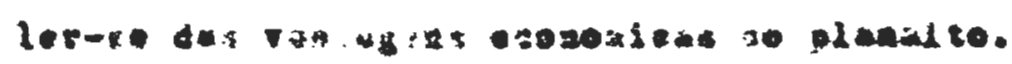

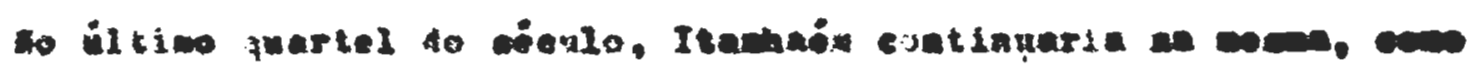

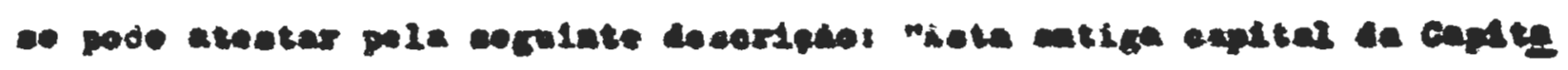

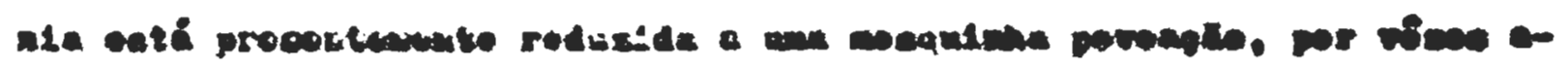

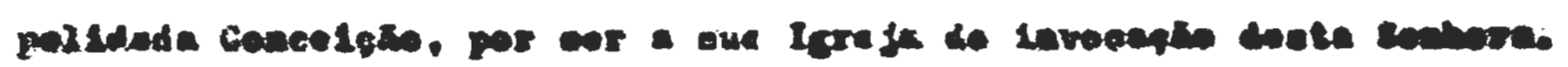

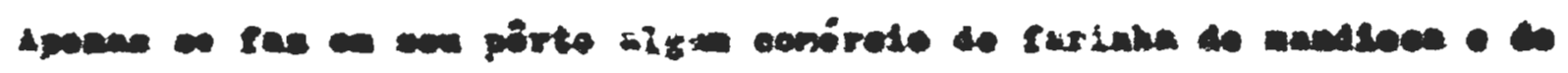
sumedam. (C2).

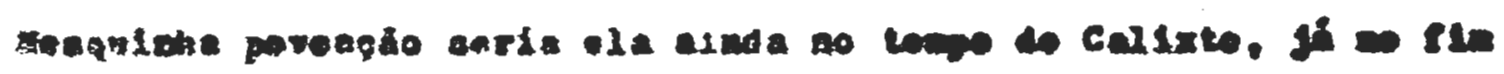

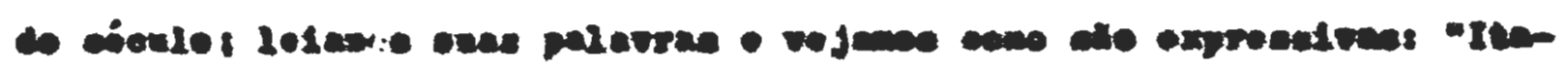

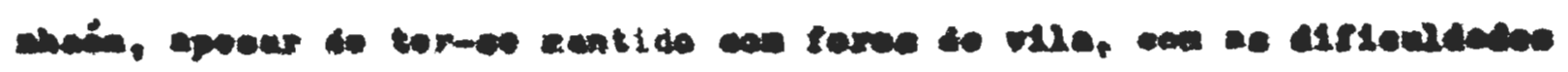

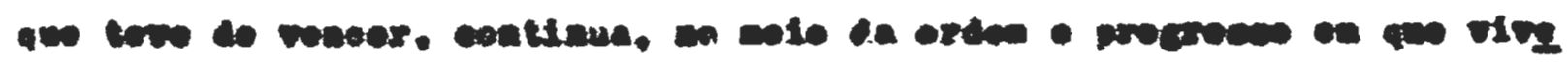

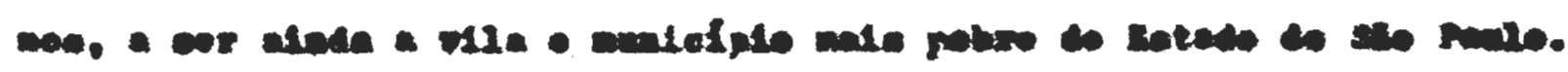

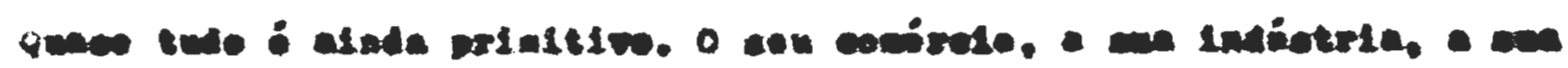

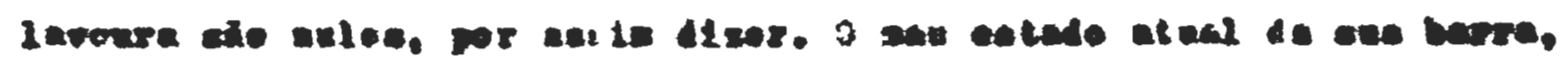

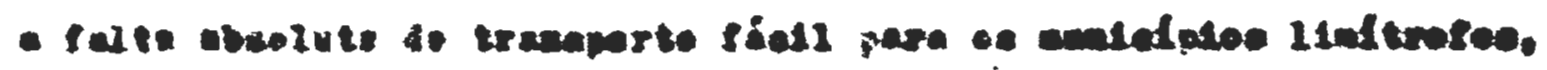

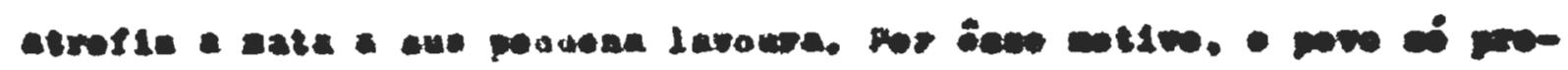

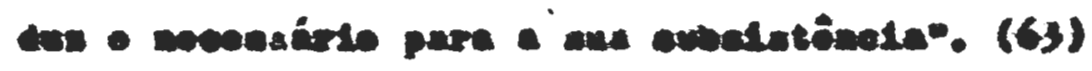

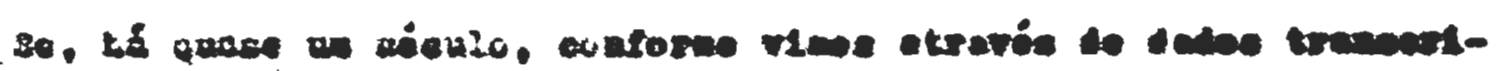

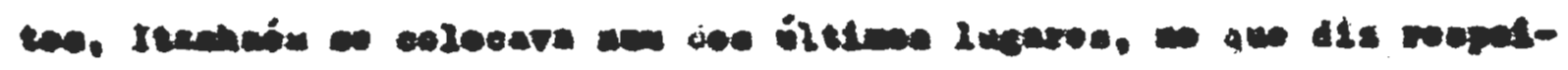

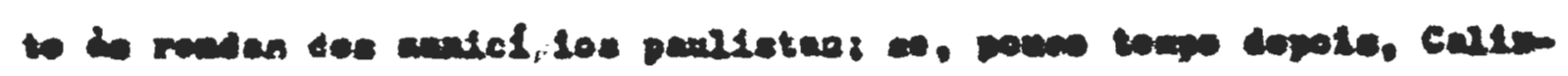

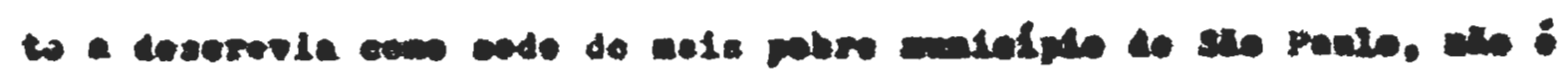

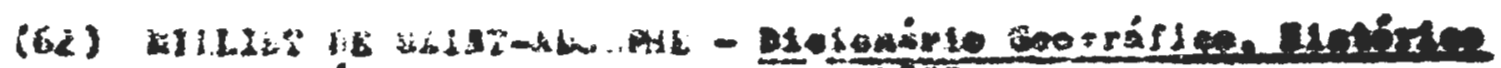

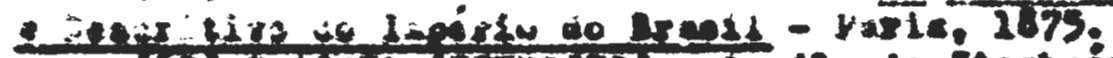

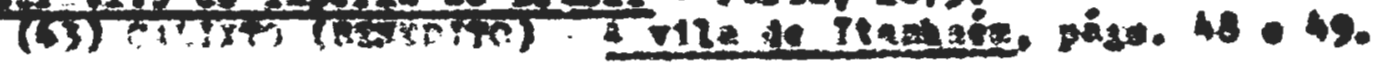




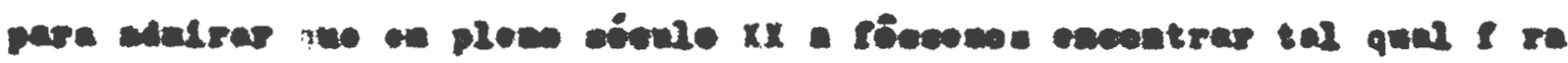

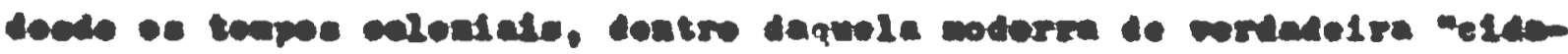
4o morta".

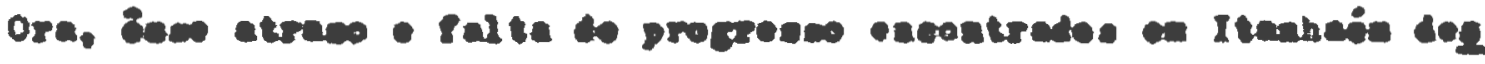

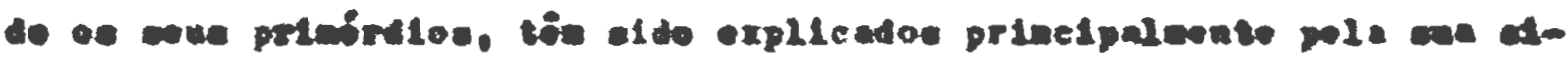

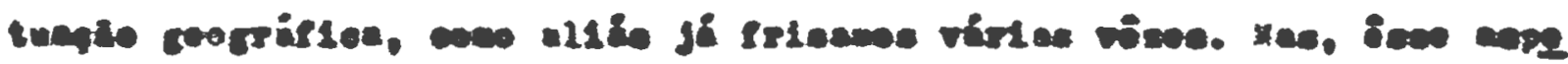

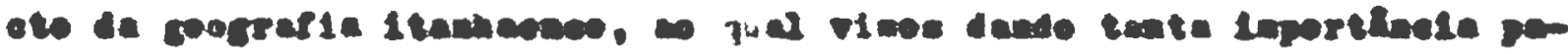

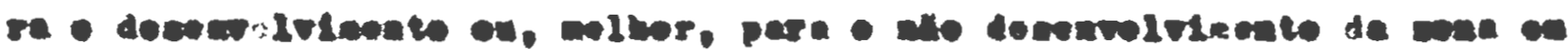

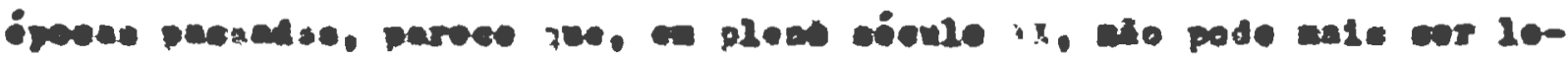
Pado on teate coned dermber

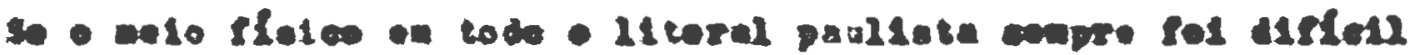

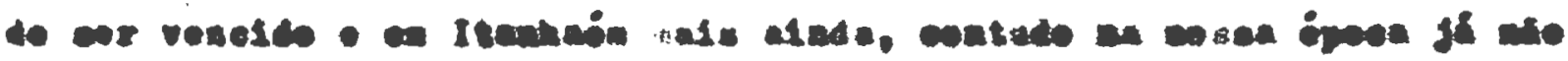

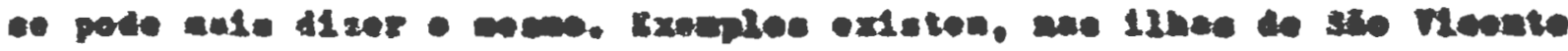

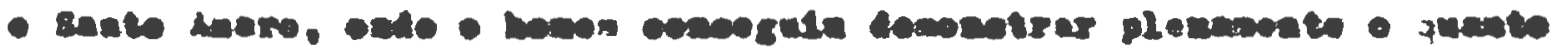

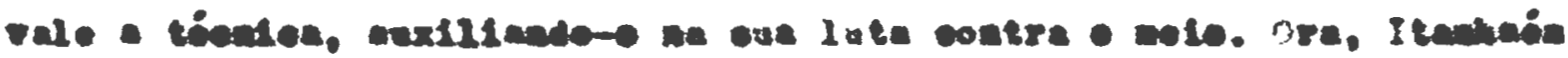

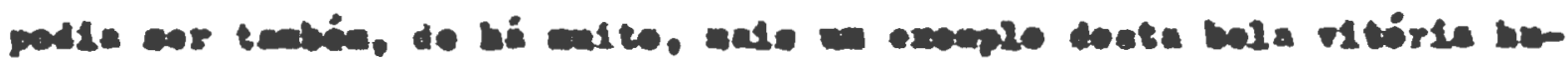

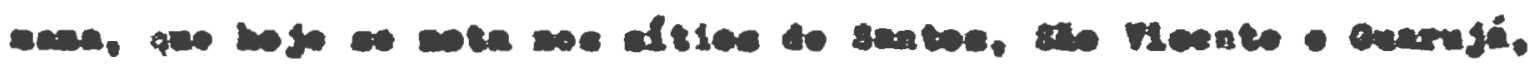

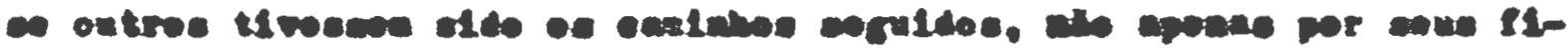

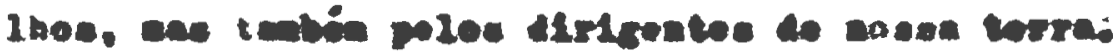

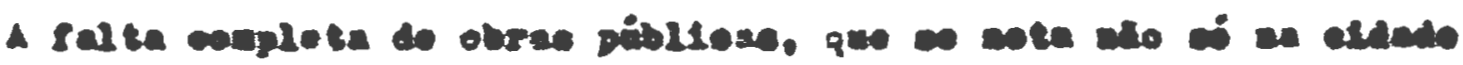

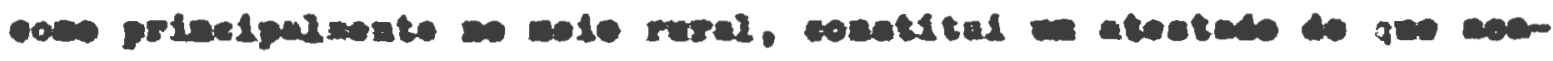

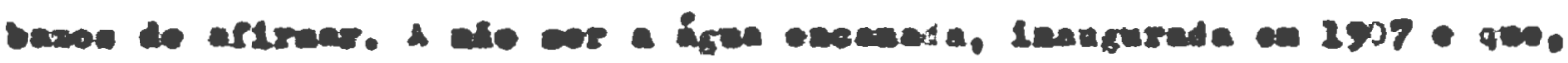

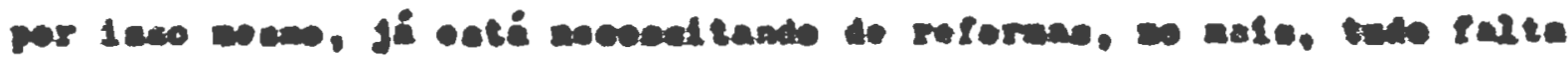

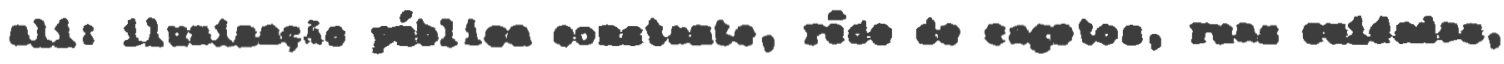

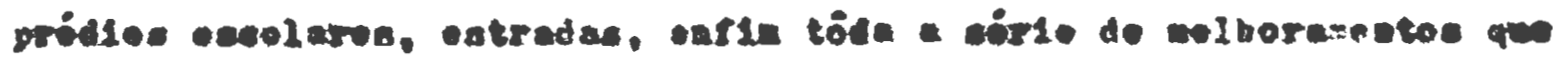

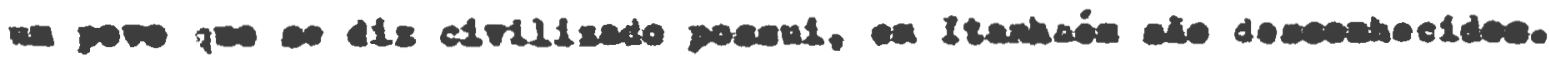




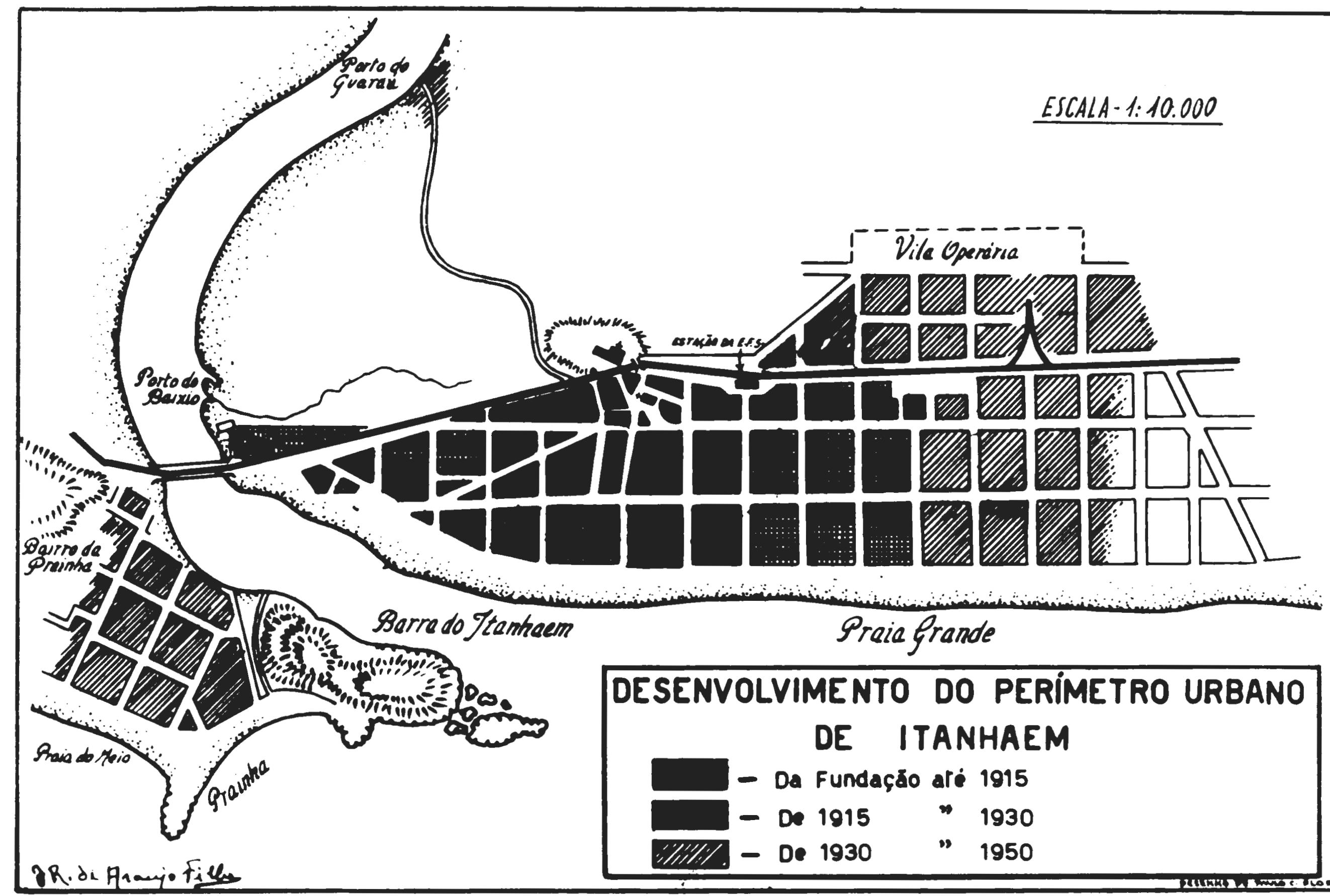




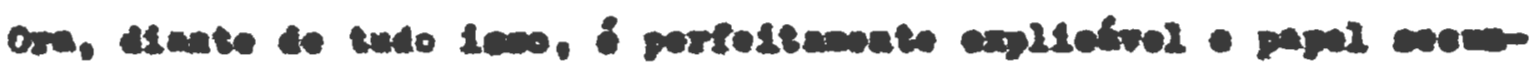

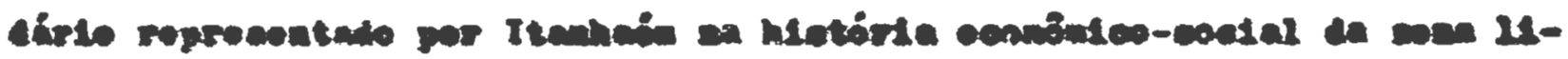

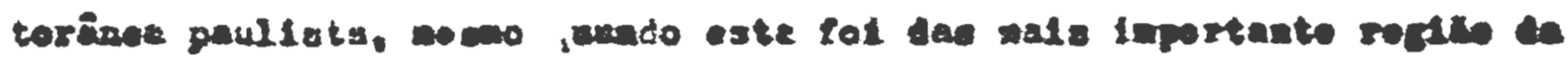

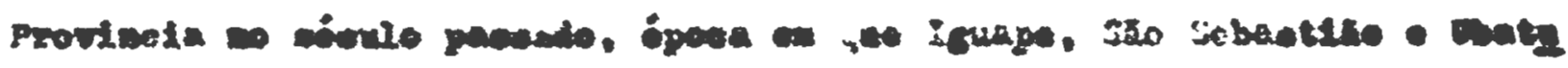

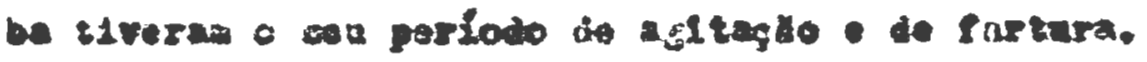

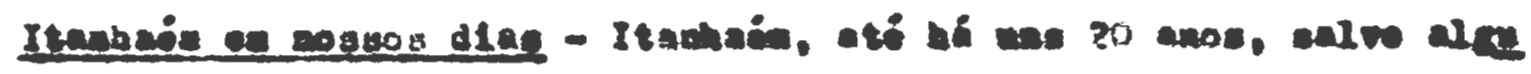

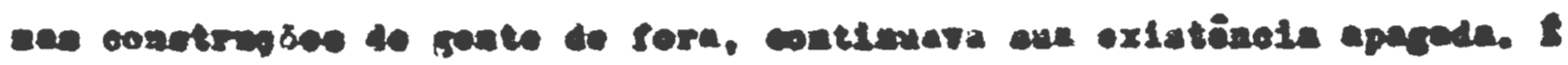

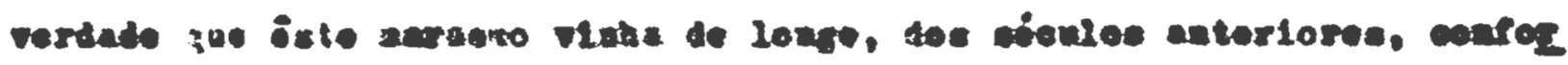

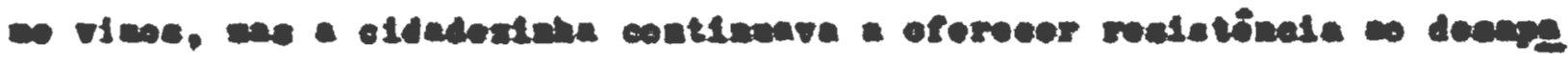

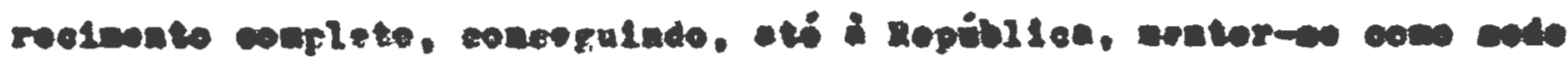

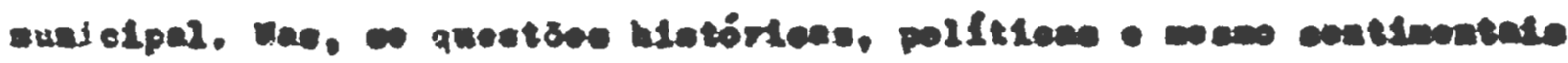

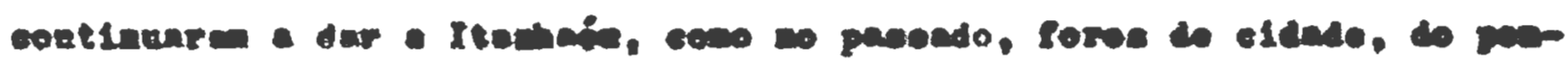

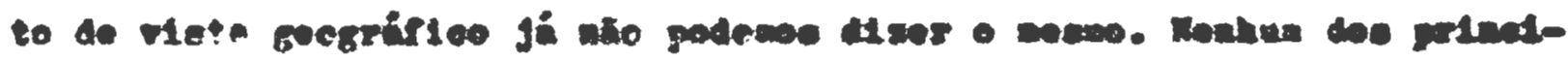

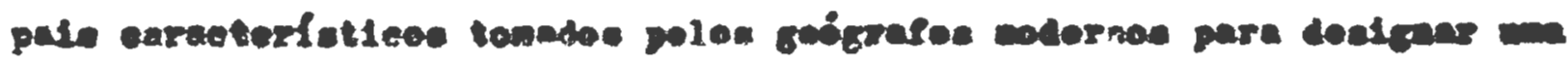
eldade (64) oxiate all.

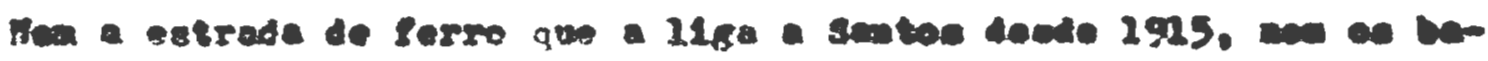

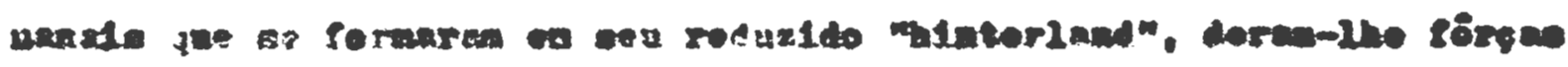

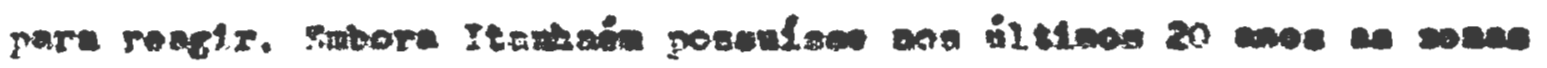

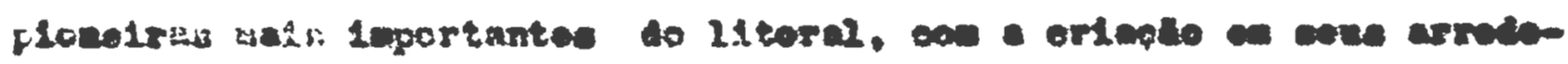

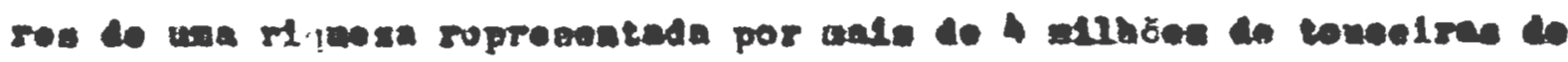

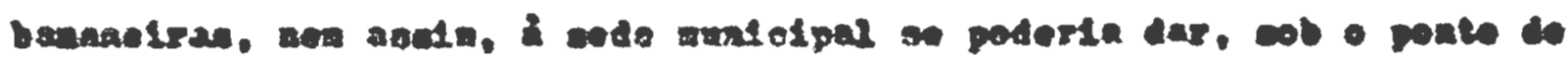

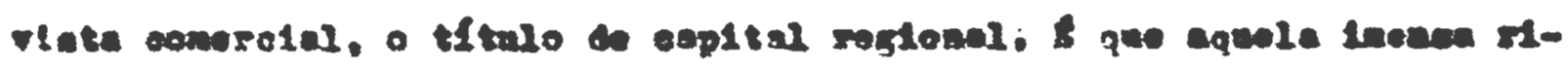

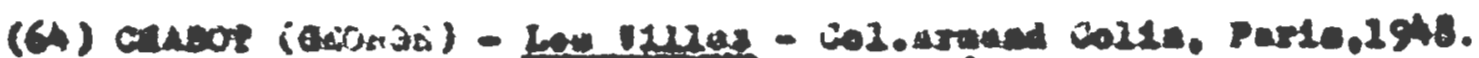

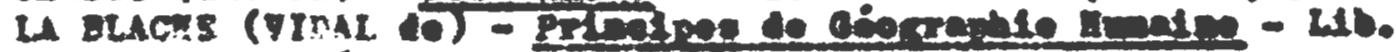
drand colla, iaris, 1936.

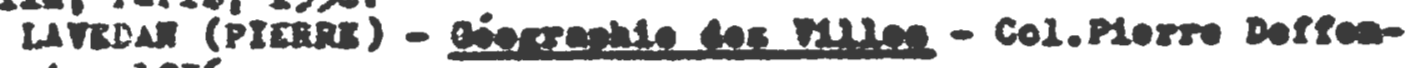
taleof, Deste, 1936. 1. 1929.

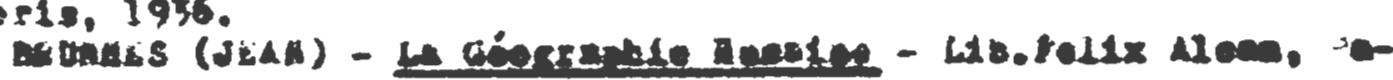




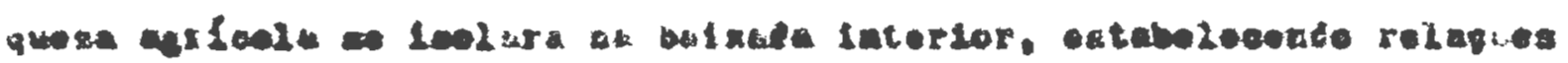

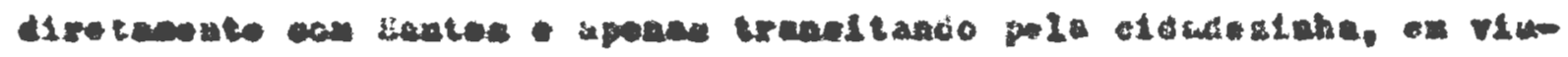

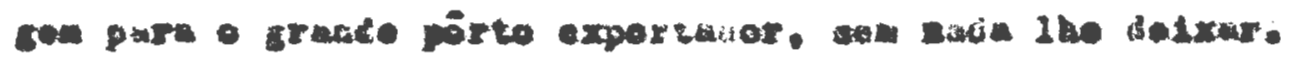

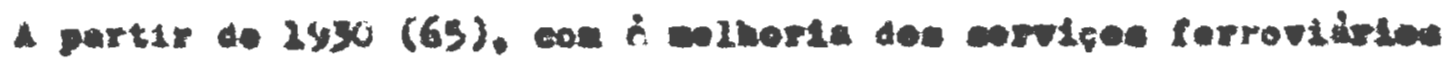

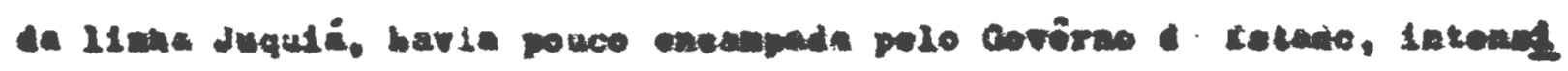

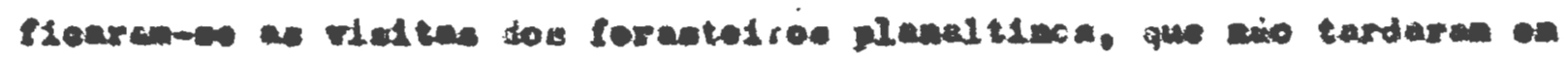

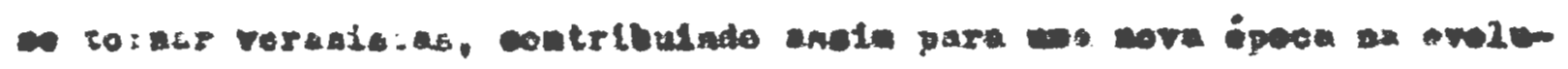

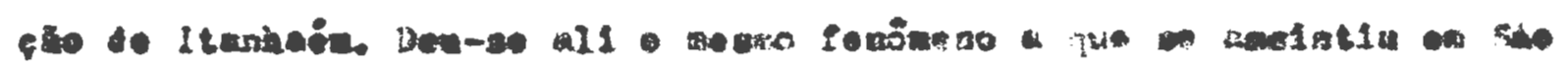

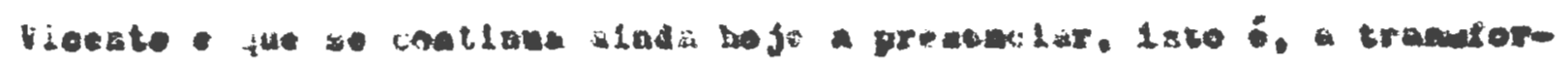

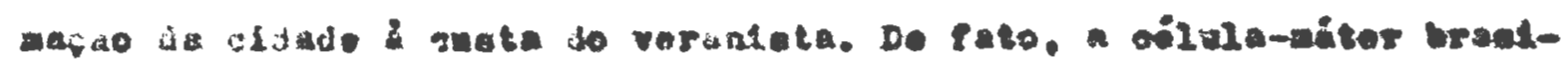

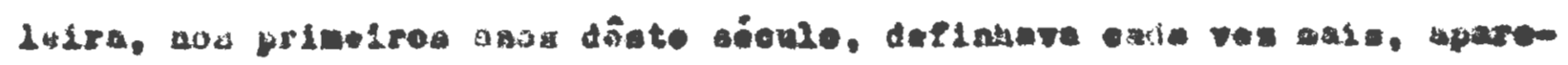
Eeado en oonilo os iautente procirsac.

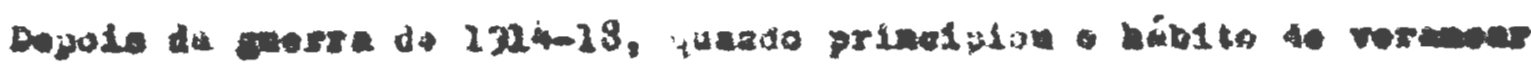

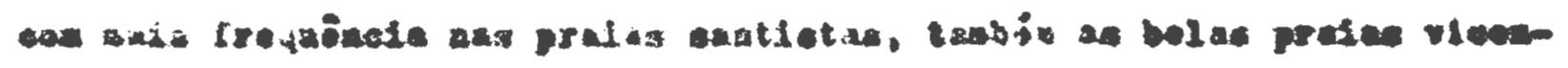

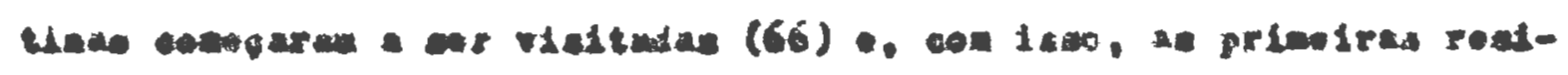

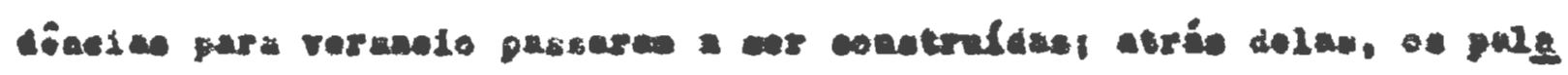

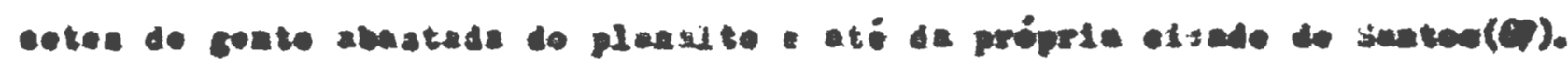

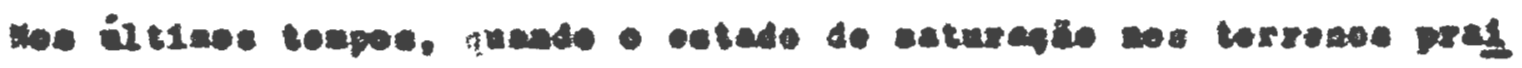

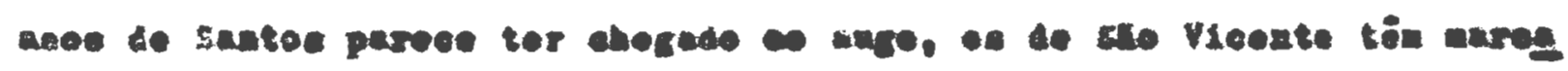

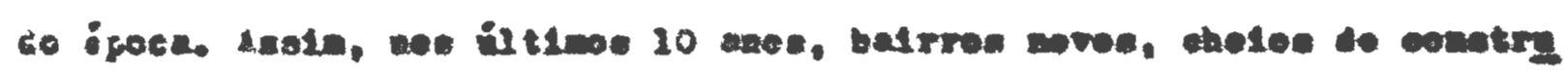

(65) Antee de 1928, an on we covirno do Entado oneanpon a for-

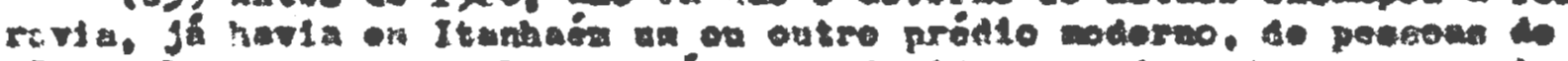

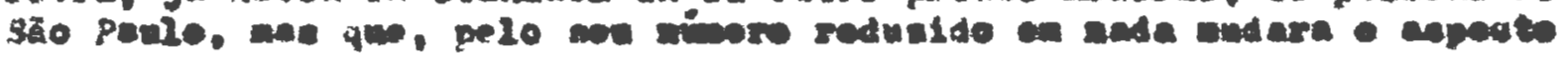
i eliede.

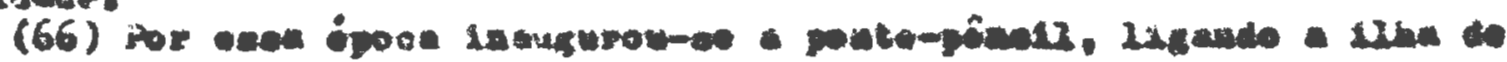

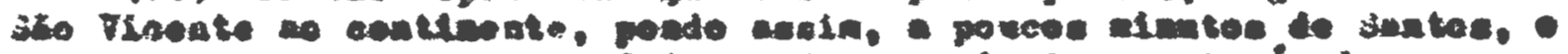

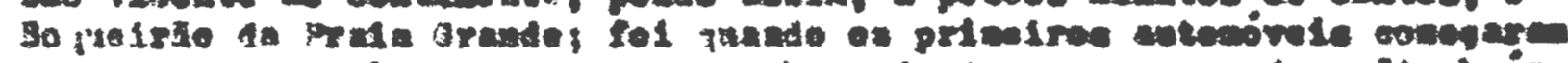

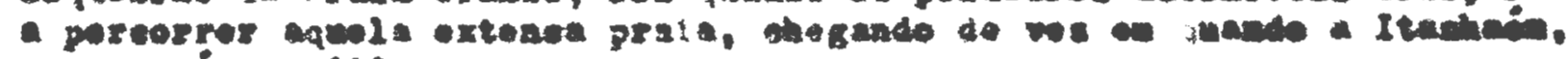
- a auro parmitisen.

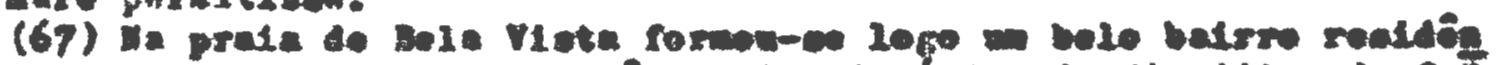

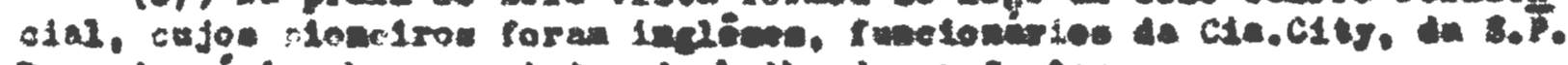

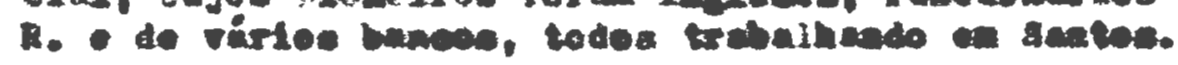




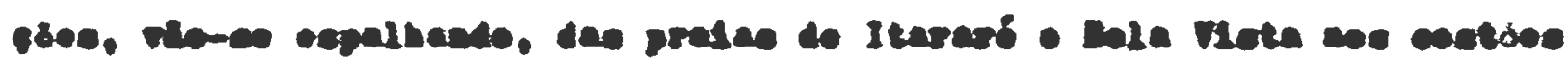

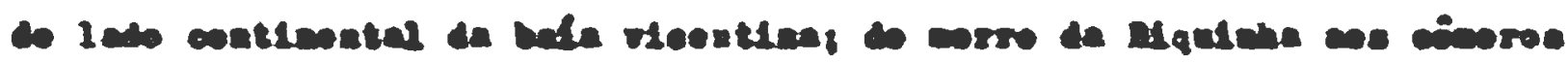

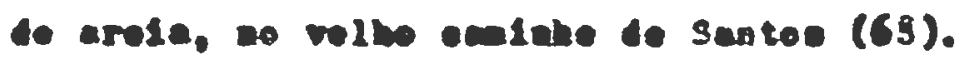

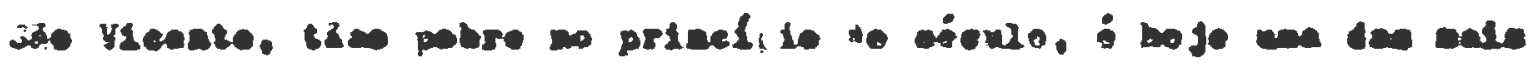

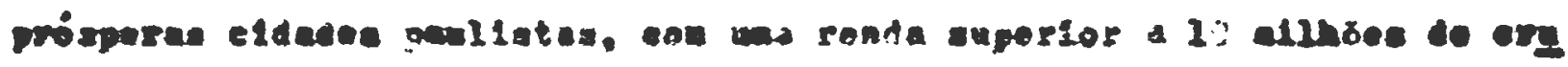

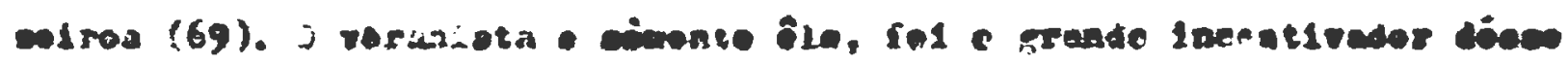
reanasingente.

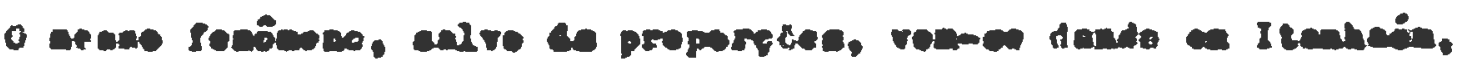

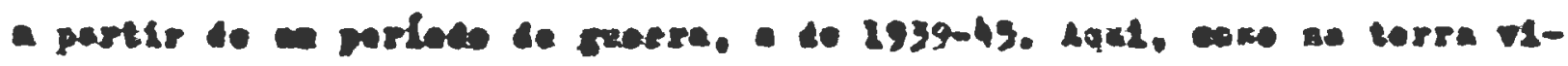

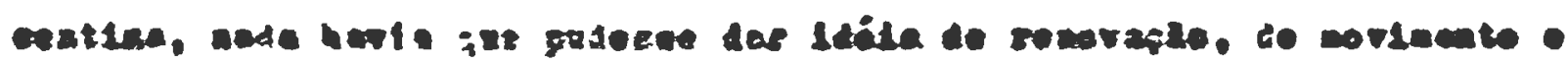

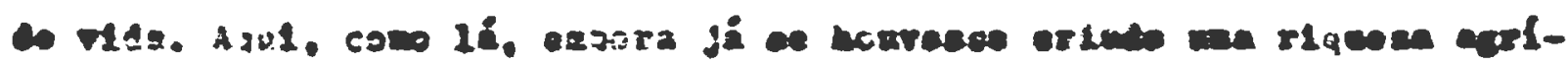

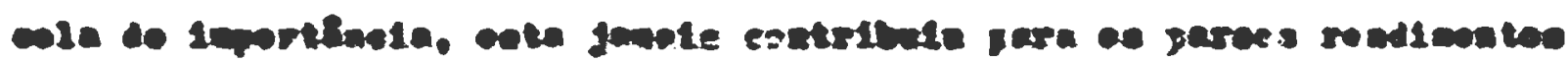

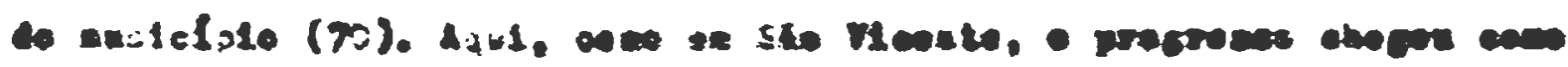

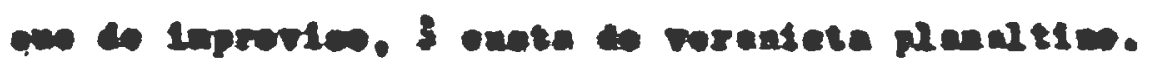

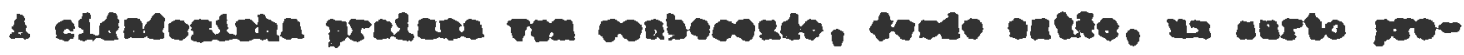

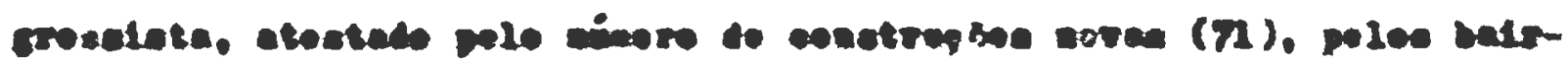

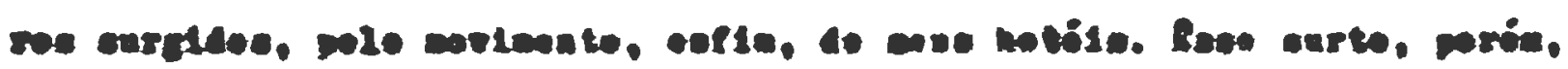

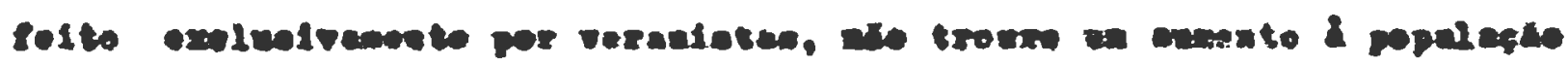

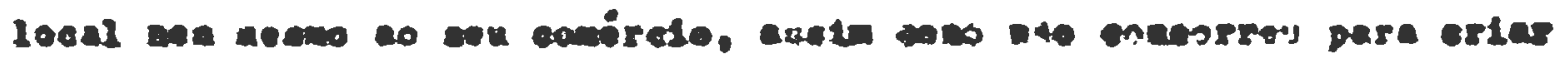

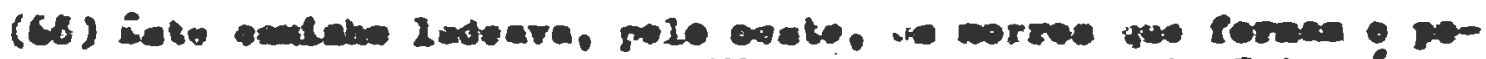

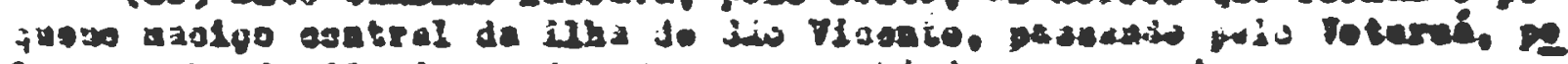

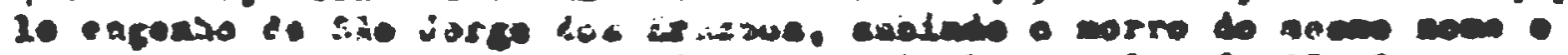

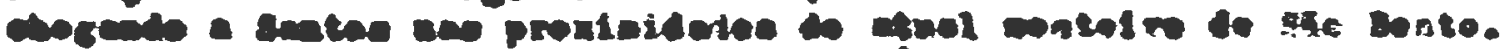

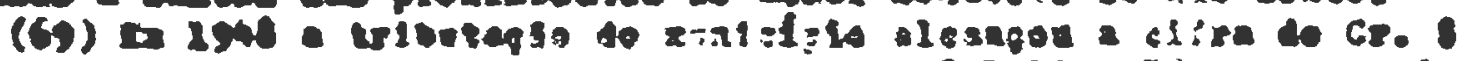

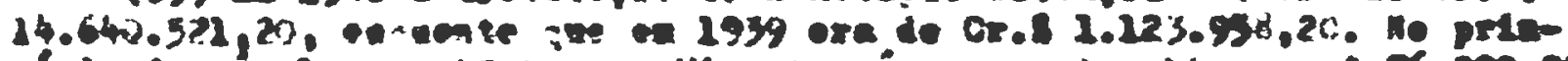

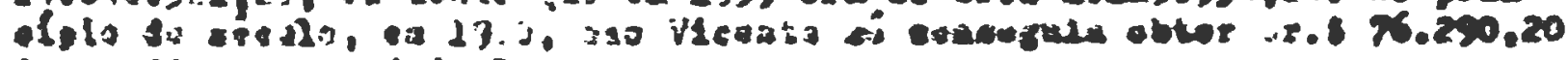

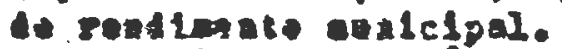

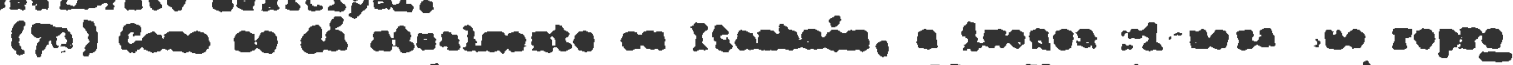

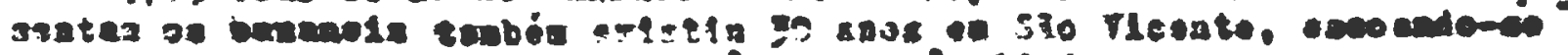

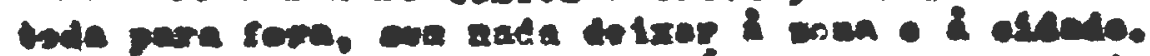

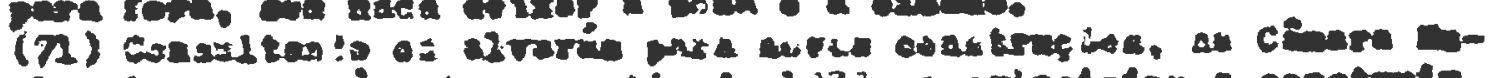

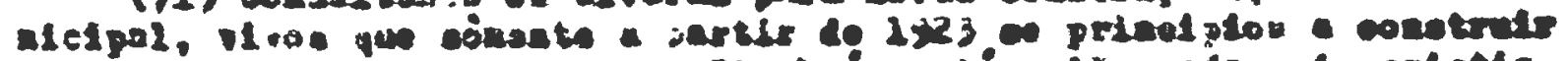

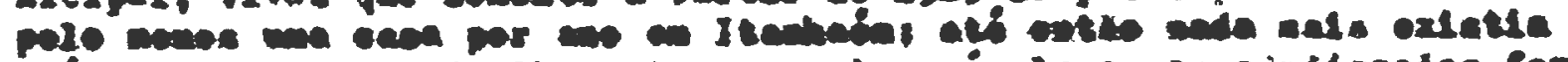

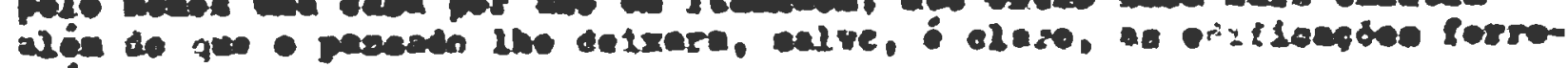
atione. 


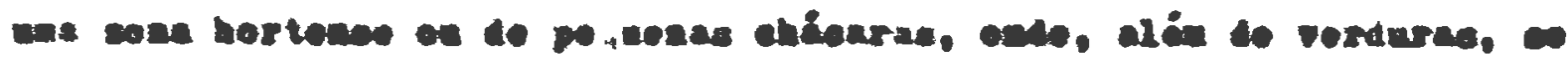

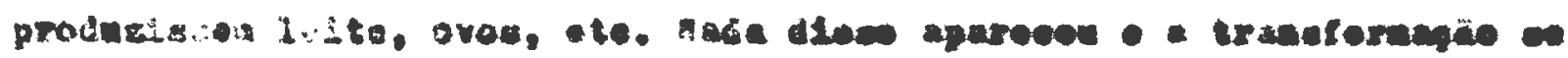

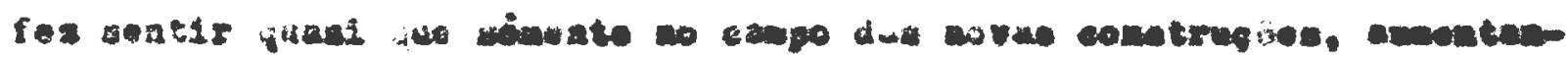

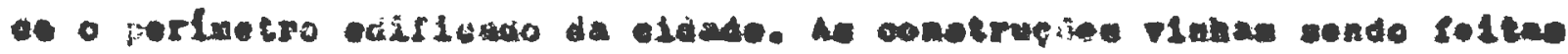

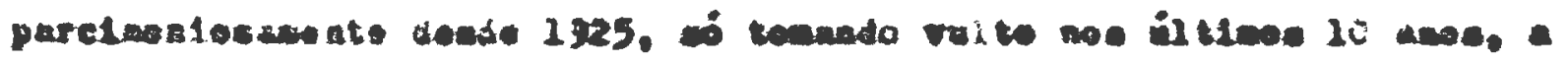

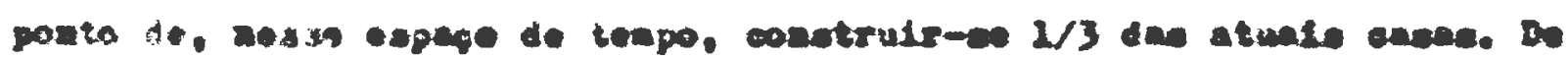

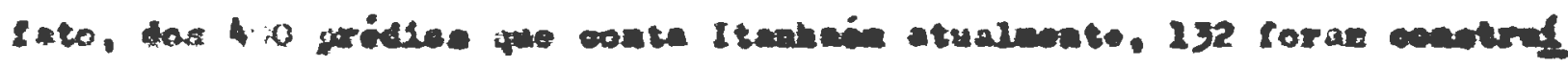

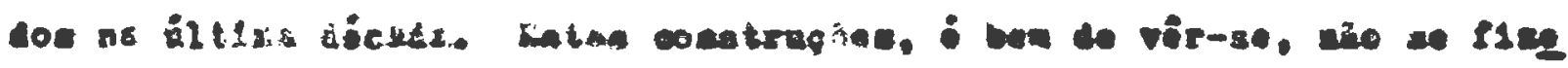

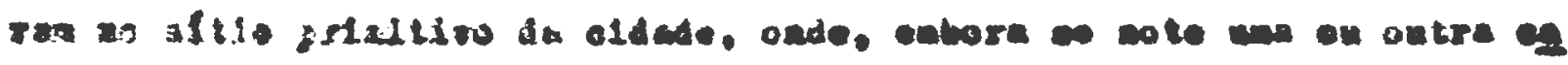

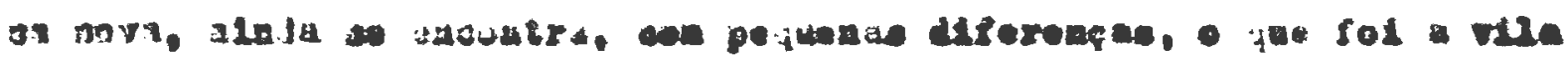

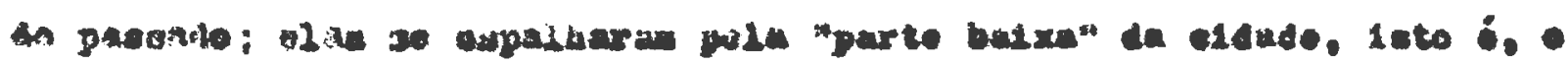

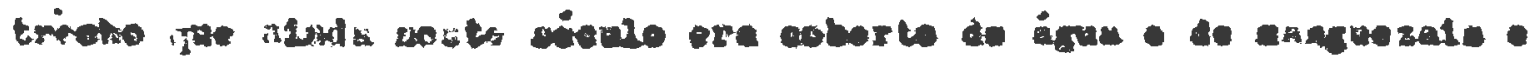

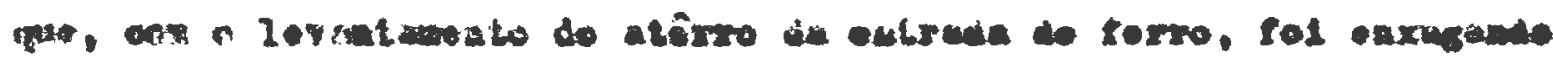

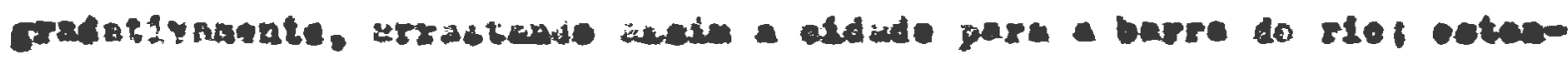

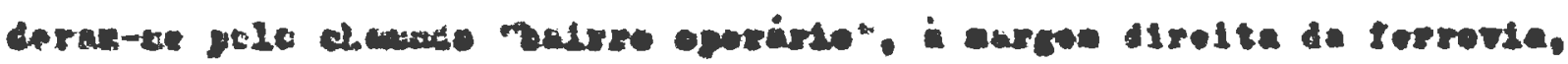

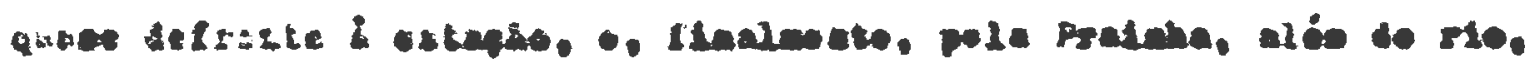

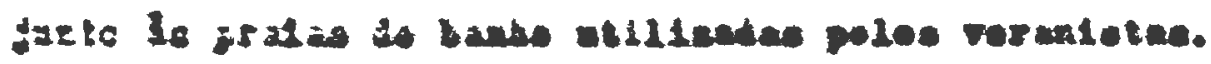

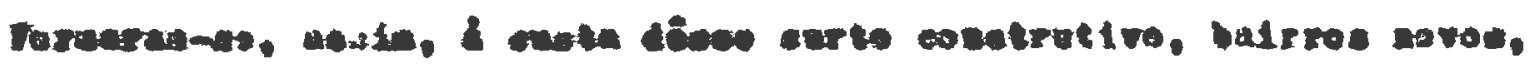

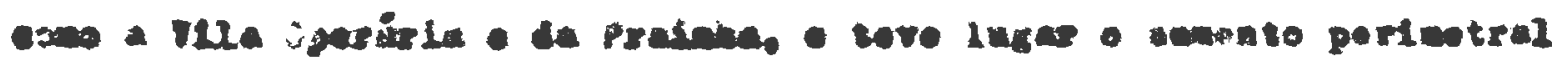

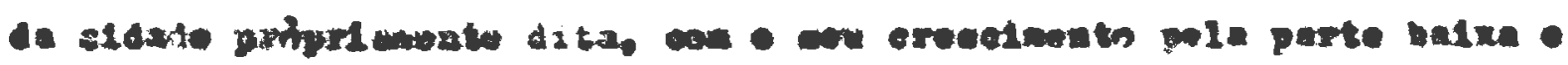

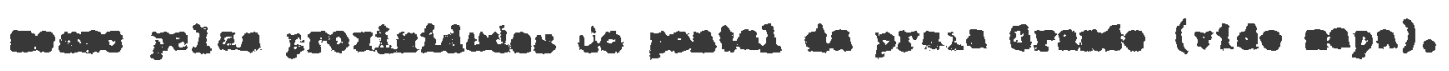

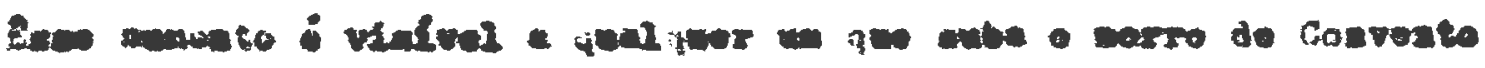

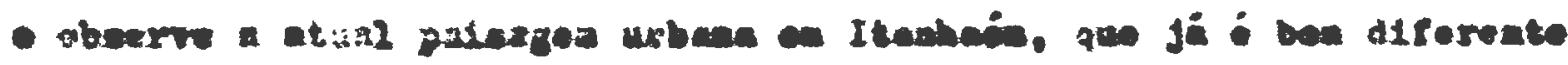

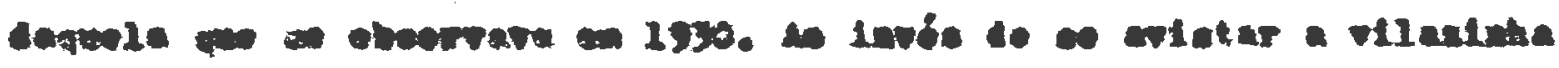

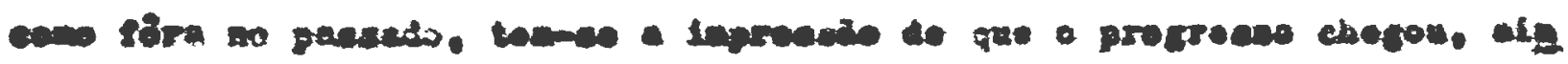

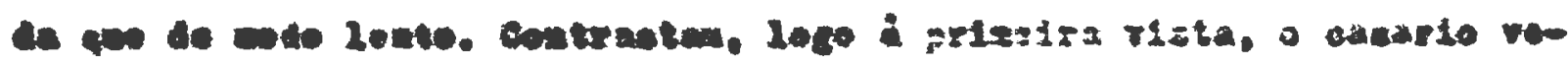




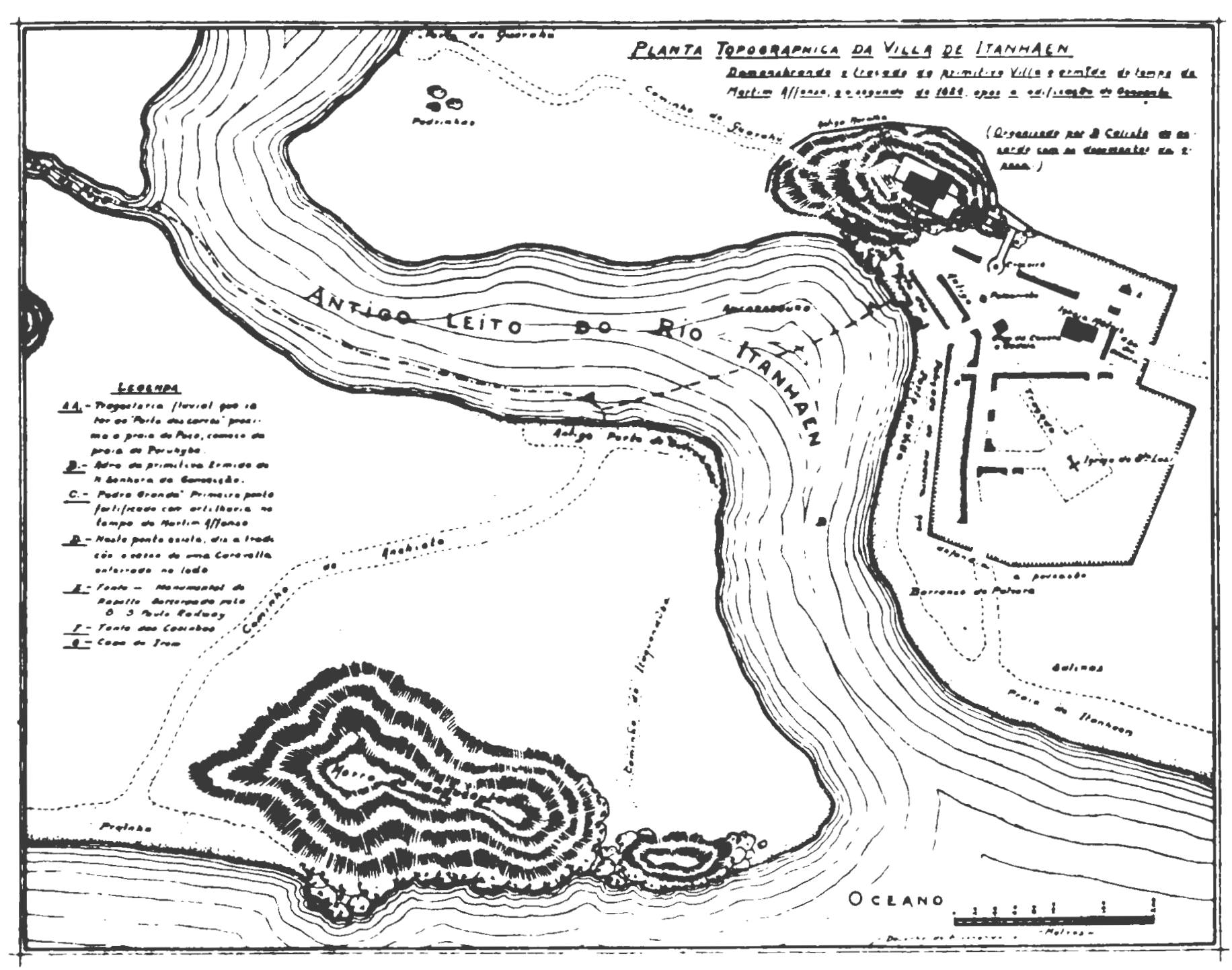




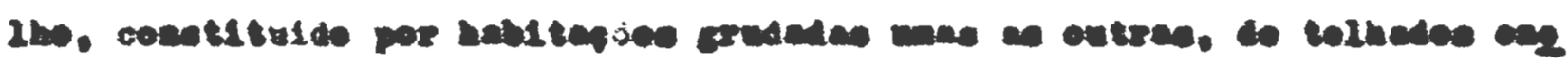

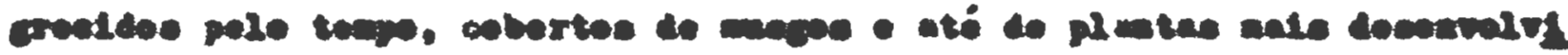

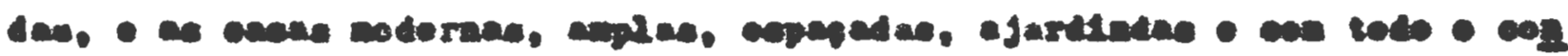

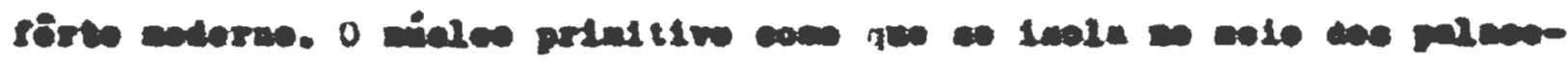

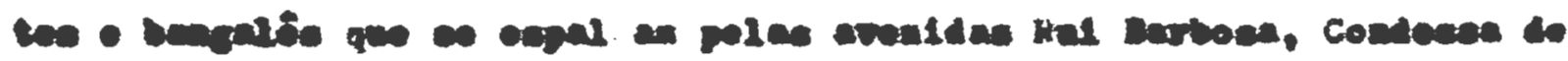

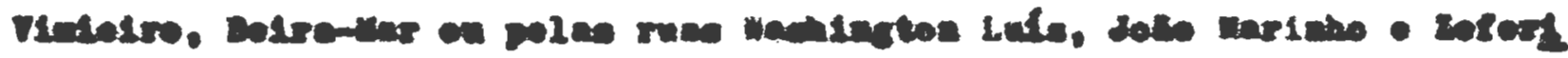

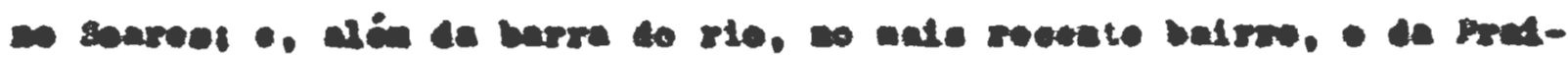

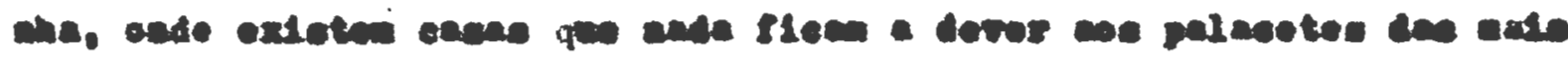

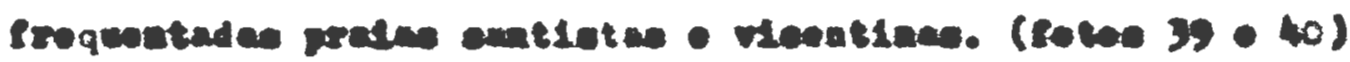

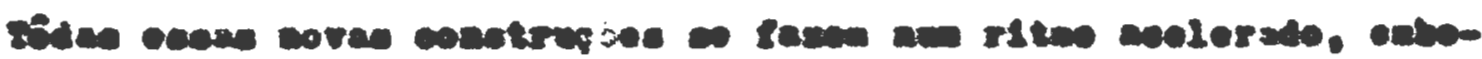

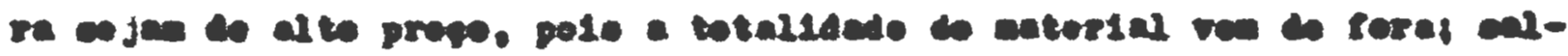

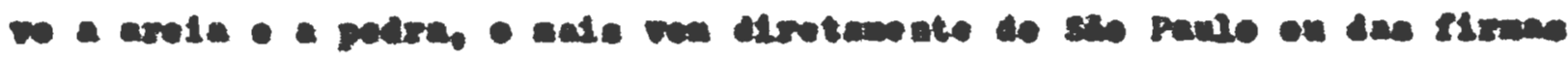
conctruteras do sateo.

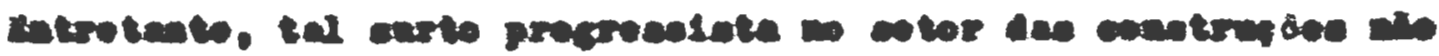

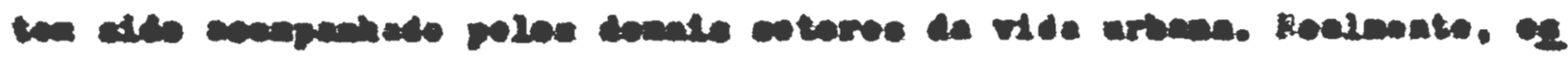

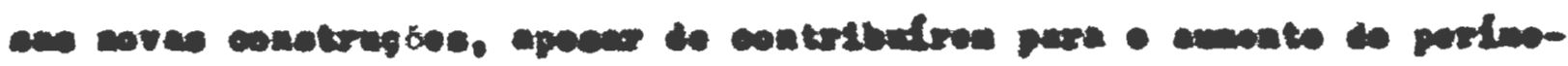

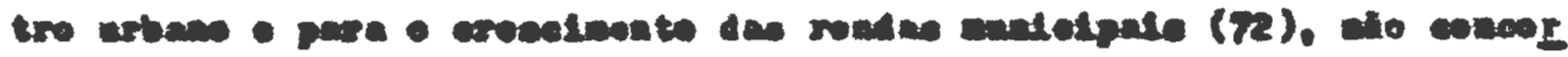

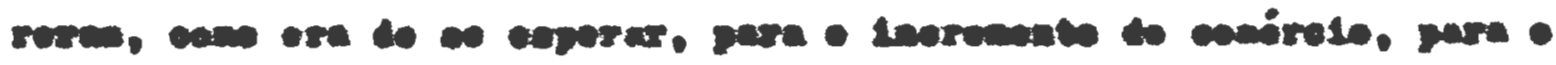

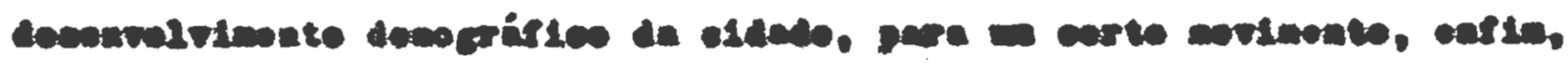

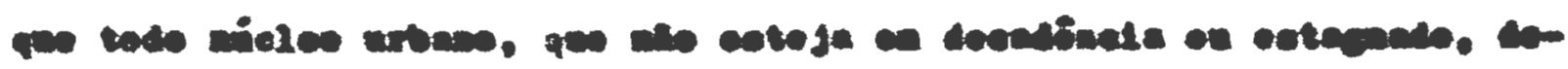

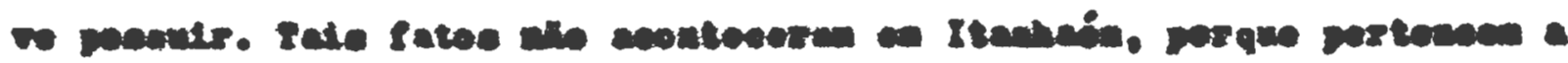

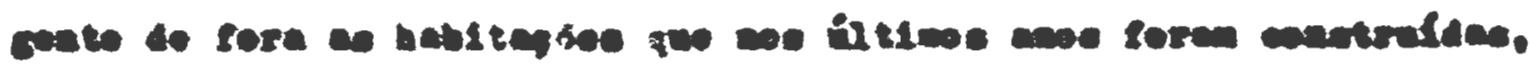

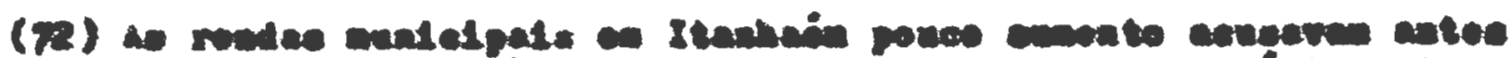

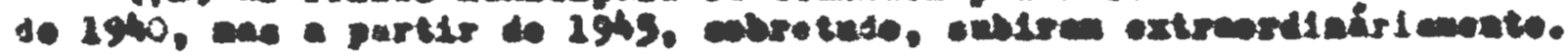

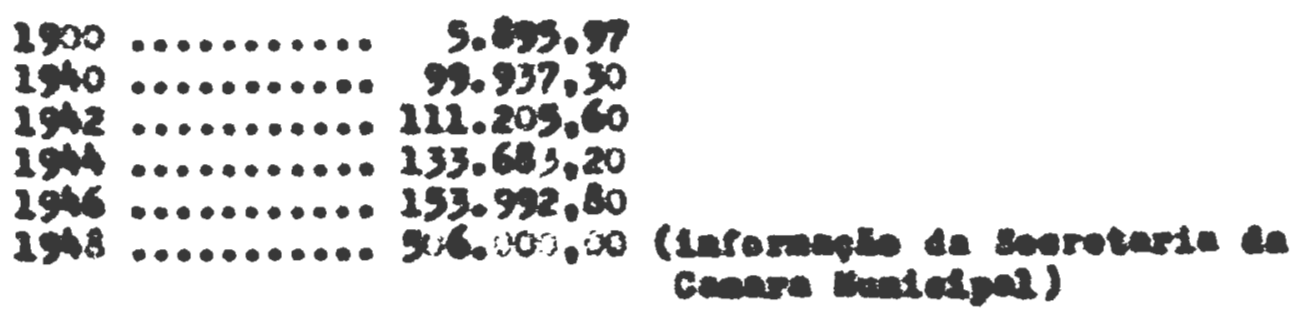


81

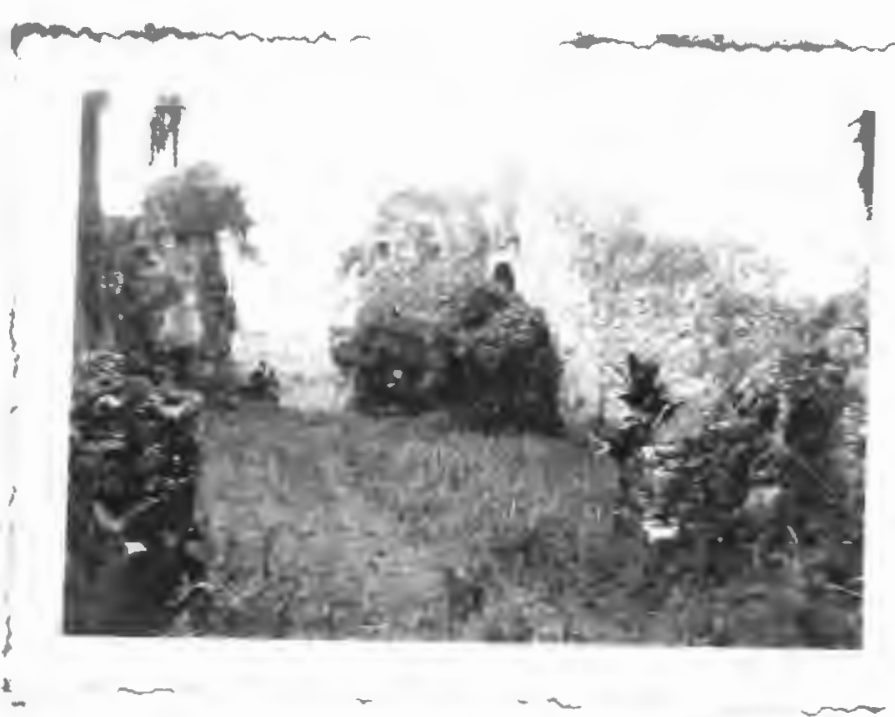

Toto 38. O que resta de primitive 1greja e comrento construldos em melados do abulo IVI polos jesultes ma prase de Peruibe, no local onde oe portugueses martim -

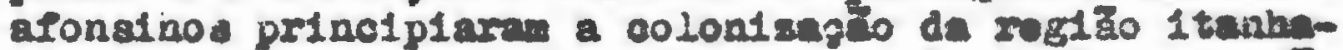
enso. Zetes restos de paredes invadidos pelo mato ato connecidas por "Ruines do Abarebobe". (loto do eutor).

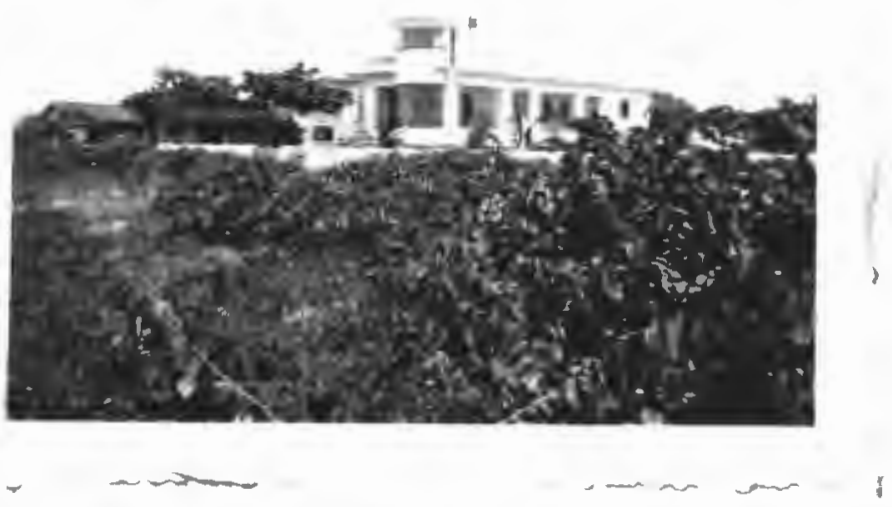

Foto 39. Un dos multos palacetes boje existentos ore Itanhaém - que tito beum denonetran o papel do ve ranfsta na orolugito de cidade. (foto do autor).

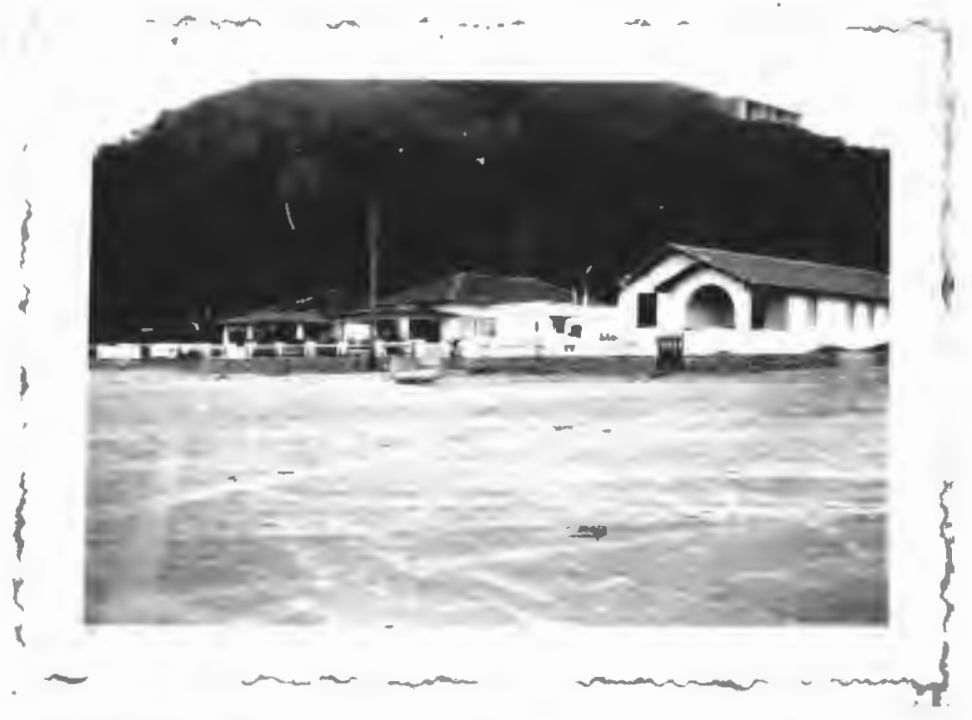

2oto 40. Un Grupo de onsas novas no batrro de Prasnha. (toto do autor). 


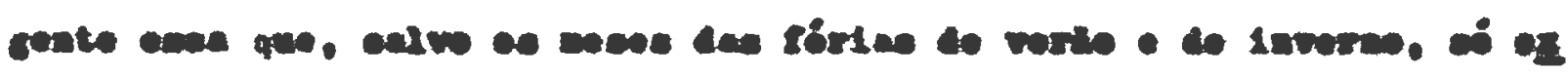

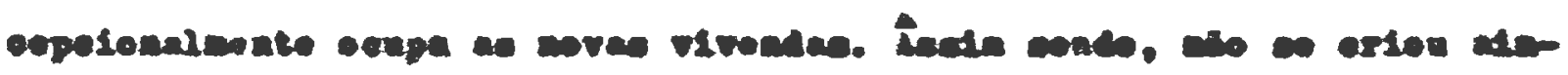

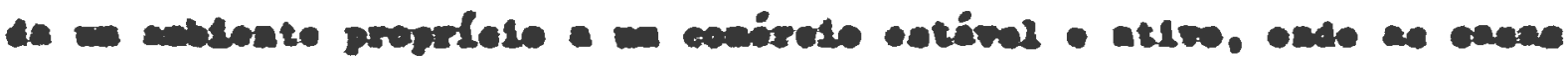

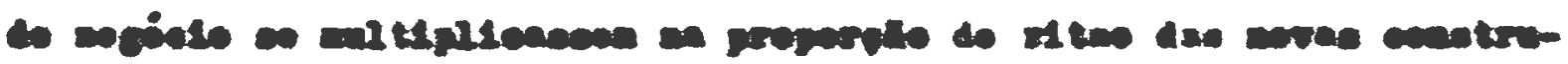

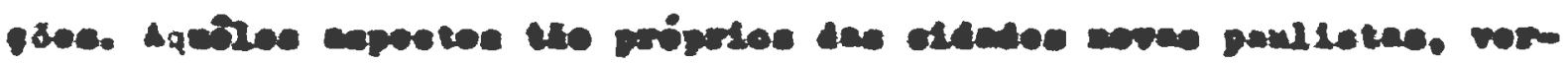

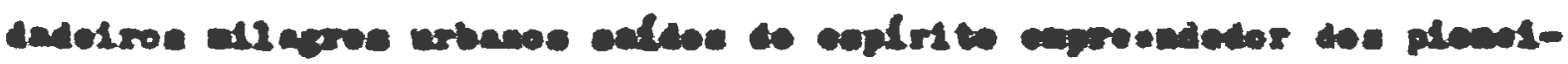

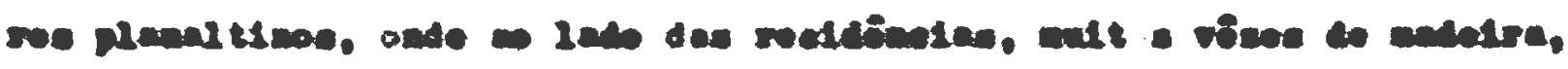

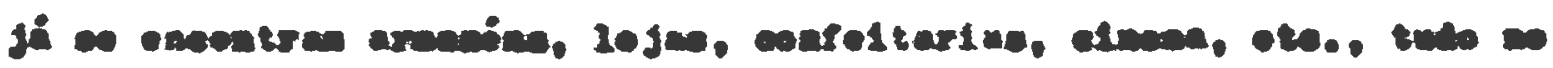

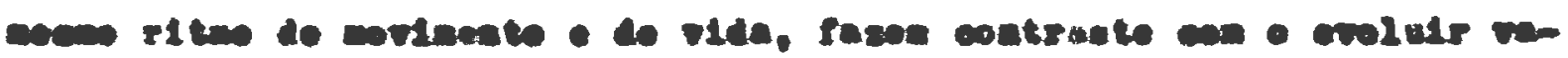

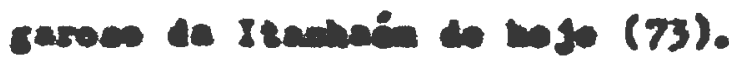

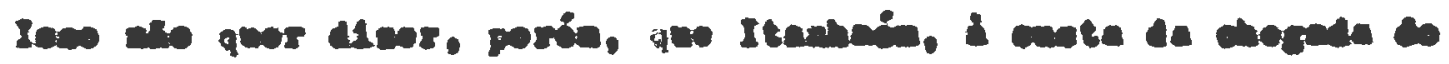

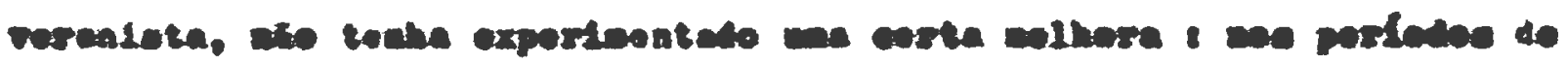

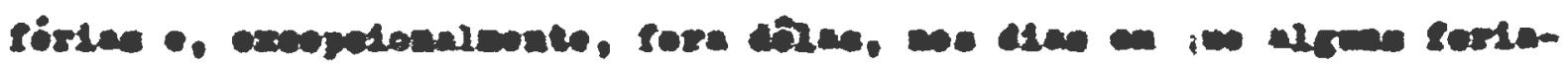

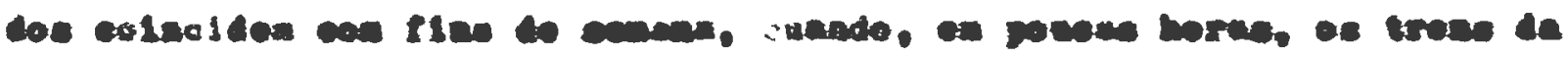

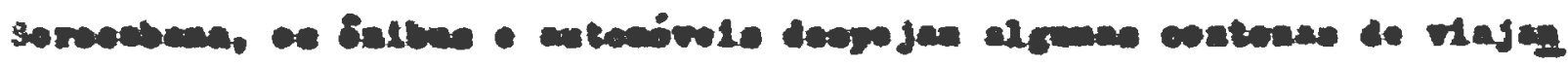

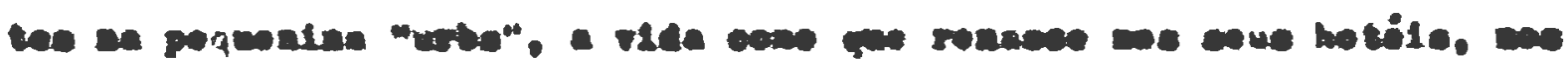

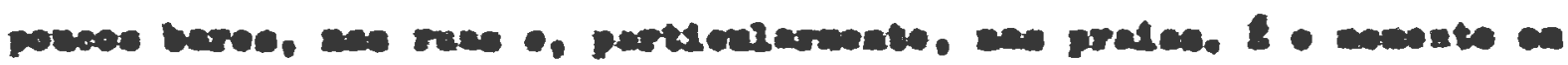

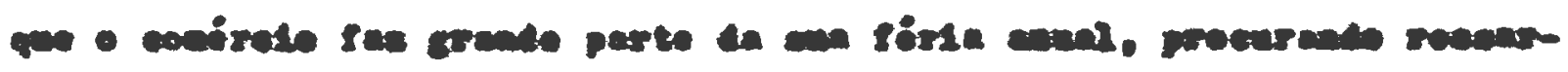

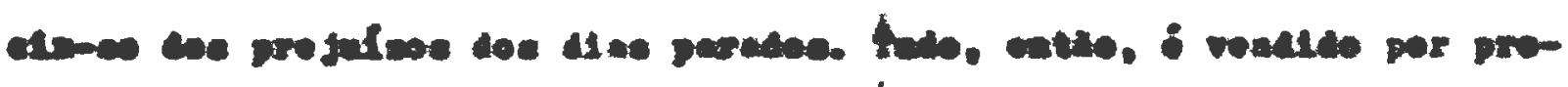

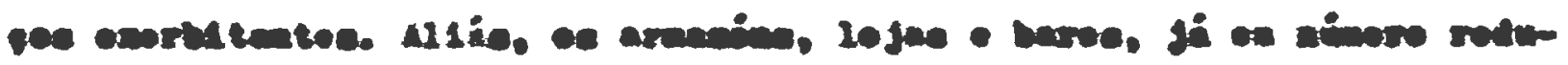

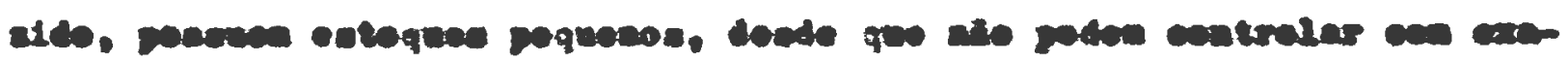

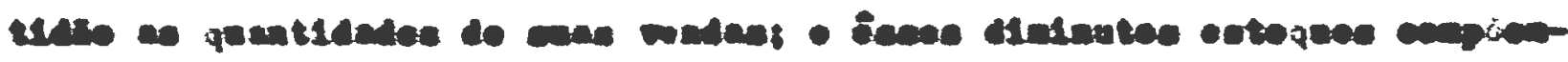

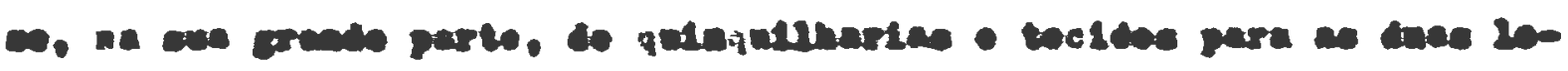

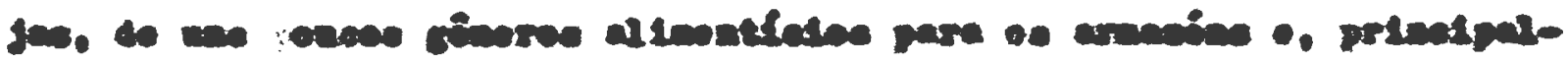

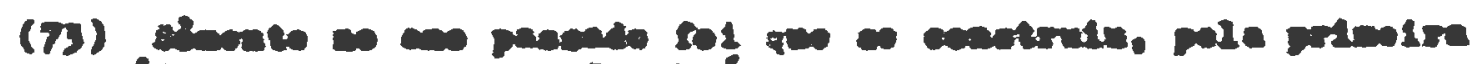

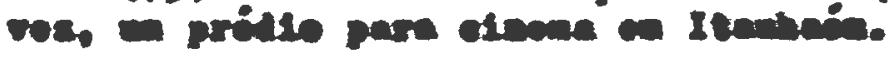




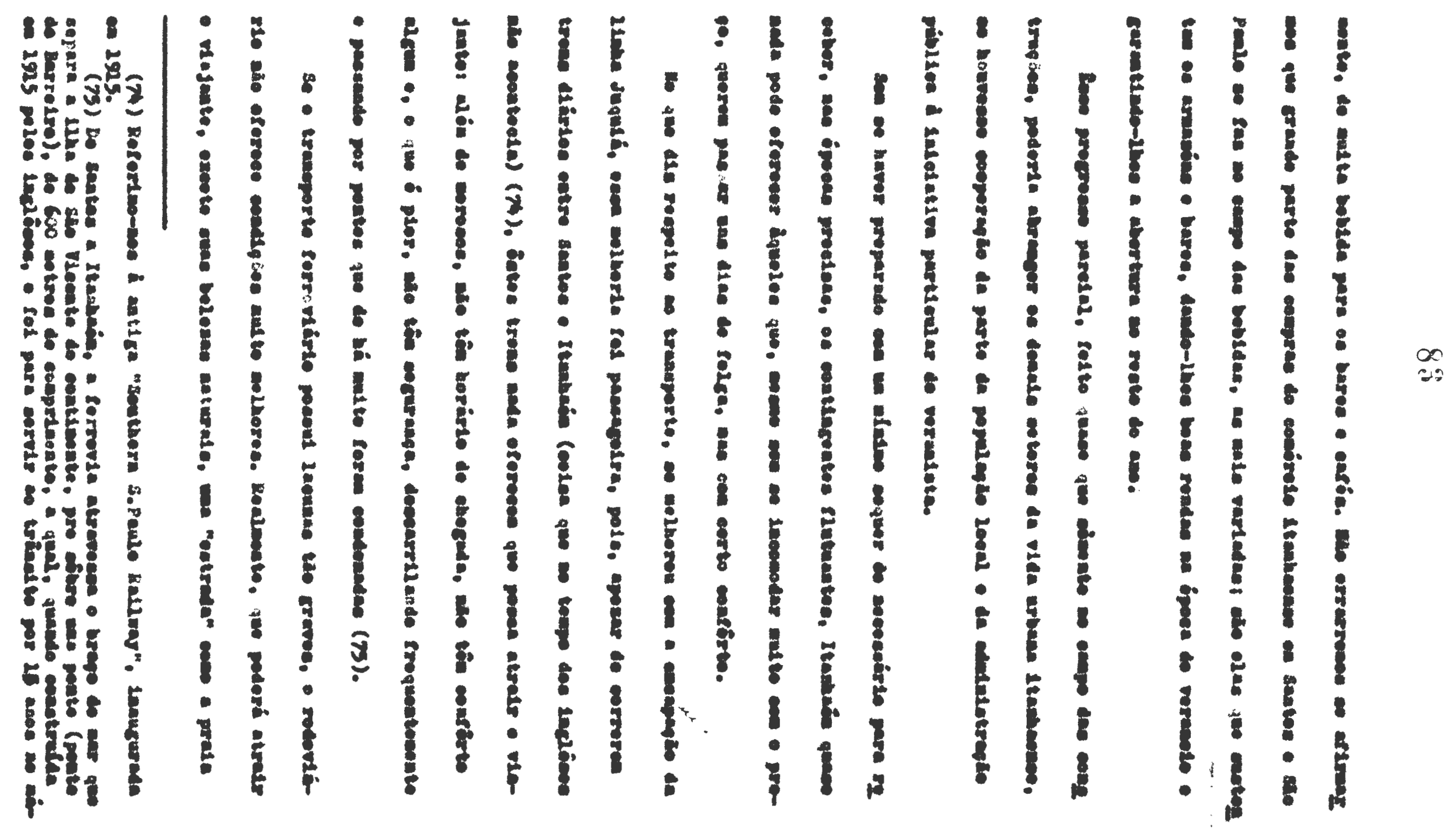




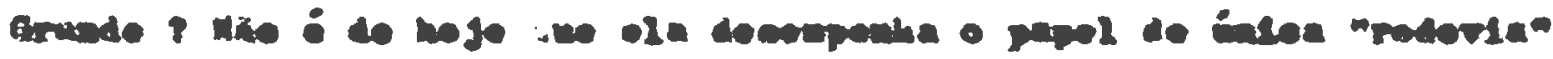

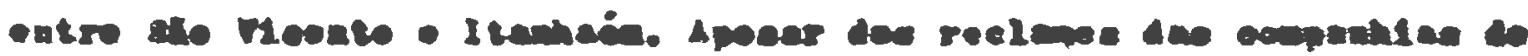

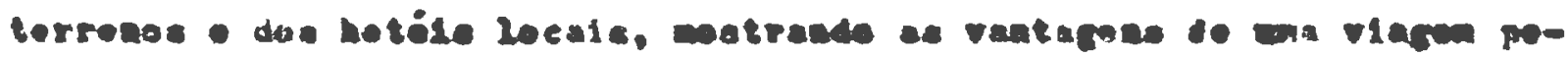

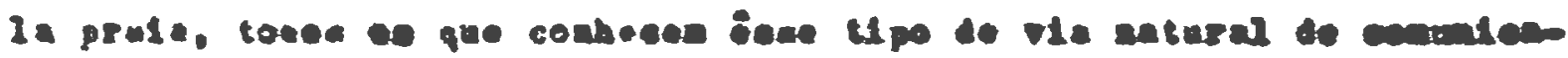

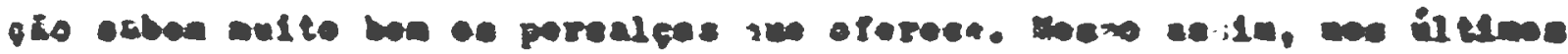

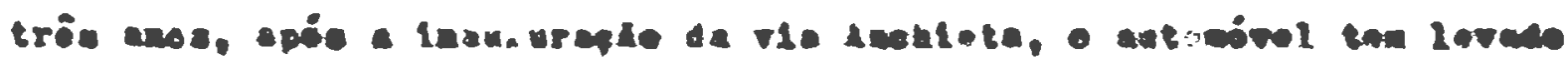

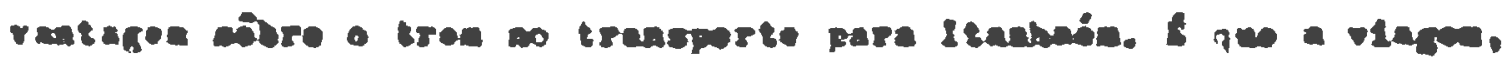

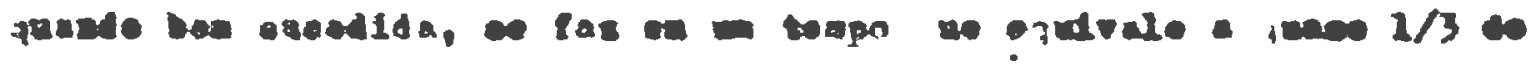

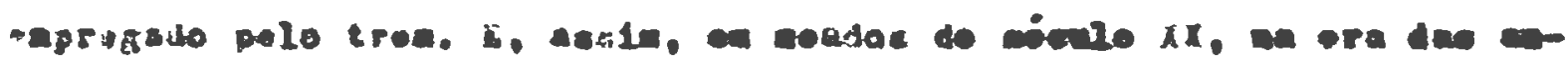

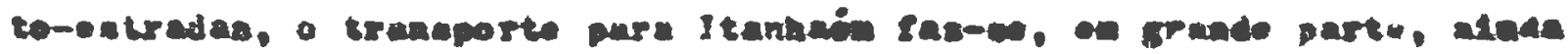

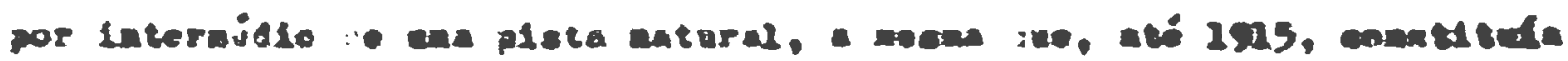

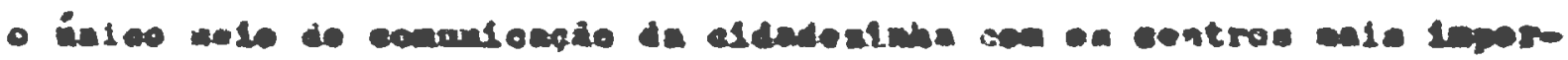

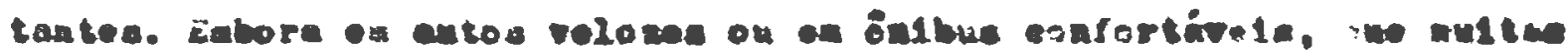

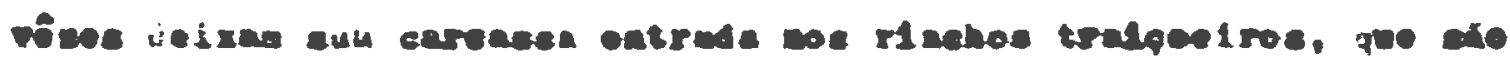

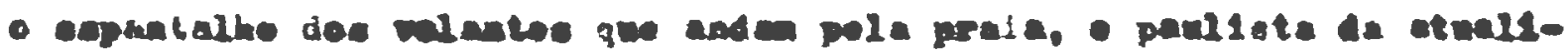

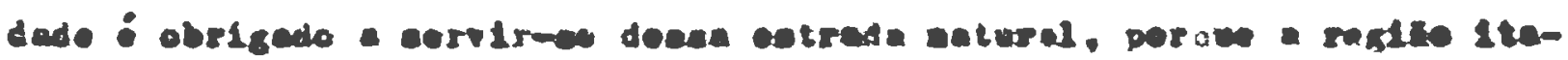

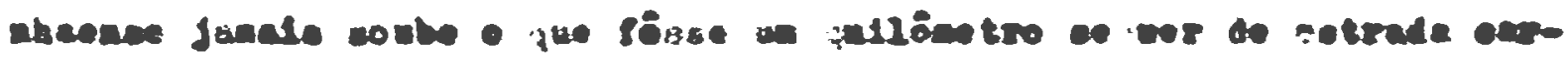
rofired.

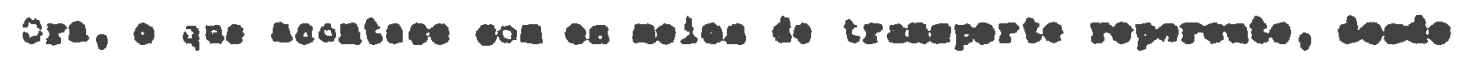

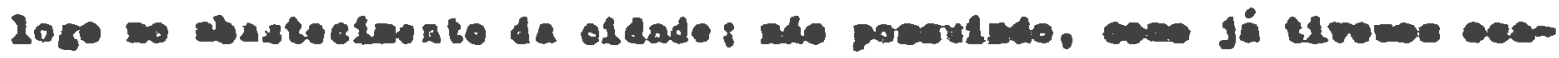

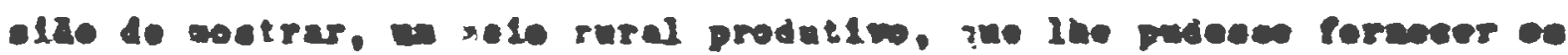

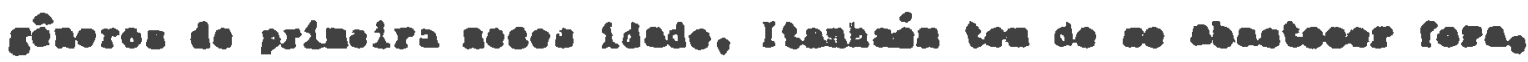

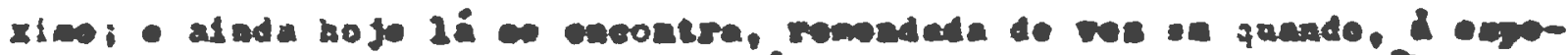

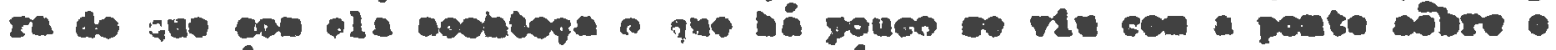

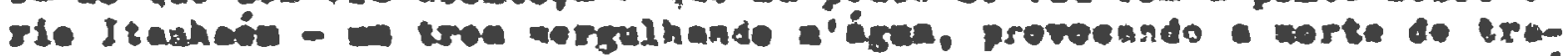

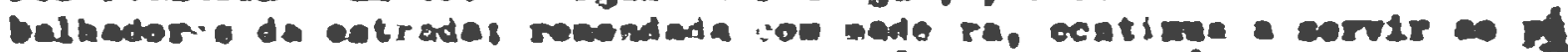

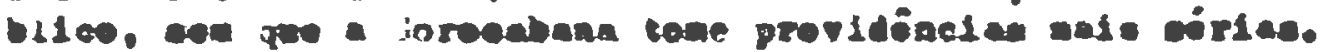




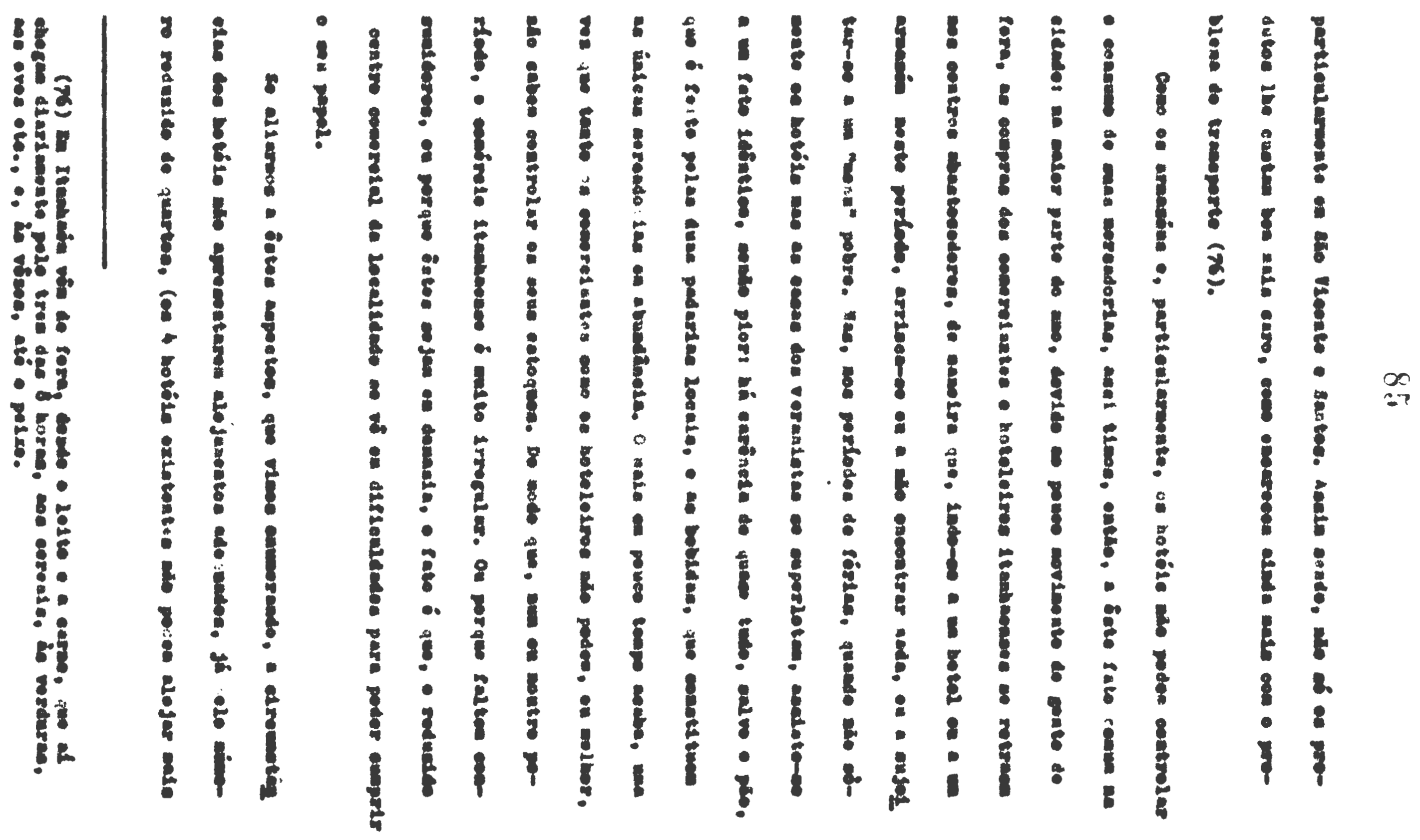




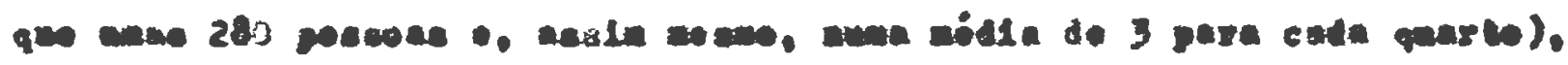

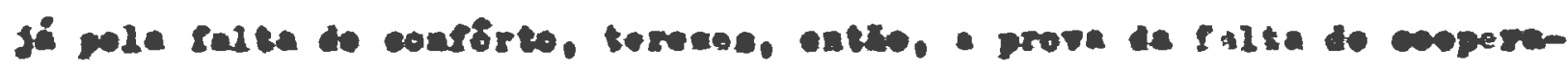

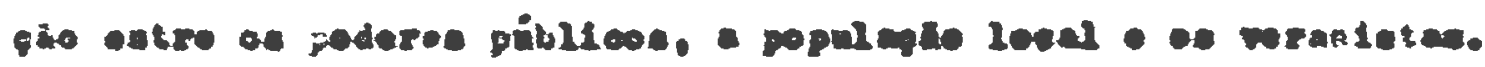

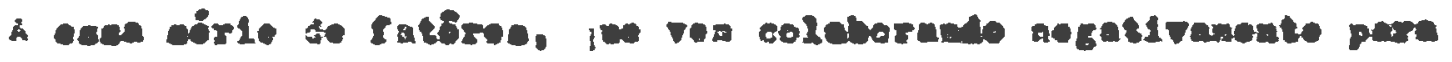

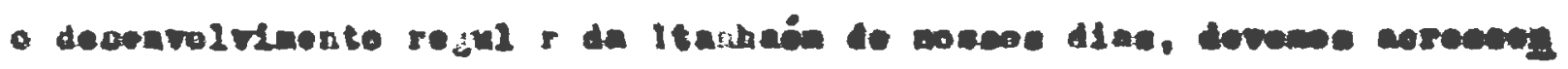

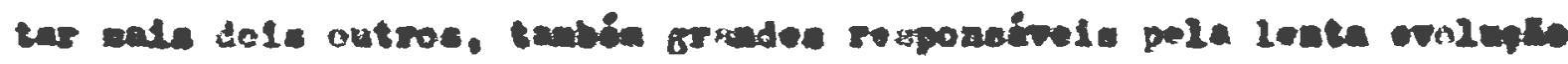

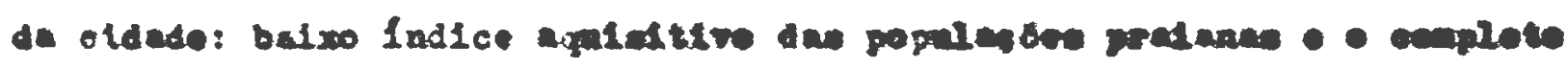

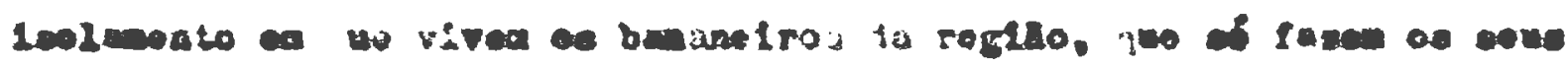

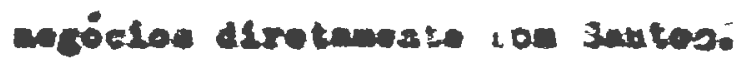




\section{caplreno II}

\section{Acoloris Rearomat}

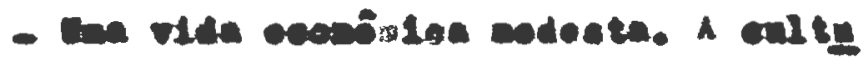

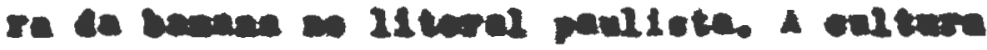

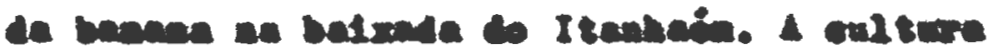

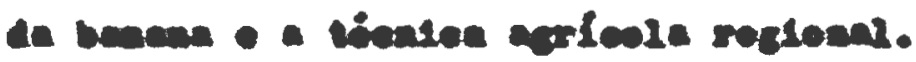

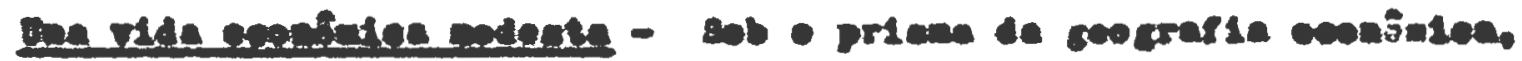

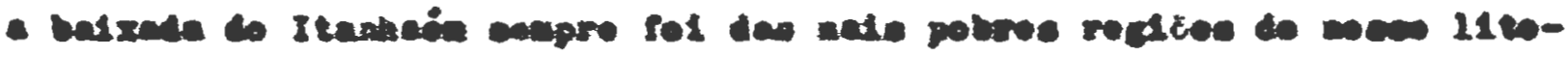

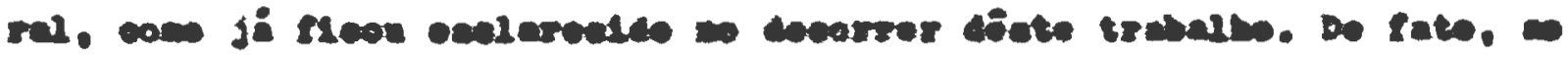

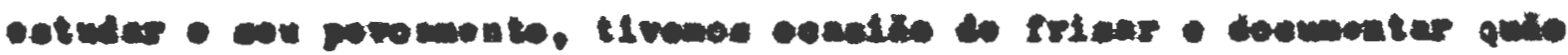

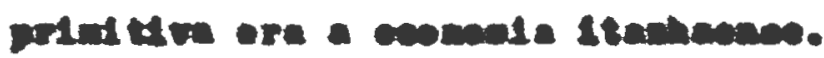

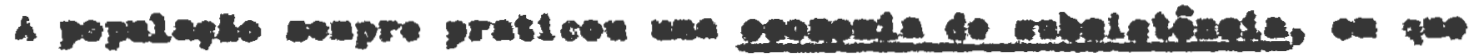

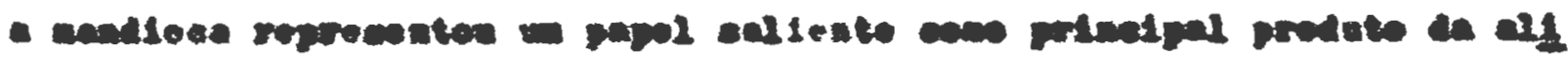

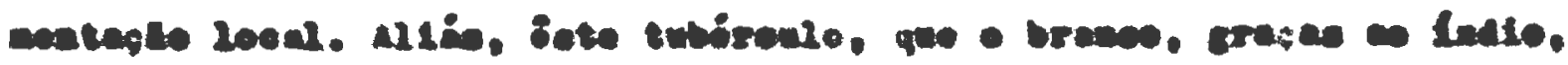

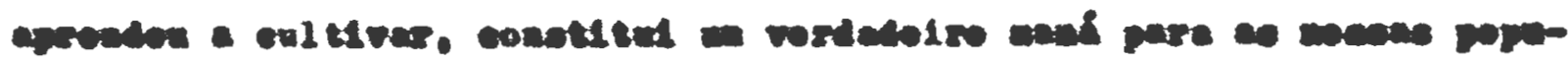

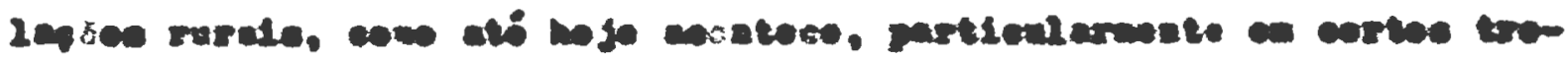

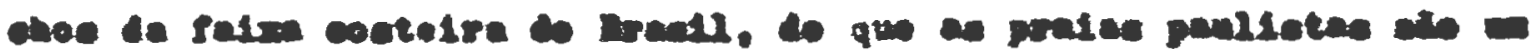

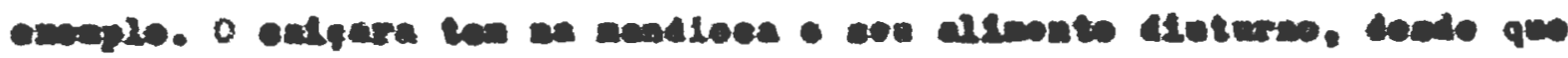

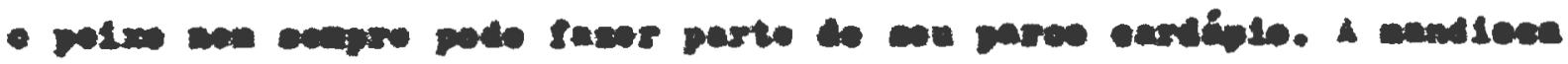

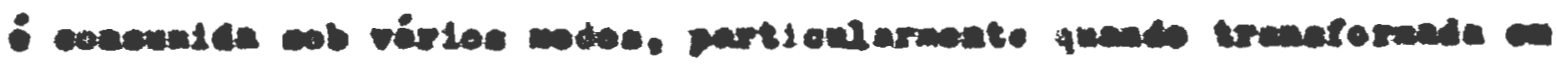

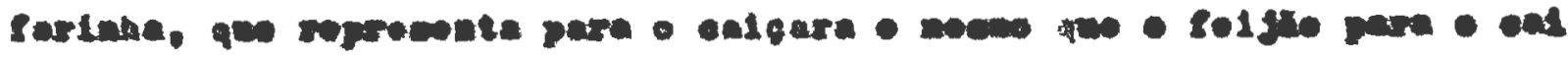




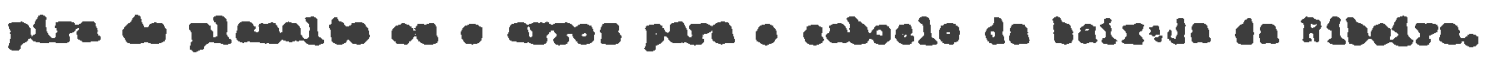

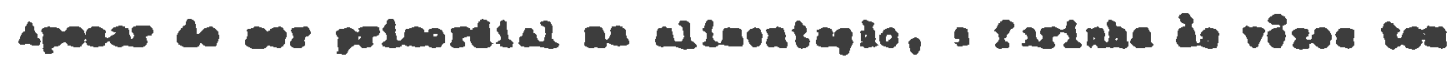

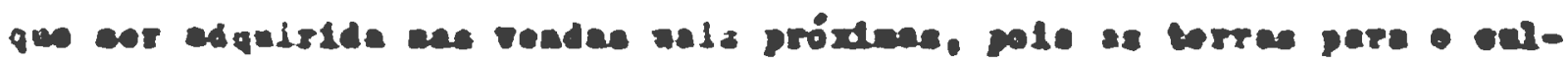

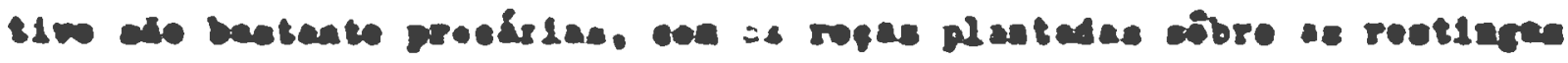
arenene.

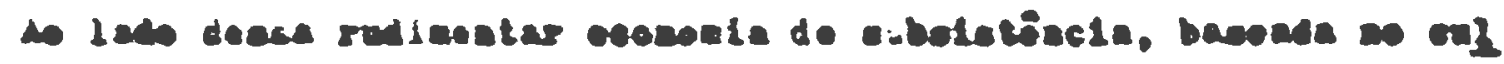

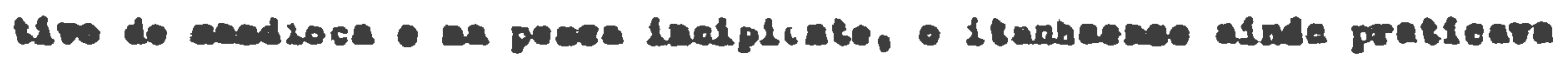

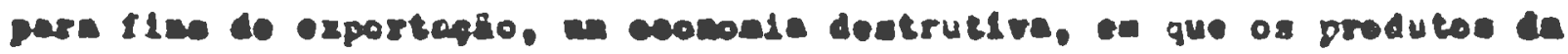

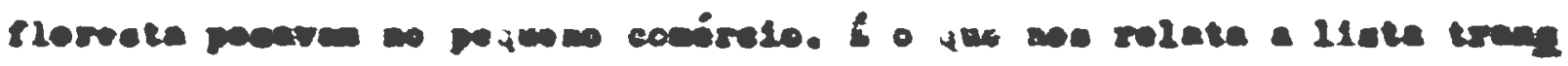

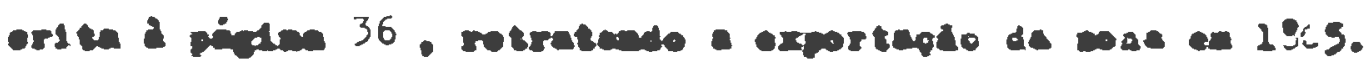

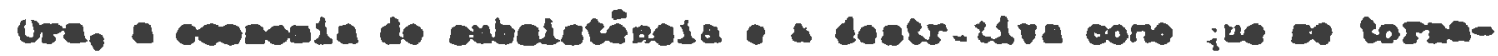

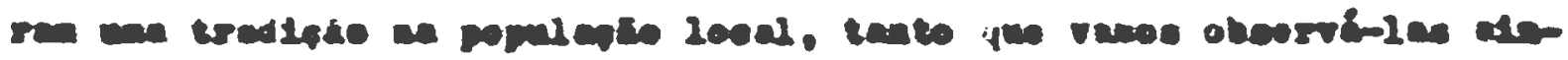

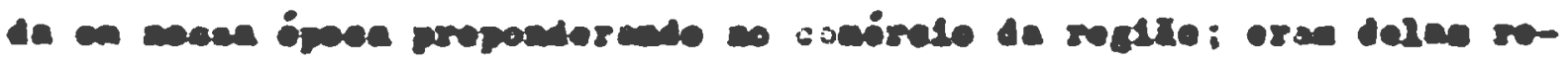

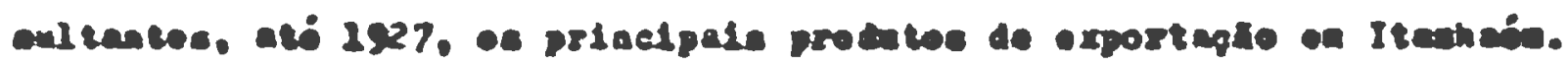

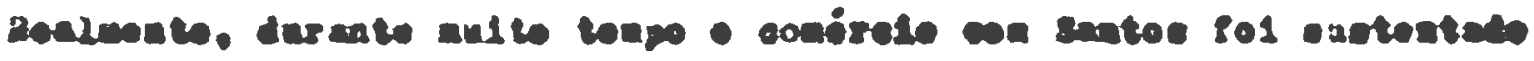

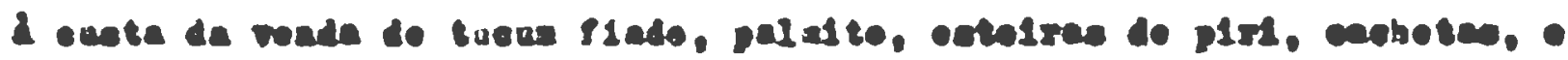

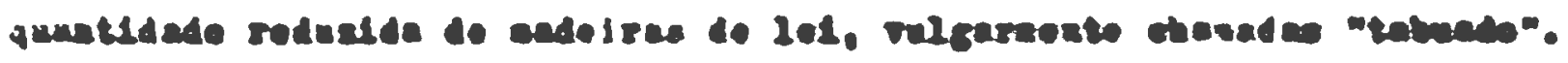

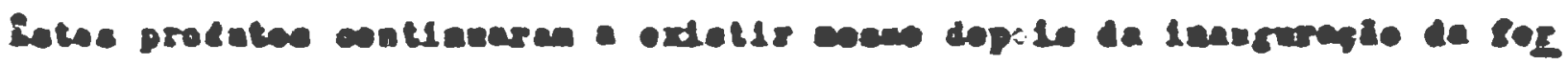

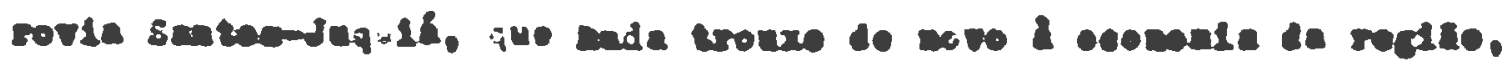

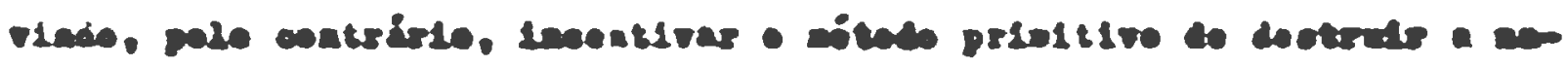

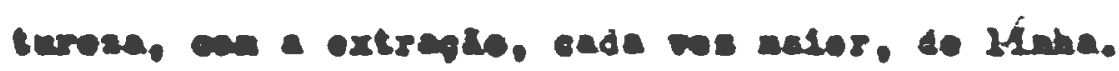

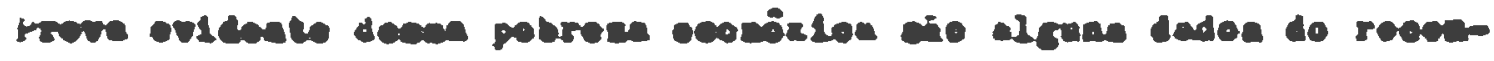

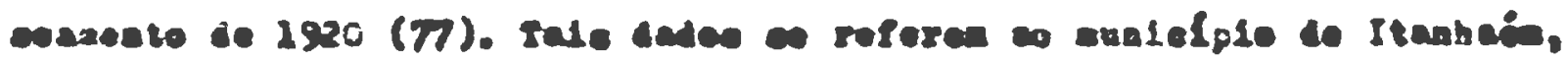

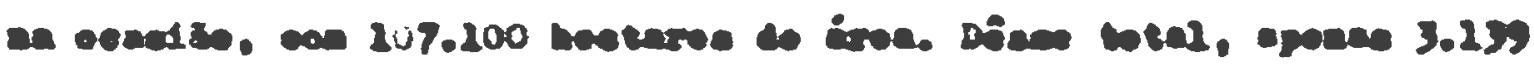




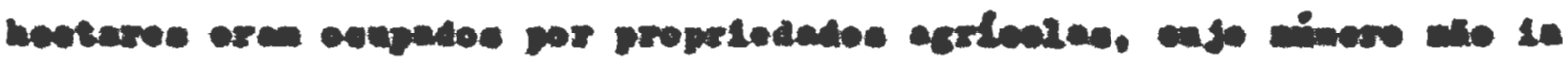
ale so s.

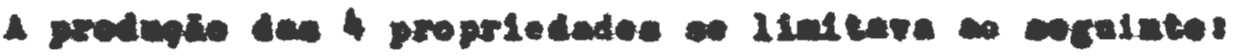

\begin{tabular}{|c|c|c|c|c|}
\hline \multicolumn{2}{|c|}{ Encresces } & \multicolumn{3}{|c|}{ Exerutyes } \\
\hline Armes ......... & 499.2 & & 27 & . \\
\hline alno ..... & 32.8 & & 24 & ๓ \\
\hline rolgen ........ & 39.9 & $\ldots \ldots$ & 35 & $\bullet$ \\
\hline mand leea $(78)$. & 214.2 & & 8 & - \\
\hline $\cos .$. & 263,8 & .... & 7 & $*$ \\
\hline
\end{tabular}

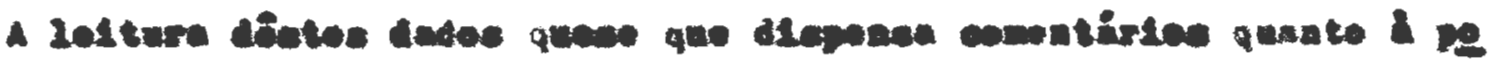

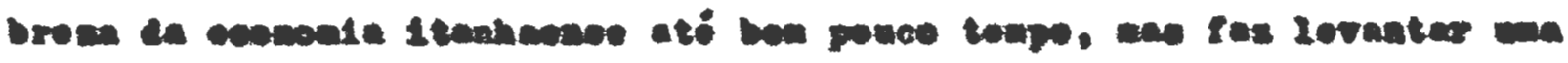

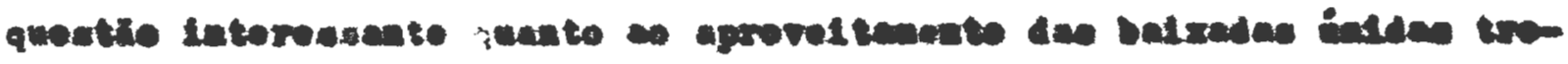

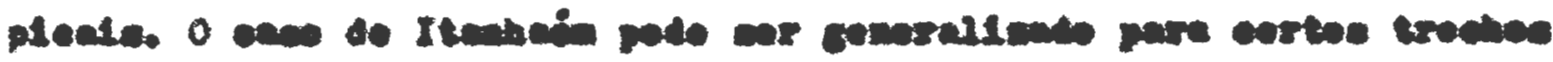

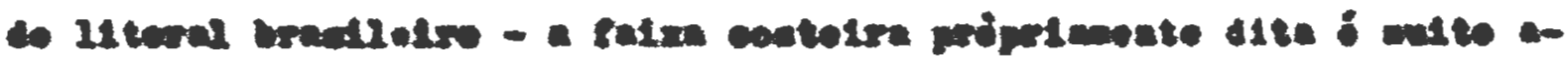

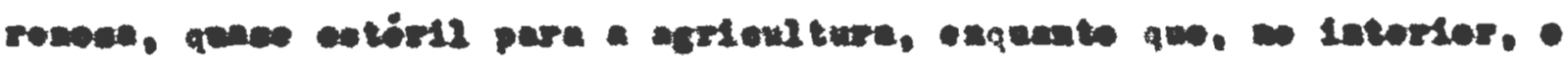

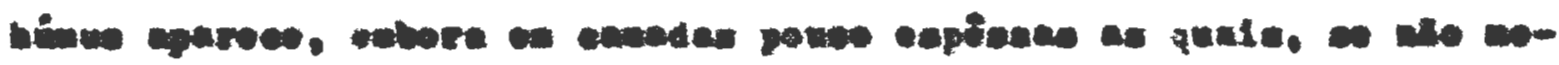

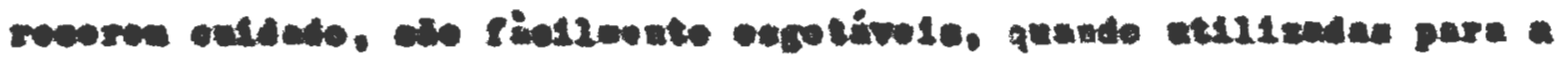

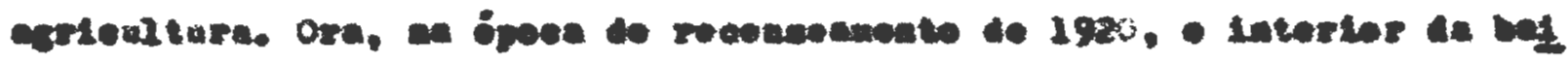

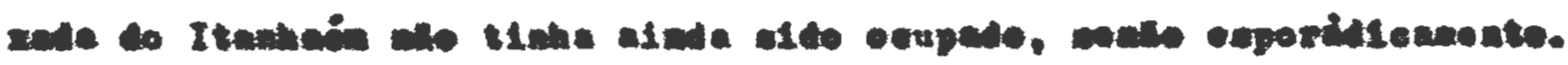

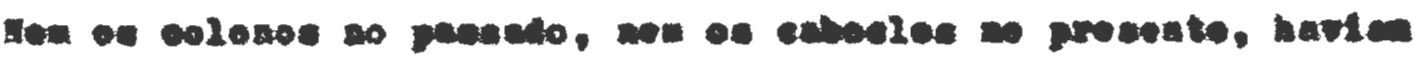

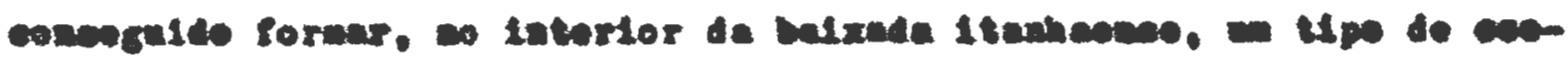

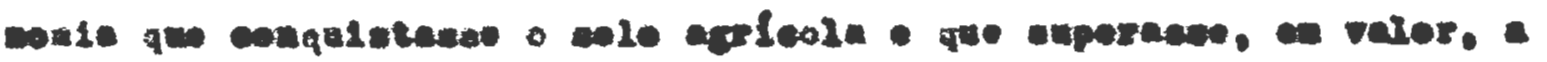
perea produsto de indietris oxtrativa.

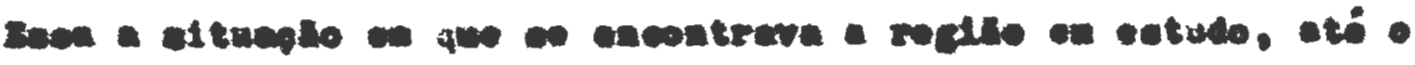

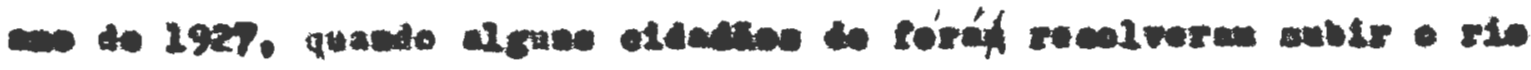

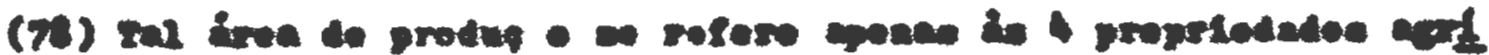

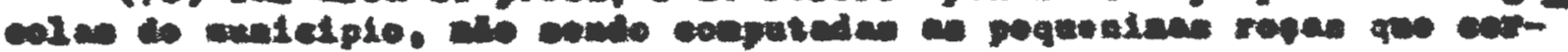

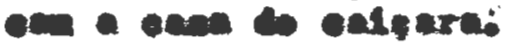




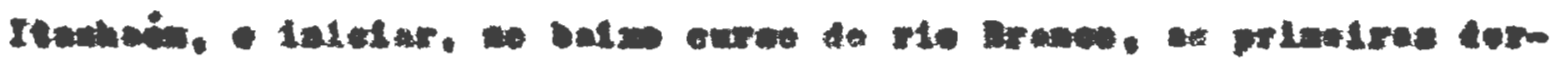

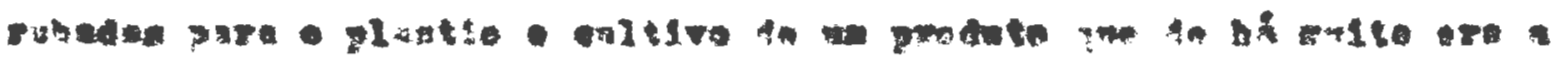

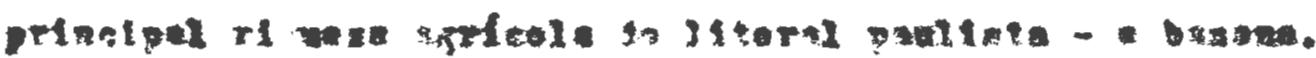

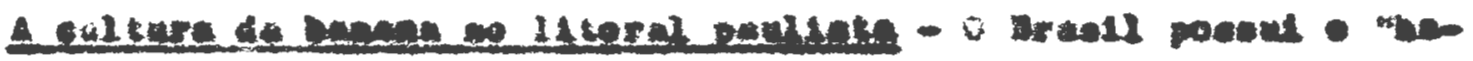

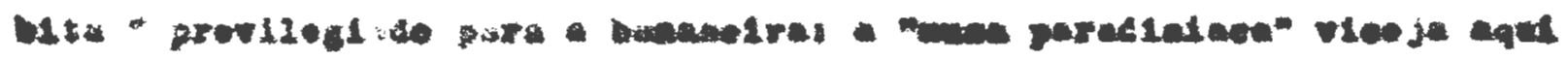

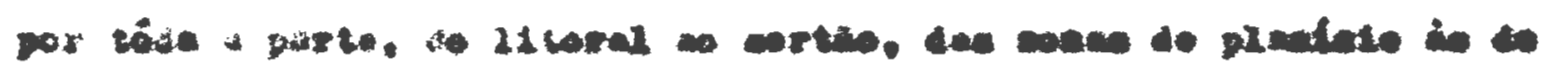

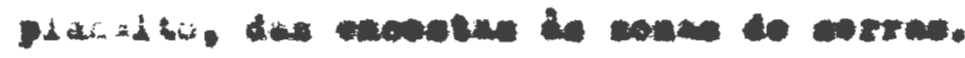

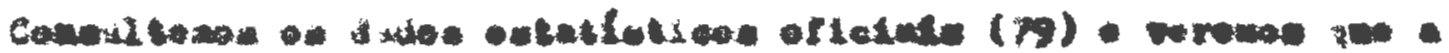

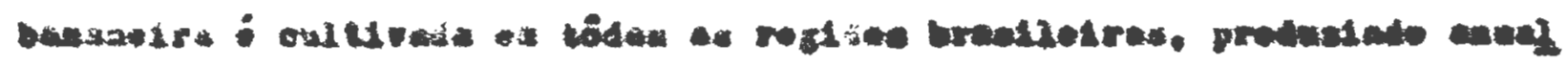

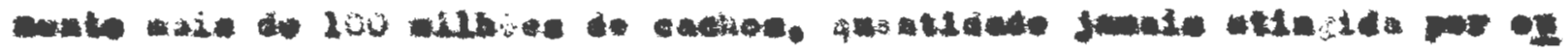

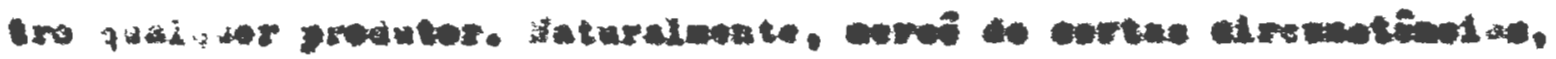

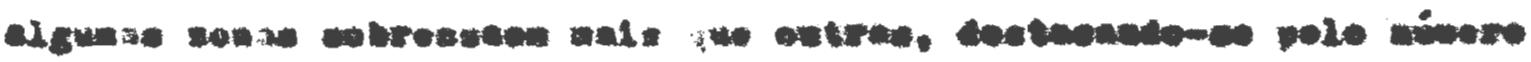

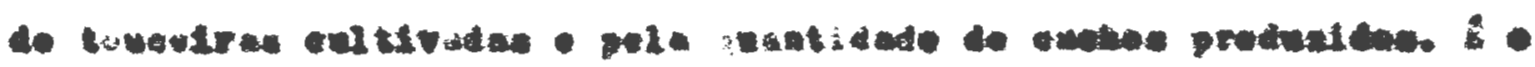

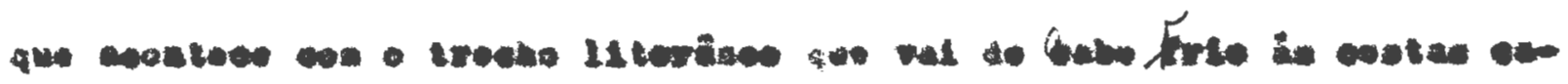
sezionacove.

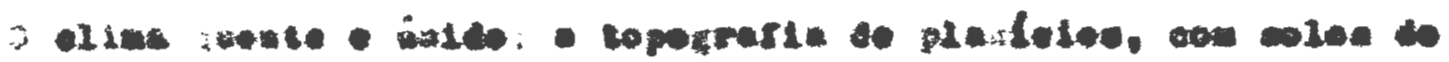

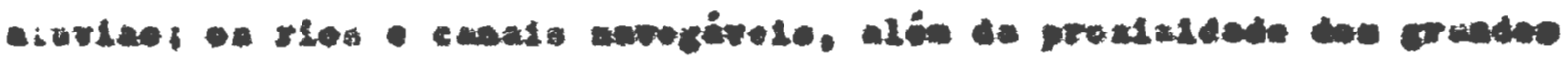

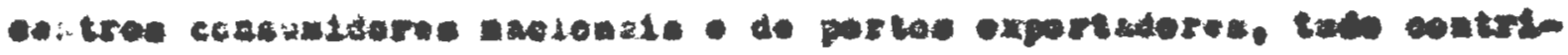

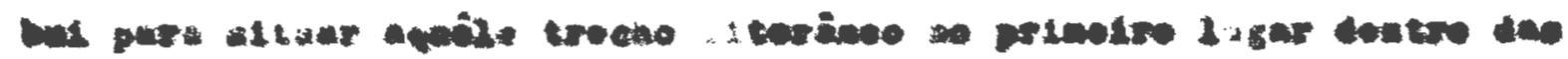

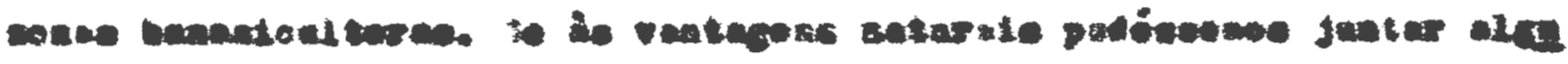

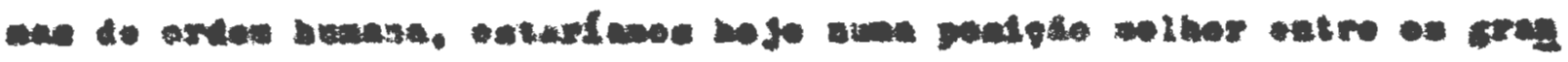

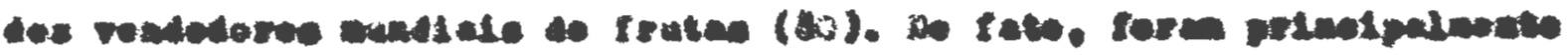

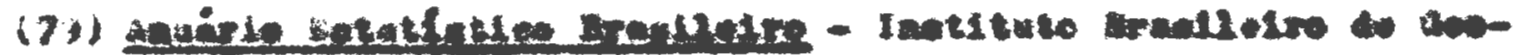

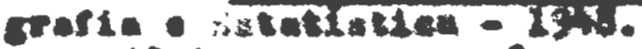

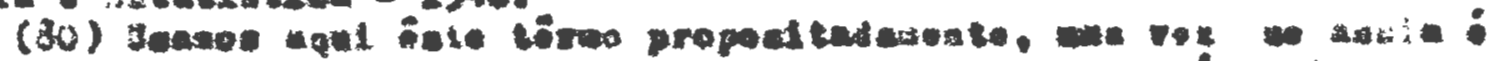

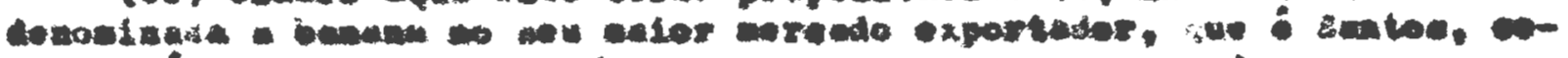

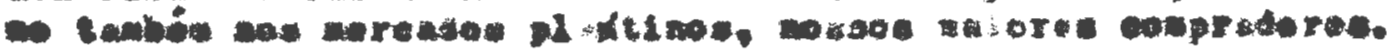




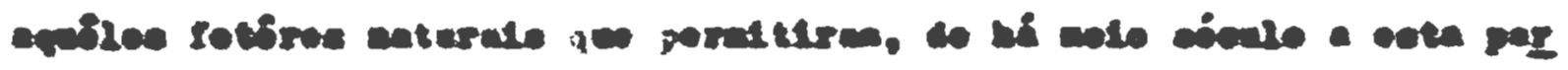

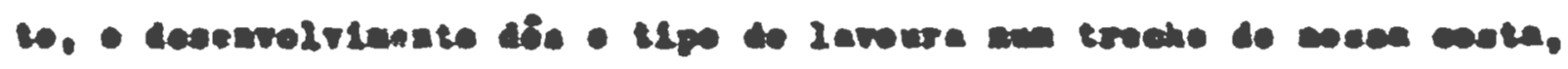

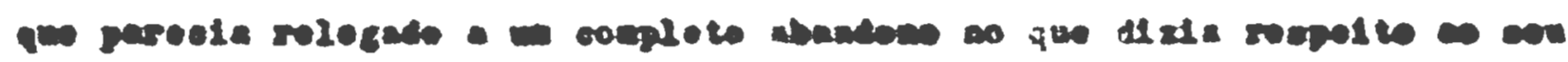

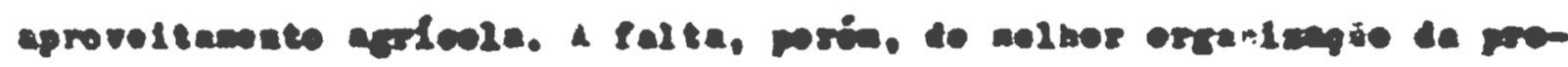

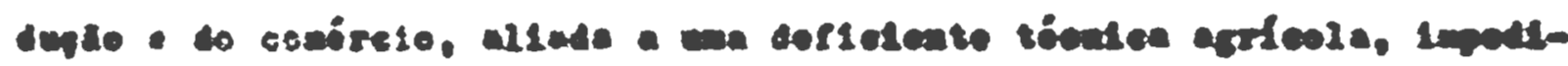

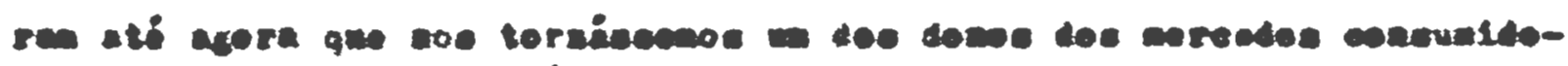

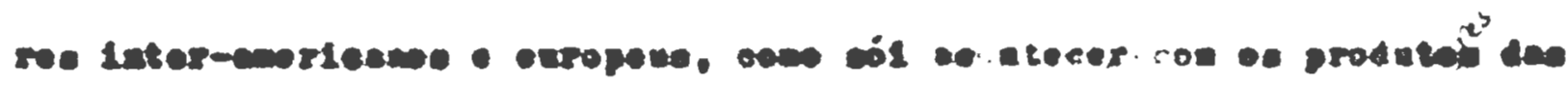

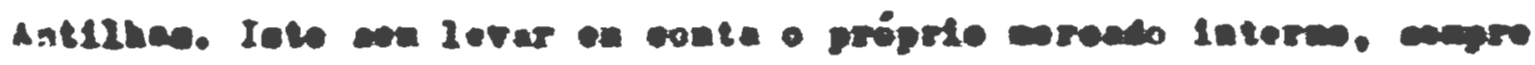

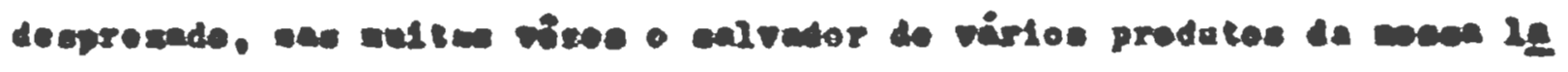

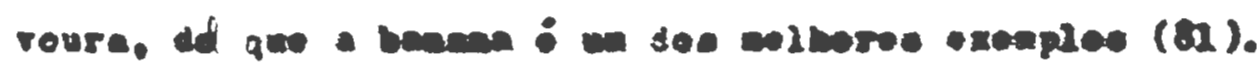

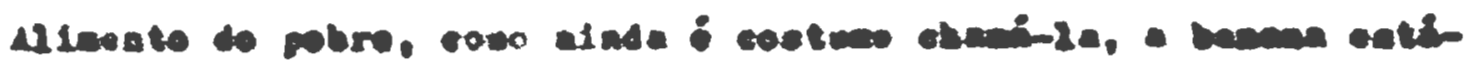

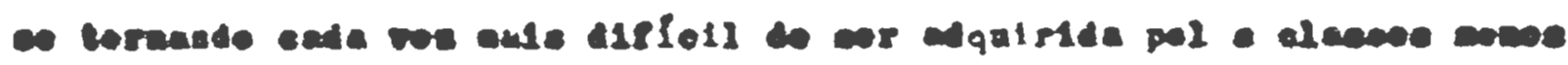

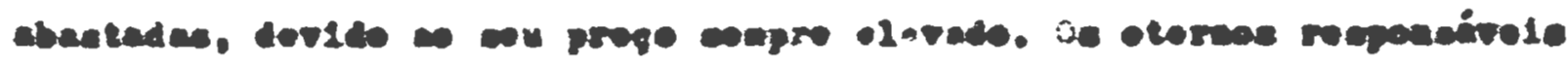

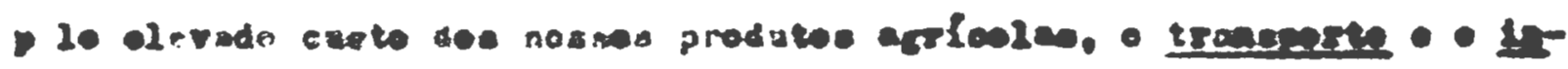

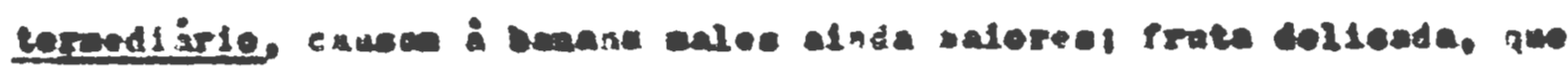

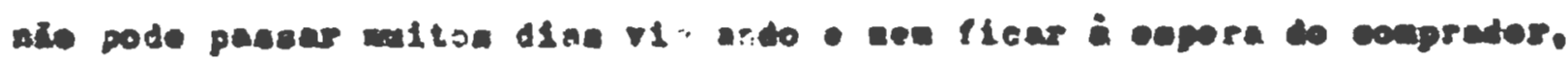

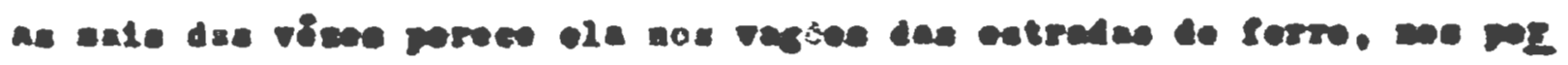

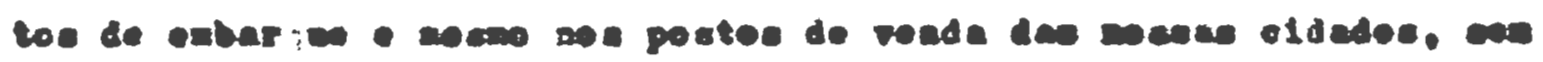

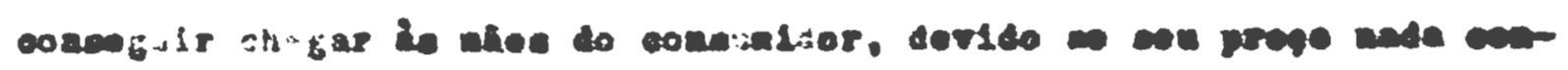
vidative.

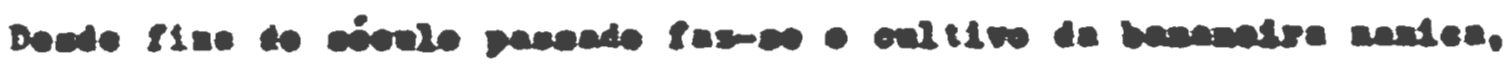

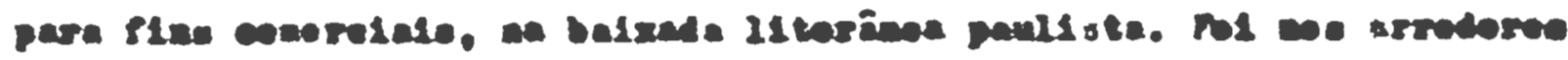

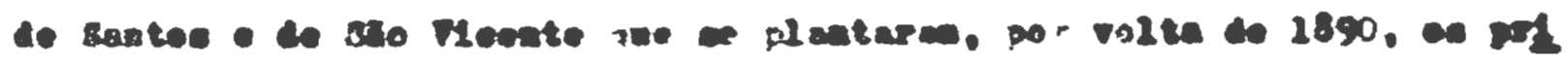

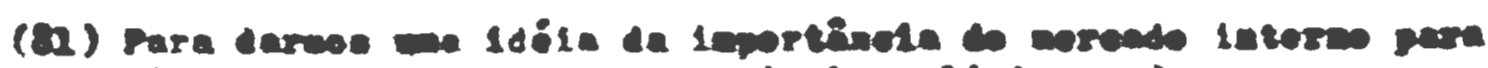

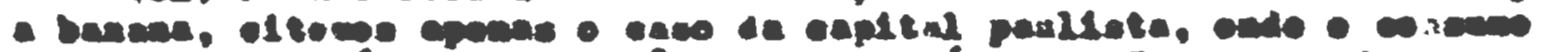

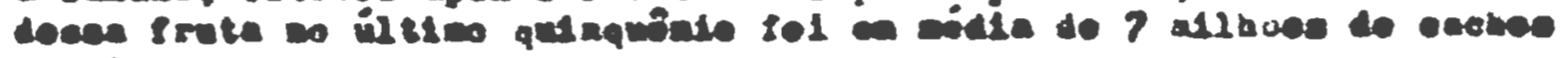
anade. 


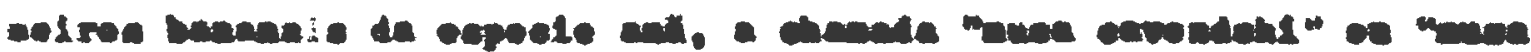

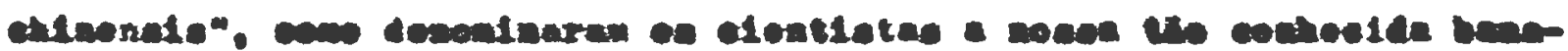
aldre santea:

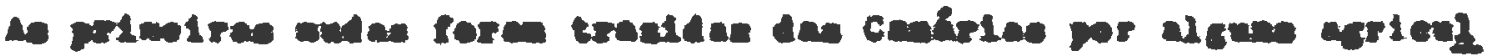

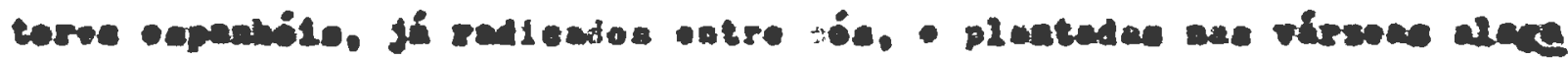

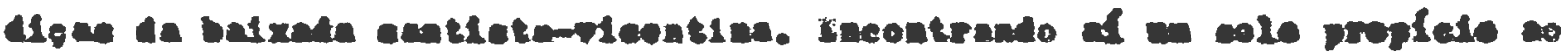

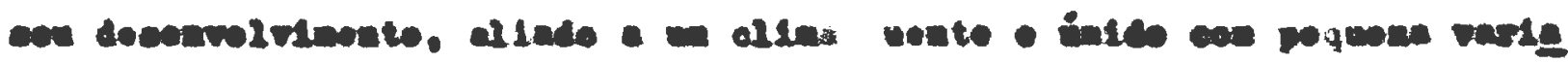

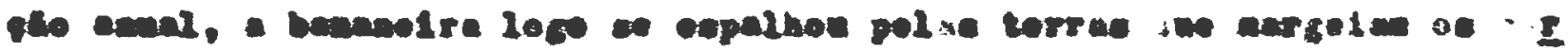

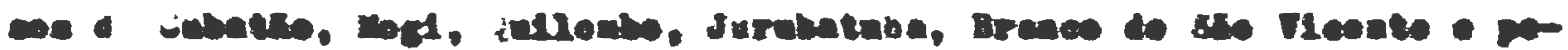

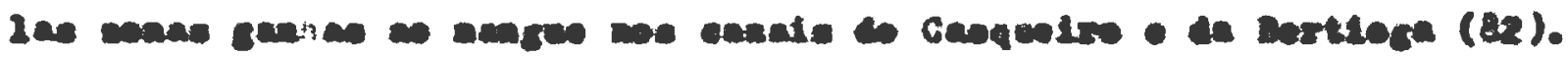

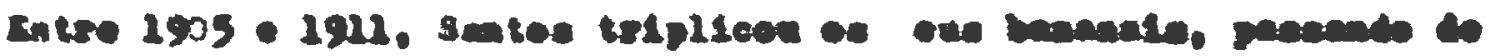

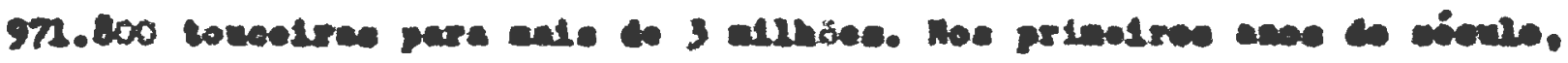

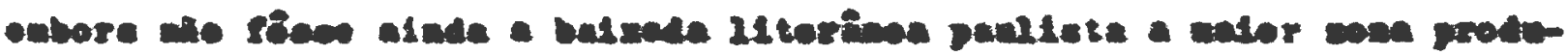

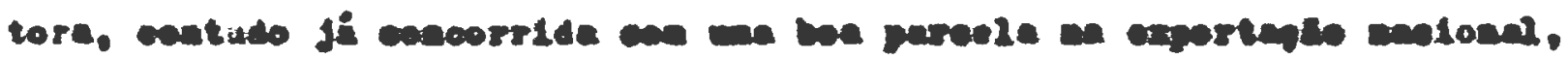

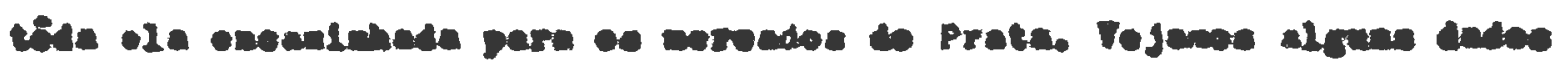

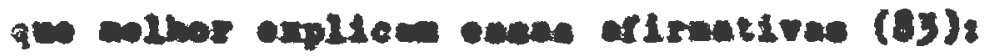

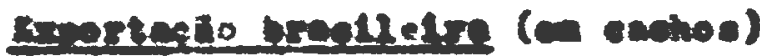

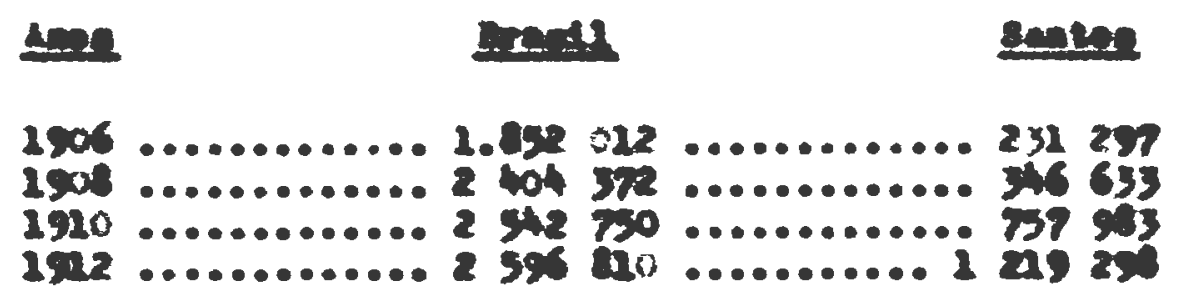

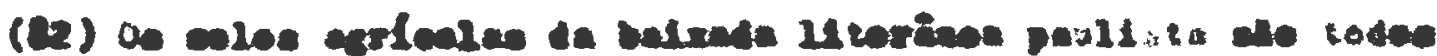

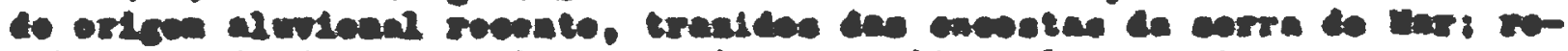

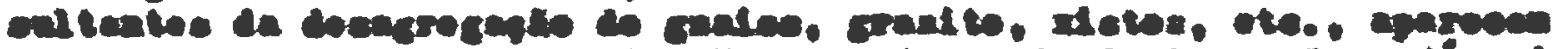

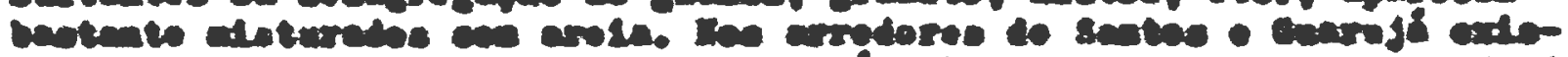

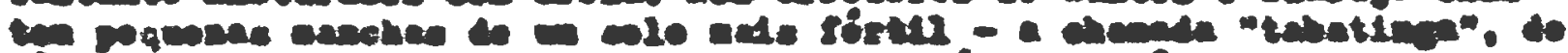

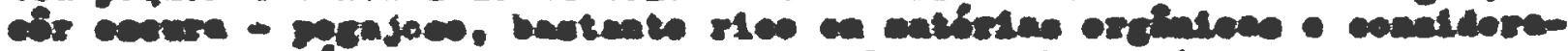

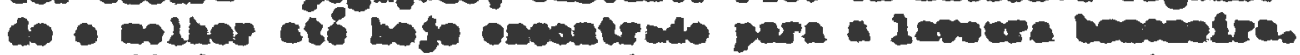

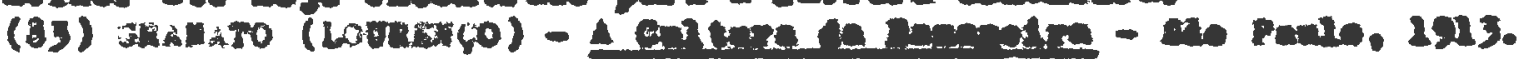




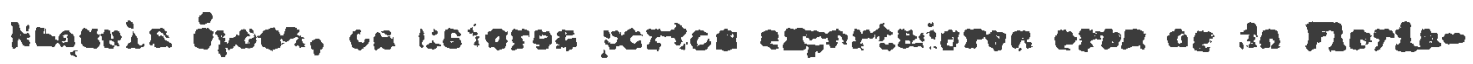

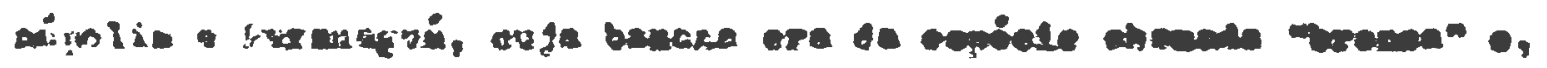

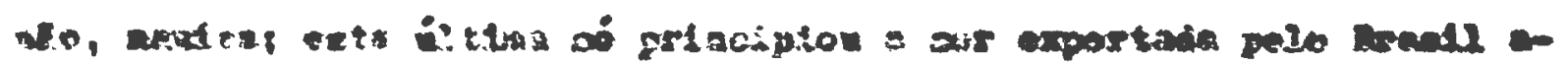
Eraviz: to porte th istoke.

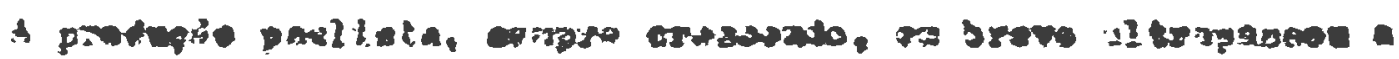

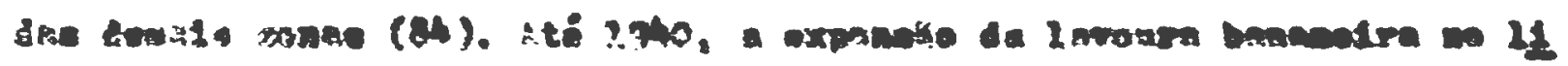

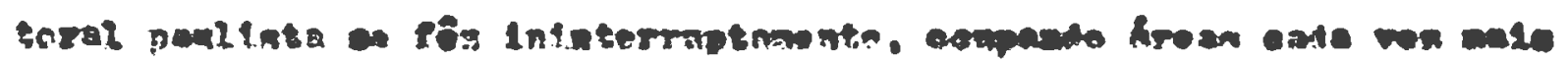

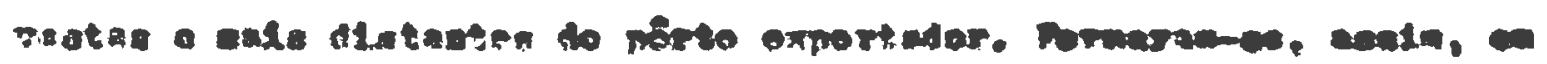

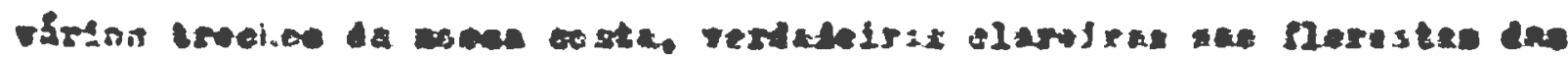

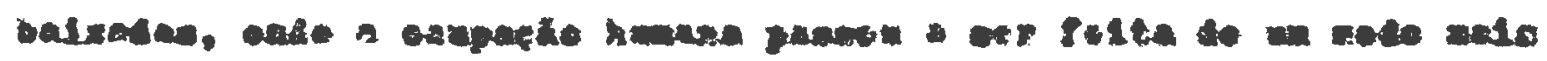

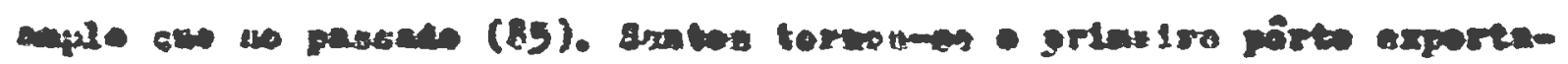

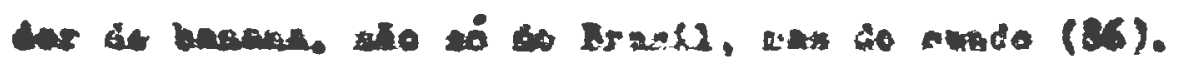

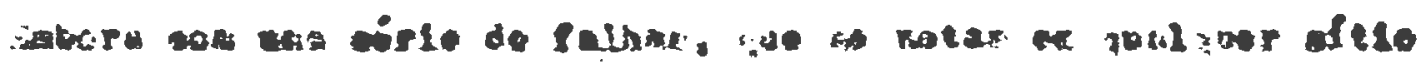

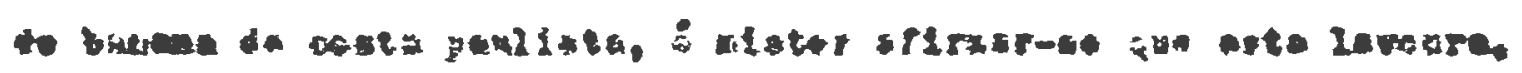

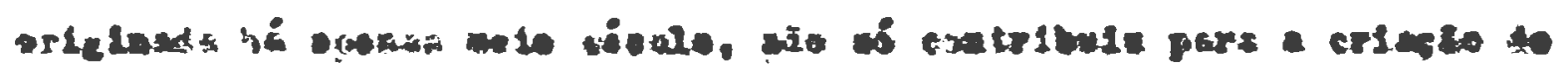

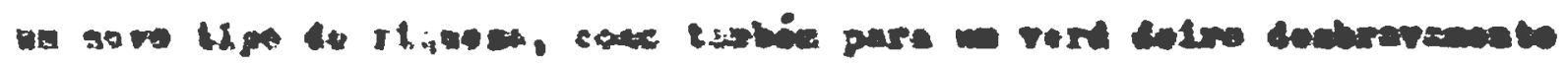

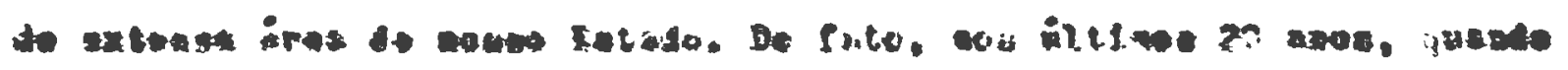

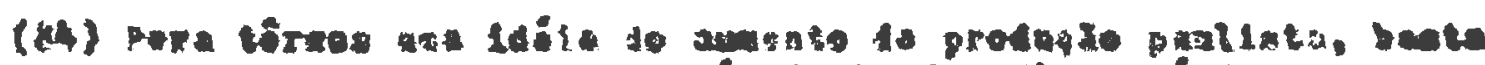

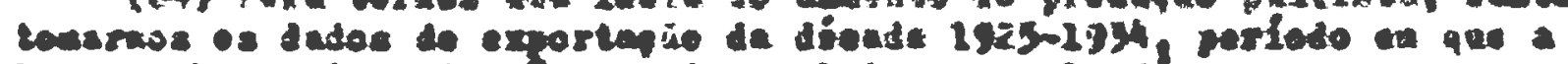

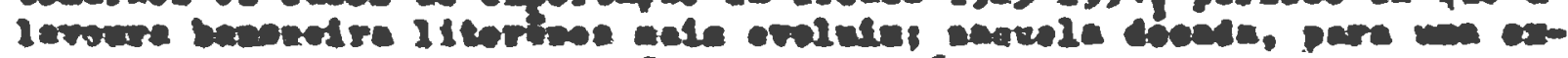

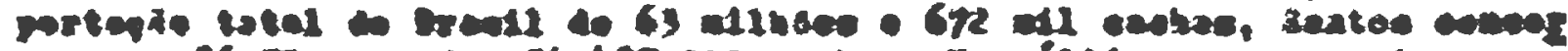

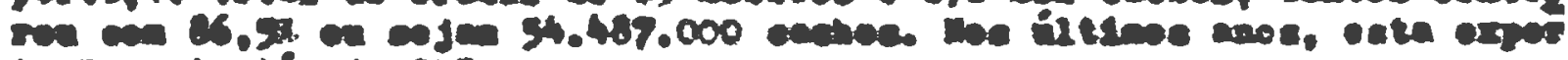
copio val ili do jot.

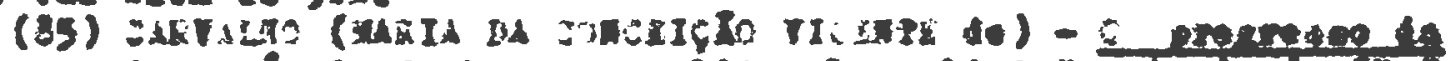

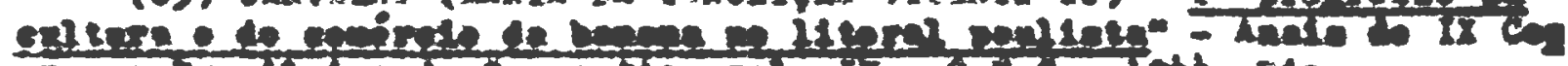

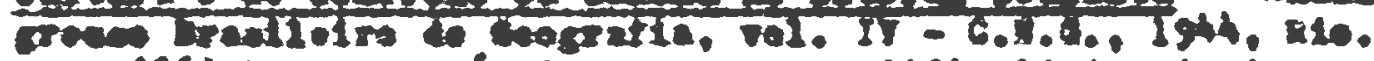

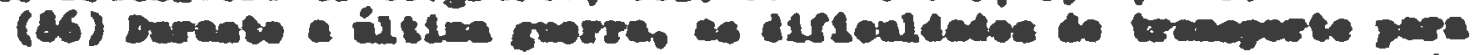

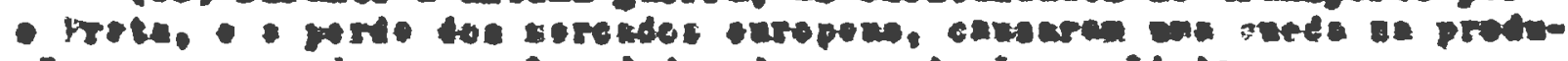

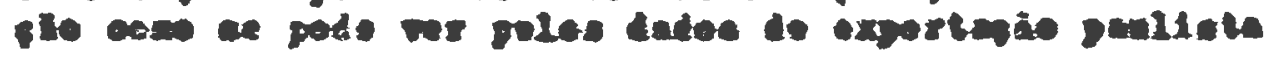

\begin{tabular}{|c|c|c|c|}
\hline $\begin{array}{l}1939 \\
1940 \\
1942 \\
1942 \\
1943 \\
1940 \\
1946\end{array}$ & 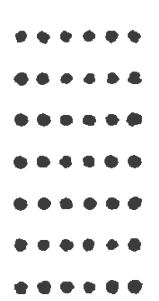 & $\begin{array}{r}12.061 .212 \\
10.05 \% .500 \\
6.17 .670 \\
3.313 .259 \\
2.265 .5 .97 \\
2.149 .57 \% \\
4.775 .216\end{array}$ & \\
\hline
\end{tabular}




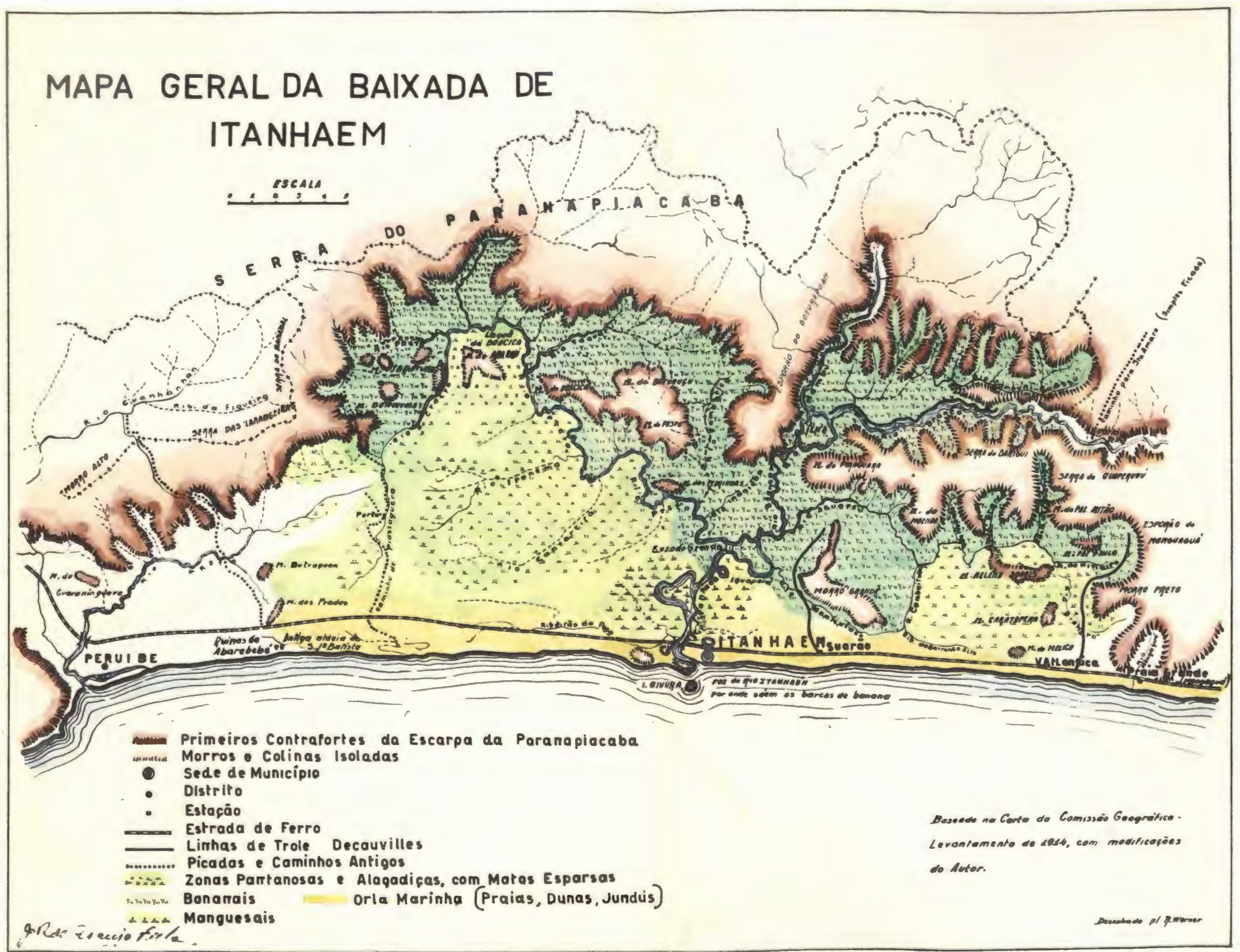




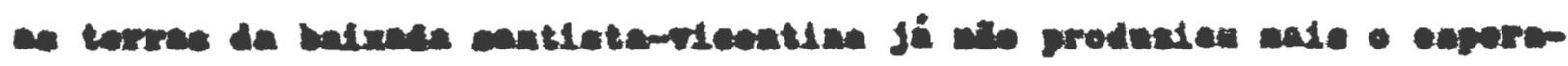

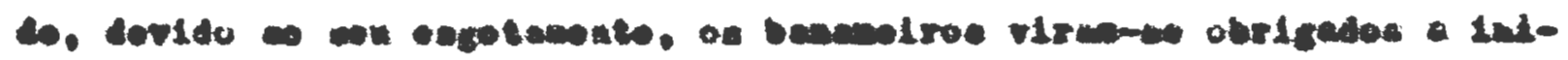

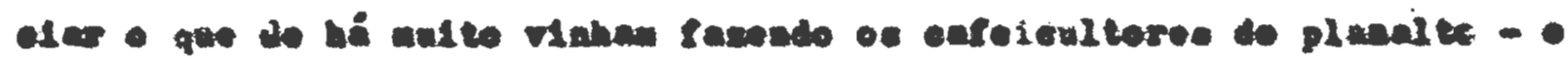

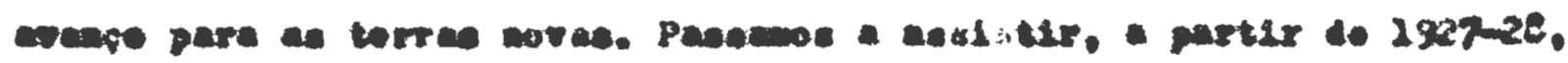

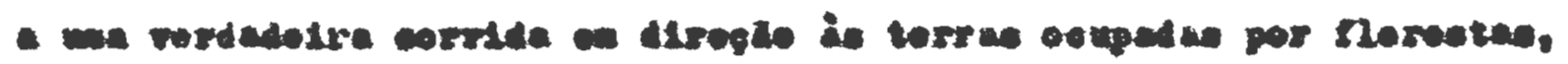

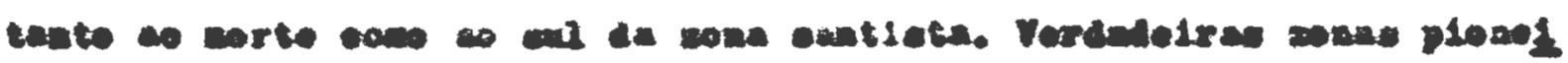

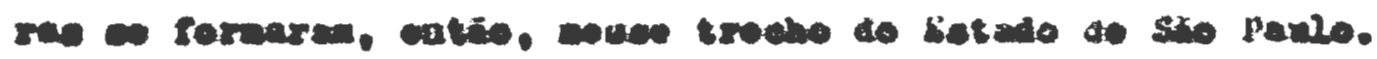

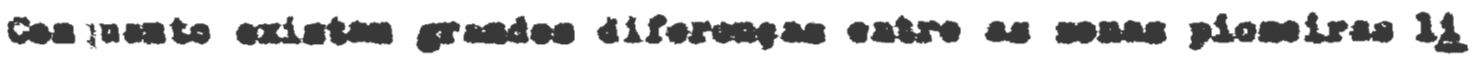

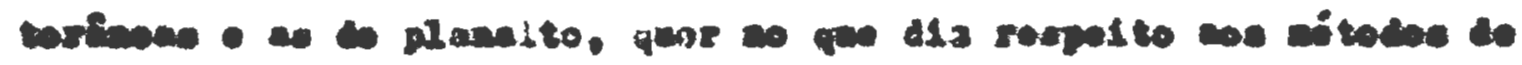

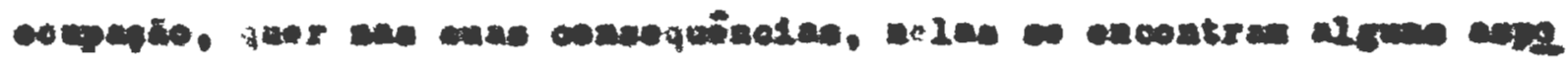

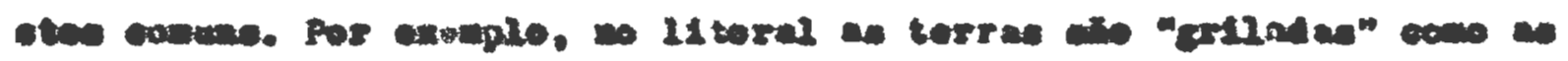

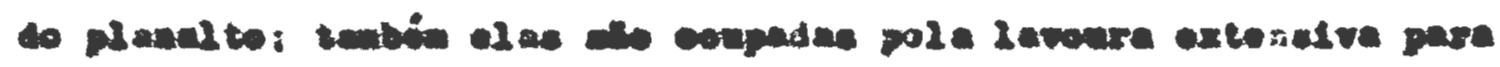

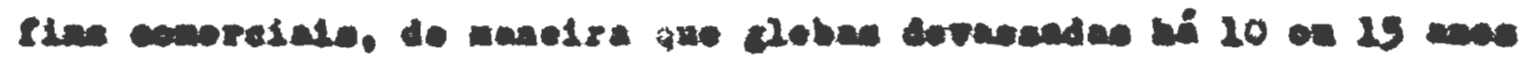

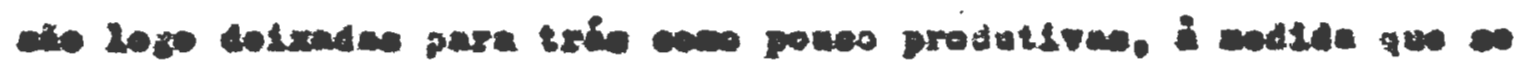

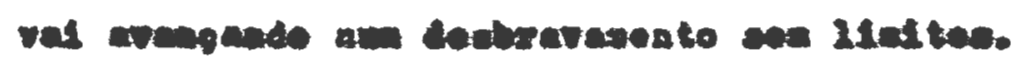

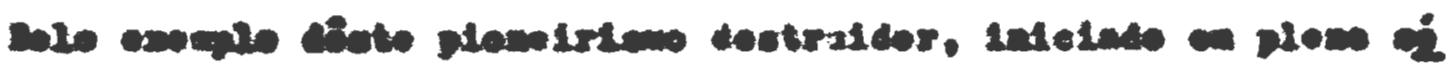

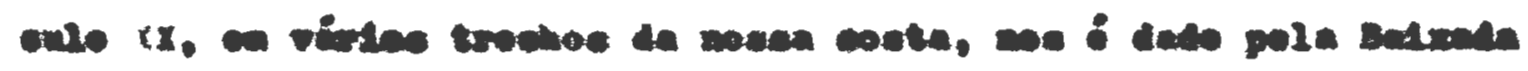

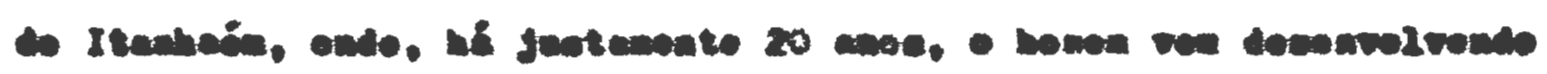

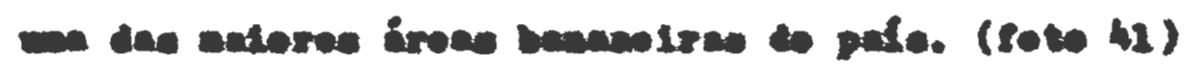

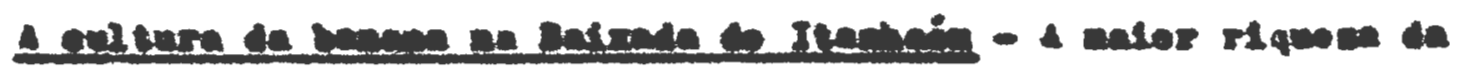

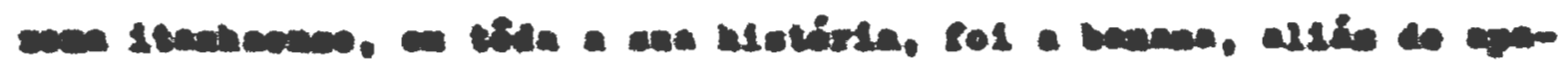

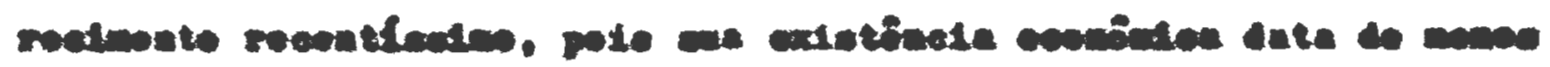

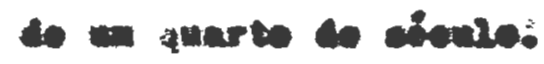

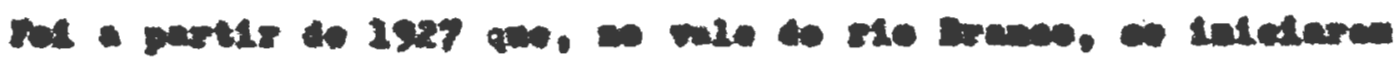

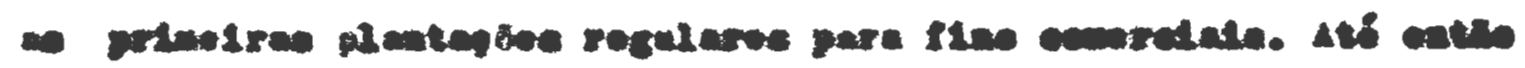




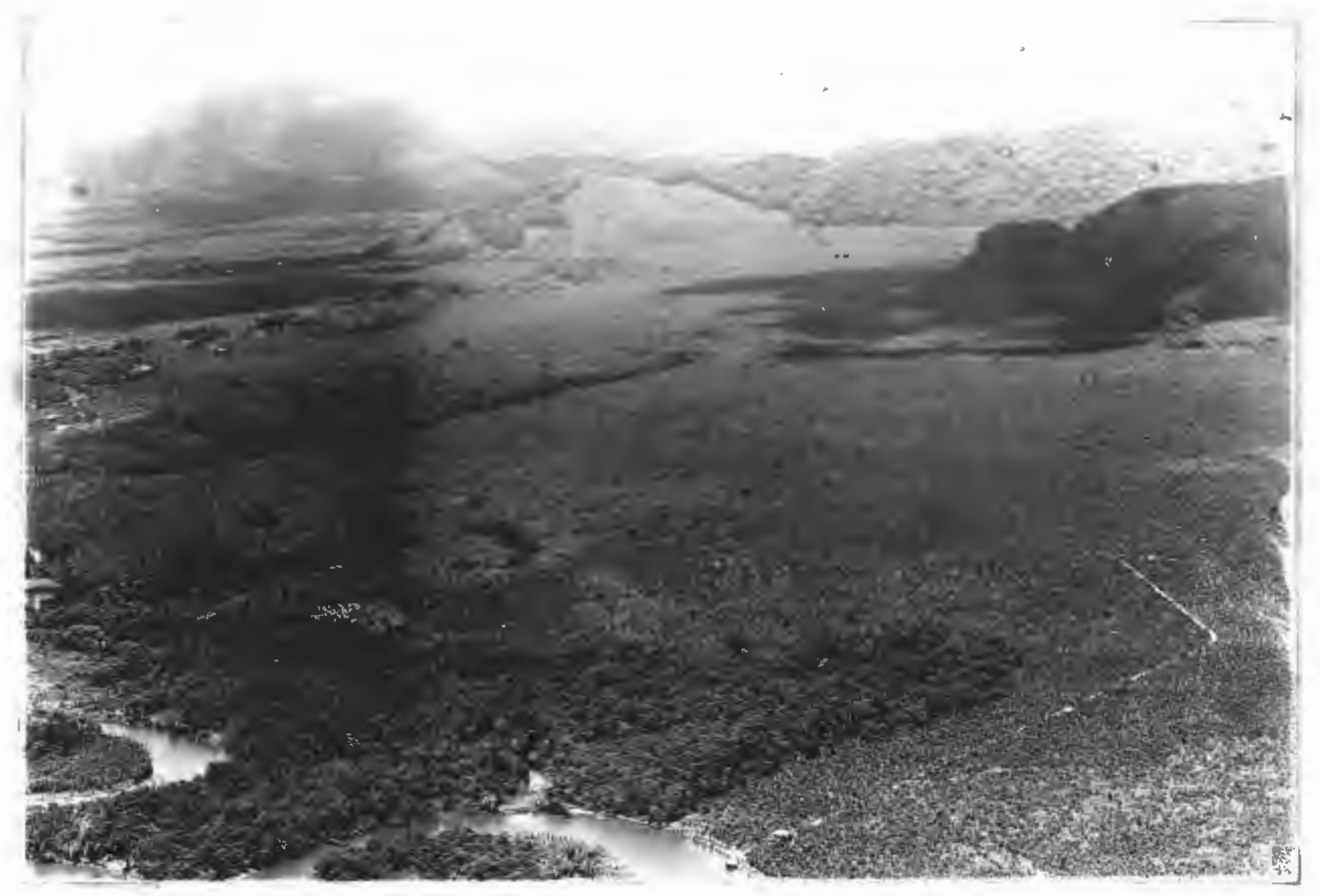

Foto 41. Vista aérea de um trecho da baixada interior, onde justamente 0 homem mais tem modificado a paisagem natural,derrubando a floresta e plantando extensos bananais. Na presente foto aparecem os dois aspéctos que os bananais itanhaenses oferecem: as lavouras da baixada e a das encostas. (foto do C.N.G. - Diretoría Regional de Geografia no Estado de São Paulo). 


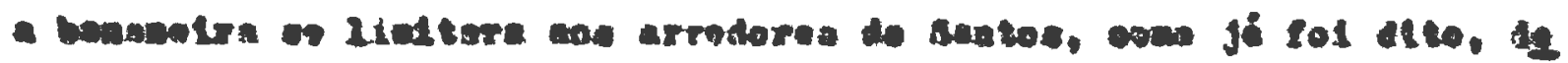

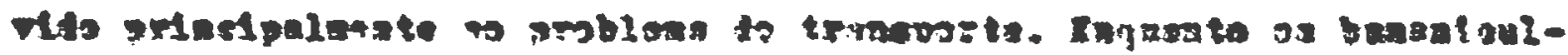

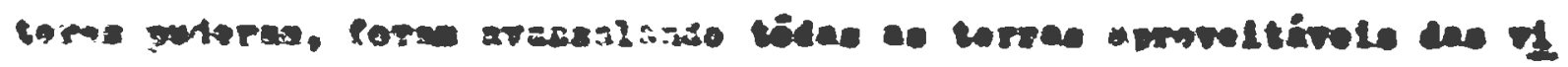

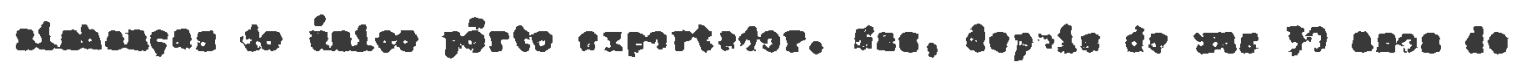

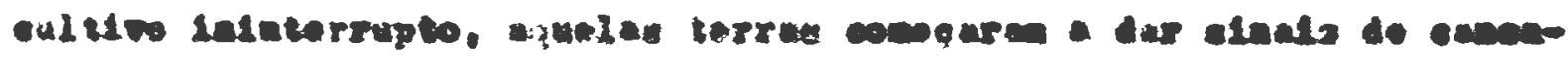
pe, e into por welta de 2924-2925.

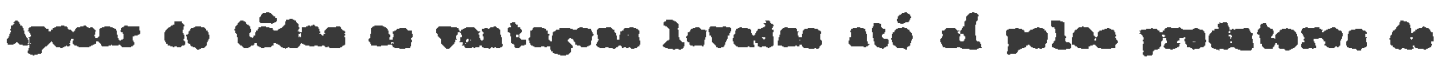

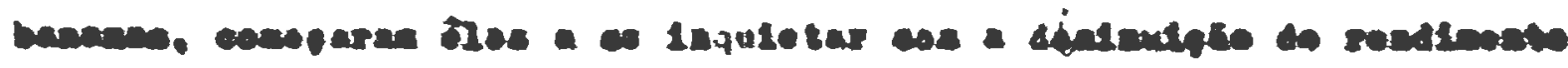

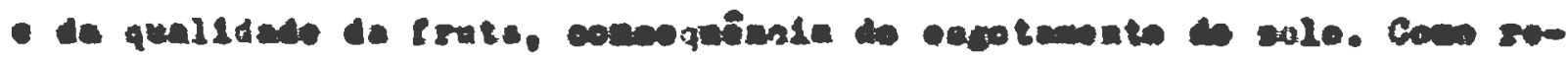

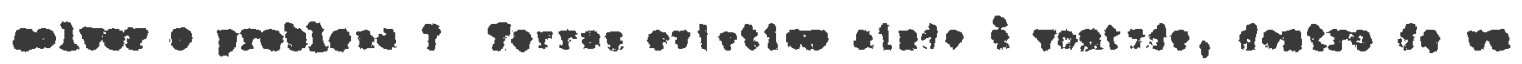

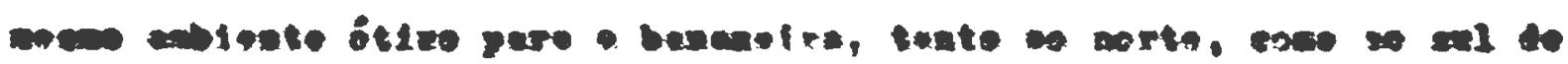

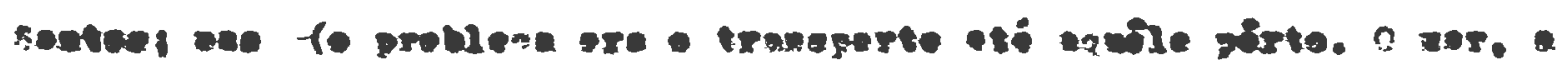

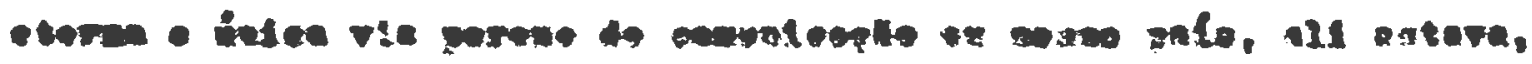

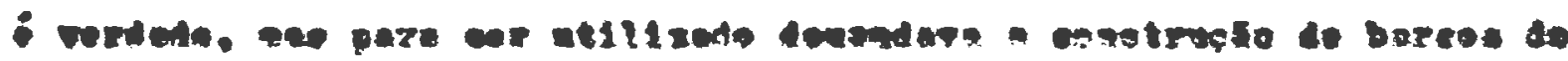

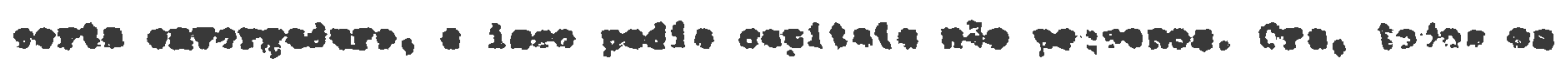

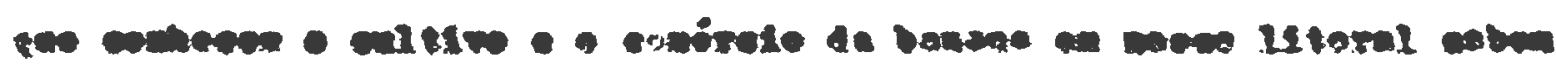

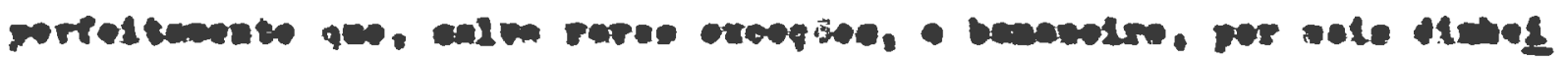

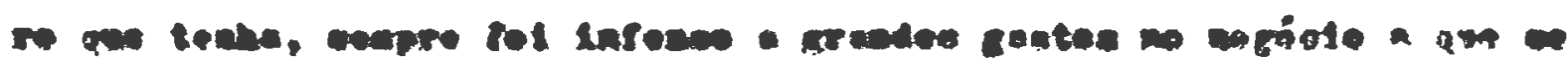

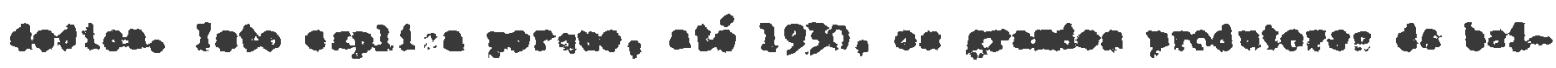

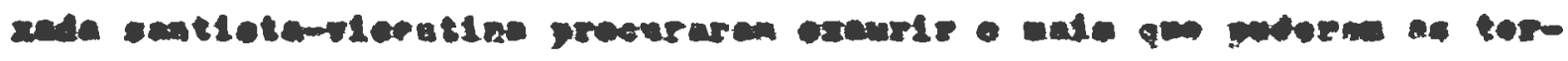

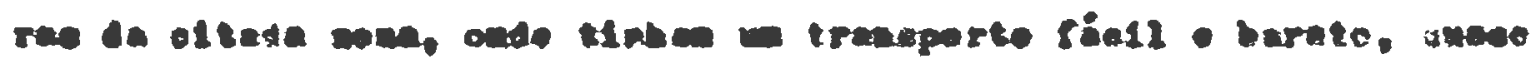

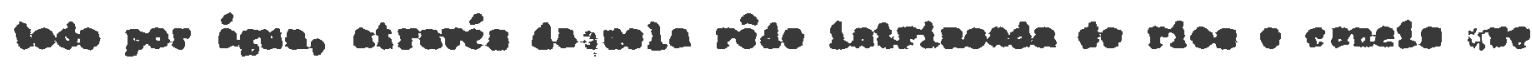

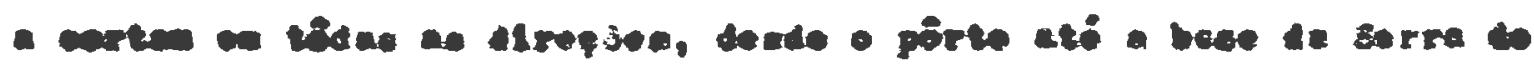
was.

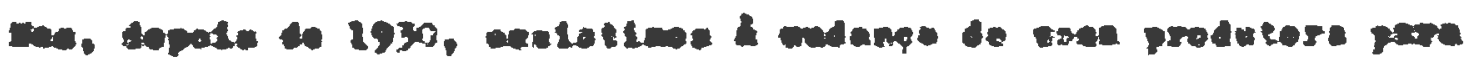

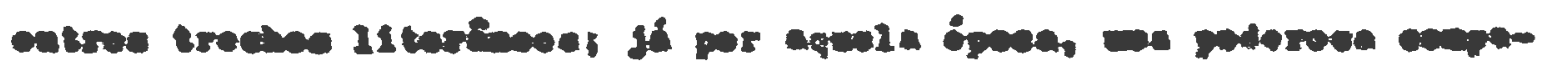




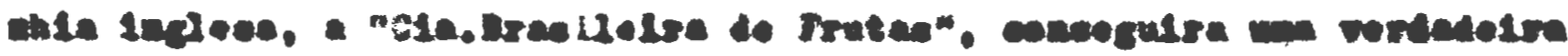

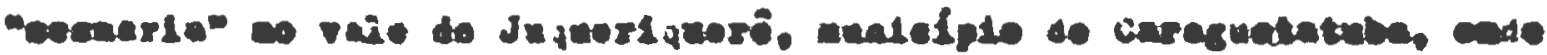

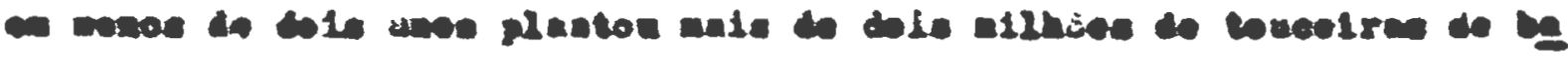
manelras.

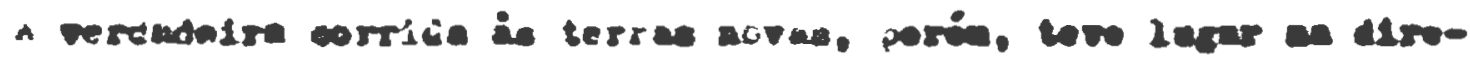

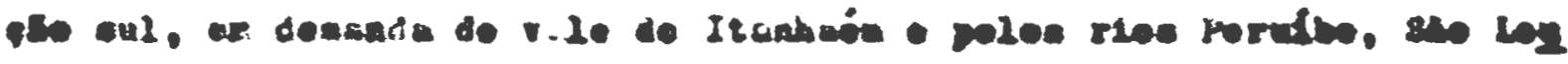

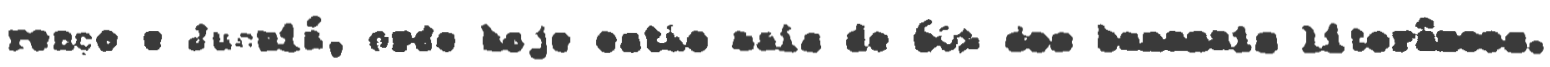

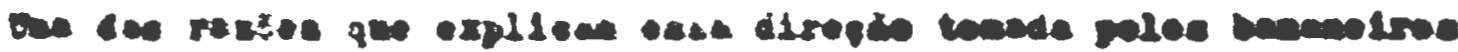

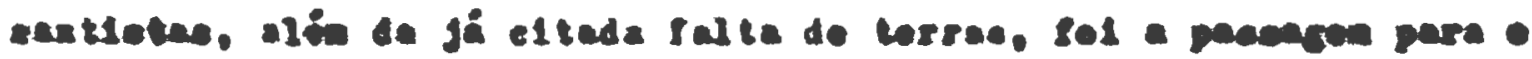

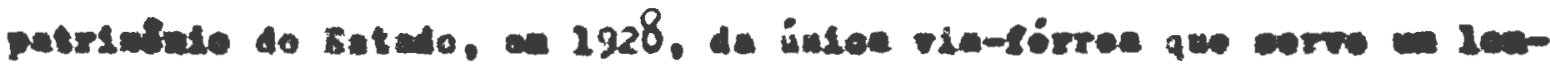

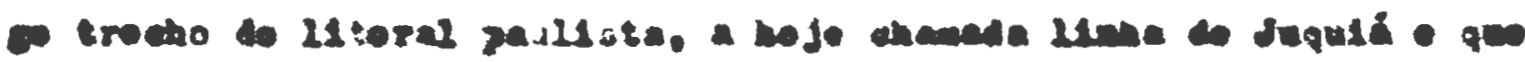

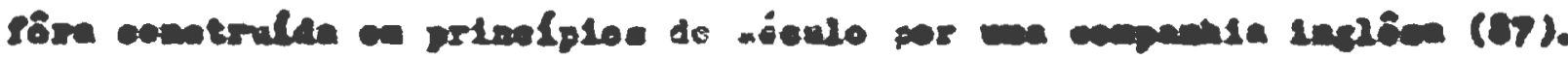

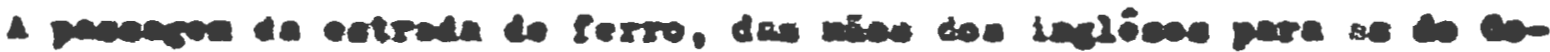

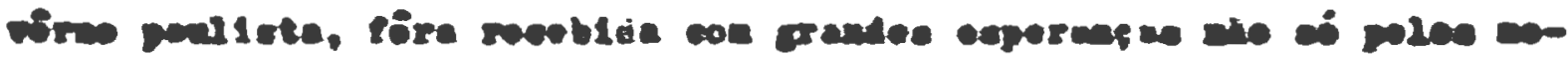

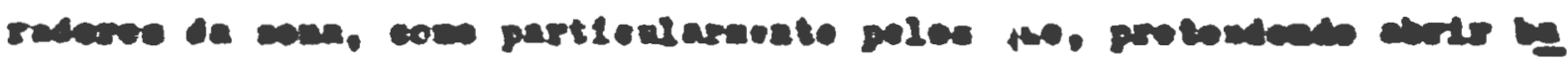

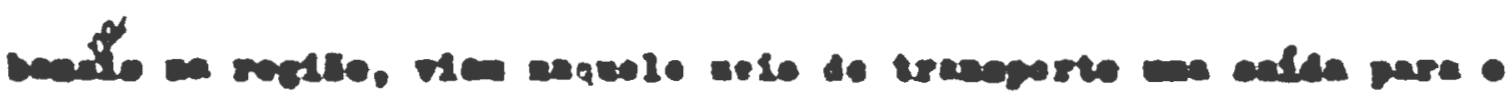

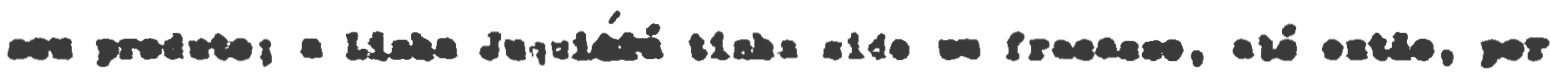

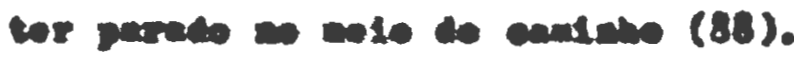

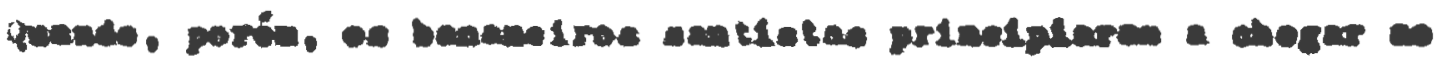

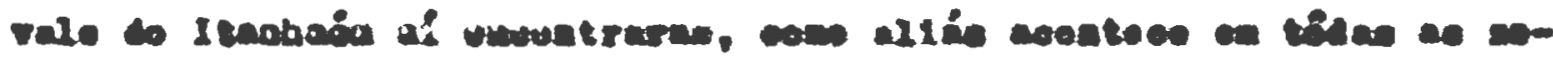

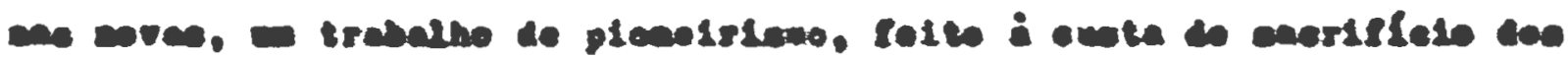

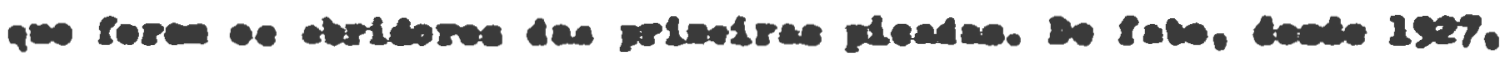

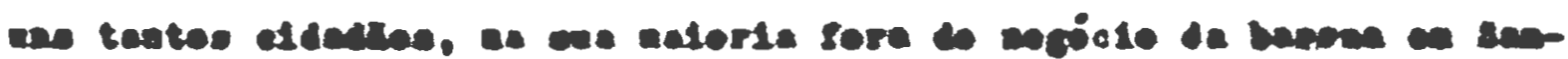

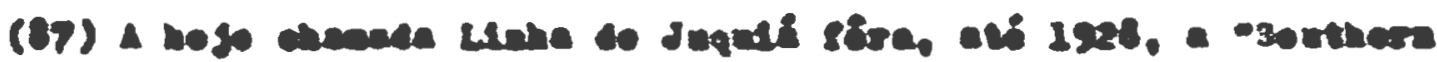

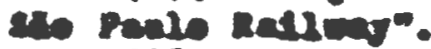

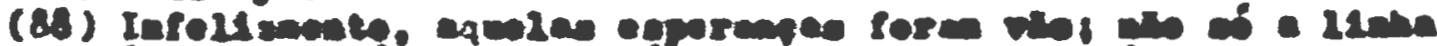

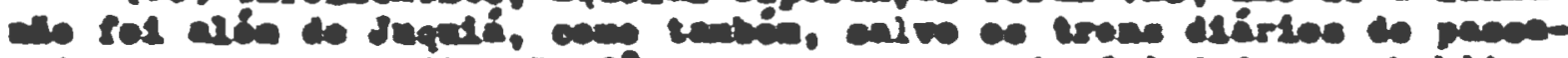

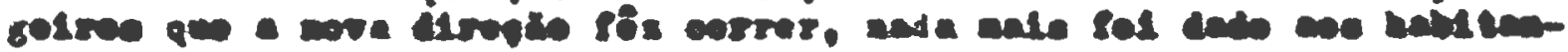
toe. 


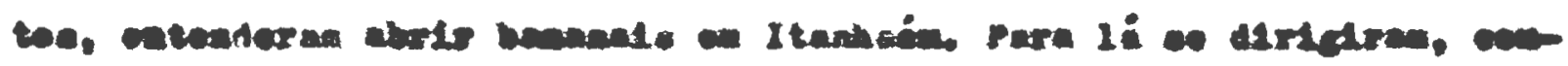

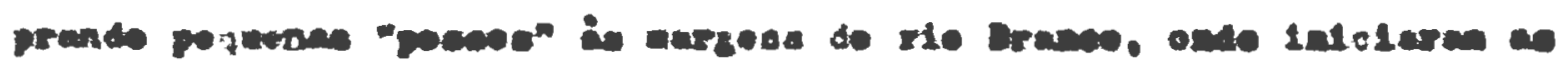

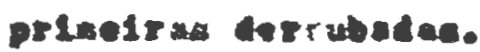

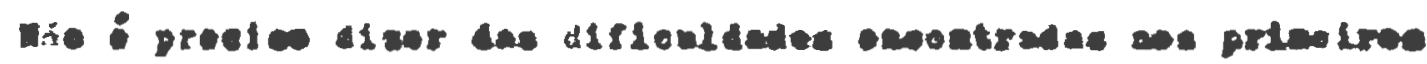

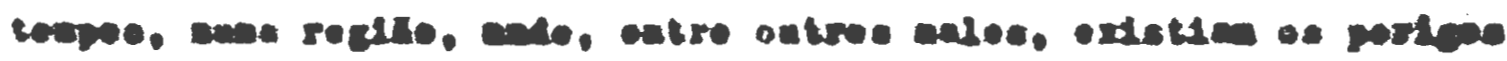

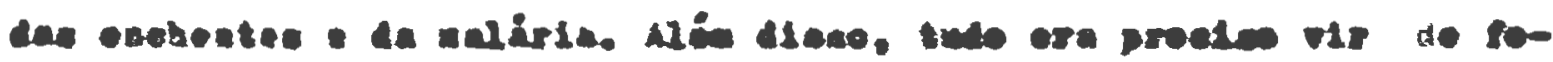

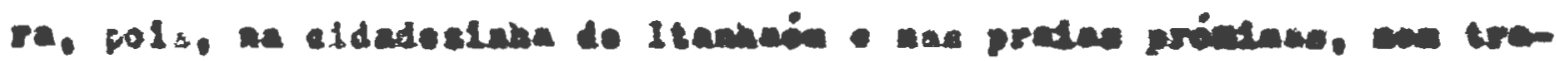

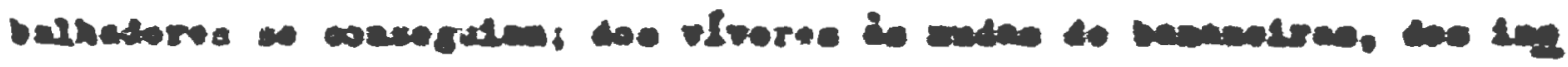

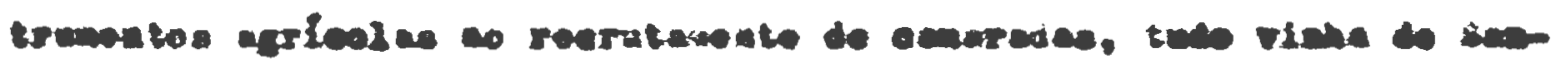
toe (0)

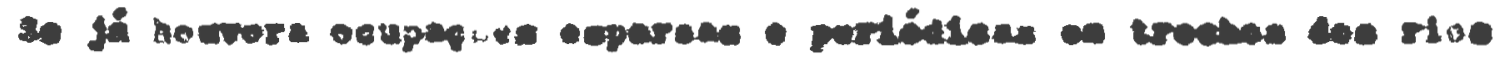

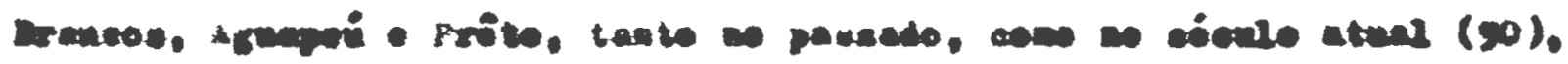

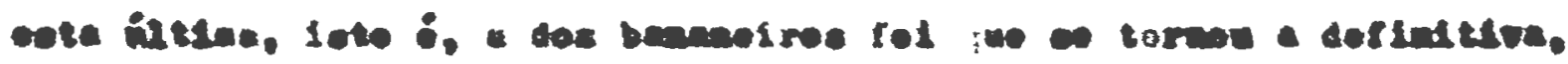

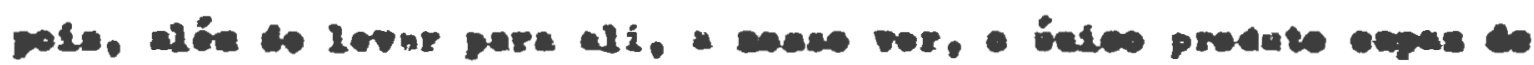

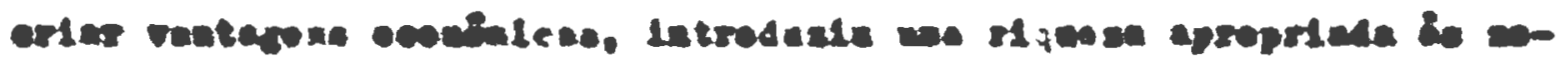

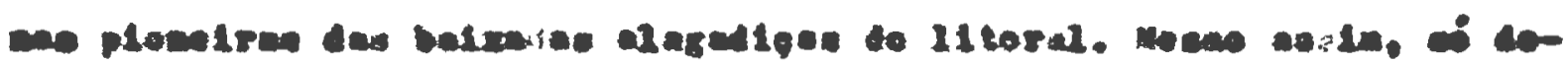

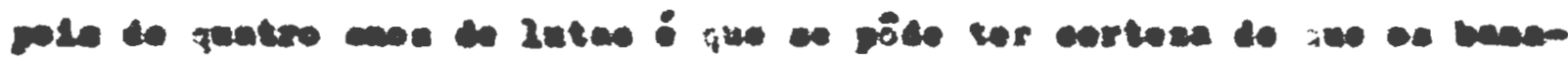
ala Lren para a Irmece.

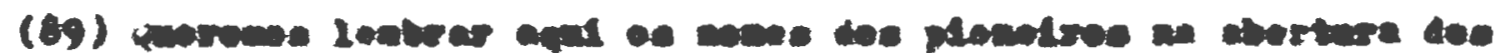

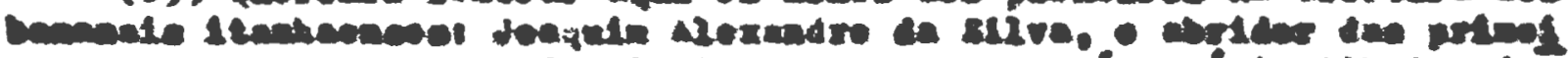

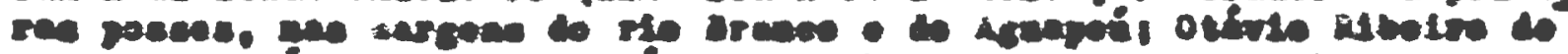

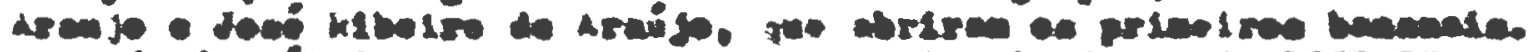

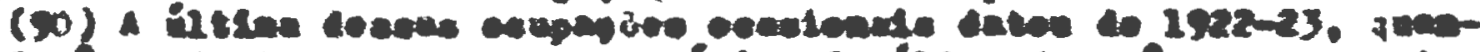

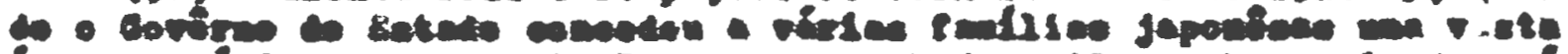

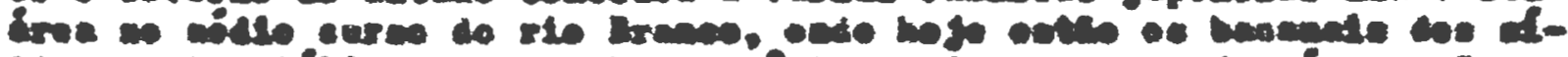

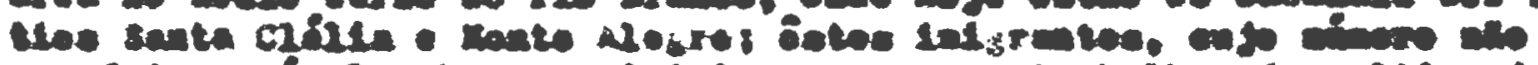

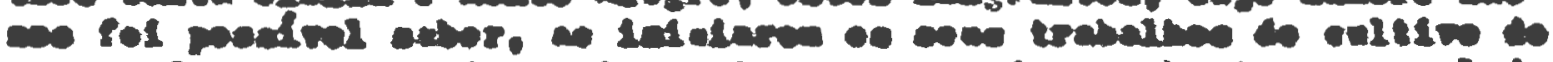

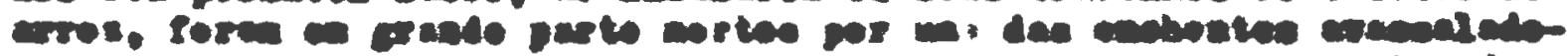

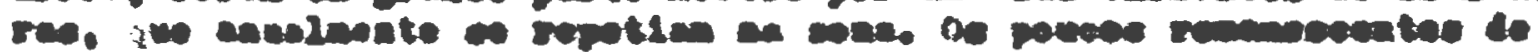

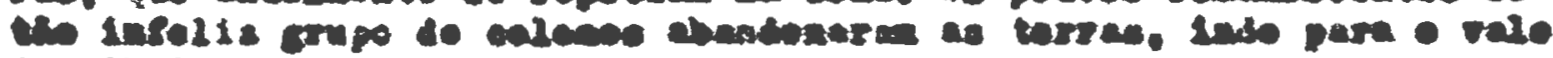
a nevelran. 


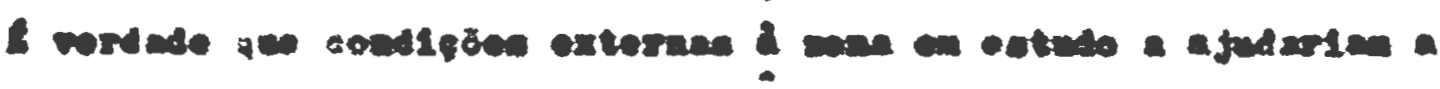

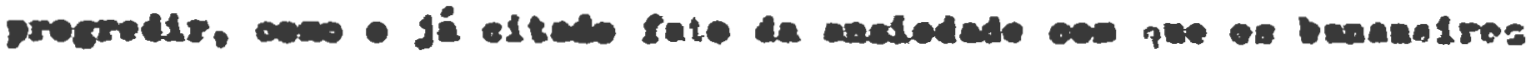

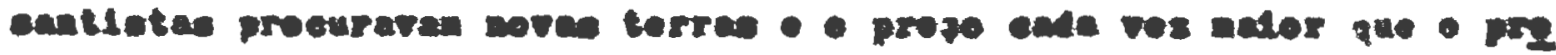

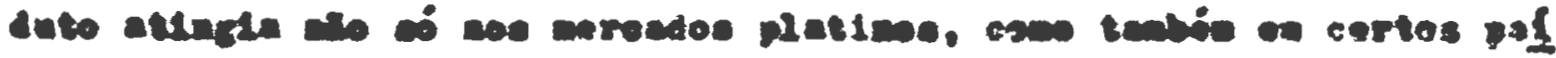

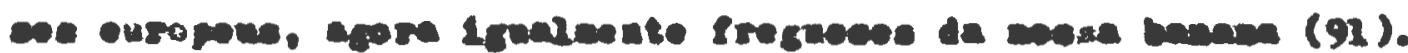

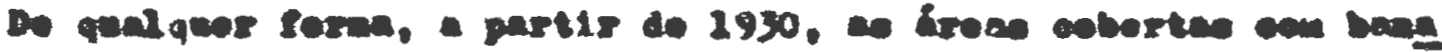

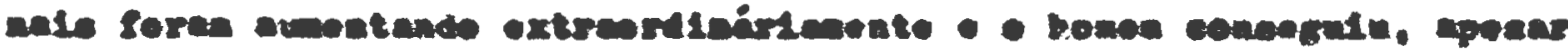

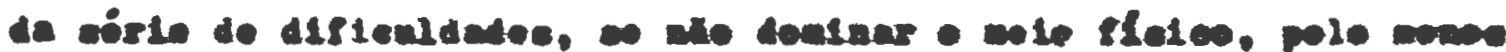

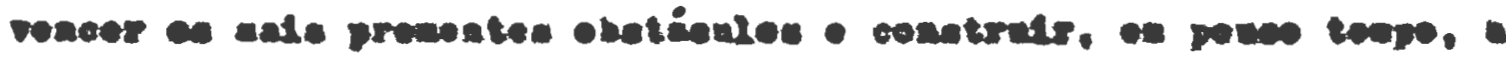

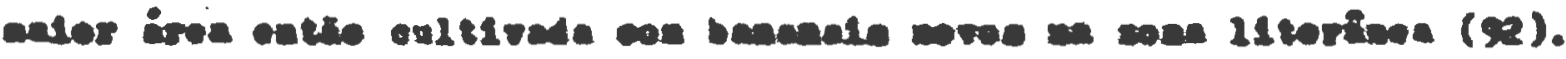
(sotee 42, 43,44, 45, 46, 47)

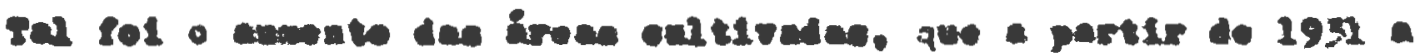

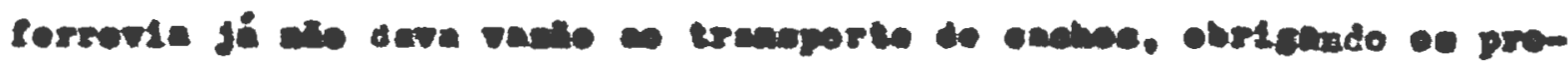

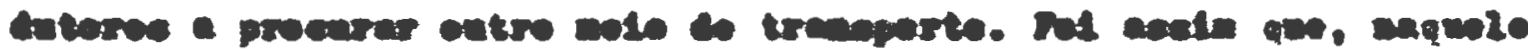

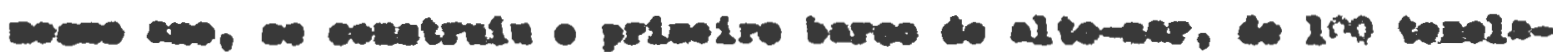

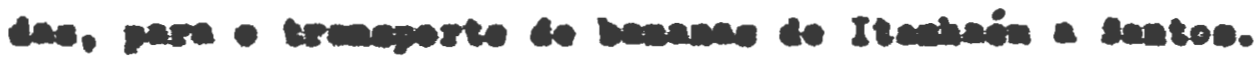

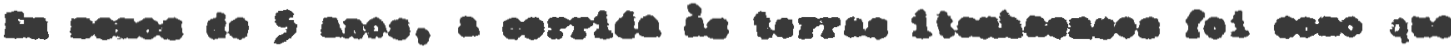

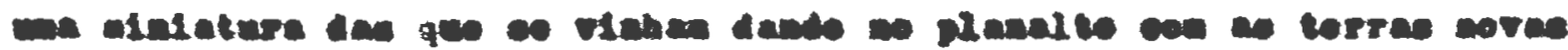

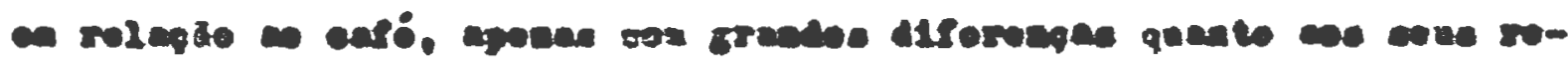

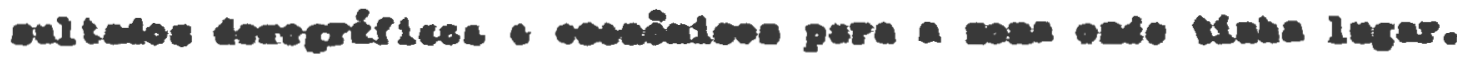

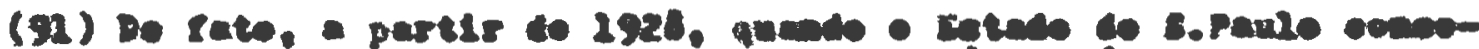

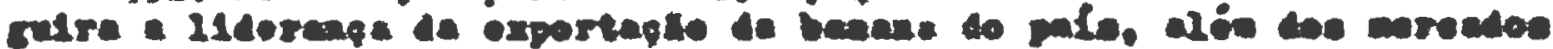

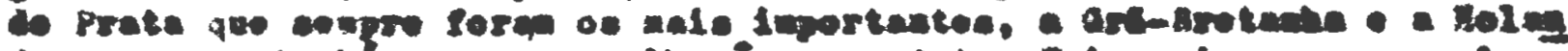

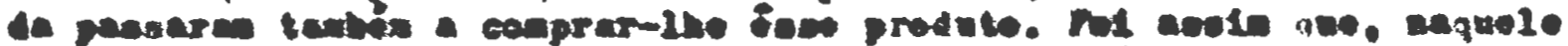

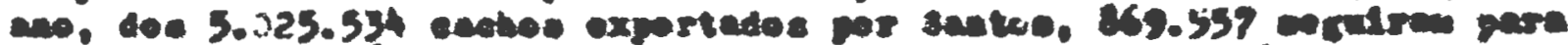

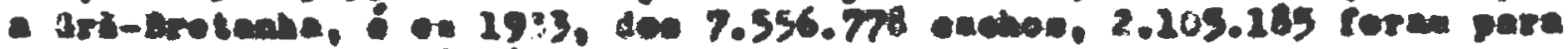

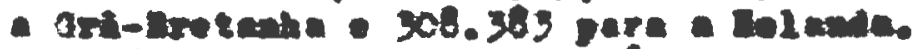

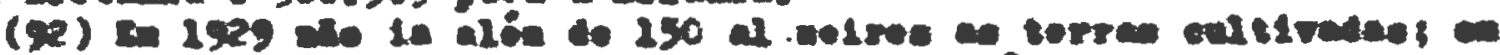

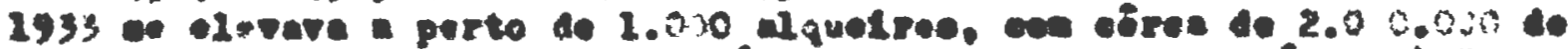

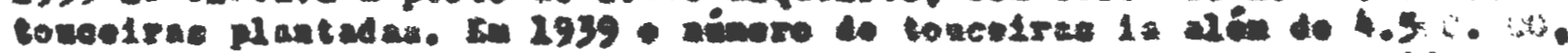

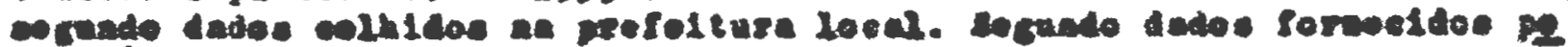

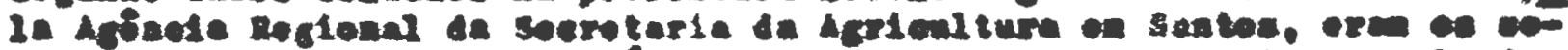

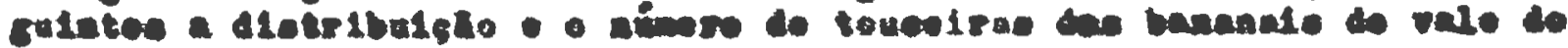




\section{0}

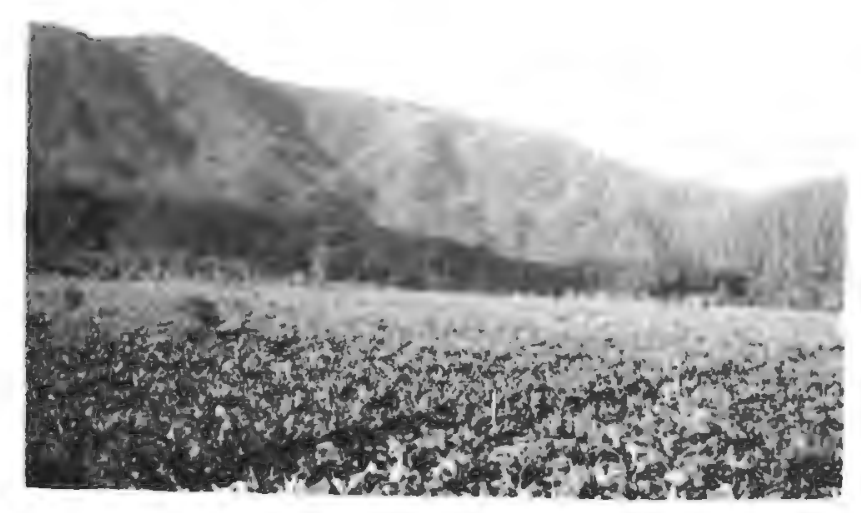

Foto 42.

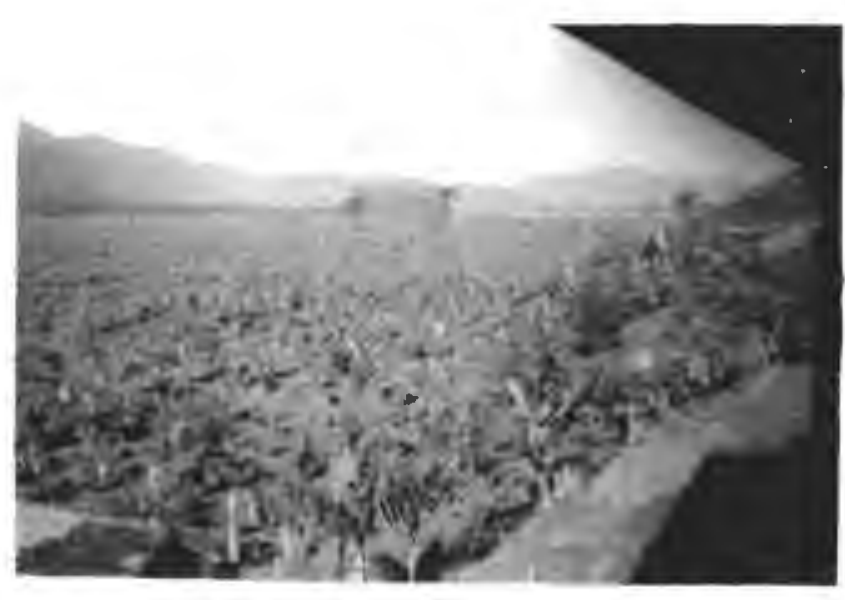

Foto 43.

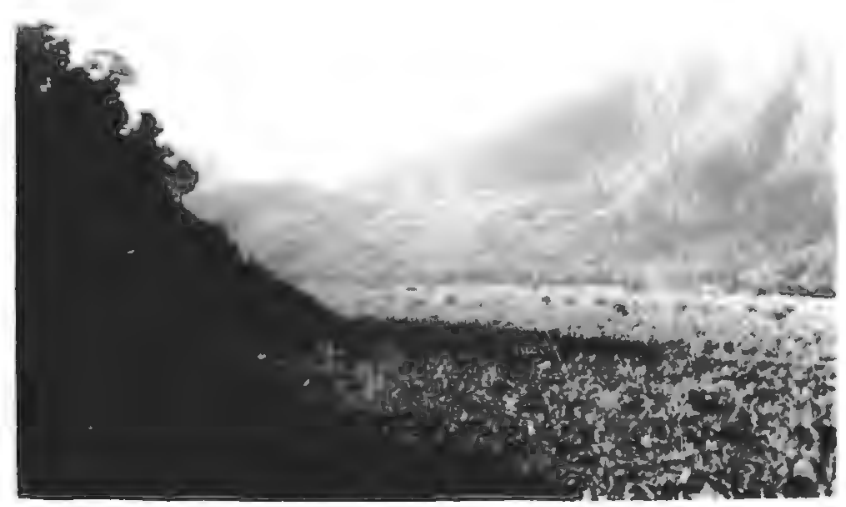

Foto 44.

Aspéctos de um dos melhores bananais da baixada do Itanhaém; vistas tomadas na "razenda Aurea", no trecho do vale do rio Branco que muito se assemelha com o do Jubatão, (foto A.R.Penteado). 


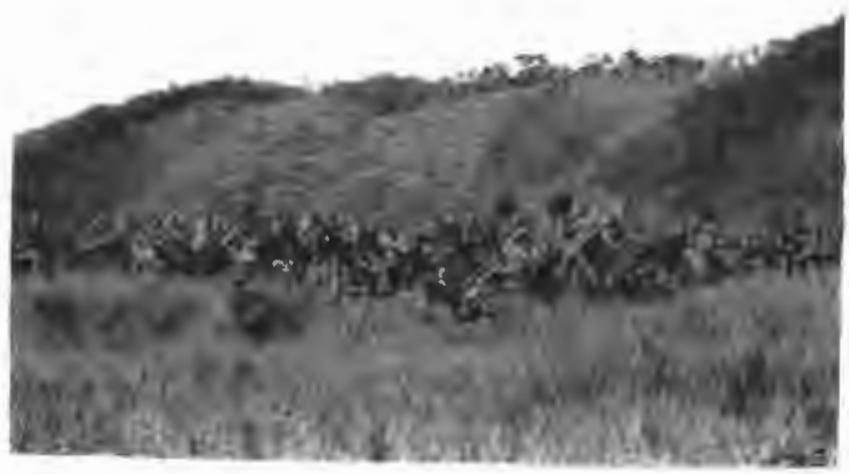

Foto 45.

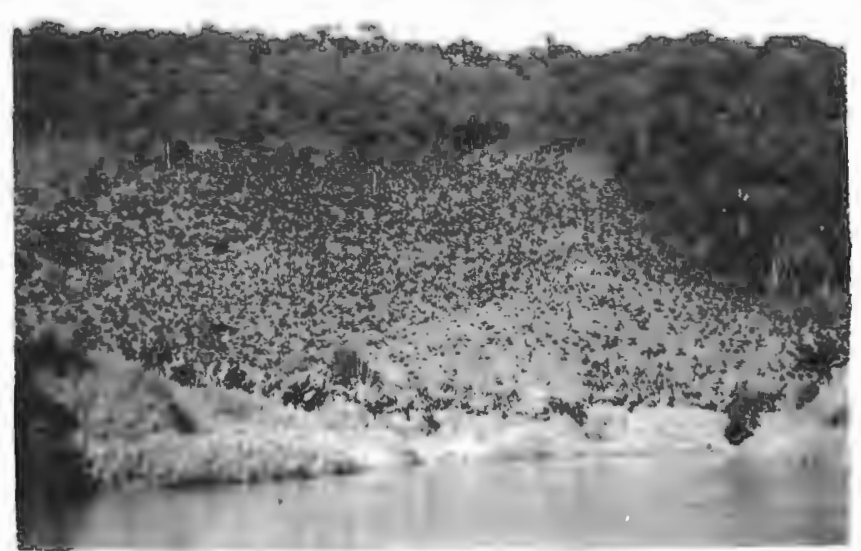

Foto 46.

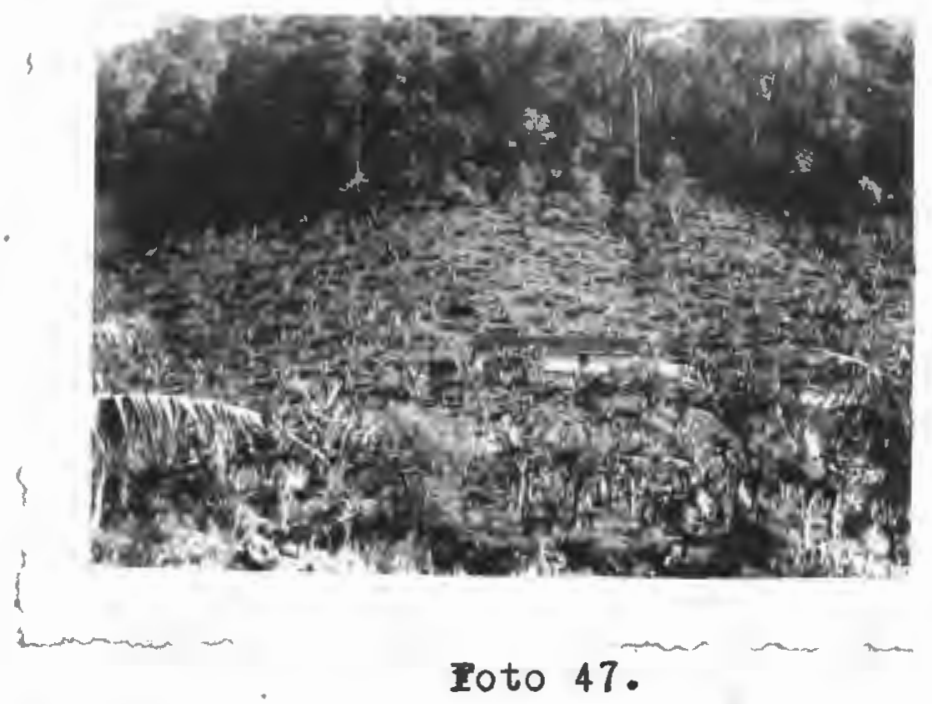

Provas do avanço do homem pelas encostas àcimafdesde que as terras da baixada já não bastam. A primeira fotografia mostra uma derrubada em toda a encosta de um trecho da serra de Guaperuvu; as outras duas dåo uma vista de bananais de encosta e por onde se pode observar o contraste com a lavoura da baixada. Nas encostas as bananais são menos viçosos e não duram mais que cinco anos economicamente.

(fotos A.R.Penteado). 


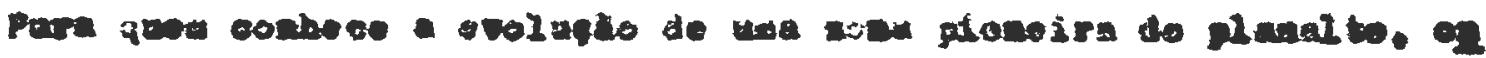

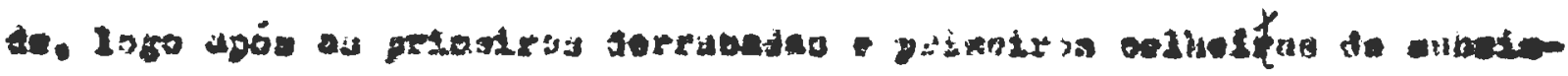

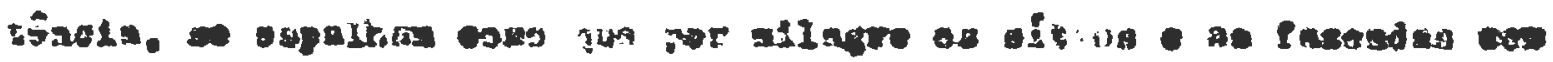

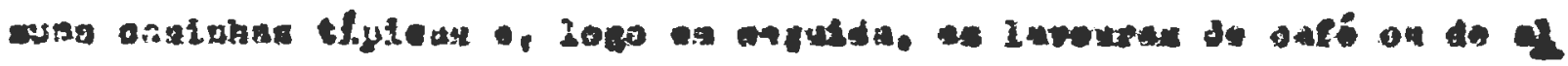

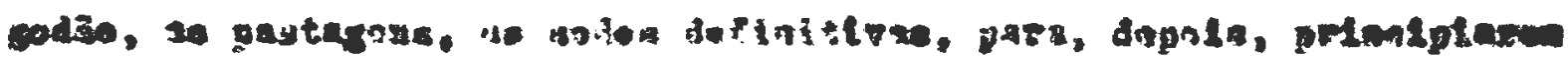

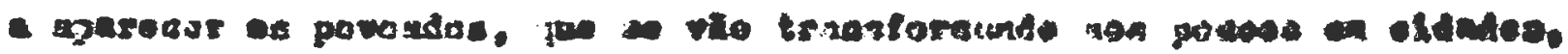

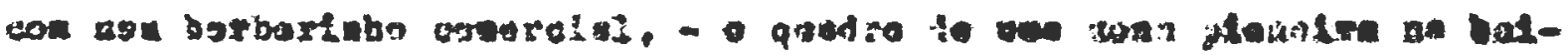

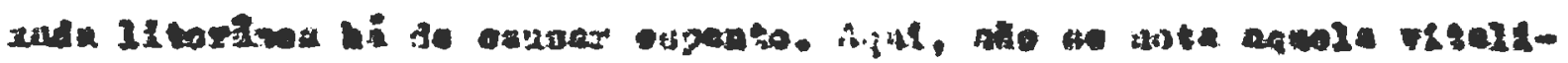

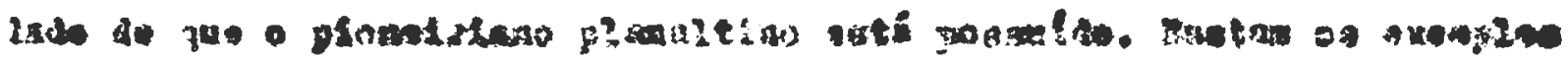

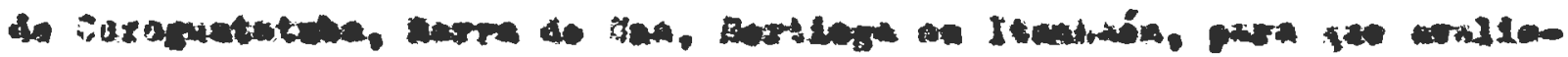

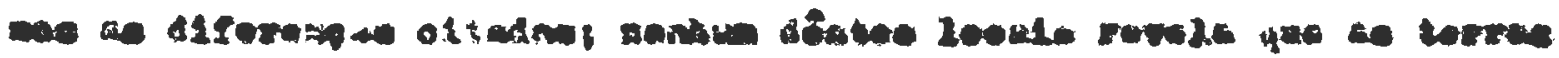

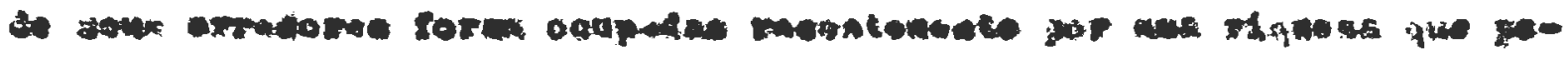

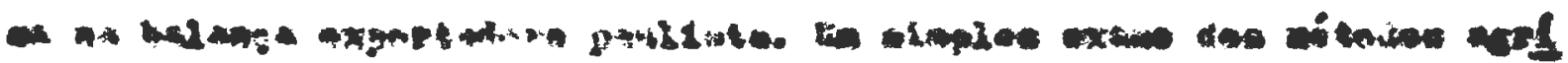

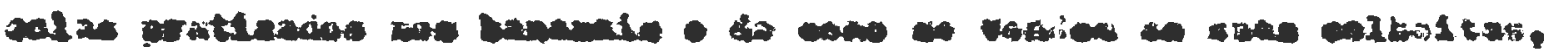

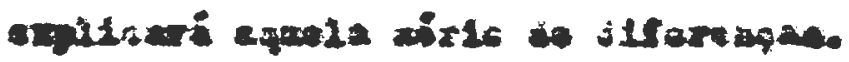

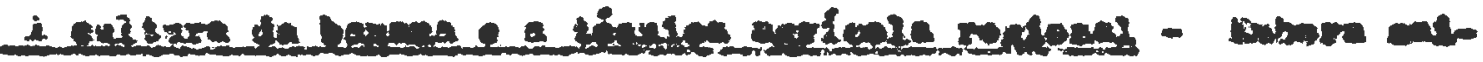

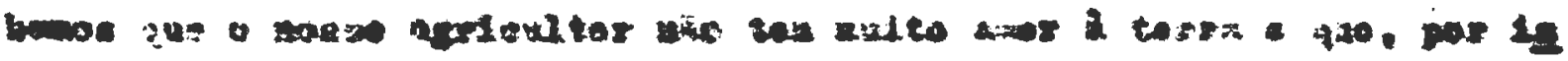

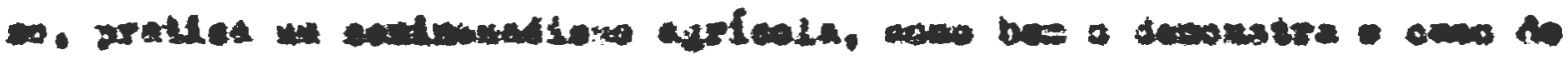

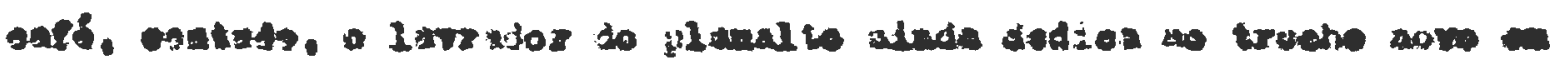

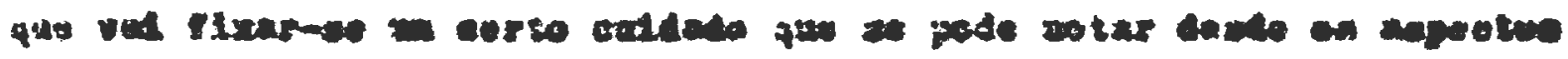

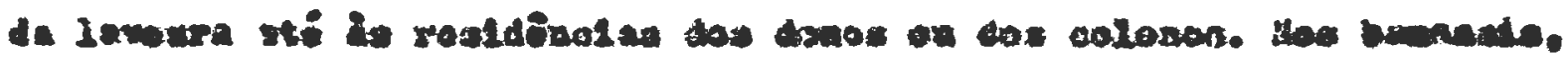

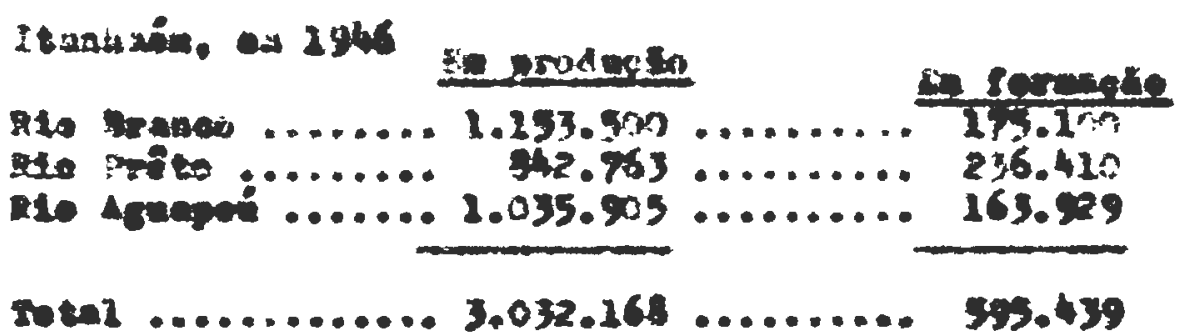

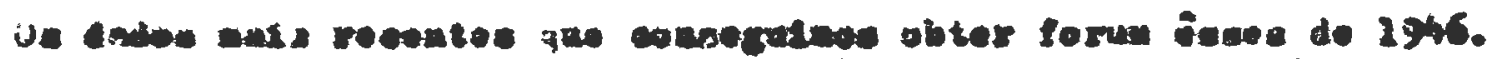

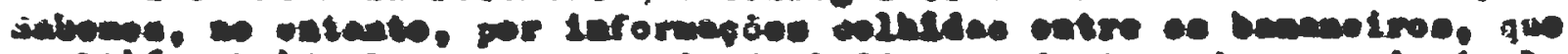

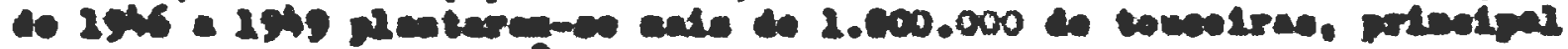

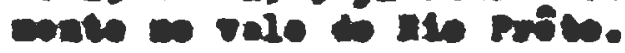




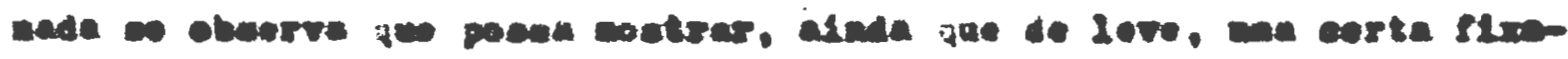

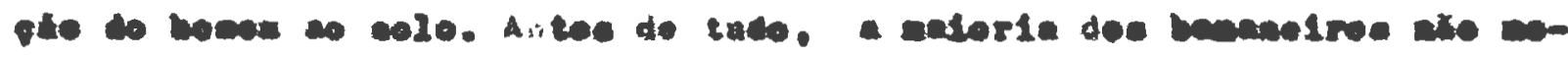

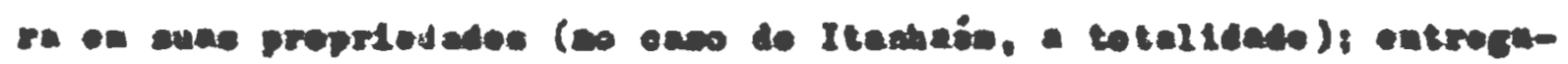

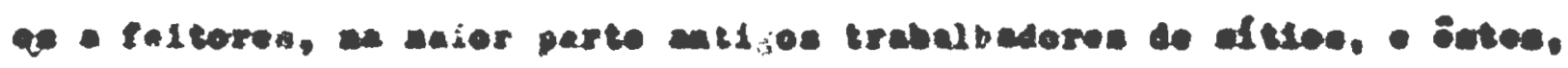

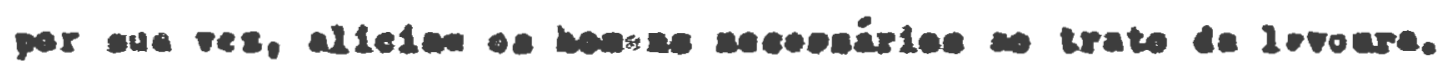

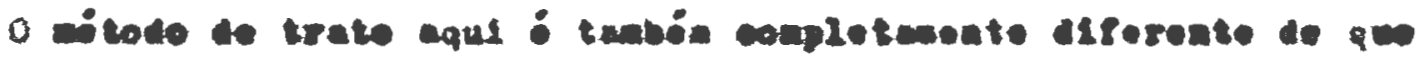

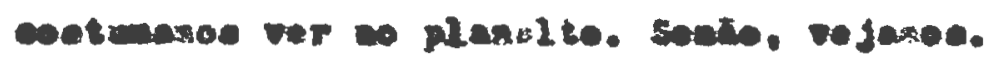

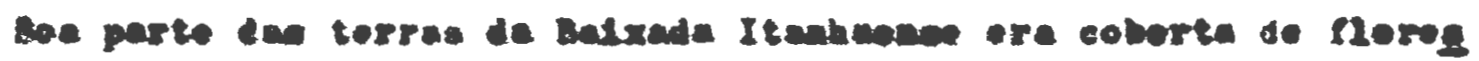

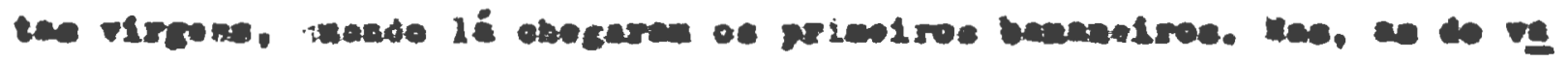

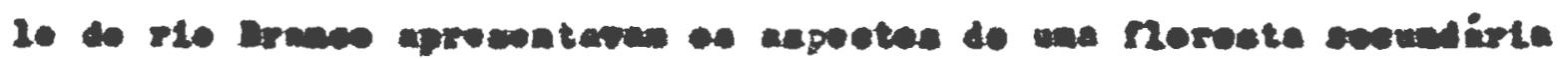

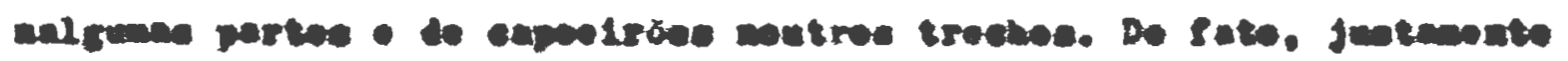

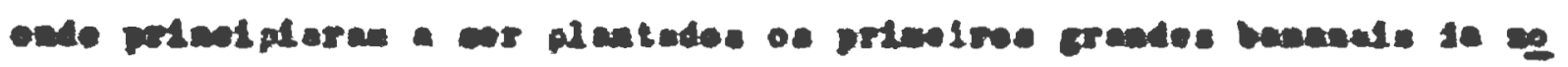

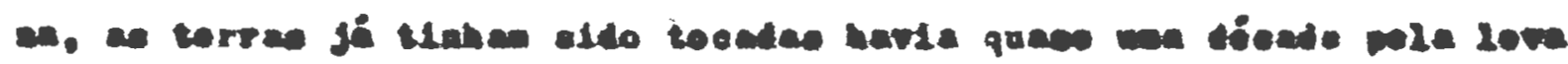

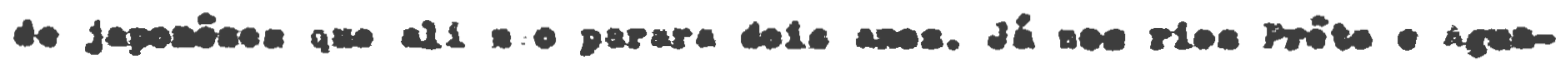

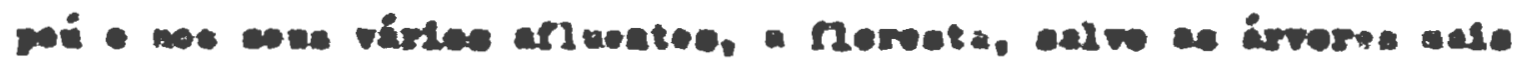

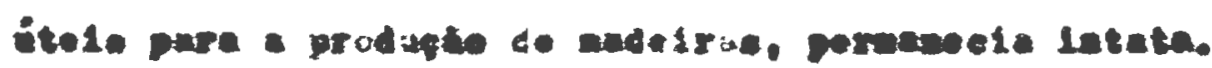

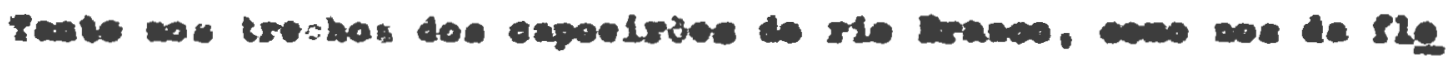

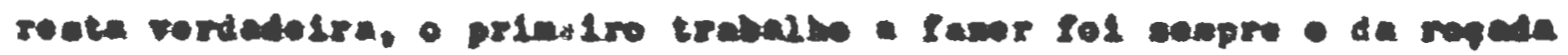

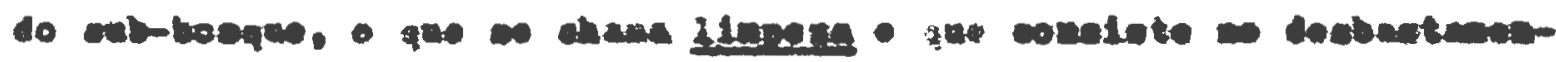

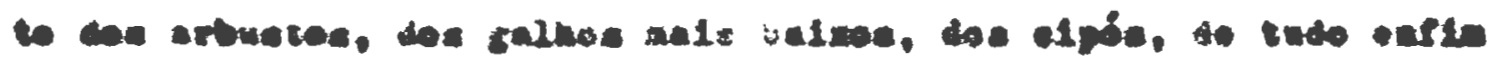

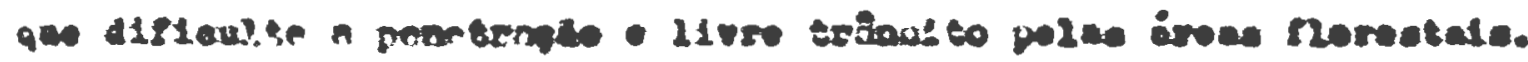

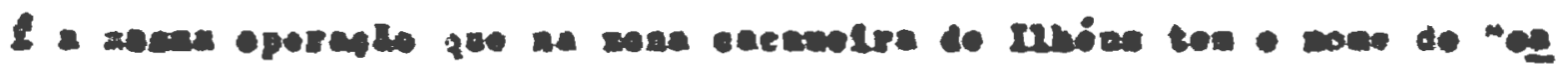
ureeneaton (93).

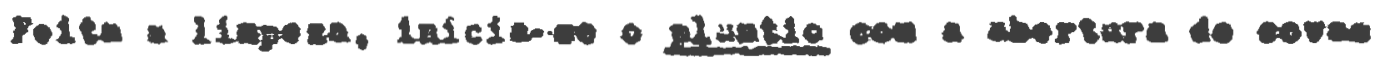

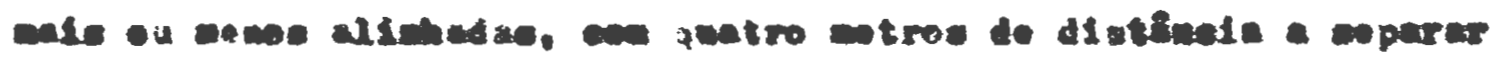




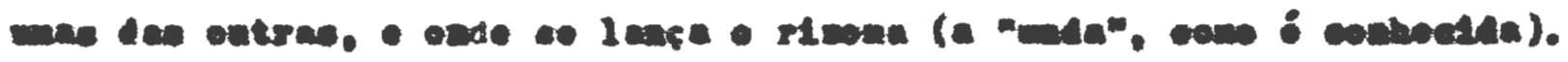

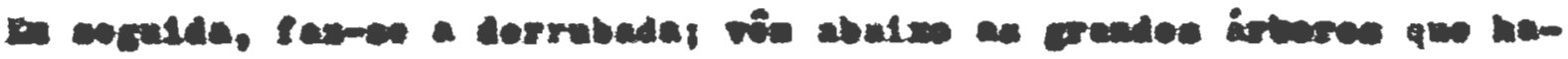

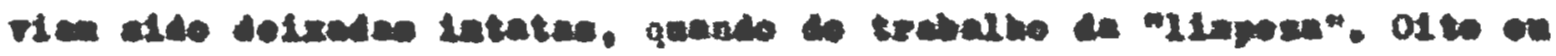

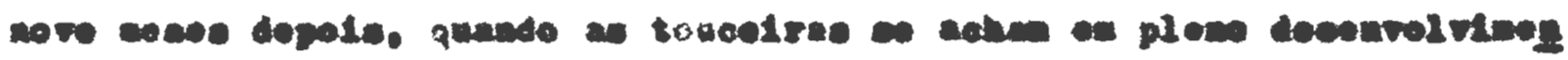

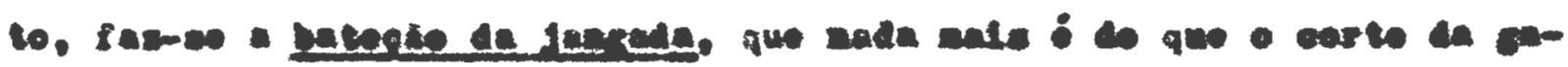

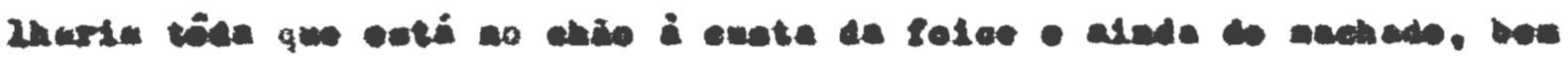

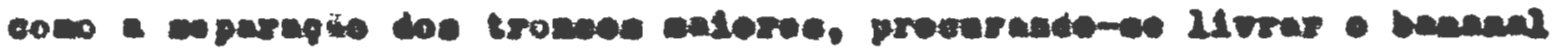

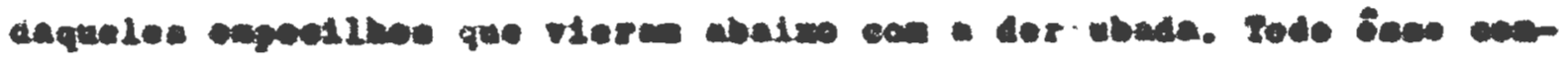

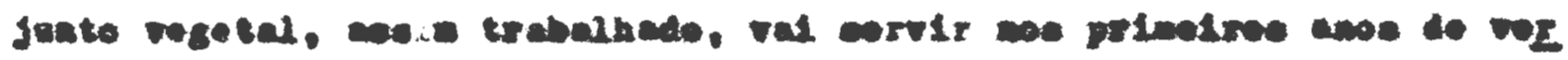

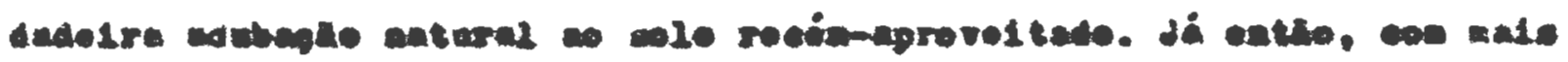

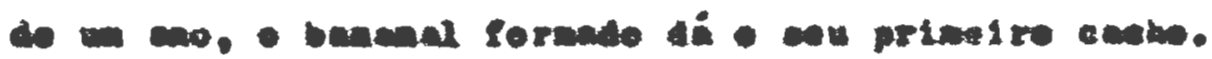

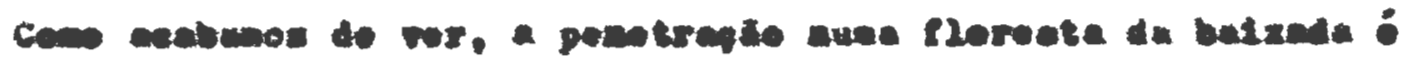

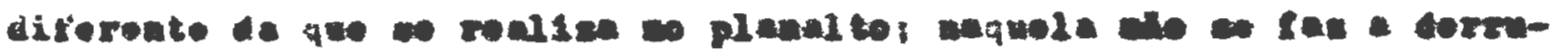

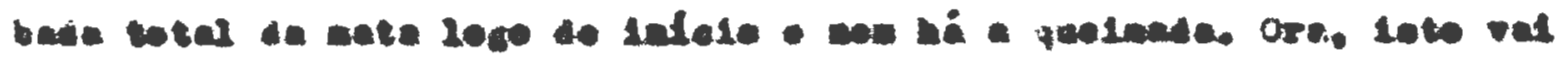

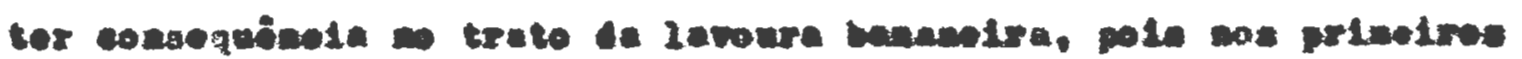

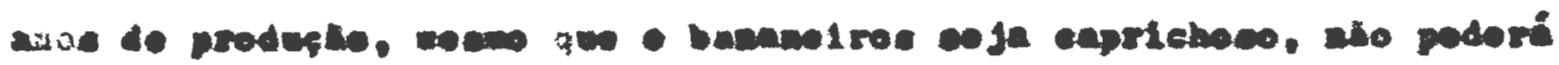

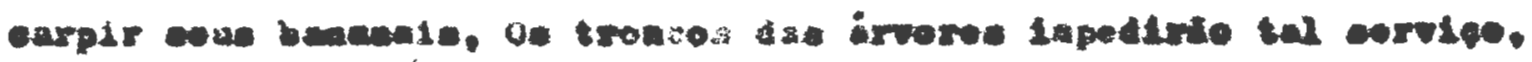

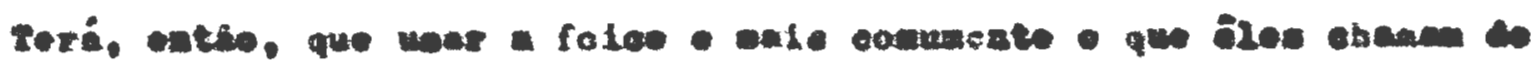

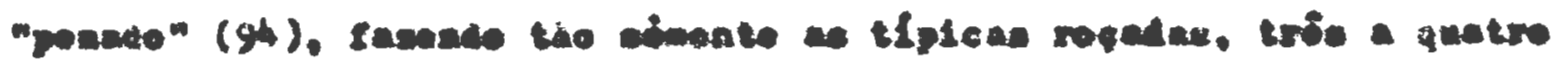
Fise so no, on will.

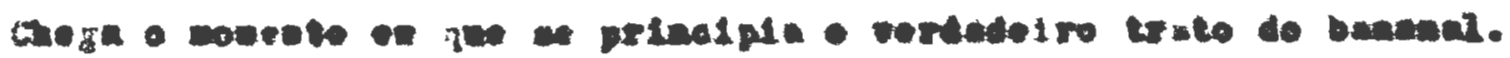

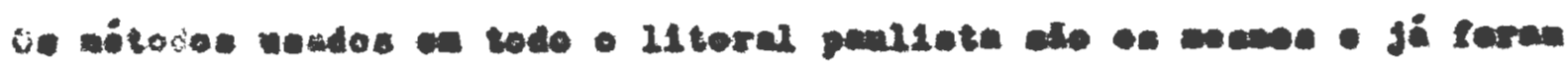

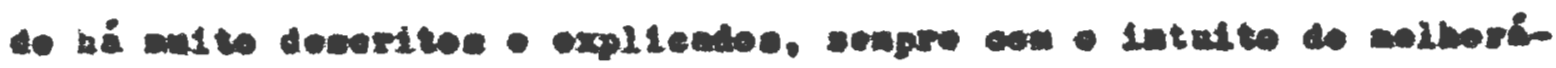

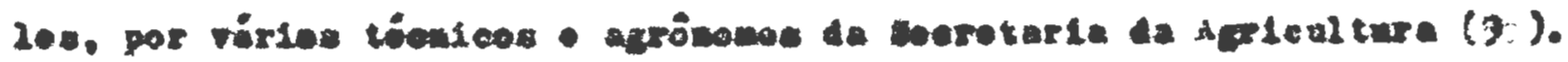
SCH I I T ( 


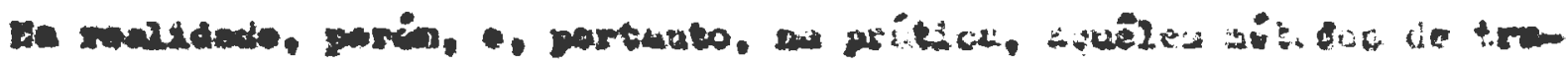

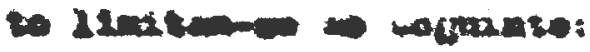

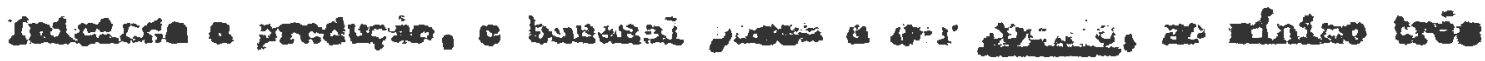

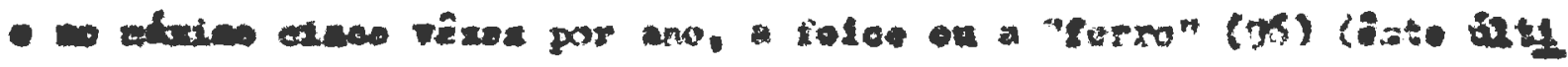

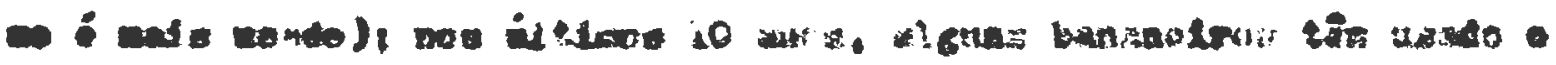

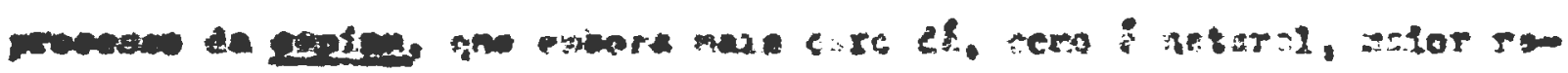

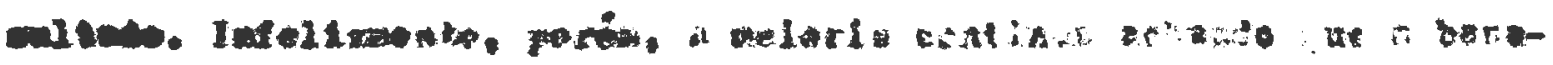

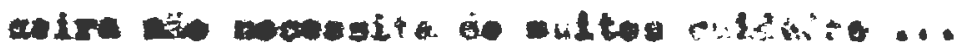

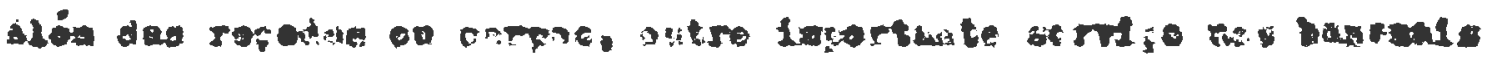

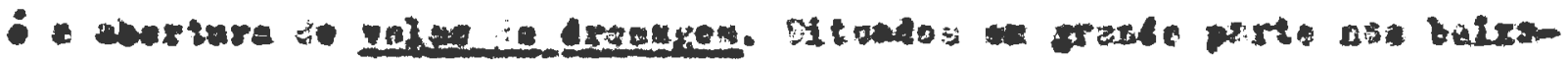

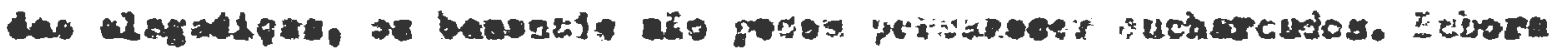

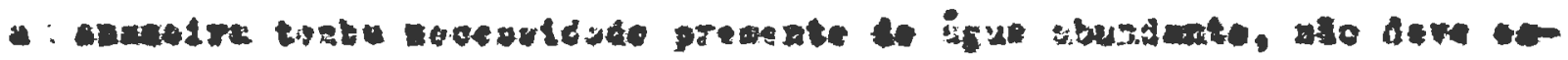

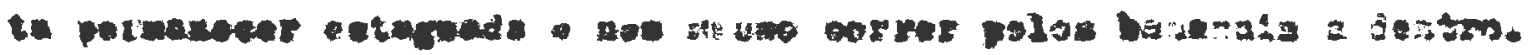

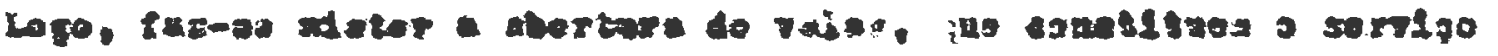

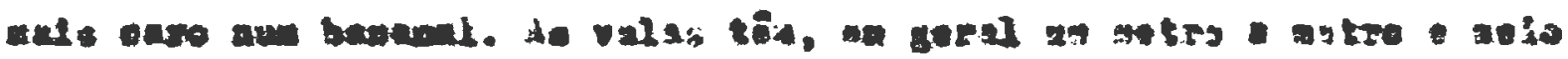

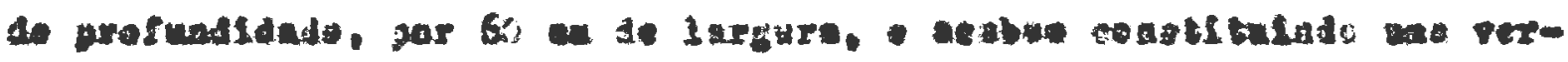

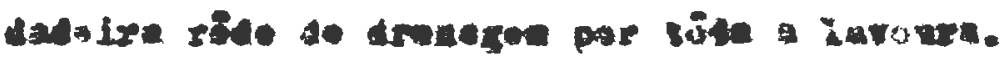

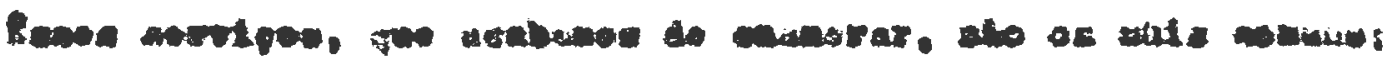

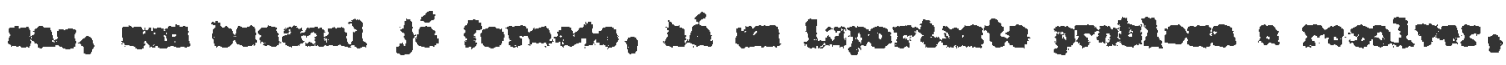

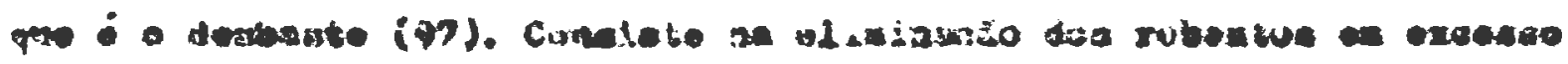

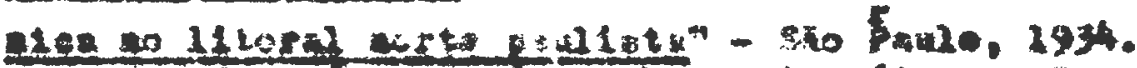

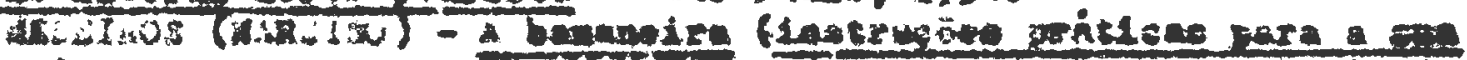

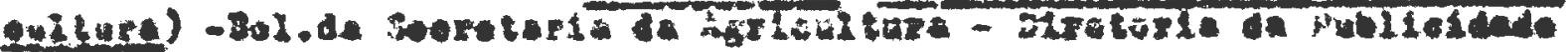
Aricola - 3io pame, 2935.

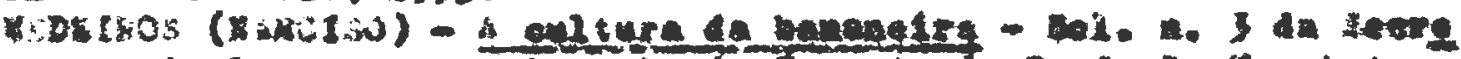

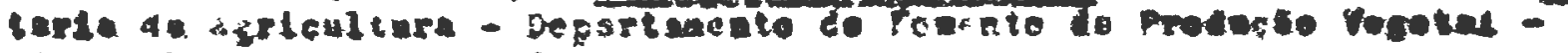
Eto seule. Sumb to 1937.

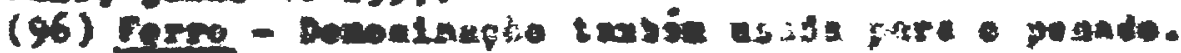

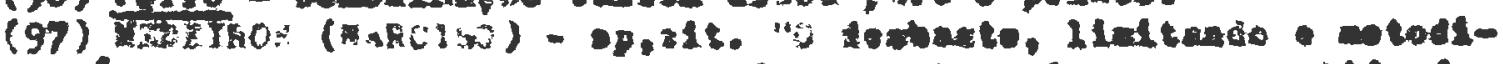

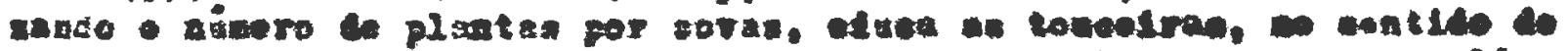

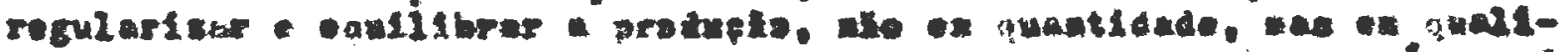

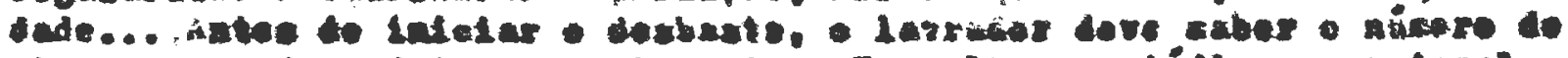

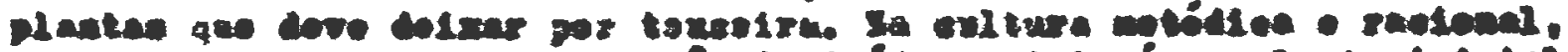

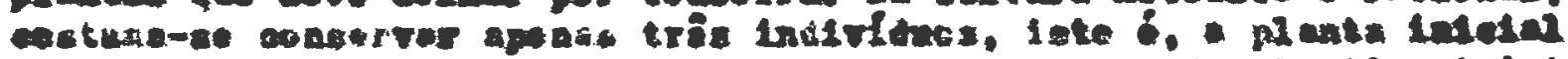

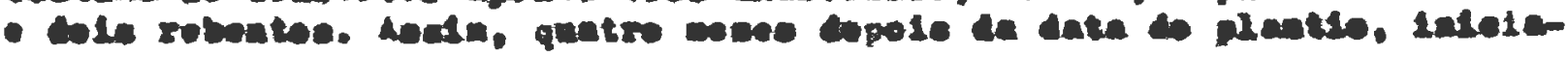




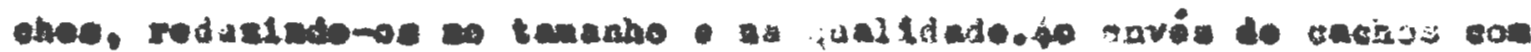

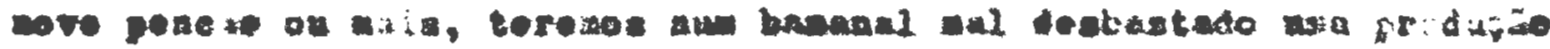

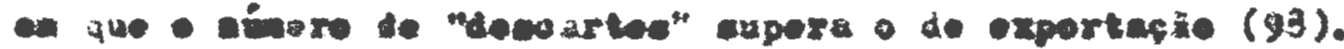

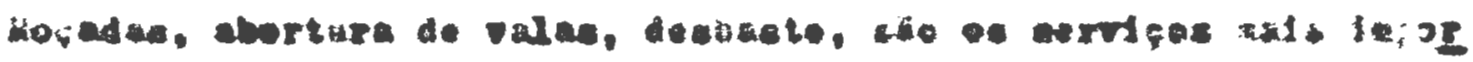

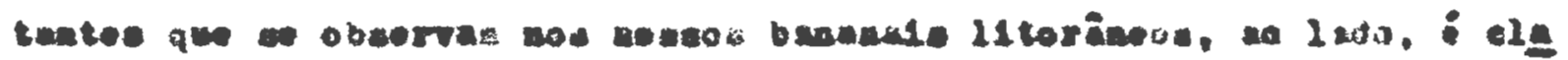

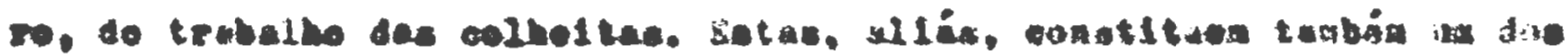

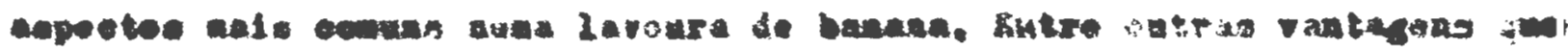

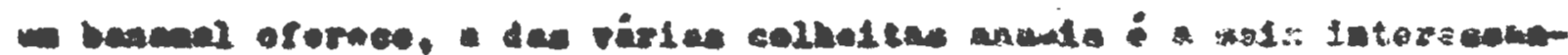

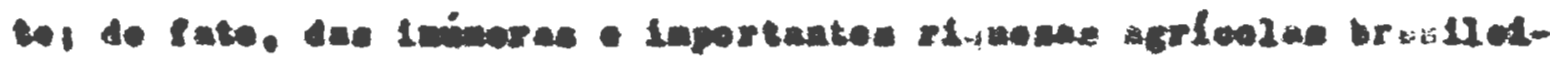

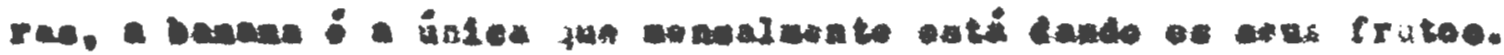

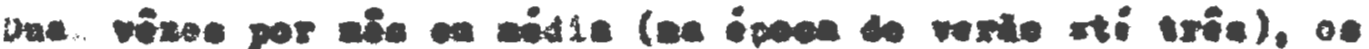

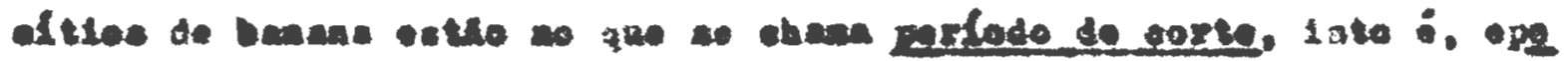

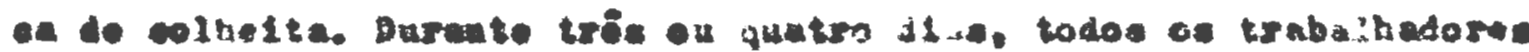

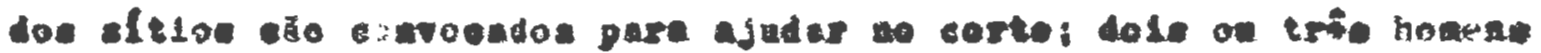

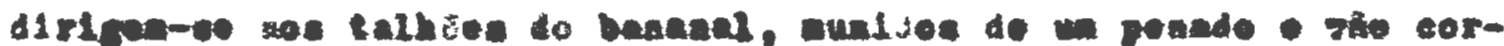

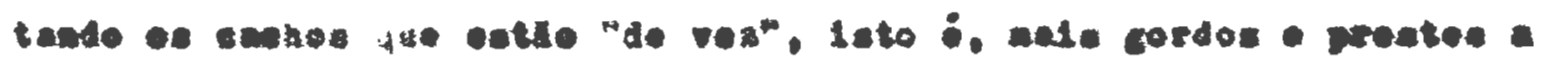

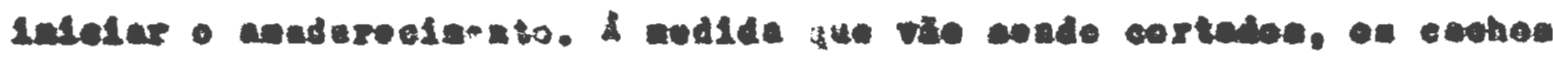

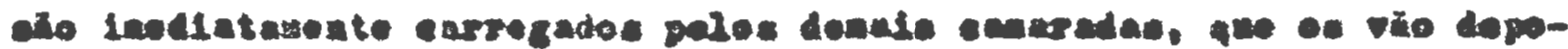

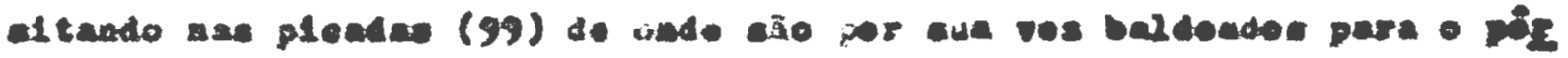

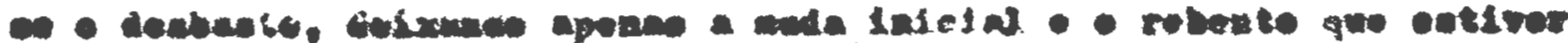

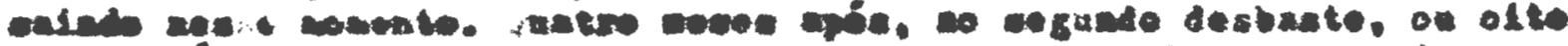

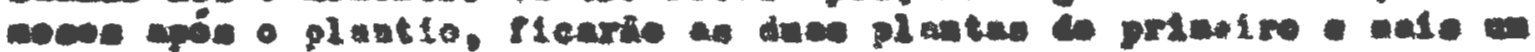

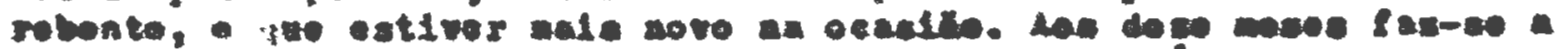

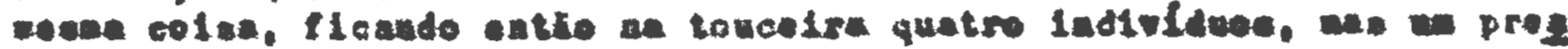

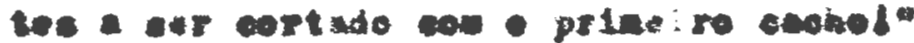

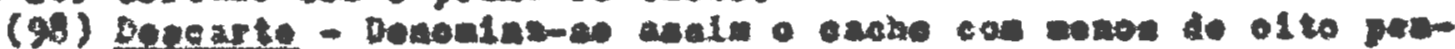

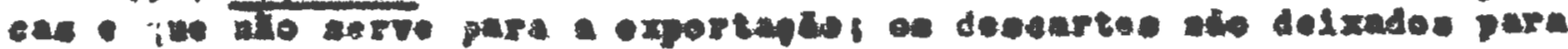

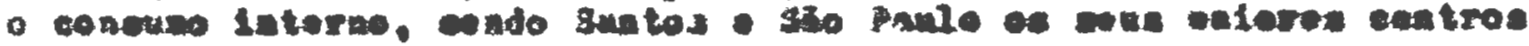
conmentores.

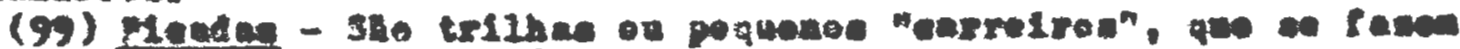

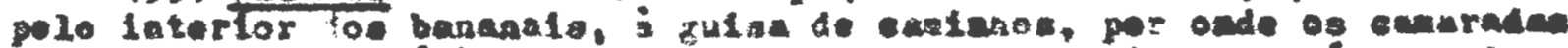

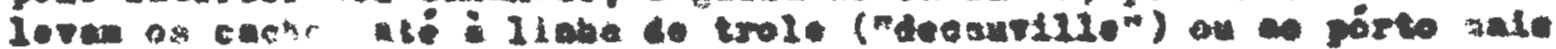
riotaro. 


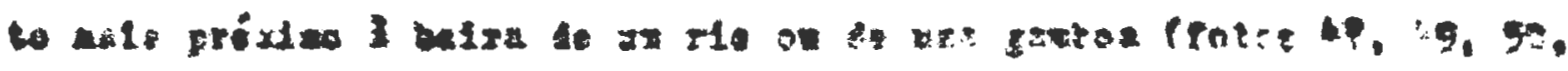

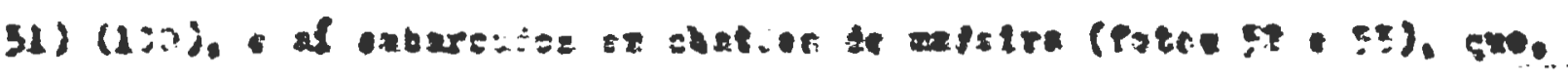

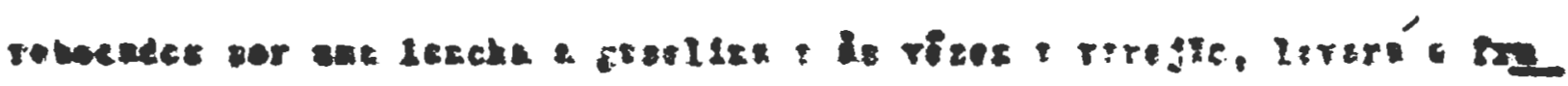

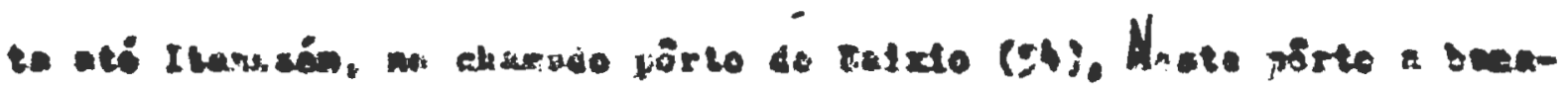

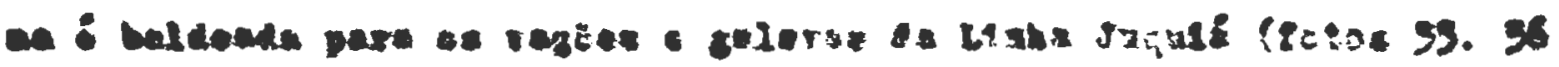

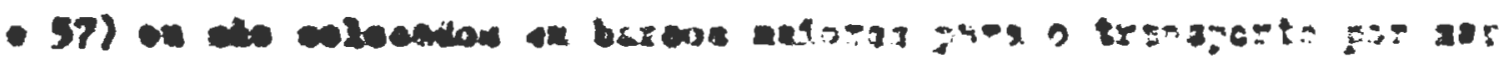

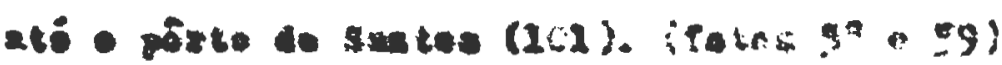

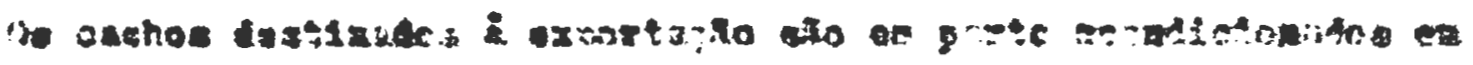

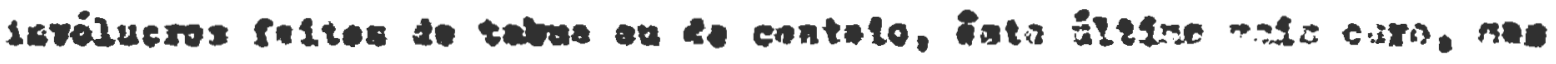

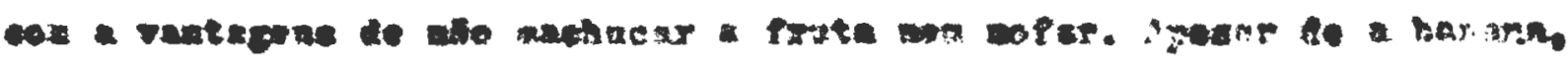

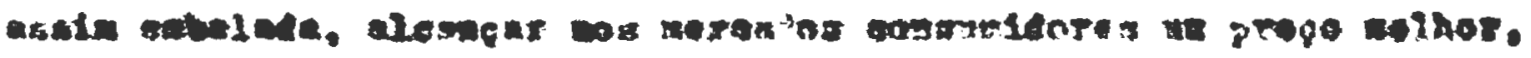

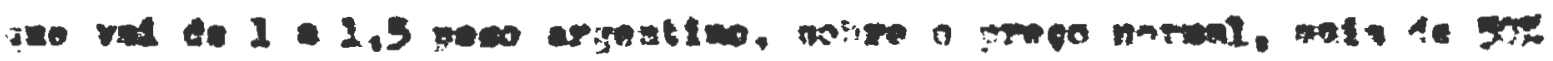

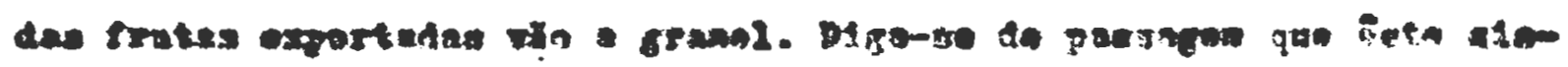

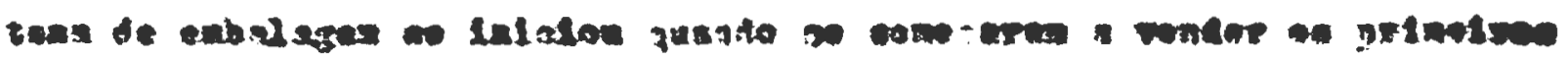

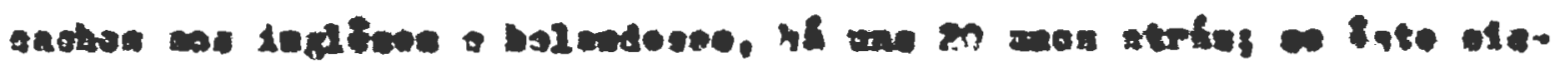

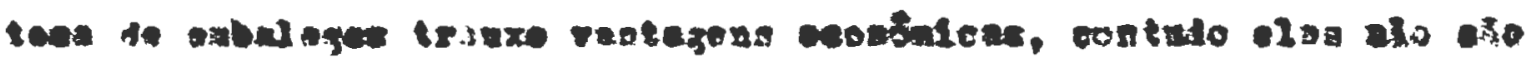

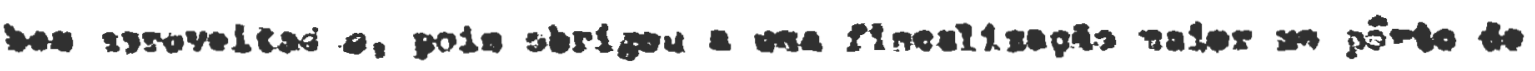

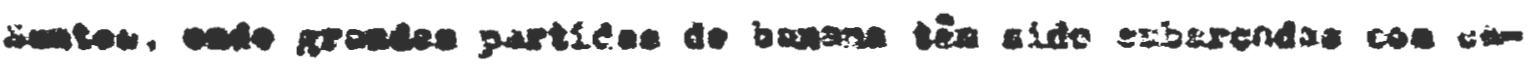

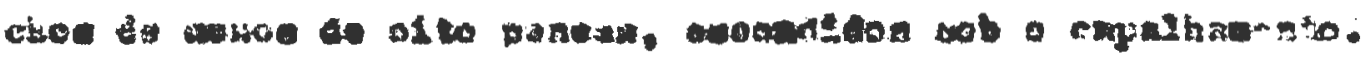

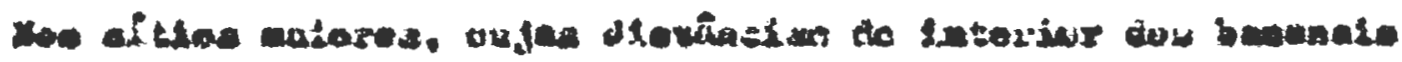

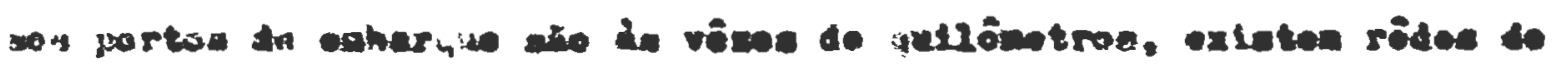

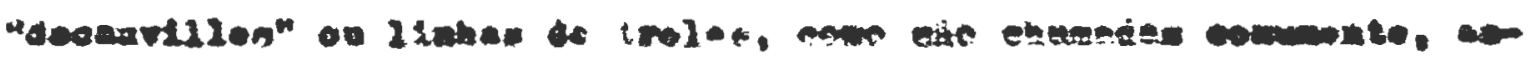

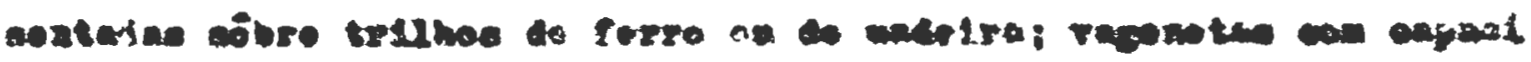

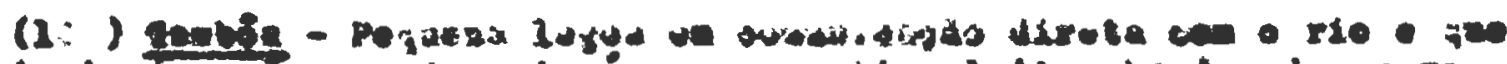

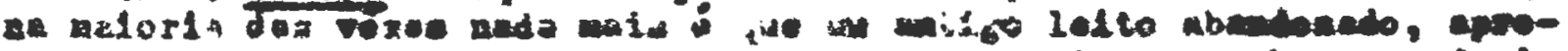

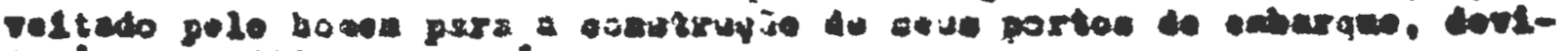

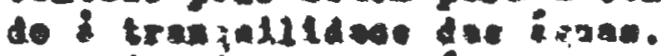

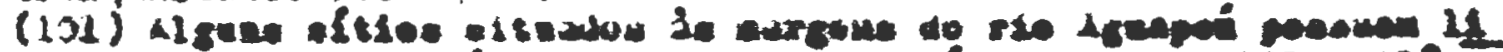

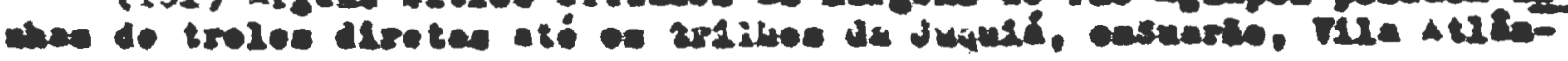
t1ea, oth.. 

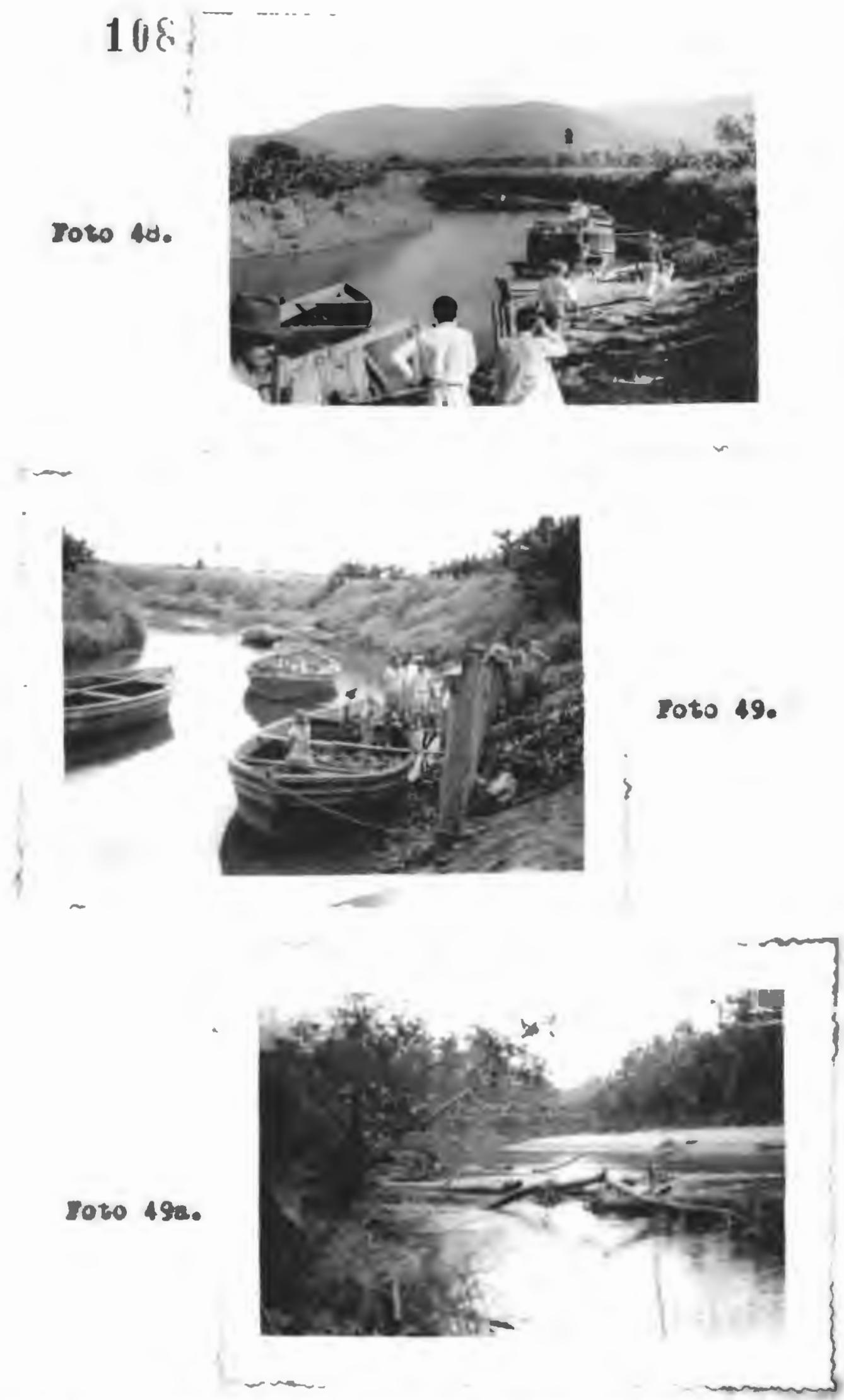

Lola eaberandouroe no alto sto Braneo no mumento es que

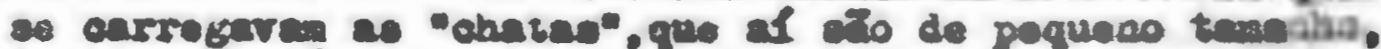

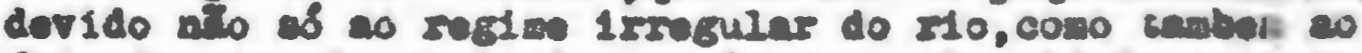
fato de er elo obelo de mendros al culdado ovmo en pode obeuster na tercolim fotogancia.

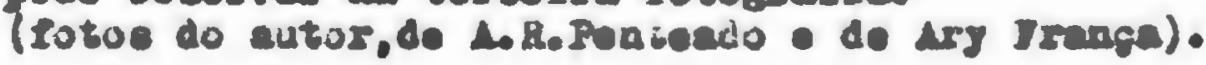




\section{$10 s$}

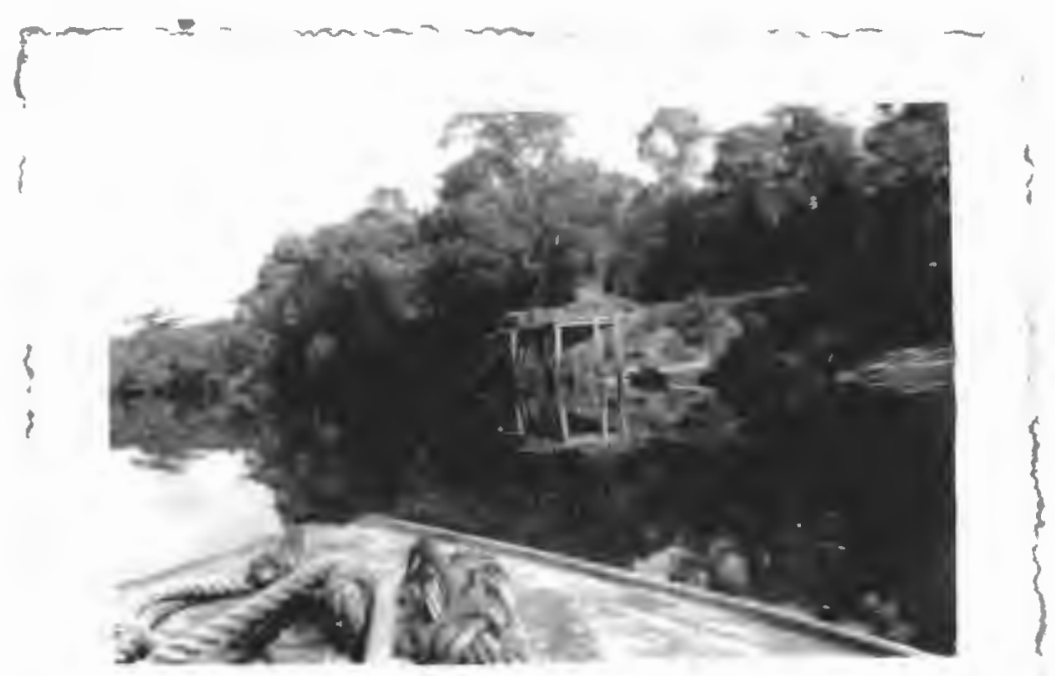

Foto 50 .

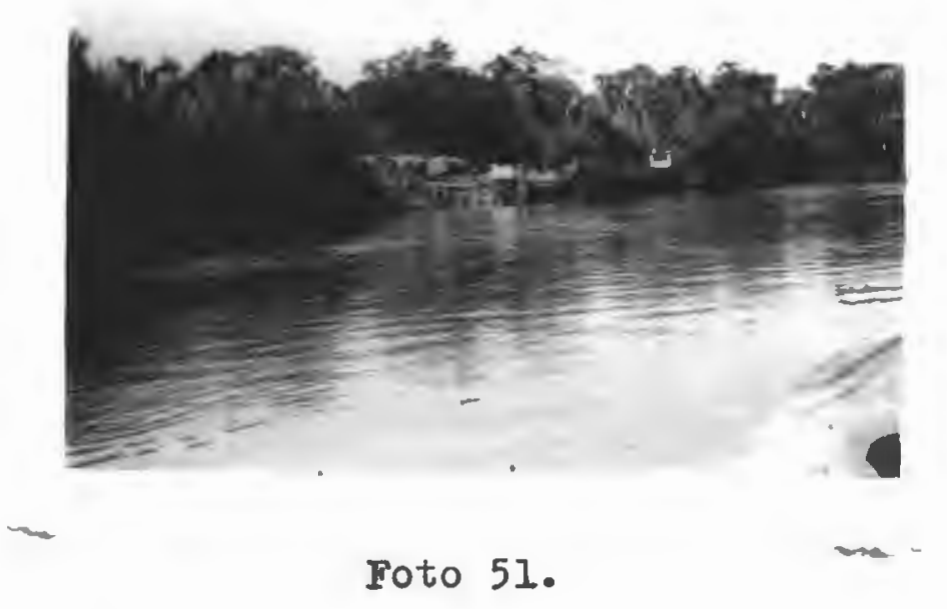

Dois portos, respectivamente nos rios Preto e Branco, em trechos onde chegam as embarcações de alto mar que aí pegam a fruta, levando-a diretamente a Santos. (fotos do Autor e de A.R.Penteado). 


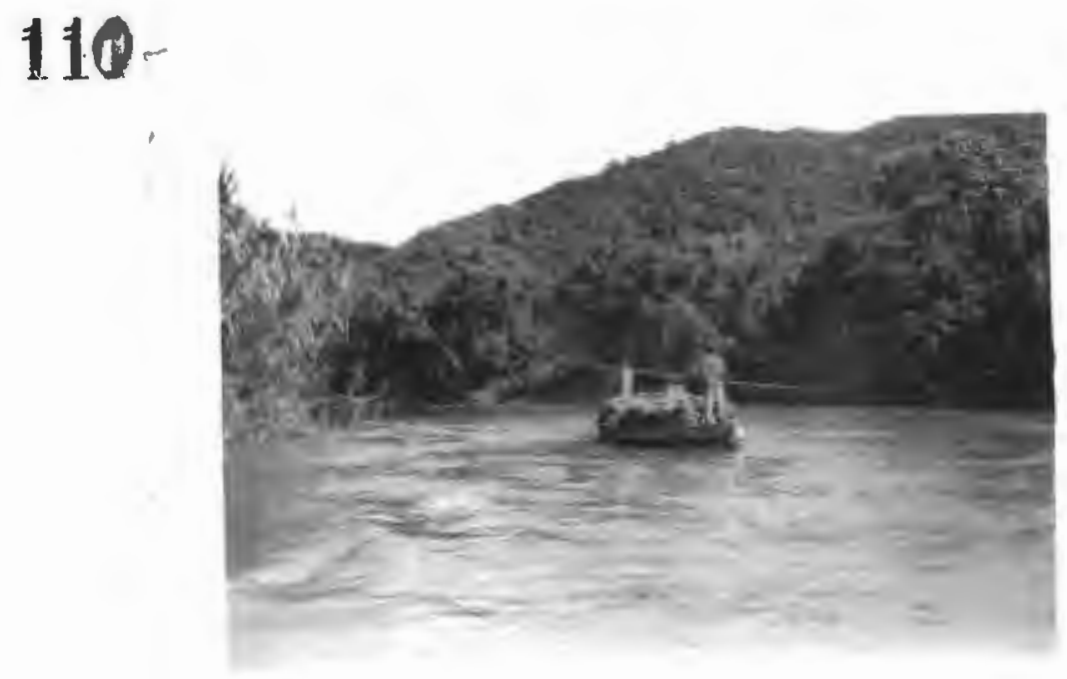

Iotoo $52 \cdot 53$.

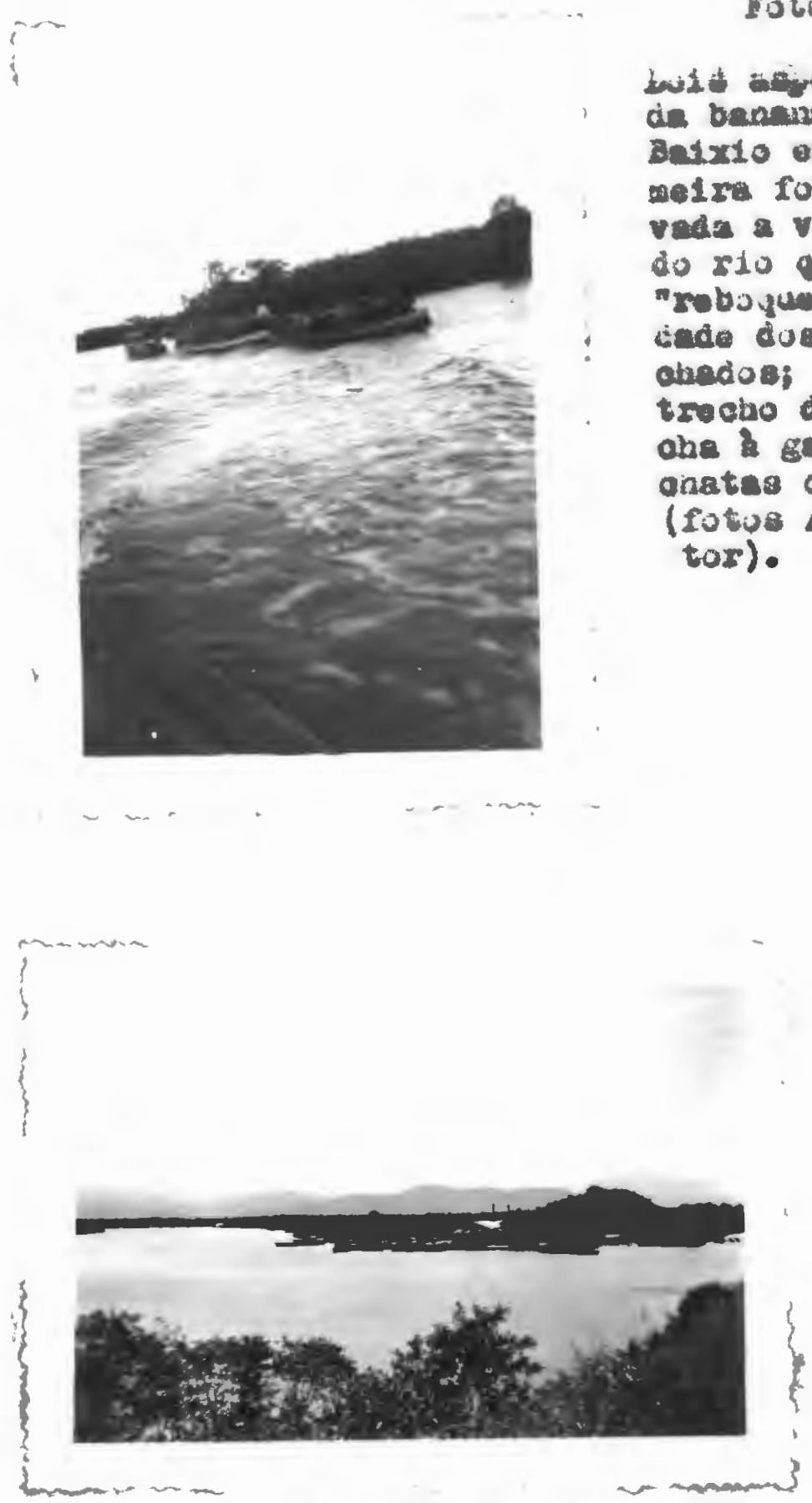

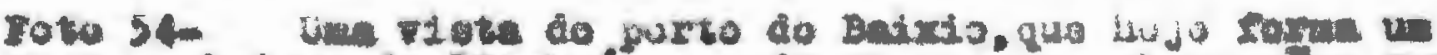

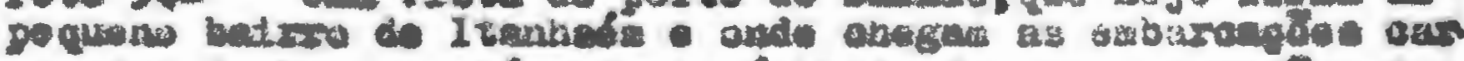

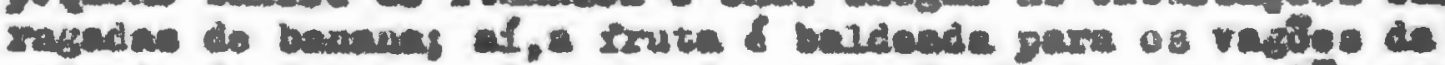

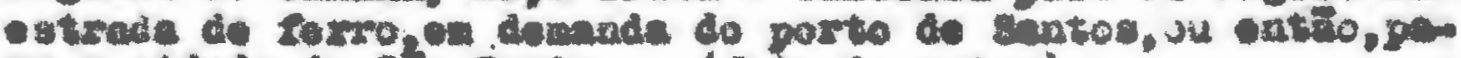
In aldad de sto palo. (toto do autor). 


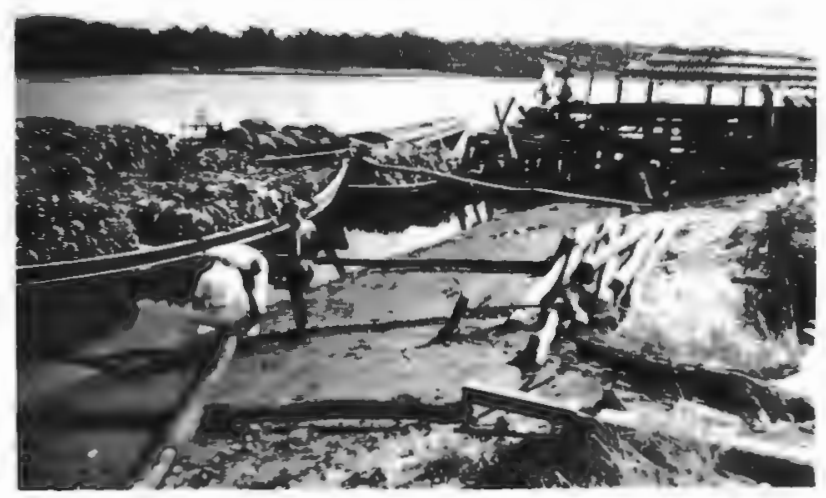

Foto 55.

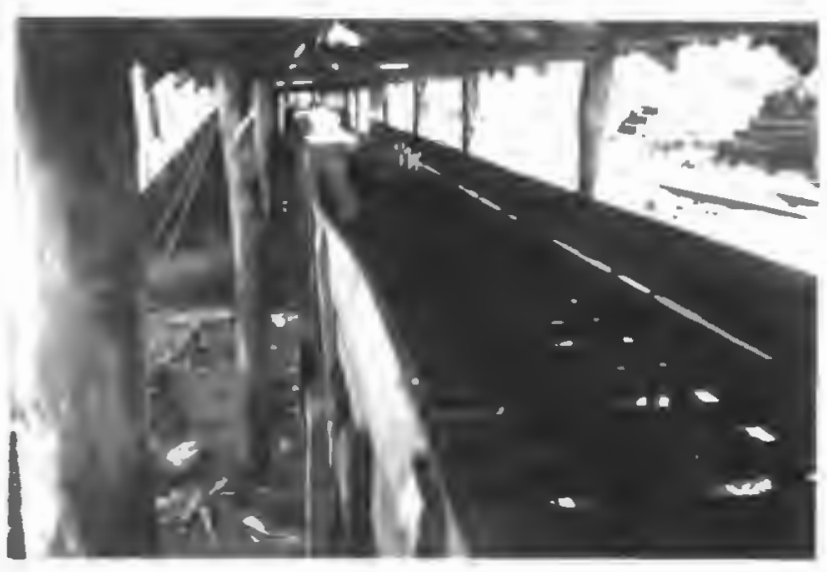

Poto 56.

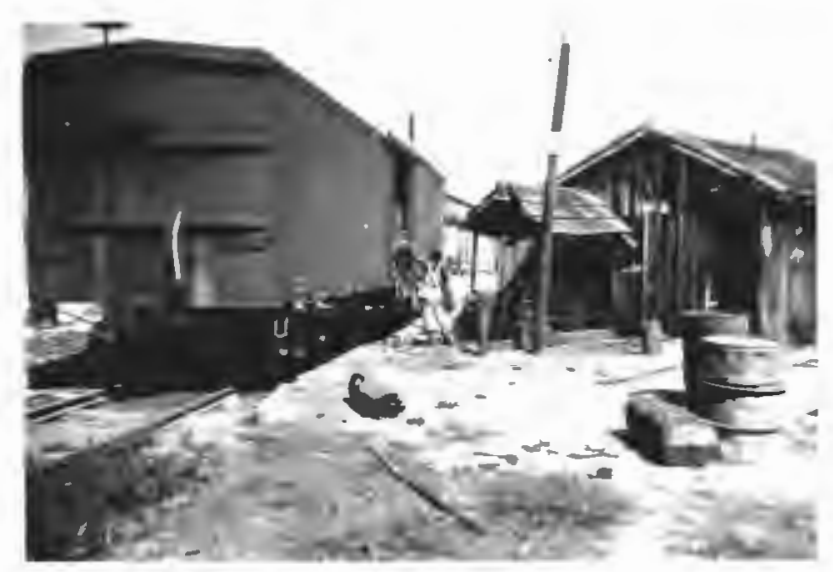

Foto 57.

Ilas presutes foto vamos a banane ser baleada des chaten para a dala (esteira roüante) exietente no porto do Baixto. - por ela, ohegar ao ragảo da estrada de ferro.

(fotos do autor). 


\section{2}

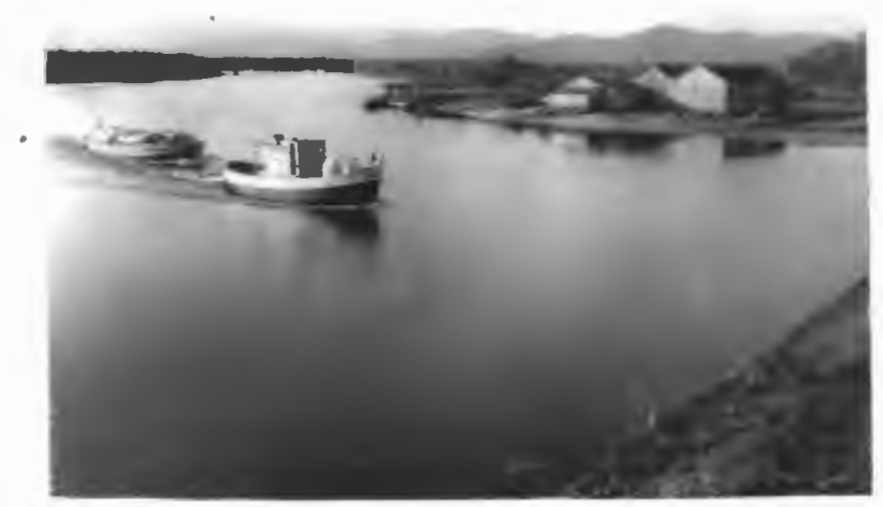

Foto 58.

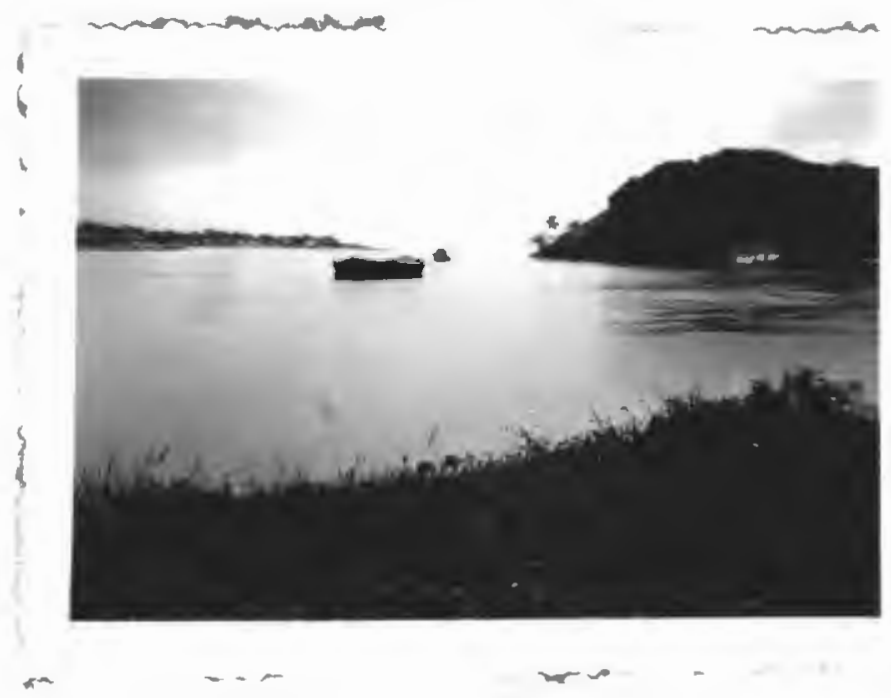

Foto. 59.

A banana para a exportação e que tem que ir a Santos, sai hoje em grande parte por mar, em embarcaçổes de maior calado (em geral chatões cobertos) e que são rebocades por pequenos rebocadores a óleo. Nas duas vistas acima, podemos observar um reboque passando defronte o porto do Baixio e depois,já na foz do Ita nhaém, quasi ganhando o mar. (fotos do autor). 


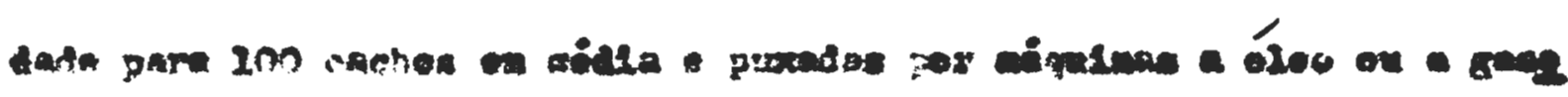

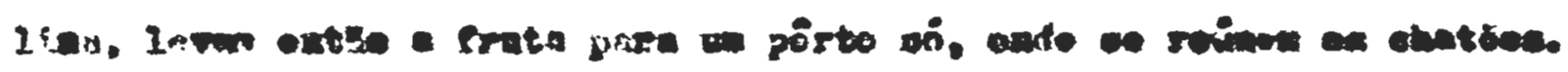
(12tos on a.).

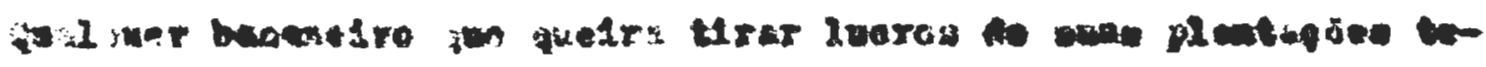

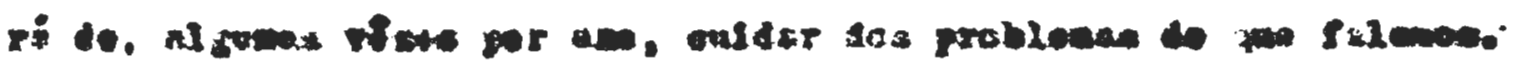

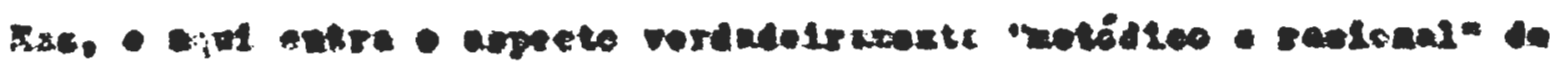

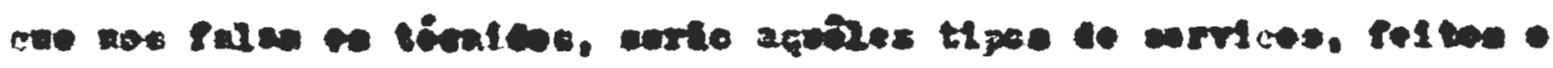

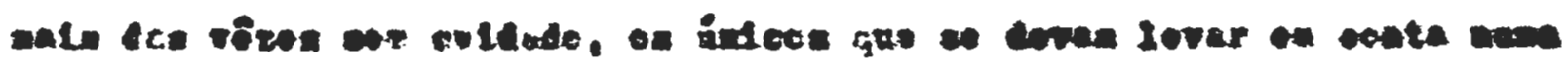

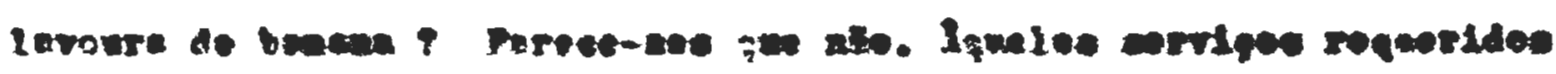

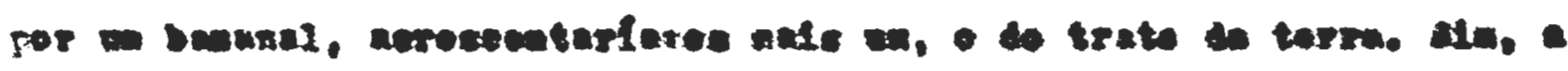

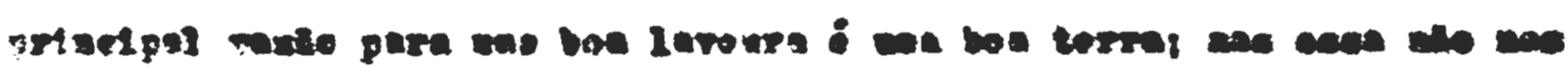

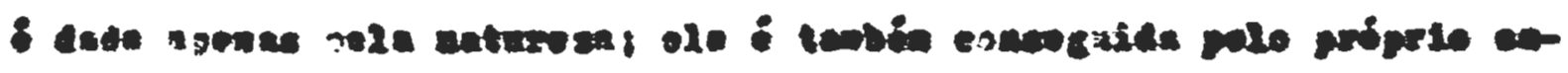

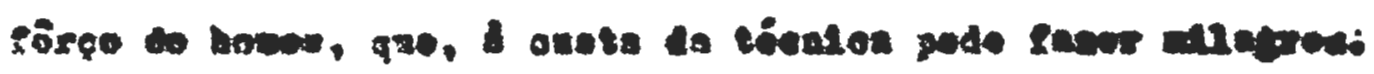

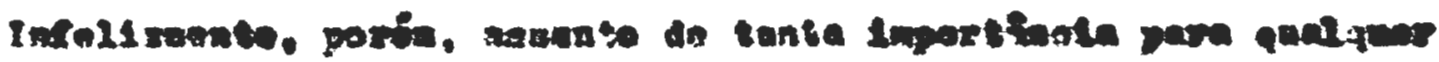

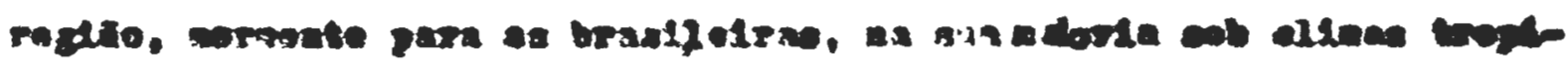

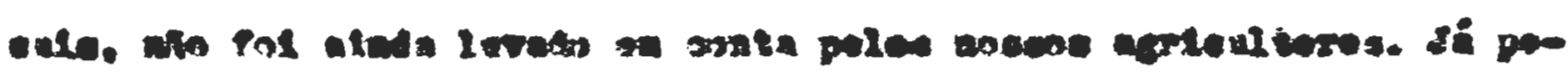

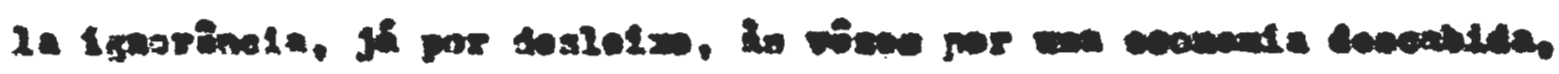

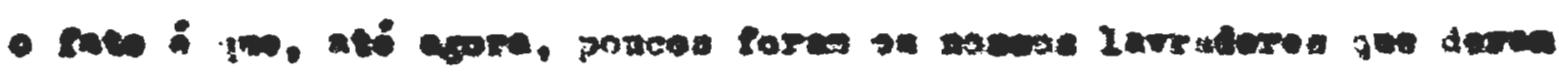

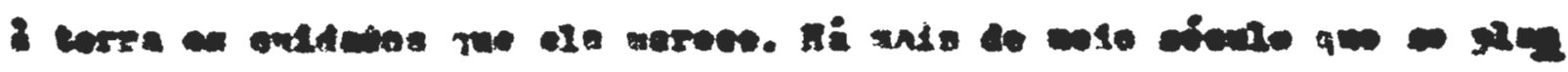

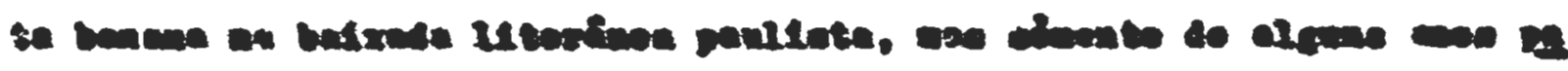

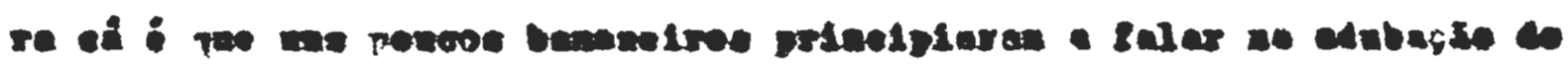

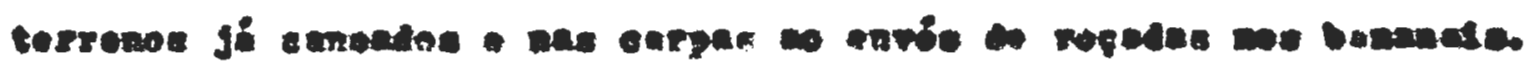

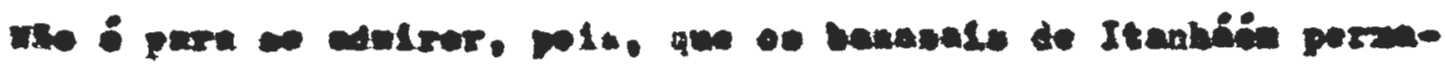

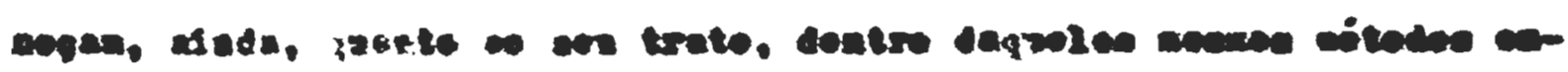

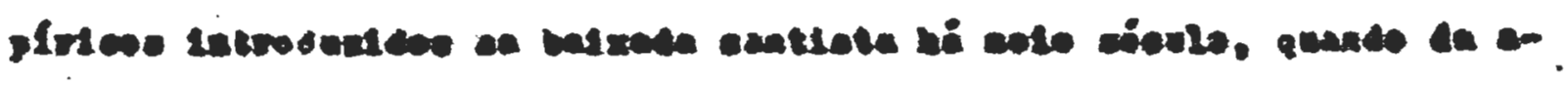

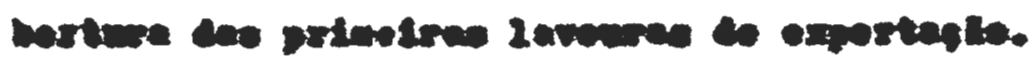




\section{4}

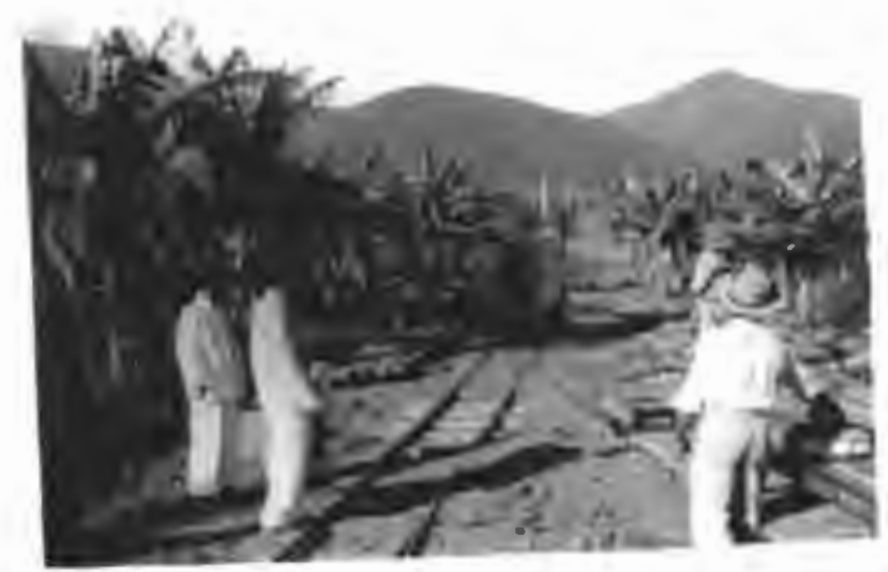

Foto 60.

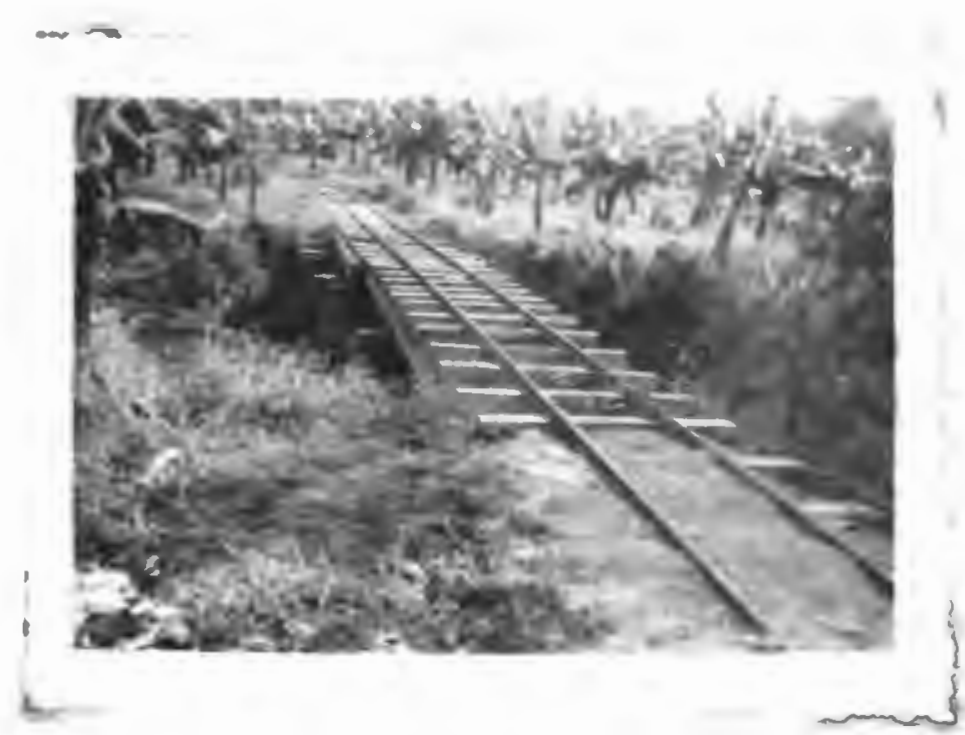

Foto 61.

Linhas de trole (dedauville) num gitio de banana,por onde a fruta é levada a um porto a margem do rio. (fotos A.R.Penteado tomaàas na "Fazenda Aurea"). 


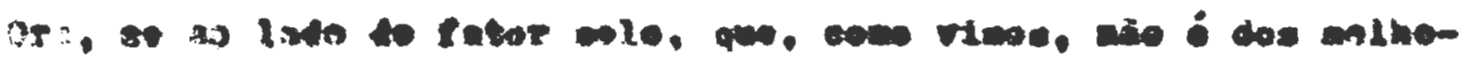

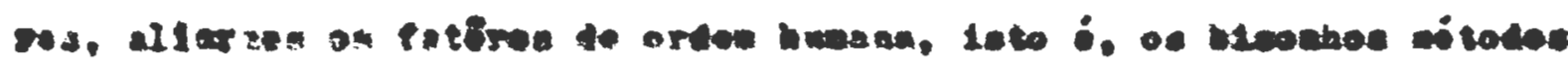

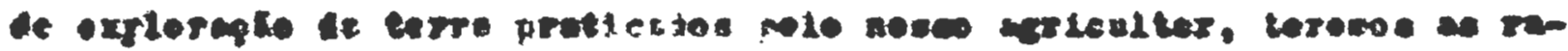

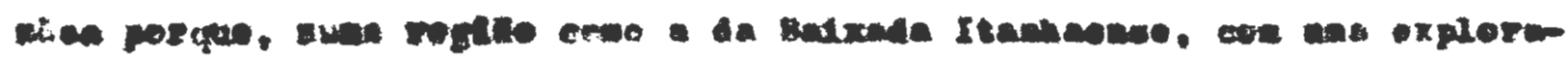

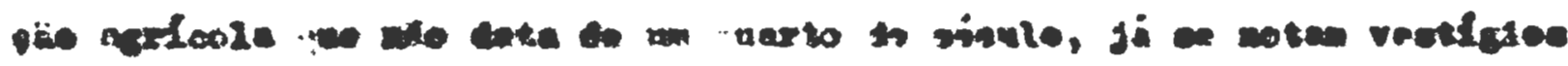

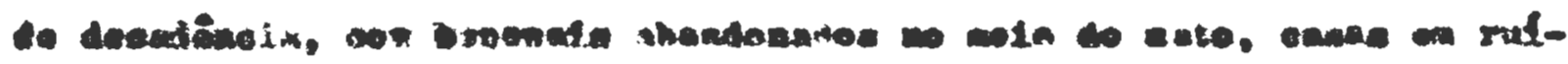
nas, porks dostrufton, ete..

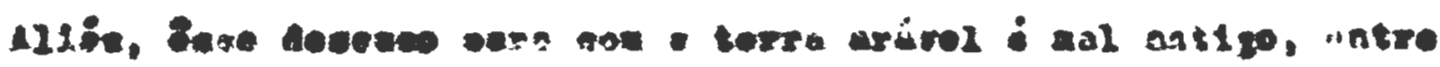

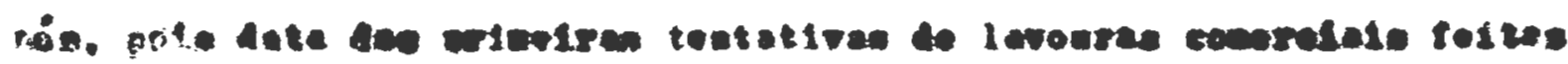

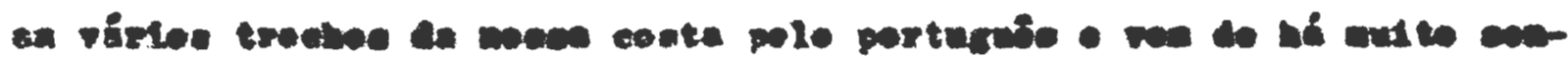

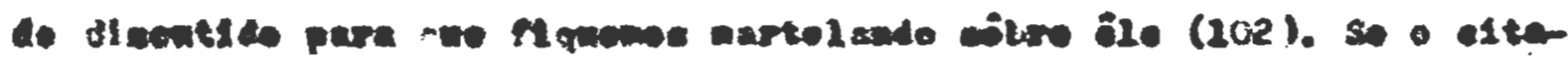

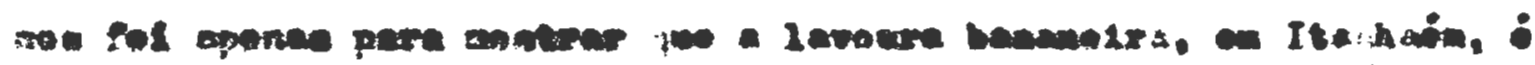

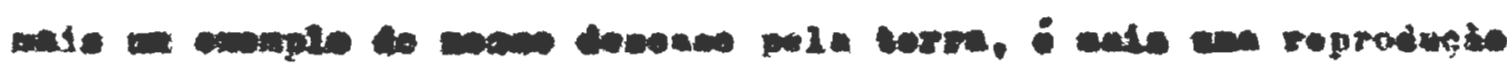

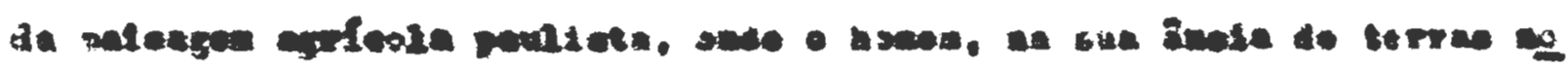

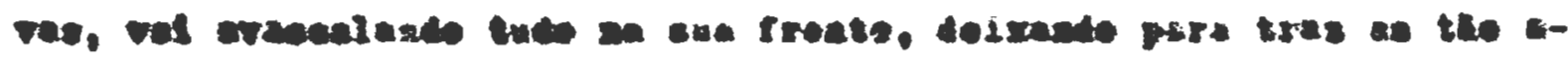

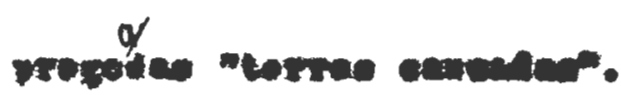

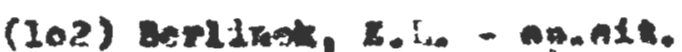

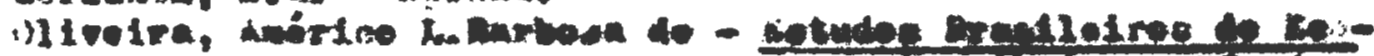

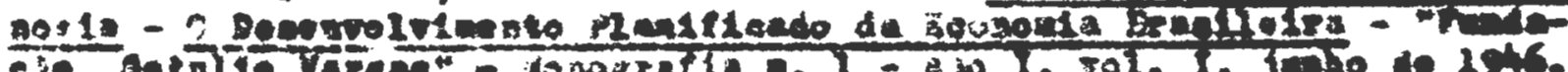

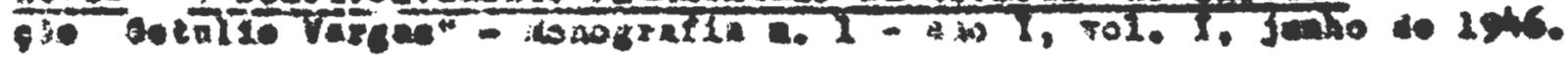




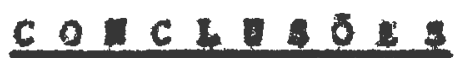

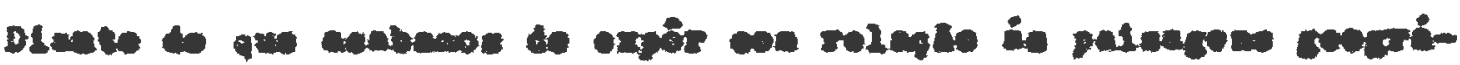

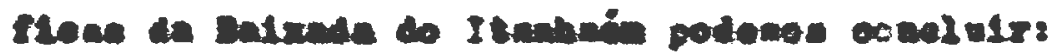

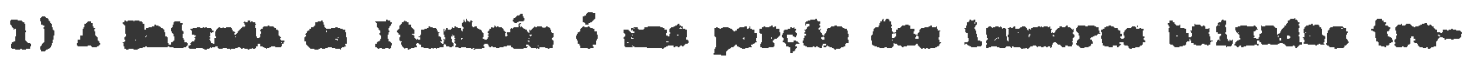

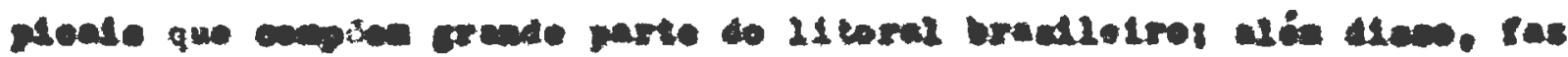

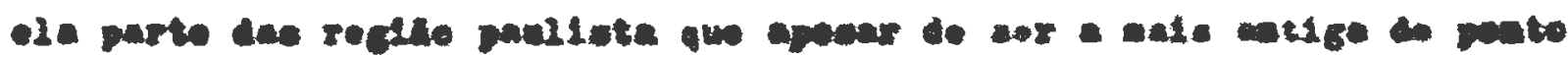

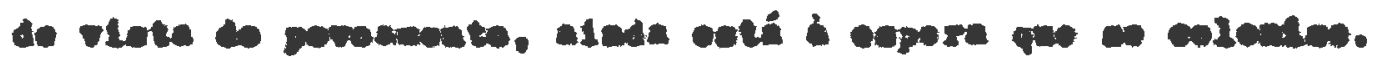

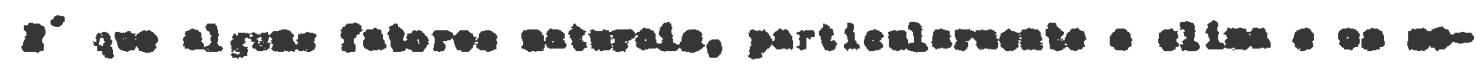

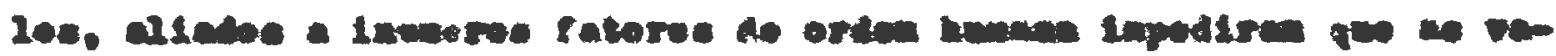

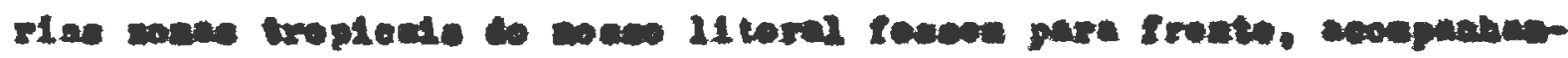

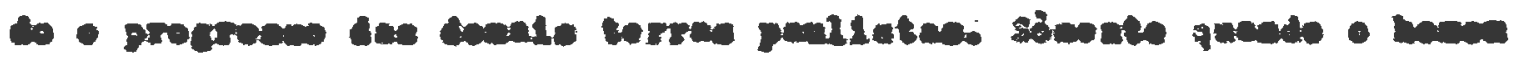

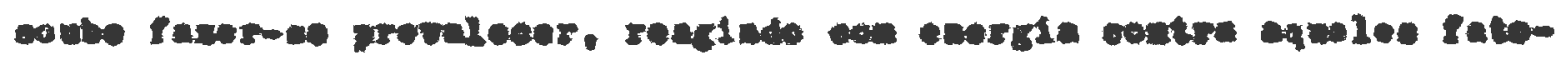

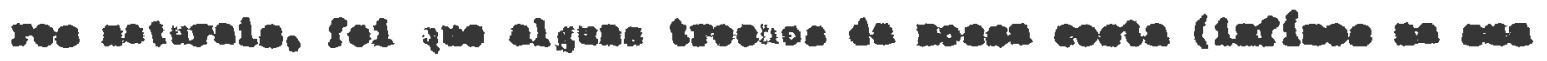

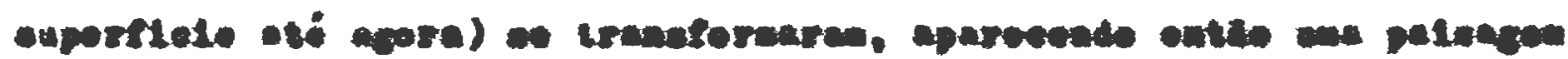

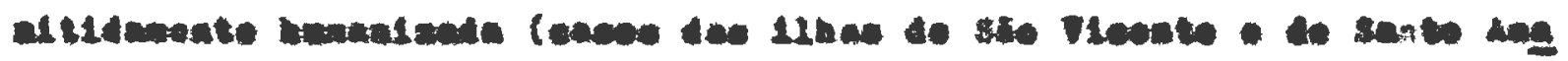

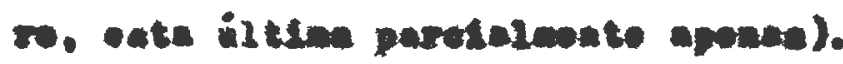

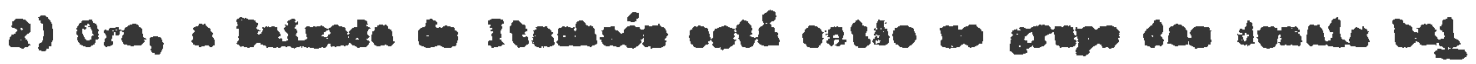

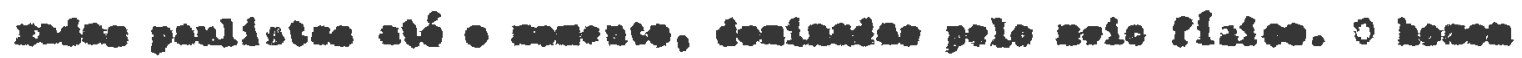

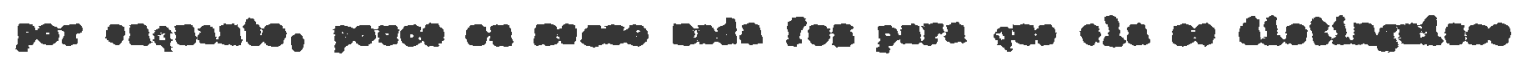

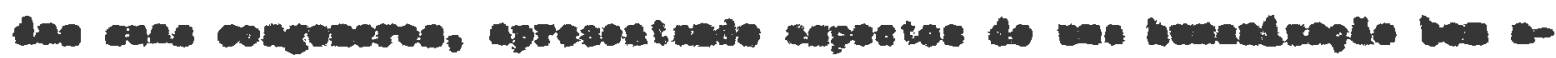
alentede.

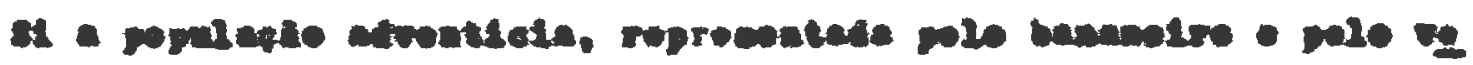

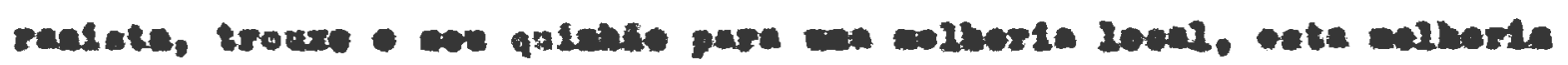

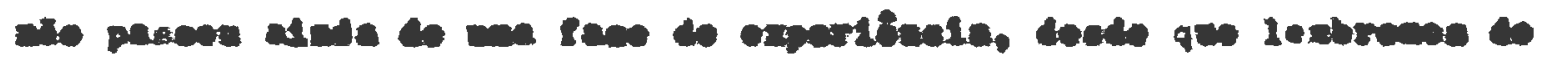

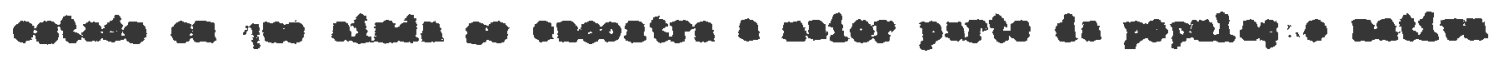

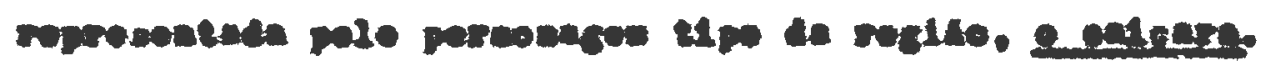

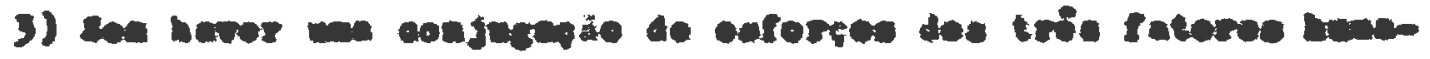

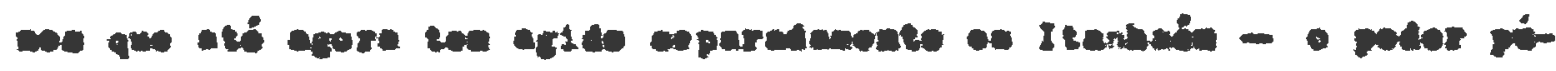

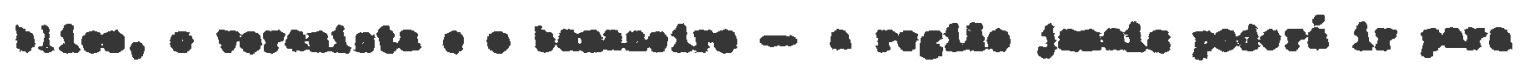




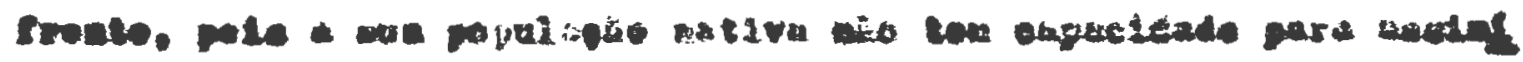

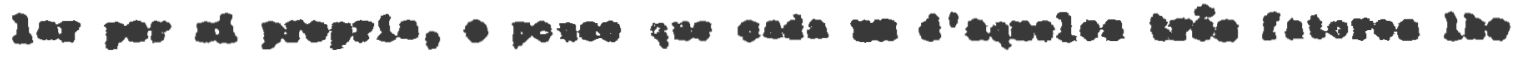

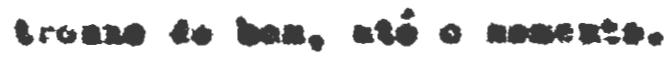

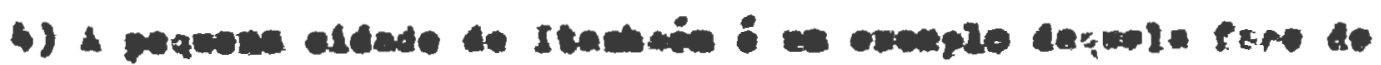

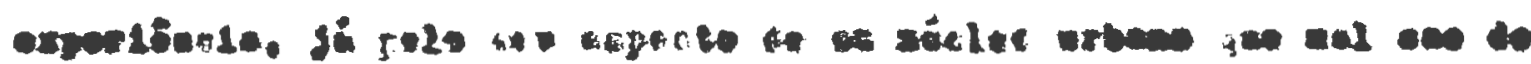

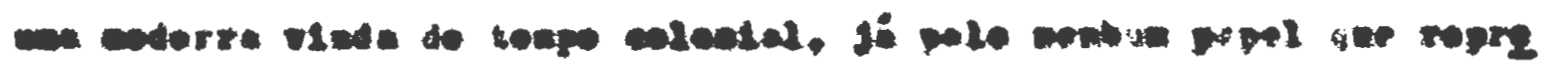

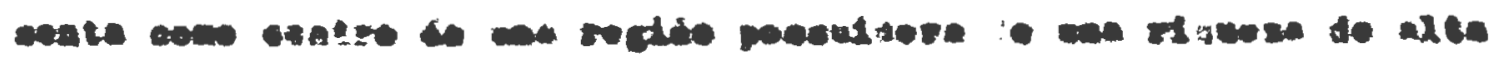
Laportasis pert Stado.

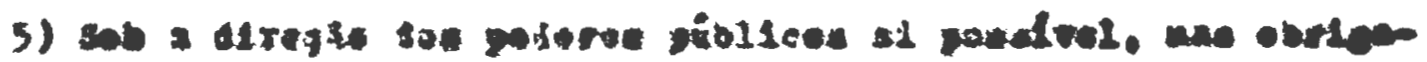

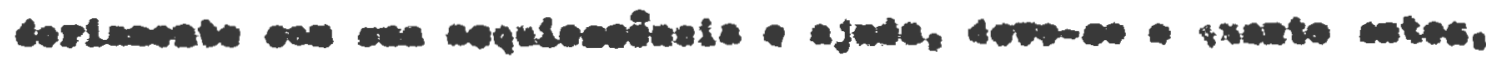

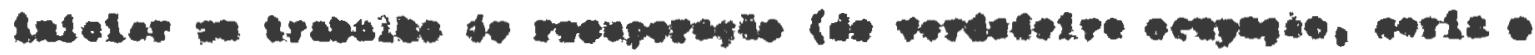

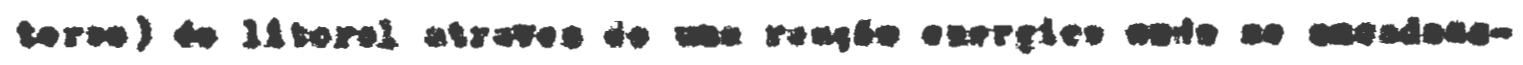

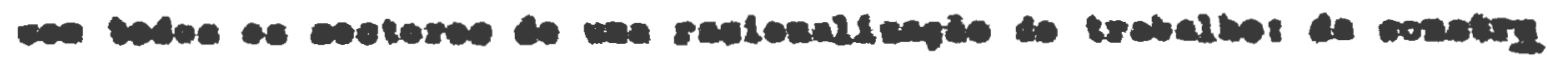

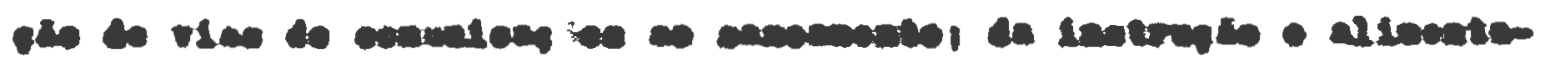

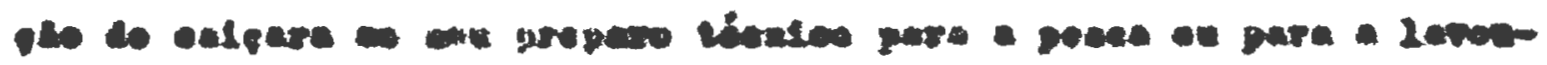

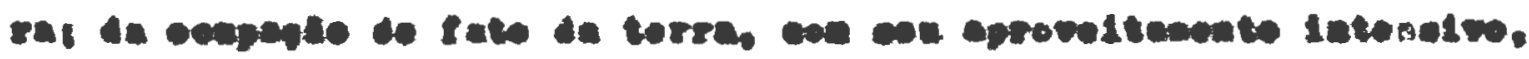

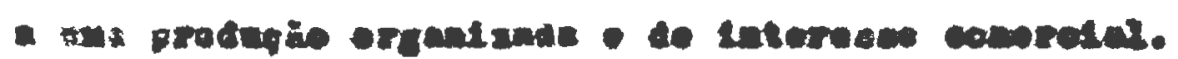




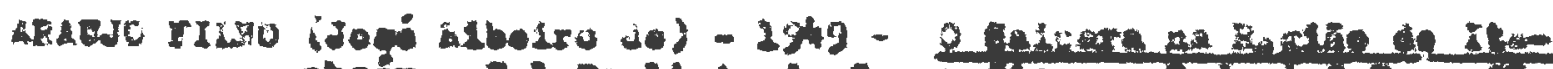

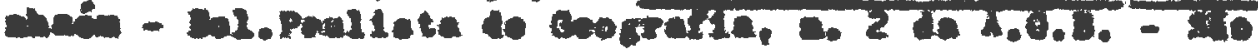
Pavilu, julibo.

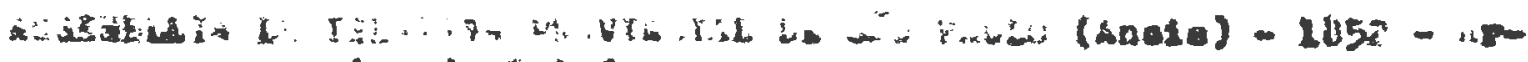
gastro do Loteds:

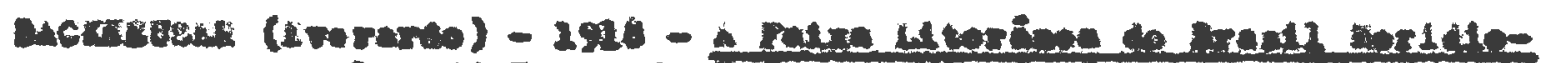

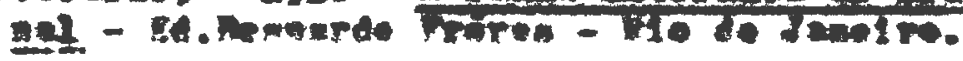

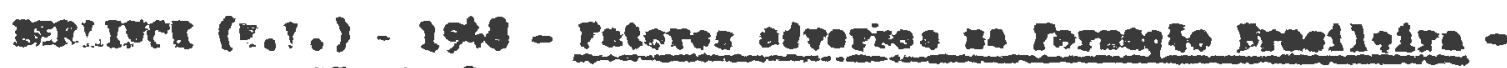
ine tralo.

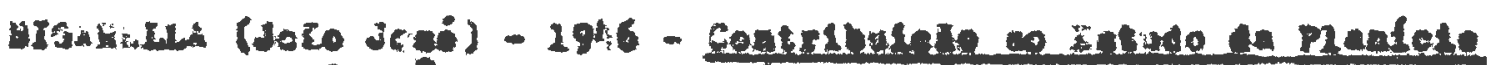

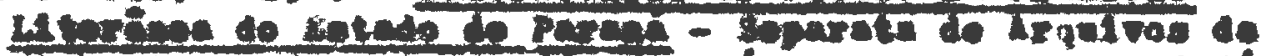

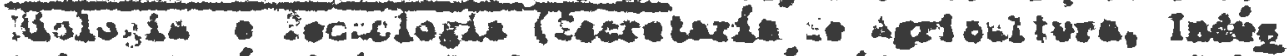

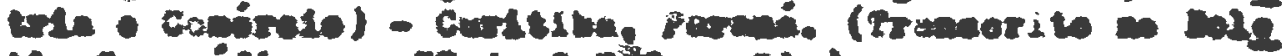

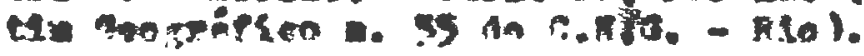

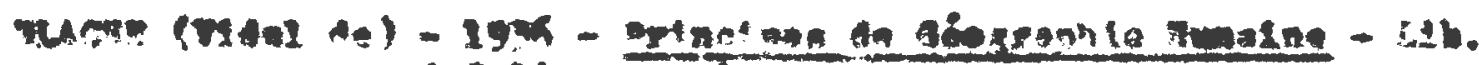

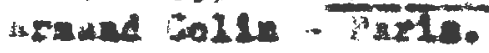

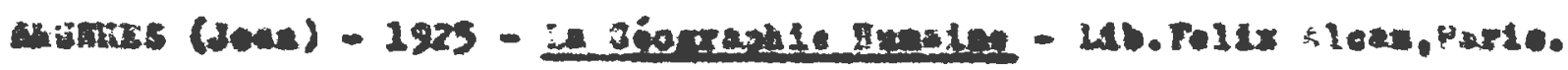

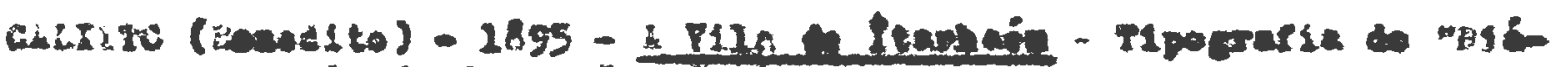

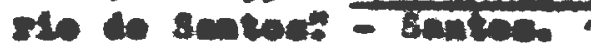

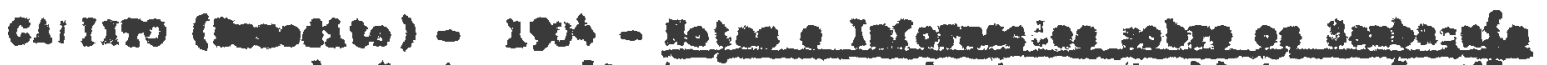

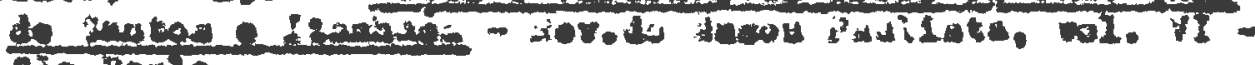
Ga Paro.

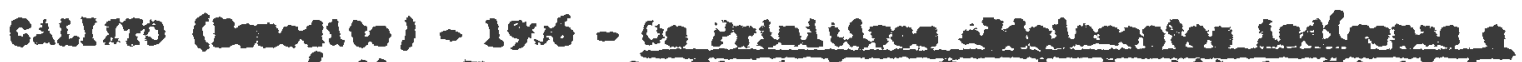

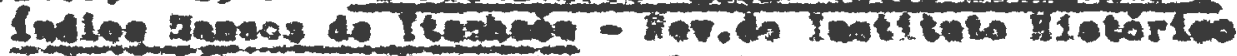
- Jeogrifico se ino Pato. val. $x$.

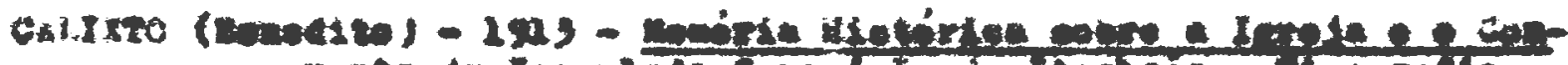

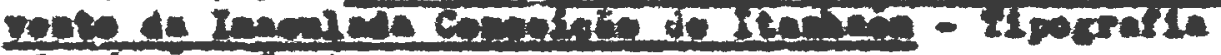
750 J0se - jatos.

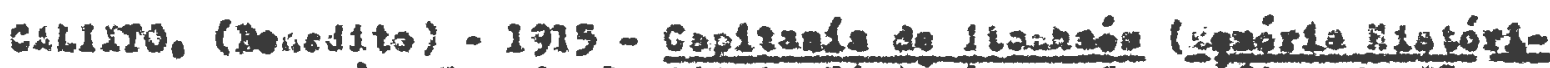

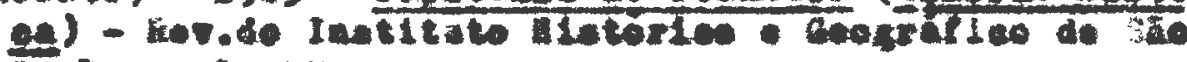
Peule, vel. Ix.

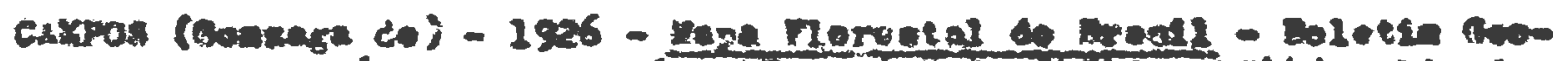
cris 100 as. $9,26 \div 17$ to Z.N.1. (IST) 194h) - R10 6 Janelro.

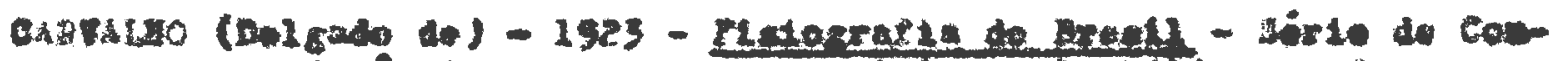

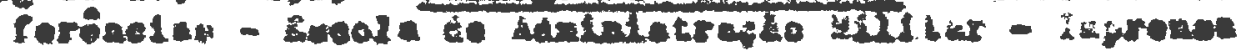
wister - hilo do Jasolvo. 


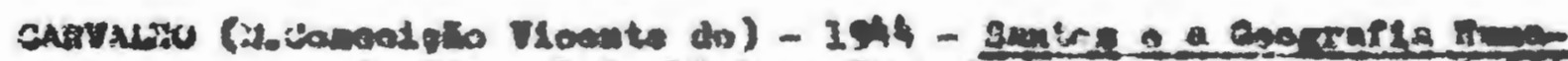

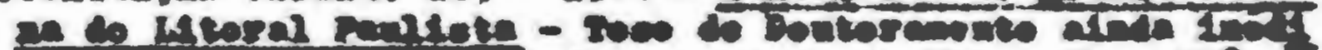

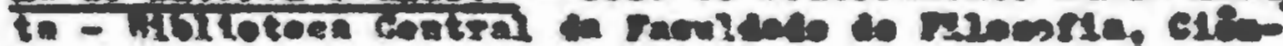

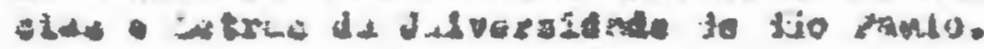

- H.

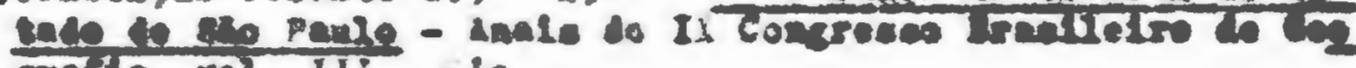
raila, wi. III- 10.

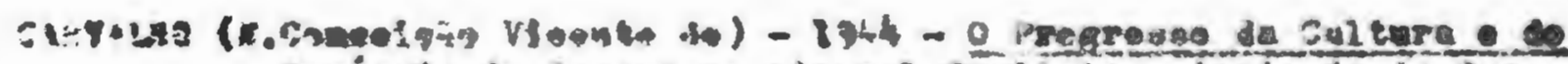

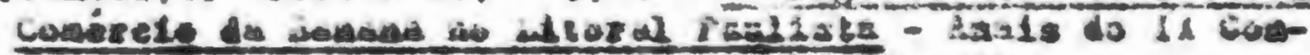

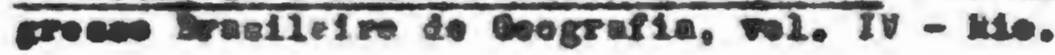

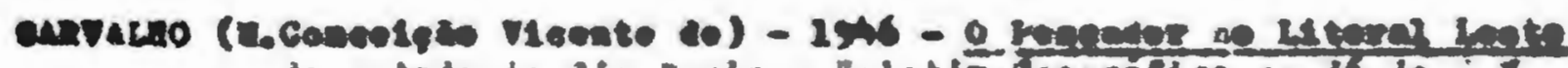

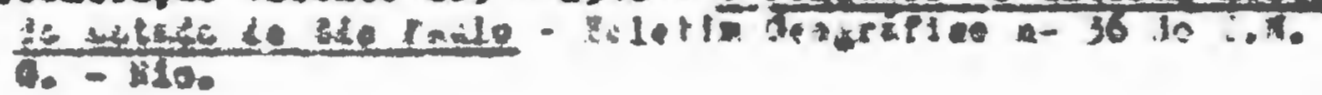

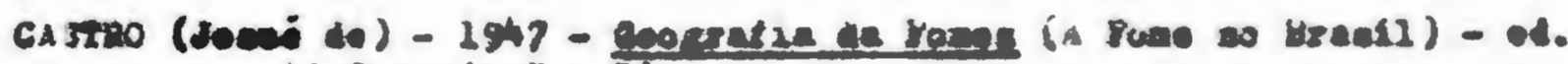
"Srosatm" - Bta.

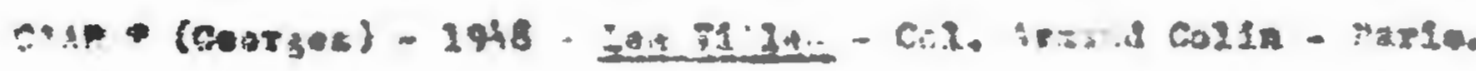

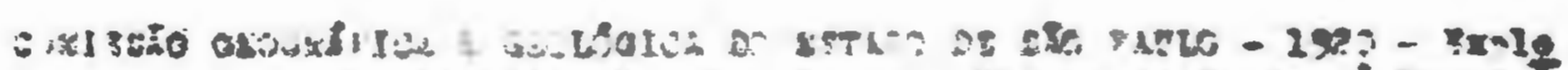

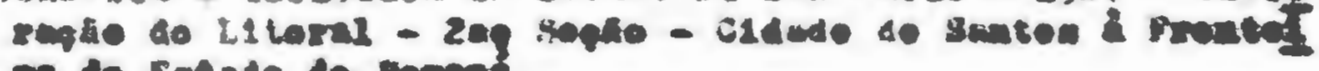
ra io reting to parand.

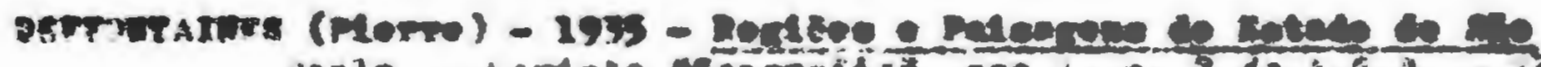

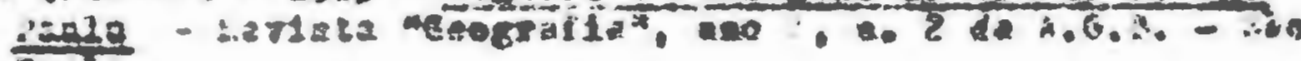
Panto.

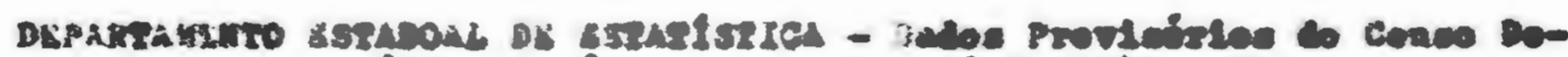

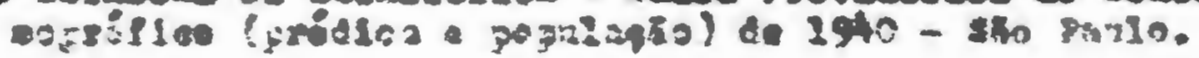

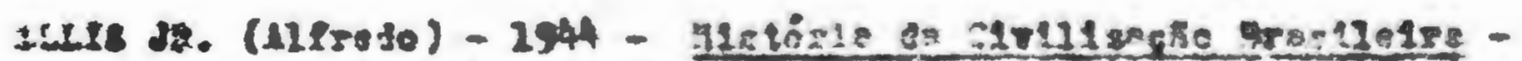

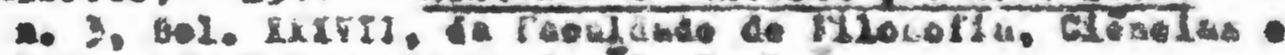

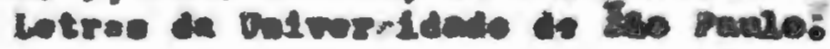

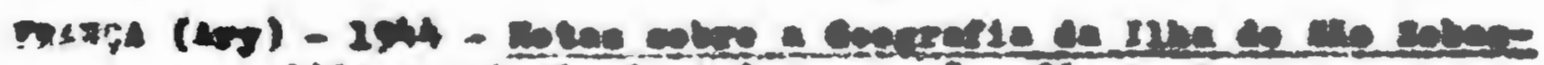

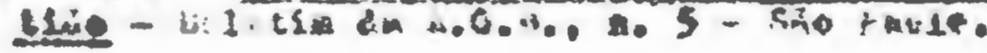

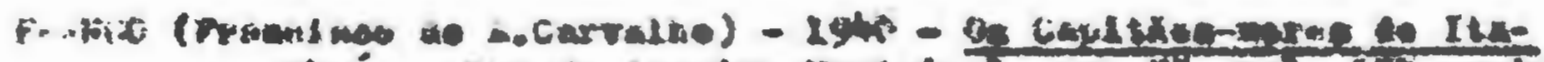

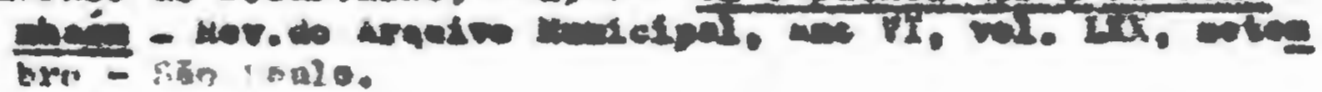

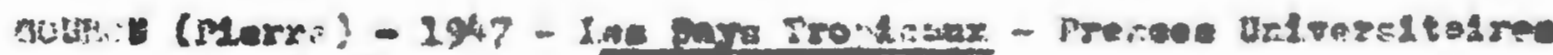

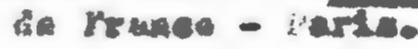

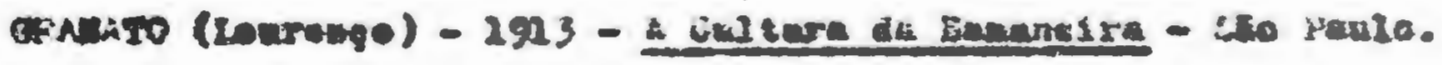

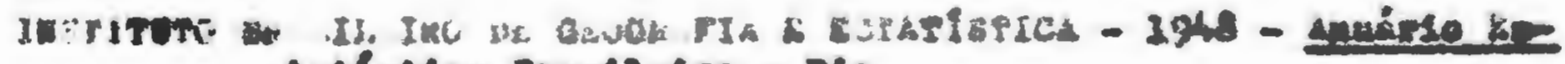

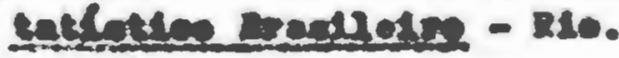

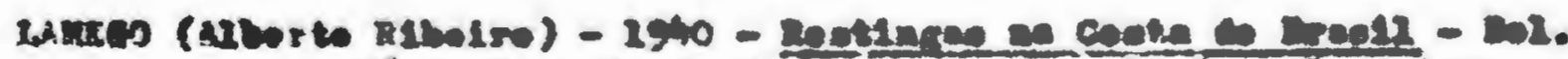

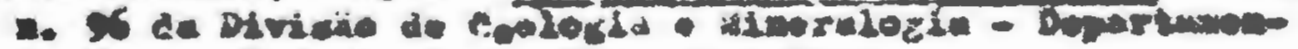

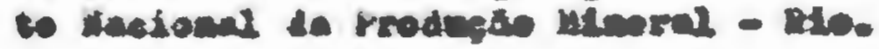




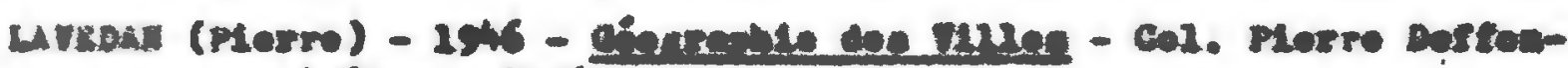
talkes - Parts.

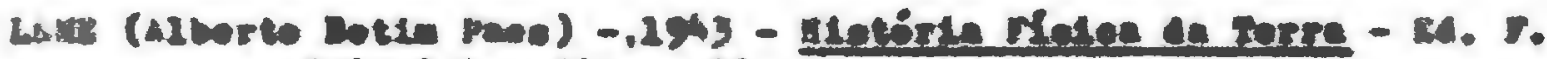

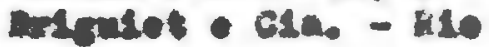

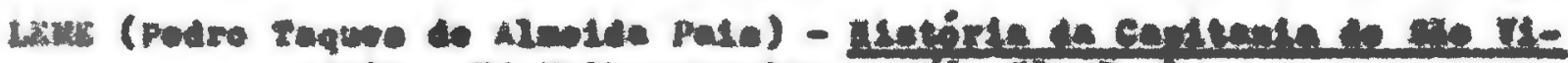

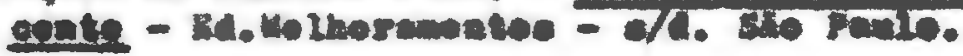

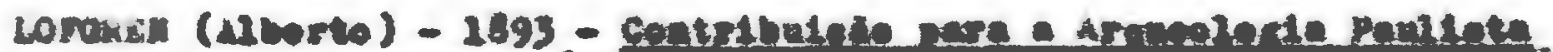

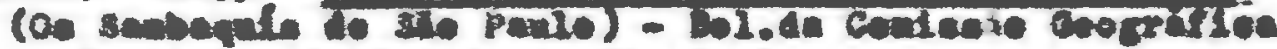

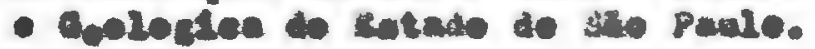

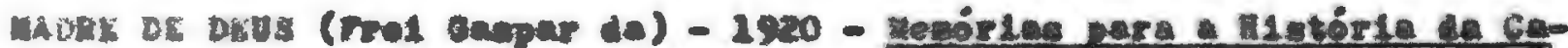

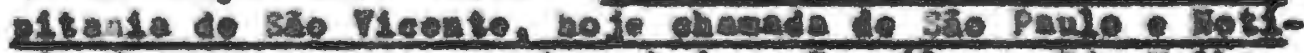

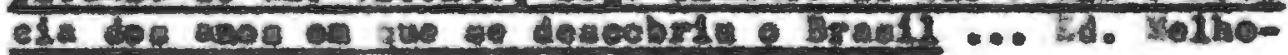
reweres - Sto Palo.

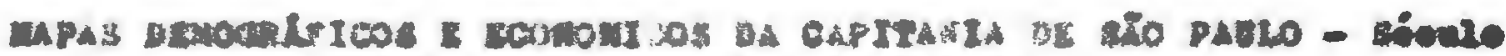
IVIII - XIX - Axantive do sotche.

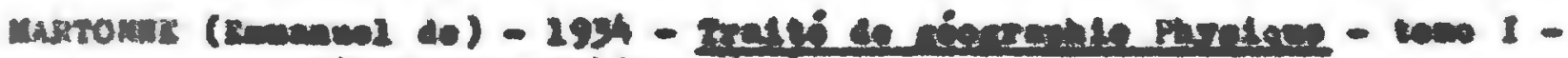
Lib. Armand colle - Parre.

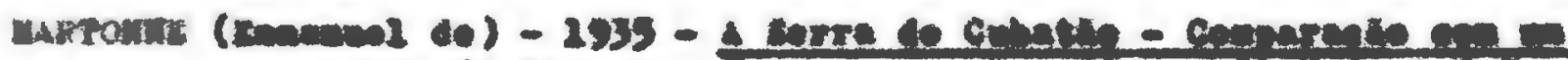

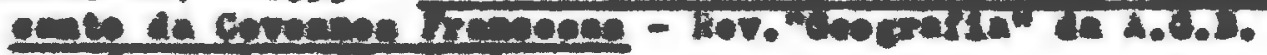

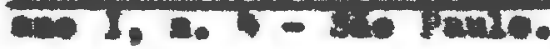

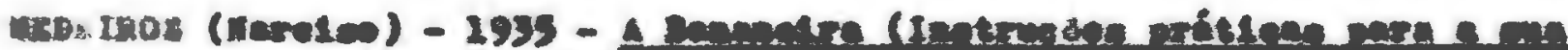

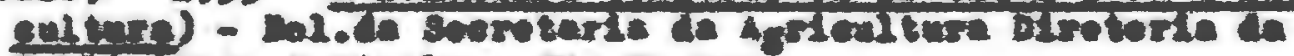

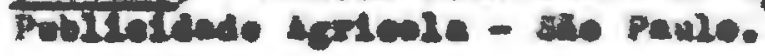

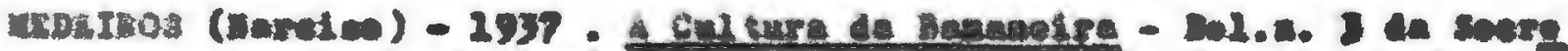

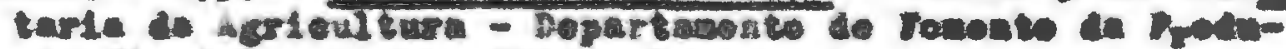

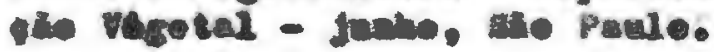

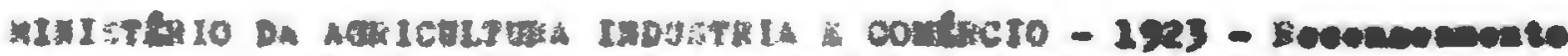

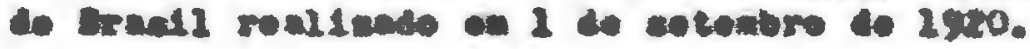

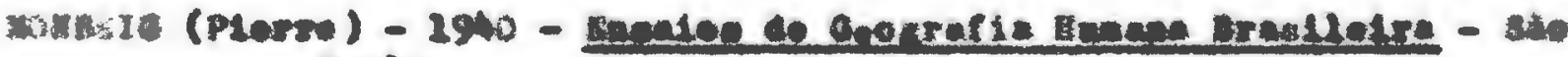
Panlo.

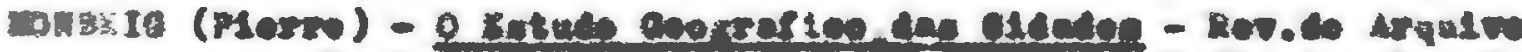

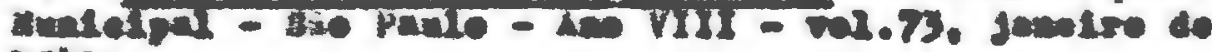
1942.

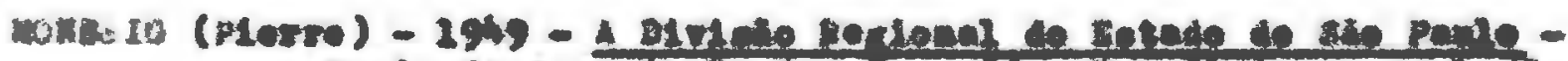

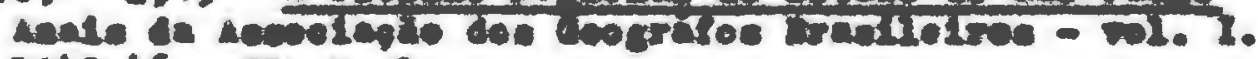
2s45-46 - 830 ranlo.

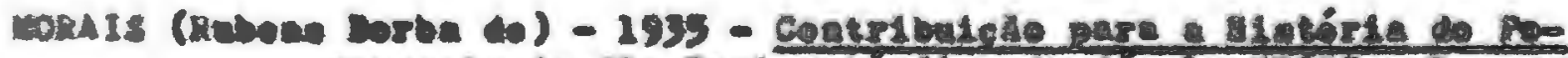

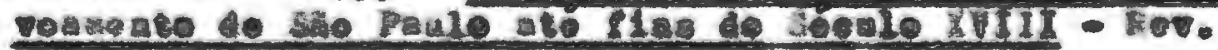

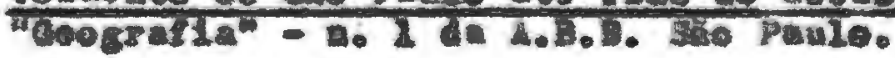

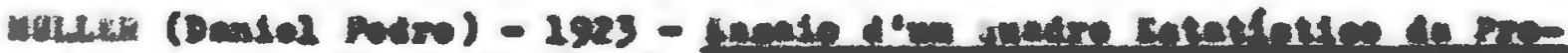

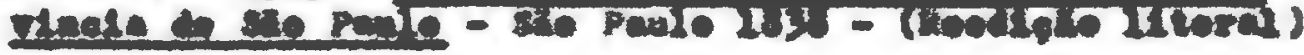




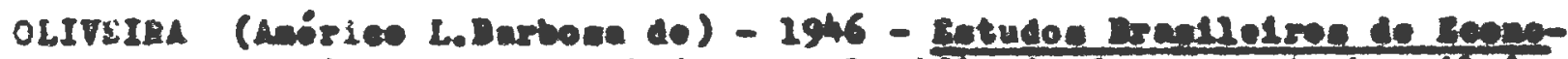

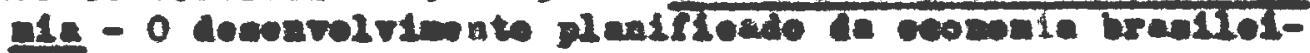
ra - rungto cotullo Targes.

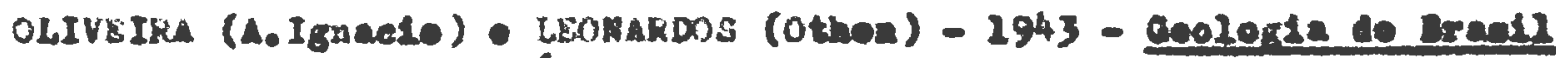
a. Mlaletirlo da agrieultura.

OLIVLIKA (J.J.Mehado de) - 2897 - suadre Hletórlee de Provlacla de

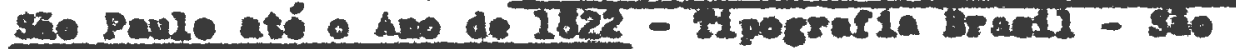
Panio.

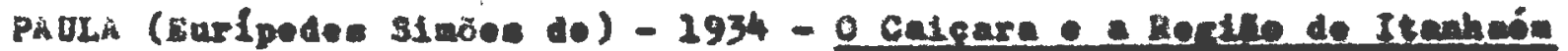

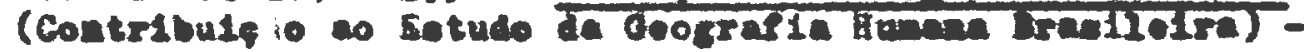
aro paulo.

PIMPO (Alfredo more1ra) - 2896 - Apatanates para e Dfelonérle Gee rifles do Breall - Inprocen Heclonal - Rlo.

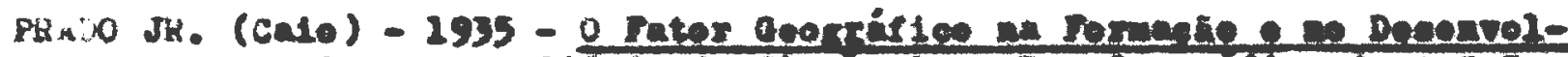

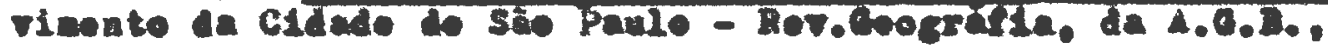
an I, n. 3 - sto Paulo. -

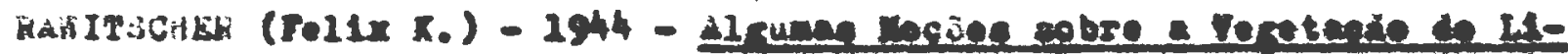

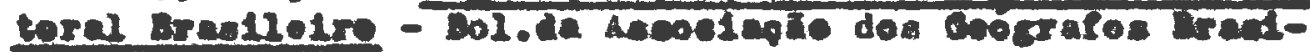
1elree, a. 5. covenbro sio Palle.

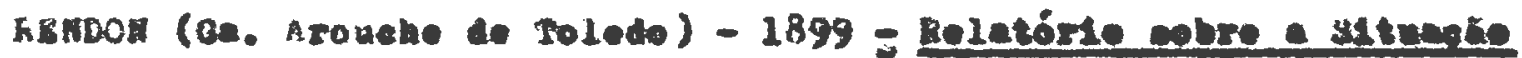

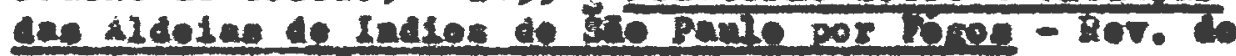

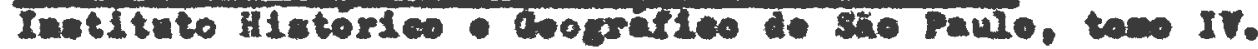

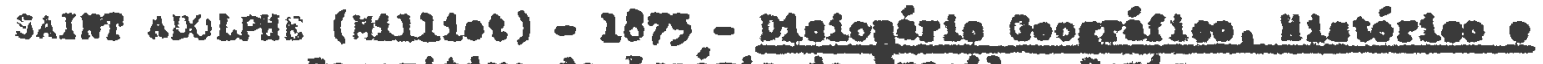
Deceritive do Iapírie de tratu - Paris.

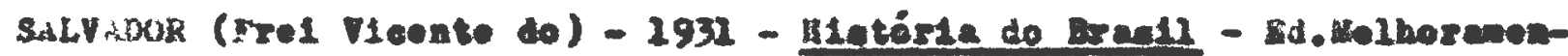
tos - sto paulo.

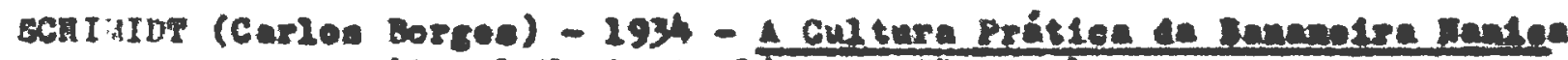

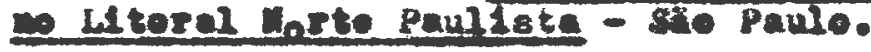

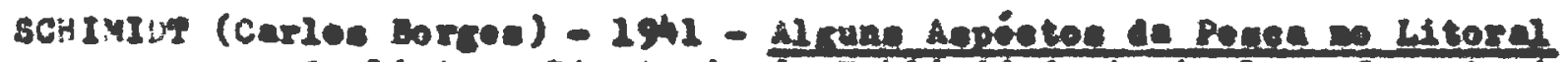
panlata - Diretoria da Pablicidade Agricola - Boarotaria de Agrienl tura - sie Paulo.

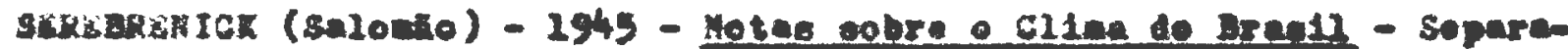

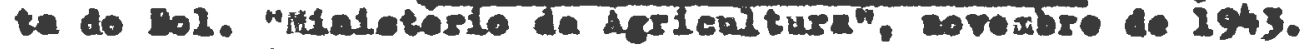
R10 do Janelro.

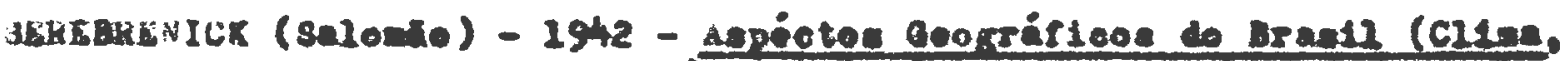

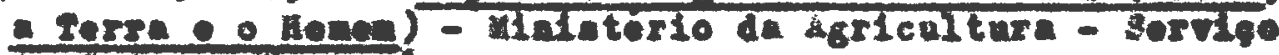
do Informeth igrieola.

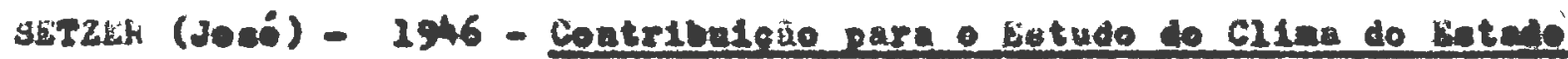

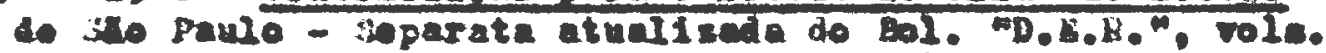
IX a X. tubro do 1943 outubre do 1945 - sxo paulo. 


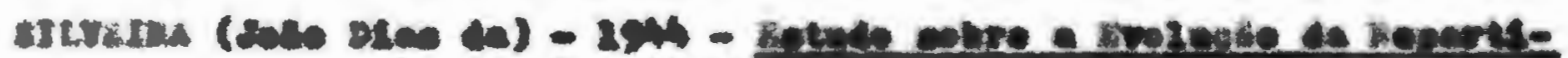

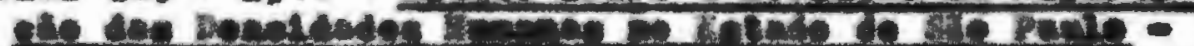

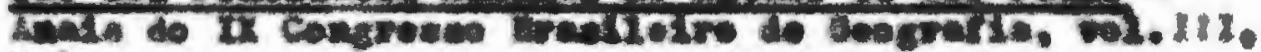
28 s.

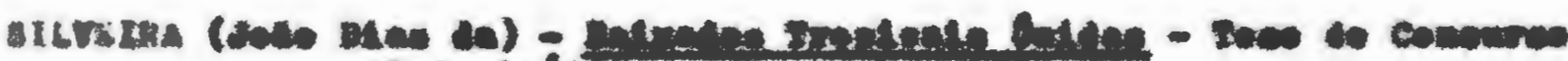

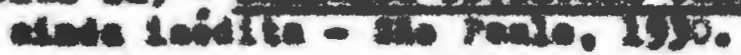

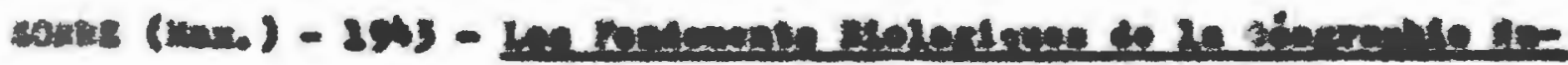

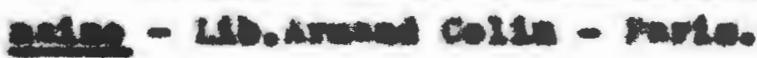

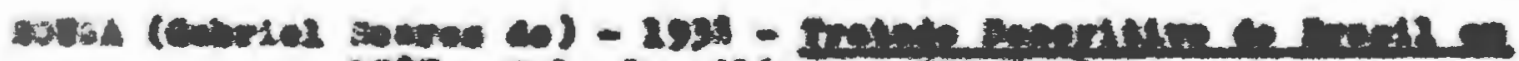

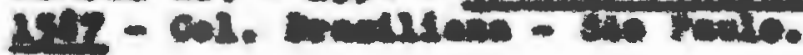

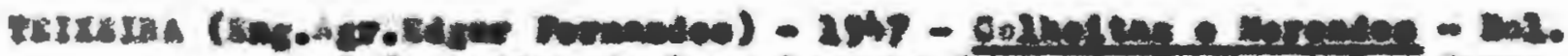

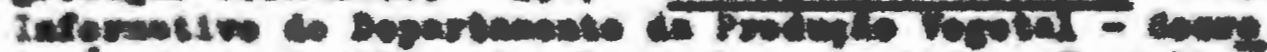

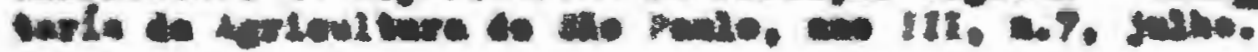

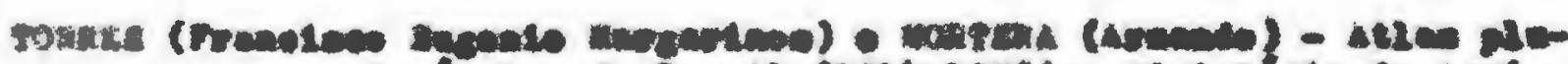

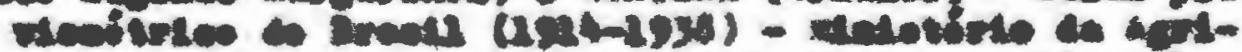

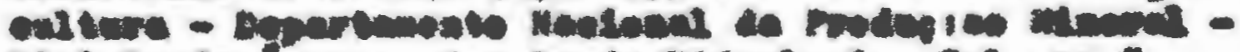

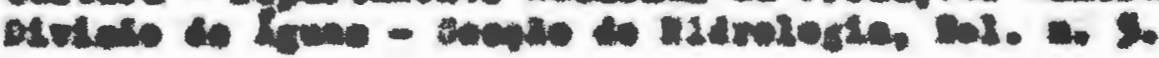

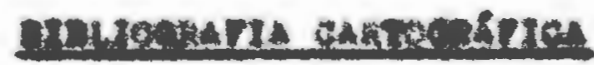

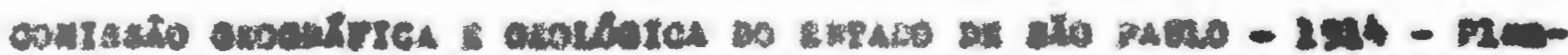

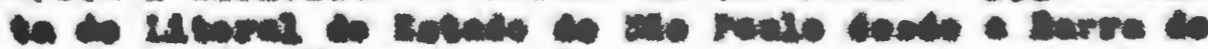

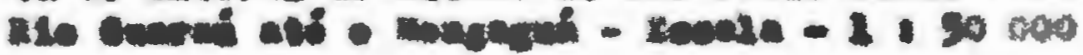

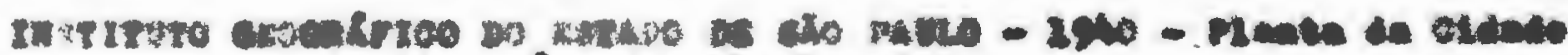

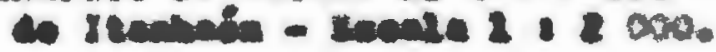

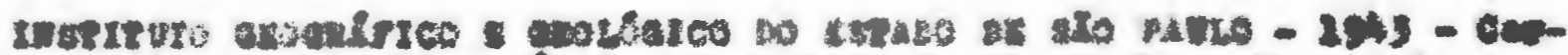

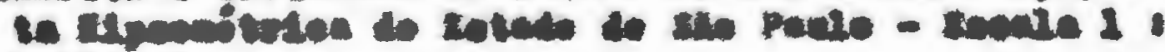
1000000.

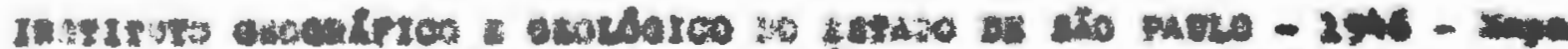

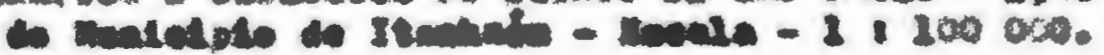

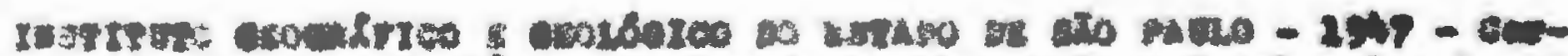

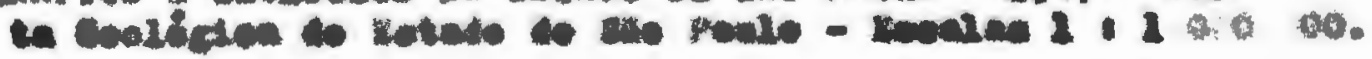




\section{Wore:}

sunerio

20

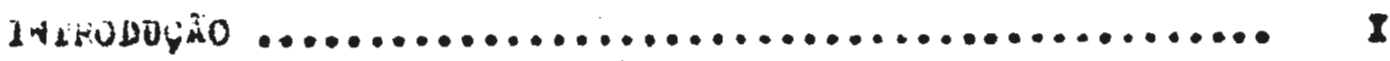

GeP. I - a batrada do ituabaéa - sev quadro antural .... 1

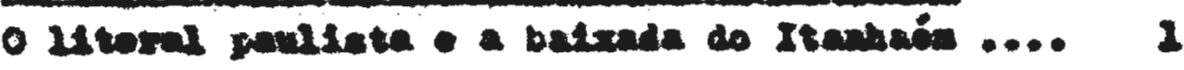

o relovo . n costa ......................... 4

A rôde nuviel ......................... 6

careateristied do oltwa ...................... 20

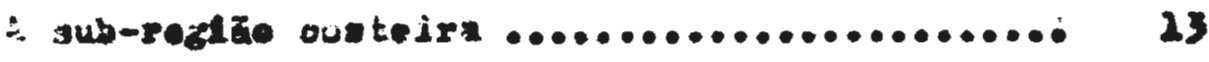

4 baxace latontor ........................... 84

c quadro sctural e a ride nusana ............. 29

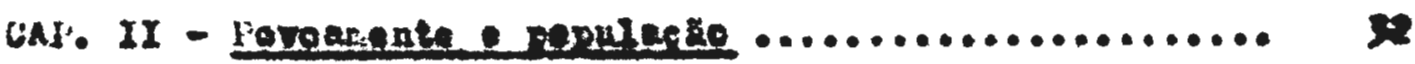

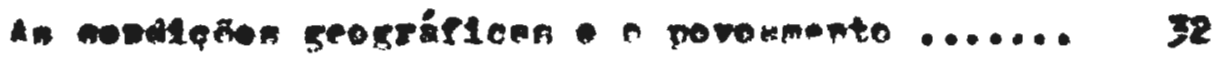

o povameato ant1go ......................... Ir

- popalagajo stual. Us tipen hanasor ........... 33

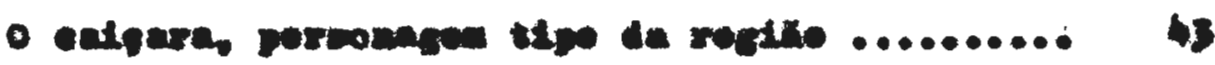

o hoved do banahil .......................... St

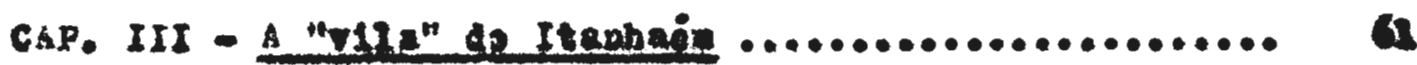

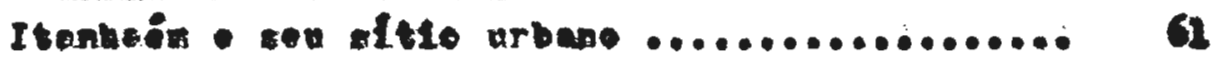

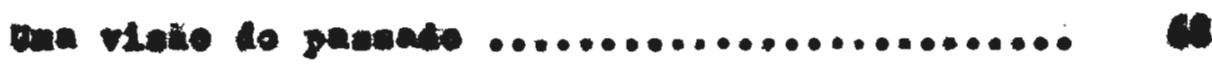

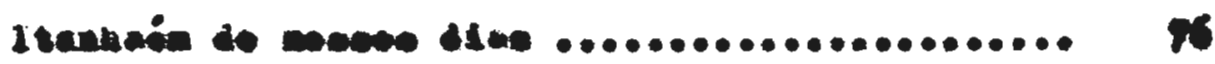

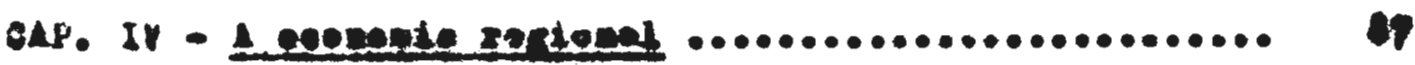

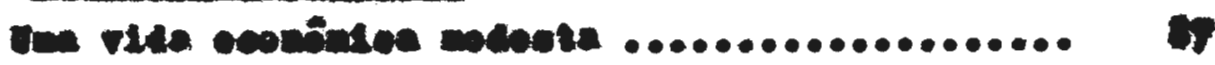

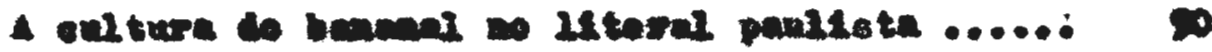

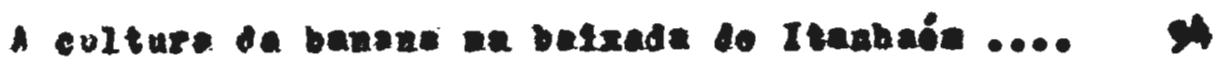

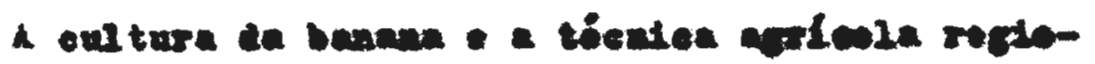

nad ........................................ Ian

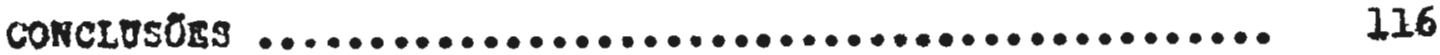

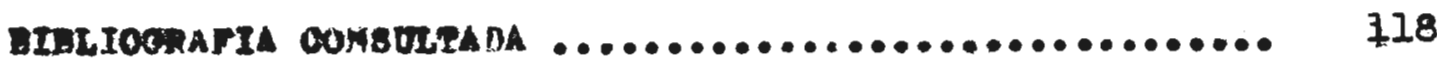

INDICE................................ 123 
A digitalização deste documento foi possível graças ao investimento do Programa de Pós-graduação em Geografia Humana (PPGH-FFLCH-USP) e realizada com recursos da Coordenação de Aperfeiçoamento de Pessoal de Nível Superior - Brasil (CAPES) - Código de Financiamento 001. Essa ação integra as atividades de comemoração dos 50 anos do PPGH no ano de 2021. Para mais informações sobre o PPGH e sua história, visite a página do programa: http://ppgh.fflch.usp.br/.

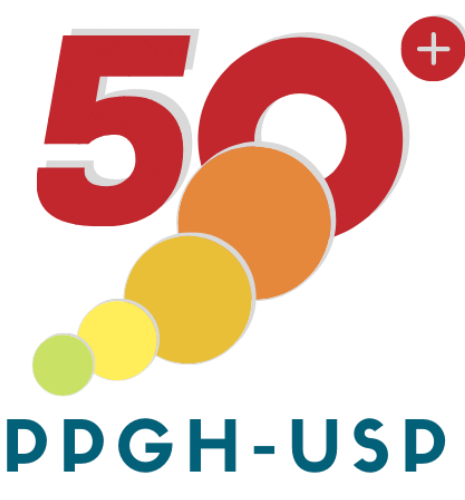

$1971-2021$ 